UNIVERSITAT JAUME I

CASTELLÓ

Facultad de Ciencias Jurídicas y Económicas

AREA PREDEPARTAMENTAL DE DERECHO DEL TRABAJO Y DE LA SEGURIDAD SOCIAL Y ECLESIÁSTICO DEL ESTADO

TESIS DOCTORAL

\title{
LA NEGOCIACIÓN COLECTIVA DE LOS DERECHOS SINDICALES DEL PERSONAL ESTATUTARIO DE LOS SERVICIOS DE SALUD
}

PRESENTADA POR:

Antonia Garrido Heras

DIRECTORES:

$\mathrm{M}^{\mathrm{a}}$ José Mateu Carruana Fernando de Vicente Pachés

Castellón, abril 2015 
Mi sincero agradecimiento a los directores de esta tesis, $\mathrm{M}^{\mathrm{a}}$ José Mateu Carruana y Fernando de Vicente Pachés, por su interés, rigor y acierto en la difícil tarea de encauzar este trabajo, que nunca habría sido el mismo sin ellos.

A mis hijos y a mi marido que, por su apoyo y paciencia a lo largo de su elaboración, bien merecen que se lo dedique. 



\section{ÍNDICE}

ABREVIATURAS

INTRODUCCION. OBJETO Y METODOLOGÍA

CAPITULO I.- MARCO HISTORICO NORMATIVO EN EL QUE SURGE LA SANIDAD COMO SERVICIO PUBLICO EN ESPAÑA Y LA REGULACION JURIDICA DE SU PERSONAL

1.1.- La necesidad de regular la relación de servicios del personal de la sanidad pública

1.2.- El origen de la función pública con la aparición del Estado moderno

1.3.- La consolidación de la función pública durante la construcción del Estado Liberal y la reivindicación sindical de protección de la salud de los trabajadores

1.4.- El triunfo de las reivindicaciones sindicales con el surgimiento del Estado Social

1.5.- Los inicios del sistema de Seguridad Social en un marco político sin libertades. Los Estatutos Jurídicos de Personal de la Seguridad Social

1.6.- La Transición y la Constitución española de 1978

CAPITULO II.- EL ACTUAL REGIMEN JURIDICO DEL PERSONAL ESTATUTARIO DE LOS SERVICIOS DE SALUD. SU CREACION Y DESARROLLO PARALELOS A LOS DEL SISTEMA NACIONAL DE SALUD

2.1.- El reparto constitucional de competencias en materia de sanidad. La creación del Sistema Nacional de Salud y su organización administrativa actual

2.2.- El personal estatutario: concepto y naturaleza jurídica de su relación de servicios. Normativa reguladora del régimen jurídico del personal estatutario de los Servicios de salud

2.3.- La negociación colectiva como fuente normativa del régimen jurídico del personal estatutario 
CAPITULO III.- EL DERECHO FUNDAMENTAL A LA LIBERTAD SINDICAL DEL PERSONAL ESTUTARIO DE LOS SERVICIOS DE SALUD. SUS DERECHOS COLECTIVOS

3.1.- Marco común de la libertad sindical de trabajadores y funcionarios. Precedentes internacionales: los Convenios de la OIT y la situación previa a la Constitución española de 1978

3.2.- La libertad sindical en la Constitución española de 1978. La doctrina del TC sobre la libertad sindical. La Ley Orgánica de libertad sindical. Tutela jurídica de la libertad sindical

3.3.- Antecedentes normativos y regulación actual de los derechos colectivos de los empleados públicos y del personal estatutario de los Servicios de salud

\section{CAPITULO IV.- EL EJERCICIO DE LA NEGOCIACION COLECTIVA DEL PERSONAL ESTATUTARIO DE LOS SERVICIOS DE SALUD EN EL MARCO LEGAL DE LA NEGOCIACIÓN COLECTIVA FUNCIONARIAL}

4.1.- El derecho a la negociación colectiva de los funcionarios públicos

4.1.2.- Doctrina del TC sobre la negociación colectiva de los funcionarios públicos

4.1.3.- Principios de la negociación colectiva funcionarial

4.1.4.- Particularidades de la negociación colectiva del personal estatutario de los Servicios de salud

4.2.- El resultado de la negociación: Pactos y Acuerdos

4.2.1.- Concepto y naturaleza jurídica de los Pactos y Acuerdos. Materias de negociación obligatoria y materias excluidas de la negociación

4.2.2.- Los derechos sindicales del personal estatutario como materia objeto de negociación colectiva

4.2.3.- Foros de negociación. Estructura de la negociación colectiva de los funcionarios públicos. Los foros de negociación específicos del personal estatutario de los Servicios de salud 


\section{Índice}

4.2.4.- Partes negociadoras. Composición de las Mesas y procedimiento de negociación

4.2.5.- Efectos de la falta de acuerdo en la negociación

4.2.6.- Ratificación de los Acuerdos por el órgano de gobierno

4.2.7.- La adhesión al Pacto o Acuerdo

4.2.8.- Vinculación de los Pactos y Acuerdos

4.3.2.- Control de legalidad e impugnación jurisdiccional de los Pactos y Acuerdos

4.3.3.- Suspensión y modificación del cumplimiento de Pactos y Acuerdos

\section{CAPITULO V.- EL CONTENIDO DE LA NEGOCIACIÓN COLECTIVA DE LOS DERECHOS SINDICALES DEL PERSONAL ESTATUTARIO DE LOS SERVICIOS DE SALUD ANTES Y DESPUÉS DE LAS MEDIDAS DE AJUSTE PRESUPUESTARIO}

5.1.-. Introducción. Objeto de la negociación

5.2.- Contenido de la negociación colectiva de los derechos sindicales del personal estatutario antes de las medidas de ajuste presupuestario

5.2.1.- La constitución de Secciones sindicales y la designación de delegados. Sus derechos

5.2.2.- El crédito horario sindical

5.2.2.1.- La liberación de funciones institucional

5.2.2.2.- La constitución de la bolsa de crédito horario y la liberación

5.2.3.- Otras garantías de la función representativa de los delegados sindicales y de los representantes del personal estatutario

5.3.-. Consideraciones sobre la negociación colectiva de los derechos sindicales en esa etapa 


\section{Índice}

5.4.- La suspensión y modificación de los Acuerdos y Pactos de derechos sindicales de los empleados públicos por los Gobiernos autonómicos

5.5.- Las medidas del Real Decreto Ley 20/2012, de 13 de julio, sobre los derechos sindicales de los empleados públicos

5.6.- La regulación actual de los derechos sindicales del personal estatutario de los Servicios de salud. Los Acuerdos autonómicos de adecuación al Real Decreto Ley 20/2012. Su contenido

5.6.1.- La dispar regulación de los derechos sindicales de los empleados públicos y del personal estatutario en particular

5.6.2.- Aspectos comunes de la nueva regulación sobre derechos sindicales en los Acuerdos de adecuación al Real Decreto Ley 20/2012

5.6.3.- Contenido de los derechos sindicales de los empleados públicos en los Acuerdos de adecuación

5.6.3.1.- El derecho a la constitución de secciones sindicales y la delimitación del centro de trabajo o unidad electoral

5.6.3.2.- Designación de delegados sindicales, su número y crédito

horario sindical

5.6.3.3.- El crédito horario de los representantes del personal

5.6.3.4.- El reconocimiento de las liberaciones institucionales

5.6.3.5.- Procedimiento de gestión de las bolsas de crédito horario y dispensas sindicales

5.6.3.6.- Derechos retributivos y otras garantías de la función 


\section{ABREVIATURAS}

AA.VV.

AJA

AN

AS

apdo./apdos.

art./arts.

CC.AA.

CC.OO.

$\mathrm{CE}$

CEMSATSE

CSI-F/CSIF

EJPM

INGESA

INP

INSALUD

LBSS

LCCSNS

LEBEP

LEM

LGSS

LJS

LJCA

LMRFP

LOLS

LORAP

\section{LOTC}

LPJDFP

$\mathrm{n}^{\mathrm{o}}$

OIT

ONU

op.cit.

p./pp.
Autores Varios

Actualidad Jurídica Aranzadi

Audiencia Nacional

Aranzadi Social

apartado/apartados

artículo/artículos

Comunidades Autónomas

Confederación Sindical de Comisiones Obreras

Constitución española de 1978

Confederación Estatal de Sindicatos Médicos y de

Enfermería

Central Sindical Independiente y de Funcionarios

Estatuto Jurídico del Personal Médico de la Seguridad Social, aprobado por Decreto 3160/1966, de 23 de diciembre

Instituto Nacional de Gestión Sanitaria

Instituto Nacional de Previsión

Instituto Nacional de la Salud

Ley 193/1963, de 28 de diciembre, de Bases de la Seguridad Social

Ley 16/2003, de 28 de mayo, de Cohesión y Calidad del Sistema Nacional de Salud

Ley 7/2007, de 12 de abril, del Estatuto Básico del Empleado Público

Ley 55/2003, de 16 de diciembre, del Estatuto Marco del personal estatutario de los Servicios de salud

Ley General de la Seguridad Social, aprobada por Decreto 2065/1974, de 30 de mayo

Ley 36/2011, de 10 de octubre, reguladora de la Jurisdicción Social

Ley 29/1998, de 13 de julio, reguladora de la Jurisdicción Contencioso administrativa

Ley 30/1984, de 2 de agosto, de Medidas para la

Reforma de la Función Pública

Ley Orgánica de Libertad Sindical

Ley 9/1987, de 12 de junio, de Órganos de representación, determinación de las condiciones de trabajo y participación del personal al servicio de las Administraciones Públicas

Ley Orgánica 2/1979, de 3 de octubre, del Tribunal Constitucional

Ley 62/1978, de 26 de diciembre, de Protección Jurisdiccional de los derechos fundamentales de las personas

número

Organización Internacional del Trabajo

Organización de Naciones Unidas

Obra citada

página/páginas 
s./ss.

SAE

SATSE

SAN

SOE

STC

STS

STSJ

TC

TRET

TS

TSJ

UGT siguiente/siguientes

Sindicato de Auxiliares de Enfermería

Sindicato de Enfermería

Sentencia de la Audiencia Nacional

Seguro Obligatorio de Enfermedad

Sentencia del Tribunal Constitucional

Sentencia del Tribunal Supremo

Sentencia del Tribunal Superior de Justicia

Tribunal Constitucional

Texto Refundido del Estatuto de los Trabajadores, aprobado por Real Decreto Legislativo 1/1995, de 24 de marzo

Tribunal Supremo

Tribunal Superior de Justicia

Unión General de Trabajadores 
INTRODUCCION. OBJETO Y METODOLOGÍA 



\section{INTRODUCCIÓN. OBJETO Y METODOLOGÍA}

El derecho a la negociación colectiva en el ámbito de las relaciones de trabajo es probablemente una de las conquistas históricas más importantes de nuestro ordenamiento jurídico y tiene una fuerte conexión con los principios democráticos y sociales en que este se apoya.

Su reconocimiento inicial en la Constitución española de 1978 se hizo extensivo por vía legal, hace casi veinticinco años, a todos los funcionarios de las diferentes Administraciones públicas españolas, entre ellos al personal que actualmente se denomina estatutario de los Servicios de salud, que presta servicios en las instituciones sanitarias del Sistema Nacional de Salud.

El mecanismo de la negociación colectiva en el ámbito de la Administración pública sanitaria ha permitido durante años la regulación consensuada de la normativa básica sobre el régimen jurídico de su personal, la de sus particulares retribuciones, la del sistema de carrera profesional, la de la jornada de trabajo, permisos y vacaciones, determinados aspectos de los procesos selectivos, y un largo etcétera de materias entre las que encontramos sus derechos sindicales.

Este desarrollo de la normativa negociada del personal del Sistema Nacional de Salud se ha llevado a cabo de forma simultánea a la que ha permitido el aumento y diversificación de las prestaciones sanitarias públicas a los ciudadanos dentro del principio de universalidad de la asistencia sanitaria.

La tendencia de las políticas legislativas actuales, sin embargo, no va en la línea de promocionar el ejercicio del derecho a la negociación colectiva para la determinación de las condiciones de trabajo de los empleados públicos, sobre todo por lo que se refiere a sus derechos sindicales. Como veremos, una de las medidas de corrección del déficit público en las Administraciones españolas se ha dirigido en los últimos tiempos, con especial intensidad, a la reducción de los medios personales y materiales de que disponen las organizaciones sindicales para el desarrollo de la acción sindical.

El objeto de este trabajo es precisamente el análisis de los efectos que han tenido las políticas de restricción de la negociación colectiva de los derechos sindicales para el personal de los Servicios de salud, mayoritariamente estatutario, que van más allá del ámbito de sus relaciones de trabajo, y que serán con toda probabilidad negativas no solo para los profesionales del Sistema Nacional de Salud, sino incluso para la defensa de los principios en los que se asienta este.

El desarrollo del trabajo está planteado en cinco capítulos, a lo largo de los cuales se trata, en primer lugar, en el Capítulo I, el lento proceso histórico normativo que da lugar al surgimiento de la Sanidad como servicio público en nuestro país, y la evolución que ha experimentado la regulación de la relación de servicios de su personal. 
Hay que tener en cuenta que los avatares históricos y políticos hicieron tardía en nuestro país la incorporación de los principios europeos sobre la función pública, así como la normativa sobre previsión social, que impulsó el Movimiento Obrero y que vio la luz durante el auge del Estado liberal cuando, además, las competencias en el ámbito sanitario pasaron a ser responsabilidad de las provincias y municipios.

También se ponen de relieve los avances legislativos durante la breve duración de la Segunda República (1931-1936), en la que nos encontramos con el triunfo de los postulados del Estado Social, que reconoce como derecho constitucional el de libertad sindical, y se atribuye al Estado la competencia para legislar en materia de coordinación sanitaria.

Tras la Guerra Civil, en un contexto de ruina económica y ausencia de libertades, se intenta reconstruir la estructura sanitaria a partir de principios de los años cuarenta, cuando se pone en marcha el sistema de previsión del Seguro Obligatorio de Enfermedad con la Ley de 1942 y la de Bases de la Sanidad Nacional de 1944. Será, sin embargo, a partir de la Ley de Bases de la Seguridad Social de 1966, cuando se inicie la construcción del Sistema público de Seguridad Social en España y sea necesario abordar el régimen jurídico del personal que se pondrá a su servicio, aspecto en el cual parece demostrada la influencia decisiva de la Organización médica colegial en su día.

La relación jurídica del personal del Sistema público de salud en España tiene su antecedente precisamente en esta ley y en su normativa de desarrollo, y es tan peculiar que ha dado origen a una denominación específica, alejada durante años tanto del régimen jurídico funcionarial como del laboral: es la del personal estatutario de la Seguridad Social, al principio; de los Servicios de salud, actualmente.

En el Capítulo II se ha tratado el actual régimen jurídico del personal estatutario de los Servicios de salud, haciendo hincapié en su conexión directa con la particular organización administrativa sanitaria española y en el dato de su avance en paralelo. Se destaca la importancia de la Ley 14/1986, de 25 de abril, General de Sanidad (LGS), que desarrolla el derecho a la protección de la salud, regulado en el artículo 43 de la Constitución de 1978, universaliza la asistencia sanitaria y transforma el anterior sistema de Seguridad Social en el Sistema Nacional de Salud. La Ley General de Sanidad previó la aprobación de un Estatuto Marco con rango de ley que sustituyera la normativa reglamentaria preconstitucional que regulaba la relación de servicios de este personal, el cual se contiene actualmente en la Ley 55/2003, de 16 de diciembre (LEM), que califica su relación jurídica como funcionarial especial.

Además, nos planteamos la cuestión de hasta qué punto es obligado en nuestro ordenamiento jurídico la vinculación del personal del Sistema público de salud mediante una relación jurídica de tipo administrativo, y qué margen de competencias tiene cada Comunidad autónoma para elegir la forma jurídica y el tipo de gestión de su Servicio de salud.

Por último, cabe destacar la importancia de la negociación colectiva como fuente de la regulación de los diversos aspectos del régimen jurídico del personal estatutario de los Servicios de salud, en particular de sus derechos sindicales. 
En el Capítulo III se aborda el reconocimiento constitucional de la libertad sindical, producto de un largo proceso que se inició a nivel internacional tras la segunda Guerra mundial, pero que, dada la situación política, no pudo incorporarse a nuestro ordenamiento jurídico hasta la etapa de la Transición, cuando España ratificó los Tratados internacionales que la reconocían. Poco después se promulga la Constitución de 1978 que la reconoce entre los derechos fundamentales y libertades públicas, en el artículo 28.1.

Se insiste en este capítulo en el carácter común de la regulación de la libertad sindical en la Ley Orgánica de Libertad Sindical de 1986 para trabajadores y funcionarios, y en los puntos principales de la doctrina del Tribunal Constitucional sobre este derecho fundamental, así como en los medios para su tutela jurídica que, a riesgo de ser reiterativos, nos parece indispensable para entender algunas reflexiones que después se harán. Las peculiaridades del ejercicio de la libertad sindical del personal estatutario se regulan en la misma ley aplicable al resto de funcionarios públicos, que desarrolla sus derechos colectivos: la Ley 7/2007, de 12 de abril, del Estatuto Básico del Empleado Público (LEBEP), así como en la Ley reguladora de su Estatuto Marco.

En el Capítulo IV se trata el derecho a la negociación colectiva del personal estatutario de los Servicios de salud, que no es más que manifestación del derecho a la negociación colectiva funcionarial, con algunos aspectos más concretos, como son la Mesa sectorial de Sanidad de cada Servicio de salud autonómico como foro de negociación específico y el Foro Marco para el Diálogo Social a nivel estatal.

La LEBEP recoge los derechos colectivos de los empleados públicos, y desarrolla el de negociación colectiva funcionarial, el de representación de los funcionarios públicos y el derecho de reunión. Determina la estructura de los foros de negociación y una serie de materias sobre las cuales es obligado intentar la negociación entre representantes de la Administración y los del personal, que son siempre las organizaciones sindicales. Entre todas las materias de negociación obligada destaca, por lo que se refiere al objeto de este trabajo, la de los derechos sindicales.

Sobre este punto se plantea qué se debe entender por derechos sindicales, dada la indefinición legal y la falta de una postura única en la doctrina. Desde nuestro punto de vista se trata del conjunto de garantías y facilidades que se ponen a disposición de las organizaciones sindicales para el libre desarrollo de la acción sindical, y que se pueden mejorar a través de la negociación colectiva, con la finalidad de superar los mínimos regulados en la ley y siempre dentro del margen que esta permite.

En el Capítulo V se hace un estudio comparativo entre el contenido de la negociación colectiva sobre derechos sindicales del personal estatutario de los Servicios de salud que estaban en vigor antes de las medidas de ajuste presupuestario que emprendieron los gobiernos autonómicos a partir de 2010, y el estatal a través del Real Decreto Ley 20/2012, de 13 de julio, de medidas para garantizar la estabilidad presupuestaria y de fomento de la competitividad, las cuales han incidido finalmente en su derogación; y los Acuerdos y normativa autonómica que actualmente regulan dicha materia en este ámbito. Finalmente, se puede constatar la pérdida de derechos y garantías de índole sindical que afectan directamente a las organizaciones sindicales y al personal de los Servicios de salud. 
En la elaboración del trabajo se han tenido en cuenta, principalmente, las fuentes normativas y la doctrina científica y jurisprudencial sobre los diversos aspectos referentes a la regulación de la organización administrativa del Sistema Nacional de Salud, el régimen jurídico del personal estatutario a su servicio, el derecho a la libertad sindical y los derechos colectivos funcionariales, atendiendo en especial al derecho de negociación colectiva de este personal, y en particular, a los aspectos referentes a las garantías de los representantes sindicales y de los del personal para el ejercicio de la acción sindical.

Asimismo, se han contrastado los Acuerdos y los Pactos sobre derechos sindicales de las Administraciones autonómicas que regulaban antes de las medidas de ajuste presupuestario las garantías y medios para la acción sindical y que afectaban al personal de su Servicio de salud, así como los actualmente vigentes.

Todo ello con el fin de extraer las conclusiones que al final del trabajo se exponen, con el propósito de tomar conciencia de que la limitación de los medios de acción a las organizaciones sindicales que representan al personal del Sistema Nacional de Salud no es un tema menor entre los problemas de nuestro modelo sanitario, porque sus consecuencias van más allá de la simple reducción de liberados o subvenciones económicas a los sindicatos con implantación en la sanidad pública.

Los efectos de estas medidas alcanzan a no muy largo plazo, no solo a las organizaciones sindicales y al personal estatutario de los Servicios de salud, sino al propio diseño original del modelo sanitario, a los principios que lo inspiraron y a todos nosotros como ciudadanos y usuarios del Sistema. 
CAPITULO I

MARCO HISTORICO NORMATIVO EN EL QUE SURGE LA SANIDAD COMO SERVICIO PUBLICO EN ESPAÑA Y LA REGULACION JURIDICA DE SU PERSONAL 



\section{CAPITULO I}

\section{MARCO HISTORICO NORMATIVO EN EL QUE SURGE LA SANIDAD COMO SERVICIO PUBLICO EN ESPAÑA Y LA REGULACION JURIDICA}

DE SU PERSONAL

\section{1.- LA NECESIDAD DE REgULAR LA RELACION DE SERVICIOS DEL PERSONAL DE LA SANIDAD PÚBLICA}

Antes de plantearnos el alcance que tienen actualmente los derechos sindicales del personal estatutario en los Servicios de salud, conviene atender a los antecedentes históricos en los que surge la regulación normativa de este tipo de personal.

La necesidad de elaborar normas jurídicas que regulen la relación de servicios de los profesionales sanitarios con la Administración pública viene dada por la atribución a esta de la responsabilidad de prestar directamente y garantizar la asistencia sanitaria a los ciudadanos. Esta competencia administrativa es relativamente moderna ya que, como veremos más adelante, en España surge entre la segunda mitad del siglo XIX y principios del XX, precisamente para dar satisfacción a una de las reivindicaciones del Movimiento sindical obrero: el derecho a la protección de la salud de los trabajadores.

Para mantener en funcionamiento ese servicio público de protección de la salud la Administración necesita del trabajo de una serie de profesionales que, actualmente, en su mayor parte, tienen una vinculación jurídica con la Administración de naturaleza administrativa, que resulta ser una especialidad del régimen jurídico funcionarial. Se trata del personal estatutario de los Servicios de salud.

Hay que decir que otros empleados públicos también tienen un estatuto regulado en normas específicas, como puede ser el personal al servicio de las Cortes Generales o los miembros de las Fuerzas Armadas, y que también es verdad que la norma que regula el régimen jurídico común de los empleados públicos en el conjunto del Estado es el Estatuto básico del empleado público (porque estatutaria es la relación de servicios del personal cuyo régimen jurídico se contiene en normas y reglamentos, no en un contrato de trabajo), pero el tradicionalmente conocido como personal estatutario es, concretamente, el que ha venido prestando servicios en las instituciones sanitarias públicas españolas. El personal con esta vinculación jurídica es el colectivo más numeroso del total de recursos humanos destinados hoy día en ese sector de la Administración pública, pero no el único, ya que a su servicio también hay, aunque en menor medida, funcionarios y personal laboral.

Respecto a los funcionarios en el ámbito sanitario público hay que decir que su relación jurídica subsiste hoy día, principalmente, debido a que tiene su antecedente en las funciones de prevención y control de la enfermedad en su ámbito colectivo, que ha sido tradicionalmente una función de naturaleza administrativa, ajena a los intereses de la medicina privada y bajo responsabilidad de los poderes públicos. 


\section{Capítulo I. Marco histórico normativo en el que surge la sanidad como servicio público en España y la regulación jurídica de su personal}

Este colectivo es minoritario en el conjunto del Sistema Nacional de Salud en comparación con el personal estatutario y, como veremos más adelante, la tendencia del legislador actual es la de primar la relación jurídica de este último.

Respecto al personal laboral al servicio de instituciones sanitarias, aparte del personal con relación laboral especial de residencia para la formación de especialistas en Ciencias de la Salud, que se regula por Real Decreto 1146/2006, de 6 de octubre $^{1}$, en la actualidad su presencia como personal vinculado con contrato laboral indefinido o temporal con la Administración pública sanitaria es excepcional ${ }^{2}$, aunque sí lo encontramos trabajando en las entidades de naturaleza privada que gestionan los servicios sanitarios públicos en base a las nuevas fórmulas de gestión sanitaria a las que nuestro ordenamiento jurídico permite recurrir.

Volviendo al personal estatutario, la normativa reguladora de su régimen jurídico se refiere a su relación jurídica como funcionarial especial y lo clasifica en toda una serie de categorías profesionales diversas, de distinto nivel y área de formación académica, que prestan sus servicios en todo tipo de instituciones sanitarias, ocupando puestos de trabajo con infinidad de denominaciones en las plantillas de las dieciocho administraciones públicas que conforman el Sistema Nacional de Salud actual.

De modo que nos encontramos con personal de profesiones sanitarias cuyo ejercicio requiere titulación universitaria en ciencias de la salud (como médicos, enfermeros, fisioterapeutas, logopedas, terapeutas ocupacionales...) y en otros casos exige una específica titulación de formación profesional (como técnicos especialistas sanitarios, auxiliares de enfermería...) así como con personal no sanitario de gestión y servicios con titulaciones académicas universitarias o no, ajenas a la rama sanitaria (trabajadores sociales, ingenieros, cocineros, personal de mantenimiento, celadores, el personal de todos los grupos de clasificación de la función administrativa...).

Respecto al conjunto de personal del Sistema Nacional de Salud, según los últimos datos publicados por el Ministerio de Sanidad, Servicios Sociales e Igualdad, en el año 2012 había 508.901 profesionales destinados en los establecimientos sanitarios de atención especializada de la red pública del Sistema Nacional de Salud y 85.757 en el ámbito de los centros dedicados a la atención primaria en ese año ${ }^{3}$. Sigue vigente la idea que en su día expresó el Acuerdo Parlamentario de 18 de diciembre de 1997, para la Consolidación y Modernización del Sistema Nacional de Salud, en cuanto a que "los profesionales sanitarios constituyen el principal activo del Sistema Nacional de Salud”.

\footnotetext{
${ }^{1}$ BOE de 7 de octubre de 2006.

2 PEREZ GALVEZ, J.F., Incidencia del Estatuto Básico del empleado público en el acceso al empleo del personal de los Servicios de salud, Instituto Nacional de Administración Pública, 2011, p. 48.

3 Portal Estadístico del Sistema Nacional de Salud. Estadística incluida en el Plan Estadístico Nacional. Aplicación de consulta interactiva del Sistema Nacional de Salud, [consulta de 20 de enero de 2015], disponible en: <http: \www.msssi.gob.es>.
} 


\section{Capítulo I. Marco histórico normativo en el que surge la sanidad como servicio público en España y la regulación jurídica de su personal}

Para entender la importancia trascendental de este sector de la Administración pública hay que tener en cuenta que el presupuesto destinado a Sanidad por el conjunto de las CC.AA. para 2015 rebasa los 53.000 millones de euros y supera el de todos los demás servicios públicos fundamentales (en un 35\% el presupuesto destinado a Educación; en un $57 \%$ el destinado a la Deuda pública; en un $77 \%$ el destinado a Seguridad, Protección y Promoción social y en un 30\% al Resto de Funciones o políticas $)^{4}$. En la Ley 36/2014, de 26 de diciembre, de Presupuestos Generales del Estado para 2015, el presupuesto destinado a este sector de actividad pública es de casi 4.000 millones de euros.

Por tratarse de empleados públicos, con determinados problemas y aspiraciones comunes, es fácil comprender que pretendan, como todos, funcionarios y resto de trabajadores del ámbito laboral, la defensa de sus derechos colectivos. Además, hay que considerar dos notas específicas, de carácter subjetivo, que caracterizan la regulación del personal estatutario:

1.- Tradicionalmente, el carácter liberal del ejercicio de las profesiones sanitarias ha condicionado ciertas particularidades del régimen jurídico de este personal, que no se ha considerado a sí mismo como un funcionario público en sentido estricto.

2.- El eje sobre el que se ha estructurado la normativa del personal estatutario ha sido fundamentalmente el de la profesión médica. Esta ha tenido más peso a la hora de que el legislador valorase a todo el personal sanitario en conjunto, a efectos de regular su vinculación laboral con la Administración pública.

Teniendo en cuenta estos parámetros, veamos brevemente cómo ha evolucionado la regulación del personal al servicio de la sanidad pública en España desde sus orígenes hasta el momento actual.

\section{2.- EL ORIGEN DE LA FUNCION PÚBLICA CON LA APARICIÓN DEL ESTADO MODERNO}

Para entender cómo ha llegado a ser la prestación sanitaria a los ciudadanos la esencia del servicio público que presta la Administración, hay que atender al momento histórico en que el Estado comienza a satisfacer determinadas necesidades de funcionamiento de su propia estructura y de sus súbditos. Los inicios de la función pública como actividad profesional se vinculan con el nacimiento del Estado moderno y coinciden con dos etapas sucesivas en el tiempo, que tienen lugar entre los siglos XVI y XVIII: el Absolutismo y el Despotismo Ilustrado ${ }^{5}$.

\footnotetext{
${ }^{4}$ Véase Presupuestos de las CC.AA., Proyectos de Presupuestos de las CC.AA. 2015. Tabla Clasificación funcional de servicios públicos fundamentales y evolución respecto al ejercicio anterior, p. 19. Disponible en. $<$ http://serviciosweb.meh.es> [consulta de 5 de enero de 2015].

${ }^{5}$ SANCHEZ MORON, M., Derecho de la Función Pública, Tecnos, Madrid, $6^{\mathrm{a}}$ ed., 2011, p. 24 y ss.
} 


\section{Capítulo I. Marco histórico normativo en el que surge la sanidad como servicio público en España y la regulación jurídica de su personal}

Anteriormente, en la época medieval, los servidores del rey eran nobles sometidos a vasallaje. Se trataba de cargos hereditarios, dedicados a lo militar, la diplomacia, justicia y recaudación de impuestos. A medida que el Rey aumenta su poder se distancia de este modelo, en el que influyen en exceso el clero y la nobleza, y se rodea de oficiales con más formación, sobre todo jurídica, que le prestan servicios con funciones asesoras y le ayudan a ejecutar su política.

Cuando en Europa surge el Absolutismo, hacia mediados del siglo XVI, los funcionarios siguen estando al servicio del rey, no del Estado. El monarca acumula todos los poderes y prácticamente ninguna obligación para con sus súbditos, ya que estos no tienen derechos que pudieran exigirle y el concepto de Estado aún es confuso. El vínculo jurídico que une a estos servidores de la Corona es una especie de mandato, representación o delegación del rey, en cuyo nombre ejercen sus prerrogativas. Rápidamente las monarquías ganan poder y lo extienden a los nuevos territorios conquistados en América, Asia..., expansión que le proporciona cuantiosos ingresos y, con ello, la necesidad y la base para crear una estructura burocrática más amplia.

Más tarde, en la época del Despotismo ilustrado, se dan los primeros indicios del nacimiento de la función pública profesional. El monarca absoluto, iluminado por las ideas de la Ilustración, pretende aplicar los principios de la razón también al ámbito de actuación de la Corona y limitar el poder religioso y de la nobleza, tan influyentes en la etapa anterior. Para ello se rodea de personas con mayor capacitación técnica, que le ayuden a llevar a cabo sus propósitos. En esta época los funcionarios, si bien al principio son principalmente de origen aristocrático, provendrán también de la emergente burguesía que poco a poco gana influencia gracias a su poder económico. Al principio sus nombramientos se basan en una decisión del rey, motivada en su confianza.

Lentamente, empieza a surgir el concepto de funcionario al servicio de un Estado que asume nuevas funciones a su cargo: el fomento de la agricultura y ganadería, construcción de puentes y caminos... A partir de ahí empieza a regularse la relación jurídica de estas personas al servicio de la Corona: el derecho al puesto, las causas de remoción, las retribuciones...

Con el triunfo de la Revolución francesa y la Declaración de derechos del Hombre y del Ciudadano de 1789, que propugna el principio de igualdad ante la ley, y en base al principio de división de poderes, se construirá el concepto moderno de la Administración pública y de los funcionarios a su servicio; cualquier ciudadano puede acceder a los cargos públicos, si bien este principio en nuestra legislación aún tardará mucho en ser aplicado ${ }^{6}$.

Por lo que respecta a nuestro país, en los siglos XVIII y XIX la función pública se desarrolló más bien de espaldas al modelo europeo, más moderno. Esto es debido a que aquí se construyó la Administración pública de una forma más desordenada e improvisada, lo

\footnotetext{
${ }^{6}$ En España, la Constitución de 1837 había declarado el principio de mérito en el acceso a los puestos públicos, pero esto no se plasmó legalmente hasta la Ley de Bases de 22 de julio de 1918, que generalizó el sistema de oposición para el ingreso en la función pública, reconociendo el principio de igualdad de acceso a los cargos públicos, ya que exigía a los candidatos requisitos objetivos adecuados a la categoría a la que optaran.
} 


\section{Capítulo I. Marco histórico normativo en el que surge la sanidad como servicio público en España y la regulación jurídica de su personal}

cual vino también condicionado por diversos factores de índole social, cultural y política, propios del país que tendrán reflejo en la legislación que regula su personal. En esa etapa, España es un país pobre, inestable políticamente y sumido en diversos conflictos tanto en las Colonias, que aspiran a la independencia, como en el interior con las Guerras Carlistas.

Las competencias de la Administración en aquel momento eran las básicas que el Estado necesitaba para su funcionamiento: militar, tributaria... La asistencia sanitaria a la población, o la higiene pública, no son aún competencia del Estado, sino de la beneficencia municipal o de la Iglesia ${ }^{7}$.

Hay que tener en cuenta también que en el siglo XVIII se ejerce un modelo de medicina liberal, muy lastrada por la falta de medios técnicos y la escasez de conocimientos, que se presta de forma particular a las clases pudientes y gratuitamente a los pobres en los establecimientos de beneficencia ${ }^{8}$. La clase médica es un sector privilegiado dentro de la burguesía, que ejerce su profesión de una forma independiente, con unos intereses de prestigio y consideración social. Actúa de manera individual y se agrupa en colegios profesionales, de acuerdo con el sistema gremial que impera en ese momento ${ }^{9}$. Este modelo continuará básicamente igual en el siglo XIX, sobre todo en las grandes ciudades.

La necesidad de atención sanitaria en esa época se cubre, por una parte, a instancia de determinados colectivos o de los ciudadanos que, individualmente, la contratan de forma directa (los gremios medievales ya habían establecido un sistema de igualas para la asistencia a sus miembros) o bien se presta por los ayuntamientos, en quienes recaen las escasas responsabilidades públicas que por entonces se reconocen, por pura necesidad de orden público, o por la Iglesia.

En efecto, la atención sanitaria a la población en esa época, y va ser así durante mucho tiempo, se presta principalmente por los municipios. Así, a finales del siglo XVIII encontramos publicadas en la Gaceta de Madrid las primeras convocatorias que realizaban los Ayuntamientos para cubrir vacantes de médico titular. Estas son frecuentes en los años posteriores, dado que sucesivas normativas atribuirán la competencia sobre los médicos titulares a los Ayuntamientos. Se trataba de puestos retribuidos conjuntamente con dinero de las arcas municipales y de los propios vecinos. La selección del médico se realizaba por parte de la autoridad municipal teniendo en cuenta, en muchos casos, los méritos del candidato según un memorandum que debía aportar el facultativo, y efectuada la elección entre los de méritos más notorios, se le hacía un nombramiento ${ }^{10}$.

\footnotetext{
7 Desde el siglo XVII en las grandes ciudades europeas se habían construido hospitales, gestionados habitualmente por la Iglesia para atender a los pobres. Sobre los orígenes de la asistencia social véase de ALONSO SECO, J.M. y GONZALO GONZÁLEZ, B., La asistencia social y los servicios sociales en España, BOE, Madrid, $2^{\mathrm{a}}$ ed., 2000.
}

${ }^{8}$ LAMATA COTANDA, F., Manual de Administración Sanitaria, Ediciones Díaz de Santos, Madrid, 1998, p. 21.

${ }^{9}$ Los primeros Colegios de médicos en España fueron los Reales Colegios de Cirugía de Cádiz, que se fundó en 1748; el de Barcelona, en 1760 y el de San Carlos -Madrid- en 1780.

${ }^{10}$ En la Gaceta de Madrid, de 4 de julio de 1797, se anuncia que: “En la Villa de Fermoselle, en Castilla, está vacante el partido de Médico; tiene dotación de 600 reales y casa pagada. La población es de 800 vecinos. 


\section{Capítulo I. Marco histórico normativo en el que surge la sanidad como servicio público en España y la regulación jurídica de su personal}

A pesar de las turbulencias históricas, en la Constitución de Cádiz de 1812 se produce la asunción de competencias del Estado en materia sanitaria. El artículo 131 señalaba como facultad vigesimatercia de las Cortes la de "aprobar los reglamentos generales para la policía y sanidad del Reino”. Esta tímida referencia constitucional a la competencia del Estado sobre la sanidad pública no se pudo hacer práctica entonces, si bien se dictó la Instrucción de 13 de junio de 1813, que atribuyó las competencias relacionadas con la higiene y la sanidad a los Ayuntamientos y a las Diputaciones provinciales a través de las Juntas de Sanidad.

Derogada esta Constitución en 1814, el proyecto reformista queda en suspenso hasta el Pronunciamiento del comandante Rafael de Riego en 1820, con el que se inicia el Trienio liberal (1820-1823) que obliga a Fernando VII a jurar la Constitución de Cádiz. Entonces, con la intención de articular un sistema sanitario público, se elabora el proyecto de Código Sanitario de 1822, de contenido progresista y muy avanzado para la época, que sin embargo, no fue aprobado en las Cortes debido a la inestabilidad política del momento ${ }^{11}$.

En 1822 se publica la Ley de Beneficencia, y más tarde la Ley de 3 de febrero de 1823, relativa al gobierno económico político de las provincias, que estableció la competencia de los Ayuntamientos en la contratación de los facultativos, para que al menos: “... Se atendiera a los pobres sin perjuicio de que, si los fondos públicos lo pueden sufrir, se extienda también a la dotación de la asistencia sanitaria a todos los demás vecinos. Los facultativos serán admitidos y contratados por el Ayuntamiento, pero si sus sueldos $u$ honorarios se hubiesen de satisfacer por iguales o repartimento vecinal, solo se sujetará a este pago a los que quieran servirse de los facultativos acogidos” (art. 12).

Esta última, sin embargo, no llegó a promulgarse, ya que repuestos los poderes absolutos de Fernando VII, en diciembre de 1823, los intentos de los liberales de regular la incipiente sanidad pública se frustran. Sin embargo, por lo que se refiere a la regulación de la función pública, sí se produce un cambio significativo, responsabilidad del ministro de Hacienda López Ballesteros, que será uno de los antecedentes más relevantes de la regulación de funcionarios en este país. Se trata del Real Decreto de 1825 sobre "el nuevo arreglo de Empleados" ${ }^{12}$. Su contenido estaba referido a la regulación de las situaciones de los funcionarios jubilados y cesantes o los sueldos y haberes a pagar, según sus cargos. Esta normativa solo era de aplicación, como señala el Real Decreto publicado el 22 de abril de

Los profesores que quieran pretenderlo se dirigirán al Ayuntamiento de esta villa". Otro anuncio en la del 18 de mayo de 1798 dice: "En la villa de Lumbrales, obispado de Ciudad-Rodrigo cuya población se compone de 540 vecinos, se halla vacante la plaza de su médico titular, que está dotada con 600 reales de vellón anuales. Los sujetos que quieran pretenderla acudirán a la Justicia y al Ayuntamiento de dicha villa a la mayor brevedad". Véase también la Gaceta de Madrid de 3 de abril de 1801, que anuncia para proveer la vacante de médico titular de la villa de Bermeo, o la de 6 de agosto de 1802, que anuncia vacante de médico titular en Santander. Disponible en: <http:// www.boe.es/legislación/gaceta/colección histórica, 1661-1959>.

${ }^{11}$ BANDO CASADO, H.C., "Evolución histórica de la protección de la salud en España: desde 1812 hasta la Ley General de Sanidad", Revista de Estudios sobre Consumo, nº 8, 1986.

${ }^{12}$ El denominado “Estatuto de López Ballesteros” consiste en varios Reales Decretos, publicados entre 1825 y 1828, que regulan de forma básica los principales aspectos del incipiente régimen jurídico funcionarial español. 


\section{Capítulo I. Marco histórico normativo en el que surge la sanidad como servicio público en España y la regulación jurídica de su personal}

1828: "a los empleados de las carreras civiles que dependen de los Ministerios de Estado, de Gracia y Justicia y de Hacienda”. Entre estos no figuran los facultativos o médicos, a los que no se considera empleados del Estado.

\section{3.- LA CONSOLIDACION DE LA FUNCION PÚBLICA DURANTE LA CONSTRUCCION DEL ESTADO LIBERAL Y LA REIVINDICACIÓN SINDICAL DE PROTECCION DE LA SALUD DE LOS TRABAJADORES}

Con la muerte de Fernando VII en 1833, el Estatuto Real de $1834^{13}$, finiquita el Antiguo Régimen en España e introduce aquí las instituciones parlamentarias propias de los países europeos más avanzados. El Estatuto Real, no obstante, carece de una declaración de derechos de los ciudadanos, que por el contrario sí recogerá posteriormente la Constitución de 1837, entre ellos, y por primera vez, el principio de igualdad de acceso a los cargos públicos.

Durante el período de reinado de Isabel II, que durará hasta 1868, se producen una serie de cambios políticos y sociales que consumarán la revolución burguesa y el triunfo del Estado liberal. Ahora se aprecia un cambio de concepto, de manera que de la sanidad y la beneficencia del Antiguo Régimen, entendidas como expresión de la caridad cristiana, se pasa a la beneficencia pública, de carácter liberal, cuya competencia se atribuirá a las provincias y municipios ${ }^{14}$. Durante esta etapa el Estado aún no asume responsabilidades significativas en materia sanitaria; la tendencia de la época es precisamente atribuir las competencias sobre sanidad a los entes locales.

En este sentido, la Ley de organización y atribuciones de los Ayuntamientos de 1843, estableció en el artículo 61: "Es privativo de los Ayuntamientos: 1. admitir, bajo las condiciones prescritas en las leyes o reglamentos, los facultativos de medicina, cirugía, farmacia y veterinaria, los maestros de primeras letras y los de otras enseñanzas que se paguen de los fondos del común" 15.

A la vez, en esta primera mitad del siglo XIX, se suceden por toda Europa reivindicaciones obreras y campesinas en lucha por los derechos laborales y sociales y, entre ellos, el de la asistencia sanitaria. El Movimiento Obrero demanda como derecho lo que la burguesía paga como un servicio privado que le presta un profesional liberal, y considera que los médicos son servidores del Estado y que la asistencia sanitaria debe ser un bien a disposición del pueblo. En los países europeos más avanzados esto deriva en la implantación de seguros de enfermedad obligatorios que servirán de precedente para la

\footnotetext{
${ }^{13}$ Carta otorgada que se promulga durante la regencia de María Cristina de Borbón, madre de Isabel II. En ella se hace dejación de los poderes absolutos de la Corona, bajo las presiones liberales, a cambio de mantener indiscutible el derecho de su hija Isabel, aún menor de edad, al trono de España.

${ }^{14}$ La ley de 20 de junio de 1849 reguló los establecimientos de beneficencia.

${ }^{15}$ Gaceta de Madrid de 31 de diciembre de 1843.
} 


\section{Capítulo I. Marco histórico normativo en el que surge la sanidad como servicio público en España y la regulación jurídica de su personal}

futura normativa en nuestro país ${ }^{16}$. En España, la población, además de las pésimas condiciones sanitarias motivadas por la penuria económica y denunciadas por los higienistas de la época ${ }^{17}$, sufre el efecto de las constantes epidemias que causaban una gran mortalidad $^{18}$.

Los autores coinciden en señalar como factores causantes del atraso sanitario en nuestro país los enfrentamientos sociales y políticos, así como el aislamiento en la formación de los profesionales médicos del resto de Europa, que provenía de la prohibición de Felipe II de estudiar en las universidades europeas para evitar la contaminación de la $\mathrm{fe}^{19}$.

Mientras, en la segunda mitad del siglo XIX, también evoluciona más rápidamente la legislación de funcionarios en nuestro país y se aprueba el Real Decreto de 18 de junio de 1852, conocido como Estatuto de Bravo Murillo. Este se considera la primera manifestación positiva de regulación con carácter general del ingreso, ascenso, clasificación, remuneración y derechos de los empleados públicos ${ }^{20}$. Sin embargo, este estatuto no es aplicable a los médicos ni profesionales sanitarios, ya que como vemos, no dependen del Estado. Sí se dicta el Real Decreto de 5 de abril de 1854, que establece las clases de facultativos que debía haber en cada pueblo, estableciendo en este aspecto, una regulación común a nivel estatal, organizando por partidos la asistencia sanitaria, que hacía recaer la carga económica de su mantenimiento sobre los ayuntamientos, dentro del sistema de la beneficencia $^{21}$.

En 1855, en un intento de organizar la Administración sanitaria, se promulga la Ley de 28 de noviembre, sobre el Servicio General de Sanidad ${ }^{22}$. Esta atribuye a los Gobernadores civiles el servicio de sanidad de sus provincias, bajo la dependencia del Ministerio de la Gobernación y crea las Juntas de Sanidad provinciales y municipales, dejando para un reglamento posterior la regulación de sus atribuciones. Ocho años antes se

${ }^{16}$ REDONDO RINCON, M.G., El seguro obligatorio de enfermedad en España: responsables técnicos y políticos de su implantación durante el franquismo, (tesis doctoral), Universidad Complutense, 2012, p. 129.

${ }^{17}$ MONLAU I ROCA, P., Elementos de higiene pública, Imprenta Pablo Riera, Barcelona, 1847, [consulta de 30 de abril de 2014], disponible en: 〈http://books.google.es>.

${ }^{18}$ LAMATA COTANDA, F., Manual de Administración Sanitaria..., op. cit. p. 32: la epidemia de cólera de 1834 en España produjo 100.000 muertos. Volverá a repetirse en 1865 y 1885.

${ }^{19}$ VIÑES RUEDA, J. J., "La Sanidad Española en el siglo XIX a través de la Junta Provincial de la Sanidad Navarra (1870-1902)", Gobierno de Navarra, 2006.

${ }^{20}$ Clasificaba a los empleados de la Administración activa del Estado en cinco categorías, a cada una de las cuales correspondía un determinado sueldo. Se fijaban, igualmente, las condiciones y requisitos que debían reunir los aspirantes para el ingreso en la Administración y para el ascenso de categoría, así como sus derechos y deberes. Nos encontramos ya frente a un primer Estatuto que sienta las bases de la organización burocrática española, aunque uno de los principales defectos del Estatuto de Bravo Murillo es que se aplicó a un número escaso de funcionarios, al excluir en bloque a las carreras especiales.

${ }^{21}$ Gaceta de Madrid de 12 de abril de 1854.

${ }^{22}$ Gaceta de Madrid de 7 de diciembre de 1855. 


\section{Capítulo I. Marco histórico normativo en el que surge la sanidad como servicio público en España y la regulación jurídica de su personal}

había creado la Dirección General de Sanidad. Por lo que se refiere a las disposiciones de la Ley del Servicio General de Sanidad relativas al personal, el artículo 11 señala: "Los empleados en el ramo de la Sanidad gozarán los mismos derechos activos y pasivos que los empleados en los demás ramas del servicio público con arreglo a lo que las leyes dispongan".

Además, en el Capítulo XIII regula ciertos derechos y deberes del personal facultativo (profesores, como los denomina) reconociendo su dependencia de los Ayuntamientos, que los contrataban como médicos titulares. Aunque la contratación de estos médicos por los Ayuntamientos ya estaba prevista en su Ley de Organización y Atribuciones de 1843, lo destacable de la Ley del Servicio General de Sanidad es que se regula para ellos unos derechos y deberes, lo cual podría considerarse un esbozo de estatuto normativo para este personal, al que se vincula con la Administración mediante una relación que presenta muchas semejanzas con la funcionarial.

Efectivamente, esta ley en su artículo 68 señala: "No se podrá obligar a los facultativos a prestar otros servicios científicos que los consignados en sus contratos". Y en el artículo 69 dice que: "Los nombramientos de facultativos titulares que hagan los pueblos serán aprobados por la Diputación provincial...”.

También se recoge el derecho de los médicos titulares a que no se anulara su escritura (nombramiento) salvo mutuo acuerdo de facultativos y municipalidades, o por causa legítima probada por el oportuno expediente y previo fallo de la Diputación provincial, recurrible ante el Tribunal de lo contencioso administrativo ${ }^{23}$. Se contempla, incluso, el derecho a indemnización en caso de inutilidad por causa del ejercicio de la profesión, o la pensión para los familiares en caso de su fallecimiento; el deber de residencia en el municipio y el de permanencia en él en caso de epidemia o contagio. Las funciones de estos médicos son de tipo asistencial y de carácter asesor de la autoridad municipal, y se aprecian ciertas notas típicas de la función pública en su contratación: los médicos perciben las retribuciones que paga la autoridad municipal de sus presupuestos, y el deber de acatar las instrucciones del superior, en este caso de la autoridad municipal: "Los profesores que disfruten sueldo o destino pagado por el presupuesto general, provincial ó municipal están obligados, si ejercen, a prestar sus servicios facultativos a la población en que residan cuando la autoridad lo exija” (art. 77).

Mientras tanto, tienen lugar los inicios del asociacionismo obrero en Europa y también más tarde en España, e inician su actividad algunas organizaciones sindicales. Con la corriente revolucionaria europea de los años sesenta del siglo XIX llegamos a la Constitución de 1869, la primera verdaderamente democrática de España, al menos por lo que se refiere a la amplia declaración de derechos que recoge, entre ellos el derecho de igualdad en el acceso a los cargos públicos (art. 2): “Todos los españoles son admisibles a los empleos y cargos públicos según su mérito y capacidad. La obtención y el desempeño de

\footnotetext{
${ }^{23}$ Véase el anuncio en la Gaceta de Madrid de 29 de mayo de 1855, de la sentencia del "Tribunal Supremo contencioso administrativo", revocando a su vez la sentencia del Consejo Provincial (de Burgos) de 14 de octubre de 1853, que condena a pagar al Ayuntamiento de Espinosa de los Monteros el salario de 7.280 reales, correspondientes al año 1852, por haber despedido a un médico titular.
} 


\section{Capítulo I. Marco histórico normativo en el que surge la sanidad como servicio público en España y la regulación jurídica de su personal}

estos empleos y cargos, así como la adquisición y el ejercicio de los derechos civiles y políticos, son independientes de la religión que profesen los españoles. El extranjero que no estuviere naturalizado no podrá ejercer en España cargo alguno que tenga aneja autoridad o jurisdicción”. En el artículo 17 también se contemplaba el derecho de asociación: "Tampoco podrá ser privado ningún español [...] del derecho de asociarse para todos los fines de la vida humana que no sean contrarios a la moral pública”.

La Constitución de 1869 fue muy relevante en cuanto a la declaración de derechos que realizó, pero tuvo escasa trascendencia práctica en la mejora de las condiciones de las clases trabajadoras, y tampoco abordó la competencia del Estado en materia sanitaria.

Así llegamos a la Primera República (1873-1874) que, dada su escasa duración, poco pudo aportar a la construcción de un sistema sanitario o al reconocimiento de la libertad sindical. Palomeque López ${ }^{24}$ destaca únicamente de esta etapa la Ley de 24 de julio de 1873 , por la que los niños y niñas menores de diez años no podían ser admitidos al trabajo en ninguna fábrica, taller, fundición o mina ${ }^{25}$.

Restaurada la monarquía de Alfonso XII, y vigente la Constitución de 1876, en la línea de dar satisfacción a las reivindicaciones obreras, se crea en diciembre de 1883 por el gobierno de Cánovas del Castillo la Comisión de Reformas Sociales ${ }^{26}$. Esta comisión estuvo dedicada "al estudio de las cuestiones que interesaban a la mejora de las clases obreras". Para la doctrina, la creación de este órgano es plasmación práctica de la política social que decide llevar a cabo la burguesía liberal preocupada por la radicalización de los planteamientos obreros ${ }^{27}$. La actividad de la Comisión se prolongó hasta 1903, año en que se fundó el Instituto de Reformas Sociales, y propició importantes avances normativos en el ámbito de lo que hoy es la Seguridad Social.

De esta manera, en 1900 se aprueba la Ley de Accidentes de Trabajo y en 1903 la creación del Instituto de Reformas sociales. La Ley de 27 de febrero de 1908 regulará las funciones del Instituto Nacional de Previsión (INP), estableciendo el régimen de contratación de pensiones de retiro de manera voluntaria para los trabajadores.

Por lo que se refiere a las asociaciones obreras, estas no se legitimaron hasta que, promulgada la Constitución de 1876, se desarrolló el derecho fundamental de asociación en la Ley de Asociaciones de 30 de junio de $\mathbf{1 8 8 7}^{28}$. Esta ley reconoció la personalidad

\footnotetext{
${ }^{24}$ PALOMEQUE LOPEZ, M.C., Derecho del Trabajo e Ideología, Tecnos, Madrid, 2011, p. 79.

${ }^{25}$ Viene publicada en la Gaceta de Madrid de 28 de julio de 1873.

${ }^{26}$ Real Decreto de 5 de diciembre de 1883, publicado en la Gaceta de Madrid de 10 de diciembre del mismo año.
}

${ }^{27}$ GONZALEZ FERNANDEZ, A., "La comisión de reformas sociales. Reformismo y clases trabajadoras en la Sevilla del s. XIX.”, Revista de Historia Contemporánea, no 6, 1995, pp. 95 a 118.

${ }^{28}$ Gaceta de Madrid de 12 de julio de 1887. A partir de 1830 habían aparecido las primeras uniones y sindicatos en Europa. En 1864, la Asociación Internacional de Trabajadores; el Partido Socialista Obrero Español se funda en 1879 y la Unión General de trabajadores en 1888. 


\section{Capítulo I. Marco histórico normativo en el que surge la sanidad como servicio público en España y la regulación jurídica de su personal}

jurídica de los sindicatos, como la de cualquier otra asociación sin ánimo de lucro. Exigía, eso sí, el registro de la asociación y había un control administrativo en su actuación. En realidad el objetivo de la ley no era el de promocionar este tipo de asociaciones obreras, que, sin embargo, se beneficiaron de la regulación del derecho de asociación que la burguesía liberal demandaba para sí. Esto supuso un avance importante para los movimientos obreros ${ }^{29} \mathrm{y}$, más adelante, también se legitimó el recurso a la huelga ${ }^{30}$.

Al mismo tiempo se produjeron a nivel internacional toda una serie de avances de la ciencia médica muy considerables, la incorporación de nuevas disciplinas y especialidades y de nuevas profesiones al ámbito sanitario, como la enfermería o la fisioterapia, a la vez que se transformaban las profesiones veterinaria y farmacéutica ${ }^{31}$.

Pero ¿qué regulación tenía el personal sanitario en esta época? Los médicos titulares seguían dependiendo de los Ayuntamientos, de acuerdo con lo que disponía la Ley del Servicio General de Sanidad. La dependencia de los caciques municipales, las bajas retribuciones y los retrasos en el cobro de sus retribuciones motivaron la reivindicación de que el Estado asumiera las competencias sobre ellos. Esta inquietud colectiva se canalizó a través de los Colegios de médicos, cuya existencia se había generalizado en todo el territorio del Estado.

En 1904 se aprueba la Instrucción general de Sanidad, aprobada por Real Decreto de 12 de enero de 1904 que, en desarrollo de la Ley de 1855, reconocía la competencia del Ministerio de la Gobernación en cuanto a la vigilancia de los servicios de Sanidad e Higiene Pública (art. 1) y haciéndose eco de los avances europeos en la materia, destacó como el texto normativo más largo y minucioso de la legislación sanitaria comparada del momento ${ }^{32}$.

En efecto, la Instrucción regula la organización sanitaria, el régimen sanitario interior (cementerios, mercados, escuelas...) y, en su Título III, las profesiones sanitarias

\footnotetext{
${ }^{29}$ PELAYO OLMEDO, J.D., El derecho de asociación en la historia constitucional española, con particular referencia a las leyes de 1887 y 1964, Revista electrónica de Historia Constitucional, no 8, septiembre 2007, [consulta de 02 de abril de 2013], disponible en: 〈http:hc.rediris.es〉.

${ }^{30}$ La Circular de la Fiscalía del Tribunal Supremo de 20 de junio de 1902 señalaba que: “...cumplido lo que dispone la Ley de Asociaciones de 1887, los trabajadores se asocian y coligan para un fin tan humano como el de mejorar las condiciones de trabajo con que atienden al diario sustento, la asociación es perfectamente lícita y si produce la huelga o la abstención colectiva del trabajo se ejercita un derecho que no puede ser cohibido, ni sometido a juicio mientras no surja la excepción que para el abuso, es decir, la violencia y amenaza establece el artículo 556 del Código Penal (de 1870)”.
}

\footnotetext{
${ }^{31}$ Durante los inicios del Movimiento Obrero, la reforma del sistema educativo propició la incorporación de la mujer a las profesiones sanitarias (Ley Moyano, 1857). Así, se crean los estudios de Practicantes. Años más tarde se funda la Escuela Nacional de Puericultura y se crea la especialidad de Enfermera Visitadora Puericultora. A principios del s. XX aparecerán las Escuelas de Enfermería y, con ellas, esta profesión se regula formalmente en 1915 .
}

32 RODRIGUEZ OCAÑA, E., “La Salud Pública en España en el contexto europeo, 1890-1925”, Revista Sanitaria de Higiene Pública, nº 68, 1994. 


\section{Capítulo I. Marco histórico normativo en el que surge la sanidad como servicio público en España y la regulación jurídica de su personal}

“libres y oficiales”. Por lo que se refiere a estas últimas, dispone la creación del Cuerpo de Médicos Titulares, al que se accedía por oposición, reconociéndoles expresamente la condición de funcionarios de la sanidad local (art. 91). La función de estos médicos era la "asistencia a los enfermos pobres" y estaban a cargo de los Ayuntamientos junto con un practicante titulado, un farmacéutico y un veterinario titulares en municipios de más de dos mil habitantes.

En el plano sindical también se producen progresos: la Ley de 27 de abril de 1909 de coligaciones, huelgas y paros reconoció el derecho de los patronos y obreros a "coligarse, declararse en huelga y declarar el paro a los efectos de sus respectivos intereses sin perjuicio de los derechos que dimanen de los contratos que hayan celebrado" (art. 1) ${ }^{33}$.

Este ideal del asociacionismo obrero se fue extendiendo a la función pública, que años más tarde verá reconocido legalmente su derecho de asociación en el "Estatuto Maura" de 1918, el cual es especialmente importante por sentar las bases de lo que será su regulación normativa posterior ${ }^{34}$. Por lo que respecta al derecho de asociación funcionarial, esta norma dispuso que estuviera sujeto a autorización del Ministerio de la Gobernación, regulando en la base décima las "Asociaciones de funcionarios". Este aspecto se desarrolló en el capítulo VI del Real Decreto de aprobación del Reglamento, artículos 78 a $85^{35}$.

En 1919 se aprueba la implantación del seguro obligatorio del retiro obrero ${ }^{36}$, cuya gestión asume el INP, y en 1922 se crea el Ministerio del Trabajo, Comercio e Industria. Ese mismo año también se aprueba el Código de Trabajo, el subsidio de maternidad en 1923, y el seguro obligatorio de maternidad en 1929, que garantizaba, entre otras, la asistencia facultativa en el embarazo y parto.

${ }^{33}$ Gaceta de Madrid de 28 de abril de 1909.

34 El denominado "Estatuto Maura" estaba conformado por la Ley de Bases de 22 de julio de 1918 y el Reglamento de 7 de septiembre del mismo año, y destaca por ser la primera norma de rango legal que utiliza el término "funcionario" para referirse al personal vinculado a la Administración por una relación de servicios profesional regulada en la ley y en los reglamentos. Era aplicable a todos los Cuerpos de cualquier nivel, ya fuesen especiales o generales, y consagró la estructura corporativa y el sistema de categorías de los funcionarios. Reguló las retribuciones, los ascensos y las pruebas selectivas o de ingreso: las oposiciones, para las que se exigían condiciones objetivas de edad, nacionalidad española y titulación adecuada.

${ }^{35}$ El artículo 78 del Reglamento disponía: "Los funcionarios podrán asociarse con arreglo a la Constitución y a las Leyes gozando a tales efectos de plena personalidad jurídica. Cualquier asociación, agrupación o representación colectiva de funcionarios dependientes de un Ministerio o de varios aunque tengan por objeto un legítimo interés o el auxilio o beneficio mutuo de los que las compongan, y no obste al buen servicio del Estado, necesitará para formarse la expresa aprobación ministerial”. El artículo 79 regulaba el procedimiento para constituir las asociaciones de funcionarios, que se iniciaba a través de instancia dirigida al Ministro de la Gobernación que, según el artículo 80, debía elevarlo para resolución al Consejo de Ministros en el caso de que la Asociación diera cabida a funcionarios de distintos ministerios. El artículo 84 daba la prerrogativa al Gobierno de disolver las asociaciones de funcionarios, dando cuenta de su acuerdo a las Cortes. El artículo 85 declaraba como supletoria la Ley de Asociaciones de 30 de junio de 1887.

${ }^{36}$ Real Decreto Ley de 11 de marzo de 1919. 


\section{Capítulo I. Marco histórico normativo en el que surge la sanidad como servicio público en España y la regulación jurídica de su personal}

Es destacable también la publicación en 1924 del Estatuto municipal y del Estatuto Provincial en 1925. Estas normas atribuyeron a los Ayuntamientos y a las Diputaciones provinciales determinadas competencias en materia de higiene y salud pública, desplegando una serie de obligaciones de estas Administraciones en el ámbito sanitario ${ }^{37}$. Sin embargo, aunque los Estatutos supusieron un intento de progreso en el ámbito de la Administración local, subyace aún en estas normas la concepción de la asistencia sanitaria como manifestación de la beneficencia, y el papel del Estado como mero facilitador del papel de los agentes implicados.

Como vemos, es, en definitiva, la demanda de las clases obreras que reclaman la asistencia sanitaria como prestación del Estado, y a la que finalmente tendrá que acceder el poder, la que condiciona el cambio de la medicina liberal a la medicina como servicio público. Esto derivará en el cambio en la relación de servicios de los médicos y sanitarios, y con el tiempo este conjunto de profesionales irá tomando conciencia de ser un colectivo con intereses comunes, de lo cual surge la necesidad de reclamar derechos laborales en cuanto tal.

\section{4.- EL TRIUNFO DE LAS REIVINDICACIONES SINDICALES CON EL SURGIMIENTO DEL ESTADO SOCIAL}

Durante la Segunda República (1931-1936) cuajan gran parte de los proyectos reformistas en torno a la sanidad pública y la libertad sindical. La doctrina destaca de esta etapa histórica el espectacular desarrollo de las relaciones colectivas de trabajo y de las normas de previsión social (protección por accidentes de trabajo, enfermedades profesionales, paro, maternidad y vejez...) que justifican que se sitúe durante la misma el nacimiento en España del Estado Social ${ }^{38}$, que inicia una "fase de consolidación y sistematización de la legislación laboral desde bases democráticas" y "una nueva y fructífera etapa en la evolución del Derecho del Trabajo" ${ }^{\text {39 }}$.

En efecto, el artículo 39 de la Constitución de 9 de diciembre de 1931, por primera vez reconoce el derecho a la libertad sindical: "Los españoles podrán asociarse o sindicarse libremente para los distintos fines de la vida humana, conforme a las leyes del Estado. Los

${ }^{37}$ El Estatuto municipal fue desarrollado a su vez por distintos reglamentos, el último de los cuales fue el Reglamento de Sanidad Municipal, de 9 de febrero de 1925, que en el Capítulo IV del Título V reguló como obligaciones sanitarias de los Ayuntamientos las referentes principalmente a la higiene municipal y salud pública, estableciendo en el articulo 207 también la de crear servicios de asistencia médico farmacéutica y asistencia en partos para familias pobres (servicios de asistencia benéfica). Declaró también subsistentes los Cuerpos de médicos, farmacéuticos y veterinarios titulares. Por su parte, el Estatuto Provincial, publicado el 21 de marzo de 1925, atribuye determinadas obligaciones a las Diputaciones provinciales en materia sanitaria, fundamentalmente por lo que se refiere a aspectos de salud pública y sostenimiento de establecimientos de maternidad, beneficencia hospitalaria, de caridad...

${ }^{38}$ DE LA VILLA GIL, L.E., La formación histórica del Derecho del Trabajo, Comares, Granada, 2003, p. 328 y ss.

${ }^{39}$ SEMPERE NAVARRO, A., MARTIN JIMÉNEZ, R.," La formación del Derecho del Trabajo en España" en AAVV, Derecho del Trabajo, Aranzadi, Navarra, 2012, pp. 77 y ss. 


\section{Capítulo I. Marco histórico normativo en el que surge la sanidad como servicio público en España y la regulación jurídica de su personal}

Sindicatos y Asociaciones están obligados a inscribirse en el Registro público correspondiente, con arreglo a la ley”.

Por lo que se refiere a la función pública, en el artículo 40 se reconoció expresamente el principio de igualdad y mérito en el acceso a los cargos públicos ${ }^{40}$, y en el artículo 41 reguló una serie de garantías, como la adecuación a la ley de sus nombramientos y ceses, el principio de libertad de opinión, así como su derecho de asociación profesional: "Los funcionarios civiles podrán constituir Asociaciones profesionales que no impliquen injerencia en el servicio público que les estuviere encomendado. Las Asociaciones profesionales de funcionarios se regularán por una ley. Estas Asociaciones podrán recurrir ante los Tribunales contra los acuerdos de la superioridad que vulneren los derechos de los funcionarios".

Y es que, a pesar de la dicción literal del artículo 39: "Los españoles podrán sindicarse libremente...”, los funcionarios públicos no quedaron incluidos en el ámbito subjetivo de este derecho, sino en el de asociación profesional. Esta exclusión de los funcionarios por lo que se refiere al disfrute del derecho a la libertad sindical en la Constitución de 1931, ha sido criticada por la doctrina, por tratarse de un criterio restrictivo con respecto a sus derechos asociativos ${ }^{41}$.

Asimismo, se publicó la Ley de 8 de abril de 1932, que reguló las asociaciones de patronos u obreros "para la defensa de las clases respectivas en determinadas profesiones, industrias o ramos de estas” (art. 1) y, en consecuencia, permitió la constitución de sindicatos ${ }^{42}$.

Respecto a la legislación de funcionarios durante la Segunda República, esta venía dada aún por el Estatuto Maura de 1918, a la que se sumaron algunas normas puntuales como la Ley de 27 de diciembre de 1934, que declaró la edad de jubilación forzosa de los funcionarios a los setenta años, pero no se dieron novedades legislativas muy significativas en esta materia.

Por el contrario, una de las principales preocupaciones del régimen republicano era precisamente la reforma del sistema sanitario español. En cuanto al diseño del sistema sanitario público, hay que tener en cuenta el artículo 15 de la Constitución, que atribuía al Estado como competencia séptima la legislación y, en su caso, a las regiones autónomas la ejecución -en la medida de su capacidad política, a juicio de las Cortes- sobre las bases mínimas de la legislación sanitaria interior. En este sentido se consideraba urgente la

\footnotetext{
${ }^{40}$ Que decía: “Todos los españoles, sin distinción de sexo, son admisibles a los empleos y cargos públicos según su mérito y capacidad, salvo las incompatibilidades que las leyes señalen”.

${ }^{41}$ GARCIA ABELlAN, J., Curso de Derecho Sindical, Universidad de Murcia, $2^{\text {a }}$ ed., 1986. En opinión de este autor, aunque el reconocimiento de la libertad sindical en la Constitución de 1931 supuso un avance jurídico muy loable, resultó restrictivo respecto a los derechos asociativos de los funcionarios públicos, reafirmándose el criterio invariable del poder público ante los primeros brotes del movimiento asociativo funcionarial.

${ }^{42}$ Gaceta de Madrid de 14 de abril de 1932.
} 


\section{Capítulo I. Marco histórico normativo en el que surge la sanidad como servicio público en España y la regulación jurídica de su personal}

supresión de la Ley del Servicio General de Sanidad de 1855, todavía vigente en aquel momento.

En el año 1932, siendo Ministro de Trabajo y Previsión Francisco Largo Caballero, se planteó una propuesta al Parlamento para la ampliación de la cobertura sanitaria y la transformación del sistema de previsión en un auténtico Sistema Nacional de Salud que, sin embargo, no prosperó.

Las competencias sobre sanidad pasaron a depender de un Ministerio propio. Así se dictó el Decreto de 25 de diciembre de 1933, según el cual la Subsecretaría de Sanidad y Beneficencia pasó del Ministerio de la Gobernación al Ministerio de Trabajo, que se denominaría en adelante Ministerio de Trabajo, Sanidad y Previsión ${ }^{43}$. Este hecho es muy significativo, ya que con la creación de un Ministerio específico se pretendía superar la desarticulación del sistema sanitario público español que estaba, como vimos antes, principalmente bajo la dependencia de los Ayuntamientos y Diputaciones.

El logro legislativo más destacable en materia sanitaria fue, sin embargo, la aprobación de la Ley de Coordinación Sanitaria de 11 de julio de $1934^{44}$, primer paso de la reforma sanitaria que de manera urgente se pretendía llevar a cabo, y que concebía la Sanidad como "una función pública de colaboración reglada de actividades municipales, provinciales y estatales, bajo la dirección técnica y administrativa del Estado” (Base $3^{\mathrm{a}}$ ).

Esta ley, además, creó un organismo administrativo en cada provincia denominado Mancomunidad de municipios, con atribuciones sanitarias delegadas por el Ministerio de Trabajo, Sanidad y Previsión, concebido como una "Junta representativa de los Municipios y Junta delegada del Estado en una labor de perfecta fusión de recursos económicos para la mayor eficacia de sus funciones, en servicio de los intereses de la Higiene y la Asistencia Pública, como elementos integrantes de la Sanidad".

La atención a los gastos sanitarios la consideraba la ley como "preferente entre las preferentes" y, en consecuencia, establecía que: "Todas las cantidades que se recauden e ingresen en la Delegación de Hacienda [...] tendrán mientras permanezcan en el Tesoro el carácter de depósito a disposición, en primer lugar del Ministerio de Trabajo, Sanidad y Previsión... en tanto no hayan sido cubiertas dichas atenciones sanitarias” (Base 12).

Las repercusiones de la Ley de Coordinación Sanitaria respecto al personal sanitario fueron importantes, y a partir de entonces las retribuciones de los médicos titulares subieron considerablemente (en la Base 18 estableció sus cuantías mínimas) y su pago, aunque seguía dependiendo de los Ayuntamientos, se garantizó por el Estado. De hecho, en la Base 13 de la Ley encontramos regulado el deber de pago inexcusable de los débitos contraídos con los sanitarios titulares hasta la aprobación de la misma.

Esta preocupación por los derechos retributivos del personal sanitario local se manifiesta en la Ley de 27 de noviembre de 1934, que estableció la obligación de los Ayuntamientos de

\footnotetext{
${ }^{43}$ Gaceta de Madrid de 26 de diciembre de 1933.

${ }^{44}$ Gaceta de Madrid de 15 de julio de 1934.
} 


\section{Capítulo I. Marco histórico normativo en el que surge la sanidad como servicio público en España y la regulación jurídica de su personal}

consignar sus nóminas para garantizarles el pago, y la competencia de las Delegaciones de Hacienda para, en caso contrario, descontar su importe de las cantidades que debían serles transferidas por el Estado ${ }^{45}$. También se reguló su relación jurídica como funcionarios técnicos del Estado, así como la provisión de sus puestos de trabajo (la Ley de 15 de septiembre de 1932 reguló la provisión de puestos de médicos titulares mediante oposición o concurso, y con intervención de las Inspecciones Provinciales de Sanidad, órganos periféricos de la Administración Central del Estado, o de un Tribunal designado por las Asociaciones profesionales, con lo cual pretendía establecer un criterio de objetividad en su selección). Igualmente se publicó el Reglamento de 29 de septiembre de 1934, del Cuerpo de médicos de Asistencia Pública Domiciliaria, desapareciendo la denominación de médico titular.

Asimismo, se aprobó el Reglamento orgánico del Cuerpo Médico de la Sanidad Nacional, de 4 de diciembre de 1935. La relación jurídica de los médicos de la Sanidad Nacional era funcionarial, a todos los efectos (art. 1). En el Cuerpo se ingresaba por oposición libre (art. 17) y tenían un régimen de incompatibilidades que prohibía el ejercicio libre de la profesión médica (art. 19) ${ }^{46}$.

En definitiva, la etapa de la Segunda República fue decisiva en el desarrollo de los planteamientos de progreso en el ámbito sanitario, siendo la clave del cambio de mentalidad el nuevo concepto de prestación de la asistencia sanitaria: ya no se pretende asistir solo a los pobres, sino al conjunto de los ciudadanos. Durante el primer bienio de la Segunda República se incrementaron en más de un $150 \%$ los créditos presupuestarios destinados al servicio público sanitario ${ }^{47}$. En ese sentido estaba orientado el proyecto de Ley Orgánica reguladora de la Sanidad, que nunca llegó a aprobarse. A pesar de estas reformas, la doctrina señala la fuerte oposición, en general, del colectivo médico a aceptar estos cambios organizativos y la creación de un modelo de sanidad pública durante esta etapa ${ }^{48}$.

\footnotetext{
45 "Las consignaciones presupuestarias correspondientes a la dotación de todos los sanitarios municipales (Médicos, Farmacéuticos titulares, Tocólogos, Oculistas. Odontólogos, Inspectores de Higiene pecuaria. Practicantes y Comadronas) serán ingresadas por los Municipios correspondientes en las Delegaciones de Hacienda de las respectivas provincias, a partir de 1 de Enero de 1935 si los Ayuntamientos respectivos han dejado de transcurrir un cuatrimestre sin efectuar el pago de las nóminas de las clases sanitarias. En el caso de que los Ayuntamientos no hayan ingresado trimestralmente la consignación referida, las Delegaciones de Hacienda descontarán su importe de los pagos que tengan que efectuar a los respectivos Ayuntamientos, en concepto de participación de éstos en los impuestos del Estado que no se abonarán en ningún caso hasta que hayan sido satisfechas como obligaciones primordiales en pago de las clases sanitarias" (art.3). Publicada en la Gaceta de Madrid de 28 de noviembre de 1934.

${ }^{46}$ Gaceta de Madrid de 6 de diciembre de 1935.

${ }^{47}$ MARSET CAMPOS, P, SAEZ GOMEZ, J.M, MARTINEZ NAVARRO, F., "La Salud pública durante el Franquismo", Revista Dynamis, no 15, 1995, p. 211-250.

${ }^{48}$ Véase de JIMENEZ-LUCENA, I., El Estado como aliado. Los médicos y el proceso de estatalización de los servicios sanitarios en la Segunda República española, [consulta de 27 de abril de 2014], disponible en: $<$ http://asclepio.revistas. csic.es $>$.
} 


\section{Capítulo I. Marco histórico normativo en el que surge la sanidad como servicio público en España y la regulación jurídica de su personal}

La inestabilidad política de los últimos años del régimen republicano no propició la aplicación práctica de la Ley de julio de 1934, pero, a pesar de ello, su contenido sirvió de presupuesto a la Ley de Bases de Sanidad de 1944.

\section{5.- LOS INICIOS DEL SISTEMA DE SEGURIDAD SOCIAL EN UN MARCO POLÍTICO SIN LIBERTADES. LOS ESTATUTOS JURÍDICOS DE PERSONAL DE LA SEGURIDAD SOCIAL}

En la etapa franquista, durante la posguerra se centran los esfuerzos sanitarios en atajar las epidemias y las enfermedades como la tuberculosis o el paludismo, que asolan a la población. La doctrina coincide en apuntar como causas del retroceso científico y legislativo en el ámbito sanitario al cambio de régimen político, junto con el panorama de empobrecimiento generalizado, provocado por la larga contienda ${ }^{49}$.

Por lo que se refiere a la previsión social, destaca la aprobación de la Ley del Seguro Obligatorio de Enfermedad de 14 de diciembre de 1942, si bien su filosofía, como indica la propia norma, desarrollo del Fuero del Trabajo, es que la prestación sanitaria es la de un seguro destinado a proteger determinadas contingencias (enfermedad, maternidad, determinadas indemnizaciones) que pueden sufrir las personas económicamente débiles que cotizan por él ${ }^{50}$.

La asistencia sanitaria no se entiende de forma general para los ciudadanos, sino como prestación de un seguro que cubre concretos riesgos, al que tienen derecho solo determinados sujetos (trabajadores titulares y sus familiares, como beneficiarios) y que se financia a través de cuotas vinculadas al trabajo ${ }^{51}$. Cabe destacar que la implantación de las prestaciones sanitarias de este seguro se realizó en tres fases que comprenden desde 1 de diciembre de 1943 hasta 1 de enero de 1948, y que aunque su gestión se atribuyó al INP, su administración se encomendó a la Caja Nacional del Seguro de Enfermedad ${ }^{52}$.

Por su parte, la Ley de Bases de la Sanidad Nacional de 25 de noviembre de 1944 ${ }^{53}$, en el Título Preliminar, atribuyó al Estado "el ejercicio de la función pública de

\footnotetext{
${ }^{49}$ HUERTAS, R., “Política sanitaria: de la Dictadura de Primo de Rivera a la II República”, Revista Española de Salud Pública, monográfico, 2000.

${ }^{50}$ BOE de 27 de diciembre de 1942. El seguro se establece, según el preámbulo de la ley, “con carácter obligatorio para los productores económicamente débiles y con la amplitud y generosidad propia de nuestra Revolución Nacionalsindicalista”.
}

${ }^{51}$ Véase de VIDA FERNANDEZ, J., "Las prestaciones sanitarias del Sistema Nacional de Salud: Catálogo de Prestaciones y Carteras de Servicios”, p. 37 y ss., en AA.VV., La Reforma del Sistema Nacional de Salud, Marcial Pons, Barcelona, 2003.

${ }^{52}$ Véase de PALOMAR OLMEDA, A., "Formas de organización y régimen de personal de los Servicios públicos sanitarios", en AAVV, La Organización de los Servicios Públicos Sanitarios, Marcial Pons, Barcelona, 2000; en especial, el apartado dedicado al apunte histórico sobre la organización de los servicios sanitarios y su repercusión en el modelo de gestión del empleo público, pp. 245 y ss.

${ }^{53}$ BOE del día 26 de noviembre de 1944. 


\section{Capítulo I. Marco histórico normativo en el que surge la sanidad como servicio público en España y la regulación jurídica de su personal}

Sanidad", organizando los servicios sanitarios bajo el principio de unidad y dependencia de la Jefatura provincial, con unos Servicios Centrales dependientes de la Dirección general de Sanidad, que de nuevo pasa a ser un órgano directivo del Ministerio de la Gobernación. Este modelo se caracterizó por componer la prestación sanitaria a través de la medicina privada, la beneficencia y la asistencia sanitaria pública, a cargo del Estado, provincias y municipios.

De acuerdo con esta ley, el Cuerpo médico de la Sanidad Nacional se mantendría dependiente de los Servicios Centrales de Sanidad $^{54}$, tal como establecía la Base Primera A), junto con Instructoras, Practicantes, Enfermeras, Auxiliares sanitarios, Peritos mecánicos, Celadores y Cuerpo administrativo sanitario... regulados todos ellos por el Reglamento de funcionarios del Estado. Junto con estos pervivía otro tipo de personal sanitario vinculado a los entes locales, integrado principalmente por médicos titulares ${ }^{55}$. Entre 1943 y 1948 se promulgaron diversas normativas que trataron de regular distintos aspectos de su relación de servicios, destacando la Orden de 20 de enero de 1948, que aprobó el Reglamento de los Servicios sanitarios del Seguro Obligatorio de enfermedad, que dedicó el Título I a regular el personal sanitario ${ }^{56}$.

El problema principal de este modelo es que no se prestaba una asistencia sanitaria integral, sino atención a determinadas enfermedades. Por ejemplo la Base Séptima de la Ley de Bases de Sanidad de 1944 reguló la Lucha contra la tuberculosis; la Base octava la Lucha contra el reumatismo y las cardiopatías; la Base Novena la Lucha contra el Paludismo... La asistencia sanitaria, gestionada a nivel estatal por el INP, responsable del Seguro Obligatorio de Enfermedad, se prestaba en los llamados consultorios y dispensarios por médicos, practicantes y enfermeras con dedicación por horas.

La disgregación de organismos que prestaban asistencia sanitaria provocó, a su vez, una diversificación del personal sanitario en tantos cuerpos como entidades participaban en la misma: médicos de Casas de socorro y Hospitales municipales, Médicos de la Lucha Antivenérea Nacional, Médicos Titulares, Médicos Internos y Auxiliares de Hospitales, Médicos Puericultores del Estado, Médicos de Higiene y Toxicomanías de Institutos provinciales de Sanidad... En el artículo 1.2 del Estatuto de Personal del INP de 1947 se establece que: "El personal permanente de los establecimientos que dependan del Instituto Nacional de Previsión, tales como Clínicas, Hospitales [...] se regirá por sus contratos o reglamentos especiales, en los que se procurará seguir los mismos principios generales que inspiran este Estatuto".

\footnotetext{
${ }^{54}$ Este Cuerpo estaba formado por un número escasísimo de Médicos: en 1953 había solo 162 médicos; MARSET CAMPOS..."La Salud Pública durante el franquismo...”, op. cit.

${ }^{55}$ Respecto a estos, visto que continuaban los problemas para cobrar sus nóminas de los presupuestos de los Ayuntamientos de tercera, cuarta y quinta categoría (los de municipios con presupuestos más exiguos), se dicta la Ley de 31 de diciembre de 1941, que establece el pago de sus haberes a cargo del Estado. Años más tarde, el Decreto de 27 de noviembre de 1953 aprueba el Reglamento de personal de los servicios sanitarios locales, que regula su condición como de funcionarios técnicos del Estado al servicio de la Sanidad local.
}

${ }^{56}$ BOE de 30 de marzo de 1948. 


\section{Capítulo I. Marco histórico normativo en el que surge la sanidad como servicio público en España y la regulación jurídica de su personal}

En los hospitales, en muchos casos adscritos a Patronatos -el de la Lucha Antituberculosa fue uno de los más importantes- el personal prestaba servicios como funcionario en el caso de los facultativos y del personal sanitario, o bien con vinculación laboral en el caso del personal de oficios o celadores. La problemática de este sistema se expone en la Exposición de motivos de la Ley 14/1986, de 25 de abril, General de Sanidad: carencia de una dirección unitaria, funciones asumidas por diversas Administraciones sin nexo de unión en sus políticas sanitarias...

La doctrina destaca, por un lado, la falta de definición global de un modelo de sanidad pública a la que, además, le faltaban medios materiales, y por otro, la descoordinación en cuanto a las normas reguladoras de su personal ${ }^{57}$.

En este marco, a principios de los años sesenta, se inicia la construcción del sistema público de Seguridad Social con la Ley 193/1963, de 28 de diciembre, de Bases de la Seguridad Social (LBSS), que generaliza la prestación de la asistencia sanitaria a gran parte de la población. La LBSS, en su Base Sexta, regulaba la Asistencia Sanitaria como una prestación de la Seguridad Social, disponiendo en el apartado 24 d) de la citada Base que: "Los servicios sanitarios de la Seguridad Social se prestarán conforme al Estatuto jurídico que reglamentariamente se establezca" ${ }^{\text {58. }}$.

En desarrollo de esta Ley de Bases se publica su Texto articulado, aprobado por Decreto 907 , de 21 de abril de $\mathbf{1 9 6 6}^{59}$, poniendo en marcha así esta normativa un modelo sanitario nuevo que supera al anterior de 1944. Este reglamento determinó que se encomendase al INP la gestión directa de la prestación de asistencia sanitaria ${ }^{60}$, y en su artículo 116.1 insiste en la misma disposición que contempló la LBSS: "El personal sanitario de la Seguridad Social prestará sus servicios conforme al Estatuto jurídico que reglamentariamente se establezca".

Conforme a esta previsión se dictó el Decreto 3160/1966, de 23 de diciembre, que aprobó el Estatuto Jurídico del personal Médico de la Seguridad Social ${ }^{61}$ (EJPM); el Estatuto de personal no Sanitario al servicio de instituciones sanitarias de la Seguridad Social por Orden del Ministerio de Trabajo de 5 de julio de $1971^{62}$ y, por último, la Orden

57 CASTILlO BLANCO, F.," El Estatuto Marco del personal estatutario", en AA.VV., La Reforma del Sistema Nacional de Salud...op.cit., pp. 317 y ss.

58 Sobre los orígenes de la regulación normativa del personal estatutario de la Seguridad Social, véase DESDENTADO BONETE, A., DESDENTADO DAROCA, E., "El sistema normativo de la relación de servicios del personal estatutario de las instituciones sanitarias de la Seguridad Social", AS, no 16/2000, (BIB 2000\1893).

${ }^{59}$ BOE de 22 y 23 de abril de 1966.

${ }^{60}$ Para las contingencias de maternidad, enfermedad común y accidente no laboral, así como, mediante concierto, la correspondiente a las contingencias profesionales, accidente de trabajo y enfermedad profesional, cuya competencia originaria correspondía a las Mutualidades Laborales.

${ }^{61}$ BOE de 30 de diciembre de 1966.

${ }^{62}$ BOE de 22 de julio de 1971. 


\section{Capítulo I. Marco histórico normativo en el que surge la sanidad como servicio público en España y la regulación jurídica de su personal}

de 26 de abril de $1973^{63}$ que aprobó el Estatuto de personal Auxiliar Sanitario Titulado y Auxiliar de Clínica de la Seguridad Social.

Estas normas reglamentarias, aprobadas por el Ministerio de Trabajo, regularon durante años la relación de servicios del personal de las instituciones sanitarias de la Seguridad Social, cuya plantilla se incrementó significativamente a medida que se desarrolló este sistema público. Efectivamente, en esta etapa se construyeron numerosos centros e instituciones sanitarios dependientes de la Seguridad Social, algunos de grandes dimensiones como las ciudades sanitarias en las grandes ciudades, que necesitaron de numerosos efectivos personales y que complementaron la red de consultorios y ambulatorios ya existentes ${ }^{64}$.

Llama la atención que el legislador dotara al personal al servicio de las instituciones sanitarias de la Seguridad Social no de un régimen jurídico funcionarial sino de otro específico y regulado en normas de rango inferior a la ley ${ }^{65}$. Hoy día está comúnmente aceptado que el personal estatutario debe tener una regulación específica y diferenciada de la del resto de funcionarios públicos, basándose en argumentos tales como las especiales características de las profesiones sanitarias, el servicio sanitario asistencial y las peculiaridades del Sistema Nacional de Salud ${ }^{66}$, premisas que se recogen, incluso, en la Exposición de motivos de la LEM (apartado II) ${ }^{67}$. Sin embargo, estas argumentaciones, en nuestra opinión, no justifican porqué el legislador de los años sesenta prefirió darle esa relación jurídica al personal sanitario, ya que entonces no existía el Sistema Nacional de Salud y el servicio sanitario asistencial de la Seguridad Social estaba aún en sus comienzos.

\footnotetext{
${ }^{63}$ BOE de 28 de abril de 1973. Este sustituyó a la regulación formada por las órdenes de 22 de abril y de 16 de junio de 1967, que aprobaron los Estatutos jurídicos de las Enfermeras, de los Practicantes, Ayudantes técnicos sanitarios y de las Matronas y Ayudantes técnicos sanitarios femeninos en posesión del Diploma de Asistencia Obstétrica, de la Seguridad Social y la Circular sobre las Auxiliares de clínica del INP.
}

${ }^{64}$ La Ley 37/1962, de 21 de julio, sobre normas reguladoras de los hospitales, unos años antes había previsto la aprobación del Plan de construcciones hospitalarias (BOE de 23 de julio de 1962).

${ }^{65}$ Existe el antecedente de la regulación del personal del INP, que también se había regulado por Estatutos específicos, si bien la naturaleza de su relación de servicios se reconocía como funcionarial. Recordemos que este organismo se creó por Ley de 27 de febrero de 1908 para gestionar las pensiones del Retiro Obrero, y en los diversos Estatutos reguladores de su personal que se fueron aprobando con el tiempo (Estatuto de Personal administrativo y Subalterno de 22 de julio de 1923 y su modificación de 1933; Estatuto de 1 de enero de 1940 y Estatuto de 30 de diciembre de 1947) también se contiene una regulación relativa a los aspectos de la clasificación, ingreso, cese, plantilla, remuneraciones, ascensos, deberes, derechos y régimen disciplinario del personal. En este último, aprobado por Orden del Ministro de Trabajo de 30 de diciembre de 1947, se hace referencia al aumento de plantilla experimentado por el INP en esos últimos siete años, que pasó de 2.035 funcionarios en 1940 a 14.905 en 1943.

${ }^{66}$ PEREZ GALVEZ, J.F., Comentarios al Estatuto Marco del personal estatutario de los Servicios de salud, Bosch, 2004, p. 133.

${ }^{67}$ Que dice: “La conveniencia de una normativa propia para este personal deriva de la necesidad de que su régimen jurídico se adapte a las específicas características del ejercicio de las profesiones sanitarias y del servicio sanitario-asistencial, así como a las peculiaridades organizativas del Sistema Nacional de Salud". 


\section{Capítulo I. Marco histórico normativo en el que surge la sanidad como servicio público en España y la regulación jurídica de su personal}

Para entender el porqué de esta decisión hay que atender a la influencia clave de la Organización Médica Colegial (el Consejo General de Colegios oficiales de médicos) tanto en el contenido del Texto Articulado de la Ley de Bases de $1963^{68}$, como posteriormente en el proyecto de EJPM de la Seguridad Social.

Esta participación tuvo lugar a través de la Comisión Especial sobre Asistencia Sanitaria de la Seguridad Social, creada por la Orden de 8 de junio de $1966^{69}$. Esta Orden ministerial constituyó la Comisión Especial, reguló su composición y le atribuyó las funciones, entre otras, de asesorar y colaborar en el estudio del proyecto del Estatuto Jurídico del personal sanitario de la Seguridad Social a que se refería el artículo 116 del Texto Articulado de la LBSS antes citado. Formaron parte de esta comisión, además de los Subsecretarios de los Ministerios de la Gobernación y de Trabajo, los Directores generales de previsión y de Sanidad, el Secretario general de Sanidad, el Delegado General del INP, cuatro vocales en representación de la Seguridad Social designados por el Ministro de Trabajo y cuatro vocales representantes de la Organización Médica Colegial, así como tres representantes de la Organización sindical (Sindicato Nacional de Actividades Sanitarias, que había sido creado en 1964).

Cabe entender que en el seno de esta Comisión, la organización médica colegial debió ejercer las presiones consecuentes a los postulados que defendían en ese momento los Colegios de médicos, en defensa de los intereses de sus colegiados. Estas posturas se evidencian en el Acuerdo de 9 de julio de 1966, del Pleno del Consejo General de Colegios de médicos, publicado en prensa, en el que se insiste en los puntos que, a su juicio, debe respetar el nuevo sistema de atención sanitaria de la Seguridad Social que iba a empezar a funcionar en España. Entre otros puntos de carácter más deontológico, se defiende fundamentalmente la retribución por acto médico para el personal facultativo, tanto para los casos en que atendieran pacientes de Seguridad Social por enfermedad común, como para el caso de que la atención médica tuviera su causa en un accidente de trabajo ${ }^{70}$.

La LBSS también había previsto la retribución de los Médicos que prestaran servicios en la Seguridad Social según el número de titulares o beneficiarios de Seguridad Social a su cargo "estableciéndose sistemas de retribución distintos cuando así lo aconseje

\footnotetext{
${ }^{68}$ Según la prensa, tomaron parte en la Comisión encargada de proyectar el Texto Articulado de la Ley de Bases de la Seguridad Social de 1963, el Presidente del Consejo General de Colegios de Médicos, Dr. Lafuente, y el Secretario del Consejo, Dr. Reparaz, así como el Presidente del Colegio de Médicos de Madrid, Dr. García Miranda. Los médicos rurales deben ser considerados como funcionarios públicos, Diario ABC [en línea] 24 de julio de 1966, p. 76, [consulta de 2 de febrero de 2013], disponible en: 〈http://hemeroteca.abc.es>.

${ }^{69}$ BOE de 14 de junio de 1966.

${ }^{70}$ Acuerdo del Consejo General de Colegios de Médicos, Diario ABC, edición Andalucía [en línea] 13 de julio de 1966 [consulta de 2 de febrero de 2013], disponible en: 〈http://hemeroteca.abc.es〉. El texto del Acuerdo, en su apartado B, letras b) y c), dice: "En las especialidades son necesarios la libre elección del médico y los honorarios por acto médico [...] las mismas normas de libre elección y pago por acto médico deben cumplirse en los accidentes de trabajo, sin excepciones enmascaradas".
} 


\section{Capítulo I. Marco histórico normativo en el que surge la sanidad como servicio público en España y la regulación jurídica de su personal}

la estructura sanitaria”. Pues bien, estos aspectos son los que finalmente recogió el EJPM de la Seguridad Social en su artículo 30, regulando los diferentes sistemas de retribución ${ }^{71}$.

Dado que el EJPM entró en vigor el 1 de enero de 1967, en su desarrollo la Orden de 28 de febrero de $1967^{72}$ aprobó las normas sobre sistemas de pago, cuantías de las retribuciones y demás emolumentos del personal médico de la Seguridad Social y estableció para cada supuesto el sistema de retribución que correspondía al médico adscrito a la Seguridad Social. La retribución en el sistema de acto médico se realizaba con arreglo a las tarifas aprobadas en la Orden por cada asistencia médica motivada por enfermedad común y accidente no laboral (norma 19) ${ }^{73}$.

En consecuencia, la opción del legislador por un régimen jurídico específico y diferenciado del funcionarial para vincular al personal sanitario de la Seguridad Social, parece que se produjo ante las presiones de la Organización médica colegial; presiones que en su momento no se ocultaron. En este sentido, el mismo día de la publicación del Estatuto jurídico de personal médico la Organización médica colegial lo presenta como un logro propio:

En prensa aparece un comunicado titulado "Los doctores y la Seguridad Social. Puntualizaciones del Consejo General de Colegios de médicos" en el que manifiestan la satisfacción por la publicación del Estatuto médico considerándolo una de las grandes ambiciones de la Organización médica colegial, en el que se mantiene el sistema de retribución por cupo de asegurados y se crea la zona médica como conjunto de servicios médicos coordinados que permitirán la libre elección del enfermo entre los médicos generales de la zona. En la misma nota también se felicitan por el aumento de los honorarios médicos y el incremento de plantilla (pediatras y médicos residentes). Se reconocen los méritos de la Comisión para el estudio de la asistencia sanitaria de la Seguridad Social como "cauce legal para que la organización médica colegial solicite y defienda todo aquello que falta y considere necesario para mejorar la asistencia de los enfermos y el ejercicio profesional del médico" "74.

En resumen, cuando se empieza a desarrollar el sistema de Seguridad Social en España una de las prestaciones que reconoce es la de la asistencia sanitaria a los asegurados. El colectivo médico, al que había que implicar obviamente en su puesta en marcha y desarrollo, era reacio a aceptar la condición de funcionario de esa Administración sanitaria

\footnotetext{
${ }^{71}$ Que podían ser "por cantidad fija por cada titular de derecho o beneficiario a la prestación de la asistencia sanitaria que tenga asignado cada facultativo; por sueldo; por cantidades fijas y periódicas para el personal adscrito a determinados Servicios jerarquizados Por cantidades calculadas en función del número y clase de las intervenciones realizadas o procesos clínicos asistidos, con arreglo al baremo que se establezca”; y "por acto médico, con arreglo a tarifa".

${ }^{72}$ BOE de 3 de marzo de 1967.

${ }^{73}$ Los efectos económicos se retrotraían a fecha 1 de enero de 1967 y, a título de curiosidad, en ese año atender un parto sin ayuda de comadrona le reportaba al médico de la Seguridad Social que optaba por este sistema de retribución 570 pesetas.

${ }^{74}$ Diario ABC, edición de Andalucía, [en línea] 30 de diciembre de 1966 [consulta de 2 de febrero de 2013], disponible en: <http://hemeroteca.abc.es>.
} 


\section{Capítulo I. Marco histórico normativo en el que surge la sanidad como servicio público en España y la regulación jurídica de su personal}

de la Seguridad Social que empezaba a funcionar, con las notas típicas de dependencia y subordinación que caracterizan esa relación. Esta postura, lógica desde la óptica de la mentalidad liberal en el ejercicio de la medicina, se constata que tuvo éxito y sus postulados llegaron a convertirse en norma.

Por tanto, parece probado que la pretensión de disponer de una norma reguladora específica y diferenciada, de la de los funcionarios venía dada por las peculiaridades de su sistema retributivo y de prestación de servicios (la retribución por acto médico de estos profesionales es un sistema del todo ajeno a la relación funcionarial) y probablemente también para evitar el régimen de incompatibilidades que pudiera comprometer el ejercicio privado de su profesión ${ }^{75}$. Esto por lo que se refiere al colectivo médico que ejercía la profesión en las ciudades.

No obstante, los sanitarios locales se mantuvieron como funcionarios del Estado al servicio de la sanidad local. Este colectivo, anclado en su mayoría en el ámbito rural, tenía una problemática particular no resuelta aún tras muchos años (retribuciones escasas, largas jornadas...) y se siguió regulando por el Decreto de 27 de noviembre de 1953, que aprobó el Reglamento de personal de los servicios sanitarios locales, que los calificaba como funcionarios técnicos del Estado al servicio de la Sanidad local ${ }^{76}$.

Cuando se implanta el sistema de Seguridad Social se dispone que los médicos y sanitarios titulares se hagan cargo del cupo de titulares y beneficiarios de Seguridad Social de su zona sanitaria ${ }^{77}$. El artículo 64 del Estatuto Jurídico del Personal Médico dispuso respecto a ellos que: "A los Médicos titulares de los Servicios Sanitarios locales corresponderá desde el momento de su nombramiento, y por todo el tiempo de duración del mismo, el desempeño de los Servicios correspondientes a plazas de Médico general de la

\footnotetext{
${ }^{75}$ La regulación de los supuestos de incompatibilidad venía dada en los artículos 82 y siguientes de la Ley de Funcionarios Civiles del Estado de 1964. El EJPM solo reguló las incompatibilidades que pudieran producirse por el desempeño simultáneo de más de una plaza "de cualquier orden dentro de la Seguridad Social”. Al fin y al cabo en el Capítulo I del EJPM, el artículo 3.2 señalaba que "Las relaciones jurídico- administrativas de los Médicos con la Seguridad Social se inspirarán en los principios generales por los que se rige el personal técnico, sin perjuicio del libre ejercicio de la profesión”.

76 La Asamblea General de presidentes y consejeros de la Organización Médica Colegial publica un comunicado de prensa en el que reivindica su condición funcionarial: Los médicos rurales deben ser considerados como funcionarios públicos, Diario ABC [en línea] 24 de julio de 1966 [consulta de 2 de febrero de 2013], disponible en: 〈http://hemeroteca.abc.es $>$.

77 El artículo 64 del Estatuto Jurídico del Personal Médico dispuso respecto a ellos que: “A los Médicos titulares de los Servicios Sanitarios locales corresponderá desde el momento de su nombramiento, y por todo el tiempo de duración del mismo, el desempeño de los Servicios correspondientes a plazas de Médico general de la Seguridad Social de las localidades en que concurran las circunstancias de referencia, con los mismos derechos y deberes de los demás médicos de la Seguridad Social”. En el mismo sentido se expresaría después el Estatuto de Personal Sanitario no facultativo de la Seguridad Social en el artículo 49, respecto a los Practicantes-Ayudantes Técnicos sanitarios y Matronas titulares de los servicios sanitarios locales. De esta forma todo el personal sanitario y facultativo titular local, también denominado de Asistencia Pública Domiciliaria, quedaba vinculado a los servicios sanitarios de la Seguridad Social en la misma localidad o distrito del ámbito de su nombramiento funcionarial, por lo que había una doble dependencia administrativa: de los Ayuntamientos y del Estado.
} 


\section{Capítulo I. Marco histórico normativo en el que surge la sanidad como servicio público en España y la regulación jurídica de su personal}

Seguridad Social de las localidades en que concurran las circunstancias de referencia, con los mismos derechos y deberes de los demás médicos de la Seguridad Social”. En el mismo sentido se expresaría después el Estatuto de Personal Sanitario no facultativo de la Seguridad Social en el art. 49, respecto a los Practicantes-Ayudantes Técnicos sanitarios y Matronas titulares de los servicios sanitarios locales. De esta forma todo el personal sanitario y facultativo titular local, también denominado de Asistencia Pública Domiciliaria, quedaba vinculado también a los servicios sanitarios de la Seguridad Social en la misma localidad o distrito del ámbito de su nombramiento funcionarial, por lo que había una doble dependencia administrativa: de los Ayuntamientos y del Estado.

Más adelante, el Texto refundido de la Ley General de Seguridad Social, aprobado por el Decreto 2065/1974, de 30 de mayo (LGSS), mantuvo esta regulación en los artículos 109 y siguientes, organizando la atención sanitaria por zonas médicas, como unidad primaria para la organización de la asistencia sanitaria. En su artículo 115 dispuso para determinados casos que los médicos, practicantes y matronas titulares de los servicios sanitarios locales tendrían el derecho y deber de desempeñar los servicios sanitarios correspondientes a las plazas de médicos generales, practicantes y matronas del régimen general.

Su sistema de retribución incluía una parte fija, compuesta de sueldo base y grado, y unas retribuciones complementarias en función del número de habitantes del partido sanitario $^{78}$. Este sistema, denominado de cupo y zona, ha subsistido hasta fechas recientes, en que ha sido suprimido por las disposiciones del Real Decreto Ley 16/2012, de 20 de abril, de Medidas Urgentes para garantizar la Sostenibilidad del Sistema Nacional de Salud y mejorar la calidad y seguridad de sus prestaciones, con lo que el personal en esta situación se ha integrado a todos los efectos en el régimen estatutario ordinario de la $\mathrm{LEM}^{79}$. En desarrollo de esta disposición todas las CC.AA. han dictado su normativa específica ${ }^{80}$.

${ }^{78}$ Desarrollado por la Orden de 8 de agosto de 1986 (BOE de 14 de agosto de 1986).

79 Publicado en el BOE de 24 de abril de 2012, añadió a la LEM la Disposición transitoria tercera, según la cual "En la forma y condiciones que en cada Servicio de salud, en su caso, se determine, el personal que percibe haberes por el sistema de cupo y zona se integrará en el sistema de prestación de servicios, de dedicación y de retribuciones que se establece en esta ley, antes del 31 de diciembre de 2013 sin perjuicio de los derechos consolidados. Queda suprimido desde esa fecha la modalidad de prestación de servicios de cupo y zona".

${ }^{80}$ Resolución de 17 de diciembre de 2013, del Director general de Recursos Humanos de la Sanidad, sobre la integración del personal estatutario de cupo y zona en el sistema de prestación de servicios, dedicación y retribuciones establecido en el Estatuto Marco del personal estatutario de los Servicios de salud (Diario Oficial de la Comunidad Valenciana de 23 de diciembre de 2014); Resolución del director general del Servicio de salud de las Islas Baleares por la que se regula el procedimiento de integración como personal estatutario fijo del personal funcionario sanitario que presta servicios en instituciones sanitarias públicas del Servicio de salud de las Islas Baleares (Boletín Oficial de las Islas Baleares de 22 de marzo de 2014); Resolución del Director Gerente del Servicio Murciano de Salud por la que se ordena la publicación del acuerdo del Consejo de Administración por el que se regulan los términos en los que se producirá la integración de los funcionarios de carrera pertenecientes a los antiguos cuerpos de sanitarios locales en las correspondientes categorías estatutarias del Servicio Murciano de Salud conforme a lo dispuesto en la Disposición adicional decimosexta de la Ley 55/2003, de 16 de diciembre, del Estatuto Marco del Personal Estatutario de los Servicios de salud (Boletín Oficial de la Región de Murcia, de 18 de febrero de 2014); Resolución del Director General de Osakidetza-Servicio Vasco de salud, por la que se procede a la integración del personal funcionario sanitario 


\section{Capítulo I. Marco histórico normativo en el que surge la sanidad como servicio público en España y la regulación jurídica de su personal}

Con la misma relación jurídica funcionarial subsistieron otras categorías de médicos, como los del Cuerpo de la Sanidad Nacional, dedicados a funciones de prevención e higiene, que con el tiempo pasarían a conformar la plantilla de personal de los actuales Centros de Salud Pública.

La regulación del régimen jurídico estatutario del personal médico fue la primera en el tiempo, pero los demás colectivos profesionales al servicio de la Seguridad Social también se incorporaron poco después al mismo. Así, en el año 1971 se publicó el Estatuto de personal no sanitario aprobado por Orden del Ministerio de Trabajo de 5 de julio ${ }^{81}$, y en 1973 el del personal Auxiliar Sanitario Titulado y Auxiliar de clínica de la Seguridad Social, aprobado por la Orden de 26 de abril ${ }^{82}$, normas que se mantuvieron vigentes durante más de treinta años, hasta que se publicó la $\mathrm{LEM}^{83}$.

El contenido de los tres Estatutos reguladores del personal era similar en su estructura. Regulaban el ámbito subjetivo de aplicación de la norma; la clasificación del personal; los procedimientos de selección y provisión de puestos; los derechos y deberes del personal; las funciones según la categoría profesional; las situaciones administrativas; las retribuciones, el régimen disciplinario y el de incompatibilidades, así como la vía laboral como jurisdicción competente para resolver los conflictos entre el personal y la entidad gestora (en el Estatuto de personal Auxiliar sanitario, en el art. 153. En el Estatuto de personal no sanitario, en el art. 4).

Con el tiempo, los tres Estatutos sufrieron modificaciones para actualizarlos a los cambios que se iban dando progresivamente (en materia retributiva, por ejemplo) destacando las modificaciones que se produjeron para incorporar a su ámbito subjetivo nuevas categorías profesionales, a medida que se modernizaba la administración sanitaria.

De este modo, el EJPM se amplió por Real Decreto 1033/1976, de 9 de abril, a los farmacéuticos que desempeñaran plaza en la Seguridad Social, transformándose en Estatuto de Personal Facultativo ${ }^{84}$. El Estatuto de Personal Sanitario titulado y Auxiliares de Clínica de la Seguridad Social, que incluyó, en principio, en su ámbito subjetivo a las enfermeras,

de carrera de las instituciones sanitarias públicas del Ente Público Osakidetza-Servicio Vasco de salud (Boletín Oficial del País Vasco de 7 de febrero de 2014)...

${ }^{81}$ Sustituyó al Reglamento de personal de Servicios Especiales, de Oficio y Subalterno de Instituciones Sanitarias de la Seguridad Social, aprobado por Orden Ministerial de 28 de junio de 1968 (BOE de 13 de julio de 1968).

${ }^{82}$ Sustituyó al Estatuto jurídico de las Enfermeras de la Seguridad Social y Practicantes-Ayudantes Técnicos Sanitarios y al de las Matronas y Ayudantes Técnicos Sanitarios Femeninos en posesión del Diploma de Asistencia Obstétrica de la Seguridad Social (BOE de 11 de mayo de 1967), al Estatuto jurídico de los Practicantes-ayudantes técnicos sanitarios de la Seguridad Social, y a la Circular de régimen interior del INP, relativa a las Auxiliares de Clínica de la Seguridad Social (el nuevo Estatuto de 1973, como dice su Exposición de Motivos, es una actualización y refundición de estos).

${ }^{83}$ BOE de 17 de diciembre de 2003.

${ }^{84}$ BOE de 11 de mayo de 1976. 


\section{Capítulo I. Marco histórico normativo en el que surge la sanidad como servicio público en España y la regulación jurídica de su personal}

Ayudantes Técnicos Sanitarios, Practicantes Ayudantes Técnicos Sanitarios, matronas, fisioterapeutas, terapeutas ocupacionales y auxiliares de clínica, transformó su denominación en virtud de la Orden de 26 de diciembre de 1986, pasando a denominarse Estatuto de Personal Sanitario no facultativo de las instituciones sanitarias de la Seguridad Social $^{85}$.

Por su parte, el Estatuto de Personal no sanitario, que regulaba la relación de servicios del personal de plantilla fijo, clasificado en los grupos de personal técnico, de servicios especiales, de oficio y subalterno (art. 5), pasó a incluir al personal de la función administrativa de la Seguridad Social desde la Orden de 28 de mayo de $1984^{86}$, incorporando al Estatuto al personal del grupo técnico, de gestión, administrativo y auxiliar administrativo.

En los años siguientes no se puso en duda la conveniencia de este régimen jurídico para el personal de la sanidad pública, de modo que la LGSS, en su artículo 45, respaldó la continuidad de los Estatutos jurídicos del personal, estableciendo que: "1. La relación entre las Entidades Gestoras y, en su caso, Servicios de la Seguridad Social y el personal a su servicio se regulará por lo previsto en los Estatutos de Personal aprobados por el Ministerio de Trabajo o, por el Estatuto general aprobado por el propio Ministerio".

En esta línea, la Ley 8/1980, de 10 de marzo, que aprueba el Estatuto de los Trabajadores, excluye al personal estatutario de su ámbito de aplicación, por su condición funcionarial" ${ }^{87}$, en el artículo primero, tres a), disponiendo: "Se excluyen del ámbito regulado por la presente Ley la relación de servicio de los funcionarios públicos, que se regulará por el Estatuto de la Función Pública, así como la del personal al servicio del Estado, las Corporaciones locales y los Entidades públicas autónomas, cuando al amparo de una Ley dicha relación se regule por normas administrativas o estatutarias".

Igualmente, la Ley 30/1984, de 2 de agosto, de Medidas para la Reforma de la Función Pública (LMRFP) excluyó de su ámbito al personal estatutario (Disposición transitoria cuarta), aunque dispuso la posibilidad de que en aplicación de la misma pudieran dictarse normas específicas para adecuarla a las peculiaridades del personal sanitario (art. 1.2).

No es de extrañar, por tanto, que algunas sentencias se refiriesen al personal estatutario como un tertium genus, visto que las leyes de referencia del ámbito laboral y del funcionarial lo excluían de su ámbito de regulación. Aunque desde el principio la cuestión

\footnotetext{
${ }^{85}$ Esta misma Orden modificó la denominación de la categoría de Auxiliar de clínica, que pasó a denominarse Auxiliar de enfermería (BOE de 12 de enero de 1987). Por Orden de 11 de diciembre de 1984 ya se había modificado este Estatuto para incluir también a los Técnicos especialistas de formación profesional de la rama sanitaria: técnicos especialistas de laboratorio, radiodiagnóstico, anatomía patológica, medicina nuclear y radioterapia (BOE de 9 de enero de 1985).

${ }^{86}$ BOE de 30 de mayo de 1984.

${ }^{87}$ Como también lo había excluido el artículo $2^{\circ}$ a) de la Ley 16/1976, de 8 de abril, de Relaciones laborales (BOE de 21 de abril de 1976).
} 


\section{Capítulo I. Marco histórico normativo en el que surge la sanidad como servicio público en España y la regulación jurídica de su personal}

de la naturaleza jurídica del personal estatutario había sido fuente de discusión doctrinal ${ }^{88}$, en general, la jurisprudencia del Tribunal Supremo mantuvo la postura de no considerarlo personal laboral, a pesar de que la vía jurisdiccional laboral era la competente para resolver sus conflictos, porque la relación del personal se establecía con la Administración pública para prestar el servicio público de Seguridad Social (STS de 4 de diciembre de $1992^{89}$ y STS de 6 de febrero de $1995^{90}$ ), siendo su vinculación jurídica de tipo funcionarial, aunque no idéntica a la de los funcionarios de carrera ${ }^{91}$.

Hay que considerar que con el paso de los años, a partir de la aprobación de la CE, gran parte de las disposiciones de los Estatutos jurídicos se quedaron desfasadas ${ }^{92}$, situación que se agravó cuando las primeras CC.AA. empezaron a asumir competencias en materia de gestión sanitaria y se encontraron con la necesidad de regular ciertos aspectos relativos al personal transferido. Esta razón era, fundamentalmente, la que argumentaba la doctrina para justificar la necesidad de aprobar un Estatuto Marco que sustituyera a los viejos reglamentos, la de superar la inseguridad jurídica que producían estas normas ${ }^{93}$.

88 Sobre la evolución jurisprudencial de la naturaleza jurídica del personal estatutario véase ARIAS CRIDADO, B., "El personal estatutario de los Servicios de salud. Cuestiones diversas. Cuestiones polémicas", Noticias jurídicas, [en línea] septiembre 2011, [consulta de 7 de marzo de 2013], disponible en: <http: Ilwww.noticiasjuridicas.com>.

${ }^{89}$ Esta sentencia de la Sala de lo Social, dictada en unificación de doctrina, argumentaba, en el Fundamento jurídico segundo: "El personal estatutario de la Seguridad Social no está vinculado a esta por una relación jurídica de naturaleza laboral, sino que su relación con ella encierra una clara condición de Derecho Público, al intervenir, y contribuir de alguna forma en la gestión, actuación y realización de un servicio público..., (RJ 1992\10421). Otras anteriores en el mismo sentido: STS de 17 de octubre de 1991, (RJ $1991 \backslash 722$,) y de 22 de enero de 1990, (RJ 1990\181).

${ }^{90}$ Fundamento jurídico tercero: “El personal estatutario de la Seguridad Social no está vinculado a esta por una relación jurídica de naturaleza laboral, sino que su relación con ella encierra una clara condición de Derecho público, al intervenir y contribuir de alguna forma en la gestión, actuación y realización de un servicio público, como es la Seguridad Social, tal y como se desprende de lo que expresa el artículo 41 de la Constitución Española. Es indiscutible la similitud y proximidad existente entre este personal estatutario de la Seguridad Social y el personal funcionario de las Administraciones públicas, si bien no puede olvidarse que aquel presenta ciertas particularidades y caracteres específicos que le dan una estructura y consistencia propias, diferenciándolo, de algún modo, de los funcionarios administrativos en sentido estricto. De ahí que, en no pocas ocasiones, se haya hablado de que este personal estatutario venía a constituir un tertium genus entre los trabajadores sometidos al Derecho laboral y los funcionarios que se rigen por el Derecho administrativo. Y así este personal estatutario de la Seguridad Social tiene sus propias y peculiares normas reguladoras, constituidas fundamentalmente por los diferentes Estatutos aplicables a las distintas clases en que el mismo se estructura”, (RJ 19957780).

${ }^{91}$ Autos de la Sala de lo Contencioso del TS de 23 de abril de 2001, (JUR 2001 183600 ), y de 28 de febrero de 2000, (RJ 2000\1958).

92 Algunas llamaban poderosamente la atención: en el Estatuto de Personal no Sanitario el artículo 33.2 regulaba la excedencia voluntaria de la mujer por contraer matrimonio; el artículo 53 reconocía un plus de residencia para el personal que prestara servicios en "las plazas de soberanía del Norte de África...”; el artículo 55 obligaba al personal a “acatar los Principios Fundamentales del Movimiento Nacional...”.

93 ALVAREZ SACRISTAN, I., "Las complicadas normas y doctrinas del personal estatutario de la Seguridad Social", AJA n ${ }^{\circ} 424,2000$, (BIB 1999\1808). 


\section{Capítulo I. Marco histórico normativo en el que surge la sanidad como servicio público en España y la regulación jurídica de su personal}

En efecto, en la práctica, además de inseguridad, había disparidad de criterios a la hora de interpretar y aplicar la normativa, incluso dentro de centros pertenecientes a la misma Administración sanitaria. La inseguridad sobre la naturaleza jurídica del personal tenía trascendencia práctica, y podía afectar, a título de ejemplo, al plazo para interponer reclamaciones en materia retributiva, de un año para el personal laboral (art. 59 del Estatuto de los Trabajadores), o cinco en el caso de los funcionarios (art. 46 de la Ley General Presupuestaria de 1988), como advertía la doctrina ${ }^{94}$.

Cuando se creó el Sistema Nacional de Salud por la Ley 14/1986, de 25 de abril, General de Sanidad, la cuestión de la naturaleza estatutaria del personal de la sanidad pública entra en crisis, propiciando fuertes polémicas al respecto ${ }^{95}$. En este sentido, hay que tener en cuenta el "Informe Abril" del año $1991^{96}$, producto de los trabajos de la Comisión de Análisis y Evaluación del Sistema Nacional de Salud, que atribuye al régimen jurídico del personal de la sanidad el defecto de carecer de mecanismos adecuados de incentivación retributiva y propone el establecimiento de sistemas de retribución personalizados, así como el cambio a la relación jurídico laboral para vincular al personal, en la línea de otras medidas liberalizadoras del sistema sanitario.

No obstante, pasado un tiempo, tomó fuerza la postura que defendía la naturaleza funcionarial del personal estatutario, lo cual se hizo más patente a medida que proliferaron normas de derecho público que regularon los aspectos relativos a su selección: Ley 30/1999, de 5 de octubre, de selección y provisión de plazas de personal estatutario de los Servicios de salud); sus retribuciones: Real Decreto Ley 3/1987, de 11 de septiembre, sobre retribuciones del personal estatutario del Instituto Nacional de la Salud (INSALUD), o la aplicación del Real Decreto 118/1989, de 29 de septiembre, sobre reconocimiento de servicios previos en la Administración Pública al personal estatutario.

En los últimos tiempos, previamente a la promulgación de la LEM, la doctrina judicial ya se manifestaba claramente a favor de la consideración del personal estatutario como funcionarial, dada la existencia en ambas relaciones jurídicas de multitud de notas comunes, cuya consecuencia fundamental fue la aplicación de forma supletoria para los estatutarios de la normativa de función pública ${ }^{97}$.

\footnotetext{
94 SEMPERE NAVARRO, A., "Personal estatutario y jurisdicción social, contradicciones y paradojas", $A S$, Vol. IV, 1997, (BIB 199入1263).

${ }^{95}$ En 1987, a título de ejemplo, el sindicato CCOO defendía la naturaleza especial de la relación de servicios estatutaria, ni laboral ni funcionarial, que se debía llevar al texto del Estatuto Marco. Esta postura tenía su razón de ser su preferencia por el mantenimiento de la competencia del orden jurisdiccional social para conocer de los conflictos del personal estatutario. Diario El País [en línea], 31 de marzo de 1987, [consulta de 5 de marzo de 2013], disponible en: 〈http: Iwww.elpais.com/hemeroteca〉.
}

\footnotetext{
${ }^{96}$ Llamado así porque la presidencia de la comisión la desempeñó Fernando Abril Martorell, Vicepresidente en el Gobierno de Adolfo Suárez.

${ }^{97}$ STSJ de La Rioja de 3 de diciembre de 2003: “Tales relaciones estatutarias poseen una configuración más próxima al modelo de la función pública que al modelo de la contratación laboral, mayor relación que se aprecia tanto en el origen normal de la relación como en la fijación de su contenido...”, (AS 2003\26).
} 


\section{Capítulo I. Marco histórico normativo en el que surge la sanidad como servicio público en España y la regulación jurídica de su personal}

Otra fuente de polémicas era la relativa a la vía jurisdiccional competente para conocer de los procesos del personal sanitario frente a su Administración empleadora. El artículo 45.2 del Texto Articulado de la Ley de Bases de Seguridad Social de 1966 dispuso que los litigios del personal estatutario con las Entidades gestoras de la Seguridad Social se conocieran por la jurisdicción laboral: "Sin perjuicio del carácter estatutario de dicha relación, la Jurisdicción de Trabajo será la competente para conocer de las cuestiones contenciosas que se susciten entre las Entidades Gestoras y su personal, con excepción del comprendido en el número siguiente" (personal directivo o que ocupe cargos de confianza).

La LGSS de 1974 mantuvo la competencia de la jurisdicción laboral, al igual que el Real Decreto Legislativo 1/1994, de 20 de junio, que aprobó el Texto Refundido de la Ley General de Seguridad Social, que declaró ese precepto subsistente en su Disposición derogatoria única, ya que el Estatuto Marco, previsto en la LGS, no se había aprobado todavía.

Si bien la vía judicial laboral era la prevista como la competente para conocer de las pretensiones del personal contra la Administración sanitaria, había alguna excepción, como la contemplada en el artículo 63 del EJPM, que dispuso la competencia de la jurisdicción contencioso-administrativa para conocer de las pretensiones relativas a la convocatoria, trámite y resolución de los concursos para la provisión de plazas de servicios jerarquizados de instituciones sanitarias; o de otras reconocidas por la jurisprudencia en materia de sanciones disciplinarias (STS de 16 de abril de $1994^{98}$ ) o de reconocimiento de la compatibilidad (STS de 30 de marzo de $1992^{99}$ ).

Aun así, después de publicada la LEM esta tampoco aclaró esta cuestión de la vía jurisdiccional competente y, además, no derogó expresamente el artículo 45.2 de la LGSS que la atribuía a la jurisdicción social, con lo que se produjo durante un tiempo una fuerte polémica al respecto ${ }^{100}$. Las discusiones podrían haberse evitado simplemente derogando el artículo 45.2 LGSS; sin embargo, quedaron zanjadas desde los autos de la Sala de conflictos del TS de 20 de junio de $2005^{101}$. El Supremo entendió que, ya que la LEM califica

98 (RJ 19943251).

99 (RJ 1992\1894).

${ }^{100}$ Desde la entrada en vigor del EM encontramos numerosas sentencias del TS que resuelven a favor de la vía social como la competente en materia de "cuestiones contenciosas de las entidades gestoras de la Seguridad Social con su personal”. Como ejemplos, basándose principalmente en el argumento de la no derogación expresa del artículo 45.2 LGSS por la LEM: STS de 8 de julio de 2004, en recurso de casación para unificación de doctrina, (RJ 20045350); STSJ de la Comunidad Valenciana de 31 de enero de 2005, (JUR 2005\86134); STSJ de Cataluña de 26 de abril de 2005, (AS 2005\1370); STSJ de Cantabria de 10 de mayo de 2005, (AS 2005\932), STSJ de Madrid de 6 de junio de 2005, (AS 25005\1393).

${ }^{101}$ El Fundamento jurídico tercero del primer auto señala: "La referida Ley 55/2003 configura la relación de personal estatutario con la Administración sanitaria a través de los distintos Servicios de salud, como una relación funcionarial, es decir, una relación de naturaleza claramente administrativa, cuya generación, desarrollo, efectos y extinción se sujeta al derecho administrativo, y en consecuencia, los conflictos que surjan entres las partes, por su naturaleza administrativa, quedan sujetos a la revisión por la Jurisdicción Contencioso-administrativa, de acuerdo con las previsiones generales de la Ley Orgánica del Poder Judicial y la Ley 29/1998 de 13 de julio, reguladora de la Jurisdicción y por exclusión de las competencias del Orden jurisdiccional Social”, (RJ $2005 \backslash 4466$ y JUR 2005\201846). 


\section{Capítulo I. Marco histórico normativo en el que surge la sanidad como servicio público en España y la regulación jurídica de su personal}

explícitamente la relación estatutaria como funcionarial especial, es la contenciosoadministrativa su jurisdicción natural, al igual que la del resto de funcionarios públicos.

Con ello las escasas dudas que aún existían relativas a la naturaleza jurídica del personal estatutario y su jurisdicción se disiparon del todo, dando satisfacción así a la insistencia de la doctrina en ese sentido ${ }^{102}$, que además de los razonamientos relativos a los cambios organizativos que se habían producido durante años para configurar el Sistema Nacional de Salud y que habían provocado un cambio en la naturaleza jurídica originaria de su personal, argumentaba también que el artículo 103.3 CE no da cobertura a ninguna otra relación jurídica del personal al servicio de la Administración pública fuera de las de funcionario o personal laboral ${ }^{103}$.

Hay que decir que la atribución de la competencia al orden jurisdiccional contencioso administrativo de los litigios de personal estatutario fue una novedad que costó de asimilar en el contexto de la práctica jurídica; tiempo después de que el TS determinara inequívocamente que la jurisdicción competente era la contencioso administrativa, seguían planteándose los recursos y reclamaciones en materia de personal como reclamaciones previas a la vía laboral.

En la actualidad, la premisa de que el personal al servicio de la sanidad pública debe tener un régimen jurídico específico y diferenciado del resto de funcionarios públicos está plenamente aceptada. De hecho, se trata de un tipo de personal cuya gestión depende de las CC.AA., pero con un nombramiento administrativo válido para todo el ámbito estatal -en el caso del personal estatutario fijo- ya que abarca el ámbito territorial del propio Sistema Nacional de Salud, dentro del que se garantiza la movilidad voluntaria de su personal.

Esta característica de la relación de servicios es exclusiva y muy particular del personal estatutario, y si se quiere respetar, que se debe, porque a ello obliga el art. 43 de la Ley 16/2003, de 28 de mayo, de Cohesión y Calidad del Sistema Nacional de Salud $\left(\operatorname{LCCSNS}^{104}\right.$ ), dificulta su asimilación, sin más, al régimen jurídico de los funcionarios autonómicos.

En definitiva, parece claro que la naturaleza jurídica del vínculo estatutario siempre fue de índole administrativa, ya que en todo momento la relación entre la Administración sanitaria y su personal se constituía, se desarrollaba y finalizaba con arreglo a normas de esa naturaleza y se prestaba para la Administración pública en el ejercicio directo de sus potestades para la prestación de un servicio público a los ciudadanos. Incluso en la redacción del precepto originario que atribuyó la competencia a la jurisdicción laboral para

\footnotetext{
${ }^{102}$ MARTINEZ MOYA, J., "La ley 55/2003 de 16 de diciembre, del Estatuto marco del personal estatutario de los Servicios de salud ¿Un marco propicio para soltar amarras definitivamente y declarar la incompetencia del orden social?", Revista de Derecho Social no 28/2004. Del mismo autor: "Personal estatutario y jurisdicción social: fin de una larga despedida", $A S$ n ${ }^{\circ} 20 / 2005$, (BIB 2005 2708).

${ }^{103}$ PALOMAR OLMEDA, A., "El fuero jurisdiccional de enjuiciamiento de las cuestiones de aplicación del régimen estatutario del personal sanitario", $A S$ n 9/2005, (BIB 2005\15539).

${ }^{104}$ BOE de 29 de mayo de 2003.
} 


\section{Capítulo I. Marco histórico normativo en el que surge la sanidad como servicio público en España y la regulación jurídica de su personal}

la resolución de sus conflictos, el artículo 45.2 del Decreto 907/1966, se puede apreciar ese reconocimiento: "Sin perjuicio del carácter estatutario de dicha relación...".

Lo que sí constituye una particularidad es que el grueso de su régimen jurídico estuviera contenido, durante más de treinta años, en los Estatutos jurídicos, aprobados por órdenes del Ministerio de Trabajo, simples reglamentos sin rango de ley, al margen de las normas funcionariales. Estas cuestiones solo se pueden explicar teniendo en cuenta que se dieron en una etapa de inicio del sistema de Seguridad Social, en la que determinados colectivos profesionales tuvieron una gran influencia sobre el legislador en la determinación del régimen jurídico que les debía ser aplicado.

Mientras estas reformas sanitarias se producen en España, por lo que respecta a la asociación de los trabajadores -no ya el derecho, que era impensable en ese momento- esta se regulará en la Ley 191/1964, de 24 de diciembre, de Asociaciones, en desarrollo del artículo 16 del Fuero de los Españoles, cuando el régimen franquista entre en una etapa más tecnificada y menos dogmática, propiciada por la mejora de las condiciones económicas del país que, sin embargo, no sería aplicable a los funcionarios públicos, ya que estableció que las asociaciones de funcionarios civiles y militares y las del personal civil empleado en los establecimientos de las Fuerzas Armadas se regularían por sus leyes especiales (art. Segundo Tres). Asimismo, en su Disposición adicional Primera dispuso que no fuera de aplicación a la Organización sindical ni a las entidades y agrupaciones encuadradas en la misma $^{105}$.

La primera regulación de la asociación sindical del régimen franquista se basó en el Fuero del Trabajo de $1938^{106}$, en la Ley de Unidad Sindical, de 26 de enero de 1940, y en la Ley de Bases de la Organización sindical, de 6 de diciembre de 1940, que sostenían una concepción del fenómeno sindical único y obligatorio. Este se constituía por ramas de actividad productiva, a escala territorial y nacional, con independencia de la voluntad de los sujetos protagonistas y carente de toda libertad de acción.

Dentro de este modelo de sindicalismo vertical se crea el Sindicato Nacional de Actividades Sanitarias, por Decreto 1184/1964, de 23 de abril. Sin embargo, existe ya en ese momento una corriente de opinión crítica también en este ámbito y son numerosas las quejas por la nula participación de los trabajadores en la organización de la sanidad. Esto se enmarca en el movimiento de reivindicación de libertades y de reformas que está teniendo lugar en ese momento en general en la sociedad española y en concreto en la Administración Pública.

Pero a lo largo de todo ese tiempo, en ninguna de estas normas hay el menor atisbo de reconocimiento de derechos colectivos para los trabajadores ni funcionarios públicos. Tampoco se admitía ninguna manifestación de índole sindical, como la huelga. El Código

\footnotetext{
${ }^{105}$ Sobre el sistema jurídico preconstitucional véase ROQUETA BUJ, R., El derecho de negociación colectiva en el Estatuto Básico del Empleado Público, La Ley, 2007, p. 19 y ss.

${ }^{106}$ Publicado el 9 de marzo de 1938 y modificado por la Ley Orgánica del Estado de 10 de enero de 1967.
} 


\section{Capítulo I. Marco histórico normativo en el que surge la sanidad como servicio público en España y la regulación jurídica de su personal}

Penal de 1944 en su artículo 222.1, reformado por Ley 104/1965, de 21 de diciembre, tipificaba el ejercicio de la huelga como delito de sedición ${ }^{107}$.

Más adelante, la Ley Sindical de 17 de febrero de 1971, dictada en desarrollo de la Declaración XIII del Fuero del Trabajo, reguló las diversas variedades de asociacionismo profesional, ello siempre “... de acuerdo con los principios del Movimiento Nacional", excluyendo de su ámbito al personal al servicio del Estado, las corporaciones locales y los organismos autónomos que tuvieran la condición de funcionarios ${ }^{108}$. Por lo que se refiere a la regulación de estos últimos, hay que destacar de esta época la aprobación de la Ley 109/1963, de Bases de los funcionarios civiles del Estado ${ }^{109}$.

\section{6.- LA TRANSICIÓN Y LA CONSTITUCIÓN ESPAÑOLA DE 1978}

Ya entrados en la etapa de la transición, en desarrollo de la Ley de Asociaciones de 1964, se publica el Real Decreto 1839/1976, de 16 de julio, de Asociaciones profesionales de funcionarios civiles $^{110}$, que tenía la finalidad de permitir la agrupación de los funcionarios y el personal contratado en régimen de Derecho administrativo, fomentar sus intereses profesionales y colaborar con la Administración a efectos de la más adecuada prestación de sus servicios ${ }^{111}$.

La idea de asociacionismo funcionarial, según esta norma, no es de tipo sindical, al menos no utiliza este término en ninguna ocasión a lo largo de su articulado, lo cual se entiende porque aún no ha sido aprobada la Ley de Asociación Sindical, que verá la luz al año siguiente, y estamos muy al principio de la Transición, pero sí es importante lo que establece respecto a que "las organizaciones de funcionarios de carrera y de empleo y el personal contratado en régimen de Derecho Administrativo al servicio de la Administración Civil del Estado y sus organismos autónomos tendrán, entre otras la finalidad de colaborar

\footnotetext{
107 Este disponía: "Serán considerados como reos de sedición los funcionarios, empleados y particulares encargados de la prestación de todo género de servicios públicos o de reconocida e inaplazable necesidad que, suspendiendo su actividad, ocasionen trastornos a los mismos o, de cualquier forma, alteren su regularidad".

108 Artículo primero, dos. En esta ley el derecho al asociacionismo sindical se reconoce a los empresarios, trabajadores y técnicos, no así a los funcionarios públicos, a los que solo se refiere la Disposición adicional tercera para indicar que en el caso de que fueran designados por Decreto para ocupar un puesto sindical les serían de aplicación las disposiciones dictadas para los supuestos de nombramiento para cargo político o de confianza de carácter no permanente.
}

\footnotetext{
${ }^{109} \mathrm{Su}$ texto articulado, que aprobó el Decreto 315/1964, de 7 de febrero, reguló el régimen jurídico de los funcionarios públicos, los órganos superiores de la función pública, las competencias en materia de personal, etc.

${ }^{110}$ BOE de 31 de julio de 1976

${ }^{111}$ Este reglamento se hace eco en su preámbulo de la doctrina de la Organización Internacional del Trabajo, ya que, según expresa esta regulación viene a dar cumplimiento al compromiso contraído por el Gobierno español ante la Conferencia técnica de ese organismo sobre Servicio Público, celebrada en Ginebra en el mes de abril de 1975.
} 


\section{Capítulo I. Marco histórico normativo en el que surge la sanidad como servicio público en España y la regulación jurídica de su personal}

con la Administración a efectos de determinar las más adecuadas condiciones para la prestación de sus servicios y en la elaboración de las disposiciones que les afecten a través de su participación en las tareas de los órganos correspondientes" lo cual apunta a los procedimientos de consulta, esbozo de lo que será después la negociación colectiva. En los años siguientes se crearán las Juntas de personal como órgano de participación de los funcionarios, tanto de carrera como de empleo ${ }^{112}$.

Cuando en el año 1977 se legitima la existencia de las organizaciones sindicales por Ley 19/1977, de 1 de abril, de Asociación Sindical ${ }^{113}$, se prevé para los funcionarios una regulación específica. Esta vendrá dada por el Real Decreto 1522/1977, de 17 de junio, de ejercicio del derecho de asociación sindical de los funcionarios públicos, que es el antecedente del reconocimiento de su derecho a la libertad sindical ${ }^{114}$. Al amparo de la regulación de 1977 comienzan a proliferar en la función pública española las asociaciones sindicales, de base corporativa. Cada cuerpo de funcionarios crea su propia estructura asociativa y aumenta la afiliación sindical tanto a las centrales sindicales de clase como a las corporativas funcionariales $^{115}$.

La organización administrativa sanitaria también se fue preparando para los nuevos cambios: en 1977 se crea el Ministerio de Sanidad, y al año siguiente, el Real Decreto Ley 36/1978, de 16 de noviembre, sobre gestión institucional de la Seguridad Social, la Salud y el Empleo, pone fin al INP y crea las entidades gestoras de la Seguridad Social: el Instituto Nacional de la Seguridad Social, el Instituto Nacional de Servicios Sociales, el INSALUD, el Instituto Nacional de Empleo y la Tesorería General de la Seguridad Social -esta como servicio común- manteniéndose hasta el momento actual la colaboración de las Mutuas Patronales de accidentes de trabajo y enfermedades profesionales.

Finalmente, la Constitución de 1978 supone verdaderamente el punto de encuentro común de trabajadores y funcionarios en cuanto al reconocimiento del derecho a la libertad

${ }^{112}$ El 4 de enero de 1977 se publica el Real Decreto 3006/1976, de 23 de diciembre, de participación y colaboración de los funcionarios en los órganos encargados de la regulación y gestión de la función pública. Los vocales eran elegidos a través de elecciones a las que podían presentar candidatura las organizaciones profesionales de funcionarios legalmente constituidas con al menos veinticinco afiliados entre el personal que prestara servicios en el Departamento ministerial (art. quinto).

113 La Ley 19/1977, publicada en el BOE de 4 de abril, en su artículo primero, uno, dice que: “Los trabajadores y los empresarios podrán constituir en cada rama de actividad a escala territorial o nacional, las asociaciones profesionales que estimen convenientes para la defensa de sus intereses respectivos", para declarar en el artículo segundo dos que: "Los trabajadores y los empresarios gozarán de protección contra todo acto de discriminación tendente a menoscabar la libertad sindical en relación con su empleo o función". En su Disposición adicional establece respecto a los funcionarios públicos: "Uno.- Queda excluido de la presente Ley el personal militar. Dos.- El ejercicio del derecho de asociación sindical por los funcionarios públicos y por el personal civil al servicio de la Administración Militar se regulará por disposiciones específicas".

114 DEL REY GUANTER, S., Estado, sindicatos y relaciones colectivas en la Función pública, Ministerio para las Administraciones Públicas, Madrid, 1986.

${ }^{115}$ La sindicación de los funcionarios, Diario El País [en línea], 6 de enero de 1979, [consulta de 12 de marzo de 2013], disponible en:< http://www.elpais.com/hemeroteca $>$. 


\section{Capítulo I. Marco histórico normativo en el que surge la sanidad como servicio público en España y la regulación jurídica de su personal}

sindical, que se contempla en el artículo 28.1. En los años siguientes este precepto se desarrollará por la Ley Orgánica 11/1985, de 2 de agosto, de Libertad Sindical (LOLS) en todos sus aspectos esenciales, aplicables a todos los trabajadores y a todo el personal al servicio de la Administración pública, salvo determinadas excepciones.

Respecto a la competencia sobre la sanidad pública, la nueva organización territorial que diseña la CE atribuye a las CC.AA. las competencias en materia de sanidad e higiene (art. 148.1. 21 ${ }^{\mathrm{a}}$ ), y deja para el Estado la competencia exclusiva sobre la sanidad exterior y las bases y coordinación general de la sanidad (art. 149.1. 16 $6^{\mathrm{a}}$ ) ello con el fin de dar efectividad al derecho a la protección de la salud de los ciudadanos regulado en el artículo $43 \mathrm{CE}$.

Con esta base constitucional se construirá en los años siguientes el Sistema Nacional de Salud que crea la Ley 14/1986 de 25 de abril, General de Sanidad (LGS), que además prevé una regulación básica común para todo el personal a su servicio: el Estatuto Marco del personal estatutario de los Servicios de salud, que había quedado al margen de la Ley 30/1984 de 2 de agosto, de medidas de reforma de la función pública, invocando las peculiaridades de su prestación de servicios ${ }^{116}$. Esta exclusión, junto con la atribución al orden social de la competencia para conocer de los conflictos que se plantearan entre el personal y su administración empleadora, prevista en el artículo 45.1 LGSS, alentó durante años la polémica doctrinal y jurisprudencial acerca de la naturaleza jurídica del personal estatutario, que se ha mantenido viva hasta la publicación de la LEM, que la reconoce finalmente como funcionarial especial.

${ }^{116}$ Disposición transitoria cuarta. 
CAPITULO II

EL ACTUAL REgIMEN JURÍdico DEL PERSONAL ESTATUTARIO DE LOS SERVICIOS DE SALUD. SU CREACION Y DESARROLLO PARALELOS A LOS DEL SISTEMA NACIONAL DE SALUD 



\section{CAPITULO II}

\section{EL ACTUAL REGIMEN JURÍDICO DEL PERSONAL ESTATUTARIO DE LOS SERVICIOS DE SALUD. SU CREACION Y DESARROLLO PARALELOS A LOS DEL SISTEMA NACIONAL DE SALUD}

Antes de continuar tratando los derechos colectivos del personal estatutario de los Servicios de salud conviene detenernos a analizar determinados aspectos del régimen jurídico que actualmente regula la relación de servicios de estos profesionales con la Administración pública sanitaria, así como la estructura organizativa de esta: el Sistema Nacional de Salud. Como veremos, la vinculación jurídica de este tipo de personal con la Administración condiciona las peculiaridades en el ejercicio de sus derechos sindicales, ya que se trata de una relación jurídica de carácter administrativo.

\section{1.- EL REPARTO CONSTITUCIONAL DE COMPETENCIAS EN MATERIA DE SANIDAD. LA CREACIÓN DEL SISTEMA NACIONAL DE SALUD Y SU ORGANIZACIÓN ADMINISTRATIVA ACTUAL}

Para entender porqué surge la necesidad de aprobar una ley estatal que regule el régimen jurídico del personal al servicio de la Administración sanitaria, un Estatuto Marco con rango de norma básica, hay que atender al hecho de la nueva organización territorial que surge con la promulgación de la CE, que da como resultado la creación de las CC.AA. como entes territoriales, a las que atribuye una serie de competencias en su texto. Según el artículo 137: "El Estado se organiza territorialmente en municipios, en provincias y en las Comunidades Autónomas que se constituyan. Todas estas entidades gozan de autonomía para la gestión de sus respectivos intereses".

Así, resulta que el Estado, entre otras muchas, tiene competencia exclusiva sobre la legislación básica de Seguridad Social (art.149.1.17a): "Legislación básica y régimen económico de la Seguridad Social, sin perjuicio de la ejecución de sus servicios por las Comunidades Autónomas" y también la tiene para establecer las bases del régimen jurídico de las Administraciones públicas y del régimen estatutario de sus funcionarios (art. 149.1.18a): "Las bases de régimen jurídico de las Administraciones Públicas y del régimen estatutario de sus funcionarios que, en todo caso, garantizarán a los administrados un tratamiento común ante ellas...".

Asimismo, también tiene la competencia exclusiva en relación con la: "Sanidad exterior. Bases y coordinación general de la sanidad. Legislación sobre productos farmacéuticos" (art. 149.1.16 ). La competencia de las CC.AA. se regula en el artículo 148.1.21": "Las CC.AA. podrán asumir competencias en las siguientes materias: [...] Sanidad e higiene". Por tanto, en materia sanitaria la CE prevé el reparto de competencias entre las CC.AA. y el Estado. 
En este sentido, corresponderá al Estado la legislación básica sobre sanidad y sobre el régimen jurídico de los funcionarios públicos, y a las CC.AA. se les reconoce competencia para aprobar normas de desarrollo legislativo sobre el régimen estatutario de sus funcionarios y para la gestión de la sanidad dentro de su ámbito territorial, aspectos que desarrollan sus Estatutos de autonomía ${ }^{117}$.

Además, en el Capítulo III del Título I, la propia CE dispone, como principio rector de la política social y económica, la obligación de los poderes públicos del mantenimiento de un régimen público de Seguridad Social para todos los ciudadanos "que garantice la asistencia y prestaciones sociales suficientes ante situaciones de necesidad, especialmente en caso de desempleo" (art. 41) ${ }^{118}$; y también por otra parte, el derecho a la protección de la salud (art. 43). Este último establece:"1.-Se reconoce el derecho a la protección de la salud. 2.- Compete a los poderes públicos organizar y tutelar la salud pública a través de medidas preventivas y de las prestaciones y servicios necesarios. La ley establecerá los derechos y deberes de todos al respecto".

En los años siguientes el derecho a las prestaciones del servicio público sanitario se configurará como un derecho universal para los ciudadanos, y dejará de conceptuarse como una prestación a la que tienen derecho los asegurados. Pasará de ser una de las prestaciones a cargo de la Seguridad Social para convertirse en una competencia de titularidad estatal, pero de gestión autonómica.

VIDA FERNANDEZ señala las diferencias entre el sistema anterior, en el que las prestaciones sanitarias derivan de la Seguridad Social, y este nuevo, que tiene su origen en el artículo $43 \mathrm{CE}$ :

$1^{\circ}$ ) A diferencia del de Seguridad Social, en el Sistema Nacional de Salud no se condiciona la cobertura de la asistencia sanitaria a la previa afiliación, sino que tiende a ser universal, aunque de forma programada.

$2^{\circ}$ ) En el Sistema Nacional de Salud la cobertura tiene carácter global frente a la pérdida de salud por cualquier causa.

$3^{\circ}$ ) El régimen de Seguridad Social se financia mediante las cuotas de los afiliados, el del Sistema Nacional de Salud lo hace mediante las partidas presupuestarias correspondientes ${ }^{119}$.

117 Como ejemplo, la Ley orgánica $5 / 1982$ de 1 de julio, de Estatuto de Autonomía de la Comunidad
Valenciana, modificada por la Ley orgánica 1/2006, de 10 de abril, dispone en el artículo 50 que: "En el
marco de la legislación básica del Estado, y, en su caso, en los términos que la misma establezca, corresponde
a la Generalitat el desarrollo legislativo y la ejecución de las siguientes materias: [...] régimen estatutario de
sus funcionarios". Asimismo, en el artículo 54.1 que "Es de competencia exclusiva de la Generalitat la
organización, administración y gestión de todas las instituciones sanitarias públicas dentro del territorio de la
Comunitat Valenciana”. El apartado 4 del mismo precepto dispone: "La Generalitat podrá organizar y
administrar para aquellas finalidades, y dentro de su territorio, todos los servicios relacionados con las
materias antes mencionadas [...] Artículo 54.5: "La Generalitat, en el ejercicio de las competencias en
materia de sanidad y Seguridad Social, garantizará la participación democrática de todos los interesados, así
como de los sindicatos de trabajadores y asociaciones empresariales en los términos que la Ley establezca".

${ }^{118}$ Sobre el contenido de la Seguridad Social en la CE, véase de FERNÁNDEZ ORRICO, F.J., "La Seguridad Social en el XXV aniversario de la Constitución”, Revista del Ministerio de Trabajo y Asuntos Sociales, $\mathrm{n}^{\circ} 49$, pp. 127-167.

${ }^{119}$ VIDA FERNANDEZ, J., “Las prestaciones sanitarias del Sistema Nacional de Salud...”, op.cit. 
Para poder hacer realidad el Sistema Nacional de Salud era necesario contar con organismos públicos con competencias específicas y para ello, el Real Decreto Ley 36/1978, de 16 de noviembre, sobre gestión institucional de la Seguridad Social, la Salud y el Empleo, crea el INSALUD, en su artículo 1.1.2, y suprime el antiguo INP ${ }^{120}$. Esta norma configura el INSALUD como una de las entidades gestoras de la Seguridad Social (junto con el Instituto Nacional de Seguridad Social y el Instituto Nacional de Servicios Sociales) adscrita al recién creado Ministerio de Sanidad y Seguridad Social, que asumió las competencias que ejercía el Ministerio de la Gobernación a través de la Dirección general de Sanidad ${ }^{121}$.

El siguiente paso fundamental es la publicación de la Ley 14/1986, de 25 de abril, General de Sanidad, que en desarrollo de los preceptos de la CE vistos, universaliza la asistencia sanitaria y transforma el Sistema de Seguridad Social en un Sistema Nacional de Salud $^{122}$.

La LGS se completa con la Ley 33/2011, de 4 de octubre, General de Salud Pública, que lleva a efecto el mandato del artículo 43.2 CE, por lo que se refiere a la acción preventiva en materia de salud y cuyo objeto es:”... establecer las bases para que la población alcance y mantenga el mayor nivel de salud posible a través de las políticas, programas, servicios, y en general actuaciones de toda indole desarrolladas por los poderes públicos, empresas y organizaciones ciudadanas con la finalidad de actuar sobre los procesos y factores que más influyen en la salud, y así prevenir la enfermedad y proteger y promover la salud de las personas, tanto en la esfera individual como en la colectiva" ${ }^{123}$.

El Sistema Nacional de Salud está formado por el conjunto coordinado de los Servicios de salud de la Administración del Estado y de los Servicios de salud de las CC.AA., que integra todas las funciones y prestaciones sanitarias que son responsabilidad

${ }^{120}$ Disposición final primera uno.

${ }^{121}$ En el Real Decreto Ley 36/1978 se reconoce la importancia de este cambio: “La creación del Ministerio de Sanidad y Seguridad Social por Real Decreto de 4 de julio de 1977, facilitó el camino de las insoslayables reformas al unificar competencias dispersas, faltas de coordinación y exentas de planificación conjunta". Se refiere al Real Decreto 1558/1977, de 4 de julio, por el que se reestructuran determinados órganos. de la Administración Central del Estado. En su artículo 12 crea el Ministerio de Sanidad y Seguridad Social (BOE de 5 de julio de 1977).

${ }^{122}$ Sobre la constitución del Sistema Nacional de Salud como fruto del desarrollo del Sistema de Seguridad Social, véase de APARICIO TOVAR, J., La Seguridad Social y la protección de la Salud, Civitas, 1989, pp. 199 y ss.

${ }^{123}$ Publicada en el BOE de 5 de octubre de 2011. Las CC.AA. tienen leyes propias de Salud pública en algunos casos anteriores a la estatal: Ley 4/2005, de 17 de junio, de Salud Pública de la Comunidad Valenciana (BOE de 17 de julio de 2005); Ley 18/2009, de 22 de octubre, de Salud Pública de Cataluña (BOE de 16 de noviembre de 2009); Ley 10/2010, de 27 de septiembre, de Salud Pública y seguridad alimentaria de Castilla y León (BOE de 23 de noviembre de 2010); Ley 16/2010, de 28 de diciembre, de Salud pública de las Islas Baleares (BOE de 4 de febrero de 2011); Ley 7/2011, de 23 de marzo, de Salud pública de Extremadura (BOE de 13 de abril de 2011) ); Ley 16/2011, de 23 de diciembre, de Salud pública de Andalucía (BOE de 20 de enero de 2012). 
de los poderes públicos para el cumplimiento del derecho a la protección de la salud (arts. 44.2 y 45 de la LGS).

Cuando se concibe el Sistema Nacional de Salud por el legislador, este se configura en virtud de las siguientes características fundamentales que establece el artículo 46 de la LGS: la extensión de sus servicios a toda la población; la organización adecuada para prestar una atención integral de la salud, comprensiva tanto de la promoción de la salud y prevención de la enfermedad como de la curación y rehabilitación; la coordinación y, en su caso, la integración de todos los recursos sanitarios públicos en un dispositivo único; la financiación de las obligaciones derivadas de la LGS mediante recursos de las Administraciones públicas, cotizaciones y tasas por la prestación de determinados servicios y la prestación de una atención integral de la salud procurando altos niveles de calidad debidamente evaluados y controlados.

Asimismo, la LGS regula las actuaciones sanitarias que llevará cabo, y que vienen dadas en los Capítulos II a IV, artículos 18 a 22, en los que se regula el abanico de acciones administrativas para la promoción y protección de la salud ${ }^{124}$.

Desde el punto de vista organizativo, como reconocerá la propia LEM años más tarde: "El Sistema Nacional de Salud es un modelo organizativo especial, que solo existe en el ámbito de los servicios sanitarios públicos, que crea y configura la LGS como medio de adaptación de tales servicios a la organización política y territorial española, y que se concibe como el conjunto de los diferentes Servicios de salud con un funcionamiento armónico y coordinado ${ }^{125}$.

Con la creación del Sistema Nacional de Salud el personal estatutario de las instituciones sanitarias de la Seguridad Social se transforma en personal estatutario de los Servicios de salud autonómicos, que ya no participan de la naturaleza de las Entidades gestoras de la Seguridad social ${ }^{126 .}$

Dado que la creación de los Servicios de salud se debía producir a lo largo de un período de tiempo, la Disposición transitoria tercera de la LGS mantuvo existente el INSALUD en tanto se produjeran los traspasos de servicios a todas las CC.AA. ${ }^{127}$, que

\footnotetext{
${ }^{124}$ El artículo 18 LGS contempla las diferentes actuaciones de las Administraciones públicas en materia sanitaria, destacando, entre otras, la adopción sistemática de acciones para la educación sanitaria, la atención primaria integral de la salud, la asistencia sanitaria especializada, la prestación de los productos terapéuticos precisos y los programas de atención a grupos de población de mayor riesgo [...] la formación del personal al servicio de la organización sanitaria; el fomento de la investigación científica y el control y la mejora de la calidad de la asistencia sanitaria en todos sus niveles.

${ }^{125}$ Exposición de Motivos, apartado II, LEM.

${ }^{126}$ Véase de BLASCO LAHOZ, J.F., "El Sistema Nacional de la Salud y la ordenación de los servicios sanitarios”, AS n 15/2001, (BIB 2001 \1516).

${ }^{127}$ Esta Disposición estableció: “1. El Instituto Nacional de la Salud continuará subsistiendo y ejerciendo las funciones que tiene atribuidas, en tanto no se haya culminado el proceso de transferencias a las CC.AA. con competencia en la materia. 2. Las CC.AA. deberán acordar la creación, organización y puesta en funcionamiento de sus Servicios de salud en el plazo máximo de doce meses, a partir del momento en que
} 
empezaron a hacerse efectivos a principios de los años ochenta, momento a partir del cual se dictó numerosa normativa relativa al personal estatutario ${ }^{128}$.

A pesar de que el Sistema Nacional de Salud se concibe en la LGS como un modelo organizativo coordinado para la prestación directa por parte de las Administraciones públicas de las prestaciones sanitarias, en 1996 se produce un cambio legislativo al que hay que prestar atención: el Real Decreto Ley 10/1996, de 17 de junio, sobre habilitación de nuevas formas de gestión del INSALUD. Un año después se publica la Ley 15/1997, de 15 de abril, que lo sustituirá ${ }^{129}$. Estas normas serán la puerta abierta a la gestión del servicio público sanitario y sociosanitario por cualesquiera entidades de naturaleza o titularidad pública admitidas en Derecho, así como por entidades privadas; eso sí, garantizando y preservando en todo caso la condición de servicio público, como establece el artículo único de la Ley $15 / 1997^{130}$. Con anterioridad, la Ley 30/1994, de 24 de noviembre, de Fundaciones e Incentivos fiscales a la participación privada en actividades de interés general, había sentado precedente para la participación de las entidades privadas en la prestación de servicios sanitarios ${ }^{131}$.

quede culminado el proceso de transferencias de servicios que corresponda a sus competencias estatutarias. 3. En los casos en que las CC.AA. no cuenten con competencias suficientes en materia de Sanidad para adaptar plenamente el funcionamiento de sus Servicios de salud a lo establecido en la presente Ley, el Estado celebrará con aquellas acuerdos y convenios para la implantación paulatina de lo establecido en la misma y para conseguir un funcionamiento integrado de los servicios sanitarios".

${ }^{128}$ GARCIA MURCIA, J., CASTRO ARGUELLES, M.A., "El Estatuto Marco del personal estatutario de los Servicios de salud: Una Presentación", AS no 21/2003, (BIB 2004162). Estos autores ponen de relieve la profusión de normas jurídicas, de origen diverso, en materia de personal antes de la publicación de la LEM.

${ }^{129}$ BOE de 18 de junio de 1996 y de 26 de abril de 1997 respectivamente.

${ }^{130}$ Lo cierto es que, con fundamento en estos precedentes normativos, en los años siguientes se llevaron a cabo los primeros contratos de concesión con entidades privadas para la gestión de los servicios públicos sanitarios en la Comunidad Valenciana. En 1999 inició su actividad el Hospital de La Ribera (Alzira-Valencia), uno de los primeros de la red sanitaria pública con gestión privada. Desde entonces se hicieron frecuentes las críticas a este sistema: "El borrador de la Ley de Ordenación Sanitaria que el Partido Popular ultima abre las puertas a las fundaciones, consorcios, sociedades estatales o fundaciones públicas para que protagonicen el modelo sanitario que pretende implantar el Consell. Pero también permite que aseguradoras sanitarias se hagan cargo de la asistencia primaria o especializada de un área de salud o la externalización de servicios hospitalarios”. Diario El País [en línea], 19 de julio de 2000, [consulta de 2 de febrero de 2013], disponible en: 〈http://www.elpais.com/hemeroteca>.

El borrador que cita la nota de prensa se transformó en la Ley 3/2003 de 6 de febrero de Ordenación Sanitaria de la Comunidad Valenciana, cuyo artículo 23 dispuso que "La gestión y administración de los centros, servicios y establecimientos sanitarios de protección de la salud o de atención sanitaria o sociosanitaria podrá llevarse a cabo directamente o indirectamente, con medios propios o ajenos, públicos o privados, mediante cualesquiera entidades admitidas en derecho, así como a través de la constitución de concesiones administrativas, consorcios, fundaciones, empresas públicas, u otros entes dotados de personalidad jurídica propia, pudiéndose establecer, además, acuerdos o convenios con personas o entidades públicas o privadas y fórmulas de gestión integrada o compartida. Las entidades públicas constituidas a tal efecto y al amparo de la Ley 15/1997 de 25 de abril serán dependientes de la Agencia Valenciana de Salud”.

${ }^{131}$ BOE de 25 de noviembre de 1994. En su Exposición de motivos se señala como una causa de la necesidad de la ley de incentivos fiscales, la de que ese estímulo es ineludible, vista la dificultad de los poderes públicos de atender plenamente el interés general y el protagonismo que la sociedad reclama y entrega a las variadas 
En cuanto a la naturaleza jurídica y el régimen de funcionamiento de las entidades que gestionan los Servicios de salud, parece que es una opción libre de cada legislador autonómico determinarlos, ya que la LGS, que regula los Servicios de salud de las CC.AA. en el Capítulo II del Título III, bajo el epígrafe "De la estructura del sistema sanitario público", no impone ninguna forma jurídica específica: "Las CC.AA. en ejercicio de las competencias asumidas en sus Estatutos, dispondrán acerca de los órganos de gestión y control de sus respectivos Servicios de salud, sin perjuicio de lo que en esta Ley se establece" (art. 52 LGS). Asimismo, "la ordenación territorial de los Servicios será competencia de las CC.AA. y se basará en la aplicación de un concepto integrado de atención a la salud” (art. 51.2).

Cada Servicio de salud autonómico está integrado por "todos los centros, servicios y establecimientos de la propia Comunidad, Diputaciones, Ayuntamientos y cualesquiera otras Administraciones territoriales intracomunitarias, que estará gestionado [...] bajo la responsabilidad de la respectiva Comunidad Autónoma" (art. 50 LGS). La norma exige su planificación con criterios de racionalización de los recursos, de acuerdo con las necesidades sanitarias de cada territorio (art. 51.1 LGS).

Por lo que se refiere al proceso de traspaso de funciones y servicios a las CC.AA., hay que tener en cuenta que este duró más de veinte años, ya que comenzó en el año 1981 con Cataluña, que junto con el País Vasco y Andalucía ya tenían traspasada la competencia antes de la promulgación de la LGS, y concluyó a finales de 2001, para tener efectos a partir del 1 de enero de $2002^{132}$.

Al principio de asumir competencias en sanidad, las CC.AA. optaron ampliamente por crear Servicios de salud con forma jurídica de organismo autónomo de carácter administrativo, con personalidad jurídica, patrimonio y tesorería propios, adscritos a la respectiva Consejería de Sanidad o Departamento con competencias en gestión de la Salud $^{133}$. Esto hoy día continúa siendo así de forma mayoritaria. Estos organismos

entidades sin ánimo de lucro. Una de las primeras en crearse fue en 1994, en Galicia, la Fundación Hospital de Verin, dependiente del Servicio Gallego de Salud.

${ }^{132}$ Por orden cronológico los traspasos se produjeron así: Cataluña: Real Decreto 1517/1981, de 8 de julio; Andalucía: Real Decreto 400/1984, de 22 de febrero; País Vasco: Real Decreto 1536/1984, de 6 de noviembre; Comunidad Valenciana: Real Decreto 1612/1987, de 27 de noviembre; Navarra: Real Decreto 1680/1990, de 28 de diciembre; Galicia: Real Decreto 1679/1990, de 28 de diciembre; Canarias: Real Decreto 446/1994, de 11 de marzo; Asturias: Real Decreto 1471/2001, de 27 de diciembre; Cantabria: Real Decreto 1472/2001, de 27 de diciembre; La Rioja: Real Decreto 1473/2001, de 27 de diciembre; Murcia: Real Decreto 1474/2001, de 27 de diciembre; Aragón: Real Decreto 1475/2001, de 27 de diciembre; Castilla-La Mancha: Real Decreto 1476/2001, de 27 de diciembre; Extremadura: Real Decreto 1477/2001, de 27 de diciembre; Baleares: Real Decreto 1478/2001, de 27 de diciembre; Madrid: Real Decreto 1479/2001, de 27 de diciembre; Castilla y León: Real Decreto 1480/2001, de 27 de diciembre.

${ }^{133}$ Véase STSJ de La Rioja de 23 de diciembre de 2005, (JUR 2005\98470): "Tras la culminación el 1 de enero de 2002 del proceso de transferencias en materia de asistencia sanitaria de la Administración Central del Estado a las distintas Administraciones Autonómicas, la asistencia sanitaria a cargo del Sistema de la Seguridad Social es prestada en la actualidad, además de por Mutualidad de Funcionarios de la Administración Civil del Estado (MUFACE), por la Mutualidad General Judicial (MUGEJU) y por el Instituto Social de las Fuerzas Armadas (ISFAS), por los distintos Servicios de salud creados por las distintas CC.AA. en ejercicio tanto de las competencias transferidas desde la Administración Central cuanto de las 
autónomos están, por tanto, sometidos plenamente al ordenamiento jurídico administrativo, autonómico y estatal.

Gómez de Hita define los organismos autónomos administrativos como entidades de Derecho Público creadas por ley, que tienen personalidad jurídica y patrimonio propio, que actúan en régimen de descentralización administrativa y que tienen como función la organización y administración de un servicio público, de los fondos que tienen adscritos y de las actividades y bienes $^{134}$.

Para completar el proceso de traspasos, el Real Decreto 840/2002, de 2 de agosto, modificó y desarrolló la estructura básica del Ministerio de Sanidad y Consumo, estableciendo la desaparición del INSALUD y la creación del Instituto Nacional de Gestión Sanitaria (INGESA). En el artículo 15 señaló que este conservaría el mismo régimen jurídico, económico, presupuestario y patrimonial y la misma personalidad jurídica y naturaleza de Entidad Gestora de la Seguridad Social que tenía el INSALUD, y que le correspondería la gestión de los derechos y obligaciones de este, las prestaciones sanitarias en el ámbito de las ciudades de Ceuta y Melilla y realizar cuantas otras actividades fueran necesarias para el normal funcionamiento de sus servicios, en el marco de lo establecido en la Disposición transitoria tercera de la LGS. Con posterioridad, el Real Decreto 1555/2004, de 25 de junio, por el que se desarrolla la estructura orgánica básica del Ministerio de Sanidad y Consumo, dispuso la adscripción del INGESA al Ministerio de Sanidad y Consumo a través de la Dirección General de Cohesión del Sistema Nacional de Salud y Alta Inspección (art. 11.5) ${ }^{135}$.

Actualmente, el Real Decreto 1746/2003, de 19 de diciembre, regula la organización de los servicios periféricos del INGESA, que es competente para la gestión de las prestaciones sanitarias en las ciudades autónomas de Ceuta y Melilla, la gestión de la Organización Nacional de Trasplantes y el Centro Nacional de Dosimetría, con sede en Valencia ${ }^{136}$. Como vemos, estas competencias las ha mantenido el Estado, no están transferidas y son gestionadas por ese organismo. En tanto esto sea así, el legislador estatal podrá decidir su naturaleza jurídica, sujetándose a la Ley 6/1997, de 14 de abril, de Organización y Funcionamiento de la Administración General del Estado ${ }^{137}$ :

reconocidas por el ordenamiento jurídico vigente, pero tales Servicios de salud carecen del carácter de Entidades Gestoras de la Seguridad Social. Son, como dice la sentencia del Tribunal Supremo, Sala IV, de 9 julio 2003 organismos autónomos de carácter administrativo dependientes de cada una de las CC.AA. que los crearon para la efectiva y cabal prestación de la asistencia sanitaria a los afiliados y beneficiarios del Sistema de la Seguridad Social, que realizan funciones análogas a las que antes efectuaba el INSALUD, pero poseen una naturaleza jurídica distinta a aquel”.

${ }^{134}$ GOMEZ DE HITA, J.L., Formas jurídicas de la organización sanitaria, Escuela Andaluza de Salud Pública, 2000, p. 118 .

${ }^{135}$ BOE de 26 de junio de 2004.

${ }^{136}$ El Centro Nacional de Dosimetría se ocupa, principalmente, de la lectura y control dosimétrico mensual de los trabajadores del Sistema Nacional de Salud profesionalmente expuestos a las radiaciones ionizantes.

${ }^{137}$ Que distingue en su artículo 43 las siguientes clases de organismos públicos “a) Organismos autónomos. b) Entidades públicas empresariales. c) Agencias Estatales, que se regirán por su normativa específica y, supletoriamente, por esta Ley". Habrá que tener en cuenta que el mismo precepto dispone una nota distintiva 
Por otra parte, las CC.AA. tienen competencia, asumida en sus Estatutos de autonomía, para regular la organización y el funcionamiento de su Administración autonómica (art. 148.1 $1^{\mathrm{a}} \mathrm{CE}$ ), por lo que la existencia, estructura y funcionamiento de su Servicio de salud se deberá adaptar a las exigencias de su normativa legal propia, en función de cual sea su naturaleza jurídica.

Véase, a título de ejemplo, el Texto Refundido de la Ley de Finanzas Públicas de Cataluña, aprobado por Decreto legislativo 3/2002, de 24 de desembre, y el Texto Refundido de la Ley del Estatuto de la empresa pública catalana, aprobado por Decreto legislativo 2/2002, de 24 de diciembre, que establecen que los organismos autónomos pueden tener carácter administrativo, o bien comercial, financiero o industrial (empresas públicas). La creación de estos organismos debe ser autorizada per una ley del Parlamento catalán, que determinará sus funciones, recursos económicos, las bases de la organización y su régimen jurídico. Así como la Ley 16/2010, de 17 de diciembre, de organización y funcionamiento de la Administración general y del sector público autonómico de Galicia ${ }^{138}$, que regula en su artículo 3 el sector público autonómico ${ }^{139}$.

Aunque las CCAA optaron ampliamente por la forma jurídica de organismo autónomo de carácter administrativo para sus Servicios de salud, a partir de los años noventa empezaron a darse otras opciones a favor de diversas formas jurídicas buscando cobijo bajo el Derecho privado. Aun así, son mayoría los Servicios de Salud que presentan todavía la forma de organismos autónomos de carácter administrativo, tal como veremos.

En efecto, era organismo autónomo de carácter administrativo hasta el 31 de diciembre de 2013, la Agencia Valenciana de Salud, cuya regulación se contenía en la Ley 3/2003, de 6 de febrero, de Ordenación Sanitaria de la Comunidad Valenciana, artículo $23^{140}$, y que, sin embargo, ha sido suprimida por la Ley 5/2013, de 23 de diciembre, de la

entre organismos autónomos y entidades públicas empresariales: “2. Los Organismos autónomos dependen de un Ministerio, al que corresponde la dirección estratégica, la evaluación y el control de los resultados de su actividad, a través del órgano al que esté adscrito el Organismo. 3. Las entidades públicas empresariales dependen de un Ministerio o un Organismo autónomo, correspondiendo las funciones aludidas en el apartado anterior al órgano de adscripción del Ministerio u organismo”. BOE de 15 de abril de 1997.

${ }^{138}$ Diario Oficial de Galicia de 31 de diciembre de 2010.

139 “A los efectos de esta ley, el sector público autonómico, además de por la propia Administración general de la Comunidad Autónoma de Galicia, está integrado por las siguientes entidades: a) Entidades públicas instrumentales dependientes de la Administración general o de otras entidades públicas instrumentales de la Comunidad Autónoma de Galicia. b) otras entidades instrumentales respecto de las cuales la Administración general de la Comunidad Autónoma de Galicia ejerce jurídicamente, de forma directa o indirecta, una posición de dominio, entendiendo como tal, a estos efectos, aquella en la que se ejerce un control análogo al de los propios servicios de la Administración. 2. Las entidades públicas instrumentales integrantes del sector público autonómico sujetarán su actividad al derecho administrativo siempre que ejerzan potestades administrativas y en cualquier otra circunstancia salvo que, en este último caso, de acuerdo con las leyes generales o sectoriales aplicables o con sus específicas normas reguladoras, puedan o deban someterse al derecho privado. En todo caso, actuarán bajo el control y la dependencia o tutela de la Administración general de Galicia o de otra entidad instrumental integrante del sector público autonómico”.

${ }^{140}$ BOE de 5 de marzo de 2003. 
Capítulo II. El actual régimen jurídico del personal estatutario de los Servicios de salud. Su creación y desarrollo paralelos a los del Sistema Nacional de Salud

Comunidad Valenciana ${ }^{141}$, pasando a desempeñar directamente esas funciones la Conselleria de Sanitat ${ }^{142}$.

Son organismos autónomos de carácter administrativo, dependientes de los Departamentos o Consejerías de Sanidad o Salud de sus respectivas Administraciones autonómicas:

- El Servicio Andaluz de Salud, regulado por Ley 2/1998, de 15 de junio, de Salud de Andalucía (art. 64) ${ }^{143}$.

- El Servicio Aragonés de Salud, que se regula en el Texto Refundido de la Ley del Servicio Aragonés de Salud, aprobado por Decreto Legislativo 2/2004, de 30 de diciembre $(\operatorname{art} .1)^{144}$.

- El Servicio Canario de Salud, según la Ley 11/1994, de 26 de julio, de Ordenación Sanitaria de Canarias (art. 50.1) ${ }^{145}$.

- El Servicio Cántabro de Salud, regulado por la Ley 10/2001, de 28 de diciembre, del Servicio Cántabro de Salud (art. 1) ${ }^{146}$.

- El Servicio de Salud de Castilla-La Mancha, según la Ley 8/2000, de 30 de noviembre, de Ordenación Sanitaria de Castilla-La Mancha (art. 68) ${ }^{147}$.

- El Servicio de Salud de Castilla y León, denominado Gerencia Regional de Salud, que se regula en el artículo 26 de la Ley 8/2010, de 30 de agosto, de Ordenación Sanitaria de Castilla y León ${ }^{148}$.

\footnotetext{
${ }^{141}$ BOE de 31 de enero de 2014.

${ }^{142}$ En la Comunidad valenciana se han dado bandazos en este sentido: La Ley del Servicio Valenciano de Salud de 1987 creó este organismo autónomo, que posteriormente se suprimió en 1995 para asumir la Conselleria de Sanitat directamente las competencias, hasta el año 2003 en el que con la Ley de Ordenación Sanitaria de la Comunidad valenciana se crea la Agencia Valenciana de Salud, que diez años después se suprime de nuevo.

${ }^{143}$ BOE de 4 de agosto de 1998.

${ }^{144}$ BOE de 14 de enero de 2005.

${ }^{145}$ BOE de 26 de agosto de 1994.

${ }^{146}$ BOE de 24 de enero de 2002.

${ }^{147}$ BOE de 27 de febrero de 2001.

${ }^{148}$ BOE de 28 de septiembre de 2010.
} 
- El Servicio Gallego de Salud, creado por la Ley 1/1989, de 2 de enero, de creación del Servicio Gallego de Salud (art. 1), reformada por Ley 8/1991, de 23 de julio ${ }^{149}$, y regulado también, posteriormente, en la Ley 8/2008, de 10 de julio, de Salud de Galicia ${ }^{150}$.

- El Servicio Riojano de Salud, según la Ley 2/2002, de 17 de abril, de Salud de la Rioja (artículo 73) ${ }^{151}$, modificada por la Ley $1 / 2005$, de 11 de febrero ${ }^{152}$.

- El Servicio Extremeño de Salud: Ley 10/2001 de 28 de junio, de Salud de Extremadura (art. 57) ${ }^{153}$.

- En el mismo caso está el Servicio Navarro de Salud (el Osasunbidea), según el artículo 1 de los Estatutos del Servicio Navarro de Salud, aprobados por Decreto Foral 62/2012, de 18 de julio ${ }^{154}$.

Por otra parte, su normativa de creación califica como Entes de Derecho Público a los siguientes Servicios de salud:

- El Servicio de Salud del Principado de Asturias, según el artículo 5 de la Ley 1/1992, de 2 de julio" ${ }^{155}$ : "1. El Servicio de salud del Principado de Asturias es un Ente de Derecho público dotado de personalidad jurídica propia y plena capacidad de obrar para el cumplimiento de sus fines, adscrito a la Consejería de Sanidad y Servicios Sociales, que se rige por los preceptos de la presente Ley y sus disposiciones complementarias de desarrollo".

\footnotetext{
${ }^{149}$ BOE de 13 de febrero de 1989.

${ }^{150}$ BOE de 21 de agosto de 2008. El Servicio Gallego de Salud tiene como objeto la provisión de los servicios y de las prestaciones de atención sanitaria individual de cobertura pública en el ámbito de la Comunidad Autónoma, dentro del marco básico de financiación del Sistema público de salud de Galicia, garantizando los derechos reconocidos a los ciudadanos. Ejerce el gobierno, la dirección y la gestión de los centros, servicios y establecimientos sanitarios propios o adscritos, garantizando la provisión de los servicios y prestaciones de asistencia sanitaria de cobertura pública; coordina la gestión de los recursos humanos, materiales y financieros que tenga asignados, y ejercerá aquellas funciones que le delegue o encomiende la Conselleria de Sanidade. El Decreto 43/2013, de 21 de febrero, desarrolla la estructura orgánica del Servicio Gallego de Salud, dotándolo de una Gerencia y tres Direcciones Generales (Diario Oficial de Galicia de 7 de marzo de 2013).
}

${ }^{151}$ BOE de 3 de mayo de 2002.

${ }^{152}$ BOE de 2 de marzo de 2005.

${ }^{153}$ BOE de 25 de julio de 2001.

${ }^{154}$ Boletín Oficial de Navarra de 7 de agosto de 2012.

${ }^{155}$ BOE de 2 de septiembre de 1992. 
- El Servicio de Salud de las Islas Baleares, regulado en el artículo 64 de la Ley $5 / 2003$, de 4 de abril, que establece las reglas básicas de la organización y el funcionamiento del Servicio de salud de las Islas Baleares, también lo califica como Ente público ${ }^{156}$.

En otro bloque tenemos a los Servicios de salud que presentan singularidades en cuanto a su régimen jurídico:

- Es el caso del Servicio Murciano de Salud, que es una empresa pública, según el artículo 21 de la Ley 4/1994, de 26 de julio, de Salud de la Región de Murcia ${ }^{157}$.

- Un caso muy particular es el que existe en Cataluña, donde conviven el Instituto Catalán de la Salud y el Servicio Catalán de la Salud bajo el Sistema sanitario integral de utilización pública (SISCAT), que se regula en el Decreto 196/2010, de 14 de diciembre ${ }^{158}$. Este sistema está configurado por los centros, servicios y establecimientos sanitarios gestionados por el Instituto Catalán de la Salud, que es una empresa pública ${ }^{159}$, así como por las entidades de naturaleza o titularidad pública de la Generalitat y por las entidades de titularidad privada cuyos servicios sean necesarios para implementar las previsiones del Plan de salud de Cataluña y así lo soliciten.

Por otra parte, el Servicio Catalán de la Salud, cuya naturaleza jurídica se regula en el artículo 4 de la Ley 15/1990, de 9 de julio, de Ordenación sanitaria, modificada por la Ley $11 / 1995$, de 29 de septiembre ${ }^{160}$, es un ente público de naturaleza institucional, dotado de personalidad jurídica propia y plena capacidad para el cumplimiento de sus fines, adscrito al Departamento de Sanidad y Seguridad Social y se rige por los preceptos de esas leyes y sus disposiciones complementarias de desarrollo, pero en lo que se refiere a las

\footnotetext{
${ }^{156}$ Que dice: “1. El Servicio de Salud de las Illes Balears es un ente público de carácter autónomo, dotado de personalidad jurídica y patrimonio propios, y con plena capacidad para actuar en el cumplimiento de sus fines, al que se confía la gestión de los servicios públicos sanitarios de carácter asistencial de las Illes Balears. 2. Esta entidad se adscribe a la consejería competente en materia de sanidad". BOE de 8 de mayo de 2003. A tener en cuenta también el más reciente Decreto Ley 9/2012, de 20 de julio, de medidas para la reorganización del Servicio de salud de las Islas Baleares.
}

${ }^{157}$ BOE de 11 de octubre de 1994. Ha sido modificada por Ley de la Región de Murcia 14/2013, de 26 de diciembre, aunque no en este aspecto (BOE de 25 de enero de 2014).

${ }^{158}$ Diario Oficial de Cataluña de 16 de diciembre de 2010.

${ }^{159}$ La Ley 8/2007, de 30 de julio, del Instituto Catalán de la Salud, regula su naturaleza jurídica como empresa pública: entidad de derecho público de la Generalitat que actúa sujeta al Derecho privado, con personalidad jurídica propia y plena capacidad de obrar para el cumplimiento de sus funciones, de conformidad con el Estatuto de la empresa pública catalana (BOE de 17 de agosto de 2007). Sus relaciones con el CatSalut se articulan a través de un contrato-programa por el cual el Instituto Catalán de la Salud se obliga a prestar los servicios y actividades sanitarios y sociosanitarios por cuenta de aquel (art. 14). Los objetivos del ICS son, entre otros, la prestación de servicios sanitarios públicos preventivos, asistenciales, diagnósticos, terapéuticos, rehabilitadores, paliativos, de cuidados y de promoción y mantenimiento de la salud destinados a los ciudadanos, de conformidad con el catálogo de prestaciones del Sistema Nacional de Salud y la cartera de servicios aprobada por el Gobierno de la Generalitat (art. 3).

${ }^{160}$ BOE de 17 de agosto de 1990 y de 28 de noviembre de 1995, respectivamente. 
relaciones jurídicas externas, se sujeta, en términos generales, al Derecho privado ${ }^{161}$. La naturaleza del Servicio Catalán de la Salud condiciona, evidentemente, la relación jurídica de su personal, que es mayoritariamente laboral, hasta el punto de que solo el 1,6\% del total de la plantilla es funcionarial ${ }^{162}$.

- En este grupo encontramos también el caso del Servicio Vasco de Salud, regulado en la Ley 8/1997, de 26 de junio, de Ordenación sanitaria ${ }^{163}$, que en su artículo 20 dispone, respecto a la naturaleza jurídica del ente público Osakidetza, que es de Derecho privado, y que está adscrito al Departamento de la Administración general competente en materia de sanidad. Se le atribuye personalidad jurídica propia y plena capacidad para obrar para el cumplimiento de su finalidad de desempeñar la provisión de servicios sanitarios mediante los organismos públicos de los servicios dependientes del mismo (art. 21).

- En cuanto al Servicio Madrileño de Salud, la Ley 12/2001, de 21 de diciembre, de Ordenación sanitaria de la Comunidad de Madrid creó dos entes de Derecho público: el Servicio Madrileño de Salud y el Instituto Madrileño de Salud ${ }^{164}$. Posteriormente se consideró que esa duplicidad no era necesaria, y el Decreto 14/2005, de 27 de enero, integró el Servicio Madrileño de Salud en el Instituto Madrileño de Salud, modificando a continuación su denominación a la actual de Servicio Madrileño de Salud y regulando su régimen jurídico y de funcionamiento. Esta norma reglamentaria, desarrollo de la ley anterior, establece que este Servicio de salud es un ente público, pero que "se sujetará con carácter general al Derecho privado, y actuará con sujeción al Derecho público cuando ejerza potestades administrativas por atribución directa o delegación, así como en cuanto a su régimen de patrimonio y en materia de responsabilidad patrimonial ante terceros por el funcionamiento de sus servicios". Por lo que se refiere a la regulación de su estructura orgánica, después de varias modificaciones, la normativa actual viene dada en el Decreto $23 / 2014$, de 6 de marzo ${ }^{165}$.

En este grupo de Servicios de salud se observa que el legislador autonómico ha optado por un régimen jurídico para su gestión que se aparta del ámbito del Derecho administrativo en mayor o menor medida, cabe entender que con la finalidad de evitar los

\footnotetext{
${ }^{161}$ En la Exposición de motivos de la Ley 11/1995 se manifiesta que se acude a la fórmula se someterlo al Derecho privado porque esta categoría se considera mucho más adecuada a su condición de entidad configurada por todos los centros, servicios y establecimientos sanitarios públicos o privados de cobertura pública (art. 5) y a la diversidad de fórmulas de gestión directa, indirecta o compartida que el Servicio Catalán de la Salud puede utilizar a efectos de la gestión y administración de los servicios y prestaciones del sistema sanitario público, según el artículo 7.2 de la Ley 15/1990.
}

\footnotetext{
${ }^{162}$ Memoria de Actividad del CatSalut año 2013, disponible en: 〈http://www20.gencat.cat〉. Solo tiene a su disposición 476 efectivos, porque sus funciones recordemos que no son asistenciales, son de dirección y gestión. Las asistenciales las lleva a cabo el Instituto Catalán de la Salud a través de centros públicos y privados concertados.

${ }^{163}$ Publicada, varios años después, en el BOE de 11 de enero de 2012.

${ }^{164}$ BOE de 5 de marzo de 2002.

${ }^{165}$ Boletín Oficial de la Comunidad de Madrid de 7 de marzo de 2014.
} 
mecanismos de control administrativos y presupuestarios que se ejercen en la Administración pública. Este hecho repercute, sin duda, en la naturaleza del vínculo jurídico que mantienen con su personal, que lógicamente tiende a ser laboral en la medida en que se estos organismos se acercan al Derecho privado para regir su funcionamiento. En este sentido compartimos la opinión de los autores que critican la huída del Derecho público en la gestión de los recursos sanitarios ${ }^{166}$.

La existencia de dieciocho administraciones públicas (diecisiete autonómicas que gestionan sus Servicios de salud junto con el Ministerio de Sanidad, que gestiona el INGESA) provoca la ineludible necesidad de la coordinación y cooperación entre las distintas administraciones. Esta exigencia hizo necesaria la promulgación de la LCCSNS que obliga al Estado y a las CC.AA. a coordinar y cooperar en el funcionamiento de los Servicios de salud con el objetivo de garantizar la equidad, calidad y participación social en todos ellos.

En esta ley se reconoció un papel muy relevante al Consejo Interterritorial del Sistema Nacional de Salud, que reguló con detalle en su Capítulo X, reconociéndole su papel de "órgano permanente de coordinación, cooperación, comunicación e información de los Servicios de salud entre ellos y con la Administración del Estado, que tiene como finalidad promover la cohesión del Sistema Nacional de Salud a través de la garantía efectiva y equitativa de los derechos de los ciudadanos en todo el territorio del Estado".

También fue relevante la LCCSNS para el personal del Sistema Nacional de Salud porque en cierto modo adelantó en su Capítulo III, (De los profesionales), algunas de las disposiciones que meses después recogería la LEM como novedades en el régimen jurídico del personal estatutario: la creación de la Comisión de Recursos Humanos del Sistema Nacional de Salud (art. 35) ${ }^{167}$; el Foro Marco para el Diálogo Social, como foro de diálogo con las organizaciones sindicales representativas en el ámbito sanitario (art. 35.3), y la carrera profesional, como mecanismo de progresión y reconocimiento de sus conocimientos, experiencia en las tareas asistenciales, investigación y cumplimiento de los objetivos de la organización en la cual prestan sus servicios.

Por lo que respecta a la coordinación y calidad del mismo sistema, la LCCSNS señalaba en su artículo 1 su objeto: “...establecer el marco legal para las acciones de coordinación y cooperación de las Administraciones públicas sanitarias, en el ejercicio de sus respectivas competencias, de modo que se garantice la equidad, la calidad y la participación social en el Sistema Nacional de Salud, así como la colaboración activa de este en la reducción de las desigualdades en salud”.

Llegados a este punto hay que destacar que esos principios en los que se basó el legislador de los años ochenta para construir Sistema Nacional de Salud han sufrido serias

\footnotetext{
${ }^{166}$ Véase GOMEZ DE HITA, J.L., Formas jurídicas de organización sanitaria...op.cit. pp. 363 y ss.

${ }^{167}$ Que desarrollará las actividades de planificación, diseño de programas de formación y modernización de los recursos humanos del Sistema Nacional de Salud y definirá los criterios básicos de evaluación de las competencias de los profesionales sanitarios, sin perjuicio de las competencias de las CC.AA..
} 
modificaciones legislativas que pueden constituir una amenaza para su supervivencia tal como lo hemos conocido. Recapitulando, hay que decir que en una primera etapa se produce el reconocimiento del derecho a la protección de la salud de los ciudadanos en el artículo 43 de la CE, y que para su desarrollo se diseña por la LGS de 1986 el Sistema Nacional de Salud. Este va más allá de lo que hasta entonces había sido el sistema de Seguridad Social, como conjunto de prestaciones que se reconocen a sus asegurados.

Este nuevo modelo se planteó en su vertiente estructural u organizativa, a través de una serie de medidas legislativas que, progresivamente, pusieron en manos de todas las CC.AA. la gestión de la sanidad pública en España a lo largo de dos décadas, proceso que culminó el 1 de enero de 2002. Pero no solo eso, sino que durante ese proceso se ha tenido en cuenta también el contenido de las prestaciones asistenciales, que con el tiempo fueron en aumento en cantidad y calidad.

En este sentido, la LCCSNS en el año 2003, incorporó los principios que inspiraron la LGS, en cuanto a la garantía de las prestaciones sanitarias de forma universal ${ }^{168}$, estableciendo una serie de medidas para favorecer la coordinación entre las distintas Administraciones públicas implicadas en la asistencia sanitaria, así como la cohesión del sistema, con el objetivo de mantener la equidad y la calidad de las prestaciones para los ciudadanos: "Se consideran prestaciones de atención sanitaria del Sistema Nacional de Salud los servicios o conjunto de servicios preventivos, diagnósticos, terapéuticos, rehabilitadores y de promoción y mantenimiento de la salud dirigidos a los ciudadanos" (art. 7.1 LCCSNS, que regula el Catálogo de prestaciones del SNS).

En cuanto a quienes debían ser considerados como receptores de estas prestaciones, el artículo 3 señalaba los titulares de los derechos a la protección de la salud y a la atención sanitaria: a) Todos los españoles y los extranjeros en el territorio nacional en los términos previstos en el artículo 12 de la Ley Orgánica 4/2000. b) Los nacionales de los Estados miembros de la Unión Europea que tienen los derechos que resulten del derecho comunitario europeo y de los tratados y convenios que se suscriban por el Estado español y les sean de aplicación. c) Los nacionales de Estados no pertenecientes a la Unión Europea que tienen los derechos que les reconozcan las leyes, los tratados y convenios suscritos. En el apartado 2 disponía que las acciones en materia de salud de las Administraciones públicas incorporasen las medidas activas que impidieran la discriminación de cualquier colectivo de población en el acceso efectivo a las prestaciones sanitarias del Sistema Nacional de Salud.

La Disposición adicional sexta de la Ley 33/2011, de 4 de octubre, General de Salud Pública, incluso extendió el derecho a la asistencia sanitaria pública para "todos los españoles residentes en territorio nacional, a los que no pudiera serles reconocido en aplicación de otras normas del ordenamiento jurídico" ${ }^{\text {169 }}$.

\footnotetext{
${ }^{168}$ En la redacción original de la LCCSNS su artículo 2 garantizaba: “a) La prestación de los servicios a los usuarios del Sistema Nacional de Salud en condiciones de igualdad efectiva y calidad. b) El aseguramiento universal y público por parte del Estado. c) La coordinación y la cooperación de las Administraciones públicas sanitarias para la superación de las desigualdades en salud...”.

169 Continuaba diciendo: "Esta extensión, que tendrá como mínimo el alcance previsto en la cartera de servicios comunes del Sistema Nacional de Salud, se hace sin perjuicio de lo expresado en los apartados siguientes y de la exigencia de las correspondientes obligaciones a aquellos terceros legalmente obligados al pago de dicha asistencia de acuerdo con lo establecido en la Ley General de Sanidad, en el texto refundido de
} 
Con esta base normativa las diferentes CC.AA. han venido gestionando sus competencias en materia sanitaria, diseñando, a su vez, la estructura y funcionamiento de sus Servicios de salud, y estableciendo carteras de servicios propias y complementarias de la común y mínima que regula para todas ellas el Ministerio de Sanidad como coordinador del SNS $^{170}$. Sin embargo, la LCCSNS ha resultado modificada por el Real Decreto Ley 16/2012, de 20 de abril, que transforma el principio de que los ciudadanos son titulares del derecho a la protección de la salud, por la de que lo son aquellas personas que ostenten la condición de asegurados ${ }^{171}$.

Respecto al personal estatutario, como veremos más adelante, otras medidas legislativas también adoptadas por los gobiernos autonómicos o por el gobierno del Estado en los últimos años con respecto a los empleados públicos, han desembocado en la pérdida de derechos retributivos y sindicales, fruto en su momento de la negociación colectiva.

En este sentido cabe destacar el Real Decreto Ley 8/2010, de 20 de mayo, por el que se adoptan medidas extraordinarias para la reducción del déficit público, que llevó a cabo, entre otras, una reducción de las retribuciones del personal del sector público; el Real Decreto Ley 20/2012, de 13 de julio ${ }^{172}$ que dispuso la supresión de la paga extraordinaria de diciembre de 2012 para todo el personal del sector público y la derogación de los Acuerdos y Pactos reguladores de derechos sindicales de los empleados públicos; así como las leyes autonómicas de suspensión de los Acuerdos sobre carrera profesional o de supresión del contenido de los Pactos y Acuerdos en materia sindical... normativa que ha estado dirigida a contener el gasto en las partidas presupuestarias del personal de las Administraciones públicas, política, por otra parte, coincidente con el Real Decreto Ley 3/2012, de 10 de febrero, de medidas urgentes para la reforma del mercado laboral, que tantas críticas ha recibido por parte de la doctrina laboral.

la Ley General de la Seguridad Social y de lo dispuesto en los reglamentos comunitarios europeos y convenios internacionales en la materia...”.

${ }^{170}$ Las carteras de servicios son los listados de actividades que cada unidad o servicio de las estructuras del sistema sanitario oferta a sus usuarios, que se aprueba por cada Servicio de salud. VIDA FERNANDEZ, J., "Las prestaciones sanitarias...", op.cit., p.62.

${ }^{171}$ Esta condición la tendrán las personas se encuentren en alguno de los siguientes supuestos: a) ser trabajador por cuenta ajena o por cuenta propia, afiliado a la Seguridad Social y en situación de alta o asimilada a la de alta. b) ostentar la condición de pensionista del sistema de la Seguridad Social. c) ser perceptor de cualquier otra prestación periódica de la Seguridad Social, incluidas la prestación y el subsidio por desempleo. d) Haber agotado la prestación o el subsidio por desempleo y figurar inscrito en la oficina correspondiente como demandante de empleo, no acreditando la condición de asegurado por cualquier otro título. Si no se está en ninguno de esos supuestos se requerirá ser de nacionalidad española o de algún Estado miembro de la Unión Europea, del Espacio Económico Europeo o de Suiza que residan en España, o tratarse de extranjeros titulares de una autorización para residir en territorio español, siempre que "acrediten que no superan el límite de ingresos determinado reglamentariamente...”. Se trata de una vuelta a la visión de la asistencia sanitaria como prestación de un seguro, tal como se concibió en 1966, cuando se creó la Seguridad Social en España.

${ }^{172}$ BOE de 14 de julio de 2013. 


\section{2.- EL PERSONAL ESTATUTARIO: CONCEPTO Y NATURALEZA JURÍDICA DE SU RELACIÓN DE SERVICIOS. NORMATIVA REGULADORA DEL RÉGIMEN JURÍDICO DEL PERSONAL ESTATUTARIO DE LOS SERVICIOS DE SALUD}

En cuanto a los antecedentes normativos de la actual Ley del Estatuto Marco del personal estatutario de los Servicios de Salud, hay que decir que la LGS, para completar el diseño y la regulación del Sistema Nacional de Salud, en su artículo 84.1 previó la aprobación de una ley, que sustituyera a los tres Estatutos reguladores del personal, y que debía ser desarrollada por las CC.AA ${ }^{173}$.

En cuanto al contenido de la futura ley, el artículo 84.2 LGS dispuso que: "Este Estatuto-Marco contendrá la normativa básica aplicable en materia de clasificación, selección, provisión de puestos de trabajo y situaciones, derechos, deberes, régimen disciplinario, incompatibilidades y sistema retributivo, garantizando la estabilidad en el empleo y su categoría profesional. En desarrollo de dicha normativa básica, la concreción de las funciones de cada estamento de los señalados en el apartado anterior se establecerá en sus respectivos Estatutos, que se mantendrán como tales" ${ }^{174}$.

Por su parte, el artículo 84.3 LGS reconoce el carácter básico del Estatuto Marco, que la normativa autonómica debe respetar: "Las normas de las CC.AA. en materia de personal se ajustarán a lo previsto en dicho Estatuto Marco. La selección de personal y su gestión y administración se hará por las Administraciones responsables de los servicios a que estén adscritos los diferentes efectivos".

La previsión de la LGS tardó en hacerse realidad, de forma que transcurrieron más de diecisiete años hasta la promulgación del Estatuto Marco en 2003. Mientras tanto, se llevaron a cabo numerosos anteproyectos, que no llegaron a aprobarse, aunque hay que tener en cuenta que el Acuerdo parlamentario para la Consolidación y Modernización del Sistema Nacional de Salud de 18 de diciembre de 1997 intentó impulsar su tramitación ${ }^{175}$.

\footnotetext{
${ }^{173}$ De esta forma, el artículo 84.1, situado en el Capítulo VI del Título III (Estructura del Sistema sanitario público) estableció: “El personal de la Seguridad Social regulado en el Estatuto Jurídico de Personal Médico de la Seguridad Social, en el Estatuto del Personal Sanitario Titulado y Auxiliar de Clínica de la Seguridad Social, en el Estatuto del Personal no Sanitario al Servicio de las Instituciones Sanitarias de la Seguridad Social, el personal de las Entidades Gestoras que asuman los servicios no transferibles y los que desempeñen su trabajo en los Servicios de salud de las CC.AA. se regirán por lo establecido en el Estatuto-Marco que aprobará el Gobierno en desarrollo de esta Ley, todo ello sin perjuicio de lo previsto en el artículo 87 de esta Ley”.

${ }^{174}$ En cuanto al tema de las funciones del personal, la LEM, en su Disposición Transitoria sexta 1 b), establece
que "Se mantendrán vigentes, en tanto se procede a su regulación en cada Servicio de salud, las disposiciones
relativas a categorías profesionales del personal estatutario y a las funciones de las mismas contenidas en las
normas previstas en la disposición derogatoria única. 1.e), f) y g)” -antiguos Estatutos de personal-. A fecha
actual, en la mayoría de Administraciones autonómicas aún no se han regulado las funciones del personal
estatutario y para determinar las que corresponden al personal de cada categoría profesional hay que atender a
las que se reflejan en los antiguos Estatutos, y a la numerosa casuística jurisprudencial sobre la materia.

${ }^{175}$ Este fue producto de las propuestas de la Subcomisión constituida al efecto el 11 de junio de 1996, para el estudio de las reformas necesarias para modernizar el sistema sanitario y garantizar su viabilidad futura, dependiente de la Comisión de Sanidad y Consumo del Congreso de los Diputados. Proponía como medida
} 
Parece que factores como la indecisión política de los sucesivos gobiernos y la falta de un planteamiento común por parte de las diferentes organizaciones sindicales representativas en el ámbito sanitario, pudieron estancar por largo tiempo la negociación del propio Estatuto Marco ${ }^{176}$. Pero, probablemente, también la demora en la promulgación de la LEM pudo deberse, en buena parte, a causas presupuestarias.

En defensa de esta afirmación hay que decir que hasta enero de 2002 no se completaron los traspasos de servicios sanitarios a todas las CC.AA. Estas, previamente debían modificar sus Estatutos de autonomía para asumir la competencia en materia de gestión de la sanidad y crear, a su vez, el correspondiente Servicio de salud que gestionara, en lo sucesivo, los servicios sanitarios transferidos por el Estado. Hasta finalizar este proceso, quizá no pareciera urgente la aprobación del Estatuto Marco del personal, dado que algunas de ellas aún no habían asumido los traspasos en materia sanitaria. Previamente se hizo necesaria, además, una reforma de la Ley Orgánica 8/1980, de 22 de septiembre, de Financiación de las CC.AA. (LOFCA) mediante la Ley Orgánica 7/2001, de 27 de diciembre ${ }^{177}$, y la adopción de una serie de medidas de financiación para la sanidad pública, que también entraron en vigor el 1 de enero de $2002^{178}$. Asimismo, se modificó el artículo 79 de la LGS para añadir como fuente de financiación de la asistencia sanitaria la proveniente de los tributos estatales cedidos a las CC.AA.

En la LCCSNS, artículo 41.2, también se menciona el Estatuto Marco que estaba en tramitación: "El estatuto marco previsto en el artículo 84 de la Ley 14/1986, de 25 de abril, General de Sanidad, contendrá la normativa básica aplicable al personal del Sistema Nacional de Salud, que será desarrollada por las CC.AA.”.

principal, entre otras: “... respetando las competencias en materia sanitaria de las CC.AA. es preciso abordar un nuevo régimen de personal compatible con la autonomía de gestión de los centros, al objeto de alcanzar los siguientes fines: a) Regular las peculiaridades del personal estatutario de las instituciones sanitarias públicas mediante un Estatuto profesional propio, de carácter básico para todo el sistema, sin perjuicio de su desarrollo por las CC.AA.".

${ }^{176}$ En 1987 aparece en prensa un artículo en el que se pone de relieve la división de posturas entre las organizaciones sindicales respecto al modelo que va a configurar sus relaciones laborales con la Administración, a propósito de la propuesta del Ministro de Sanidad de negociar el Estatuto Marco. El estatuto del personal sanitario, caballo de batalla de los sindicatos en el actual conflicto, Diario El País [en línea], 31 de marzo de 1987, [consulta de 4 de abril de 2013], disponible en: 〈http://www.elpais.com/hemeroteca〉.

${ }^{177}$ BOE de 31 de diciembre de 2001.

${ }^{178}$ En esta línea se publica la Ley 21/2001, de 27 de diciembre, por la que se regularon medidas fiscales y administrativas del nuevo sistema de financiación de las CC.AA. de régimen común y Ciudades con Estatuto de Autonomía. El apartado VII de su Exposición de Motivos dice: "Una de las características o principios del nuevo sistema de financiación consiste en integrar la financiación de las competencias comunes traspasadas a las CC.AA., la de los servicios de asistencia sanitaria de la Seguridad Social y la de los servicios sociales de la Seguridad Social...". En el artículo 4 B) apartado c) regula el bloque de competencias de gestión de los servicios de asistencia sanitaria de la Seguridad Social, y crea el Fondo de Cohesión sanitaria, que tiene por finalidad garantizar la igualdad de acceso a los servicios de asistencia sanitaria públicos en todo el territorio español, y la atención a ciudadanos desplazados procedentes de países de la Unión Europea o de países con los que España tenga suscritos convenios de asistencia sanitaria recíproca, gestionado por el Ministerio de Sanidad y Consumo. 
Cabe interpretar que estos últimos traspasos de funciones y servicios del INSALUD a las CC.AA. ${ }^{179}$ debieron acuciar la tramitación de la ley del Estatuto Marco del personal estatutario de los Servicios de salud, que se aprobó, por fin, el 16 de diciembre de 2003, se publicó al día siguiente y al siguiente día de la publicación entró en vigor ${ }^{180}$.

En virtud de la LEM, el personal estatutario es actualmente aquel vinculado con la Administración por un nombramiento de naturaleza administrativa, que tiene, por tanto, una relación jurídica funcionarial, pero de carácter específico para prestar servicios en centros e instituciones sanitarias públicas, desempeñando puestos de trabajo con determinadas funciones de índole sanitaria o de gestión y servicios. De ahí que la LEM haya calificado su naturaleza jurídica como funcionarial especial (art.1), poniendo fin a las divergentes posturas de los órganos jurisdiccionales al respecto ${ }^{181}$, naturaleza no discutida por la LEBEP (art. 2.4) cuando establece que: "Cada vez que este Estatuto haga mención al personal funcionario de carrera se entenderá comprendido el personal estatutario de los Servicios de salud".

No obstante, a pesar de la similitud de la relación de servicios del personal estatutario y funcionario, existen una serie de peculiaridades en la relación del primero que vienen dadas, principalmente por el contenido de sus funciones, y por la particular formación requerida al personal, cuestión que es objeto, incluso, de una regulación particular por la Ley 44/2003, de 21 de noviembre, de Ordenación de las Profesiones Sanitarias ${ }^{182}$.

Al personal estatutario se refiere también el artículo 2.3 de la LEBEP para disponer que este "se regirá por la legislación específica dictada por el Estado y por las CC.AA. en el ámbito de sus respectivas competencias y por lo previsto en el presente Estatuto...”.

\footnotetext{
${ }^{179}$ Recordemos que eran: Asturias, Cantabria, La Rioja, Murcia, Aragón, Castilla-La Mancha, Extremadura, Baleares, Madrid, Castilla y León.

${ }^{180}$ Disposición Final tercera. Entrada en vigor: "La presente Ley entrará en vigor el día siguiente al de su publicación en el Boletín Oficial del Estado”. Se trata de una excepción a la regla del artículo 2.1 del Código Civil que dispone que las leyes entrarán en vigor a los veinte días de su completa publicación en el Boletín Oficial del Estado, si en ellas no se dispone otra cosa. De todas formas la aplicación de la LEM se produjo de forma paulatina para algunas materias (Disposición Transitoria Segunda: equiparación del personal estatutario a los grupos de clasificación de los funcionarios públicos, que después reguló la LEBEP, y Disposición Transitoria Sexta: retribuciones).
}

181 Destaca la STSJ de Cataluña de 26 de abril de 2005, (AS 2005\1370), en cuyo Fundamento jurídico segundo declara que "La entrada en vigor de la LEM ha supuesto una modificación sustancial en la calificación de la naturaleza de la relación existente entre el personal y la administración de salud, pues mientras que hasta la entrada en vigor de dicha disposición la antes mencionada naturaleza lo era como personal estatutario, especie de tertium genus entre funcionario y laboral, en la actualidad y a partir de su vigencia se le da naturaleza de funcionario”. En el mismo sentido la STSJ de La Rioja de 24 de febrero de 2005, (JUR 2005\98250).

${ }^{182}$ Esta regula los aspectos básicos de las profesiones sanitarias tituladas respecto a su ejercicio por cuenta propia o ajena, la estructura general de la formación de los profesionales, el desarrollo profesional de estos, y su participación en la planificación y ordenación de las profesiones. 
El legislador estatal ha optado por someter la relación jurídica del personal estatutario de los Servicios de salud al Derecho administrativo, ya que aquella no es más que una especialidad de la relación jurídica funcionarial, aunque con determinadas particularidades normativas ${ }^{183}$. Ello en contra de algunas propuestas de la doctrina favorables, en su momento, a un cambio de su relación jurídica por una relación laboral de carácter especial $^{184}$.

Hemos visto que las CC.AA. pueden elegir la forma jurídica que revistan los entes que gestionan sus Servicios de salud, y nos podemos plantear hasta qué punto pueden también optar por una relación jurídica de naturaleza diferente a la estatutaria para vincular al personal que presta servicios en sus centros sanitarios. Parece que este interrogante se debe resolver en el sentido de considerar, como razona el preámbulo de la Ley 9/2010, de 23 de diciembre, de personal estatutario de Instituciones Sanitarias de la Comunidad Autónoma de Cantabria que: "La Ley 55/2003, de 16 de diciembre, del Estatuto Marco del personal estatutario de los Servicios de salud, cumplió casi dos décadas después con dicha previsión (la del art. 84 LGS) estableciendo las normas básicas de tal personal estatutario al amparo del artículo 149.1 .18 de la Constitución, optando expresamente por la especificidad de un régimen de naturaleza funcionarial especial, el estatutario, para el personal de los Servicios de salud que conforman el Sistema Nacional de Salud”.

Es decir, el legislador autonómico no es libre de elegir la naturaleza jurídica que quiere dar al personal al servicio de las instituciones sanitarias de sus Servicios de salud, porque el estatal ya la ha decidido en base a sus competencias constitucionales y esa naturaleza es la de personal estatutario. En el mismo sentido se expresa el apartado II de la Exposición de motivos de la Ley 2/2007, de 7 de marzo, del Estatutario del Servicio de salud de Castilla y León.

En esta línea, a lo largo de los años en que se ha ido construyendo el Sistema Nacional de Salud se ha constatado la tendencia general a la estatutarización de su personal, a través de los procesos de selección y de integración voluntaria de los funcionarios y el personal laboral en el régimen estatutario.

Así, nos encontramos, por ejemplo, con la Orden de 22 de diciembre de 1987, que reguló la integración de determinado personal de Instituciones Sanitarias del extinguido organismo autónomo Administración Institucional de la Sanidad Nacional en los regímenes estatutarios de la Seguridad Social de forma voluntaria; o con el Real Decreto 1343/1990, de 11 de octubre, que reguló el mismo procedimiento de integración para el personal fijo que prestaba servicios en instituciones Sanitarias Públicas o de la Cruz Roja con Convenio de administración y gestión con el INSALUD ${ }^{185}$.

\footnotetext{
183 GARCIA COBOS, S., "Naturaleza jurídica de la relación estatutaria, Sentencias de TSJ y AP y otros Tribunales", Tribuna Social no 174/2005, p. 35-52.

${ }^{184}$ LANDA ZAPIRAIN, J.P., La Reforma de la Sanidad Pública y del Régimen Jurídico de su personal, Consejo Económico y Social, 1999, p. 356.

${ }^{185}$ BOE de 7 de noviembre de 1990.
} 
Este es el planteamiento que se recoge en la Disposición adicional quinta LEM: “ $A l$ objeto de homogeneizar las relaciones de empleo del personal de cada uno de los centros, instituciones o Servicios de salud, y con el fin de mejorar la eficacia en la gestión, las Administraciones sanitarias públicas podrán establecer procedimientos para la integración directa, con carácter voluntario, en la condición de personal estatutario, en la categoría y titulación equivalente, de quienes presten servicio en tales centros, instituciones o servicios con la condición de funcionario de carrera o en virtud de contrato laboral fijo. Asimismo, se podrán establecer procedimientos para la integración directa del personal laboral temporal y funcionario interino en la condición de personal estatutario temporal, en la categoría, titulación y modalidad que corresponda”.

De esta forma se han publicado periódicamente ofertas de integración en el régimen estatutario para el personal funcionario y laboral de las instituciones sanitarias de los Servicios de salud autonómicos, o por el Estado para el personal que aún depende de él ${ }^{186}$.

La última disposición que se ha orientado hacia la estatutarización del personal funcionario sanitario viene dada en el artículo 10 del Real Decreto Ley 16/2012, de 20 de abril, que añade la Disposición adicional decimosexta a la LEM: "1. Los médicos, practicantes y matronas titulares de los servicios sanitarios locales que presten sus servicios como médicos generales, practicantes y matronas de los Servicios de salud, y el resto del personal funcionario sanitario que preste sus servicios en instituciones sanitarias públicas, dispondrán hasta el 31 de diciembre de 2013 para integrarse en los Servicios de salud como personal estatutario fijo, sin perjuicio de los derechos consolidados. A tal fin, las CC.AA. establecerán los procedimientos oportunos. 2. En caso de que este personal opte por permanecer en activo en su actual situación, en los cuerpos y escalas en los que ostenten la condición de personal funcionario, las CC.AA. adscribirán a este personal a órganos administrativos que no pertenezcan a las instituciones sanitarias públicas...”.

Cuestión distinta es que la prestación de la asistencia sanitaria a los ciudadanos se realice no de forma directa por la Administración, sino de forma indirecta, a través de las diversas fórmulas de gestión privada del servicio público, en cuyo caso, las entidades privadas implicadas asumen la contratación de su personal para esa finalidad, dentro del régimen laboral común, se entiende.

Un supuesto excepcional respecto a la regla general de la relación estatutaria del personal de los Servicios de salud es el que se da en la Comunidad Foral de Navarra, en la que el personal adscrito al Servicio Navarro de Salud es mayoritariamente funcionario, excepción que se justifica constitucionalmente dentro del marco de la singularidad de su régimen Foral.

\footnotetext{
186 Basándose en esta disposición, el Real Decreto 187/2008, de 8 de febrero, reguló un procedimiento voluntario de integración en el régimen estatutario para el personal laboral de la red hospitalaria de Defensa, cuya última modificación por Real Decreto 1049/2013, de 27 de diciembre (BOE de 28 de diciembre de 2013) establece que: "El proceso de integración del personal laboral del Área de actividades específicas de la Red Hospitalaria de la Defensa deberá estar concluido con anterioridad a 1 de enero de 2015”. La doctrina judicial exige que estos procesos sean negociados con las organizaciones sindicales (STSJ Madrid de 10 de marzo de 2010 y de 24 de mayo de 2011).
} 
Según la Memoria de Actividad del Servicio Navarro de Salud de 2013 el personal estatutario representa solo el 3,5\% del personal a su servicio; el laboral el 0,86 \% y el funcionario el 95,64\% del total de efectivos ${ }^{187}$.

Esta excepción se contempla en la LEM, que en su Disposición adicional primera prevé que: "Las disposiciones básicas de esta Ley se aplicarán en la Comunidad Foral de Navarra en los términos establecidos en el artículo 149.1.18 ${ }^{a}$ y en la disposición adicional primera de la Constitución y en la Ley Orgánica 13/1982, de 10 de agosto, de Reintegración y Amejoramiento del Régimen Foral de Navarra" ${ }^{188}$.

En cuanto a la normativa reguladora del régimen jurídico del personal estatutario, esta viene dada, fundamentalmente en la LEM. Su estructura se basa en ochenta artículos, distribuidos en catorce capítulos, diecisiete disposiciones adicionales, ocho disposiciones transitorias, una derogatoria única y tres finales, tras las últimas modificaciones. En cuanto a su contenido, trata los aspectos básicos del régimen jurídico del personal estatutario: normas generales, clasificación, planificación y ordenación del personal, adquisición y pérdida de la condición de personal estatutario fijo, provisión y selección de plazas, movilidad, retribuciones, jornada de trabajo, situaciones administrativas, régimen de incompatibilidades, y derechos de representación, participación y negociación colectiva.

El capítulo I es conciso, pero especialmente relevante. En él se destaca la naturaleza jurídica funcionarial de la relación de servicios del personal estatutario; se insiste en la condición de norma básica del Estatuto Marco y en las competencias que para su desarrollo poseen las CC.AA., así como en los principios y criterios de ordenación del régimen jurídico estatutario. Estos son reflejo, a su vez, de los que se aplican en el ámbito de la función pública, y entre ellos destaca el más particular, regulado en el apartado d) del artículo 4: la libre circulación del personal estatutario en el conjunto del Sistema Nacional de Salud, además de otros específicos del servicio público sanitario ${ }^{189}$.

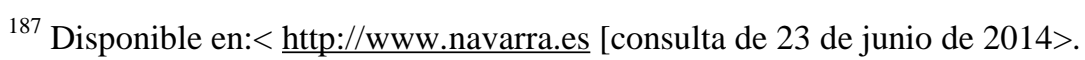

${ }^{188}$ La Ley Orgánica 13/1982 de Reintegración y Amejoramiento del Régimen Foral de Navarra, que atribuye a la Comunidad Foral la competencia exclusiva sobre el régimen estatutario de sus funcionarios públicos, respetando los derechos y obligaciones esenciales de la legislación básica del Estado (art. 49. 1 b). El régimen jurídico del personal adscrito al Servicio Navarro de Salud, Osasunbidea, se rige por la Ley Foral 11/1992, de 20 de octubre, cuyo artículo 30 dispone que: "El personal que ingrese en el Servicio Navarro de Salud, Osasunbidea, tendrá la consideración de funcionario al servicio de la Administración de la Comunidad Foral de Navarra y de sus organismos autónomos, salvo el personal que sea contratado en régimen laboral fijo a tiempo parcial..." Por su parte, el Decreto Foral 347/1993, de 22 de noviembre, regula el ingreso y la provisión de puestos de trabajo del Servicio Navarro de Salud y en todo lo no previsto en esta normativa específica es de aplicación supletoria el Texto Refundido del Estatuto del personal al servicio de las Administraciones públicas de Navarra, aprobado por Decreto Foral Legislativo 251/1993, de 30 de agosto.

${ }^{189}$ Como son la integración en el régimen organizativo y funcional del Servicio de salud y de sus centros e instituciones; la incorporación de los valores de integridad, neutralidad, transparencia en la gestión, deontología y servicio al interés público y a los ciudadanos, tanto en la actuación profesional como en las relaciones con los usuarios. Asimismo la dedicación prioritaria al servicio público y la transparencia de los intereses y actividades privadas como garantía de dicha preferencia. 
Así, dice que la LEM tiene como objeto "establecer las bases reguladoras de la relación funcionarial especial del personal estatutario de los Servicios de salud que conforman el Sistema Nacional de Salud, a través del Estatuto Marco de dicho personal" (art. 1).

En efecto, esta ley es una norma básica porque se dicta al amparo de las competencias que la CE reconoce, en su artículo 149.1.18 , al Estado para regular las bases del régimen estatutario del personal de los Servicios de salud ${ }^{190}$. Estas bases deberán ser objeto de desarrollo por el propio Estado para el personal a su servicio, y por las CC.AA. para el suyo ${ }^{191}$. Es, por tanto, una ley estatal básica y específica para la regulación del régimen jurídico del personal estatutario.

Hay que destacar que la LEM mantiene la tradicional denominación de personal estatutario, que como sabemos y recuerda su Exposición de Motivos, deriva directamente de los tres estatutos de personal (el Estatuto del Personal Facultativo, el Estatuto del Personal Sanitario no facultativo y el Estatuto del personal no sanitario) de los centros e instituciones sanitarias de la Seguridad Social, derogados expresamente por su Disposición Derogatoria Única.

Si bien la ley no define claramente el concepto del personal estatutario, sí establece en el artículo 2.1 que: "El personal estatutario desempeñará su trabajo en los centros e instituciones sanitarias de los Servicios de salud de las CC.AA. o en los centros y servicios sanitarios de la Administración General del Estado”, y además proporciona una clasificación funcional de dicho personal, atendiendo a la función desarrollada y al nivel del título exigido para el ingreso (art. 5 y ss.) ${ }^{192}$.

190 DAMIAN MORENO, J.R., "La negociación colectiva de las condiciones de trabajo básicas de los funcionarios públicos tras la reforma de la LORAP”, AJA, n 720/2006. En opinión de este autor, el Estatuto Marco es una regulación básica importante, ya que afecta a uno de los colectivos más numerosos de la función pública española. Entiende que más que la ordenación directa y automática lo que pretende la LEM es el establecimiento de un marco común, integrado por principios y normas, que sirva de plataforma jurídica para iniciar una posterior negociación colectiva en los ámbitos inferiores de cada territorio, a modo de Acuerdo Marco, al cual deben ajustarse en el futuro los respectivos ordenamientos de cada Servicio de salud en las CC.AA.

${ }^{191}$ Cuestión que nos recuerda la doctrina: SALA FRANCO, T., El Estatuto Marco del Personal estatutario de los Servicios de salud, Tirant lo Blanch, Valencia, 2004, p. 37.

192 Con estos criterios la ley distingue entre personal estatutario sanitario (art. 6), que es el que, junto al oportuno nombramiento, acredita título habilitante para el ejercicio de una profesión o especialidad de carácter sanitario, y personal estatutario de gestión y servicios (art. 7). En el artículo 6.2 la LEM establece la clasificación del personal sanitario "atendiendo al nivel académico del título exigido para el ingreso", transcribiendo lo dispuesto en la Ley 44/2003 de ordenación de las Profesiones Sanitarias, y así distingue entre: a) Personal de formación universitaria: quienes ostentan la condición de personal estatutario en virtud de nombramiento expedido para el ejercicio de una profesión sanitaria que exija una concreta titulación de carácter universitario o un título de tal carácter acompañado de un título de especialista. Este personal se divide en: $1^{\circ}$ Licenciados con título de especialista en Ciencias de la Salud. $2^{\circ}$ Licenciados sanitarios. $3^{\circ}$ Diplomados con título de Especialista en Ciencias de la Salud. $4^{\circ}$ Diplomados sanitarios. b) Personal de formación profesional: quienes ostenten la condición de personal estatutario en virtud de nombramiento expedido para el ejercicio de profesiones o actividades profesionales sanitarias, cuando se exija una concreta titulación de formación profesional. Este personal se divide en: $1^{\circ}$ ) Técnicos superiores. $2^{\circ}$ ) Técnicos. Por otra parte, el personal de gestión y servicios es el nombrado para el desempeño de funciones de gestión, 
Por otra parte, el Estatuto Marco constituye normativa básica supletoria para el personal sanitario funcionario y el personal sanitario laboral que preste servicios en los Servicios de salud (art. 2.3). Incluso estos podrán establecer la aplicación del régimen estatutario a las estructuras administrativas y de gestión del Servicio de salud respectivo (Disposición adicional décima LEM).

En lo no previsto en la LEM, el artículo 2.2 dispone que hay que atender a las normas desarrollo de la misma, al contenido de los Pactos o Acuerdos regulados en el capítulo XIV, y por último las disposiciones y principios generales sobre función pública de la Administración correspondiente. Claro está que en ese momento aún no existía la LEBEP.

La normativa básica estatal que afecta al personal estatutario no se contiene únicamente en la LEM, ya que también la LEBEP, al amparo de las competencias del Estado previstas en el artículo $149.1 .18^{\mathrm{a}}$, regula las bases del personal de las Administraciones públicas y afecta y es de aplicación directa al personal estatutario. Al delimitar su ámbito de aplicación, en el artículo 2 apartado 3, establece que: "El personal docente y el personal estatutario de los Servicios de salud se regirán por la legislación específica dictada por el Estado y por las CC.AA. en el ámbito de sus respectivas competencias y por lo previsto en el presente Estatuto, excepto el Capítulo II del Título III (relativo al derecho a la carrera profesional y a la promoción interna, salvo el artículo 20 sobre evaluación del desempeño que sí será de aplicación) y los artículos 22.3 y 24 (relativos a las retribuciones complementarias) y el 84, sobre movilidad voluntaria en las Administraciones Públicas”.

Respecto a la relación entre la LEM y la LEBEP, hay que partir de la idea de que la primera es una norma más específica que la segunda, ya que su ámbito subjetivo es precisamente el personal estatutario al servicio del Sistema Nacional de Salud. Aun así, la LEBEP es directamente aplicable también al personal estatutario, en cuanto norma básica que es, ya que su artículo 2.4 establece: "cada vez que este Estatuto haga mención al personal funcionario de carrera se entenderá comprendido el personal estatutario de los Servicios de salud" ${ }^{193 .}$

Como reconoce la doctrina, la mayor parte de las disposiciones de la LEM son perfectamente compatibles con el contenido de la $\mathrm{LEBEP}^{194}$, pero si no lo fueran, habría que

administración o servicios o para el desarrollo de profesiones u oficios que no tengan carácter sanitario. Este, a su vez, puede ser de formación universitaria (art. 7.2 a) o de formación profesional (art. 7.2 b). También hay una clase de personal residual: "otro personal" (art. $7.2 \mathrm{c}$ ) en el que se engloban las categorías en las que se exige certificación acreditativa de los años cursados de las calificaciones obtenidas en la Educación Secundaria obligatoria, o título o certificado equivalente. Tanto el personal sanitario como de gestión y servicios puede a su vez tener carácter fijo o temporal, según los artículos 8 y 9 LEM.

193 LORENZO DE MEMBIELA, J.B., “Análisis sucinto del Estatuto Básico del Empleado Público, Ley 7/2007, de 13 de abril”, AJA no 733/2007, (BIB 200入1083).

194 VAZQUEZ GARRANZO, J., "Regímenes estatutario, funcionario y laboral. Jerarquía, convivencia normativa y escenario de aplicación en los Servicios de salud", Actualidad del Derecho sanitario, n 146, pp. $121-124,2008$. 
aplicar esta última si la disposición es norma básica y considerar derogadas aquellas del Estatuto Marco o la normativa autonómica que se opongan a ella. En este sentido la Disposición derogatoria, apartado g) LEBEP establece: "Quedan derogadas con el alcance establecido en la Disposición final cuarta las siguientes disposiciones [...] todas las normas de igual o inferior rango que contradigan o se opongan a lo dispuesto en este Estatuto"195.

En consecuencia, la normativa aplicable al personal estatutario vendrá dada por las normas básicas contenidas en la $\operatorname{LEBEP}^{196}$ y en la LEM; después habrá que atender a la legislación autonómica específica dictada en desarrollo del Estatuto Marco para este personal en cada Servicio de salud; al contenido de sus Pactos y Acuerdos, y, por último, de forma supletoria, habría que acudir al resto de la normativa autonómica y estatal sobre función pública.

En cuanto a las leyes autonómicas de desarrollo de la LEM, actualmente nos encontramos con el siguiente panorama jurídico: del total de las diecisiete CC.AA., solo tres han publicado leyes propias para desarrollar de forma global el régimen jurídico previsto en la LEM, de aplicación al personal estatutario que depende de ellas:

1.- Castilla y León, que por Ley $2 / 2007$, de 7 de marzo, ha regula el Estatuto Jurídico del Personal Estatutario del Servicio de salud de Castilla y León, modificada por la Ley $1 / 2008$, de 27 de marzo ${ }^{197}$.

2.- Cantabria, por Ley $9 / 2010$, de 23 de diciembre, de personal estatutario de Instituciones Sanitarias de la Comunidad autónoma de Cantabria ${ }^{198}$.

3.- Murcia, que pocos días antes de asumir el traspaso de servicios sanitarios por Real Decreto 1474/2001, de 27 de diciembre, publicó la Ley 5/2001, de 5 de diciembre, de personal estatutario del Servicio Murciano de Salud, anticipándose así a la publicación de la LEM, modificada por la Ley 5/2002, de 3 de junio ${ }^{199}$.

\footnotetext{
195 SANCHEZ MORON, M., "Objeto y ámbito de aplicación de la LEBEP“, en AAVV, Comentarios a la Ley del Estatuto Básico del Empleado Público, Lex Nova, Valladolid, 2007, p. 63.

${ }^{196}$ Precisamente algunas reformas normativas que han afectado al personal estatutario en los últimos tiempos han venido por la vía de modificar la LEBEP mediante Reales Decretos Leyes. Ese es el caso de las modificaciones operadas por el artículo 8 del Real Decreto Ley 20/2012, de 13 de julio, en los artículos 48 y 50 LEBEP, que los han modificado para convertirlos en norma de carácter imperativo para todos los funcionarios. Igualmente el derecho a veintidós días de vacaciones anuales ha pasado de ser una norma mínima a ser norma imperativa para todos los funcionarios de las Administraciones públicas, incluido el personal estatutario.

${ }^{197}$ BOE de 3 de abril de 2007 la primera, en el de 23 de abril de 2008, la segunda.

${ }^{198}$ BOE de 22 de enero de 2011; corrección de errores en el del día 24 de febrero de 2011.

${ }^{199}$ BOE de 21 de diciembre de 2001 la primera; BOE de 8 de octubre de 2002 la segunda.
} 
Estas normas son la excepción, ya que el resto de los Servicios de salud no tienen todavía una ley específica sobre el régimen jurídico de su personal estatutario en desarrollo de la LEM. En ellas se reitera buena parte del contenido del Estatuto Marco, ya que es norma básica y sus disposiciones no se pueden eludir. En estas leyes autonómicas también se recogen las disposiciones de la LEBEP que se aplican directamente al personal estatutario por su condición de básicas, así como el régimen de incompatibilidades de la Ley 53/1984, de 26 de diciembre, y normas de desarrollo, imperativo para todo el personal de las Administraciones públicas.

Es de destacar que la Ley 2/2007, de 7 de marzo, del Servicio de salud de Castilla y León regula en un anexo las funciones más relevantes de las distintas categorías de personal estatutario sanitario, y de gestión y servicios, siendo hasta el momento la única que ha cumplido, en este aspecto, la previsión de la Disposición transitoria sexta b) LEM, que estableció que se mantendrían vigentes, en tanto se procediera a su regulación en cada Servicio de salud, las disposiciones de los Estatutos Jurídicos relativas a categorías profesionales del personal estatutario y a las funciones de las mismas contenidas en ellos.

Sin embargo, en la mayoría de Servicios de salud su normativa de personal estatutario se contiene en las leyes de ordenación sanitaria; en las que crean y regulan el correspondiente Servicio de salud; en sus leyes de medidas fiscales y administrativas que cada año acompañan a las de Presupuestos de su Comunidad autónoma, o en estas mismas cuando se tratan aspectos retributivos, por ejemplo.

En todo caso las leyes autonómicas que regulen los diferentes aspectos del régimen jurídico del personal estatutario de su Servicio de salud deberán respetar las normas básicas contenidas en la LEM, tal como señala la STC 215/2013, de 19 de diciembre, dictada en recurso de inconstitucionalidad contra los artículos 12 y 28 de la Ley 3/2008, de 29 de diciembre, de medidas fiscales y administrativas de la Comunidad de Madrid, que regularon la situación administrativa de servicios bajo otro régimen jurídico para el personal del Servicio Madrileño de Salud ${ }^{200}$.

Además de esto, hay que tener en cuenta que el régimen jurídico del personal estatutario se desarrolla también a través de las normas autonómicas de rango reglamentario, que incorporan el contenido de los Acuerdos consensuados en los correspondientes foros de

\footnotetext{
${ }^{200}$ En el Fundamento jurídico cuarto señala que: “... hay que concluir que el artículo 12, apartado 2, segundo párrafo, de la Ley 3/2008 no impide la aplicación de la regulación de la norma básica estatal sobre requisitos y condiciones de la reincorporación durante los tres primeros años; y hace uso de las competencias de desarrollo de la norma básica estatal establecida en el artículo 65 de la Ley 55/2003, regulando además la reincorporación del personal estatutario fijo al servicio activo cuando haya pasado más de tres años en la «situación de servicios bajo otro régimen jurídico». Únicamente para este supuesto, el precepto legal impugnado garantiza, en cualquier momento y con anterioridad a la fecha de cumplimiento de la edad de jubilación, la reincorporación al servicio activo como personal estatutario en plaza de la misma categoría en el Servicio de Salud Madrileño. La disposición enjuiciada, interpretada de este modo, resulta respetuosa con la norma básica estatal (arts. 65 y 69 de la Ley 55/2003) y, además, permite una lectura integradora coherente con el fin que, según se expone en el preámbulo de la Ley 3/2008, pretende conseguir el legislador de la Comunidad Madrid con esta previsión legislativa: que «el personal estatutario fijo pueda pasar a prestar servicios en Instituciones sanitarias acogidas a estas nuevas formas de gestión, sin que ello suponga perder su derecho a reincorporarse como personal estatutario”, (RTC 2013\215).
} 
negociación, ya que tratan materias sujetas a negociación obligatoria por afectar a las condiciones de trabajo del personal estatutario (selección y provisión de puestos, jornada de trabajo, permisos, carrera profesional, régimen retributivo...).

\section{3.- LA NEGOCIACIÓN COLECTIVA COMO FUENTE NORMATIVA DEL RÉGIMEN JURÍDICO DEL PERSONAL ESTATUTARIO}

En el ámbito del servicio público sanitario nos hemos encontrado durante una fase de crecimiento del Sistema Nacional de Salud con el aumento y diversificación de las prestaciones sanitarias y el consiguiente incremento del número y tipología de profesionales destinados en él. Esta modernización de la sanidad pública ha provocado también la exigencia por parte del personal estatutario de una regulación más actual, y negociada, de su régimen jurídico. De hecho, la negociación colectiva como mecanismo para la determinación de las condiciones de trabajo del personal de la sanidad pública ha sido durante años una fuente muy importante de derechos para este colectivo.

Hay que tener en cuenta que a finales de los años ochenta se empiezan a concertar los primeros Acuerdos y Pactos en el ámbito del INSALUD, algunos de ellos incluso antes de publicarse la LORAP, lo cual, como señala la doctrina, dio origen a posturas jurisprudenciales encontradas en cuanto a la aceptación de su validez ${ }^{201}$. El dato de que la aparición del Sistema Nacional de Salud es coincidente en el tiempo con el reconocimiento del derecho a la negociación colectiva funcionarial nos da una idea del volumen que puede haber alcanzado el global de lo negociado en este ámbito.

Efectivamente, durante esos años se ha llevado a cabo una prolífica negociación colectiva, tanto al principio en el ámbito del INSALUD ${ }^{202}$, como después en los Servicios

${ }^{201}$ SALA FRANCO, T. y ROQUETA BUJ, R., Los derechos sindicales de los funcionarios públicos, op. cit., p. 232, nota al pie $\mathrm{n}^{\mathrm{o}} 15$.

${ }^{202}$ De la época del INSALUD uno de las primeras normativas negociadas de las que hemos encontrado constancia es la Orden del Ministerio de Sanidad y Consumo, de 8 de agosto de 1986, por la que se fijan las retribuciones del personal del INSALUD, Instituto Catalán de la Salud y la Red de Asistencia Sanitaria de la Seguridad Social en Andalucía (BOE de 14 de agosto de 1986) que expresamente menciona: "En este marco de referencia el INSALUD ha mantenido negociaciones con los sindicatos representativos, con objeto de consensuar los aspectos más significativos de la política retributiva, estableciendo los incrementos salariales de cada colectivo concreto de acuerdo con las líneas de actuación que, emprendidas en 1983, se han desarrollado paulatinamente a lo largo de este período de tiempo”. La Orden regulaba las retribuciones del personal de Cupo y Zona, de Equipos de Atención primaria, del personal médico de Hospitales y de Servicios de urgencia de la Seguridad social, del sanitario y del no sanitario. Sobre materia de retribuciones son también los Acuerdos de 25 de marzo de 1987 y de 25 de abril del mismo año; el Acuerdo de 9 de junio de 1987; los Acuerdos de 19 y de 23 de junio de 1987; el Acuerdo de 7 de octubre de 1988, que además de las retribuciones también trata otros aspectos de personal para el año 1989; el Acuerdo de 1990 sobre régimen retributivo de los funcionarios Sanitarios locales (BOE de 14 de marzo de 1990); el Pacto de 17 de julio de 1990 sobre diversos asuntos estatutarios y de carrera profesional... Son relevantes también el Acuerdo de 22 de febrero de 1992 sobre diversos aspectos profesionales, económicos y organizativos en las instituciones sanitarias dependientes del INSALUD (BOE de 3 de marzo de 1992) y el Acuerdo de 3 de julio de 1992 sobre Atención primaria (BOE de 2 de febrero de 1993), que dieron lugar posteriormente a otros Acuerdos derivados de los mismos. Asimismo en 1997 se concertaron sendos Pactos, de fecha 23 de julio de 1997, con el fin de introducir como concepto retributivo la productividad variable. 
de salud autonómicos y en determinada medida también en el INGESA, que ha sido fuente de derechos retributivos y profesionales para el personal estatutario.

Los aspectos del régimen jurídico del personal estatutario que destacan por haber sido objeto de desarrollo a través de la negociación colectiva en todos los Servicios de salud han sido las normas reglamentarias que regulan sus retribuciones; los sistemas de acceso y progresión en su carrera profesional; las normas relativas a la evaluación del desempeño ${ }^{203}$; las que afectan a los criterios de selección del personal temporal, las que regulan la jornada de trabajo, los permisos y licencias, y por supuesto, las que tratan las garantías y derechos sindicales.

En la LEM se hace hincapié en el principio de participación de las organizaciones sindicales en la determinación de las condiciones de trabajo del personal estatutario a través de la negociación en las Mesas correspondientes (art. 4 k) y, en concreto, en la negociación de la normativa de desarrollo de la propia ley. Según su artículo 3: "En desarrollo de la normativa básica contenida en esta Ley, el Estado y las CC.AA., en el ámbito de sus respectivas competencias, aprobarán los estatutos y las demás normas aplicables al personal estatutario de cada Servicio de salud. Para la elaboración de dichas normas, cuyas propuestas serán objeto de negociación en las Mesas correspondientes en los términos establecidos en el capítulo III de la Ley 9/1987, de 12 de junio, de Órganos de Representación, Determinación de las Condiciones de Trabajo y participación del personal al servicio de las Administraciones públicas...”.

En este sentido hay que decir que los Acuerdos y Pactos son una fuente especialmente rica en el reconocimiento de derechos y garantías para el personal funcionario y estatutario, en especial por lo que se refiere a la materia sindical. Esto es así porque la vía de la negociación colectiva abre para todos los empleados públicos y para el personal estatutario, en particular, un camino de mejoras de las condiciones legales que establece la normativa reguladora.

Conviene destacar que el primer Pacto sobre derechos sindicales del personal estatutario, se firmó el de 30 de junio de 1989, entre la Administración del INSALUD y las organizaciones sindicales Confederación Estatal de Sindicatos Médicos y de Enfermería (CEMSATSE), CC.OO. y la Central Sindical Independientes y de Funcionarios (CSIF). Existe otro posterior firmado solo con UGT, de fecha 17 de julio de 1989, también sobre permisos y uso del crédito horario para la realización de funciones sindicales y de representación del personal al servicio de instituciones sanitarias del INSALUD ${ }^{204}$. Estos fueron modificados, a su vez, por el Pacto de 20 de diciembre de 1995 sobre permisos,

\footnotetext{
${ }^{203}$ La evaluación del desempeño se regula en el artículo 20 LEBEP, como "el procedimiento mediante el cual se mide y valora la conducta profesional y el rendimiento o el logro de resultados". Es materia de obligada negociación (art. 37.1 d) LEBEP). En el ámbito sanitario, en la práctica, consiste en el establecimiento de objetivos asistenciales cuyo cumplimiento debe alcanzar el personal y cuya consecución se recompensa mediante el complemento retributivo de productividad variable, y como presupuesto de su progresión en la carrera profesional.

${ }^{204}$ Ambos publicados en el BOE de 18 de agosto de 1989.
} 
Capítulo II. El actual régimen jurídico del personal estatutario de los Servicios de salud. Su creación y desarrollo paralelos a los del Sistema Nacional de Salud

secciones sindicales y uso del crédito horario para la realización de funciones sindicales y de representación del personal al servicio de instituciones sanitarias ${ }^{205}$.

La promoción y defensa de la negociación colectiva es precisamente una de los puntos más destacados de las posiciones que mantiene en la actualidad la OIT, que hace hincapié en la importancia del diálogo social como mecanismo de negociación, consulta e intercambio de información entre los sujetos implicados, especialmente en el ámbito de la Sanidad $^{206}$.

${ }^{205}$ Disponible en: 〈http://www.ingesa.msssi.gob.es〉.

206 OIT, El diálogo social en los Servicios de salud: Instituciones, capacidad y eficacia, [libro en línea], Ginebra, 2002, p. 26 y ss [consulta de 3 de abril de 2014], disponible en: 〈http:|lbooks.google.es>. 
CAPITULO III

EL DERECHO FUNDAMENTAL A LA LIBERTAD SINDICAL DEL PERSONAL ESTATUTARIO DE LOS SERVICIOS DE SALUD. SUS DERECHOS COLECTIVOS 



\section{CAPITULO III}

\section{EL DERECHO FUNDAMENTAL A LA LIBERTAD SINDICAL DEL PERSONAL ESTATUTARIO DE LOS SERVICIOS DE SALUD. SUS DERECHOS COLECTIVOS}

\section{1.- MARCO COMÚN DE LA LIBERTAD SINDICAL DE TRABAJADORES Y FUNCIONARIOS. PRECEDENTES INTERNACIONALES: LOS CONVENIOS DE LA OIT Y LA SITUACIÓN PREVIA A LA CONSTITUCION ESPAÑOLA DE 1978}

Las aspiraciones colectivas del personal estatutario del Sistema Nacional de Salud no distan mucho de las del resto de los empleados de las Administraciones públicas, y se dirigen, en general, a la mejora de sus condiciones de trabajo, pero no solo eso, sino también a la de otros aspectos, como el reconocimiento y la promoción profesional, la formación, y la defensa del propio Sistema dentro del esquema público y social en el que tuvo su origen.

Por lo que se refiere a esto último, cabe recordar la importancia que ha tenido la movilización del personal de los Servicios de salud, a lo largo de los últimos años, en contra de las políticas privatizadoras del servicio público ${ }^{207}$, y la contribución decisiva de las organizaciones sindicales, que tienen reconocida constitucionalmente la función de defensa y promoción de los intereses económicos y sociales de los trabajadores, también en el ámbito funcionarial. Ese reconocimiento no es más que manifestación del derecho a la libertad sindical.

A nivel internacional el reconocimiento de este derecho tiene su origen a finales de los años cuarenta del siglo pasado, en respuesta al desastre que supuso la Segunda Guerra mundial, cuando se reaviva el debate en defensa de los derechos humanos y la justicia social. En esta línea, se adopta el 10 de mayo de 1944 por la OIT la Declaración referente a sus fines y objetivos, señalando como principios de esta la libertad de expresión y asociación para alcanzar el progreso de los pueblos ${ }^{208}$. Asimismo, la ONU aprobará el 10 de diciembre de 1948, la Declaración Universal de los Derechos Humanos. En esta última se recoge el derecho a la libertad sindical en su artículo 23.4: "La libertad sindical es el derecho de toda persona a fundar sindicatos y a sindicarse para la defensa de sus intereses".

\footnotetext{
${ }^{207}$ Es el caso, por ejemplo, de lo sucedido en el Servicio Madrileño de Salud desde finales de 2012 hasta enero de 2014. El gobierno de la Comunidad autónoma de Madrid pretendía la privatización de la gestión de seis hospitales públicos mediante concesión administrativa, y se encontró con el rechazo de su personal, de las organizaciones sindicales y de los ciudadanos, que pudieron frenarla mediante movilizaciones y promoviendo actuaciones judiciales, hasta el punto de que el proceso de externalización fue retirado: Madrid da marcha atrás a la privatización sanitaria tras el último revés judicial, MARCOS, J., SEVILLANO, E., 27 de enero de 2014, [consulta de 23 de noviembre de 2014], disponible en: 〈http://www.elpais.com/hemeroteca〉

${ }^{208}$ Si bien la OIT había nacido en 1919 con el Tratado de Versalles, que puso fin a la Primera Guerra Mundial, es en 1946 cuando pasa a formar parte de la Organización de Naciones Unidas (ONU).
} 
Hay que tener muy en cuenta el papel de la OIT como impulsora del reconocimiento de la libertad sindical y del diálogo social, que se traducirá en la aprobación del Convenio $\mathbf{n}^{\mathbf{0}} 87$ sobre la Libertad sindical y el derecho de sindicación, adoptado el 9 de julio de 1948, que España ratificó en Instrumento dado el 13 de abril de 1977, ya durante la Transición.

El Convenio $\mathrm{n}^{\mathrm{o}}$ 87, en su artículo 2, reconoce el derecho de los trabajadores y los empleadores, sin ninguna distinción y sin autorización previa, a constituir las organizaciones que estimen convenientes, así como el de afiliarse a estas organizaciones, con la sola condición de observar los Estatutos de las mismas. Se entiende por organización aquella destinada a fomentar y defender los intereses de los trabajadores y empleadores. En los artículos siguientes se reconoce el derecho de los sindicatos a redactar sus estatutos y reglamentos internos (art. 3); a no ser estos disueltos o suspendida su actividad por la autoridad administrativa (art. 4); a constituir federaciones y confederaciones y a afiliarse a las mismas o que estas se afilien a organizaciones internacionales (art. 5); el deber de respetar la legalidad nacional y el derecho a que las leyes nacionales no menoscaben las garantías del Convenio (arts. 8 y 9). Dispone también que los Estados obligados por el Convenio adopten las medidas necesarias para garantizar a los trabajadores y a los empleadores el libre ejercicio del derecho de sindicación.

Este importante Convenio se completa con el $\mathbf{n}^{\mathbf{0}} \mathbf{9 8}$, adoptado por la OIT el 1 de julio de 1949, también ratificado por España el 13 de abril de 1977, y que trata sobre la aplicación de los principios del derecho de sindicación y de negociación colectiva. En el Convenio $n^{\circ} 98$ se determinan una serie de normas de protección para los trabajadores en cuanto al ejercicio del derecho de sindicación, y se regula el derecho a la protección de las organizaciones de trabajadores y empleadores contra injerencias mutuas, así como el deber de adoptar medidas de fomento de los procedimientos de negociación voluntaria con objeto de reglamentar, por medio de contratos colectivos, las condiciones de empleo. Por lo que se refiere a los funcionarios, su artículo 6 establece que: "El Convenio no trata de la situación de estos en la administración del Estado y no deberá interpretarse, en modo alguno en menoscabo de sus derechos o de su estatuto”.

La libertad sindical se reconoce también en el Convenio del Consejo de Europa para la protección de los derechos humanos y de las libertades fundamentales, de 4 de noviembre de 1950, que la regula en su artículo 11 junto con el derecho de reunión pacífica y de asociación ${ }^{209}$.

Asimismo, debemos tener en cuenta el reconocimiento de la libertad sindical que se contiene en el Pacto internacional de derechos civiles y políticos (art. 22) y en el Pacto Internacional de derechos económicos, sociales y culturales (art. 8), adoptados ambos por la Asamblea General de Naciones Unidas el 16 de diciembre de 1966. Estos dos instrumentos internacionales reconocen el derecho a la libertad sindical de las personas para la defensa o protección de los intereses económicos y sociales.

${ }^{209}$ El control judicial de las disposiciones del Convenio corresponde desde 1959 al Tribunal Europeo de Derechos Humanos, cuya jurisprudencia relativa a la libertad sindical es particularmente relevante porque tiene la particularidad de conocer acerca del cumplimiento o tutela por las autoridades públicas de las normas del Convenio. 
En estos Pactos internacionales se contemplan como facultades del derecho de libertad sindical la de fundar sindicatos y la de afiliarse a los mismos. Solo se admiten las restricciones que prevea la ley o sean necesarias en una sociedad democrática, en interés de la seguridad nacional, de la seguridad pública o del orden público, o para proteger la salud o la moral públicas o los derechos y libertades de los demás; en particular, para los miembros de las fuerzas armadas y de la policía.

En el artículo 8 del Pacto de derechos económicos, sociales y culturales se reconoce el derecho de los sindicatos a formar Federaciones o Confederaciones nacionales y el de estas a fundar otras a nivel internacional, el derecho de los sindicatos a funcionar libremente de acuerdo con la ley, así como el derecho de huelga, ejercido de conformidad con las leyes de cada país.

Otros antecedentes internacionales relevantes del reconocimiento de la libertad sindical, también aplicables a los funcionarios públicos, son el Convenio de la OIT $\mathbf{n}^{\mathbf{0}} \mathbf{1 3 5}$ de 23 de junio de 1971, relativo a la protección y facilidades que deben otorgarse a los representantes de los trabajadores en la empresa, que entró en vigor para España el 21 de diciembre de 1973, y la Recomendación nº 143, de la misma fecha.

No obstante, el más específico sobre la libertad sindical de los funcionarios es el Convenio de la OIT $n^{0}$ 151. Este trata de la protección del derecho de sindicación y los procedimientos para determinar las condiciones de empleo en la Administración Pública, que se adoptó en Ginebra el 27 de junio de $1978^{210}$ y fue ratificado por España el 22 de junio de $1984^{211}$.

\footnotetext{
${ }^{210}$ La prensa recoge la noticia: "La sindicación de funcionarios de la Administración pública, uno de los temas de mayor importancia de la agenda de trabajo de la 64 conferencia de la Organización Internacional de Trabajo, que se está celebrando en Ginebra, desde la perspectiva de los trabajadores españoles ha adquirido rango de convenio internacional. La comisión de función pública de la conferencia, que ha estudiado la revisión de un proyecto elaborado sobre este tema en la edición anterior, después de una semana de debates en los que no se han logrado avances significativos, ha aprobado el criterio de otorgar rango de convenio internacional y recomendación para el citado proyecto. Este acuerdo se logró pese a la oposición de algunos delegados gubernamentales, miembros de la comisión, a que el proyecto se convirtiera en convenio. La mayor fuerza jurídica y moral que implica un convenio, dentro de lo que es la mecánica de la Organización Internacional del Trabajo, ha hecho que la discusión adquiera caracteres más sutiles y que hayan quedado en evidencia nuevas posturas retrógradas por parte de algunos Gobiernos, que no plantean una negativa rotunda a la sindicación, pero sí intentan limitarla y restringirla con una serie de proposiciones y enmiendas. La delegación de los trabajadores españoles ha jugado un papel destacado en estas discusiones, defendiendo el derecho a la sindicación para los funcionarios públicos. A este ambiente, confuso en ocasiones, ha contribuido la presión extraoficial, ejercida por el secretario de la Unión Internacional de Sindicatos de Policía (UISP), que en calidad de observador en la comisión ha dado a conocer un documento en el que solicita que los miembros o funcionarios policiales sean incluidos con los mismos derechos en el texto del futuro convenio internacional sobre sindicación y libertades sindicales para los funcionarios públicos...”. La sindicación de funcionarios adquirió rango de convenio de la OIT, Diario El País [en línea], 18 de junio de 1978, [consulta de 5 de abril de 2013]. disponible en: 〈http: Ilwww.elpais.com/hemeroteca>

${ }^{211}$ BOE de 12 de diciembre de 1984.
} 
Este convenio estableció la conveniencia de adoptar medidas adecuadas a las condiciones nacionales para estimular y fomentar el pleno desarrollo y utilización de procedimientos de negociación entre las autoridades públicas competentes y las organizaciones de empleados públicos acerca de las condiciones de empleo, o de cualesquiera otros métodos que permitan a los representantes de los empleados públicos participar en la determinación de dichas condiciones (art.7) ${ }^{212}$.

Destaca la doctrina que el Convenio $\mathrm{n}^{\mathrm{o}} 151$ no hace sino reconocer la existencia de estos procedimientos de negociación, que se realizaban desde los años sesenta de manera informal en las Administraciones de algunos países como Canadá, Francia e Italia, y lo que pretende es fomentar su pleno desarrollo para determinar las condiciones de empleo de los funcionarios $^{213}$.

Asimismo, hay que tener en cuenta la Recomendación $\mathbf{n}^{\mathbf{0}} \mathbf{1 5 9}$ sobre los procedimientos para determinar las condiciones de empleo en la administración pública, de 27 de junio de 1978, que se remite al Convenio $\mathrm{n}^{\mathrm{o}} 135$ y a la Recomendación $\mathrm{n}^{\circ} 143$, disponiendo que se debería tener en cuenta su contenido también para los representantes de las organizaciones de empleados públicos. Esta Recomendación trata del reconocimiento de la representatividad de las organizaciones de empleados públicos con miras a determinar las organizaciones a las que han de atribuirse derechos preferentes o exclusivos a efectos de la negociación, en base a criterios objetivos y preestablecidos, y la determinación en la legislación o por otros medios apropiados de las personas u órganos competentes para negociar en nombre de la autoridad pública. Alude a los procedimientos para poner en práctica las condiciones de empleo convenidas, así como los métodos distintos de la negociación para permitir a los representantes de los empleados públicos participar en la fijación de las condiciones de empleo.

Cabe destacar también la ratificación por España el 29 de abril de $1980^{214}$ de la Carta Social europea, que regula en el artículo 5 el "Derecho sindical". Esta, de manera genérica reconoce el derecho de fundar sindicatos y organizaciones de empleadores y a adherirse a ellas, con la única limitación para los miembros de las Fuerzas Armadas, dejando para las leyes nacionales su regulación. Además, en el artículo 6 regula el derecho de negociación colectiva, estableciendo medidas para su ejercicio efectivo, como son: promover el establecimiento de procedimientos de negociación voluntaria entre

\footnotetext{
${ }^{212}$ La adopción de este Convenio despertó gran interés, destacando el hecho de que los anteriores Gobiernos, habían sido contrarios a su ratificación: "Es fácil comprender que para que en el ámbito funcionarial se implante la negociación colectiva ha sido preciso transitar un muy largo camino sembrado de obstáculos tanto fácticos como conceptuales [...] una nueva concepción de la función pública se va progresivamente afirmando en detrimento de las reglas tradicionales fundadas sobre el principio jerárquico. La administración de mando se eclipsa ante la administración de consentimiento, la adhesión sustituye a la autoridad". GONZALEZ-HABA, V., LOPEZ PENA, I., Los funcionarios y la negociación colectiva, Diario El País [en línea], 6 de enero de 1984, [consulta de 4 de abril de 2013], disponible en: < $\underline{\text { http://www.elpais.com/hemeroteca> }}$.

${ }^{213}$ DEL REY GUANTER, S., Estado, sindicatos y relaciones colectivas en la Función pública..., op. cit., p. 140.

${ }^{214}$ BOE de 26 de junio de 1980.
} 
empleadores y organizaciones de trabajadores con objeto de regular las condiciones de empleo por medio de Convenios Colectivos; fomentar el establecimiento y la utilización de procedimientos adecuados de conciliación y arbitraje voluntarios para la solución de conflictos laborales, así como el derecho a emprender acciones colectivas, incluido el derecho de huelga ${ }^{215}$.

Por último, el Convenio de la OIT $\mathbf{n}^{0} 154$ regula la negociación colectiva. Fue adoptado en Ginebra el 3 de junio de 1981, y ratificado por España el 26 de julio de $1985^{216}$ $\mathrm{y}$, aunque está dirigido principalmente al ámbito laboral, no excluye a los funcionarios públicos. Su contenido parece perfectamente aplicable a la negociación funcionarial, permitiendo que la legislación nacional de cada país fije para los funcionarios "modalidades particulares de aplicación del convenio" (art. 1.3).

El concepto de negociación colectiva que proporciona el convenio (art. 2) es amplio en cuanto a los sujetos que pueden intervenir: "A los efectos de este Convenio, la expresión negociación colectiva comprende todas las negociaciones que tienen lugar entre un empleador, un grupo de empleadores o una organización o varias organizaciones de empleadores, por una parte, y una organización o varias organizaciones de trabajadores, por otra, con el fin de fijar las condiciones de trabajo y empleo, o regular las relaciones entre empleadores y trabajadores, o regular las relaciones entre empleadores o sus organizaciones y una organización o varias organizaciones de trabajadores, o lograr todos estos fines a la vez".

El Convenio $\mathrm{n}^{\circ} 154$ regula una serie de medidas de fomento de la negociación colectiva que deberán tomarse en la legislación de cada Estado para hacerla posible para todos los empleadores y trabajadores, sobre determinadas materias que establece el Convenio (art. 5). También establece reglas de procedimiento convenidas entre las partes, así como órganos y procedimientos de solución de los conflictos laborales.

Es relevante destacar que los Convenios $\mathrm{n}^{\mathrm{o}} 87 \mathrm{y} \mathrm{n}^{\mathrm{o}} 98$ se publicaron en el BOE de 11 y 10 de mayo de 1977 respectivamente, aunque los Instrumentos de ratificación respectivos establecieron la entrada en vigor de ambos en fecha 20 de abril de 1978. La ratificación de estos Convenios internacionales, junto con la del Pacto internacional de derechos económicos, sociales y culturales realizada por España el mismo día ${ }^{217}$, a la vez que se tramitaba ante las últimas Cortes franquistas la Ley que sería la 19/1977, de 1 de abril, sobre regulación del derecho de Asociación Sindical, son datos que reflejan claramente que una de

\footnotetext{
${ }^{215}$ La doctrina interpreta que el derecho a la libertad sindical de los funcionarios públicos está incluido en ese artículo 5, ya que este solo excluye a los miembros de las Fuerzas Armadas, si bien el Instrumento de ratificación firmado por España incluye una cláusula de reserva por la cual la interpretación y aplicación de ese precepto de la Carta se condiciona a su compatibilidad con los artículos 28, 37, 103.3 y 127 CE. ROQUETA BUJ, R., La negociación colectiva en la función pública, Tirant lo Blanch, Valencia, 1996, p. 49.

${ }^{216}$ BOE de 9 noviembre de 1985.

${ }^{217}$ BOE de 30 de abril de 1977.
} 
las prioridades importantes del legislador del momento era la de incorporar a nuestro ordenamiento jurídico el derecho a la libertad sindical ${ }^{218}$.

La Ley de Asociación Sindical de 1977 se basó en estos antecedentes internacionales y con ella se pretendió, según se lee en su preámbulo, llevar a cabo una trascendente reforma, propia de una sociedad democrática, que consiste en dar cobertura a la "libertad de asociación sindical de los trabajadores y empresarios para la defensa de sus intereses peculiares, sin otros limites funcionales que los inherentes a la naturaleza profesional de sus fines estatutarios y al deber de acatamiento de la legalidad" ${ }^{, 219}$.

Aunque el derecho fundamental a la libertad sindical se reconocerá como tal en la CE, la aprobación de esta ley fue uno de los primeros pasos hacia ese objetivo, lo que da idea de la importancia de la normalización de la actividad sindical para la consolidación del régimen democrático. A ello se sumaron otras medidas legislativas imprescindibles, como fueron la legalización de las organizaciones sindicales por Real Decreto 873/1977, de 22 de abril, y la derogación del modelo del sindicalismo vertical por Real Decreto Ley 31/1977, de 2 de junio, sobre la extinción de la sindicación obligatoria, reforma de estructuras sindicales y reconversión del organismo autónomo Administración institucional de Servicios socio profesionales ${ }^{220}$.

Por su parte, el Real Decreto 3149/1977, de 6 de diciembre, sobre elección de representantes de los trabajadores en el seno de las empresas, reguló provisionalmente los órganos de representación de los trabajadores (Delegados de Personal y Comités de empresa) y el procedimiento electoral sindical hasta que se aprobara la correspondiente ley el futuro Estatuto de los trabajadores- (art. 3). Dispuso también que en su ámbito de

\footnotetext{
${ }^{218}$ El impulsor de la LAS fue el Ministro de Relaciones Sindicales Enrique de la Mata, cuyas declaraciones recoge la prensa al presentar el proyecto de ley ante la Comisión de leyes fundamentales de las Cortes: “... el señor De la Mata aludió a los tres objetivos de la ley que se proyecta: el reconocimiento de las libertades sindicales y la defensa de su libre ejercicio; la necesaria y recíproca independencia entre las organizaciones sindicales de trabajadores y de empresarios, y la autonomía de las asociaciones sindicales, amparándolas frente a cualquier injerencia extraña a sus propios y claros objetivos”. Diario El País [en línea], 12 de enero de 1977, [consulta de 5 de abril de 2013], disponible en: 〈httpllwww.elpais.com/hemeroteca〉.

219 “El nacionalsindicalismo o sindicalismo vertical, que durante los últimos cuarenta años sirvió en el plano laboral a los intereses del régimen nacido el 18 de julio de 1936, quedó ayer legalmente desmontado con la aprobación por el Pleno de las Cortes de la ley Reguladora del derecho de Asociación Sindical. Ello, sin embargo, no supone el restablecimiento de la libertad sindical que las centrales democráticas han reclamado y reclaman, y en cuyo apoyo han convocado movilizaciones obreras para el mes que mañana comienza. La libertad de asociación sindical, que acaba con la unidad de sindicación obligatoria verticalista, dista aún mucho de la libertad sin adjetivos que permita a los trabajadores decidir por sí mismos el modelo de sindicato que mejor defienda sus propios intereses frente a las organizaciones patronales, cuya constitución necesita de la misma libertad”. FERNANDEZ PRADES, C., Libertad Sindical, pero menos, Diario El País [en línea], 31 de marzo de 1977, [consulta de 6 de abril de 2013], disponible en: 〈http://www.elpais.com/hemeroteca $\rangle$.

${ }^{220}$ Dice su preámbulo: "El desarrollo de la Ley 19/1977, de 1 de abril, reguladora del derecho de Asociación Sindical, requiere para su eficacia operativa la adaptación de la legislación sindical preexistente a los postulados de libertad, en los que se inspiran tanto dicha Ley como los Convenios internacionales recientemente ratificados por España destacando con especial exigencia revisora las normas sobre sindicación obligatoria de empresarios, técnicos y trabajadores...".
} 
aplicación pudieran incluirse todas las empresas privadas o públicas, industriales, comerciales o de servicios, salvo los establecimientos militares (art. 4.1).

Respecto a los funcionarios públicos, la Disposición adicional dos de la Ley de Asociación Sindical había dispuesto que: "El ejercicio del derecho de asociación sindical por los funcionarios públicos y por el personal civil al servicio de la Administración Militar se regulará por disposiciones específicas" ${ }^{221}$.

Estas disposiciones específicas, que tendrán por finalidad regular las particularidades del derecho de asociación sindical de los funcionarios con respecto al régimen general de los trabajadores, son las del Real Decreto 1522/1977, de 17 de junio, de ejercicio del derecho de asociación sindical de los funcionarios públicos ${ }^{222}$. El artículo primero, punto uno, de este reglamento señaló que: "Los funcionarios públicos y el personal contratado en régimen de derecho administrativo al servicio de la Administración Civil del Estado, Administración local, organismos autónomos dependientes de una u otra y Entidades Gestoras de la Seguridad Social podrán constituir, sin autorización previa, las asociaciones $u$ organizaciones que estimen conveniente para la defensa de sus intereses, así como afiliarse a las mismas con la sola condición de observar sus Estatutos”.

En su ámbito quedó incluido el personal estatutario, ya que la norma se refiere a él como "personal contratado en régimen de Derecho administrativo al servicio de [...] las Entidades Gestoras de la Seguridad Social". Particularmente importante es el artículo quinto de este reglamento, que dispuso: "Las organizaciones profesionales de funcionarios públicos podrán participar, a través de los procedimientos de consulta y colaboración que se establezcan, en la determinación de las condiciones de su empleo".

Esta disposición apunta al reconocimiento de un incipiente derecho a la participación en la determinación de sus condiciones de trabajo, aunque sin el carácter de negociación colectiva, con lo que la doctrina recuerda que básicamente continuó aplicándose el principio

\footnotetext{
${ }^{221}$ Parece ser que la postura del Gobierno de Adolfo Suárez, mantenida principalmente por el Vicepresidente del Gobierno, Alfonso Osorio, era la de reconocer simplemente el derecho de asociación profesional a los funcionarios públicos, en la línea de los Reales Decretos que se habían publicado el año antes, y no el derecho a la libertad sindical. Sin embargo, cuando el texto del proyecto de la LAS llegó a las Cortes sucede que en la Comisión de Leyes fundamentales se modifica y se aprueba el texto definitivo que queda: "el ejercicio del derecho de asociación sindical de los funcionarios públicos civiles se regirá por disposiciones específicas”. La prensa destacó precisamente ese reconocimiento: "El punto más progresista del actual texto de la Ley de Asociación Sindical, elaborado en el seno de la Comisión de Leyes Fundamentales de las Cortes, es el relativo a la sindicación de dos importantes grupos de trabajadores de la Administración Pública: los funcionarios públicos, sean del Estado, de la Administración Local, o de los organismos autónomos, y los trabajadores civiles al servicio de la Administración militar”. El derecho de Sindicación de los Funcionarios, Diario El País [en línea], 1 de febrero de 1977, [consulta de 6 de abril de 2013], disponible en: <http://www.elpais.com/hemeroteca>.

${ }^{222}$ Esta norma deroga expresamente el Real Decreto 1839/1976, de 16 de julio (BOE de 31 de julio de 1976) sobre asociación profesional de los funcionarios civiles del Estado y el Real Decreto 3006/1976, de 23 de diciembre, sobre participación y colaboración de los funcionarios en los órganos encargados de la regulación y gestión de la función pública, que hasta ese momento habían regulado el derecho de asociación profesional, no sindical, de los funcionarios públicos.
} 
jurídico de la unilateralidad a la hora de fijar las condiciones de trabajo en la Administración pública, tendencia que se mantuvo hasta entrados los años noventa ${ }^{223}$.

Prueba de esta resistencia de la Administración a reconocer el fenómeno sindical en la Administración es que, por lo que respecta al ámbito de la sanidad pública, a pesar de la celebración de elecciones sindicales al amparo de la normativa de elecciones de diciembre de 1977, el rechazo de las autoridades a reconocer los resultados y las reivindicaciones de las organizaciones sindicales desembocó en la convocatoria de una larga huelga, a finales de enero de 1979, en las instituciones sanitarias de la Seguridad Social ${ }^{224}$.

\section{2.- LA LIBERTAD SINDICAL EN LA CONSTITUCIÓN ESPAÑOLA DE 1978. LA DOCTRINA DEL TC SOBRE LA LIBERTAD SINDICAL. LA LEY ORGÁNICA DE LIBERTAD SINDICAL. TUTELA JURÍDICA DE LA LIBERTAD SINDICAL}

El disfrute del derecho a la libertad sindical constituye una de las primeras aspiraciones del Movimiento Obrero que, como vimos en el Capítulo I, tiene sus inicios en Europa en la primera parte del siglo XIX y que retrasa su aparición en España hasta finales del mismo, cuando se constituyen las principales organizaciones sindicales con apoyo en la Ley de Asociaciones de 1887. En efecto, la constitución libre de sindicatos para la defensa de los intereses de los trabajadores y el ejercicio libre de su actividad son el presupuesto del nacimiento y desarrollo de otras facultades y derechos que se reconocen a nivel individual a estos, como es la libertad de afiliarse a estas organizaciones, derecho que con el tiempo reclamarán también los funcionarios al servicio de la Administración pública ${ }^{225}$.

${ }^{223}$ ROQUETA BUJ, R., La negociación colectiva en la función pública, op. cit. p. 29.

224 “El personal de instituciones sanitarias de la Seguridad Social -unos 160.000 trabajadores- iniciarán el próximo martes día 30 una huelga en apoyo de las reivindicaciones presentadas ante el Ministerio de Sanidad y Seguridad Social por la comisión negociadora mixta del sector [...] Los representantes de los trabajadores justifican la convocatoria de la misma por la falta de respuesta de las autoridades a su tabla reivindicativa, que se concreta en los siguientes puntos sobre los que no han obtenido respuesta de la dirección de la Seguridad Social. Aumento salarial [...] Definición de una política de empleo por parte de la Seguridad Social que implique la derogación de la orden de congelación de plantillas y la limitación de horas extraordinarias. Reconocimiento de los derechos sindicales de los comités de empresa elegidos el pasado año y que hasta ahora permanecen sin papel y contenido a nivel oficial. Reconocimiento de la capacidad del sector para suscribir convenios colectivos que regulen sus relaciones laborales, que hasta ahora se hacen de forma estatutaria [...] La dirección de la Seguridad Social, definida confusamente -según indican los sindicatos- por el estado de reorganización del departamento (sustitución del INP por el INSALUD), no ha respondido a las demandas de los representantes de los trabajadores, ya que no reconoce su capacidad de negociación. Una vez hechas las elecciones sindicales en los centros de la Seguridad Social, no se arbitró el sistema de representación a nivel estatal...”, Diario El País [en línea], 28 de enero de 1979, [consulta de 5 de abril de 2013], disponible en: <httpllwww.elpais.com/hemeroteca>.

${ }^{225}$ Recordemos que el derecho de asociación de los funcionarios públicos se reconoció en el Estatuto Maura de 1918, y que la Constitución de 1931 elevó este derecho a categoría de constitucional en el artículo 41 (derecho de asociación profesional) pero no les concedió el de libertad sindical que regulaba en el artículo 39 para los trabajadores. 
Cuando se promulga la CE, una de las bases fundamentales en que apoya la construcción del Estado Social y Democrático de Derecho que proclama, y que recoge el Título Preliminar ${ }^{226}$, es precisamente el pluralismo político y el sindical, de forma que la creación y actividad de los partidos políticos y de los sindicatos son libres dentro del respeto a la Constitución y a la ley, con la exigencia, eso sí, de que su estructura interna y funcionamiento sean democráticos.

El artículo 7 CE reconoce el papel fundamental de los sindicatos y asociaciones empresariales en cuanto a la defensa y promoción de los intereses económicos y sociales que les son propios, y su libertad de creación y acción dentro del marco del ordenamiento jurídico constitucional.

Aunque tanto sindicatos como asociaciones empresariales tengan cabida en este precepto constitucional, difieren en cuanto al derecho fundamental que ampara a cada tipo de institución: la libertad sindical a los sindicatos (art. $28 \mathrm{CE}$ ); el derecho de asociación a las asociaciones empresariales (art. $22 \mathrm{CE})^{227}$.

Por su parte, el artículo 10.2 CE dispone que las normas sobre la libertad sindical se "interpretarán de conformidad con la Declaración Universal de Derechos Humanos y los Tratados y acuerdos internacionales sobre las mismas materias ratificados por España”, lo que supone una remisión a los Convenios de la OIT, al Convenio del Consejo de Europa de 1950 y al resto de los Tratados internacionales que haya ratificado el Estado español.

La CE reconoce en el Título I los derechos y deberes fundamentales, regulando en la Sección primera de su Capítulo II los derechos fundamentales y libertades públicas, entre los que se encuentra el de libertad sindical, en el artículo 28.1. Este precepto, que está estrechamente relacionado con el artículo 7, establece que: "Todos tienen derecho a sindicarse libremente. La ley podrá limitar o exceptuar el ejercicio de este derecho a las Fuerzas o Institutos armados o a los demás Cuerpos sometidos a disciplina militar y regulará las peculiaridades de su ejercicio para los funcionarios públicos. La libertad sindical comprende el derecho a fundar sindicatos ${ }^{228}$ y a afiliarse al de su elección, así

\footnotetext{
${ }^{226}$ En su artículo 1: "Principios básicos. 1. España se constituye en un Estado Social y Democrático de Derecho, que propugna como valores superiores de su ordenamiento jurídico la libertad, la justicia, la igualdad y el pluralismo político”.

${ }^{227}$ STC 75/1992 de 14 de mayo, (RTC 1992\75), STC 92/1994 de 21 de marzo, (RTC 199492).

${ }^{228}$ Sobre el derecho a fundar sindicatos, la STC 121/1997 de 1 de julio, en el Fundamento jurídico noveno, argumenta que:"...el derecho fundamental a la libertad sindical incorpora como contenido esencial del mismo, y en plena sintonía con lo dispuesto en los Convenios internacionales suscritos por España sobre la materia, el derecho a fundar y crear libremente sindicatos sin autorización previa. La constitución de un sindicato, en tanto que asociación de relevancia constitucional, no está sometida a más límites que los derivados de los artículos 7 y 22 de la CE, ni requiere de algún complemento estatal autorizante de la voluntad fundacional de sus miembros. Por ello mismo, el cumplimiento de la obligación de depósito obedece, pues, a la necesidad de establecer un sistema de reconocimiento que permita la identificación jurídica del grupo como sujeto unitario de derechos y su incorporación a un status especialmente favorable para el ejercicio de su acción. [...] Ha de estimarse contraria a la Constitución cualquier disposición legal que coloque a las organizaciones sindicales en la necesidad de tener que adquirir nuevamente una personalidad jurídica y una capacidad de obrar de la que previamente ya disfrutaban...”, (RTC 1997121).
} 
como el derecho de los sindicatos a formar confederaciones y a fundar organizaciones sindicales internacionales o afiliarse a las mismas. Nadie podrá ser obligado a afiliarse a un sindicato".

Respecto a los titulares de este derecho fundamental, vemos que se atribuye su titularidad a nivel individual a todos los trabajadores y funcionarios en sentido amplio, ya que el precepto utiliza el término todos para expresar el sujeto del derecho a sindicarse libremente. También habrá que interpretar que todos son los que pueden libremente fundar sindicatos y afiliarse al de su elección.

Sobre el concepto de sindicato, la doctrina coincide en señalar que es la organización que reúne tres notas características: estar constituida por trabajadores asalariados, poseer una cierta estabilidad o permanencia como tal, y tener como objetivo la representación, defensa y promoción de los intereses de los trabajadores que lo componen. Es al sindicato que cumple estos requisitos al que protege el artículo $7 \mathrm{CE}$, como ente de relevancia constitucional, exigiendo tan solo que respete en su constitución y funcionamiento las reglas del sistema democrático ${ }^{229}$.

Hemos visto que el artículo 28.1 CE también prevé que la ley pueda limitar o exceptuar el ejercicio del derecho de sindicación a los miembros de las Fuerzas o Institutos armados o Cuerpos sometidos a disciplina militar, como así ha sido. Efectivamente, el artículo 1.3 LOLS ha exceptuado del derecho a la libertad sindical a los miembros de las Fuerzas Armadas e Institutos armados de carácter militar.

Asimismo, establece que la ley regulará las peculiaridades de su ejercicio para los funcionarios públicos (entendido este concepto como el personal vinculado con la Administración pública mediante una relación de servicios de carácter administrativo, con independencia de que su vinculación sea fija o de carácter temporal) que tienen también reconocido el derecho de sindicación. En efecto, el artículo 103.3 CE también recalca que la ley regulará las peculiaridades del ejercicio del derecho a sindicación de los funcionarios públicos.

Además, a nivel colectivo, el derecho a la libertad sindical tiene como titulares a los sindicatos, a los que se reconoce el derecho a formar confederaciones y a fundar organizaciones sindicales internacionales o afiliarse a las mismas.

En cuanto a la protección constitucional que se otorga a este derecho fundamental, hay que referirse al artículo 53 CE, situado en el Capítulo V del Título I, que regula las garantías de las libertades y los derechos fundamentales, y dispone varios niveles de garantías:

$1^{\circ}$.- De entrada, todos los derechos y libertades reconocidos en el Capítulo II CE (arts. 14 a 38) vinculan a todos los poderes públicos, y su regulación se debe hacer por norma con rango de ley, que además, deberá respetar su contenido esencial. Esta disposición tiene como consecuencia como advierte la doctrina, que el derecho de libertad sindical es de

229 ALFONSO MELLADO, C.L., "Libertad sindical y derecho de asociación”, en AAVV, Derecho del Trabajo, Valencia, Tirant lo Blanch, $3^{\mathrm{a}}$ ed., 2013, p. 547. 
aplicabilidad directa inmediata sin necesidad de desarrollo legislativo; no obstante, si esta se lleva a cabo debe serlo mediante una ley, no cualquier otra norma de rango jerárquico inferior $^{230}$.

Además, si se trata de un derecho fundamental o libertad pública, como es el caso de la libertad sindical, la norma que lo desarrolle debe ser una ley orgánica, que requiere para su aprobación, modificación o derogación la mayoría absoluta del Congreso en una votación final sobre el conjunto del proyecto (art. 81 CE). También, como garantía, el artículo 161.1 a) prevé el recurso de inconstitucionalidad contra las leyes y disposiciones normativas con fuerza de ley que no se adecuen a la CE.

$2^{\circ}$.- Además, los derechos fundamentales reconocidos en la Sección Primera del Capítulo II, del Título I de la CE, así como el artículo 14 de la misma, están protegidos por el recurso preferente y sumario de la Ley 62/1978, de 26 de diciembre, de Protección Jurisdiccional de los derechos fundamentales de las personas (LPJDFP), y por el Recurso de amparo ante el Tribunal Constitucional (regulado en el art. 41 y siguientes de la Ley Orgánica 2/1979, de 3 de octubre, del Tribunal Constitucional -LOTC).

Si bien el reconocimiento constitucional del derecho a la libertad sindical en el artículo 28.1 CE supuso un gran avance, al igual que el reconocimiento del resto de derechos y libertades públicas, la interpretación del precepto no está exenta de dudas a causa de una redacción que seguramente pretende ser lo más abierta posible, pero que por eso mismo resulta incompleta y ambigua. Por estos motivos la jurisprudencia del TC ha sido determinante para completar la doctrina sobre la libertad sindical. Estos son, en resumen, los puntos principales en los que el TC la fundamenta:

1.- El derecho de libertad sindical tiene una vertiente individual, que viene dada por la libertad que tienen los trabajadores y los funcionarios como personas físicas para afiliarse a sindicatos o a constituirlos, y otra vertiente colectiva, que se refiere a facultades similares cuyo titular son las organizaciones sindicales ${ }^{231}$. El derecho fundamental tiene tanto un aspecto de ejercicio positivo, como un aspecto negativo, que consiste en el libre derecho a no afiliarse a un sindicato ${ }^{232}$.

2.- El artículo 28.1 no hace referencia directamente a la facultad de acción o actividad sindical que pueden tener estas organizaciones una vez constituidas, por eso hay que relacionar el contenido de este artículo con el 7 antes citado, que recordemos que señalaba que "su creación y el ejercicio de su actividad es libre...", para concluir que tendrán derecho a llevar a cabo su actividad libremente en defensa de los intereses del colectivo al que representen ${ }^{233}$. Es decir, además de la vertiente estática de la libertad

\footnotetext{
${ }^{230}$ VICENTE PACHES, F. DE, "La libertad sindical en el Derecho español", en AAVV, Manual de Derecho Sindical, Atelier, Barcelona, $2^{a}$ ed., 2007, pp. 85 y ss.

${ }^{231}$ STC 73/1984, de 27 de junio, (RTC 1984 73) y STS de 30/1992 de 18 de marzo, (RTC 1992\30).

${ }^{232}$ STC 70/1982, de 29 de noviembre, (RTC 1982\70) y 12/1983 de 22 de febrero (RTC 1983\/2).

${ }^{233}$ STC 62/2004, de 19 de abril, (RTC. 2004462).
} 
sindical, que consiste en las facultades que señala el artículo 28.1, este derecho fundamental también comprende los derechos de actividad y medios de acción de los sindicatos, como son la huelga, la negociación colectiva de los trabajadores laborales y la promoción de conflictos colectivos. Estos derechos forman parte también del núcleo mínimo, indispensable e indisponible de la libertad sindical ${ }^{234}$ o, lo que es lo mismo, del contenido esencial $^{235}$ del derecho a la libertad sindical.

Por tanto, el contenido esencial del derecho a la libertad sindical no está cerrado con la enumeración de los derechos que cita el artículo $28.1^{\circ}$ (afiliarse, no afiliarse, constituir sindicatos) ya que para llevar a cabo la defensa de los intereses de los trabajadores en un Estado democrático, el abanico de funciones de los sindicatos será muy amplio, y no queda acotado en la $\mathrm{CE}^{236}$. Esta idea ha sido también respaldada por la doctrina, considerando que el derecho a la libertad sindical debe incluir las posibilidades de acción sindical para ser completo, ya que considerado desde un punto de vista dinámico, el derecho de libertad sindical reclama el de actividad sindical ${ }^{237}$.

La conexión entre el artículo 28.1 y 7 CE, también se recoge en el preámbulo de la LOLS: "Reconocido el derecho a la libre sindicación como derecho fundamental de los españoles, forzosa resulta su conexión con el reconocimiento expreso que efectúa el artículo 7 de la Constitución a los sindicatos de trabajadores y asociaciones empresariales como organizaciones que contribuyen a la defensa y promoción de los intereses económicos y sociales que les son propios y al imperativo constitucional de que su creación y el ejercicio de su actividad son libres dentro del respeto a la Constitución y a la Ley, con la precisión de que su estructura interna y su funcionamiento deberán ser democráticos".

${ }^{234}$ STC 37/1983, de 11 de mayo, Fundamento jurídico segundo: "La libertad sindical implica la libertad para el ejercicio de la acción sindical comprendiendo en ella todos los medios lícitos (...) que incluyen la negociación colectiva y la huelga, debiendo extenderse también a la incoación de conflictos colectivos", (RTC 1983\37).

${ }^{235}$ Sobre el concepto de "contenido esencial" de los derechos fundamentales, es básica la STC 11/1981, de 8 de abril, cuyo Fundamento jurídico octavo argumenta que: "Constituyen el contenido esencial de un derecho subjetivo aquellas facultades o posibilidades de actuación necesarias para que el derecho sea reconocible como perteneciente al tipo descrito y sin las cuales deja de pertenecer a ese tipo" [...] es la parte del contenido del derecho que es absolutamente necesaria para que los intereses jurídicamente protegibles, que dan vida al derecho, resulten real, concreta y efectivamente protegidos...", (RTC 1981 11).

${ }^{236}$ STC 70/1982, de 29 de noviembre, Fundamento jurídico quinto: “... la legalidad ordinaria debe ser reinterpretada a la luz de los preceptos constitucionales, entre los cuales tienen hoy singular relevancia el artículo 7, que consagra los sindicatos de trabajadores como instrumentos que contribuyen a la defensa y promoción de los intereses económicos y sociales que le son propios; el artículo 28, que reconoce el derecho de sindicación y de libertad sindical, y el artículo 37, que reconoce el derecho a la negociación colectiva y a la adopción de medidas de conflicto colectivo", (RTC 1982\70). La STC 23/1983, de 25 de marzo, insiste en el carácter no exhaustivo de la enumeración que hace el artículo 28.1 CE en el Fundamento jurídico segundo, que señala: “...por muy detallado y concreto que parezca el artículo 28.1 de la CE, a propósito del contenido de la libertad sindical, no puede considerársele como exhaustivo o limitativo, sino meramente ejemplificativo, con la consecuencia de que la enumeración expresa de los derechos concretos que integran el genérico de libertad sindical no agota, en absoluto, el contenido global o total de dicha libertad", (RTC 1983V23). Véase también la STC 51/1984, de 25 de abril, Fundamentos jurídicos primero y tercero, (RTC 1984 51).

${ }^{237}$ GIUGNI, G., Derecho sindical, Ministerio de Trabajo y Seguridad Social, Madrid, 1983, p. 81. 
3.- El contenido del derecho fundamental de libertad sindical se puede ampliar por el legislador ordinario, respetando en todo caso el contenido esencial del derecho, que no puede verse modificado. Estos derechos que emanan del legislador son los adicionales, como el de representación institucional ${ }^{238}$ o el derecho de promoción de elecciones sindicales para órganos de representación de los trabajadores en las empresas y en las Administraciones públicas ${ }^{239}$ y el de presentación de candidaturas en dichas elecciones ${ }^{240}$.

De este modo, el derecho fundamental de libertad sindical se integra no solo por su contenido esencial mínimo indispensable, sino también por esos derechos o facultades adicionales de origen legal o convencional con la consecuencia de que los actos contrarios a estos últimos son susceptibles de infringir el art. 28.1 CE en determinados casos en los que esté en juego la función que reconoce a los sindicatos la $\mathrm{CE}^{241}$.

Este es el caso de algunos de los derechos sindicales de los funcionarios públicos, como los de disponer de órganos de representación unitarios o el de negociación colectiva funcionarial, que para el TC son, sin discusión, de creación legal y se deben ejercer de acuerdo con los presupuestos y requisitos que marca la ley. Solo en el caso de que, a propósito del ejercicio de estos derechos, se excluya o perjudique al sindicato, de forma que no pueda desarrollar su función constitucional, se podría ver lesionado el derecho fundamental a la libertad sindical y en consecuencia se podría acceder a la protección constitucional del recurso de amparo.

Es decir, el TC entiende que los derechos adicionales, que son de origen legal o convencional, disponen en ocasiones de la protección en amparo si la vulneración de los

${ }^{238}$ STC 39/1986, de 31 de marzo, (RTC 198639).

${ }^{239}$ STC 164/1993, de 18 de mayo, Fundamento jurídico tercero: “El artículo 28.1 CE integra los derechos de actividad y medios de acción de los Sindicatos que constituyen el núcleo mínimo e indispensable de la libertad sindical, estos son: huelga, negociación colectiva y promoción de conflictos. Sin embargo, junto a los anteriores los Sindicatos pueden ostentar derechos o facultades adicionales atribuidos por normas o convenios que pasen a añadirse a aquel núcleo esencial; que son: la participación institucional [...] la facultad de los sindicatos para promover y participar en las elecciones para órganos de representación de los trabajadores. Así pues, el derecho fundamental comprende no solo el contenido esencial, sino también esos derechos o facultades adicionales, de modo que los actos contrarios a estos últimos sí son susceptibles de infringir dicho artículo 28.1 CE”, (RTC 1993\164).

${ }^{240}$ STC 51/1988, de 22 de marzo, (RTC 1988\51).

241 Así se recoge esa argumentación en las STC 9/1988, de 25 de enero, Fundamento jurídico segundo: "Dichas facultades o derechos adicionales (a los que forman el núcleo mínimo que menciona expresamente el art. 28.1 CE) pueden quedar remitidos por la Constitución, a efectos de su regulación, a la normativa legal, o, en su caso, reglamentaria que la crea, no teniendo, per se, carácter de derechos fundamentales o constitucionales con sujeto determinado”, (RTC 198819). En el mismo sentido la STC 51/1988, de 22 de marzo, Fundamento jurídico quinto, (RTC 1988\51). STC 61/1989, de 3 de abril, Fundamento jurídico segundo, (RTC 1989\61); STC 101/1991, de 13 de mayo, Fundamento jurídico segundo, (RTC 1991 101); STC 75/1992, de 14 de mayo, Fundamento jurídico segundo, (RTC 1992\75). STC 173/1992, de 29 de octubre, Fundamento jurídico tercero, (RTC 1992\17). STC 272/1993, de 20 de septiembre, (RTC 1993\272); STC 164/1993, de 18 de mayo, Fundamento jurídico tercero, (RTC 1993\/64); STC 62/2004, de 19 de abril, (RTC 2004 62) y STC 70/2000, de 13 de marzo, (RTC 2000\70). 
mismos es de tal calado que llega a afectar a la función constitucional que ejerce la organización sindical eventualmente afectada. Por esta vía, algunos derechos creados por el legislador ordinario' pasarían a gozar de una protección en amparo que, sin embargo, no poseen otros derechos reconocidos expresamente en la $\mathrm{CE}$, como son el derecho a la negociación colectiva, regulado en el artículo 37.1 CE, o el derecho de adopción de medidas de conflicto colectivo, del artículo 37.2 CE. Estos, en principio, al estar regulados fuera de la sección $1^{\mathrm{a}}$ del Capítulo II del Título I CE no gozan de protección constitucional, sino tan solo de protección legal ordinaria.

En definitiva, los actos realizados en contra del contenido esencial del derecho a la libertad sindical lesionarán siempre este derecho fundamental, y por tanto, serán recurribles en amparo ante el TC (art. 41.1, inciso primero, LOTC). Además, los actos que lesionen derechos que formen parte del contenido adicional del derecho de libertad sindical, como es el de disfrute de crédito horario sindical, no van a lesionar necesariamente el derecho fundamental, ya que deberán darse determinados requisitos para calificar el acto como lesivo constitucionalmente y que quepa, en consiguiente, recurso de amparo ${ }^{242}$.

4.- La libertad sindical, además, se puede apreciar desde una perspectiva orgánica o funcional del derecho fundamental. La concepción orgánica de la libertad sindical mantiene que este derecho fundamental protege las actividades de las organizaciones sindicales que se dirigen a la defensa de los intereses de los trabajadores tal como reconoce la $\mathrm{CE}$, y que debe existir una conexión sindical para que el TC reconozca la protección del recurso de amparo contra las conductas antisindicales: STC 95/1996, de 29 de mayo ${ }^{243}$.

En esta misma sentencia, el voto particular contiene la teoría de la concepción funcional del derecho a la libertad sindical, que considera que su protección en amparo se

\footnotetext{
${ }^{242}$ Así, la STC 61/1989, de 3 de abril, Fundamento jurídico segundo, declara: "No ha de confundirse el ámbito del contenido esencial del derecho, límite que se impone a la actividad del legislador (artículo 53.1 CE) con el ámbito de protección en amparo del derecho fundamental (artículo $53.2 \mathrm{CE}$ ) que incluye el efectivo goce del derecho en el marco de su regulación legal, la cual puede, respetando ese contenido esencial, y dentro del margen de actuación política, regular de forma más amplia o restrictiva los derechos o medios instrumentales que faciliten al sindicato y a sus afiliados el ejercicio de la actividad sindical en la empresa. La consagración legislativa de tales derechos trae consigo que los mismos vengan a integrarse dentro del propio contenido del derecho fundamental....", (RTC 1989\61).
}

${ }^{243}$ La perspectiva orgánica del derecho se defiende en el Fundamento jurídico cuarto: “... Las facultades que, desde un punto de vista individual y en su vertiente organizativa y de actividad, integra el derecho de libertad sindical tienen, en principio, como titulares a los afiliados a los sindicatos y a quienes quieren constituir un sindicato y afiliarse al mismo. A los trabajadores corresponde el derecho a afiliarse o no afiliarse, y una vez que hayan optado por la afiliación, y en tanto que afiliados, el de participar en la actividad sindical [...]... en los demás casos en que el TC ha considerado que podían estar en juego las garantías del artículo 28.1 se trataba, por lo general, del ejercicio de una actividad propiamente sindical llevada a cabo por representantes sindicales, que motivaba una decisión empresarial cuya compatibilidad con la Constitución debía ser contrastada o cuando menos, existía siempre una conexión sindical, lo que permitía afirmar la posibilidad de que estuviera en juego la presencia o la actividad del sindicato en la empresa, instrumentada no pocas veces de forma preferente, a través de las representaciones unitarias o electivas. Ciertamente el hecho de que el representante unitario o electivo, en cuanto tal, no sea titular del derecho fundamental de libertad sindical tiene como obligada consecuencia que las infracciones de sus derechos, garantías y facilidades no pueden ser reparadas, en principio, por la vía del recurso de amparo constitucional, si en este se invoca el artículo 28.1 CE”, (RTC 199695). 
debe extender a todas las actividades sindicales, tanto las realizadas por los sindicatos como las que lleven a cabo los trabajadores, incluso sin exigirse la pertenencia a una organización sindical $^{244}$. Esta misma concepción funcional del derecho a la libertad sindical se recoge también en la STC 134/1994, de 9 de mayo, que argumenta que aunque la supuesta vulneración del derecho fundamental no afecte a un sindicato, el trabajador como tal (también el empleado público) podrá recabar la tutela de su derecho a la libertad sindical ante el TC a través del recurso de amparo ${ }^{245}$.

En definitiva, el artículo 28.1 CE está protegiendo actividades que serán llevadas a cabo fundamentalmente en el ámbito del sindicato, aunque en ocasiones también puedan serlo por los propios trabajadores -incluidos los no afiliados- e incluso en un momento presindical: STC 197/1990, de 29 de noviembre ${ }^{246}$.

En cuanto a la doctrina del TC sobre la libertad sindical de los funcionarios públicos, hay que tener en cuenta que esta ha experimentado una evolución favorable a su promoción a lo largo de los años. Al principio y hasta la promulgación de la LOLS (período 19791986) el TC no contó con más herramientas normativas estatales que la propia norma constitucional y el texto de los Tratados internacionales, que según la CE debía tener en cuenta a la hora de interpretarla, aunque en opinión de la doctrina "poco solucionaban"247.

Por eso, en aquella etapa, por lo que se refiere a la libertad sindical de los funcionarios públicos, el TC interpretaba que, si bien la CE no los excluía del derecho fundamental de sindicación, tampoco se les podía reconocer la titularidad de todos los derechos de índole sindical como a los trabajadores sometidos a la legislación laboral. Ello en base a la naturaleza del vínculo jurídico que les une al empleador, de carácter administrativo, en el que prima la posición de supremacía de la Administración, que no es equiparable a la de otro empleador ${ }^{248}$.

En efecto, el vínculo funcionarial se constituye con arreglo a la ley y los reglamentos, no mediante un contrato que vincule a las partes como en el derecho laboral

\footnotetext{
${ }^{244}$ Voto particular del magistrado JIMENEZ DE PARGA, al que se adhirió GIMENO SENDRA.

${ }^{245}$ Fundamento jurídico cuarto: "En suma, el artículo 28.1 CE no puede ser entendido de modo tal que quede en todo caso fuera de su ámbito de tutela la actividad sindical de aquellos trabajadores que siguiendo una actividad no declarada ilícita, programada o promovida por asociaciones sindicales o en las que estas tengan un particular interés, no estén afiliados a las mismas. La represalia o sanción frente a esas conductas vulneraría el artículo 28.1 CE. El propio legislador lo ha entendido así, al incluir en la sanción de nulidad los actos o normas que supongan discriminación por razón de la adhesión... a sus acuerdos (del sindicato) o al ejercicio en general de actividades sindicales (artículo $12 \mathrm{LOLS}$ ), y también en términos análogos se ha pronunciado anteriormente este Tribunal...", (RTC 199413).

${ }^{246}$ (RTC 1990\197).

${ }^{247}$ SALA FRANCO, T., ROQUETA BUJ, R., Los derechos sindicales de los funcionarios públicos, Tirant lo Blanch, Valencia, 1995, p. 225.

${ }^{248}$ ORTEGA ALVAREZ, L., Los derechos sindicales de los funcionarios públicos, Tecnos, Madrid, 1983, p. 323.
} 
común. Como señala la STC 57/1982, de 27 de julio, es distinta esa situación de la del personal laboral al servicio de las diferentes Administraciones públicas, cuyas condiciones de trabajo vienen establecidas en parte por las leyes o reglamentos y en parte también por Convenios colectivos y/o por contratos individuales entre el trabajador y el ente público, al igual que ocurre entre particulares ${ }^{249}$. La distinta naturaleza del régimen jurídico de los funcionarios justificaba en aquel momento para el TC que estos no pudieran ejercitar, en concreto, el derecho a la negociación colectiva que el legislador aún no había desarrollado ${ }^{250}$.

Esta postura inicial del TC, sin embargo, fue evolucionando con el tiempo a favor de un reconocimiento más amplio de los derechos colectivos de los funcionarios, sobre todo a partir de la publicación de su normativa específica que desarrolló las peculiaridades del ejercicio de su derecho a la libertad sindical. Esta, verá la luz gracias a presión de las organizaciones sindicales que prepararon el camino para la aprobación por el Consejo de Ministros, el 19 de diciembre de 1985, del proyecto de la Ley de Órganos de representación, determinación de las condiciones de trabajo y participación del personal al servicio de las Administraciones Públicas (LORAP), que acabó publicándose el 17 de junio de 1987.

Por su parte, el desarrollo legislativo del derecho fundamental a la libertad sindical del artículo 28.1 CE tiene lugar con la LOLS. Esta se estructura en cinco Títulos, precedidos de un preámbulo, y se compone de quince artículos, cuatro disposiciones adicionales, una derogatoria y tres finales. A lo largo de su articulado, la LOLS regula el ámbito subjetivo y el contenido del derecho fundamental a la libertad sindical (arts.1 a 3); el régimen jurídico sindical -los requisitos para la válida constitución de sindicatos y el principio de responsabilidad de estos (arts. 4 y 5). También se aborda la representatividad sindical (arts. 6 y 7); la acción sindical: derechos de los sindicatos, de los cargos electos sindicales, de los sindicatos representativos en empresas, el descuento de la cuota sindical (arts. 8 a 11), y, por último, en el Título $\mathrm{V}$, se regula la tutela de la libertad sindical y represión de las conductas antisindicales (arts. 12 a 15).

El proyecto de la LOLS fue objeto de varios recursos previos de inconstitucionalidad resueltos finalmente por STC 98/1985, de 29 de julio ${ }^{251}$, que confirmaron su adecuación a la CE. Por otra parte, ha sido modificada desde su aprobación en 1986, por la Ley Orgánica 14/1994, de 19 de mayo, para incluir la Disposición adicional cuarta, por la que los representantes del personal con mandato prorrogado no se computan a efectos de determinar la capacidad representativa de la organización sindical, y por la Ley Orgánica 9/2011, de 27 de julio, de derechos y deberes de las Fuerzas Armadas.

\footnotetext{
${ }^{249}$ Fundamento jurídico cuarto, (RTC 1982\57).

${ }^{250}$ STC 57/1982, Fundamentos jurídicos cuarto y sexto: “En la actualidad la negociación colectiva de las condiciones de trabajo del personal vinculado a cualquiera de las Administraciones públicas solo es posible legalmente cuando se trate de personal sometido al Derecho laboral, pero no, en cambio, en relación al personal vinculado al Derecho administrativo, sea funcionario en cualquiera de sus modalidades -de carrera o empleo- o asimilado, por tener una relación funcional sujeta a esta última rama del Derecho, donde no está admitido tal sistema por ausencia de aceptación y regulación y por contradecir el régimen legalmente [...] Por tanto, los funcionarios públicos y asimilados de las Administraciones públicas, entre ellos los funcionarios de las Administraciones Locales, están sometidos a las condiciones de empleo determinadas por la ley y los reglamentos, con exclusión del sistema de negociación colectiva”, (RTC 1982\57).

${ }^{251}$ (RTC 1985ר98).
} 
Todo el régimen jurídico que contiene la Ley 11/1985, de 2 de agosto, de Libertad Sindical, es común para los trabajadores y para los funcionarios al servicio de la Administración pública. El derecho de libertad sindical se trata en su Título I: "Todos los trabajadores tienen derecho a sindicarse libremente para la promoción y defensa de sus intereses económicos y sociales" (art. 1.1).

Para que no quepa duda respecto a los funcionarios públicos, también los incluye expresamente en su ámbito subjetivo: "A los efectos de esta Ley, se consideran trabajadores tanto aquellos que sean sujetos de una relación laboral como aquellos que lo sean de una relación de carácter administrativo o estatutaria al servicio de las Administraciones públicas" (art. 1.2).

Este tratamiento común es uno de los objetivos de la LOLS ya que, según dice en su preámbulo, pretende "unificar sistemáticamente los precedentes y posibilitar un desarrollo progresivo y progresista del contenido esencial del derecho de libre sindicación reconocido en la Constitución, dando un tratamiento unificado en un texto legal único que incluya el ejercicio del derecho de sindicación de los funcionarios públicos a que se refiere el artículo 103.3 CE y sin otros límites que los expresamente introducidos en ella”.

Como se dijo arriba la LOLS exceptúa del ejercicio del derecho de sindicación a los miembros de las Fuerzas e Institutos Armados de carácter militar (art. 1.3 LOLS). Aunque la Ley Orgánica 9/2011, de 27 de julio, permite que puedan asociarse ${ }^{252}$.

Tampoco pueden sindicarse los Jueces, Magistrados y Fiscales mientras se hallen en activo (art. 1.4 LOLS en relación con el art. 127.1 CE), aunque sí pueden constituir asociaciones profesionales y asociarse a las mismas (Ley Orgánica 6/1985 de 1 de julio y Ley 50/1981 de 30 de diciembre).

Respecto a las Fuerzas de Seguridad, el artículo 1.5 LOLS remite a una norma específica la regulación del derecho de libertad sindical de los miembros de las Fuerzas de Seguridad e Institutos Armados de carácter civil, que hoy viene dada por la Ley Orgánica 2/1986, de 13 de marzo, sobre Fuerzas y Cuerpos de Seguridad del Estado. Esta ley establece el régimen jurídico sindical de los funcionarios de policía. Esta, en su artículo 52.2 respecto a la policía local, estableció que sería de aplicación la ley que se dictara en desarrollo de la Disposición adicional segunda, apartado 2 de la LOLS (que sería la LORAP y actualmente es la LEBEP).

En el artículo 2.1 LOLS se regula el contenido de la libertad sindical, desde su vertiente individual, y señala como tal: a) el derecho a fundar sindicatos sin autorización previa, así como el derecho a suspenderlos o a extinguirlos, por procedimientos democráticos; b) el derecho del trabajador a afiliarse al sindicato de su elección con la sola condición de observar los estatutos del mismo o a separarse del que estuviese afiliado, no pudiendo nadie ser obligado a afiliarse a un sindicato; c) el derecho de los afiliados a elegir

\footnotetext{
${ }^{252}$ El artículo 14 contempla que puedan crear asociaciones y asociarse libremente para la consecución de fines lícitos, de acuerdo con lo previsto en la Ley Orgánica 1/2002, de 22 de marzo, reguladora del Derecho de Asociación, teniendo en cuenta que las asociaciones de miembros de las Fuerzas Armadas no podrán llevar a cabo actividades políticas ni sindicales, ni vincularse con partidos políticos o sindicatos.
} 
libremente a sus representantes dentro de cada sindicato, y por último, d) el derecho a la actividad sindical.

En cuanto a la libertad sindical colectiva, el artículo 2.2 dispone que las organizaciones sindicales, entre otras facultades, tienen derecho a: “... el ejercicio de la actividad sindical en la empresa o fuera de ella, que comprenderá, en todo caso, el derecho a la negociación colectiva, al ejercicio del derecho de huelga, al planteamiento de conflictos individuales y colectivos y a la presentación de candidaturas para la elección de Comités de empresa, y Delegados de Personal, y de los correspondientes órganos de las Administraciones Públicas, en los términos previstos en las normas correspondientes" (apartado d).

El Título II está dedicado a regular el régimen jurídico sindical (constitución y responsabilidad de los sindicatos), como antes dijimos. Y en cuanto al Título III, en el que se regula la representatividad sindical, este es particularmente importante, ya que incorpora en nuestro ordenamiento jurídico el criterio de la audiencia sindical en base a los resultados electorales obtenidos por la organización en las elecciones a representantes unitarios de los trabajadores y funcionarios, considerado ajustado a la CE por STC 98/1985, de 29 de julio $^{253}$.

En función de la mayor representación obtenida en estos órganos de representación del personal se atribuye a las organizaciones sindicales esta condición, que a su vez les otorga ciertas prerrogativas legales. Este criterio, objetivo y razonable para el TC, no vulnera el principio de igualdad y no discriminación entre organizaciones sindicales, ya que la reserva de determinadas funciones o prerrogativas a las asociaciones sindicales más representativas tiene la finalidad de proteger otro derecho también necesitado de atención, cual es la más eficaz defensa de los intereses de los trabajadores, pues tal defensa se vería perjudicada por una atomización sindical, según la STC 164/1993, de 18 de mayo $^{254}$.

El Título IV LOLS regula la acción sindical, siendo particularmente importante el artículo 8, dedicado a las secciones sindicales. Su contenido viene dado en la ley como un

\footnotetext{
${ }^{253}$ Que argumenta: "La promoción de elecciones prevista en el apartado e) del artículo 6.3 LOLS pretende tan solo ordenar de forma razonable dichas elecciones, partiendo del principio elemental de que únicamente a los interesados y no al Estado compete acordar la celebración de las mismas. Su limitación a quienes tengan un mínimo de representatividad es una medida lógica de ordenación del proceso electoral que pretende evitar las disfunciones derivadas de una atribución indiscriminada, y no altera los derechos de los excluidos, pues éstos pueden presentar su candidatura en base al artículo 2.2 d) LOLS”, (RTC 1985198).

${ }^{254}$ (RTC 1993\164).
} 
mínimo, mejorable a través de la negociación colectiva ${ }^{255}$. De igual forma, el artículo 10.2 trata de los delegados sindicales, aspecto también sujeto a mejora por ese mecanismo ${ }^{256}$.

Por último, la LOLS regula en su Capítulo V "La tutela de la libertad sindical y represión de las conductas antisindicales”. Destaca Alfonso Mellado que en cuanto a los medios de tutela de la libertad sindical, hay que tener en cuenta como principal la declaración de nulidad de las conductas antisindicales ${ }^{257}$, bien sea en el ámbito de las relaciones de trabajo, que viene regulada en el artículo 12 LOLS $^{258}$, como frente a cualquier otra actuación de cualquier persona física o jurídica, según el artículo 13 LOLS $^{259}$.

En efecto, la tutela de este derecho fundamental es posible por varias vías:

$1^{\text {a }}$.- A través del procedimiento especial de tutela de los derechos fundamentales y libertades públicas, que prevé el artículo 13 LOLS, y que actualmente está regulado en el artículo 177 y siguientes de la Ley 36/2011, de 10 de octubre, reguladora de la Jurisdicción social (LJS) ${ }^{260}$. Este procedimiento cumple los requisitos exigidos por el artículo 53.2 CE, que disponía la protección de los derechos fundamentales mediante un procedimiento judicial basado en los principios de preferencia y sumariedad. Su tramitación tiene carácter urgente con respecto a los demás que se tramiten ante el órgano jurisdiccional, a todos los efectos (art. 179.1 LJS). A través de este proceso especial se verán las demandas de tutela de los derechos fundamentales y libertades públicas que se susciten en el ámbito de las

255 "Sin perjuicio de lo que se establezca mediante convenio colectivo, las Secciones Sindicales de los sindicatos más representativos y de los que tengan representación en los comités de empresa y en los órganos de representación que se establezcan en las Administraciones públicas o cuenten con Delegados de Personal, tendrán los siguientes derechos...”.

256 "Bien por acuerdo, bien a través de la negociación colectiva, se podrá ampliar el número de delegados establecidos en la escala a la que hace referencia este apartado, que atendiendo a la plantilla de la empresa $o$, en su caso, de los centros de trabajo corresponden a cada uno de éstos...

257 ALFONSO MELLADO, C.L., "Libertad Sindical y derecho de asociación”, en AAVV, Derecho del Trabajo, Tirant lo Blanch, Valencia, $3^{\text {a }}$ ed., 2013, p. 556 y ss.

${ }^{258}$ Que establece: “Los preceptos reglamentarios, las cláusulas de los convenios colectivos, los pactos individuales y las decisiones unilaterales del empresario que contengan o supongan cualquier tipo de discriminación en el empleo o en las condiciones de trabajo, sean favorables o adversas, por razón de la adhesión o no a un sindicato, a sus acuerdos o al ejercicio, en general de actividades sindicales”.

259 "Cualquier trabajador o sindicato que considere lesionados los derechos de libertad sindical, por actuación del empleador, asociación patronal, administraciones públicas o cualquier otra persona, entidad o corporación pública o privada, podrá recabar la tutela del derecho ante la jurisdicción competente, a través del proceso de protección jurisdiccional de los derechos fundamentales de la persona”.

${ }^{260}$ Artículo 177. 1: "Cualquier trabajador o sindicato que, invocando un derecho o interés legítimo, considere lesionados los derechos de libertad sindical, huelga u otros derechos fundamentales y libertades públicas, incluida la prohibición de tratamiento discriminatorio y del acoso, podrá recabar su tutela a través de este procedimiento cuando la pretensión se suscite en el ámbito de las relaciones jurídicas atribuidas al conocimiento del orden jurisdiccional social o en conexión directa con las mismas, incluidas las que se formulen contra terceros vinculados al empresario por cualquier título, cuando la vulneración alegada tenga conexión directa con la prestación de servicios". 
relaciones jurídicas atribuidas al conocimiento del orden jurisdiccional social, por lo que el personal laboral de las Administraciones públicas puede acudir a este procedimiento especial, no así los funcionarios ni el personal estatutario, por el motivo que veremos a continuación.

Precisamente ante el orden contencioso administrativo de la jurisdicción es ante el que se conocen los procesos en demanda de protección de la libertad sindical de los funcionarios públicos. El "procedimiento para la protección de los derechos fundamentales de la persona” se regula en el Capítulo I del Título V de la Ley 29/1998, de 13 de julio, reguladora de la Jurisdicción contencioso administrativa (LJCA), artículos 114 y ss ${ }^{261}$, estando, por tanto, excluidas las posibles vulneraciones de cualquiera de las facultades del derecho fundamental a la libertad sindical de los funcionarios del conocimiento del orden social. La causa de la exclusión, que viene dada en el artículo 3 LJS, tiene que ver con la importancia que le ha dado la ley a la condición de los sujetos implicados. La Administración pública y el personal funcionario no son equiparables para el legislador a los empresarios y trabajadores, y se considera que sus litigios se deben conocer en su cauce procesal específico: el contencioso administrativo; ello incluso en el caso de que traten sobre los derechos de libertad sindical ${ }^{262}$.

$2^{\mathrm{a}}$.- También hay protección de la libertad sindical a través de los procedimientos judiciales ordinarios correspondientes ante los órganos jurisdiccionales del orden social ${ }^{263}$, contencioso administrativo ${ }^{264}$ o penal $^{265}$.

${ }^{261}$ Artículo 114: “1. El procedimiento de amparo judicial de las libertades y derechos, previsto en el artículo $53.2 \mathrm{CE}$, se regirá, en el orden contencioso-administrativo, por lo dispuesto en este capítulo y, en lo no previsto en él, por las normas generales de la presente Ley. 2. Podrán hacerse valer en este proceso las pretensiones a que se refieren los artículos 31 y 32, siempre que tengan como finalidad la de restablecer o preservar los derechos o libertades por razón de los cuales el recurso hubiere sido formulado.3. A todos los efectos, la tramitación de estos recursos tendrá carácter preferente”.

${ }^{262}$ El artículo 3 LJS dice: "No conocerán los órganos jurisdiccionales del orden social [...] c) de la tutela de los derechos de libertad sindical y del derecho de huelga relativa a los funcionarios públicos, personal estatutario de los Servicios de salud y al personal a que se refiere la letra a) del apartado 3 del artículo 1 del Texto Refundido de la Ley del Estatuto de los Trabajadores" (es decir, aquellos cuya vinculación jurídica con la Administración sea de naturaleza administrativa). Esta exclusión, que no es novedosa puesto que ya venía contemplada en el Texto Refundido de la Ley de Procedimiento Laboral, aprobado en su día por el Real Decreto legislativo 2/1995 de 7 de abril (art. 3.1 a), y ha motivado una abundante jurisprudencia que corrobora ese criterio legal.

${ }^{263}$ MONEREO PEREZ, MOLINA NAVARRETE Y MORENO VIDA apuntan al proceso de impugnación de los estatutos de los sindicatos en el caso de no ser conformes a Derecho (arts. 173 a 175 LJS). Manual de Derecho Sindical, Comares, Granada, $8^{\text {a }}$ ed., 2013, p. 118. Probablemente, por su trascendencia para el ejercicio de la actividad del sindicato, podrían incluirse también en este apartado el procedimiento previsto en los artículos 133 a 136 LJS, relativo a la impugnación de la resolución administrativa de la Oficina Pública de Registro que deniegue el registro o la certificación de la representatividad sindical, y el procedimiento de impugnación de la resolución administrativa que deniegue el depósito de los estatutos del sindicato (arts. 167 a 172 LJS).

${ }^{264}$ Como los recursos contra las decisiones de la Administración pública excluyendo a un sindicato de una mesa de negociación. El artículo 19.1 b) LJCA legitima a los sindicatos para acudir a este orden de la jurisdicción en defensa de sus derechos e intereses legítimos colectivos. 
$3^{\text {a }}$.- Agotada la vía jurisdiccional de los Tribunales ordinarios, se dispone del recurso de amparo ante el TC, regulado en el artículo 41.1 LOTC: "Los derechos y libertades reconocidos en los artículos 14 a 29 CE serán susceptibles de amparo constitucional, en los casos y formas que esta Ley establece, sin perjuicio de su tutela general encomendada a los Tribunales de Justicia. Igual protección será aplicable a la objeción de conciencia reconocida en el artículo 30 de la Constitución”.

$4^{\text {a }}$-- Por último, también existe un tipo de tutela administrativa, por lo que determinados comportamientos lesivos de los aspectos de la libertad sindical constituyen infracciones administrativas laborales que, correlativamente, tienen aparejada su sanción en la ley ordinaria: actualmente en la Ley de Infracciones y Sanciones del Orden Social, regulada por Real Decreto legislativo 5/2000, de 4 de agosto (LISOS).

La protección que reconoce esta norma es amplia, tipificando como faltas graves y muy graves las infracciones de las diversas facultades del derecho a la libertad sindical ${ }^{266}$. En el Capítulo VI la LISOS regula las responsabilidades y sanciones que se pueden imponer en función de la infracción cometida. La Inspección de Trabajo es el órgano al que se atribuye la capacidad de actuación en esta materia.

Como vemos, la tutela jurídica de la libertad sindical se articula mediante procedimientos y desde aspectos diversos, que ponen de relieve la importancia que tiene en nuestro ordenamiento jurídico este derecho fundamental.

${ }^{265}$ El artículo 315 del Código Penal tipifica como delito tanto impedir o limitar el derecho a la libertad sindical o el derecho de huelga mediante engaño o abuso de situación de necesidad, fuerza, violencia o intimidación, como la coacción colectiva para iniciar o continuar una huelga.

${ }^{266}$ Entre otras, se tipifican como infracciones graves relacionadas con la protección del derecho a la libertad sindical en el artículo 7 (apdos. 7, 8 y 9): “La transgresión de los derechos de información, audiencia y consulta de los representantes de los trabajadores y de los delegados sindicales en los términos en que legal o convencionalmente estuvieren establecidos. La transgresión de los derechos de los representantes de los trabajadores y de las secciones sindicales en materia de crédito de horas retribuidas y locales adecuados para el desarrollo de sus actividades, así como de tablones de anuncios, en los términos en que legal o convencionalmente estuvieren establecidos, y la vulneración de los derechos de las secciones sindicales en orden a la recaudación de cuotas, distribución y recepción de información sindical, en los términos en que legal o convencionalmente estuvieren establecidos". En el artículo 8 se tipifican como infracciones muy graves las acciones u omisiones que impidan el ejercicio del derecho de reunión de los trabajadores, de sus representantes y de las secciones sindicales, en los términos en que legal o convencionalmente estuvieran establecidos. La vulneración del derecho de asistencia y acceso a los centros de trabajo, en los términos establecidos por el artículo 9.1 c) LOLS de quienes ostenten cargos electivos a nivel provincial, autonómico o estatal en las organizaciones sindicales más representativas [...] La transgresión de las cláusulas normativas sobre materia sindical establecidas en los convenios colectivos. [...] Las decisiones unilaterales de la empresa que impliquen discriminaciones directas o indirectas desfavorables por razón de edad o discapacidad o favorables o adversas en materia de retribuciones, jornadas, formación, promoción y demás condiciones de trabajo, por circunstancias de sexo, origen, incluido el racial o étnico, estado civil, condición social, religión o convicciones, ideas políticas, orientación sexual, adhesión o no a sindicatos y a sus acuerdos, vínculos de parentesco con otros trabajadores en la empresa o lengua dentro del Estado español, así como las decisiones del empresario que supongan un trato desfavorable de los trabajadores como reacción ante una reclamación efectuada en la empresa o ante una acción administrativa o judicial destinada a exigir el cumplimiento del principio de igualdad de trato y no discriminación. 
Por último, hay que decir que la doctrina destaca el papel protector que lleva a cabo a nivel internacional la OIT, bien mediante procedimientos generales compartidos con el resto de derechos laborales, o bien a través de procedimientos específicos de tutela de la libertad sindical ${ }^{267}$.

\section{3.- ANTECEDENTES NORMATIVOS Y REGULACIÓN ACTUAL DE LOS DERECHOS COLECTIVOS DE LOS EMPLEADOS PÚBLICOS Y DEL PERSONAL ESTATUTARIO DE LOS SERVICIOS DE SALUD}

Hasta ahora hemos visto que nuestro ordenamiento jurídico durante los años de la Transición se inspiró en los Convenios y Tratados internacionales que reconocían y promocionaban la libertad sindical, cuyo contenido incorporó progresivamente y que, de manera general, no se excluía de su disfrute a los funcionarios públicos. Sin embargo, es desde la promulgación de la $\mathrm{CE}$ que se puede afirmar que estos disfrutan verdaderamente del derecho a la libertad sindical en España, si bien con ciertas peculiaridades como son las que afectan a la regulación de sus órganos de representación del personal o el derecho a la negociación colectiva ${ }^{268}$.

Estos aspectos los desarrolla la ley reguladora de su Estatuto funcionarial y tienen su razón de ser en la particularidad de su régimen jurídico, ya que su empleador es la Administración pública que presta servicios a los ciudadanos. En ese sentido, el artículo 103.3 CE señala: "La ley regulará el estatuto de los funcionarios públicos, el acceso a la función pública de acuerdo con los principios de mérito y capacidad, las peculiaridades del ejercicio de su derecho a sindicación, el sistema de incompatibilidades y las garantías para la imparcialidad en el ejercicio de sus funciones".

La regulación general de la libertad sindical vino dada en la LOLS, con su visión integradora del derecho a la libertad sindical, estableciendo un régimen común para trabajadores y funcionarios, y en su Disposición adicional segunda, apartado dos, estableció que: "En el plazo de un año y en desarrollo de lo previsto en el artículo 103.3, de la Constitución el Gobierno remitirá a las Cortes un proyecto de Ley en el que se regulen los órganos de representación de los funcionarios de las Administraciones públicas”.

En efecto, la norma a la que se refiere la LOLS y que ha regulado las particularidades del ejercicio del derecho a la libertad sindical de los funcionarios públicos, incluido el personal estatutario, durante casi veinte años, ha sido la LORAP. En su

\footnotetext{
${ }^{267}$ Véase de RODRIGUEZ IZQUIERDO, R., "La tutela de la Libertad sindical", en AA.VV. Manual de Derecho Sindical, op. cit., pp. 407 y ss.

${ }^{268}$ STC 98/1985, de 29 julio, Fundamento jurídico primero: “... hemos de partir del dato de que si bien en principio el derecho de libertad sindical de los trabajadores stricto sensu y de los funcionarios en general se somete a un régimen legal unitario, criterio unitario que se continúa en el régimen de los respectivos sindicatos de unos y otros, pues tal fue la opción elegida por el legislador en la Ley Orgánica de Libertad Sindical (Exposición de Motivos, párrafo sexto y art. 1.2) la propia Ley, con pleno ajuste a la Constitución (artículo $28.1 \mathrm{CE}$ ), que habla de las peculiaridades del derecho de sindicación de los funcionarios públicos, prevé la posibilidad de un tratamiento diferencial en ciertos aspectos”, (RTC 1985198).
} 
Exposición de motivos señalaba lo siguiente: "Queda de esta forma, en virtud de la Ley Orgánica de Libertad Sindical, regulado el ejercicio del derecho de libre sindicación a los funcionarios públicos, sin otros límites que los expresamente establecidos en ella [...] es, consecuentemente, de aplicación directa a las Administraciones Públicas lo preceptuado en la Ley orgánica de Libertad Sindical en materia de libertad sindical, régimen jurídico sindical, representatividad sindical, acción sindical, tutela de la libertad sindical y represión de las conductas antisindicales”.

La LORAP señaló, en el artículo 1, como objeto de la misma "la regulación de los órganos de representación, la participación y los procedimientos de determinación de las condiciones de trabajo" del personal que prestara servicios en las distintas Administraciones Públicas, siempre que estuviera vinculado a las mismas a través de una relación de carácter administrativo o estatutario, incluido el personal al servicio de la Administración de Justicia. En el artículo 2 determinaba el personal excluido de su ámbito de aplicación (miembros de las Fuerzas armadas, jueces, magistrados, fiscales en activo, Cuerpos y Fuerzas de Seguridad, el personal laboral...).

Asimismo, esta ley trató los órganos de representación del personal para la defensa "de sus intereses ante las Administraciones públicas y otros Entes públicos": Delegados de Personal y Juntas de personal (art. 4), disponiendo la proporción de representantes a elegir en función del número de funcionarios representados; sus facultades, garantías y derechos y también las reglas sobre el procedimiento de elección de estos órganos (Capítulo II).

En el Capítulo III se abordó la participación en la determinación de las condiciones de trabajo (aún no el derecho a la negociación colectiva) en el que intervendrían exclusivamente los sindicatos, teniendo en cuenta los criterios sobre representatividad regulados en la LOLS. Y es que con la aprobación de la LORAP se evidenció para la doctrina el protagonismo que iban a tener en el ámbito de la Administración Pública las organizaciones sindicales en cuanto al ejercicio de la negociación colectiva ${ }^{269}$.

También se regularon las Mesas de negociación generales en el Estado, en cada Comunidad autónoma y en las entidades locales para la determinación de las condiciones de trabajo de los funcionarios de su ámbito, así como las Mesas sectoriales (art. 31.1), entre las que se encontraba la Mesa para el personal al servicio de las instituciones sanitarias públicas. La participación en las Mesas de negociación venía dada en función de la representatividad obtenida por las organizaciones sindicales en las elecciones a representantes del personal, exigiéndose bien la condición de sindicato más representativo a nivel estatal o de Comunidad autónoma, bien la obtención de un mínimo del 10\% de los representantes en las elecciones sindicales en un ámbito concreto. En el mismo Capítulo se regulaban las materias objeto de negociación obligatoria (art. 32), las que debían ser objeto de consulta (art. 33) y las excluidas de la obligatoriedad de la consulta o negociación (art. 34). Se regularon los conceptos de Acuerdo y Pacto (art. 35), su publicación (art. 36) y las consecuencias de la falta de acuerdo en la negociación (art. 37.2 y art. 38).

\footnotetext{
${ }^{269}$ DEL REY GUANTER, S., Comentarios a la Ley de Órganos de representación y determinación de las condiciones de trabajo y participación del personal al servicio de las Administraciones públicas, Ministerio para las Administraciones Públicas, Madrid, 1988, p.11.
} 
La participación institucional se materializaba a través del Consejo Superior de la Función Pública (Capítulo IV). Este se configuró como órgano superior de participación del personal al servicio de las Administraciones Públicas (en el que participaban diecisiete representantes designados por las organizaciones sindicales más representativas y por las que hubieran obtenido, al menos, el $10 \%$ de representantes del personal) existiendo la posibilidad de que las Administraciones públicas establecieran otros órganos colegiados para la participación de las organizaciones sindicales en las materias relacionadas con el régimen retributivo y de personal (art. 40).

En cuanto al derecho de reunión, este se reguló en el Capítulo V, artículos 41 a 43, en los que se trataba la legitimación para convocar reuniones, la forma y requisitos de las convocatorias, así como el derecho al uso de un local para los representantes sindicales y del personal y el tablón de anuncios. Le seguían cinco Disposiciones adicionales, siete transitorias y la Disposición final que calificaba determinados preceptos como norma básica en el sentido del artículo $149.1 .18^{\mathrm{a}} \mathrm{CE}$.

Ante la publicación de la LORAP, procedía la convocatoria de las primeras elecciones sindicales para la designación de los representantes de los funcionarios en el ámbito de la Administración del Estado, lo cual se llevó a cabo por Orden de 23 de julio de 1987, del Ministro de Administraciones Públicas, ya que la Disposición transitoria tercera de la ley había dispuesto que las elecciones se convocarían "en el plazo máximo de nueve meses, a partir de la entrada en vigor de la Ley, a propuesta de las Organizaciones Sindicales más representativas" ${ }^{\prime 270}$.

El Capítulo III de la LORAP sería años más tarde modificado por la Ley 7/1990, de 19 de julio, para incluir la mención expresa al derecho de negociación colectiva, la Mesa sectorial de negociación de las condiciones de trabajo del personal de la Administración Central e Institucional y de las Entidades Gestoras de la Seguridad Social (no de instituciones sanitarias, que ya existían) y una ampliación considerable de las materias objeto de negociación; entre ellas la del apartado h) del artículo 32, relativa a las propuestas sobre derechos sindicales y de participación, que se añadió a la que ya contemplaba el apartado e) del mismo artículo antes de esta reforma y que hacía mención a las materias de indole sindical.

En los años posteriores tuvieron lugar diversas reformas de la LORAP, las más importantes de las cuales vinieron dadas por la 18/1994, de 30 de junio, que implanta el sistema de medición continuada de la representatividad, la celebración de elecciones al fin de cada mandato representativo y la acreditación de la representatividad en el momento de ejercer las

\footnotetext{
${ }^{270}$ Esta convocatoria fue publicada en el BOE de 25 de julio de 1987. Las elecciones se convocaron a propuesta de CCOO, CSIF, ELA-STV y UGT. La citada Disposición también había previsto que "A partir de esta convocatoria, en el plazo de un mes las elecciones deberán convocarse por los órganos competentes de las CC.AA. y de las Entidades Locales. El mandato de los miembros de las juntas de personal y de los Delegados de Personal elegidos en la primera convocatoria finalizará como máximo el 31 de diciembre de 1990”.
} 
funciones correspondientes ${ }^{271}$; así como por la Ley 21/2006, de 20 de junio, que creó la Mesa General de Negociación de las Administraciones públicas ${ }^{272}$.

Actualmente, casi toda la LORAP ha sido derogada por la Disposición derogatoria única c) de la LEBEP ${ }^{273}$, que es la norma básica reguladora del régimen estatutario de los funcionarios públicos, al amparo del artículo 149.1.18 ${ }^{\mathrm{a}} \mathrm{CE}$, según su Disposición final primera. En esta ley la regulación sobre los derechos colectivos de los empleados públicos se contiene en los Capítulos I y IV del Título III ("Derechos y deberes: código de conducta de los empleados públicos").

En el Capítulo I se sitúa la regulación de los "derechos individuales de los empleados públicos, ejercidos colectivamente", en concreto, en el artículo 15 señala: "Los empleados públicos tienen los siguientes derechos individuales que se ejercen de forma colectiva: a) A la libertad sindical. b) A la negociación colectiva y a la participación en la determinación de las condiciones de trabajo. c) Al ejercicio de la huelga, con la garantía del mantenimiento de los servicios esenciales de la comunidad. d) Al planteamiento de conflictos colectivos de trabajo, de acuerdo con la legislación aplicable en cada caso. e) Al de reunión, en los términos establecidos en el artículo 46 de este Estatuto”.

En el Capítulo IV de la LEBEP se desarrolla el derecho a la negociación colectiva, la representación y participación institucional, regulando los principios generales aplicables al ejercicio de estos derechos para todos los empleados públicos (art. 31). Asimismo, se regula la negociación colectiva, la representación y la participación del personal laboral al servicio de las Administraciones públicas (art. 32). Seguidamente se contempla la negociación colectiva funcionarial y los requisitos de legitimación de las organizaciones sindicales para acceder a las Mesas de negociación (art. 33); las Mesas propias de los funcionarios de cada Administración territorial (Estado, CC.AA., Ceuta y Melilla y entidades locales) y las Mesas Sectoriales que dependen de estas (art. 34), así como su constitución y composición (art. 35). Las Mesas Generales de negociación, que tratan temas comunes a todo el personal con cualquier relación jurídica (art. 36); las materias objeto de negociación (art. 37) y los conceptos y efectos de los Acuerdos y Pactos (art. 38). También se concretan los órganos de representación unitaria de los funcionarios (art. 39), sus funciones y facultades (art. 40); las garantías de la función representativa del personal (art. 41); la duración del mandato representativo (art. 42); la promoción de elecciones sindicales (art. 43); el procedimiento electoral para dichas elecciones (art. 44) y

${ }^{271}$ BOE de 1 de julio de 1994.

${ }^{272}$ BOE de 21de junio de 2006.

${ }^{273}$ BOE de 13 de abril de 2007. No obstante, los apartados 1 y 2 del artículo 7 LORAP, que regulaban las unidades electorales, continuaron vigentes hasta que el Real Decreto Ley 20/2012 los ha derogado (Disposición derogatoria única, 4, apartado b). Asimismo, según su Disposición transitoria quinta se mantienen vigentes hasta que se publique la normativa correspondiente los artículos de la LORAP relativos al procedimiento electoral: "En tanto se determine el procedimiento electoral general previsto en el artículo 39 del presente Estatuto, se mantendrán con carácter de normativa básica los siguientes artículos de la Ley 9/1987, de 12 de junio, de Órganos de Representación, Determinación de las Condiciones de Trabajo y Participación del Personal al Servicio de las Administraciones Públicas: 13.2, 13.3, 13.4, 13.5, 13.6, 15, 16, $17,18,19,20,21,25,26,27,28$ y $29 "$. 
la solución extrajudicial de conflictos colectivos (art. 45), así como, por último, el derecho de reunión (art. 46).

Por lo que se refiere a los derechos colectivos del personal laboral al servicio de la Administración pública, hay que decir, de entrada, que su relación jurídica está tan matizada por el carácter del empleador en este caso, que la doctrina la ha llegado a considerar una relación laboral de carácter especial ${ }^{274}$.

El artículo 11.1 LEBEP a este respecto establece que: "Es personal laboral el que en virtud de contrato de trabajo formalizado por escrito, en cualquiera de las modalidades de contratación de personal previstas en la legislación laboral, presta servicios retribuidos por las Administraciones Públicas. En función de la duración del contrato éste podrá ser fijo, por tiempo indefinido o temporal”.

Tradicionalmente el régimen jurídico del personal laboral al servicio de las Administraciones públicas se regulaba por la misma normativa que la del resto de los trabajadores, a pesar de las dificultades de hacerla compatible con los principios de Derecho Administrativo a los que se debe someter la Administración Pública en su actuación. Sin embargo, desde la LEBEP se ha producido un cambio sustancial, consistente en aplicar con preferencia al personal laboral las normas específicas previstas en esa ley, que son legislación laboral, no administrativa ${ }^{275}$. Tal como señala la LEBEP en su Exposición de Motivos, la ley "contiene aquello que es común al conjunto de los funcionarios de todas las Administraciones Públicas, más las normas legales específicas aplicables al personal laboral a su servicio”.

Efectivamente, el artículo 1.2, que regula el objeto y ámbito de aplicación de la ley, aparte de establecer las bases del régimen estatutario de los funcionarios públicos incluidos en su ámbito de aplicación, dice que la misma tiene por finalidad "determinar las normas aplicables al personal laboral al servicio de las Administraciones Públicas”.

En consecuencia, al personal laboral de las Administraciones públicas se le aplicará la LEBEP y el resto de legislación laboral que proceda, teniendo en cuenta el sistema de fuentes laboral (art. 3.1 TRET) ${ }^{276}$. Así, el artículo 7 LEBEP dispone que: "El personal laboral al servicio de las Administraciones Públicas se rige, además de por la legislación laboral y por las demás normas convencionalmente aplicables, por los preceptos de este Estatuto que así lo dispongan”.

La remisión de la LEBEP a la legislación laboral y los Convenios colectivos es completa en algunas materias, como su clasificación (art. 77), la provisión de puestos y

\footnotetext{
${ }^{274}$ SALA FRANCO, T., "El personal laboral. La relación laboral especial de empleo público", en AAVV, Comentarios a la Ley del Estatuto Básico del Empleado Público, Lex Nova, Valladolid, 2007.

${ }^{275}$ El Estado es competente para ello en virtud de la competencia que le atribuye la CE en el artículo 149.1.7 ${ }^{\mathrm{a}}$

${ }^{276}$ Que establece: “Los derechos y obligaciones concernientes a la relación laboral se regulan: a) Por las disposiciones legales y reglamentarias del Estado. b) Por los convenios colectivos. c) Por la voluntad de las partes manifestada en el contrato de trabajo...
} 
movilidad (art. 83), así como las situaciones (art.92). Otras, sin embargo, vienen reguladas de forma específica en su texto para el personal laboral y su contenido es básicamente coincidente con las de los funcionarios: la limitación del incremento de las retribuciones según lo que establezca la ley de Presupuestos (art. 21.1); la regulación de la jornada de trabajo, permisos y vacaciones (art. 51); el régimen disciplinario (art. 93 y ss.) y los procedimientos de selección (art. 55.2) ${ }^{277}$.

Precisamente, la regulación de los derechos colectivos que realiza la LEBEP es común para todos los empleados públicos, tanto funcionarios -entre los que se encuentra el personal estatutario- como personal laboral (art. 15). También son comunes los principios generales sobre la negociación colectiva (art. 31), o la regulación de la Mesa General común de negociación (art. 36.3); así como la regulación del derecho de reunión (art. 46); aunque no lo son sus órganos de representación, que para el personal laboral vienen regulados en el Texto Refundido del Estatuto de los Trabajadores, aprobado por Real Decreto Legislativo 1/1995 de 24 de marzo (TRET): Delegados de Personal (art. 62) y Comité de empresa (art. 63). Estos preceptos están situados en el Título II del TRET, que contiene la regulación de los derechos de representación colectiva y de reunión de los trabajadores en la empresa. Los derechos de información y consulta y las competencias del Comité de empresa, su capacidad, sigilo profesional y composición se regulan en el artículo 64 y siguientes. El artículo 67 establece los preceptos legales sobre promoción de elecciones sindicales del personal laboral y mandato electoral de los representantes del personal. El artículo 68 trata las garantías de los miembros del Comité de empresa y Delegados de Personal; y por último, desde el artículo 69 al 76 se regula el procedimiento electoral sindical.

Por lo que respecta al derecho de reunión del personal laboral, se aplica la regulación específica para todos los empleados públicos que establece la LEBEP (art. 46).

Efectivamente, el régimen legal de los órganos de representación del personal funcionario y laboral es diferente y viene dado, como hemos visto, en la LEBEP en el primer caso y en el TRET en el segundo. Ello conlleva que el procedimiento de elección es diferente para el personal laboral que, al igual que para el resto de trabajadores, se tramita conforme al reglamento de elecciones a órganos de representación de los trabajadores en la empresa, aprobado por Real Decreto 1844/1994, de 9 de septiembre.

No obstante, los procesos electorales en la Administración pública suelen ser coincidentes para todos los empleados públicos del ámbito respectivo, ya que casi siempre se utiliza el mecanismo de la promoción generalizada de elecciones sindicales en uno o varios ámbitos funcionales y territoriales. Esta opción debe ser fruto de un acuerdo mayoritario entre los sindicatos más representativos y simplemente representativos en el ámbito de que se trate, y que posean, conjuntamente, una representatividad acreditada superior al 50\% de los representantes elegidos en el ámbito o ámbitos concretos a los que afecte la promoción de elecciones (art. 2.4 del Real Decreto 1844/1994 y art. 6 del Real Decreto 1846/1994). Por tanto, aunque el procedimiento de elecciones a órganos de representación del personal laboral sea diferente al de los funcionarios, ello no afecta a que las elecciones sindicales se celebren habitualmente en un marco conjunto.

\footnotetext{
${ }^{277}$ Si bien con alguna salvedad, como el concurso de valoración de méritos, que es exclusivo para el personal laboral (art. 61.7).
} 
Por lo que se refiere al personal estatutario de los Servicios de salud, hay que tener en cuenta la regulación que sobre esta materia se contiene en la LEM, como fuente de sus derechos colectivos, si bien en su mayor parte ahora resulta reiteración de lo dispuesto en la LEBEP para todos los funcionarios públicos.

En el Capítulo IV LEM, titulado “Derechos y deberes", se reconocen los derechos colectivos del personal estatutario, en los términos establecidos en la $\mathrm{CE}$ y en la legislación específicamente aplicable a los funcionarios públicos. Esta lista de derechos, regulada en el artículo 18, está formada por algunos que ya están reconocidos en la LOLS, en desarrollo de los artículos 7 y $28 \mathrm{CE}$ y que, por tanto, son comunes a todos los trabajadores y empleados públicos, así como por otros derechos específicos de los funcionarios públicos que hemos visto que recoge la LEBEP. Son los siguientes: a) libre sindicación. b) actividad sindical. c) huelga, garantizándose en todo caso el mantenimiento de los servicios que resulten esenciales para la atención sanitaria a la población. d) negociación colectiva, representación y participación en la determinación de las condiciones de trabajo. e) reunión. f) el derecho a disponer de servicios de prevención y de órganos representativos en materia de seguridad laboral.

A su vez, algunos de estos derechos se desarrollan en el Capítulo XIV de la LEM bajo el epígrafe "Representación, participación y negociación colectiva", en el que se regula la aplicación al personal estatutario en materia de representación, participación y negociación colectiva para la determinación de sus condiciones de trabajo, de las normas generales contenidas ahora en la LEBEP (art. 78); las Mesas sectoriales de negociación de los Servicios de salud (art. 79); y los Pactos y Acuerdos (art. 80).

Si comparamos la regulación que contiene el artículo 18 LEM con la más actual del artículo 15 LEBEP, podemos concluir que:

1.- En cuanto al derecho a la libre sindicación, este ya viene regulado en los artículos 28.1 CE y 2.1.a), b) y c), 2.2.a), b) y c) y 3 LOLS. Hemos visto que efectivamente esta regulación es común para todos los trabajadores en sentido amplio, y no presenta más que algunas excepciones en relación con determinados funcionarios públicos. Aunque la LEM considere este derecho como un derecho colectivo, el artículo 15 LEBEP matiza su carácter de derecho individual que se ejerce de forma colectiva.

2.- El derecho a la actividad sindical, regulado en los arts. 7 CE y 2.1.d), 2.2.d) y 8 a 11 de la LOLS, se reitera en el apartado b) del artículo 18 LEM, y se concreta, entre otras facultades, en la constitución de las secciones sindicales a través de las cuales se lleva a cabo la acción sindical en los centros de trabajo de las Administraciones públicas.

3.- El derecho fundamental a la huelga, artículo 18 c) LEM, que es un derecho del que dispone todo trabajador, sea laboral, funcionario o estatutario, consistente en la cesación del trabajo y que viene regulado en el artículo $28.2 \mathrm{CE}$. En el ámbito de los servicios públicos tiene la particularidad que señala el apartado c) del artículo 15 LEBEP, que insiste en la "... garantía del mantenimiento de los servicios esenciales de la comunidad”. En todo caso se garantiza el mantenimiento de los servicios sanitarios que resulten esenciales para la 
población $^{278}$, para lo cual se deberá dictar una norma reglamentaria acordando los servicios mínimos a prestar en todo caso, razonada y justificada, a efectos de su posible control jurisdiccional posterior.

Debemos tener en cuenta que, para todos los trabajadores y empleados públicos, el derecho de huelga viene regulado, aún, en el Real Decreto Ley 17/1977, de 4 de marzo, de Relaciones de Trabajo que exige el preaviso por escrito de la fecha de inicio, la duración, los objetivos de la huelga y la determinación de qué trabajadores componen el comité de huelga $^{279}$.

4.- El apartado d) del artículo 18 LEM trata sobre el derecho a la negociación colectiva, a la representación y a la participación en la determinación de las condiciones de trabajo del personal estatutario, derechos que son comunes para todos los funcionarios públicos y que tienen particularidades muy significativas que los distancian de los mismos derechos que se reconocen en el ámbito laboral a los trabajadores.

El derecho a la representación de los funcionarios se concreta en la elección, constitución y funcionamiento de sus órganos de representación unitarios, que son las Juntas y Delegados de Personal. A través de estos órganos unitarios se instrumenta la interlocución entre las Administraciones Públicas y sus empleados, no así la negociación colectiva, que queda reservada a las organizaciones sindicales que cumplan unos requisitos mínimos de representatividad. La regulación básica de esta materia la encontramos en los artículos 39 a 44 LEBEP, que tratan los órganos de representación del personal, su composición, funciones y legitimación, las garantías de la función representativa, duración del mandato, promoción de elecciones sindicales y el procedimiento electoral.

Por lo que se refiere a este, el procedimiento de celebración de elecciones sindicales viene dado por el Real Decreto 1846/1994, de 9 de septiembre, por el que se aprueba el Reglamento de elecciones a los órganos de representación del personal al servicio de la Administración General del Estado. Además, por lo que respecta a los procesos de elecciones sindicales tenemos que remitirnos a los Acuerdos que se celebran entre la Administración y las organizaciones sindicales promotoras de elecciones para su desarrollo.

5.- El derecho de reunión, del apartado e) de los artículos 18 LEM y 15 LEBEP, se deberá ejercer de acuerdo con lo regulado en el artículo 46 de esta última, que regula los sujetos legitimados para la convocatoria de reuniones: además de las organizaciones sindicales, directamente o a través de los delegados sindicales, los Delegados de Personal, las Juntas de Personal, los Comités de Empresa, y por último los empleados públicos de las Administraciones respectivas en número no inferior al 40 por 100 del colectivo convocado. Las reuniones en el centro de trabajo se autorizarán, como regla general, fuera de las horas

\footnotetext{
${ }^{278}$ Entendiendo por esenciales los que indica la STC 26/1981 de 17 de julio, (RTC 1981126), en su Fundamento jurídico décimo, que señala que "Para que el servicio sea esencial deben ser esenciales los bienes e intereses satisfechos. Como bienes e intereses esenciales hay que considerar los derechos fundamentales, las libertades públicas y los bienes constitucionales protegidos".

${ }^{279}$ El Proyecto de Ley Orgánica del derecho de Huelga presentado el 22 de mayo de 1992 al Congreso de los Diputados fue aprobado en este el 1 de abril de 1993, pero no llegó a completar su procedimiento parlamentario posterior a causa de la disolución anticipada de las Cortes para convocar elecciones generales.
} 
de trabajo, salvo acuerdo entre el órgano competente en materia de personal y quienes estén legitimados para convocarlas. La celebración de la reunión no perjudicará la prestación de los servicios y los convocantes de la misma serán responsables de su normal desarrollo.

6.- El derecho a disponer de servicios de prevención y de órganos representativos en materia de seguridad laboral, reconocido en el apartado f) del artículo 18 LEM, es la incorporación del derecho regulado en la Ley 31/1995, de 8 de noviembre, de Prevención de Riesgos Laborales. Incorpora lo dispuesto en el artículo 40.2 CE que regula, como un principio rector de la política social y económica, la obligación de los poderes públicos de velar por la seguridad e higiene en el trabajo y la salud de los trabajadores mediante la prevención de riesgos derivados de su trabajo ${ }^{280}$.

7.- Otro derecho colectivo de los empleados públicos que regula la LEBEP en los apartados 1 y 4 del artículo 31, es la participación institucional para la determinación de sus condiciones de trabajo, que ya no se realiza a través del Consejo Superior de la Función Pública $^{281}$. Supone el derecho a participar, a través de las organizaciones sindicales, en los órganos de control $\mathrm{y}$ seguimiento de las entidades $\mathrm{u}$ organismos que legalmente se determine.

Hay que tener en cuenta que el ejercicio de los derechos colectivos de los empleados públicos se garantiza y se lleva a cabo a través de los órganos y sistemas específicos regulados en la LEBEP, "sin perjuicio de otras formas de colaboración entre las Administraciones Públicas y sus empleados públicos o los representantes de éstos” (art. 31.5), y que en todo caso deberá respetar el contenido de esa ley y de sus leyes de desarrollo (art. 31.7).

\footnotetext{
${ }^{280}$ Sobre este derecho véase de VAZQUEZ GARRANZO, J., "El profesional sanitario al servicio de la Administración" en AAVV, Marco jurídico de las profesiones sanitarias, Lex Nova, Valladolid, 2007, p. 301.

${ }^{281}$ El Consejo Superior de la Función Pública, creado en su día por la LMRFP, fue suprimido por la LEBEP, tal como se argumenta en la Exposición de Motivos de esta: "dada la escasa operatividad que ha tenido este órgano y porque las funciones de que fue dotado hace más de veinte años han sido ya sustituidas en la práctica por la actividad de los órganos de coordinación entre el Estado y las CC.AA. y por las Mesas de Negociación y otras vías de participación de las organizaciones sindicales.”.
} 


\section{CAPITULO IV}

EL EJERCICIO DE LA NEGOCIACION COLECTIVA DEL PERSONAL ESTATUTARIO DE LOS SERVICIOS DE SALUD EN EL MARCO LEGAL DE LA NEGOCIACIÓN COLECTIVA FUNCIONARIAL 



\section{CAPITULO IV}

\section{EL EJERCICIO DE LA NEGOCIACION COLECTIVA DEL PERSONAL ESTATUTARIO DE LOS SERVICIOS DE SALUD EN EL MARCO LEGAL DE LA NEGOCIACIÓN COLECTIVA FUNCIONARIAL}

\section{1.- EL DERECHO A LA NEGOCIACIÓN COLECTIVA DE LOS FUNCIONARIOS PÚBLICOS}

El derecho a negociar las condiciones de trabajo de los trabajadores ha sido tradicionalmente una de las principales aspiraciones de las organizaciones sindicales, que tienen en esta facultad y en el ejercicio del derecho a la huelga sus principales herramientas de acción. El ejercicio de este derecho posibilita a los trabajadores, ya sean del ámbito privado o público, la participación activa en las decisiones que afectan a las condiciones de su prestación de servicios y actúa como garantía frente a la imposición de estas por parte del empleador.

Hoy día la negociación colectiva para la determinación de las condiciones de trabajo de los empleados públicos es una institución plenamente incorporada a nuestro ordenamiento jurídico, que ha producido un desarrollo muy ventajoso de sus derechos. Entre los factores que han contribuido a su consolidación como mecanismo para la determinación de su régimen jurídico cabe destacar el aumento de las plantillas de personal, que se produjo en nuestro país a partir de los años ochenta del siglo pasado, motivado por las nuevas atribuciones de competencias y actividad de las diferentes Administraciones públicas, en consecuencia con el crecimiento económico y demográfico del país.

La doctrina destaca el hecho de que la negociación colectiva es una conquista histórica de los trabajadores, superadora del paternalismo y la imposición en que se había movido el Derecho del Trabajo tradicional y que les permite consensuar las condiciones de prestación de sus servicios. Sin embargo, se plantean dudas sobre si es o no compatible esta institución con la formulación estricta de la teoría estatutaria que rige la función pública, ya que en esta la esencia se encuentra en la determinación unilateral de las condiciones de trabajo por parte de la Administración pública ${ }^{282}$.

En la $\mathbf{C E}$ la negociación colectiva se regula en el artículo 37, que se encuentra incluido en la Sección segunda, "De los derechos y deberes de los ciudadanos", del Capítulo II, "Derechos y libertades" del Título I, "De los Derechos y Deberes Fundamentales". Este precepto dispone: "1.- La ley garantizará el derecho a la negociación colectiva laboral entre los representantes de los trabajadores y empresarios, así como la fuerza vinculante de los convenios. 2. - Se reconoce el derecho de los trabajadores y empresarios a adoptar medidas de conflicto colectivo...".

${ }^{282}$ PALOMAR OlMEDA, A., Derecho de la Función Pública, Dykinson, Madrid, 1996, p. 639. 
La protección jurídica que tiene este derecho constitucional es la general de los derechos y deberes regulados en la Sección segunda del Capítulo II, que a diferencia de los de la Sección primera, entre los que se encuentra la libertad sindical, no disponen de la protección automática del recurso de amparo ante el TC, ni del procedimiento judicial sumario y preferente ante los Tribunales ordinarios, pero sí de tutela de acuerdo con su ley de desarrollo, así como de la posibilidad de presentar recurso y cuestión de inconstitucionalidad contra la ley que los regule, en el caso de que su contenido se considere contrario a la CE. Actualmente este derecho encuentra su desarrollo legal en el TRET, que dedica el Título III (arts. 82-92) a regular la negociación colectiva y los convenios colectivos en el ámbito laboral común ${ }^{283}$.

En cuanto al derecho a la negociación colectiva de los empleados públicos, vimos antes que este se regula en la LEBEP como un derecho individual de ejercicio colectivo (art. 15), que es hasta tal punto importante que, además, fundamenta la actuación de las Administraciones públicas, según el artículo 1.3 k) LEBEP: "Este Estatuto refleja, del mismo modo, los siguientes fundamentos de actuación [...] k) Negociación colectiva y participación, a través de los representantes, en la determinación de las condiciones de empleo". En la Exposición de motivos de esta ley se dice también que: "La negociación colectiva de los funcionarios públicos y del personal laboral, en los términos que contempla el presente Estatuto, habrá de contribuir finalmente a concretar las condiciones de empleo de todo el personal al servicio de la Administración, como ya sucede en la actualidad".

Este derecho viene definido en esta ley como "el derecho a negociar la determinación de condiciones de trabajo de los empleados de la Administración Pública (art. 31.2), y se predica de "los empleados públicos", tanto sean laborales como funcionarios (art. 31.1 LEBEP). Se desarrolla en los artículos 32 a 38, y se caracteriza por una serie de particularidades que lo diferencian del derecho a la negociación reconocido a los trabajadores.

En la LEM el derecho a la negociación colectiva viene reconocido para el personal estatutario de los Servicios de salud en los artículos 4 k), 18 d) y 78 y siguientes, remitiéndose en lo fundamental a lo regulado en la LEBEP sobre la negociación colectiva funcionarial.

Antes de continuar conviene recordar que, por lo que se refiere a la negociación colectiva del personal laboral en la Administración pública, esta ha dado tradicionalmente como fruto un Convenio colectivo, al igual que sucede entre los trabajadores y sus empresarios. En la LEBEP, la negociación colectiva del personal laboral de la Administración pública se regula en el primer párrafo del artículo 32, junto con los derechos a la representación y participación, estableciendo que estos se regirán por la legislación laboral, sin perjuicio de los preceptos de aquella que expresamente le son de aplicación. El

\footnotetext{
${ }^{283}$ En los últimos años del régimen preconstitucional la Ley 18/1973, de 19 de diciembre reguló los Convenios colectivos sindicales, sustituyendo a la de 24 de abril de 1958.
} 
Capítulo IV. El ejercicio de la negociación colectiva del personal estatutario de los Servicios de salud en el marco legal de la negociación colectiva funcionarial

resultado de la negociación en este caso será un Convenio colectivo, que se someterá en su regulación al Título III del TRET $^{284}$.

La negociación conjunta de las condiciones de trabajo del personal funcionario incluido el estatutario- y laboral, se lleva a cabo en las Mesas de negociación comunes, que vienen reguladas en el artículo 36.3 LEBEP, y tiene para el personal laboral los efectos que prevé el artículo 38.8: "Los Pactos y Acuerdos que, de conformidad con lo establecido en el artículo 37, contengan materias y condiciones generales de trabajo comunes al personal funcionario y laboral, tendrán la consideración y efectos previstos en este artículo para los funcionarios y en el artículo 83 del Estatuto de los Trabajadores para el personal laboral”.

\subsection{1.- ORIGEN Y REGULACIÓN LEGAL DE LA NEGOCIACIÓN COLECTIVA FUNCIONARIAL}

En cuanto a los antecedentes de la negociación colectiva en el ámbito de la función pública hay que decir que la primera norma con rango legal en nuestro ordenamiento jurídico que la admitió fue la LMRFP. En su Exposición de motivos declaró: "Se aborda en esta Ley una reforma en profundidad de las competencias en materia de personal [...] muy particularmente, en un aspecto específicamente novedoso, cuál es el de la negociación de las condiciones de empleo de los funcionarios públicos”. Y en su artículo 3.1, entre las competencias del Gobierno, señaló que: "2. Corresponde en particular al Gobierno: [...] b) Determinar las instrucciones a que deberán atenerse los representantes de la Administración del Estado cuando proceda la negociación con la representación sindical de los funcionarios públicos de sus condiciones de empleo, así como dar validez y eficacia a los Acuerdos alcanzados mediante su aprobación expresa y formal, estableciendo las condiciones de empleo para los casos en que no se produzca acuerdo en la negociación" y c) Establecer las instrucciones a que deberá atenerse la representación de la Administración del Estado en la negociación colectiva con el personal sujeto al derecho laboral".

Aunque la doctrina destaca algunas carencias de esta norma (ya que no concretó qué organizaciones sindicales tendrían legitimación para llevar a cabo la negociación, ni los supuestos ni materias sobre las que esta debería recaer) no deja de tener su relevancia porque, si bien no realiza una regulación pormenorizada de la negociación colectiva de los funcionarios, sí aporta las primeras pinceladas de una futura regulación de la materia y es el precedente de la regulación que unos pocos años después se llevaría a cabo ${ }^{285}$.

$\mathrm{Y}$ es que para que fuera posible el reconocimiento del derecho a la negociación colectiva a favor de los funcionarios públicos fue determinante la corriente internacional a

\footnotetext{
${ }^{284}$ Aunque el artículo 87.1 TRET legitima a los representantes unitarios del personal y a los sindicales para la negociación de los Convenios colectivos de empresa, en el ámbito de la Administración General del Estado o de cualquier Comunidad autónoma, los representantes unitarios carecen de capacidad negociadora y la legitimación para negociar la tienen las organizaciones sindicales, según el apartado 2 del mismo artículo.

${ }^{285}$ SALA FRANCO, T. y ROQUETA BUJ, R., Los derechos sindicales de los funcionarios públicos..., op. cit. p. 225 y ss. ROQUETA BUJ, R., La negociación colectiva en la función pública..., op. cit. p. 76.
} 
su favor, que se plasmó en la adopción de los Convenios de la OIT n ${ }^{\circ} 151$, sobre protección del derecho de sindicación y procedimientos para la determinación de condiciones de empleo en la Administración pública, y $\mathrm{n}^{\mathrm{o}} 154$ sobre negociación colectiva, que fueron ratificados por España en 1984 y 1985 respectivamente ${ }^{286}$.

En 1987 se publicó la LORAP, y esta en su Capítulo III abordó la participación en la determinación de las condiciones de trabajo de los funcionarios públicos, pero fue la Ley 7/1990, de 19 de julio, negociada a su vez entre el Gobierno y las organizaciones sindicales más representativas, la que, además de referirse expresamente a la negociación colectiva de los funcionarios públicos, completó la regulación de la LORAP con un mecanismo efectivo de determinación de sus condiciones de trabajo, ampliando asimismo el ámbito de las materias sujetas a negociación.

Actualmente la regulación de la negociación colectiva funcionarial, que incluye al personal estatutario de los Servicios de salud como funcionario especial que es, se encuentra en los artículos 33 a 38 LEBEP.

\subsection{2.- DOCTRINA DEL TRIBUNAL CONSTITUCIONAL SOBRE LA NEGOCIACIÓN COLECTIVA DE LOS FUNCIONARIOS PÚBLICOS}

Para entender la institución de la negociación colectiva funcionarial es imprescindible referirnos a la doctrina del TC. Esta admite que, si bien el derecho fundamental a la libertad sindical que reconoce la $\mathrm{CE}$ ampara a todos, trabajadores y funcionarios, de igual forma, y que el régimen jurídico sindical que establece la LOLS es general y único para todo tipo de trabajadores y organizaciones sindicales, cuando se trata del derecho a la negociación colectiva la cosa cambia.

El TC considera que el derecho a la negociación colectiva que reconoce el citado artículo $37 \mathrm{CE}$ es el de los trabajadores vinculados por el régimen jurídico laboral y en él no están incluidos los funcionarios públicos. Según su criterio, el derecho a la negociación colectiva laboral forma parte del contenido esencial del derecho a la libertad sindical (art. 28.1) ya que hace efectivo el papel que reconoce la $\mathrm{CE}$ a los sindicatos en el artículo 7; es más: "La exclusión de un sindicato de la negociación colectiva laboral supone de hecho la exclusión de su función de participación [...] que es una de sus funciones esenciales" ${ }^{287}$.

\footnotetext{
${ }^{286}$ Convenios cuyo contenido tendrá en cuenta tiempo después el artículo 31.8 LORAP: “Los procedimientos para determinar condiciones de trabajo en las Administraciones Públicas tendrán en cuenta las previsiones establecidas en los Convenios y Acuerdos de carácter internacional ratificados por España”.

${ }^{287}$ STC 73/1984, de 27 de junio, Fundamento jurídico cuarto, (RTC 198473). En el mismo sentido la STC 4/1983, de 28 de febrero, Fundamento jurídico tercero:"...el derecho que reconoce el artículo 28 es el de que las organizaciones sindicales libremente creadas desempeñen el papel y las funciones que a los sindicatos de trabajadores reconoce el artículo 7 CE, de manera que participen en la defensa y protección de los intereses de los trabajadores...”, (RTC 1983\4). STC 107/2000, de 5 de mayo: “...como repetidamente ha declarado nuestra jurisprudencia, la libertad sindical comprende el derecho a que los sindicatos realicen las funciones que de ellos es dable esperar, de acuerdo con el carácter democrático del Estado y con las coordenadas que a esta institución hay que reconocer, a las que se puede sin dificultad denominar contenido esencial de tal derecho; parte de este núcleo del artículo 28.1 CE lo constituye, sin duda, la negociación colectiva de condiciones de trabajo, puesto que resulta inimaginable que sin ella se logre desarrollar eficazmente las
} 
A pesar de que el derecho a la negociación colectiva laboral tenga su reconocimiento constitucional y que se incluya en el ámbito del contenido esencial del de libertad sindical, ello no significa que, necesariamente y en todo caso, la tutela de cualquier infracción del derecho a la negociación colectiva se pueda realizar por la vía del recurso de amparo. Este solo es viable si se aprecia una eventual lesión del derecho fundamental a la libertad sindical, la cual se producirá, entre otros supuestos, en el caso de que se impida a los sindicatos "ejercer aquellas actividades dirigidas a la defensa, protección y promoción de los intereses de los trabajadores, en suma, a desplegar los medios de acción necesarios para que puedan cumplir las funciones que constitucionalmente les corresponden",288.

Pero por lo que se refiere a la negociación colectiva de los funcionarios públicos, el TC entiende que esta no tiene un reconocimiento constitucional expreso, sino que es un derecho de creación legal, que no emana del artículo $37 \mathrm{CE}$, sino directamente de la ley. Por ello, en cuanto a la tutela jurídica de la negociación colectiva funcionarial, esta se debe exigir de acuerdo con el procedimiento contencioso administrativo ante los Tribunales de ese orden, tal como vimos cuando se trató la tutela de la libertad sindical, por razón de los sujetos a los que afecta. Sin embargo, en el supuesto de que se excluya a un sindicato de esa negociación, vulnerando su derecho fundamental a la libertad sindical, siguiendo la doctrina del TC, tendrá abierta la vía de amparo, con la misma protección constitucional que la negociación colectiva laboral ${ }^{289}$.

En definitiva, la jurisprudencia constitucional defiende que el derecho a la negociación colectiva de los funcionarios no pertenece al contenido esencial del derecho fundamental a la libertad sindical, sino al contenido adicional, puesto que es un derecho de creación legal, a diferencia del derecho a la negociación colectiva del personal laboral sometido al TRET, al que se refiere el artículo $37 \mathrm{CE}$, pero no niega la protección constitucional en los casos en los que una organización sindical quede excluida del libre ejercicio de la acción sindical ${ }^{290}$.

Entre la doctrina científica hay dos principales posturas. Algunos autores se adscriben a la tesis llamada de "ausencia de tratamiento constitucional". Esta defiende la idea de que los funcionarios, o más bien sus organizaciones sindicales, disponen del derecho a la negociación colectiva solo porque se les reconoce en la ley, y está por tanto sometido a los cambios que el legislador pueda decidir en cada momento. Dentro de esta corriente doctrinal se sitúa Del Rey Guanter que entiende que la CE ni admite ni impide la negociación colectiva de los funcionarios públicos, sino que se remite a la regulación que la

finalidades recogidas en el artículo 7 CE...”, (RTC 2000\107). Otras en el mismo sentido: STC 108/1989, (RTC 1989\108); STC 208/1993, (RTC 1993\208); STC 58/1985, (RTC 1985 58).

${ }^{288}$ STC 108/2008, de 22 de septiembre, (RTC 2008\108).

${ }^{289}$ STC 222/2005, de 12 septiembre: “... el derecho a la negociación colectiva de los funcionarios públicos, aisladamente considerado, no constituye un derecho fundamental tutelable en amparo; no obstante, cuando afecta a la actividad del sindicato se integra como contenido adicional del derecho a la libertad sindical", (RTC 2005\222).

${ }^{290}$ STC 80/2000, de 27 de marzo, (RTC 2000, 80). 
ley establezca sobre la materia ${ }^{291}$. También es esta la postura más extendida en la jurisprudencia, según la que el derecho a la negociación funcionarial debe ajustarse a las disposiciones de la ley que lo regulen, con sus límites, presupuestos y excepciones, y no deriva directamente de la $\mathrm{CE}^{292}$.

Sin embargo, en la doctrina hay otra corriente divergente a la anterior y favorable a entender el derecho a la negociación colectiva de los funcionarios como parte del contenido esencial del derecho fundamental a la libertad sindical. Esta considera la facultad de las organizaciones sindicales de negociar las condiciones de trabajo de sus representados, sean laborales o funcionarios públicos, como derivación del artículo 28.1 CE, y a ella se adhieren autores como Sala Franco o Roqueta Buj, que argumentan que, si bien es cierto que la CE no reconoce en ningún precepto expresamente el derecho a la negociación colectiva de los funcionarios públicos, este se puede entender incluido en el de libertad sindical en su vertiente funcional, porque la negociación colectiva es un medio necesario para el ejercicio de la acción sindical que reconocen los artículos 7 y 28.1 CE a los sindicatos; es más, es su función principal ${ }^{293}$.

Esto no significa que la tutela jurídica del derecho a la negociación colectiva funcionarial sea la del derecho fundamental en todo caso, ya que en la CE este derecho no dispone del cuadro de garantías privilegiado y doblemente reforzado propio de los derechos fundamentales y libertades públicas, aunque ello no impide que goce de las garantías propias de toda norma constitucional y que vincule a todos los poderes públicos ${ }^{294}$. La protección constitucional del derecho a la negociación colectiva funcionarial deberá darse si la vulneración afectara al contenido esencial del derecho; es decir, si se lesionara el derecho a ejercitar la defensa de los intereses que el sindicato defiende en cuanto tal.

El riesgo de la postura de ausencia de tratamiento constitucional, en nuestra opinión, es que si partimos de la idea de que la negociación colectiva funcionarial es meramente un derecho de creación legal, sin conexión constitucional, hay que aceptar, en consiguiente, que por la mera decisión del legislador ordinario se elimine, o se suspenda indefinidamente, el derecho a la negociación colectiva de las organizaciones sindicales para determinar las condiciones de trabajo de los funcionarios.

En cualquier caso, no parece justificado que la actividad de los sindicatos merezca menos protección cuando se realiza por cuenta del personal con relación jurídicoadministrativa que cuando lo es en representación de personal con relación jurídico laboral. Recordemos que el ejercicio del derecho a la negociación colectiva de los funcionarios se

${ }^{291}$ DEL REY GUANTER, S., Estado, sindicatos y negociación colectiva en la Función pública, op. cit., pp. 110 y ss.

${ }^{292}$ El TS entiende el derecho a la negociación colectiva funcionarial no como un derecho derivado de la CE, sino solo de la ley. Esta jurisprudencia se mantiene en la STS de 20 de enero de 1995, (RJ 1995\609).

${ }^{293}$ SALA FRANCO, T., ROQUETA BUJ, R., Los derechos sindicales de los funcionarios públicos... op.cit. p. 224.

${ }^{294}$ ROQUETA BUJ, R., La negociación colectiva en la función pública ..., op. cit., p. 71. 
atribuye a las organizaciones sindicales y son estas las que la llevan a cabo, no los funcionarios directamente, ni sus órganos de representación. Incluso en el caso de que un sindicato solo represente intereses funcionariales y no tenga casi implantación, o la tenga escasa, en el ámbito privado, como es el caso de determinados sindicatos que operan en el ámbito de la sanidad pública, su función constitucional probablemente queda vacía de contenido sin la facultad de la negociación colectiva. Si en el ámbito funcionarial las organizaciones sindicales no pudieran intervenir para conseguir la mejora de las condiciones laborales de los funcionarios mediante la negociación colectiva, entonces ¿a qué papel se les relegaría?

Y es que por lo que a la negociación colectiva de los funcionarios se refiere son las organizaciones sindicales las únicas legitimadas para llevarla a cabo, siempre que cumplan determinados requisitos de audiencia electoral basados en su capacidad representativa, de acuerdo con la LOLS. Y esto a pesar de que, literalmente, la LEBEP atribuya a los empleados públicos la titularidad del derecho a la negociación colectiva como un derecho individual de ejercicio colectivo (art.15 y 31.1) o la LEM diga que es un derecho colectivo del personal estatutario (art. 18).

Hay que atender al conjunto de la normativa implicada para concluir que el ejercicio de este derecho está encomendado con exclusividad a los sindicatos y los funcionarios no pueden ejercitarlo por sí mismos ni a través de sus órganos de representación ${ }^{295}$. Por ello, si la finalidad última de la elección de los representantes del personal en nuestro ordenamiento es la de atribuir la representatividad sindical a las organizaciones sindicales a las que pertenecen para que puedan llevar a cabo, entre otras facultades, la negociación colectiva, de la que ellos carecen ¿qué sentido tendría esa elección si el legislador ordinario suprimiera este derecho? ${ }^{296}$.

Es más, ¿de qué sirve que los funcionarios ejerzan el derecho a la huelga, que sí les reconoce el artículo 28.2 CE, si con ello no se puede conseguir el objetivo de ese recurso extremo que no es más que ejercer presión para la negociación? ¿Resultaría eficaz a los funcionarios la afiliación sindical a unas organizaciones que difícilmente podrían mejorar sus condiciones de trabajo si el legislador suprime el derecho a la negociación colectiva?

En nuestra opinión, la diferencia fundamental es que si se considera la negociación colectiva de los funcionarios como parte del contenido esencial del derecho fundamental a la libertad sindical del artículo 28.1 CE, si se considera su relación constitucional, su ley reguladora deberá respetar este contenido y, si bien el legislador ordinario podrá modificarlo y adaptarlo a las circunstancias del momento, no podrá eliminarlo por sí del ordenamiento jurídico.

\footnotetext{
${ }^{295}$ Las Juntas de Personal y Delegados de Personal no tienen atribuida por la ley la capacidad de negociación (art. 39.1 en relación con el art. 40 LEBEP) a diferencia de los órganos de representación unitaria de los trabajadores en la empresa (art. 87 TRET).

${ }^{296}$ Sobre los sujetos titulares del derecho a la negociación colectiva véase LAHERA FORTEZA, J., La titularidad de los derechos colectivos de los trabajadores y funcionarios, Consejo Económico y Social, 2000, p. 115 y ss.
} 


\subsection{3.- PRINCIPIOS DE LA NEGOCIACIÓN COLECTIVA FUNCIONARIAL}

Respecto al ejercicio del derecho a la negociación colectiva en el ámbito funcionarial hay que tener en cuenta que le afectan una serie de peculiaridades que regula la ley, que vienen dadas por la exigencia de que la negociación se produzca en el seno de unos órganos concretos, que son las Mesas de negociación, entre sujetos legitimados de acuerdo con los requisitos que se exigen y a través de un procedimiento dado, inspirado en una serie de principios. Algunos de estos principios tienen un origen constitucional y vienen después desarrollados en la ley, como los de legalidad, jerarquía normativa, publicidad, o cobertura presupuestaria; otros, en cambio, vienen contemplados directamente en la ley, como el principio de buena fe en la negociación. De cualquier manera, prácticamente todos ellos son también aplicables a la negociación colectiva de la Administración pública con su personal laboral.

Para empezar, son principios que limitan el marco de la negociación colectiva funcionarial el principio de reserva de ley, así como el de legalidad, ambos conectados entre sí. El de reserva de ley implica que la regulación de determinadas materias se debe hacer en todo caso por norma con rango de ley, y se recoge en el artículo 103.3 CE, que la exige precisamente para la regulación del régimen estatutario de los funcionarios públicos ${ }^{297}$ : "La ley regulará el estatuto de los funcionarios públicos, el acceso a la función pública de acuerdo con los principios de mérito y capacidad, las peculiaridades del ejercicio de su derecho a sindicación, el sistema de incompatibilidades y las garantías para la imparcialidad en el ejercicio de sus funciones".

Hay que matizar que lo que este precepto constitucional dispone es que estas materias deben ser finalmente reguladas por norma con rango de ley, pero su contenido no solo puede ser negociado previamente, sino que debe serlo, porque el artículo $37.1 \mathrm{k}$ ) LEBEP establece la obligatoriedad de negociación sobre las materias que afecten a las condiciones de trabajo y a las retribuciones de los funcionarios cuya regulación exija norma con rango de ley. Ahora bien, esta negociación no tendrá efectos por sí sola, requiriéndose en todo caso la aprobación por los órganos legislativos correspondientes (art. 38.3 LEBEP).

Por su parte, los principios de legalidad y jerarquía normativa se contemplan en el artículo 9.3 CE: "La Constitución garantiza el principio de legalidad, la jerarquía normativa, la publicidad de las normas...".

El primero somete a todas las instituciones, ciudadanos y Administración pública a la CE y a la ley, el segundo, es consecuencia del anterior, y prohíbe que el contenido de una

\footnotetext{
${ }^{297}$ La STC 99/1987, de 11 de junio, que, en interpretación del artículo 103.3 CE, determina que están reservadas a la ley las siguientes materias: 1) el Estatuto de los funcionarios públicos, pero no todos los aspectos de este sino solo la adquisición y pérdida de la condición de funcionario, las condiciones de promoción en la carrera administrativa y las situaciones administrativas, derechos y deberes y responsabilidad de los funcionarios y el régimen disciplinario; la creación e integración de Cuerpos y Escalas funcionariales y la provisión de puestos de trabajo al servicio de las Administraciones Públicas; 2) el acceso a la función pública de acuerdo con los principios de mérito y capacidad; 3 ) las peculiaridades del ejercicio de su derecho a sindicación; 4) el sistema de incompatibilidades y las garantías para la imparcialidad en el ejercicio de sus funciones.
} 
norma de rango inferior, como puede ser Pacto, un Acuerdo o un Convenio colectivo, la $\operatorname{contradigan}^{298}$.

Si bien no se trata de disposiciones administrativas, la aplicación de este principio para la doctrina judicial conlleva que el contenido de los Acuerdos y Pactos no puede contradecir lo establecido en la ley y, a su vez, la ley puede modificar, suspender o suprimir lo dispuesto en ellos. Además, en el caso de concertar un Acuerdo, al requerir lo acordado la aprobación del órgano de gobierno de la Administración pública competente, lo convenido se incorpora como norma reglamentaria al ordenamiento jurídico, y las instrucciones de orden interno o las circulares, o cualquier otra norma reglamentaria de rango inferior, deberán respetar su contenido ${ }^{299}$. Sin embargo, la aplicación del principio no debe ser tan estricta que comprometa la posibilidad de que la negociación colectiva funcionarial llegue a término ${ }^{300}$.

En la negociación colectiva funcionarial también hay que tener en cuenta el principio de cobertura presupuestaria de las obligaciones que se asuman en la negociación ${ }^{301}$, teniendo en cuenta, además, que las Administraciones públicas adecuarán sus actuaciones al principio de estabilidad presupuestaria y, por tanto, no podrán incurrir en un déficit

${ }^{298}$ El principio de jerarquía normativa de las disposiciones administrativas se desarrolla en el artículo 51 LRJPAC: “1. Las disposiciones administrativas no podrán vulnerar la Constitución o las Leyes ni regular aquellas materias que la Constitución o los Estatutos de Autonomía reconocen de la competencia de las Cortes Generales o de las Asambleas Legislativas de las Comunidades Autónomas.2. Ninguna disposición administrativa podrá vulnerar los preceptos de otra de rango superior.3. Las disposiciones administrativas se ajustarán al orden de jerarquía que establezcan las leyes”.

299 STSJ de Canarias de 15 de enero de 1997, Fundamento jurídico segundo: los Acuerdos de personal estatutario, puesto que se dan en el ámbito de la función pública, deben someterse al principio de jerarquía normativa, (AS 199\174). En el mismo sentido la STSJ del mismo órgano, de 26 de junio de 1996, (AS 19962342):

${ }^{300}$ STSJ de Cantabria de 23 de abril de 1992: “...Una negociación que solo pudiera versar válidamente sobre materias no reguladas en normas de rango superior quedaría vacía de contenido alguno porque todas las condiciones de trabajo de los funcionarios se rigen por normas reglamentarias formalmente superiores a las negociadas, que, además, podrían ser posteriormente invalidadas por aquellas, incluso por una Orden Ministerial, si hubiesen de entenderse sometidas al referido principio. En su consecuencia, deben afirmarse aplicables criterios no esencialmente dispares de los que lo son a los Convenios Colectivos laborales, que en este punto consisten, muy resumidamente, en su vigencia y aplicabilidad como normas resultantes de la concorde voluntad negociadora colectiva en cuanto establezcan condiciones de trabajo más favorables para los asalariados que las fijadas por disposiciones estatales, apreciadas en su conjunto, y en cómputo anual respecto de conceptos susceptibles de esta última contemplación, a salvo el respeto de la legalidad imperativa. No resultarán tan precisos en el orden de los servicios administrativos como en el ámbito laboral, probablemente, los mínimos legales de Derecho necesario que hayan de superarse a través de los Pactos y Acuerdos, y seguramente será más extensa y precisará ser menos imperativa la legalidad inderogable por la negociación funcionarial, lo que implicará tan solo la atenuación y adaptación de los principios que irrenunciablemente han de serle propios, según lo expuesto”, (AS 1992\1941).

${ }^{301}$ STS de 23 de marzo de 1994, (RJ 19942626); STSJ de Canarias de 27 de febrero de 1996, Fundamento jurídico segundo: “... la fijación de cualquier concepto retributivo (en un Acuerdo o Pacto) devengable por el personal estatutario o de otra naturaleza que preste sus servicios para entes públicos, está sujeto a las disponibilidades presupuestarias, sin que esté permitido sobrepasar el tope máximo señalado en cada caso", (AS 1996254). En el mismo sentido: STSJ de Canarias de 2 de septiembre de 1996, (AS 19963430). 
Capítulo IV. El ejercicio de la negociación colectiva del personal estatutario de los Servicios de salud en el marco legal de la negociación colectiva funcionarial

estructural que supere los márgenes establecidos, en su caso, por la Unión Europea para sus Estados Miembros (art. $135 \mathrm{CE}$ ).

Recordemos que la Administración tiene como límite la dotación económica en las correspondientes partidas presupuestarias que resulten afectadas por lo convenido en el Pacto o Acuerdo. La responsabilidad de la elaboración de los Presupuestos es del legislador estatal o autonómico, por lo que este límite escapa a la voluntad de las partes negociadoras y en todo caso actúa como marco de la negociación. Un aspecto de este principio o límite se contiene también en el artículo 21.2 LEBEP: "No podrán acordarse incrementos retributivos que globalmente supongan un incremento de la masa salarial superior a los límites fijados anualmente en la Ley de Presupuestos Generales del Estado para el personal”.

Por su parte, el artículo 33.1 LEBEP establece que la negociación colectiva de condiciones de trabajo de los funcionarios públicos estará sujeta a los principios de legalidad, cobertura presupuestaria, obligatoriedad, buena fe, publicidad y transparencia, y que se efectuará mediante el ejercicio de la capacidad representativa reconocida a las organizaciones sindicales en los artículos 6.3.c); 7.1 y 7.2 de la LOLS y lo previsto en la LEBEP $^{302}$.

Respecto al principio de buena fe, este viene reconocido en el artículo 34.7 LEBEP: "Ambas partes estarán obligadas a negociar bajo el principio de la buena fe y proporcionarse mutuamente la información que precisen relativa a la negociación”.

Este principio, de particular importancia, exige que se dé no solo una apariencia de negociación sino que implica que se produzca realmente un intento de aproximar posturas entre las partes implicadas. En este sentido, diferentes resoluciones judiciales han declarado que la negociación colectiva funcionarial es algo más que el acuerdo final a que, en su caso, aquella pueda conducir, consistiendo antes que en este, en la propia actuación negociadora $^{303}$. La exigencia de la buena fe en la negociación conlleva la prohibición de obstruirla acudiendo a medios de presión mientras el proceso de diálogo está en marcha; se exige el intento serio y razonado de llegar a acuerdos sobre el objeto de la negociación, es decir, la veracidad de la negociación, no su mera apariencia, para intentar alcanzar el

\footnotetext{
${ }^{302}$ Estos principios, que en su momento no reguló la LORAP, han sido elaborados a lo largo del tiempo por la jurisprudencia y finalmente incorporados a la LEBEP.

${ }^{303}$ La STSJ de Castilla-La Mancha de 14 de febrero de 2005, sobre la existencia de una negociación previa al margen de la Mesa Sectorial, de la Administración con solo algunos sindicatos, ha declarado que no son equiparables las negociaciones en el seno del colegio y las negociaciones separadas, y por tanto, que no se satisface el derecho a la negociación colectiva de una organización sindical mediante la negociación alternativa del Sindicato con la Administración al margen de la Mesa de negociación. Ello porque la negociación colectiva es algo más que el acuerdo final a que en su caso se pueda llegar, consistiendo, antes que en este, "en la propia actuación negociadora y en las deliberaciones por medio de las que se va realizando”, (JUR 2005 91843). En el mismo sentido la STSJ de Castilla y León de 5 de diciembre de 2012, sobre la negociación de los calendarios laborales de personal estatutario del Servicio de salud de Castilla y León, (JUR 2013\32090).
} 
acuerdo $^{304}$. Los mismos principios de buena fe y voluntad negociadora aparecen reflejados en el artículo 80.3 LEM.

El principio de obligatoriedad de la negociación, por otra parte, implica que la Administración está obligada a negociar con los sindicatos en todos aquellos aspectos contemplados en la ley como materia objeto de negociación (art. 37 LEBEP). Con este principio se garantiza que la regulación de las condiciones de trabajo de los funcionarios establecidas en este precepto no puede ser sustituida, al menos directamente, por la voluntad unilateral de la Administración.

Ello es porque se entiende que la negociación tiene carácter imperativo se alcance o no un resultado, y da igual que se requiera o no el refrendo del órgano de gobierno sobre lo pactado; se deben sentar las partes a negociar. En el caso de que no haya existido negociación sobre una materia de obligada negociación, la consecuencia es la sanción de nulidad del acto o disposición en cuya elaboración se haya omitido este requisito formal, de carácter esencial para la correcta formación de voluntad del órgano autor de la norma, si bien, cuando intentada la negociación esta fracasa, cabe que la Administración decida la regulación correspondiente, como veremos más adelante.

Por el mismo motivo señala la doctrina que si la Administración llegase a elaborar un reglamento que contuviera disposiciones contrarias a lo previamente acordado, esa norma será declarada nula porque se considera la negociación como una fase fundamental del procedimiento de elaboración de las normas reglamentarias ${ }^{305}$. En el mismo sentido se manifiesta la jurisprudencia, que interpreta que la negociación de estas materias es una condición previa para dictar las disposiciones pertinentes.

Así se expresó la STS de 18 de octubre de 1995, dictada en proceso de tutela del derecho fundamental a la libertad sindical en un supuesto en que se excluyó a CEMSATSE de un Acuerdo de la Mesa sectorial de Sanidad del Servicio Valenciano de Salud sobre retribuciones de su personal que derivó en la aprobación por el Gobierno valenciano del Decreto 169/1990 de 15 de octubre, declarado finalmente nulo ${ }^{306}$.

304 FERnANDEZ, J.J., AGRA VIFORCOS, B., ALVAREZ CUESTA, H., Derechos colectivos de los funcionarios públicos, Bosch, Barcelona, 2006, p. 114.

${ }^{305}$ CANTERO MARTINEZ, J., "La negociación colectiva en el ámbito de la función pública", en AA.VV., Régimen jurídico de la función pública, Lex Nova, Valladolid, 2013.

${ }^{306}$ Fundamento jurídico tercero: “... en el caso de que en el desarrollo de la negociación colectiva hubiera sido vulnerada la libertad sindical de alguno de los sindicatos intervinientes, debemos entender que el procedimiento seguido por la Administración para ejercer su competencia normativa aparece viciado por la violación de un derecho fundamental, lo que determina que por esta razón formal sea nula la disposición afectada”, (RJ 1995\7566). También la STSJ de La Rioja 347/2012 de 21 noviembre, (RJCA 2013\28), basándose en la STS de 13 de octubre de 2010, (RJ 2010 7244), en relación con la impugnación del Acuerdo del Consejo de Gobierno de 29 de diciembre de 201, por el que se adoptan medidas de planificación en materia de Recursos Humanos para los años 2012 y 2013, que considera insuficiente que la Administración informe a las organizaciones sindicales presentes en la Mesa General de Negociación la víspera de la publicación en el Boletín Oficial de La Rioja y en consecuencia el Acuerdo es nulo por no haber existido negociación previa de su contenido en la Mesa. 
Sobre la consideración de estos principios aplicables a la negociación colectiva es de obligada referencia la SAN de 7 de noviembre de 2000, sobre la congelación de las retribuciones de los funcionarios públicos ${ }^{307}$. Esta resolución judicial elaboró una fundada argumentación a favor de la negociación colectiva funcionarial, pero posteriormente fue anulada por la STS de 21 de marzo de 2002, que determinó la supeditación de los Acuerdos a la ley $y^{308}$.

Por último, son obligados también los principios de publicidad y transparencia, que se traducen en la obligación de que los Pactos y Acuerdos funcionariales se remitan a la Oficina Pública y se publiquen en el Diario Oficial correspondiente (art. 38.6 LEBEP).

Con la aplicación de estos principios se pretende impedir la negociación de cláusulas ocultas al resto de sindicatos no participantes en la negociación y al conjunto de los empleados públicos. La obligación de publicidad y transparencia se debe extender al contenido y al procedimiento de la negociación, incluyendo el conocimiento de las actas de las reuniones entre las partes que se deben hacer públicos por cualquier medio que permita su difusión.

La aplicación a la negociación colectiva funcionarial de todos estos principios es esencial para conseguir un resultado válido. En este sentido, la STSJ de Castilla-La Mancha de 5 de octubre de $2004^{309}$, relativa a la selección de personal estatutario temporal a través de la bolsa de trabajo, declaró que: “... el ámbito de las materias a negociar queda condicionado por la vinculación de la Administración al principio de reserva legal, por la vinculación a la ley, por la observancia de ciertos principios constitucionales y la naturaleza y posición institucional de la Administración pública como servidora objetiva del interés general”.

\subsection{4.- PARTICULARIDADES DE LA NEGOCIACIÓN COLECTIVA DEL PERSONAL ESTATUTARIO DE LOS SERVICIOS DE SALUD}

La negociación colectiva del personal estatutario de los Servicios de salud no contiene más que algunas peculiaridades en relación con la regulación general que establece actualmente la LEBEP, que es desde luego más exhaustiva. Esto es lo que dispone el artículo 78 LEM, que regula los criterios generales de la representación, participación y negociación colectiva del personal estatutario, remitiéndose a lo que disponía en su día la LORAP: "Resultarán de aplicación al personal estatutario las normas generales contenidas en la Ley 9/1987, de 12 de junio, de Órganos de Representación, Determinación de las Condiciones de Trabajo y de Participación del personal al Servicio de las

\footnotetext{
307 (RJCA 2000 2585). A favor de los argumentos de la SAN de 7 de noviembre 2000 véase de MARIN ALONSO, I., "La congelación salarial de los funcionarios públicos mediante determinación unilateral del correspondiente ministro para las Administraciones Públicas a propósito de la SAN de 7 noviembre 2000", AS $n^{\circ}$ 20/2000, (BIB 2001\311).

${ }^{308}$ (RJ 2002\4318).

${ }^{309}$ (JUR 2004286138).
} 
Capítulo IV. El ejercicio de la negociación colectiva del personal estatutario de los Servicios de salud en el marco legal de la negociación colectiva funcionarial

Administraciones Públicas, y disposiciones de desarrollo, con las peculiaridades que se establecen en la LEM”.

Como peculiaridades sí destacan, por una parte, la existencia del Foro Marco para el Diálogo social (art. 11); las Mesas Sectoriales de Sanidad como foros particulares de negociación del personal estatutario en cada uno de los Servicios de salud autonómicos (art. 79.2 LEM), o la determinación del área de salud como unidad electoral habitual a los efectos de la constitución de las secciones sindicales y del órgano de representación unitario del personal estatutario: la Junta de Personal.

Asimismo, hay que tener en cuenta que determinadas materias, como son los sistemas de carrera profesional del personal estatutario, o la regulación de la evaluación del desempeño en el ámbito sanitario, así como la regulación de los procedimientos de selección de personal estatutario temporal para la cobertura de las necesidades de contratación de personal en instituciones sanitarias; o los mecanismos de retribución de la jornada complementaria, como las guardias médicas o la atención continuada, son aspectos muy particulares y específicos del régimen jurídico del personal en el ámbito público sanitario, que no tienen en común con el resto de los funcionarios de sus Administraciones autonómicas, y por tanto, difícilmente se pueden abordar en el ámbito de las Mesas de negociación generales.

\section{2.- EL RESULTADO DE LA NEGOCIACIÓN: PACTOS Y ACUERDOS}

La negociación colectiva de los funcionarios públicos se plasma en Pactos y Acuerdos. Respecto a estos, el artículo 38.1 LEBEP dispone: "En el seno de las Mesas de Negociación correspondientes, los representantes de las Administraciones Públicas podrán concertar Pactos y Acuerdos con la representación de las Organizaciones Sindicales legitimadas a tales efectos, para la determinación de condiciones de trabajo de los funcionarios de dichas Administraciones".

\subsection{1.- CONCEPTO Y NATURALEZA JURÍDICA DE LOS PACTOS Y ACUERDOS. MATERIAS DE NEGOCIACIÓN OBLIGATORIA Y MATERIAS EXCLUIDAS DE LA NEGOCIACIÓN}

El concepto y las notas características de los Pactos y Acuerdos se regularon en el artículo 35 LORAP $^{310}$, cuyo contenido ha pasado de forma similar al actual 38.2 LEBEP: "Los Pactos se celebrarán sobre materias que se correspondan estrictamente con el ámbito competencial del órgano administrativo que lo suscriba y se aplicarán directamente al personal del ámbito correspondiente”.

\footnotetext{
${ }^{310}$ Con el siguiente tenor: "Los Pactos se celebrarán sobre materias que se correspondan estrictamente con el ámbito competencial del órgano administrativo que lo suscriba y vincularán directamente a las partes. Los Acuerdos versarán sobre materias competencia del Consejo de Ministros, Consejos de Gobierno de CC.AA. $u$ órganos correspondientes de las Entidades Locales. Para su validez y eficacia será necesaria la aprobación expresa y formal de estos órganos en su ámbito respectivo”.
} 
Por otra parte, el concepto de Acuerdo se recoge en el apartado 3 del mismo artículo: "Los Acuerdos versarán sobre materias competencia de los órganos de gobierno de las Administraciones Públicas. Para su validez y eficacia será necesaria su aprobación expresa y formal por estos órganos. Cuando tales Acuerdos hayan sido ratificados y afecten a temas que pueden ser decididos de forma definitiva por los órganos de gobierno, el contenido de los mismos será directamente aplicable al personal incluido en su ámbito de aplicación, sin perjuicio de que a efectos formales se requiera la modificación o derogación, en su caso, de la normativa reglamentaria correspondiente".

En la LEM, el artículo 80.1, bajo el título "Pactos y Acuerdos" establece los mismos conceptos, pero referidos a la negociación colectiva del personal estatutario: "En el seno de las Mesas de negociación, los representantes de la Administración o Servicio de salud y los representantes de las organizaciones sindicales podrán concertar Pactos y Acuerdos. Los Pactos, que serán de aplicación directa al personal afectado, versarán sobre materias que correspondan al ámbito competencial del órgano que los suscriba. Los Acuerdos se referirán a materias cuya competencia corresponda al órgano de gobierno de la correspondiente Administración pública y, para su eficacia, precisarán la previa, expresa y formal aprobación del citado órgano de gobierno".

Del análisis de ambos preceptos, concluimos las principales notas diferenciadoras de Pactos y Acuerdos:

$1^{\mathrm{a}}$.- Los Pactos los puede negociar y suscribir el titular del órgano administrativo con competencia en la materia de que se trate. En los Acuerdos, la competencia para vincularse por ellos corresponde al órgano de gobierno de la correspondiente Administración Pública.

$2^{\text {a }}$ - Los requisitos formales de aprobación para su eficacia; más estrictos para los Acuerdos que para los Pactos, porque se obliga a intervenir al órgano de gobierno correspondiente en el acto de su aprobación mediante la ratificación ${ }^{311}$.

En cuanto a la naturaleza jurídica de los Pactos y Acuerdos, esta cuestión no termina de estar zanjada en la jurisprudencia. Así, la STS de 17 de marzo de 2005 se refiere a los Pactos y Acuerdos como "productos convencionales, instrumentos, productos propios de la negociación colectiva en el ámbito de la función pública, que regula la Ley 9/1987”. Acerca de la resolución que inscribe y publica el Pacto impugnado considera que "constituye una disposición administrativa de carácter general o cuando menos un acto administrativo dictado para dar cumplimiento al Pacto" 312 .

\footnotetext{
311 Sobre la interpretación de estos conceptos véase la STSJ de Andalucía de 18 de abril de 1994, (AS 19941655) y la del mismo órgano jurisdiccional de 20 de octubre de 1997. Esta última dice: "Pactos y Acuerdos como fórmulas a alcanzar en la negociaciones entre los representantes de las Administraciones Públicas y las organizaciones sindicales. Los primeros se celebran sobre materias que se corresponden estrictamente con el ámbito competencial del órgano administrativo que lo suscribe, en tanto que los segundos versan sobre materias que son competencia del Consejo de Ministros, Consejo de Gobierno de las CC.AA. [...] los Pactos vinculan directamente a las partes, mientras que los Acuerdos quedan sometidos para su validez y eficacia a la necesaria aprobación expresa y formal de los órganos mencionados, lo cual es lógico si se tiene en cuenta que quien los negocia carece de competencia para obligarse respecto de dichas materias", (AS 199入4701).
}

312 (RJ 2005 3877). 
Entre la doctrina también hay variedad de opiniones. Algún administrativista mantiene que los Acuerdos y Pactos son modalidades de terminación convencional del procedimiento administrativo, legitimadas en último extremo por el artículo 88 de la Ley 30/1992, de 26 de noviembre, de Régimen Jurídico y Procedimiento administrativo común $(\text { LRJ-PAC) })^{313}$.

Por su parte, Alfonso Mellado entiende que los Pactos y Acuerdos no ponen fin a un procedimiento administrativo, ya que por su naturaleza el procedimiento administrativo se dirige a la producción de actos administrativos, y los Acuerdos y Pactos no lo hacen. Además, los efectos de estos instrumentos convencionales no tienen lugar solo para los sujetos que intervienen en la negociación, sino también para todos los funcionarios del ámbito de representación de los sujetos negociadores. Según este autor, la verdadera naturaleza jurídica de los Pactos y Acuerdos no es la de contratos administrativos ni privados de la Administración, tampoco se trata de un derecho de participación o consulta en la elaboración de disposiciones de carácter general, sino que su naturaleza jurídica es singular; se trata de contratos colectivos normativos: contratos por su origen, norma por su eficacia jurídica. Incluso aunque para los Acuerdos sea necesario el acto posterior de aprobación del órgano de gobierno, ya que este es prácticamente obligado si se han respetado los requisitos de la negociación ${ }^{314}$.

Para Palomar Olmeda, el concepto de Pacto que da la LEBEP, con eficacia directa, se asimila al de Convenio colectivo en el ámbito laboral; y por el contrario, los Acuerdos carecen de eficacia vinculante directa porque las materias sobre las que recaen son competencia de los órganos de gobierno en unos casos, y en otros, están reservadas a la $\operatorname{ley}^{315}$.

\footnotetext{
${ }^{313}$ DE PALMA DEL TESO, A., Los Acuerdos procedimentales en el Derecho Administrativo, Tirant lo Blanch, Valencia, 2000. Esta autora los concibe como instrumentos negociales para el ejercicio paccionado de potestades administrativas, configurados por la ley como mecanismo preferente y alternativo a la actuación unilateral de la Administración, y previstos en el artículo 88 de la LRJ-PAC, que establece: "Las Administraciones Públicas podrán celebrar Acuerdos, Pactos, convenios o contratos con personas tanto de derecho público como privado, siempre que no sean contrarios al ordenamiento jurídico ni versen sobre materias no susceptibles de transacción y tengan por objeto satisfacer el interés público que tienen encomendado, con el alcance, efectos y régimen jurídico específico que en cada caso prevea la disposición que lo regule, pudiendo tales actos tener la consideración de finalizadores de los procedimientos administrativos o insertarse en los mismos con carácter previo, vinculante o no, a la resolución que les ponga fin. Los citados instrumentos deberán establecer como contenido mínimo la identificación de las partes intervinientes, el ámbito personal, funcional y territorial, y el plazo de vigencia, debiendo publicarse o no según su naturaleza y las personas a las que estuvieran destinados. Requerirán en todo caso la aprobación expresa del Consejo de Ministros los Acuerdos que versen sobre materias de la competencia directa de dicho órgano. Los Acuerdos que se suscriban no supondrán alteración de las competencias atribuidas a los órganos administrativos o de las responsabilidades que correspondan a las autoridades y funcionarios relativas al funcionamiento de los servicios públicos".
}

314 ALFONSO MELLADO, C.L., Los Derechos Colectivos de los empleados públicos en el Estatuto Básico, Bomarzo, Albacete, 2008, p. 41.

${ }^{315}$ PALOMAR OLMEDA, A., El nuevo Estatuto del Empleado Público, Aranzadi, Navarra, 2007, p. 86. 
Sobre el contenido mínimo de los Pactos y Acuerdos, hay que tener en cuenta lo dispuesto en el artículo 38.4 LEBEP, que regula lo que podríamos llamar su estructura formal, de modo que tienen que determinar las partes que los conciertan, el ámbito personal, funcional, territorial y temporal, así como la forma, plazo de preaviso y condiciones de denuncia de los mismos.

En cuanto al contenido material de los Pactos y Acuerdos, la negociación colectiva funcionarial tiene como objeto determinadas materias de negociación obligatoria, que se regulan en el artículo 37.1 LEBEP, y de forma específica para el personal estatutario en el artículo 80.2 LEM, que expresamente indica: "Serán objeto de negociación, en su ámbito respectivo y en relación con las competencias de cada Administración Pública y con el alcance que legalmente proceda en cada caso, las materias siguientes...”.

Por lo que se refiere a las materias objeto de negociación, la doctrina ha destacado la conveniencia de ser interpretadas de forma amplia ${ }^{316}$, y efectivamente habrá que realizar una labor de interpretación individual de cada una de ellas por el elevado nivel de complejidad en su regulación que ha introducido la LEBEP, principalmente a la hora de determinar a qué tipo de mesa corresponde su negociación ${ }^{317}$.

El listado de materias de negociación obligatoria lo encontramos detallado en el artículo 37.1 LEBEP, para los empleados públicos en el "ámbito respectivo y en relación con las competencias de cada Administración Pública y con el alcance que legalmente proceda en cada caso", y en el artículo 80.2 LEM, específicamente para el personal estatutario de los Servicios de salud, en el que se reiteran algunos puntos de los anteriores. Este segundo precepto recoge y adapta para el personal de ese ámbito la relación de materias que en su día establecía la LORAP, vigente en el momento de publicarse la LEM.

A la relación de materias que recoge el artículo 37.1 LEBEP hay que añadir otras que encontramos a lo largo de su articulado, como es la que se refiere al incremento global de las retribuciones del personal al servicio de las Administraciones Públicas que corresponda incluir en el Proyecto de Ley de Presupuestos Generales del Estado de cada año, que se debe negociar en el ámbito de la Mesa General de Negociación de las Administraciones Públicas (art. 36.2 segundo párrafo) y el establecimiento y modificación de unidades electorales (art. 39.4).

Asimismo, la LEM también establece otras materias de negociación obligada, además de las que se contienen en el artículo 80.2, como son: la normativa básica que afecte al personal estatutario y que elabore el Ministerio de Sanidad en el Foro Marco para el

\footnotetext{
${ }^{316}$ Para ROQUETA BUJ, el contenido posible de la negociación debe interpretarse en sentido amplio, y comprenderá, no solo las condiciones en que tiene lugar la prestación del trabajo, sino el que el legislador decida dentro del respeto al conjunto de las normas constitucionales, respetando, claro está el principio de reserva de ley. El derecho a la negociación colectiva en el Estatuto Básico del Empleado público..., op.cit., p. 55.

${ }^{317}$ LINDE PANIAGUA, E., "Notas sobre la naturaleza, el ámbito y el desarrollo del Estatuto Básico del Empleado Público, en AA.VV., El Estatuto Básico del Empleado Público y su desarrollo por el Estado y las CC.AA, Colex, Madrid, 2008, pp. 37-41.
} 
Diálogo Social (art. 11.4); los Planes de Ordenación de Recursos Humanos (art. 13.2); la elaboración de los sistemas de agrupamiento y enumeración de puestos de trabajo (art. 14.2); la determinación de los procedimientos de selección y provisión de puestos de trabajo de personal fijo y temporal (art. 29.1 f) y 33); la elaboración de la normativa sobre carrera profesional (art. 40.1); la determinación de las categorías profesionales que deban realizar jornada complementaria (art.48.1); así como la regulación de la jornada y descansos diarios (art. 51).

El conjunto de materias de obligada negociación probablemente admite diversas clasificaciones, una de las cuales podría distinguir entre las materias que estén o no sometidas a reserva de ley, como lo están las retribuciones básicas de los empleados públicos (apdo. a del art. 37 LEBEP), o los demás aspectos de las condiciones de trabajo que deban ser reguladas por norma con rango de ley (apdo. k). También se puede distinguir entre aquellas sobre las que cabe negociar tan solo los criterios generales (como es el caso de las ofertas de empleo público, del apdo. 1; la materia de acción social, del apdo. i y la determinación de prestaciones sociales y pensiones de clases pasivas, del apdo. g del mismo precepto $^{318}$ ).

Entre todas estas materias de obligada negociación, y por lo que interesa al objeto de este estudio, destaca la regulada en el apartado h) del artículo 37.1 LEBEP ("las propuestas sobre derechos sindicales y de participación"), que coincide con la del apartado j) del artículo 80.2 LEM ("las propuestas sobre la aplicación de los derechos sindicales y de participación") y tienen la misma redacción del apartado h del derogado artículo 32 LORAP, según la modificación operada por la Ley 7/1990, que lo introdujo ${ }^{319}$.

Lo que llama la atención es que la materia de derechos sindicales de los funcionarios y del personal estatutario deba ser negociada a nivel de propuesta, lo cual nos lleva a preguntarnos qué significado le ha dado el legislador a esa expresión. Teniendo en cuenta que cabe interpretar el concepto de propuesta en este contexto como un planteamiento, no definitivo, que deberá ser aceptado por el órgano con competencia para su aprobación definitiva, no parece tener ningún sentido que la ley emplee esa expresión para referirse a una materia sobre la que cabe perfectamente un Pacto entre las partes, vinculante desde el mismo momento de su firma.

De cualquier forma, parece el legislador ha tenido especial sensibilidad para entender en un sentido favorable al ejercicio de la negociación colectiva del personal estatutario la materia sindical, sobre todo teniendo en cuenta que el apartado 2 letra k) del artículo 80 de la LEM contiene una norma "de atracción” de la negociación, disponiendo la negociación obligatoria también de "en general, cuantas materias afecten a las

\footnotetext{
${ }^{318}$ Apartado, por cierto, muy criticado por la doctrina, ya que parece permitir que las prestaciones del régimen público de Seguridad social se lleven a una mesa de negociación. PALOMAR OLMEDA, A., El nuevo Estatuto del Empleado Público, op.cit., p. 87.

${ }^{319}$ El artículo 32 LORAP contemplaba en el listado de materias de negociación obligatoria el apartado e) relativo, entre otras, a las materias de índole sindical. La reforma de la Ley 7/1990 añadió a aquel precepto este apartado h) que se refiere a las propuestas sobre derechos sindicales y participación, manteniendo también el otro como apartado $\mathrm{k}$ ).
} 
Capítulo IV. El ejercicio de la negociación colectiva del personal estatutario de los Servicios de salud en el marco legal de la negociación colectiva funcionarial

condiciones de trabajo y al ámbito de relaciones del personal estatutario y sus organizaciones sindicales con la Administración pública o el Servicio de salud”.

En definitiva, la materia derechos y garantías sindicales era con la LORAP, y es ahora igualmente, una de las de obligada negociación, según el artículo 37.1 h) LEBEP $^{320}$ y 80.2.j) LEM, lo que implica que se trata de una negociación colectiva obligatoria para la Administración, no pudiendo dictar norma alguna sobre estas materias sin haberla intentado previamente.

También vienen dadas en la ley una serie de materias excluidas de la obligatoriedad de la negociación, que la LORAP ya trató en su momento en el artículo 34.1, y que ahora se regulan en el apartado 2 del artículo 37 de la LEBEP y en el apartado 4 del artículo 80 LEM, que establece: " Quedan excluidas de la obligatoriedad de negociación las decisiones de la Administración pública o del Servicio de salud que afecten a sus potestades de organización, al ejercicio de derechos por los ciudadanos y al procedimiento de formación de los actos y disposiciones administrativas".

\subsection{2.- LOS DERECHOS SINDICALES DEL PERSONAL ESTATUTARIO COMO MATERIA OBJETO DE NEGOCIACIÓN COLECTIVA}

Cuando la LEBEP y la LEM establecen que los derechos sindicales es una materia de negociación obligada ¿A qué derechos se refieren? ¿Son los derechos sindicales sinónimo de derechos colectivos? ¿Es posible el desarrollo de los derechos colectivos de los funcionarios y del personal estatutario a través de la negociación colectiva? ¿Las normas que reconocen estos derechos son normas de mínimos?

Para dar respuesta a estas cuestiones entendemos que hay que concretar en primer lugar qué se entiende por derechos sindicales, y diferenciarlos, si procede, del concepto de derechos colectivos, porque no hay que perder de vista que la ley, literalmente, reconoce como materia de obligada negociación a los primeros y no habla de derechos colectivos (art. $37.1 \mathrm{~h}$ ) LEBEP y art. 80.2 j) LEM).

La doctrina no es uniforme cuando trata el concepto de derechos sindicales, ya que encontramos autores que identifican ese concepto con el de derechos colectivos, y otros que no. Así, Sala Franco y Roqueta Buj incluyen en la clasificación de derechos sindicales de los funcionarios públicos: la libertad sindical, el derecho de representación colectiva, el de representación sindical, el de representación sindical, la acción institucional, la participación en la determinación de las condiciones de trabajo, la huelga y el planteamiento de conflictos

\footnotetext{
320 Son las siguientes: "a) Las decisiones de las Administraciones Públicas que afecten a sus potestades de organización. Cuando las consecuencias de las decisiones de las Administraciones Públicas que afecten a sus potestades de organización tengan repercusión sobre condiciones de trabajo de los funcionarios públicos contempladas en el apartado anterior, procederá la negociación de dichas condiciones con las Organizaciones Sindicales a que se refiere este Estatuto. b) La regulación del ejercicio de los derechos de los ciudadanos y de los usuarios de los servicios públicos, así como el procedimiento de formación de los actos y disposiciones administrativas. c) La determinación de condiciones de trabajo del personal directivo. d) Los poderes de dirección y control propios de la relación jerárquica. e) La regulación y determinación concreta, en cada caso, de los sistemas, criterios, órganos y procedimientos de acceso al empleo público y la promoción profesional".
} 
$\operatorname{colectivos}^{321}$.

Es más, para Roqueta Buj las materias de índole sindical deben entenderse como actuación colectiva de los funcionarios públicos y sus representantes, tanto de los unitarios como de los sindicales ${ }^{322}$, con lo que el contenido que abarcan es abierto ${ }^{323} \mathrm{y}$, por lo mismo, inconcreto. Parece que esta es también la postura la OIT, que utiliza el concepto de derechos sindicales en sentido amplio y aboga por potenciar su desarrollo en el ámbito de la Administración pública ${ }^{324}$. En la misma línea podemos considerar la jurisprudencia del Tribunal de Justicia de la Unión Europea cuando ha tratado el principio fundamental de no discriminación por razón de la nacionalidad en el ejercicio de los derechos sindicales, entendidos más bien como sinónimo de libertad sindical ${ }^{325}$.

Por el contrario, Manzana Laguarda opina que los derechos colectivos y los sindicales no son sinónimos, sino que los primeros son aquellos derechos que posee el funcionario en cuanto integrante de un colectivo y encaminados a la defensa de sus intereses en cuanto tal, sin perjuicio de los aspectos individuales que conlleva su disfrute y, por el contrario, la expresión derechos sindicales está referida específicamente a la participación de los sindicatos como tales, no de los funcionarios ${ }^{326}$.

En la LEBEP, en su Exposición de Motivos, se mencionan los derechos sindicales y los colectivos, y respecto a los primeros, señala la competencia del Estado para regular los aspectos intrínsecamente vinculados a su ejercicio, considerando entre estos los de representación y el procedimiento electoral. Más adelante vuelve a referirse a los derechos sindicales en el artículo $95.2 \mathrm{k}$ ) que tipifica como falta muy grave "la obstaculización al ejercicio de las libertades públicas y derechos sindicales ${ }^{, 327}$.

También la LEM menciona los derechos sindicales en el supuesto regulado en el artículo $72.2 \mathrm{n}$ ), para tipificar como falta disciplinaria muy grave "los actos dirigidos a

${ }^{321}$ SALA FRANCO, T. y ROQUETA BUJ, R., Los derechos sindicales..., op. cit. índice.

${ }^{322}$ ROQUETA BUJ, R., La negociación colectiva en la función pública, op.cit., p. 303.

${ }^{323}$ ROQUETA BUJ, R., El derecho de negociación colectiva en el Estatuto Básico del Empleado Público, La Ley, 2007, p. 345.

324 Véase La negociación colectiva en el ámbito de la Administración pública: un camino a seguir, Conferencia Internacional del Trabajo, 102 a reunión, 2013 [en línea], [consulta de 18 de junio de 2014], disponible en: 〈http: Ilwww.ilo.org>.

${ }^{325}$ Sentencia del Tribunal de Justicia de la Unión Europea de 18 de mayo de 1994.

326 MANZANA LAGUARDA, R., Derechos y deberes de los funcionarios públicos, Tirant lo Blanch, Valencia, 1996, p. 221, nota al pie n' 359.

${ }^{327}$ Con idéntica expresión a la que utilizó la LORAP en su momento en el artículo 31.1 i) de la LMRFP se tipificaba como falta muy grave en el régimen disciplinario de los funcionarios "La obstaculización al ejercicio de las libertades públicas y derechos sindicales”. 
Capítulo IV. El ejercicio de la negociación colectiva del personal estatutario de los Servicios de salud en el marco legal de la negociación colectiva funcionarial

impedir o coartar el libre ejercicio de los derechos fundamentales, las libertades públicas y los derechos sindicales".

Para aclarar conceptos se puede traer a colación el Acuerdo AdministraciónSindicatos 2003-2004 para la modernización y mejora de la Administración Pública, en cuyo Título VII bajo el epígrafe "Medidas destinadas a mejorar el marco de las relaciones laborales" se establece que: "Se regularán de forma integrada y unitaria los derechos y garantías sindicales que se reconocen en el ámbito de la Administración General del Estado para facilitar el desarrollo de la acción sindical”, ${ }^{228}$.

En este sentido hay que hacer notar que las propias organizaciones sindicales suelen utilizar la expresión derechos sindicales para referirse a las facultades, garantías y derechos relacionados con la actividad de los representantes sindicales y representantes unitarios del personal; es decir, con el ejercicio del derecho a la acción sindical ${ }^{329}$.

Este concepto es también el que recogen los Acuerdos y Pactos de los empleados públicos referidos a esta materia y que son objeto de este estudio, por lo que en nuestra opinión, este es precisamente el concepto de derechos y garantías sindicales más ajustado: el que se circunscribe a los derechos, facilidades y garantías de las organizaciones sindicales, de los representantes sindicales y de los del personal para llevar a cabo la acción sindical $^{330}$, y por tanto, no se debe confundir con el concepto más amplio de derechos colectivos.

El Acuerdo de la Mesa General de Negociación de la Administración General del Estado sobre asignación de recursos y racionalización de las estructuras de negociación y participación, de 29 de octubre de $2012^{331}$, argumenta que: "La aplicación de estas normas (la LORAP, la LEBEP) así como de los sucesivos Pactos que en esta materia se han venido produciendo en diversos ámbitos orgánicos, funcionales y territoriales, que en principio podrían considerarse como una mejora en el ejercicio de los derechos sindicales..."; más adelante, el texto del Acuerdo dice que en aplicación del Real Decreto Ley 20/2012 "han dejado de tener validez y surtir efectos todos los Pactos, Acuerdos y Convenios colectivos que establecían derechos adicionales a favor de las organizaciones sindicales”.

Entendemos, por tanto, que los derechos colectivos de los empleados públicos, y del personal estatutario en particular, son los que determina el legislador y que hemos visto que regulan los artículos 15 LEBEP y 18 LEM, y que no todos pueden ser objeto de negociación colectiva en el ámbito funcionarial; no pueden serlo, por ejemplo, los derechos

\footnotetext{
${ }^{328}$ BOE de 18 de noviembre de 2002.

${ }^{329}$ CC.OO, Código de utilización de los derechos sindicales, Consejo Confederal de CC.OO [en línea] 17 a 18 abril de 2012 [consulta de 20 de abril de 2013], disponible en: 〈http:|lwww.ccoo.es〉.

${ }^{330}$ Como ejemplo, el Acuerdo de 10 de abril de 2006 sobre desarrollo de la acción sindical en el ámbito de la Administración de las Islas Baleares (art. 1.1), Boletín Oficial de las Islas Baleares de 15 de abril de 2006.

${ }^{331}$ BOE de 14 de noviembre de 2012.
} 
Capítulo IV. El ejercicio de la negociación colectiva del personal estatutario de los Servicios de salud en el marco legal de la negociación colectiva funcionarial

fundamentales a la libertad sindical o a la huelga, que requieren para su regulación de una ley orgánica (art. 81.1 CE).

La negociación colectiva sobre derechos sindicales y de participación puede ampliar los derechos y garantías sindicales que reconoce la LOLS, la LEBEP o la LEM, pero solo en la medida en que estas lo permiten. Por ello, se pueden desarrollar determinados aspectos sobre la constitución de secciones sindicales; los requisitos para la designación de los delegados sindicales o la determinación de su número; el crédito horario para actividad sindical que tienen estos; el derecho al uso de los locales sindicales; el tablón de anuncios o el correo interno, que son garantías para el ejercicio de la acción sindical.

También por Pacto o Acuerdo se puede ampliar el crédito horario de los representantes del personal para ejercer funciones de representación sindical, cuestión que regula la LEBEP; se pueden concretar las condiciones de ejercicio del derecho de reunión, o regular detalladamente el régimen de funcionamiento de las Comisiones paritarias de seguimiento de los Pactos y Acuerdos para el conocimiento y resolución de los conflictos derivados de su interpretación y aplicación, con base en el artículo 38.5 LEBEP. Asimismo, se puede negociar sobre la determinación de las unidades electorales, en las que se constituyen los órganos de representación unitarios del personal, con los efectos correspondientes en cuanto al número de representantes que se podrán elegir (art. 39.4 LEBEP $^{332}$ ).

La LEBEP también prevé la posibilidad de que mediante Acuerdo o Pacto, en sus respectivos ámbitos y en relación con las competencias de cada Administración, se pueda establecer la estructura de la negociación colectiva y fijar las reglas para resolver los conflictos de concurrencia entre las negociaciones de distinto ámbito y los criterios de primacía y complementariedad entre las diferentes unidades negociadoras (art. 38.9) ${ }^{333}$.

Otro aspecto que se puede derivar a la negociación colectiva es el que señala el artículo 45 LEBEP, que regula la posibilidad de que por acuerdo entre la Administración y los sindicatos se creen, configuren y desarrollen sistemas de solución extrajudicial de

\footnotetext{
332 "El establecimiento de las unidades electorales se regulará por el Estado y por cada Comunidad Autónoma dentro del ámbito de sus competencias legislativas. Previo acuerdo con las Organizaciones Sindicales legitimadas en los artículos 6 y 7 de la Ley Orgánica 11/1985, de 2 de agosto, de Libertad Sindical, los órganos de gobierno de las Administraciones Públicas podrán modificar o establecer unidades electorales en razón del número y peculiaridades de sus colectivos, adecuando la configuración de las mismas a las estructuras administrativas o a los ámbitos de negociación constituidos o que se constituyan”.

333 Véase el Acuerdo Administración-Sindicatos para la ordenación de la negociación colectiva en la Administración General del Estado, de fecha 20 de mayo de 2008, por el que se establece la estructura de la negociación en ese ámbito, los criterios inspiradores de la negociación y los principios de coordinación de la negociación. Se regulan las funciones de la Mesa General de Negociación de la Administración General del Estado, las Comisiones Técnicas derivadas de ella: de riesgos laborales, formación, acción social, de igualdad de oportunidades, para el personal laboral en el Exterior, de temporalidad y empleo y de responsabilidad social de la Administración General del Estado. También las Mesas delegadas para la negociación; la resolución extrajudicial de conflictos, el ámbito temporal de vigencia y la Comisión de seguimiento (BOE de 6 de junio de 2008).
} 
Capítulo IV. El ejercicio de la negociación colectiva del personal estatutario de los Servicios de salud en el marco legal de la negociación colectiva funcionarial

conflictos colectivos, fundamentalmente la mediación y el arbitraje $\mathrm{e}^{334}$.

Sin embargo, no se pueden acordar nuevos órganos representativos del personal no previstos en la ley porque el legislador ha sido taxativo a la hora de su regulación, ni se pueden innovar funciones que la ley no haya contemplado para estos, simplemente porque la ley no ha dejado esa opción abierta a la negociación colectiva.

Entonces, cabe plantearse si la normativa funcionarial y en concreto, los derechos de carácter sindical de los empleados públicos, que vienen regulados en la LOLS y en la LEBEP, así como en la LEM para el personal estatutario, son normas de mínimos mejorables por la negociación colectiva. Hay que decir que, tradicionalmente, la jurisprudencia no ha aceptado esta tesis, ni antes con la regulación de la LORAP (STS de 20 de enero de $1998^{335}$ ), ni actualmente con la LEBEP (STSJ de Castilla-La Mancha de 20 de diciembre de $2012^{336}$ ). Ello porque entiende que, en base al artículo $103.3 \mathrm{CE}$, existe una reserva de ley para regular el régimen jurídico de los funcionarios públicos, incluidas las peculiaridades de su derecho a sindicación, y que la negociación colectiva funcionarial no puede producir Acuerdos ni Pactos que desconozcan lo dispuesto en la ley ni siquiera para mejorarla, al contrario de lo que sucede con la negociación colectiva laboral en que es válida la negociación de condiciones de trabajo distintas y más beneficiosas para los trabajadores a las previstas en la ley.

\footnotetext{
${ }^{334}$ La mediación, que ya se reguló en su momento en el artículo 38 LORAP, es obligatoria si lo solicita una parte, aunque sus decisiones pueden ser libremente aceptadas o rechazadas por los sujetos implicados. El arbitraje es una novedad de la LEBEP y es voluntario acordarlo, pero obligatorio asumir su contenido.

${ }^{335}$ El Fundamento jurídico cuarto declara no aplicable el principio de norma más favorable a la negociación colectiva funcionarial: “... por infracción de los artículos 32 y 35 de la Ley 9/1987, en cuanto que las características de pormenorización, rigidez y uniformidad inherentes al régimen estatutario funcionarial, emanado de la legislación básica del Estado y, en su caso, de la legislación de las CC.AA., no permiten que por analogía con el sistema de relaciones laborales, tal bloque normativo sea catalogable como plataforma de mínimos, sobre las que puedan actuar las diferentes unidades negociadoras, pactando según el buen criterio de la Mesa de Negociación...”, (RJ 1998\1419). En el mismo sentido la STS de 22 de diciembre de 1997, (RJ 19981315) y la de 24 de febrero de 1997, (RJ 19971544).
}

\footnotetext{
${ }^{336}$ Fundamento jurídico tercero: "En relación con la alteración pactada del sistema de créditos horarios, por la que con independencia del número de funcionarios en el centro de trabajo otorga a todos los representantes el mismo crédito horario, debe señalarse que es doctrina de esta Sala siguiendo la sentada por el Tribunal Supremo [...] que viene estableciendo con una claridad absoluta y meridiana que los derechos reconocidos por las leyes a los funcionarios públicos, no tienen, como sí sucede en el caso de los trabajadores (utilizado este término en sentido jurídico estricto), carácter de mínimos mejorables, sino de condiciones legales o reglamentarias fijas [...] No es permisible que por analogía con el sistema de relaciones laborales el bloque legislativo que regula el régimen estatutario de los funcionarios sea identificable como plataforma de "mínimos", sobre la que puedan pivotar una constelación de unidades negociadoras pactando cada una a su libre albedrío, bajo el lema de que lo que no está permitido por la ley debe presumirse que está permitido y puede ser objeto de regulación con arreglo al buen criterio de la Mesa de Negociación, refrendado por la respectiva Corporación Municipal. Por ello, visto el contenido de los Acuerdos por el que se procede a reconocer el máximo legalmente previsto a todos los representantes sindicales sin relación con los funcionarios del respectivo centro de trabajo, procede estimar el recurso en este punto anulando los pactos relativos a los créditos horarios de los representantes sindicales por no ajustarse a la regulación legal que prevé un sistema escalonado relativo a los funcionarios del centro de trabajo", (JUR 2013\29711).
} 
Esta postura ha sido objeto de cierta crítica por la doctrina, que considera que la oposición de la jurisprudencia a que las normas funcionariales en general sean normas de mínimos mejorables por la negociación colectiva, tal como lo son las normas laborales (art. 3.3 TRET), debe evolucionar para actualizarse ${ }^{337 .}$.

En nuestra opinión, hay que tener en cuenta que, efectivamente, el principio de reserva de ley constitucional para la regulación del estatuto de los funcionarios públicos es un principio que limita su derecho a la negociación colectiva, o más bien la enmarca, le pone límites. Pero no se puede desconocer que la negociación en materia sindical, se produce precisamente para lograr mejoras, ventajas o facilidades en el ejercicio de determinados derechos porque así lo prevé la ley. En ese sentido entendemos que sí se podría decir que tanto la LOLS ${ }^{338}$, la LEBEP o la LEM contienen en algunos aspectos las garantías y derechos mínimos o básicos de las organizaciones sindicales, de sus delegados y de los representantes de personal para salvaguardar y hacer viable el derecho a la acción sindical, facultad que deriva directamente del derecho fundamental a la libertad sindical, y que se puede desarrollar y ampliar mediante el mecanismo de la negociación colectiva funcionarial.

\subsection{3.- FOROS DE NEGOCIACIÓN. ESTRUCTURA DE LA NEGOCIACIÓN COLECTIVA DE LOS FUNCIONARIOS PÚBLICOS. LOS FOROS DE NEGOCIACIÓN ESPECÍFICOS DEL PERSONAL ESTATUTARIO DE LOS SERVICIOS DE SALUD}

La negociación colectiva funcionarial, y la del personal estatutario de los Servicios de salud no es más que eso, no se puede producir de forma válida en cualquier foro. La ley regula los foros de negociación donde se puede llevar a cabo, los sujetos intervinientes, su composición, y los productos de su actividad negociadora.

Entendemos por foro de negociación, el órgano en el cual se lleva a cabo el procedimiento de negociación con la finalidad de concertar Pactos y Acuerdos entre los representantes de la Administración y los de las organizaciones sindicales. Este recibe en la ley la denominación de Mesa de negociación. El art. 38.1 LEBEP dice al respecto que: "En el seno de las Mesas de Negociación correspondientes, los representantes de las Administraciones Públicas podrán concertar Pactos y Acuerdos con la representación de las organizaciones sindicales legitimadas a tales efectos, para la determinación de condiciones de trabajo de los funcionarios de dichas Administraciones".

Las Mesas de negociación son órganos dotados de una cierta estabilidad, ya que se constituyen por dos años, renovables, y sus ámbitos de negociación están predeterminados en la ley. Aunque algún autor, seguramente basándose en pronunciamientos judiciales que

\footnotetext{
${ }^{337}$ ALFONSO MELLADO, C.L., "Cuestiones actuales en torno a la eficacia de la negociación colectiva de los empleados públicos", Revista de Derecho Social n² 27, 2004. Este autor se decanta por una interpretación de la negociación colectiva funcionarial más flexible.

${ }^{338}$ Favorable a la interpretación de los derechos reconocidos a las secciones sindicales en la LOLS como un mínimo legal mejorable por la negociación colectiva funcionarial: ROQUETA BUJ, R., La negociación colectiva en la función pública, op.cit. p. 305.
} 
se orientan en esa dirección ${ }^{339}$, considera que las Mesas son las titulares del derecho a la negociación colectiva funcionarial (Manzana Laguarda ${ }^{340}$ ), la mayoría entiende que estas no son las titulares del derecho a la negociación; son únicamente el órgano que se constituye con la finalidad de llevar a cabo la misma, ya que las partes legitimadas para negociar son las Administraciones Públicas y las organizaciones sindicales (Rivero Lamas, de Val Tena $\left.^{341}\right)$.

Sobre la naturaleza jurídica de las Mesas de negociación hay que decir que no cabe duda de que se trata de órganos colegiados, pero no necesariamente sometidos al régimen de la LRJ-PAC (Capítulo II, artículo 22 y siguientes), puesto que no son parte de la estructura organizativa de la propia Administración pública; no obstante, se puede convenir que esta ley sea norma supletoria de las reglas que rijan su funcionamiento ${ }^{342}$. La jurisprudencia entiende que las Mesas de negociación no tienen personalidad jurídica propia, sino que son órganos mixtos "formados por la Administración y los administrados para el desarrollo de una gestión participativa del empleo público"343.

Acerca de la distinción de las Mesas de negociación de otros órganos, hay que diferenciar su papel del de las ponencias preparatorias o grupos de trabajo, que se crean para elaborar datos y propuestas que después se llevan a la Mesa de negociación, pero sin capacidad ni legitimación para llevar a cabo negociación válida, como tienen declarado el TC y el $\mathrm{TS}^{344}$.

\footnotetext{
${ }^{339}$ La STS de 14 de julio de 1994, en su Fundamento jurídico séptimo, atribuye el derecho a la negociación colectiva funcionarial no a los sindicatos, sino a las Mesas de negociación, (RJ 1994 6017). En el mismo sentido la STSJ de Castilla y León, de 13 de marzo de 2007, “... el derecho de negociación colectiva de los empleados públicos se deposita en órganos estables de creación legal, como son las Mesas de negociación, sin que, por tanto, se atribuya de modo directo a los Sindicatos. En ese sentido, estos carecen de legitimación propia para la negociación, siendo solo la Mesa correspondiente la que puede reclamar esta, o la que, en su caso puede reclamar si se omite. La posición de los sindicatos debe limitarse a reclamar su participación en ese órgano, pero las eventualidades de la negociación o de la no negociación se sitúan en el plano de la actuación de ése órgano de creación legal, y no propiamente en el contenido esencial de la libertad sindical", (JUR 200入215209). En el mismo sentido, la STSJ de Murcia de 18 de octubre de 2010, (JUR 2010入383423).

${ }^{340}$ MANZANA LAGUARDA, R., Derechos y deberes de los funcionarios públicos, op.cit. p. 262.

${ }^{341}$ RIVERO LAMAS, J., DE VAL TENA, A.L., El derecho a la negociación colectiva de los funcionarios públicos, Revista del Ministerio de Trabajo y Asuntos Sociales, $\mathrm{n}^{\circ}$ 68, p. 197-236.
}

\footnotetext{
${ }^{342}$ Así lo ha establecido el Reglamento de la Mesa Sectorial Nacional de Sanidad (MSNS) en su artículo 1, segundo párrafo, que dispone: "En lo no definido en el presente Reglamento, se estará a lo dispuesto en la Ley 30/1992, de 26 de noviembre, de Régimen Jurídico de las Administraciones Públicas y del Procedimiento Administrativo Común”.

${ }^{343}$ SAN de 14 de abril de 2010, (RJCA 2010^425).

${ }^{344}$ Que ha venido señalando que estos órganos técnicos ad hoc carecen de las atribuciones legales para llevar a cabo la negociación y que no se puede restringir la capacidad negociadora de un sindicato, que le otorga la LOLS, y el derecho de negociación derivado que le reconoce la Ley ordinaria, por ningún tipo de pacto de los demás partícipes en la Mesa, que se manifiesta llevando la negociación a la Ponencia. En este sentido la STC 80/2000, de 27 de marzo, Fundamento jurídico quinto, (RTC 2000\80), y la STS de 19 de septiembre de 2000, antes citada, sobre acceso de la Confederación Intersindical Galega a la Mesa Sectorial de Sanidad del Servicio Gallego de Salud, Puede vulnerar la libertad sindical de las organizaciones sindicales la táctica de
} 
En cuanto a los antecedentes inmediatos de la regulación actual de los foros de negociación, hay que recordar que la LORAP reguló una estructura de Mesas territoriales en las que el ámbito de la Mesa de negociación se correspondía con el ámbito de la respectiva Administración Pública implicada en la negociación (art. 31), de manera que existía una Mesa General de Negociación en el ámbito de la Administración General del Estado, otra en cada una de las CC.AA. y una en cada una de las Entidades Locales. Además de ello, la LORAP creó las Mesas Sectoriales para negociar otros temas que no hubieran sido objeto de negociación en la correspondiente Mesa General y que estaban previstas para determinados sectores: personal docente no universitario; personal universitario; personal de Correos, Telégrafos y Caja Postal de Ahorros; personal al servicio de la Administración de Justicia y personal de las Entidades Gestoras de la Seguridad Social. En estas debían estar presentes, además de los sindicatos más representativos en ese ámbito estatal o autonómico, los sindicatos que hubieran obtenido en el correspondiente sector el $10 \%$ o más de los representantes en las elecciones para Delegados y Juntas de Personal.

Por otra parte, es necesario antes de centrarnos en los foros de negociación, recordar que la legitimación de las organizaciones sindicales para formar parte de ellos se basa en el cumplimiento del requisito legal de la representatividad que configura la LOLS. Recordemos que la LOLS contempla tres niveles de representatividad sindical, en función del número de representantes del personal obtenidos por las organizaciones sindicales en los procesos electorales correspondientes, y que esa condición de la representatividad sindical instituye al sindicato que la obtiene como representante de los intereses de todo el colectivo de trabajadores o funcionarios al que representa, independientemente de su afiliación sindical ${ }^{345}$.

Así, en primer lugar, está la condición de la mayor representatividad sindical de ámbito estatal, regulada en el artículo 6.2 a) LOLS. Los sindicatos más representativos de ámbito territorial estatal son los que acrediten en ese ámbito una especial audiencia expresada en la obtención del $10 \%$ o más del total de Delegados de Personal o de los miembros de los Comités de empresa y de los correspondientes órganos de las Administraciones Públicas. La expresión "sindicato más representativo a nivel estatal", utilizada por la LOLS, está refiriendo la mayor representatividad a nivel estatal a las Confederaciones, no a los entes sindicales concretos que se integran en las mismas. Las organizaciones sindicales que acreditan este nivel de representatividad son la Confederación Sindical de Comisiones Obreras (CC.OO.) y la Unión General de Trabajadores (UGT).

desviar la negociación desde la Mesa de negociación a una ponencia preparatoria de la misma. Siguiendo la doctrina del TC declara que "...la alegada exclusión no se ha producido de la Mesa Sectorial de Sanidad, sino de una ponencia preparatoria de la negociación de aquella, constituida en virtud de un pacto concertado entre la Administración y otros sindicatos titulares del derecho de participación en la Mesa. En cuanto a la función real de la ponencia, esta se concibió en origen como un órgano técnico, creado desde la propia Mesa Sectorial para preparar la actuación final de esta de modo que desde su inicio, y al margen de que a la ponencia no se le dotase de capacidad decisoria definitiva, existía una parcial coincidencia entre la función legalmente atribuida a la Mesa Sectorial y la delegada desde esta a la ponencia. El dato mismo de que lo negociado en la ponencia se refiriese a una materia de inequívoca atribución legal a la negociación de la Mesa pone de manifiesto la coincidencia funcional entre los cometidos desarrollados en la ponencia y los correspondientes legalmente a la Mesa”, (RJ 2000\8338).

345 MARTINEZ GAYOSO, M.N., El derecho a la negociación colectiva de los funcionarios públicos en la Constitución, Universidad del País Vasco, 2002, p. 205. 
Capítulo IV. El ejercicio de la negociación colectiva del personal estatutario de los Servicios de salud en el marco legal de la negociación colectiva funcionarial

La mayor representatividad de ámbito autonómico viene regulada en el artículo 7.1 a) LOLS y es algo así como un segundo nivel de representatividad. Esta condición la tienen los sindicatos que en el ámbito territorial autonómico acrediten una especial audiencia expresada en la obtención de, al menos, el 15\% de Delegados de Personal y de miembros de los Comités de empresa y de los órganos correspondientes de las Administraciones Públicas, siempre que cuenten con un mínimo de 1.500 representantes y no estén federados o confederados en organizaciones sindicales de ámbito estatal, según el artículo 7.1 a) LOLS. Acreditan esta representatividad las organizaciones Euskal Langileen Alkartasuna (ELA) y la Confederación Intersindical Galega (CIG).

Por último, la representatividad de ámbito territorial y funcional específico, recogida en el punto 2 del artículo 7 LOLS, es aquella que poseen "las organizaciones sindicales que, aun no teniendo las consideración de más representativas, hayan obtenido en un ámbito territorial y funcional específico el 10\% o más de Delegados de Personal y miembros de Comités de empresa y de los correspondientes órganos de las Administraciones Públicas”.

El ámbito funcional identifica la rama, sector o subsector de actividad económica, la empresa o centro de trabajo, e incluso el ámbito interprofesional de aplicación, mientras que el ámbito territorial delimita el espacio geográfico, local, comarcal, provincial, interprovincial, de Comunidad autónoma, estatal, etc. Se trata de un tercer nivel de representatividad al que también se le denomina simple o suficiente.

En el ámbito del conjunto de las Administraciones Públicas tiene este nivel de representatividad la Confederación Sindical Independiente y de Funcionarios (CSI-F). En el Sistema Nacional de Salud tiene la condición de sindicato más representativo de sector CEMSATSE.

Respecto a la estructura de la negociación colectiva funcionarial distinguiremos entre los foros de negociación regulados en la LEBEP para todos los empleados públicos, o solo para los funcionarios; los foros de negociación regulados en la LEM, específicamente para el personal estatutario, y trataremos otros foros de negociación surgidos, a su vez, de la negociación colectiva.

Antes de centrarnos en la estructura de la negociación colectiva funcionarial, hay que decir que en función de la materia a tratar y del ámbito objetivo y subjetivo al que afecte la negociación esta se conducirá a unas Mesas u otras.

\section{A) Foros de negociación regulados en la LEBEP}

La estructura de la negociación colectiva funcionarial la encontramos en los artículos 34 y 36 LEBEP, y es la siguiente:

\section{1.- La Mesa General de Negociación de las Administraciones Públicas.}

Regulada en los apartados 1 y 2 del artículo 36 de la LEBEP, en la que se negocia sobre materias comunes a los empleados públicos de todas las Administraciones públicas españolas susceptibles de regulación estatal con carácter de norma básica. Es, por tanto, un foro de ámbito estatal. Está presidida por la Administración General del Estado y se compone también de representantes de las CC.AA., de las ciudades autónomas de Ceuta y 
Melilla y de la Federación Española de Municipios y Provincias, en función de las materias a negociar ${ }^{346}$.

Por parte de la representación sindical estarán legitimadas para negociar en este foro aquellas organizaciones sindicales más representativas a nivel estatal (art. 6.2 LOLS) las más representativas a nivel autonómico (art. 7.1 LOLS) y las suficientemente representativas, es decir, aquellas que obtengan el 10\% de la representatividad en el ámbito específico funcional y territorial que corresponde al conjunto del empleo público de todas las Administraciones Públicas (art. 7.2 LOLS).

Es competencia de esta Mesa la negociación sobre las materias del artículo 37 LEBEP que requieren regulación estatal con carácter de norma básica, como es el incremento global de las retribuciones del personal al servicio de las Administraciones Públicas que corresponda incluir en el Proyecto de Ley de Presupuestos Generales del Estado de cada año, supuesto previsto específicamente en el segundo párrafo del artículo 36.2 LEBEP.

\section{$2^{\circ}$.- La Mesa General de Negociación en cada Administración Pública.}

Se prevé en el apartado 3 del artículo 36 LEBEP. En ella se negocian todas aquellas materias y condiciones de trabajo comunes al personal laboral, funcionario y estatutario de cada Administración Pública. Se constituirá una en la Administración General del Estado, una en cada una de las CC.AA., Ceuta y Melilla y una en cada una de las Entidades locales.

En estas mesas están presentes las organizaciones sindicales que, según los resultados obtenidos en las elecciones a los órganos de representación del personal funcionario y laboral del correspondiente ámbito de representación, hayan obtenido la condición de más representativas o suficientemente representativas en ese ámbito y, además, las organizaciones sindicales que formen parte de la Mesa General de Negociación de las Administraciones Públicas siempre que hubieran obtenido el $10 \%$ de los representantes a personal funcionario o personal laboral en el ámbito correspondiente a la Mesa de que se trate (esta última mención no era necesaria porque esta es la legitimación mínima exigida en todo caso).

Las materias que pueden negociar estas Mesas serán aquellas comunes a todos los empleados públicos de cada Administración, reguladas en el artículo 37 LEBEP, excepto las que correspondan a la Mesa General de Negociación de las Administraciones Públicas, como el acceso y provisión de puestos de personal, materia retributiva, carrera profesional y promoción interna, los planes de formación y de igualdad, acción social, salud laboral, movilidad, jornada, permisos, licencias...

\footnotetext{
${ }^{346}$ La doctrina sitúa los antecedentes de esta Mesa en la Ley 21/2006, de 20 de junio, de reforma de la LORAP que la creó, y de ahí ha pasado a la LEBEP. ALFONSO MELLADO, C., Los derechos colectivos de los empleados públicos..., op.cit., p. 14.
} 
Capítulo IV. El ejercicio de la negociación colectiva del personal estatutario de los Servicios de salud en el marco legal de la negociación colectiva funcionarial

\section{$3^{\circ}$.- Las Mesas Generales de negociación de personal funcionario.}

Se constituirá una en el ámbito de la Administración General del Estado, así como en cada una de las CC.AA., Ceuta y Melilla y Entidades Locales (art. 34.1 LEBEP). Sus competencias son las relacionadas con las condiciones de trabajo comunes a los funcionarios de su ámbito, por lo que no incluye al personal laboral (art. 34.3 LEBEP) ${ }^{347}$.

\section{$4^{\mathrm{o}}$.- Las Mesas Sectoriales.}

Son de creación potestativa, ya que su existencia depende de un Acuerdo que debe producirse en la sede de la respectiva Mesa General de Negociación de funcionarios "en atención a las condiciones específicas de trabajo de las organizaciones administrativas afectadas o a las peculiaridades de sectores concretos de funcionarios públicos y a su número" (art. 34.4 LEBEP). Son, por tanto, órganos dependientes de cada Mesa General de Negociación de funcionarios de la respectiva Administración autonómica. Estas Mesas podrán negociar sobre los temas comunes a los funcionarios del sector, que no hayan sido objeto de decisión por parte de la Mesa General respectiva, o sobre los que esta explícitamente les reenvíe o delegue (art. 34.5 LEBEP).

\section{B) Foros de negociación regulados en la LEM}

Para el personal estatutario de los Servicios de salud, el artículo 78 LEM, que trata los criterios generales de la representación, participación y negociación colectiva del personal estatutario, se remite a la LORAP, norma que regulaba la estructura de la negociación cuando se promulgó el Estatuto Marco. Ahora la remisión se debe entender hecha a la LEBEP, con lo que la estructura de la negociación de la LEBEP vista antes se aplica del todo al personal estatutario ${ }^{348}$.

Además, en el artículo 79 prevé la regulación de la Mesa sectorial de negociación de cada Servicio de salud: "En el ámbito de cada Servicio de salud se constituirá una Mesa sectorial de negociación, en la que estarán presentes los representantes de la correspondiente Administración pública o Servicio de salud y las organizaciones sindicales más representativas en el nivel estatal y de la Comunidad Autónoma, así como las que

\footnotetext{
${ }^{347}$ Sobre la distinción entre las Mesas Generales de negociación de Administración Pública y las que llama Generales de negociación de funcionarios, véase la STS de 17 de abril de 2013, Fundamento jurídico noveno, (RJ 2013\3784): "En primer lugar el artículo 36.3 LEBEP, debe ponerse en contraste con el artículo 34 del propio texto legal; lo que pone de manifiesto que en la LEBEP se establecen dos tipos diferentes de Mesas Generales de Negociación: unas, las del artículo 34, Mesas Generales de Negociación para la negociación colectiva de los funcionarios públicos; y otras las del 36, Mesas Generales de Negociación para la negociación "de aquellas materias y condiciones de trabajo comunes al personal funcionario, estatutario y laboral de cada Administración Pública" (art. 36.3 LEBEP)”.

348 El artículo 78 LEM dispone: "Resultarán de aplicación al personal estatutario, en materia de representación, participación y negociación colectiva para la determinación de sus condiciones de trabajo, las normas generales contenidas en la Ley 9/1987, de 12 de junio, de Órganos de Representación, Determinación de las Condiciones de Trabajo y de Participación del Personal al Servicio de las Administraciones Públicas, y disposiciones de desarrollo, con las peculiaridades que se establecen en esta Ley”.
} 
Capítulo IV. El ejercicio de la negociación colectiva del personal estatutario de los Servicios de salud en el marco legal de la negociación colectiva funcionarial

hayan obtenido el 10 por 100 o más de los representantes en las elecciones para Delegados y Juntas de Personal en el Servicio de salud".

Aunque según la redacción de este precepto las Mesas sectoriales de sanidad autonómicas son de existencia obligada (dice "se constituirá"), desde la LEBEP hay que ponerlo en relación con su artículo 34.4, que como hemos visto dispone que la creación de las Mesas sectoriales sea decisión de la Mesa General de negociación de funcionarios de la Administración autonómica, por lo que hay que tener en cuenta el requisito que impone esta última norma. Insistimos en que hay que prestar atención al aspecto de la constitución potestativa de estas Mesas, que han sido durante años el foro específico de negociación del personal estatutario.

La Administración pública representada en la Mesa sectorial de Sanidad es la de la Comunidad autónoma, ya que es la que posee la competencia sobre la gestión de la sanidad a través del Servicio de salud. Por parte de la representación sindical están legitimadas para participar en las Mesas sectoriales las organizaciones sindicales más representativas o que hayan obtenido al menos el $10 \%$ de los representantes del personal en el ámbito específico de que se trate, que para el personal estatutario será el conjunto de las unidades electorales del ámbito de su Servicio de salud.

Otro foro de negociación regulado en la LEM es el ámbito de negociación del Foro Marco para el Diálogo Social. Este órgano se menciona por primera vez en el artículo 35.3 de la LCCSNS $^{349}$ aunque sin concretar sus funciones, y se regula posteriormente en los tres primeros apartados del artículo 11 LEM. Sus competencias no son negociadoras, sino de tipo asesor o consultivo: promover el desarrollo armónico de los recursos humanos del SNS y prestar apoyo y asesoramiento en todas las funciones de coordinación de las políticas de recursos humanos que la LEM atribuye a la Comisión de Recursos Humanos del Sistema Nacional de Salud.

Deberá ser informado de los Acuerdos de las Mesas sectoriales del sector sanitario, así como de los de las Mesas generales que afecten a dicho sector (art. 11.3 LEM). Este órgano, insistimos, no tiene funciones negociadoras, pero sí las tiene el que regula el mismo artículo, en su apartado 4, órgano que se ha dado en llamar "ámbito de negociación del Foro Marco". Este precepto contempla la posibilidad de que el Ministerio con competencias en Sanidad "convoque a las organizaciones sindicales representadas en el Foro Marco para el Diálogo Social a fin de negociar los contenidos de la normativa básica relativa al personal estatutario de los Servicios de salud que dicho Ministerio pudiera elaborar [...] en todo aquello que no afecte a las competencias de las CC.AA. y sin perjuicio de los asuntos atribuidos a la Mesa General de Negociación de la Administración General del Estado...”.

\footnotetext{
${ }^{349}$ La Ley 16/2003 de 28 de mayo de Cohesión y Calidad del Sistema Nacional de Salud es la norma de creación del Foro Marco para el Diálogo Social, al que atribuye en el apartado a) del artículo 35.3 el objetivo de ser un ámbito de diálogo e información de carácter laboral, promoviendo el desarrollo armónico de sus condiciones -las de los trabajadores del Sistema Nacional de Salud-. Esta ley también prevé la existencia del Comité Consultivo de Sanidad, en el artículo 67.2, como órgano dependiente del Consejo Interterritorial del SNS “mediante el que se hace efectiva la participación social de organizaciones sindicales y empresariales.
} 
Respecto a las materias que se negocian en este foro, aunque el artículo 11.4 LEM hace referencia a las materias reguladas en la LORAP, en la actualidad hay que entender que se podrán negociar los contenidos de la normativa básica del personal estatutario del Sistema Nacional de Salud, en lo que sea materia de negociación conforme al artículo 37 LEBEP, y hay que tener en cuenta que sus reuniones "podrán ser convocadas por decisión del Ministerio, por acuerdo entre este y las organizaciones sindicales, y por solicitud de todas las organizaciones sindicales presentes en el Foro Marco, realizándose, al menos, una al año".

En cuanto a las organizaciones sindicales que pueden formar parte del Foro Marco para el Diálogo Social, hay que destacar la deficiente redacción de los artículos 11.2 LEM y 35.3 LCCSNS, que solo se refiere como legitimadas para estar presentes en él a las "organizaciones sindicales más representativas del sector sanitario", con lo que, literalmente, parece excluir a las más representativas a nivel estatal y de Comunidad autónoma, posibilidad del todo contraria a la regulación de la representatividad de la LOLS. Por tanto, la interpretación que resulta más ajustada es la de considerar legitimadas para formar parte del Foro Marco para el Diálogo Social tanto a las organizaciones sindicales más representativas, como a las representativas en el sector de la sanidad pública, poniendo en relación estos preceptos con los artículos 6 y 7 LOLS $^{350}$.

En efecto, estas son las que en mayo de 2005 lo constituyeron: CCOO y UGT, como sindicatos más representativos a nivel estatal, aunque también cumplen la representatividad de sector específico; CIG, como sindicato más representativo autonómico; y además, como organización sindical representativa en el sector sanitario, por haber obtenido al menos el $10 \%$ de los representantes del personal en este ámbito, CEMSATSE. Se constata, sin embargo, la ausencia voluntaria de ELA-STV, sindicato más representativo de Comunidad autónoma, a pesar de contar con legitimación para estar presente.

El Foro Marco para el Diálogo Social está presidido por el titular de la subsecretaría del Ministerio de Sanidad, y por parte de la Administración pública, se compone de representantes de los Ministerios con competencia en Sanidad, Economía, Hacienda, Empleo y Educación, así como por los de las CC.AA.

Es de lamentar la escasa operatividad que ha tenido este foro de negociación desde su constitución en Madrid el 28 de febrero de 2005; tendencia que parecía mejorar en los últimos tiempos, a raíz de las reclamaciones y exigencias de convocatoria de las organizaciones sindicales que lo componen ${ }^{351}$.

\footnotetext{
350 DAMIAN MORENO, J.R., "La negociación colectiva de las condiciones de trabajo básicas de los funcionarios públicos tras la reforma de la LORAP”, AJA nº 720, 2006, (BIB 2006\1747). PEREZ CHARCO, J. "El foro Marco para el diálogo social en el Estatuto Marco de personal estatutario de los Servicios de salud", Revista de Derecho Social, $\mathrm{n}^{\circ}$ 25, enero 2004, pp. 215-226.

${ }^{351}$ Cabe destacar que la reunión de noviembre de 2010 del Foro Marco para el Diálogo Social, en la modalidad de "ámbito de negociación", lo fue en ejecución de la SAN de 14 de abril de 2010, dictada en proceso de tutela de la libertad sindical, ya que el Ministerio no atendía las reiteradas solicitudes de los sindicatos para su convocatoria. El recurso jurisdiccional se interpuso por los trámites del procedimiento de protección de los derechos fundamentales, por infracción del artículo 28.1 CE en relación con el artículo 37 de la misma, contra la desestimación por silencio, del requerimiento hecho al Ministerio de Sanidad y Política Social el 6 de octubre de 2009, y frente a su inactividad material para que, al amparo del artículo 11.4 de la Ley 55/2003, de 16 de diciembre, del Estatuto Marco del Personal estatutario de los Servicios de salud, se convocara el "ámbito de negociación". La demanda interpuesta por CEMSATSE, explica que la Administración constituyó
} 


\section{C) Otros Foros de negociación}

Una cuestión que nos planteamos es si las Mesas pueden tener también origen convencional; es decir, si pueden existir otros foros de negociación producto de la negociación colectiva, que nazcan precisamente de Acuerdos entre la Administración y las organizaciones sindicales legitimadas. Es decir, si cabe la existencia de foros de negociación diferentes y complementarios de los que se regulan en las correspondientes normas con rango de ley.

Debemos tener en cuenta que la jurisprudencia no acepta la existencia de Mesas de negociación que no hayan sido previstas en la ley, y posteriormente creadas al margen de la estructura de negociación que se articula en ella ${ }^{352}$.

Sin embargo, nos encontramos, por ejemplo, con el Foro de Diálogo Social en las Administraciones públicas, cuya creación se acordó en la Declaración para el Diálogo Social en las Administraciones públicas, de fecha 21 de septiembre de 2004, firmada por el Gobierno y las Organizaciones Sindicales UGT, CC.OO. y CSI-CSIF, representativas en el conjunto de ese ámbito.

En su sede se alcanzó el Acuerdo Gobierno-Sindicatos para la función pública en el marco del Dialogo Social 2010-2012, de 25 de septiembre de 2009, que parece reunir las características de lo que sería un Acuerdo Marco: "El marco de actuación que propone este Acuerdo no puede dejar de hacer referencia a la atención que las Administraciones

el Foro Marco para el Diálogo Social el 28 de mayo de 2005, al amparo del artículo 11.1 LEM y que convocó a la demandante a las reuniones celebradas entre 2005 y 2009 en calidad de organización representativa. En virtud del artículo 11.4 LEM se constituyó, además, el "ámbito de negociación" -luego denominado Comisión Negociadora- que se reunió siete veces en 2005 y una en 2006 "sin que se haya vuelto a reunir pese a que se ha reclamado a los efectos del artículo 29.1 LJCA. Tal inactividad material vulnera el derecho fundamental a la negociación colectiva, como contenido adicional de la libertad sindical, luego tiene relevancia como derecho fundamental cuando afecta a sindicatos". La demanda alegaba también que no cabe confundir el Foro con el "ámbito de negociación", que es lo que hace la Administración, por lo que aunque se haya reunido el Foro no se ha convocado el "ámbito de negociación", con lo que va contra sus propios actos al haberlo constituido; además, al identificar el Foro con el citado ámbito se niega a este capacidad negociadora pues el Foro es una instancia de diálogo e información, de apoyo y asesoramiento, (RJCA 2010 425).

Una de las últimas reuniones del ámbito negociador del Foro Marco para el Diálogo Social se produjo en abril de 2013, tras las denuncias de las organizaciones sindicales integrantes que llevaron su queja a la Defensora del Pueblo.

\footnotetext{
${ }^{352}$ Tal como se declara en la STS de 17 de abril de 2013, relativa a un supuesto de exclusión del sindicato profesional de policías y bomberos de la Comunidad Valenciana de la Mesa de negociación del Servicio de Prevención, Extinción de Incendios y Salvamento de la Comunidad Valenciana, que para el Supremo no tiene cabida en la estructura negocial de la ley. Dice en su Fundamento jurídico octavo: "... la determinación de cual sea la índole jurídica de la Mesa de Negociación respecto de la que se discute, encuadrándola, si es posible, en el marco de los supuestos regulados al respecto en la LEBEP, art. 31 y ss., cuyo marco es, a su vez, el parámetro de referencia de la legitimación del sindicato recurrente para participar en la Mesa. Y debe afirmarse que dicha Mesa no se corresponde con ninguna de las reguladas en el art. 33 a 36 de esta Ley, como de inmediato razonaremos, lo que tiene como consecuencia que la pretendida legitimación del Sindicato recurrente para participar en dicha Mesa y la alegada discriminación por haber sido excluido de la misma carece de la base legal que el recurrente afirma como infringida en este caso...", (RJ 2013\3784).
} 
Públicas deben prestar a la garantía y buen ejercicio de los derechos sindicales" dice textualmente su apartado cuatro. Precisamente, ese mismo apartado, trata sobre las Mesas Sectoriales estatales ${ }^{353}$. En consecuencia, parece más bien un foro de participación y diálogo entre la Administración y las organizaciones sindicales para realizar propuestas y determinar propósitos y líneas de actuación, no una Mesa de negociación, propiamente dicha.

Por otro lado, en septiembre de 2011, a propuesta del Ministerio de Sanidad, se creó la Mesa Sectorial Nacional de Sanidad (MSNS). En el preámbulo del Reglamento de la MSNS se declara que: "La Mesa Sectorial de Sanidad nace, sin vinculación a ningún otro ámbito de negociación por voluntad de las partes, como órgano colegiado de pleno derecho al amparo del Acuerdo suscrito el pasado 8 de septiembre de 2011 entre el Ministerio de Sanidad, Política Social e Igualdad y las Organizaciones Sindicales: CCOO, CEMSATSE, CSIF, SATSE (Sindicato de Enfermería) y UGT” ${ }^{354}$.

Por su parte, la Confederación Unión sindical y Auxiliares de enfermería impugnó ante la Audiencia Nacional su constitución por no haberla incluido, alegando la vulneración de su derecho fundamental a la libertad sindical, en la modalidad de negociación colectiva, cuestión que ha decidido la SAN de 3 de mayo de 2013, desestimando la pretensión de esta organización sindical de formar parte de la misma por no acreditar representatividad suficiente, pero aceptando la existencia de la MSNS como órgano de negociación de los de la LEBEP ${ }^{355}$.

El Reglamento de la MSNS señala que la Mesa se configura: "Como un órgano de participación democrática de los representantes del personal estatutario del SNS y la Administración Sanitaria para negociar, dialogar y abordar aspectos comunes de la normativa básica de competencia estatal...” (art.2).

La constitución de la MSNS fue polémica, por la negativa de las CC.AA. gobernadas por el Partido Popular a participar en ella, ya que su nacimiento tuvo lugar en los últimos tiempos del gobierno del PSOE; de forma que en la primera reunión solo estuvieron presentes Asturias, Navarra, Cataluña, Aragón, Canarias y Andalucía, y la aprobación de su Reglamento interno tuvo lugar también sin su participación. En cuanto a su composición, formaban parte de este foro, por parte de la Administración Sanitaria, el Ministerio de Sanidad, Servicios Sociales e Igualdad y las diecisiete CC.AA. Por la parte sindical otros

\footnotetext{
${ }^{353}$ Estableciendo que: "Se desarrollará la estructura de la Negociación Colectiva surgida del Estatuto Básico del Empleado Público. Con carácter transitorio y hasta cuando se alcance un acuerdo definitivo, en base a la estructura de la Negociación Colectiva y dependientes de la Mesa General de Negociación de las Administraciones Públicas, dadas las peculiaridades de los colectivos afectados, y sin perjuicio de que la propia Mesa pueda acordar la creación de otras, se propondrá la constitución de las Mesas Sectoriales Estatales que a continuación se especifican: Mesa Sectorial Estatal de Educación, Mesa Sectorial Estatal de Sanidad, Mesa Sectorial Estatal de Justicia, Mesa Sectorial de Universidades [...] Las medidas señaladas anteriormente serán negociadas con las organizaciones sindicales más representativas en el conjunto de las Administraciones Públicas”.

${ }^{354}$ Puede consultarse en la web de Diario Actasanitaria [en línea] [consulta de 1 de mayo de 2013], disponible en <http: llwww.actasanitaria.com>.

${ }^{355}$ (JUR 2013\161976).
} 
dieciocho miembros, en representación de las organizaciones sindicales con la condición de más representativas y representativas en el ámbito sanitario ${ }^{356}$.

En consecuencia tiene, o tenía, las mismas competencias que el ámbito de negociación del Foro Marco para el Diálogo Social, y decimos tenía porque, visto que desde 2011 en su sede no se ha concertado ni un solo Acuerdo, las dudas sobre su operatividad parecen fundadas, a pesar de las peticiones de convocatoria de las organizaciones sindicales.

Sucede con la MSNS algo similar a la situación que se da en el ámbito de negociación del Foro Marco para el Diálogo Social. Los sindicatos integrantes han reclamado continuamente su convocatoria al Ministerio, sin éxito, hasta el punto de que se constata el hecho de que la anterior titular del Ministerio de Sanidad trasladó la negociación sobre el personal estatutario, que debería producirse en esta Mesa o en el ámbito de negociación del Foro Marco para el Diálogo Social, a los grupos de trabajo dependientes del Foro de la Profesión Médica, en el que se adoptó el Acuerdo Marco de colaboración para el desarrollo del Pacto por la Sanidad, con el consiguiente rechazo por parte de las organizaciones sindicales ${ }^{357}$.

El Foro de la Profesión Médica es un órgano que se encuentra al margen del sistema de negociación colectiva diseñado por nuestro ordenamiento jurídico. Está compuesto por el Consejo General de Colegios Médicos de España, los propios Colegios de médicos, la Confederación Estatal de Sindicatos Médicos (CEMS), Sociedades científicas, Universidades y representantes de los estudiantes de medicina.

Esta negociación, que se inició en febrero de 2013, y a la que se añadió posteriormente el Consejo General de Enfermería y el Sindicato de Enfermería, ha culminado en el "Pacto por la Sostenibilidad y la Calidad del Sistema Nacional de Salud", firmado el 30 de julio de 2013, al margen del resto de representantes de las organizaciones sindicales representativas en el Sistema Nacional de Salud y fuera del foro competente para la negociación. En este Acuerdo Marco, entre varias áreas en las que se prevé la colaboración entre el Ministerio de Sanidad y el Foro de la Profesión Médica, destacan las siguientes líneas de trabajo: la política de recursos humanos y la sostenibilidad del SNS;

\footnotetext{
${ }^{356}$ CSI-CSIF, que no tuvo legitimación suficiente en su día para participar en la constitución del Foro Marco para el Diálogo Social, sí la acreditó seis años más tarde para formar parte de esta Mesa. Los porcentajes de representatividad que acreditaron fueron son los siguientes: CCOO el 23,51 \%; CEMS el 14,63 \%; CIG que tiene el 1,74 \%; CSI-F con el 17,68 \%; SATSE el 19,98 \% y UGT el 22,46 \%. Estos porcentajes se debían revisar cada cuatro años con los resultados que, a treinta de septiembre del año se certificaran por las Oficinas Públicas de Registro.
}

\footnotetext{
357 “... Los sindicatos han presentado una queja a la Defensora del Pueblo por la "reiterada y constante" vulneración del derecho a la libertad sindical y a la negociación colectiva llevado a cabo por el Ministerio de Sanidad. En la denuncia, los sindicatos sanitarios critican que el departamento que dirige Ana Mato está vulnerando hasta cuatro convenios de la Organización Internacional del Trabajo (OIT); los artículos 27.10, 28.1 y 37.1 de la Constitución; la Ley que establece la Libertad Sindical; el capítulo IV del título III del Estatuto Básico del Empleado Público; los artículos 11 y 78 del Estatuto Marco del Personal Estatutario de los Servicios de salud; el artículo 22 de la Ley 50/1999 de Gobierno; y el artículo 11.4 del Estatuto Marco”. Diario Gaceta Médica [en línea] 8 de abril de 2013, [consulta de 10 de abril de 2013], disponible en: <http:Ilwww.gacetamedica.com>.
} 
análisis y revisión de las relaciones jurídicas de los profesionales sanitarios en el SNS; características de la formación, perfiles profesionales más demandados y adecuación de los contenidos curriculares, formación continua, evaluación, promoción profesional y recertificación, troncalidad y áreas de capacitación específica; planificación de las necesidades de recursos humanos [...] movilidad, flexibilidad y políticas retributivas...materias, en su mayoría, de obligada negociación (art. 37 LEBEP) ${ }^{358}$. Actualmente, está pendiente la constitución del Foro de las Profesiones Sanitarias para tratar "el estudio del marco jurídico específico del profesional médico en el SNS"359.

La actividad negociadora de todas estas Mesas de negociación incide en las condiciones de trabajo del personal estatutario de los Servicios de salud, pero, en concreto, por lo que se refiere a la negociación de sus derechos sindicales, hay que decir que esta se ha llevado a cabo, tradicionalmente, en las Mesas Sectoriales de Sanidad de cada Administración autonómica. Debe ser así si se pretende que el resultado de la negociación afecte solo al personal de su Servicio de salud, aunque los derechos y garantías sindicales pueden ser también negociados en las Mesas Generales de Funcionarios si su contenido debe vincular también al resto de funcionarios de la Administración autonómica, o en las Comunes de funcionarios, estatutarios y laborales de cada Administración autonómica para el caso de que afecte a todos sus empleados públicos. Asimismo, la negociación sobre esta materia que se dirija al personal del INGESA deberá darse en la Mesa General de Negociación de la Administración General del Estado.

\subsection{4.- PARTES NEGOCIADORAS. COMPOSICIÓN DE LAS MESAS Y PROCEDIMIENTO DE NEGOCIACIÓN}

Las partes negociadoras de los Pactos y Acuerdos que se sentarán a la Mesa de Negociación son los representantes de la Administración pública y las organizaciones sindicales legitimadas por la LOLS en el ámbito correspondiente. Así lo establece el artículo 33.1, segundo párrafo LEBEP, que dice que a efecto de llevar a cabo la negociación colectiva: "Se constituirán Mesas de Negociación en las que estarán legitimados para estar presentes, por una parte, los representantes de la Administración Pública correspondiente,

\footnotetext{
${ }^{358}$ El texto del Acuerdo se puede consultar en la web del Consejo General de Colegios Oficiales de Médicos de España: La ministra de Sanidad firma el Pacto por la Sanidad con el Foro de la Profesión Médica, [en línea], [consulta de 12 de febrero de 2013], disponible en: 〈http: \\ www.cgcom.es $\rangle$. No hay que confundir el Foro de la Profesión Médica con el Foro Profesional, que nació como un órgano dependiente de la Comisión de Recursos Humanos del Sistema Nacional de Salud y que reguló el artículo 35.3 b) de la LCCSNS. Tenía funciones de diálogo e información sobre formación de postgrado y continuada, y sobre los requisitos formativos, de evaluación y competencia de las profesiones sanitarias sobre materia de formación. Este órgano, que nunca llegó a tener actividad, ha sido derogado por la Ley 3/2014 de 27 de marzo (BOE de 28 de marzo de 2014), para ser incorporado a la Ley 44/2003, de 21 de noviembre, de Ordenación de las profesiones sanitarias como un órgano de participación de las profesiones sanitarias tituladas, dependiente del Ministerio de Sanidad, Servicios Sociales e Igualdad.

359 "El Ministerio se compromete a que el Foro de las Profesiones Sanitarias esté constituido en el plazo de quince días, así ha quedado pactado en la reunión (a ella acudió el ministro Alfonso Alonso) entre Sanidad y el Foro de la Profesión Médica en la Comisión de Seguimiento de los Pactos firmados en 2013; en el orden del día de la reunión constitutiva, en la Mesa de la Profesión Médica irá el estudio del marco jurídico específico del profesional médico en el SNS...”, 9 de febrero de 2015, [consulta de 10 de febrero de 2015], disponible en: <http://www.elmedicointeractivo.com>.
} 
Capítulo IV. El ejercicio de la negociación colectiva del personal estatutario de los Servicios de salud en el marco legal de la negociación colectiva funcionarial

y por otra, las Organizaciones Sindicales más representativas a nivel estatal, las Organizaciones Sindicales más representativas de Comunidad Autónoma, así como los sindicatos que hayan obtenido el 10 por 100 o más de los representantes en las elecciones para Delegados y Juntas de Personal, en las unidades electorales comprendidas en el ámbito específico de su constitución".

Los sindicatos firmantes deben poseer personalidad jurídica y capacidad plena e independiente para realizar actos jurídicos con terceros. La legitimación de los sindicatos que pueden negociar en cada Mesa viene dada por ostentar la condición de la representatividad que se exija en el ámbito concreto de negociación. Por ello, habrá que tener en cuenta que, en el caso de que una coalición de sindicatos haya presentado candidaturas conjuntas para las elecciones sindicales, igualmente deberá demostrar cada organización sindical de forma independiente su legitimación a la hora de negociar y firmar lo acordado, no así si se trata de una agrupación sindical: STS de 6 de julio de $2004^{360}$.

La contraparte Administración pública deberá ser titular de la competencia sobre la materia a negociar, y sus representantes serán los de los órganos administrativos que tengan asumidas las atribuciones correspondientes en la normativa estatal o autonómica de aplicación.

El artículo 33.2 LEBEP regula la posibilidad de que las Administraciones Públicas puedan encargar el desarrollo de las actividades de negociación colectiva a órganos creados por ellas, de naturaleza estrictamente técnica, que ostentarán su representación en la negociación colectiva, previas las instrucciones políticas correspondientes y sin perjuicio de la ratificación de los Acuerdos alcanzados por los órganos de gobierno o administrativos con competencia para ello. Sin embargo, hay que distinguir esta posibilidad de la representación de la Administración pública por órgano técnico, cuya existencia y presupuestos vemos que están previstos en la ley, de la situación que se puede producir si de facto se traslada la negociación a una ponencia o grupo de trabajo, que no tiene esa función. En este último supuesto, nos encontraríamos con que la negociación se asume por otro órgano diferente de la Mesa, lo que produciría una infracción del procedimiento legalmente establecido y con ello una eventual lesión de la libertad sindical de las organizaciones sindicales participantes.

En cuanto a los requisitos para la válida constitución y composición de las Mesas de negociación, la LEBEP regula este aspecto en su artículo 35.1, siendo esta cuestión de particular importancia, ya que puede afectar al derecho a la libertad sindical de las organizaciones sindicales implicadas en el proceso negociador. Para la válida constitución de las Mesas de negociación la ley exige que: “... además de la representación de la Administración correspondiente, y sin perjuicio del derecho de todas las organizaciones sindicales legitimadas a participar en ellas en proporción a su representatividad, tales

\footnotetext{
${ }^{360}$ Sobre supuesta falta de legitimación para la firma de un Acuerdo del INSALUD por parte del Sindicato de Enfermería SATSE, argumenta que “...CEMSATSE no es una coalición de sindicatos sino una organización única dotada de capacidad plena e independiente para realizar con terceros actos de tráfico jurídico externo", ello porque, según razona el TS, en base a la prueba practicada en el proceso "el sector médico (CEMS) y el sector de enfermería (SATSE) son meras divisiones organizativas del sindicato, y cualquiera de ellas exteriorizan la voluntad de toda la organización”, (RJ 20047567).
} 
Capítulo IV. El ejercicio de la negociación colectiva del personal estatutario de los Servicios de salud en el marco legal de la negociación colectiva funcionarial

organizaciones sindicales representen, como mínimo, la mayoría absoluta de los miembros de los órganos unitarios de representación en el ámbito de que se trate”.

La finalidad de la norma parece ser la de hacer coincidir la legitimidad de la Mesa con la representatividad real de las organizaciones sindicales en cada ámbito de negociación. Como advierte Alfonso Mellado, si las organizaciones sindicales no cumplen este requisito de poseer la mayoría absoluta de los representantes unitarios en el ámbito correspondiente, no puede haber negociación válida, pero la Administración pública puede tener contactos con los sindicatos para procurar el consenso de las normas que deba $\operatorname{aprobar}^{361}$. Esa representatividad se debe acreditar por las organizaciones sindicales interesadas mediante el correspondiente certificado de la Oficina Pública de Registro competente, cada dos años a partir de la fecha inicial de constitución de la Mesa (art. 35.2 LEBEP) $)^{362}$.

El requisito de la legitimación para participar en la negociación en la Mesa provoca en la práctica conflictos que pueden afectar a la libertad sindical de las organizaciones sindicales interesadas, ya que esa participación sindical es una manifestación del derecho fundamental de libertad sindical de las organizaciones sindicales representativas, porque a través de ella llevan a cabo la acción sindical protegida en los artículos 7 y $28.1 \mathrm{CE}$.

En cuanto a las posturas de la doctrina judicial sobre el acceso de las organizaciones sindicales al debate en las Mesas de negociación existe una importante casuística a tener en cuenta, que se podría resumir en los siguientes puntos principales:

$1^{\circ}$.- El cumplimiento de los requisitos legales para el ejercicio del derecho de negociación colectiva de los funcionarios es imprescindible, hasta tal punto que, si no se respetan esos principios, la negociación deviene nula por ausencia de un elemento esencial que vicia el procedimiento ${ }^{363}$. 
$2^{\mathbf{o}}$.- Es necesaria la acreditación de la representatividad sindical correspondiente en el ámbito de la Mesa de negociación, no es suficiente la representatividad en otro ámbito ${ }^{364}$.

$3^{\circ}$.- La sede de la negociación es la Mesa; por tanto, no cabe negociación previa o al margen de esta. La STS de 18 de octubre de 1995 declara nulo un Acuerdo de Mesa sectorial de Sanidad sobre retribuciones de personal estatutario por haberse firmado previamente a la reunión de la Mesa entre la Administración sanitaria y determinados sindicatos componentes de esta, con exclusión de otro, legitimado para formar parte de la misma $^{365}$. Por tanto, la negociación se debe intentar con todos los sindicatos legitimados para estar presentes en la Mesa de negociación, por lo que no cabe excluir a ninguno de ellos de la misma.

$4^{\mathrm{o}}$.- Igualmente, no cabe la negociación directa de una materia con un sindicato con independencia de la Mesa ${ }^{366}$. Asimismo, la STS de 19 de septiembre de 2000 entiende que: "La pluralidad de los miembros del colegio, portadores de intereses distintos, y el conocimiento por cada uno de ellos de las posiciones de los demás en la negociación, con el consiguiente interés de poder debatir la posición de cada uno de ellos, pone de manifiesto que no son equiparables la negociación en el seno del colegio, y las negociaciones separadas. Resulta claro, por tanto, que el derecho a negociar en un determinado colegio no se satisface mediante la negociación alternativa del sindicato con la Administración al margen de él" ${ }^{367}$.

Es decir, el Pacto o Acuerdo válido es el que se produce en el seno de la Mesa de negociación, no en otro foro, tal como señala la STSJ de Cantabria de 20 de mayo de

${ }^{364}$ En este sentido, la SAN de 1 de marzo de 2006 exigió la representatividad superior al 10\% para formar parte de la Mesa de Diálogo Social, no bastando en este caso al Sindicato de Administración Pública la legitimación que ostentaba por tener la condición de miembro de la Mesa General de negociación de la Administración General del Estado, al ser sindicato más representativo en el ámbito de esta. En este caso, el sindicato no pudo acreditar la representatividad en el ámbito de todas las Administraciones públicas, incluida la autonómica y local, requisito exigido para formar parte de la Mesa de Diálogo Social, (JUR 2006\23125).

${ }^{365}$ El TS considera que: “Es jurídicamente correcto que uno o más sindicatos de los definidos en el artículo 35 LORAP lleguen a Acuerdos con los representantes de la Administración, sin que esto atente a la libertad sindical de las restantes organizaciones, sin embargo, sí le afecta que se sustraiga a la Mesa General, y por tanto a sus legítimos componente, el debate pleno de las materias que le son propias, mediante una puntual y oficial negociación de las mismas, en tiempo inmediatamente anterior a la reunión de aquella, con alguno o algunos de los sindicatos representados en la misma, aprobando oficialmente un acuerdo obtenido mediante unas negociaciones en las que uno, al menos, de los sindicatos de la Mesa había sido eludido", (RJ 1995ר7566).

366 STSJ de Castilla-La Mancha, de 20 de marzo de 2002, (JUR 2002\162809), y las del mismo órgano jurisdiccional, de 4 de junio de 2003, (JUR 2003\234126), y de 17 de julio de 2004, (JUR 2004 55531) argumentan que la negociación de los funcionarios legalmente reconocida puede pasar a formar parte del derecho constitucional a la libertad sindical, y el sindicato, en tanto que miembro de la Mesa negociadora, posee legitimación activa para invocarlo. La negociación debe tener lugar en la Mesa correspondiente, no directamente con el sindicato. Todo ello sin perjuicio de que en algunas materias la Mesa Sectorial de Sanidad acordase en su momento la posibilidad de diálogo a niveles inferiores con el fin de concretar la ejecución de lo acordado en la Mesa.

${ }^{367}$ Fundamento jurídico sexto, (RJ 2000\8338). 
$2005^{368}$. Además, la negociación se debe llevar a cabo en la sede de la Mesa legalmente establecida; no se puede desvirtuar la negociación y reducir la reunión de la Mesa a un trámite meramente formal para llevar a cabo la auténtica negociación en otro foro (bien sea una ponencia técnica, órgano ad hoc...) excluyendo a las organizaciones que tienen derecho a participar en la negociación ${ }^{369}$.

$5^{\circ}$.- Se ha de intentar la negociación realmente y ejercitarla de acuerdo con el principio de buena fe, pero si no se consigue llegar a un acuerdo, la Administración puede regular unilateralmente las condiciones de trabajo de sus funcionarios. Es decir, si en la Mesa de negociación correspondiente no se alcanza el acuerdo, la Administración podrá hacer uso de su facultad de decisión unilateral, aunque solo subsidiariamente, en caso de fracaso de la negociación. De cualquier manera, precisamente porque se exige que el acuerdo sea real y no solo aparente, no hay obligación legal de llegar a un acuerdo, ya que la exigencia de negociación no es asimilable a la exigencia de lograr acuerdos: STS de 14 de septiembre de $2004^{370}$ y SAN de 4 de mayo de $2005^{371}$.

$6^{\circ}$.- La vía jurisdiccional competente para conocer de los litigios que surjan en cuanto al acceso al debate de la Mesa de negociación es el orden contencioso

\footnotetext{
${ }^{368}$ Los Grupos de trabajo, previstos en el Acuerdo Marco para el Desarrollo y Mejora de la Sanidad en la Comunidad Autónoma de Cantabria, tienen carácter meramente técnico y de estudio, constituyendo sus conclusiones simplemente propuestas y proyectos de concertación que deben posteriormente someterse a formal negociación y aprobación en la Mesa Sectorial, no hallándose en modo alguno vinculada por el contenido de dichas conclusiones al negociar en este órgano, (RJCA 2005】282).
}

En el mismo sentido se expresa otra sentencia del mismo órgano jurisdiccional de 18 de noviembre de 2004, que señala en el Fundamento jurídico quinto, respecto a la impugnación del Acuerdo sobre jornada del personal estatutario del Servicio Cántabro de Salud, de 18 de diciembre de 2003, que independientemente de la actuación de los Grupos de trabajo que crea dicho Acuerdo “...resulta acreditado, a través de la documentación aportada en el expediente administrativo que demuestra [...] que se trató y se intentó llegar a una Acuerdo por ambas partes, estando presididas sus posturas por el principio de la confianza y de la buena fe, pero no se llegó a un consenso entre las dos partes, ante lo cual y teniendo la Administración motivos argumentados que expuso en la Mesa Sectorial acerca de un compromiso de implantar la reducción de jornada de 35 horas el 1 de enero de 2004 y razones de dificultad presupuestaria para admitir las conclusiones propuestas por los Grupos de trabajo y lo pretendido por la representación social se optó por ejercer la facultad que ostenta la Administración conforme al artículo 80.5 LEM y artículo 37.2 LORAP [...] la actuación de la Administración no puede ser considerada vulneradora del principio de libertad sindical ya que no se ha cercenado en modo alguno el derecho a negociar de las partes, pues a ello en nada empece el no haberse obtenido un consenso", (JUR 2005\20676).

${ }^{369}$ STS de 18 de octubre de 1995: "Siendo jurídicamente correcto que uno o más sindicatos de los definidos en el artículo 35 de la Ley 9/1987 lleguen a Acuerdos o Pactos con representantes de la Administración, sin que esto atente a la libertad sindical de las restantes organizaciones, sin embargo sí le afecta que se sustraiga a la Mesa General y, por tanto, a sus legítimos componentes, el debate pleno de las materias que le son propias, mediante una puntual y oficial negociación de las mismas, en tiempo inmediatamente anterior a la reunión de aquella, con alguno o algunos de los sindicatos representados en la misma, aprobando oficialmente un acuerdo obtenido mediante unas negociaciones en las que uno, al menos, de los sindicatos de la Mesa había sido eludido", (RJ 1995\7566). En el mismo sentido la SAN de 4 de mayo de 2005, (JUR 2005 266281).

${ }^{370}$ (RJ 20045828).

${ }^{371}$ (JUR 2005\266281). 
administrativo: STSJ de Madrid de 20 de enero de 2009 ${ }^{372}$; STSJ de Cantabria de 13 de diciembre de $2004^{373}$.

En cuanto al número de miembros de las Mesas de negociación, hay que tener en cuenta que el apartado cuatro del artículo 35 LEBEP establece que: "En las normas de desarrollo del presente Estatuto se establecerá la composición numérica de las Mesas correspondientes a sus ámbitos, sin que ninguna de las partes pueda superar el número de quince miembros".

Esta norma, para la doctrina se debe interpretar en el sentido de reconocer un representante, como mínimo, para cada organización sindical y, posteriormente, repartir los restantes puestos de la Mesa de forma proporcional, según los resultados electorales obtenidos en la representación unitaria de referencia ${ }^{374}$.

Sobre el procedimiento de negociación ${ }^{375}$, hay que decir que este se iniciará en los términos del artículo 34.6 LEBEP: "El proceso de negociación se abrirá, en cada Mesa, en la fecha que, de común acuerdo, fijen la Administración correspondiente y la mayoría de la representación sindical. A falta de acuerdo, el proceso se iniciará en el plazo máximo de un mes desde que la mayoría de una de las partes legitimadas lo promueva, salvo que existan causas legales o pactadas que lo impidan".

Una vez iniciado el procedimiento de negociación, este se debe ajustar a una serie de principios que vimos anteriormente y, en la práctica conviene, además, que se ajuste a un iter previsto en el reglamento de funcionamiento de la Mesa. En efecto, las Mesas de negociación, generales, autonómicas o sectoriales, deben tener su reglamento de organización y funcionamiento; incluso parece conveniente que este sea objeto de publicación ${ }^{376}$.

$\mathrm{Al}$ reglamento interno le corresponderá regular la forma de tomar los acuerdos en la Mesa, partiendo del principio de la mayoría de votos favorables, aunque hay que tener en

${ }^{372}$ (AS 20099931).

${ }^{373}$ Que dice: “... el orden social carece de competencia para conocer de la impugnación de los Acuerdos colectivos de la función pública por infracciones sustantivas o por vulneración de las reglas sobre la legitimación y el procedimiento de la negociación colectiva”. (JUR 2005\14551).

${ }^{374}$ CANTERO MARTINEZ, J., "La negociación colectiva en el ámbito de la función pública..." op.cit.

${ }^{375}$ Sobre el procedimiento de negociación véase de ROQUETA BUJ, R., "Derechos individuales ejercidos colectivamente", p. 146 y ss, en AA.VV., El Estatuto Básico del Empleado público y su desarrollo por el Estado y las CC.AA., Colex, Madrid, 2008.

${ }^{376}$ El Reglamento de organización y funcionamiento de la Mesa Sectorial de Negociación del Servicio Gallego de Salud viene publicado en el Diario Oficial de Galicia, de 25 de febrero de 2008, según lo acordado por la Administración sanitaria y las organizaciones sindicales integrantes de la misma en fecha 6 de noviembre de 2007. 
Capítulo IV. El ejercicio de la negociación colectiva del personal estatutario de los Servicios de salud en el marco legal de la negociación colectiva funcionarial

cuenta que el porcentaje de representatividad obtenido por cada sindicato es el que determina el valor de su voto en los acuerdos que se toman en el foro de negociación ${ }^{377}$.

Por último, aunque la Mesa se deberá constituir válidamente y la negociación deberá intentarse con todas las organizaciones presentes en ella, ello no significa que para que sea válido el Acuerdo o Pacto definitivo que se tome tenga que ser aceptado por una mayoría sindical. En este sentido se expresa la STS de 17 de octubre de 2003 según la que el Acuerdo incluso con una sola parte sindical es válido, siempre que se hayan cumplido los requisitos y principios de la negociación ${ }^{378}$.

\subsection{5.- EFECTOS DE LA FALTA DE ACUERDO EN LA NEGOCIACIÓN}

Cuando fracasa la negociación, siempre que se haya respetado el procedimiento establecido al efecto y los principios de la negociación, está legitimada la Administración para llevar a cabo una regulación de la materia de forma unilateral, según el artículo 38.7 LEBEP, que dispone que: "En el supuesto de que no se produzca acuerdo en la negociación o en la renegociación y una vez agotados, en su caso, los procedimientos de solución extrajudicial de conflictos, corresponderá a los órganos de gobierno de las Administraciones Públicas establecer las condiciones de trabajo de los funcionarios con las excepciones contempladas en los apartados 11, 12 y 13 del presente artículo" (excepciones que se refieren a la prórroga tácita que se puede haber establecido, o a la posibilidad de que en el Acuerdo o Pacto que llega a su fin se haya dispuesto la vigencia de ciertos aspectos).

La misma disposición se recoge en el artículo 80.5 LEM respecto a la negociación colectiva en el ámbito del personal estatutario, diciendo que: "Corresponderá al Gobierno, $o$ a los Consejos de Gobierno de las CC.AA., en sus respectivos ámbitos, establecer las condiciones de trabajo del personal estatutario cuando no se produzca acuerdo en la negociación o no se alcance la aprobación expresa y formal a que alude el apartado 1 de este artículo".

El recurso a la decisión unilateral de las condiciones de trabajo de los funcionarios públicos está respaldado por la jurisprudencia, siempre y cuando se hayan cumplido los trámites de la negociación y respetado el principio de la buena fe negocial (STS de 1 de junio de $2011^{379}$ ), al igual que respecto a la negociación colectiva del personal estatutario de los Servicios de salud, exigiéndose normalmente que conste que las partes intentaron el acuerdo en la Mesa de negociación, pero que no se consiguió. Esa

\footnotetext{
${ }^{377}$ Véase como ejemplo el artículo 11 del Reglamento de la MSNS relativo al régimen de adopción de Pactos y Acuerdos.

378 "... en relación a la mayoría sindical, aparte de que de los preceptos de aplicación no se deduce la necesidad, para la validez del acuerdo administrativo final, que cierra el proceso negociador mediante, en su caso, la oportuna ratificación de lo acordado, de que en el mismo se haya llegado a una mayoría sindical que respalde lo que se ratifica”, (RJ 2003\7824).

379 (RJ 201 15799$)$.
} 
Capítulo IV. El ejercicio de la negociación colectiva del personal estatutario de los Servicios de salud en el marco legal de la negociación colectiva funcionarial

circunstancia se puede acreditar, por ejemplo, a través de las actas de las reuniones de la $\mathrm{Mesa}^{380}$

\subsection{6.- RATIFICACIÓN DE LOS ACUERDOS POR EL ÓRGANO DE GOBIERNO}

Si se produce el acuerdo final en la negociación, nos encontramos con la fase de firma del Pacto o Acuerdo. Una vez firmados por las partes negociadoras, ambos instrumentos normativos tienen distinta eficacia, ya que los efectos jurídicos de los Pactos se producen a partir de su firma, tras un procedimiento válido de negociación entre las partes legitimadas, (art. 38.2 LEBEP), y los de los Acuerdos requieren otro requisito, como es el acto de la ratificación del órgano de gobierno (art. 38.3 LEBEP): "Los Acuerdos versarán sobre materias competencia de los órganos de gobierno de las Administraciones Públicas. Para su validez y eficacia será necesaria su aprobación expresa y formal por estos órganos".

Para la jurisprudencia, la aprobación del órgano de gobierno no podrá subsanar defectos de nulidad, como puede ser la falta de legitimación de las partes firmantes. Así, lo declara la STS de 10 de noviembre de 1997, en un supuesto en el que SATSE impugnó la exclusión de la Comisión de seguimiento de un Acuerdo de la Mesa sectorial del INSALUD en el que no participó como firmante ${ }^{381}$.

El acto de ratificación está considerado como un acto meramente formal y obligado, a no ser que el Acuerdo que se deba aprobar contenga algún tipo de defecto, material o formal, o se advierta que la materia debía ser regulada por ley.

\footnotetext{
${ }^{380}$ Véase la STSJ de Castilla y León, de 13 de marzo de 2007, en un supuesto de impugnación de resoluciones de la Gerencia Regional de Salud de Castilla y León sobre criterios de reparto de retribuciones en concepto de productividad variable de personal estatutario, en el Fundamento jurídico cuarto, entiende justificada la decisión unilateral de la Administración porque intentada la negociación no hubo acuerdo en la Mesa sectorial correspondiente, (JUR 200入215209). Asimismo, con similar argumentación, la STSJ de Cantabria 30 de junio de 2006, Fundamento jurídico quinto: “...no puede aceptarse el segundo de los motivos aducidos por el recurrente de que se haya actuado por el Gobierno de Cantabria en fraude de ley por el uso del poder de regulación unilateral que le confieren los preceptos mencionados anteriormente y como dice la referida sentencia de la sala, "acreditada la falta de consenso en el seno de la Mesa sectorial y derivada la misma de la existencia de diferencias insalvables por diversas razones (presupuestarias, sobre todo), sin que se haya demostrado la existencia de mala fe o ausencia de voluntad negociadora por parte de la Administración, no cabe sino concluir que ejerció dicho poder con arreglo a la finalidad o el propósito legalmente perseguido al prever ese cauce alternativo de regulación. Así, pues, no podemos acoger la causa de ilegalidad que, por fraude de ley, alega la entidad recurrente, ni tampoco, como diremos luego, el motivo de impugnación referido a la desviación de poder en que habría incurrido la Administración según la recurrente..(JUR 2006248417).

${ }^{381}$ Fundamento jurídico segundo: "Aunque es cierto que el Consejo de Ministros, en su reunión de 10 de junio de 1992, procedió a la aprobación del Acuerdo, haciendo constar como parte del mismo al Sindicato de Enfermería (SATSE) y que su validez y eficacia se condiciona por la Ley al mencionado acto aprobatorio del Gobierno, sin embargo ello no obsta a que este acto no pueda desnaturalizar los elementos subjetivos que, con arreglo a la propia Ley, puedan ser considerados parte del mismo, con todos los derechos a ello inherentes, como la de ser miembro de la Comisión de Seguimiento, por lo que no desvirtuados en este punto los argumentos dados por la Sala de instancia sobre la imposibilidad del Sindicato accionante de ser parte de pleno derecho en el Acuerdo, por no tener la calidad de más representativo", (RJ 19979014).
} 
Algunas resoluciones judiciales consideran que la ratificación en sí misma ya es suficiente para dar valor a lo acordado y no es necesaria la publicación de norma reglamentaria alguna que incorpore su contenido ${ }^{382}$. Otras, en cambio, entienden que la ratificación es meramente un acto administrativo y que, en consecuencia, es necesaria la aprobación del correspondiente reglamento que incorpore lo convenido ${ }^{383}$. De cualquier manera, sí coincide la doctrina judicial en considerar que la ratificación del órgano de gobierno es imprescindible, y en todo caso una particularidad de la negociación colectiva de los funcionarios públicos, condicionada a la aprobación de la autoridad ${ }^{384}$.

Una vez ratificado el Acuerdo por el órgano de gobierno, el artículo 38.3.1 LEBEP dispone que: "Cuando tales Acuerdos hayan sido ratificados y afecten a temas que pueden ser decididos de forma definitiva por los órganos de gobierno, el contenido de los mismos será directamente aplicable al personal incluido en su ámbito de aplicación, sin perjuicio de que a efectos formales se requiera la modificación o derogación, en su caso, de la normativa reglamentaria correspondiente".

En el caso de que la materia sobre la que recae el Acuerdo esté sometida al principio de reserva de ley, y por tanto, solo pueda ser definitivamente decidida por las Cortes Generales o las Asambleas Legislativas de las CC.AA., la LEBEP dispone que el contenido de los Acuerdos carecerá de eficacia directa, y el órgano de gobierno respectivo que tenga la iniciativa legislativa procederá a la elaboración, aprobación y remisión a las Cortes Generales o Asambleas Legislativas de las CC.AA. del correspondiente proyecto de ley conforme al contenido del Acuerdo y en el plazo que se hubiera acordado" (art. 38.3.2) ${ }^{385}$.

\footnotetext{
382 STSJ de Cantabria de 30 de junio de 2006, que en su Fundamento jurídico séptimo, respecto a la impugnación del Acuerdo del Consejo de Gobierno de 18 de diciembre de 2003 que fijaba la jornada de trabajo del personal estatutario del Servicio Cántabro de Salud, establece que basta la simple aprobación expresa y formal por parte del Consejo de Gobierno de la Comunidad autónoma para dar validez y eficacia a los Acuerdos sobre condiciones de empleo de los funcionarios públicos, y no es necesaria la aprobación del acuerdo siguiendo el procedimiento previsto para la elaboración de disposiciones de carácter general y con la forma propia de Decreto, (JUR 2006248417). En el mismo sentido la sentencia del mismo órgano jurisdiccional de 15 de diciembre de 2006, (JUR 200خ52674).
}

383 STSJ de Andalucía de 22 de marzo de 2010, que no considera de rango reglamentario el Acuerdo del Consejo de Gobierno andaluz por el que se aprueba el Acuerdo de la Mesa Sectorial de Sanidad de 30 de diciembre de 2003 sobre régimen de vacaciones, permisos y licencias del personal de centros e instituciones sanitarias del Servicio Andaluz de Salud por "no tratarse de una disposición general, sino de un acto administrativo del Consejo de Gobierno”, (JUR 2010 331047).

${ }^{384}$ La STSJ de Cantabria de 2 de abril de 1996, Fundamento jurídico único, en un supuesto de reclamación de la retribución de productividad fija por una matrona en base a un Acuerdo suscrito con el INSALUD que no había sido ratificado por el Consejo de Ministros ni publicado en el boletín oficial declaró: “... la negociación colectiva se rige por la Ley 9/1987, de 12 junio. Supone esta última norma la falta de aplicación del Estatuto de los Trabajadores y del artículo 37, apartado 1 de la Constitución Española, al existir una negociación colectiva distinta y más limitada, una de cuyas exigencias es precisamente la establecida en el artículo 35 de la Ley 9/1987, dentro del Capítulo III (participación en la determinación de las condiciones de trabajo), es decir la aprobación expresa y formal del Consejo de Ministros, (AS 1996\1999).

${ }^{385}$ Véase DIAZ REVORIO, F. J., El derecho a la negociación colectiva de los empleados públicos: algunas ideas desde la perspectiva constitucional, Repertorio Aranzadi del Tribunal Constitucional, Aranzadi, Pamplona, 1998. En opinión de este autor, la negociación colectiva de los funcionarios se limita en los 
Es decir, si lo acordado afecta a materia reservada a la ley, el Acuerdo tan solo recogerá el compromiso del gobierno de elaborar un proyecto de ley que contenga lo previamente pactado y someterlo a las Cortes, teniendo en cuenta que el resultado podrá diferir de lo que se convino en la Mesa de negociación, si así lo decide el órgano legislativo.

Puede pasar también que el órgano de gobierno decida no ratificar el Acuerdo o que se niegue a presentar el proyecto de ley correspondiente. En este caso la LEBEP determina que deberá iniciarse la renegociación de las materias tratadas en el plazo de un mes, si así lo solicitara al menos la mayoría de una de las partes (art. 38.3.3). Los Pactos, sin embargo, no requieren ratificación. Una vez aprobados es competencia de la autoridad administrativa la firma de la resolución que ordene su depósito y publicación en el boletín oficial que corresponda.

\subsection{7.- LA ADHESIÓN AL PACTO O ACUERDO}

La adhesión a lo acordado implica la manifestación de voluntad por parte de una organización sindical, que no ha participado en el procedimiento de negociación del Pacto o Acuerdo, en el sentido de aceptar lo convenido en él por las partes firmantes y vincularse por su contenido, sin reservas, con los efectos jurídicos que procedan.

Respecto a la naturaleza jurídica de la adhesión a los Pactos y Acuerdos, la STSJ de Cantabria de 19 de febrero de 2004, ha declarado que esta no es una mera declaración formal abstracta, sino una expresión de la voluntad real de la parte, que debe responder a un fondo de asentimiento del acuerdo, según el artículo 1.281 Código Civil. En caso contrario, prevalece la intencionalidad real sobre la forma, con lo que si faltara el consentimiento no sería válida la adhesión al Acuerdo ${ }^{386}$. La adhesión le da también derecho al sindicato a participar en las Comisiones de seguimiento del Acuerdo o Pacto, junto con el resto de firmantes.

supuestos de reserva de ley a ser simplemente una condición previa para el ejercicio de la correspondiente iniciativa legislativa por parte del Gobierno central o los Gobiernos autonómicos.

${ }^{386}$ Se trata de un supuesto de adhesión de un sindicato a dos Acuerdos vigentes del Servicio Cántabro de Salud utilizando la cláusula "por imperativo legal". La sentencia declara que "cuando la forma de expresar el consentimiento revela la falta de asentimiento sobre el fondo, entonces la interpretación de la voluntad de las partes ha de atenerse a su intencionalidad real y no a la mera expresión formal, como determina el segundo párrafo del artículo 1281 del Código Civil -si las palabras parecieren contrarias a la intención evidente de los contratantes, prevalecerá esta sobre aquellas- que determina en nuestro Derecho la prevalencia de la voluntad sobre la forma. Así en este caso el añadido de la expresión por imperativo legal a la manifestación formal de adhesión deja vacía de contenido esta, puesto que revela el desacuerdo con el fondo del contenido de aquel contrato colectivo al que la parte se adhiere, por lo que tal manifestación puramente formal es incapaz de desplegar su eficacia. Es obvio que quien negocia y firma un contrato, individual o colectivo, puede sentirse más o menos satisfecho con lo conseguido durante su negociación, pero finalizada esta lo que a la postre importa es si, sopesados inconvenientes y ventajas, decide libremente su firma o adhesión. Si así lo hace no caben reservas que indiquen su disconformidad, puesto que con ello lo único que se hace es privar de validez a la expresión de su consentimiento, que queda reducido a mera formalidad sin contenido", (AS 2004442). 
En cuanto a qué organizaciones sindicales se pueden adherir a los Pactos o Acuerdos, nos encontramos con que la ley no regula esta cuestión. Por ello mismo, las condiciones en las que podrá tener lugar se deben prever en los propios instrumentos negociados. Parece que no se puede discutir el derecho a adherirse con posterioridad a las organizaciones sindicales con legitimación para formar parte de la Mesa que, por el motivo que fuere, no firmaron lo pactado en su momento; pero hay Acuerdos que contemplan incluso la posibilidad de adhesión por parte de los sindicatos que no tengan esa legitimación y tan solo alguna, o determinada, representación en los órganos unitarios del personal en el ámbito de la Administración pública correspondiente ${ }^{387}$.

En cuanto a la forma en que se deberá producir la adhesión, esta deberá ser expresa y manifestada por escrito para su constancia, pero es discutible si basta una declaración unilateral de la organización sindical interesada en este sentido o la adhesión debe ser aceptada por las demás organizaciones sindicales. Este aspecto deberá ser también objeto de negociación en el propio Pacto o Acuerdo entre las partes firmantes, pudiendo pactarse un protocolo de adhesión que sea exigible a las organizaciones sindicales que quieran, posteriormente a su firma, vincularse a los mismos ${ }^{388}$.

En estos casos, el procedimiento de adhesión se inicia por solicitud de la organización sindical que la desea y, previa convocatoria formal de la correspondiente Mesa de negociación, se celebra una reunión en la que los participantes acuerdan, por mayoría, aceptar la adhesión solicitada. A continuación para su constancia se levanta acta del acuerdo adoptado en Mesa, para su posterior publicación en el boletín correspondiente ${ }^{389}$.

En otras ocasiones, la adhesión se produce mediante la comunicación del sindicato a la Administración firmante que, posteriormente, se remite a la Oficina Pública de Registro y se publica en el boletín correspondiente, sin la intervención del resto de sindicatos firmantes ${ }^{390}$.

${ }^{387}$ El artículo 2.3 del Acuerdo de 29 de octubre de 2012, de la Mesa General de Negociación de la Administración General del Estado, exige a las organizaciones sindicales que deseen solicitar su adhesión al Acuerdo, que hayan obtenido más del $2 \%$ de los representantes en las elecciones a Delegados de Personal, comités de empresa y juntas de personal en el ámbito del mismo y, además, la aprobación por la mayoría de las organizaciones sindicales presentes en la Mesa.

${ }^{388}$ Como ejemplo, en el Pacto sobre derechos sindicales en el ámbito de la Administración de la Generalitat de Cataluña, de 22 de diciembre de 2004, se exigía el cumplimiento de un procedimiento concreto, que requería que la adhesión de la organización sindical se produjera en el marco de la Mesa de negociación correspondiente, no siendo suficiente la mera comunicación a la Mesa o a la autoridad administrativa y al resto de las organizaciones sindicales. Diario Oficial Generalitat Catalana, de 21 de abril de 2005.

389 Ejemplo reciente es la Resolución de 5 de febrero de 2013, de la Dirección de Recursos Humanos del Servicio Gallego de Salud, por la que se publica el acta de adhesión al Pacto sobre selección de personal estatutario temporal en el ámbito del Servicio Gallego de Salud y entidades públicas adscritas a la Consejería de Sanidad. Diario Oficial de Galicia de 15 de febrero de 2013.

${ }^{390}$ Es el caso de la adhesión de CC.OO. al Pacto de 3 de octubre de 2003, sobre permisos, secciones sindicales y uso de crédito horario para la realización de funciones sindicales y de representación del personal al servicio de las Instituciones Sanitarias del Servicio Cántabro de Salud. Boletín Oficial de Cantabria de 30 de octubre de 2003. 
Capítulo IV. El ejercicio de la negociación colectiva del personal estatutario de los Servicios de salud en el marco legal de la negociación colectiva funcionarial

\subsection{8.- VINCULACIÓN DE LOS PACTOS Y ACUERDOS}

Los Acuerdos y Pactos tienen un ámbito subjetivo y objetivo concreto: serán de aplicación a un colectivo determinado de personal funcionario, estatutario e incluso laboral que esté representado en el foro en el que se ha llevado a cabo la negociación con los representantes de la Administración pública, al cual van destinadas las disposiciones acordadas.

En este sentido, cabe destacar que, en cuanto a los efectos de la negociación conjunta para funcionarios y laborales, el artículo 38.8 LEBEP dispone que: "Los Pactos y Acuerdos que, de conformidad con lo establecido en el artículo 37, contengan materias y condiciones generales de trabajo comunes al personal funcionario y laboral, tendrán la consideración y efectos previstos en este artículo para los funcionarios y en el artículo 83 del Estatuto de los Trabajadores para el personal laboral”.

Estos instrumentos negociados tendrán, en consecuencia, unos determinados efectos jurídicos para todo el personal incluido en su ámbito subjetivo; si bien, como hemos visto antes, en el caso de los Acuerdos, habrá que esperar a que el órgano de gobierno los ratifique.

En definitiva, lo acordado en los Pactos y Acuerdos tiene eficacia general para todo el personal representado que cumpla, objetivamente, los requisitos para estar incluido en su ámbito personal. Así se desprende del apartado 1 del artículo 38 LEBEP: “...para la determinación de condiciones de trabajo de los funcionarios de dichas Administraciones”.

Todo ello en el caso de que la materia que se negocie afecte a cualquier aspecto del régimen jurídico de los empleados públicos, según la relación de materias dada en la ley: retribuciones, carrera profesional, derechos sindicales...

Pero además, el contenido de lo negociado vincula a las partes; es decir, a la propia Administración y a las organizaciones sindicales que lo firmaron o se adhirieron con posterioridad $^{391}$. En este sentido, la STSJ de Canarias de 30 de abril de 1996 ha declarado la vigencia del principio pacta sunt servanda que obliga a respetar el Acuerdo firmado a todas las partes implicadas, a excepción de que vulnere norma imperativa ${ }^{392}$.

\footnotetext{
${ }^{391}$ Sobre la distinción entre el contenido normativo (las disposiciones acordadas que tienen como destinatario al personal afectado) y el contenido obligacional (las que obligan a la Administración y a los sindicatos firmantes) de los Pactos y Acuerdos, véase ROQUETA BUJ, R., El derecho de negociación colectiva en el Estatuto..., op.cit. p. 491 y ss.

392 Fundamento jurídico primero: “...la contradicción entre la Instrucción del INSALUD y el Acuerdo (adoptado entre las organizaciones sindicales y la Administración aprobado por el Consejo de Ministros de 20 de noviembre de 1992) se salva a favor de lo dispuesto en el Acuerdo, aunque este nazca de una fuente convencional, por aplicación del principio de jerarquía normativa. Un Acuerdo del Consejo de Ministros no puede ser contradicho por Instrucciones o resoluciones del INSALUD, según los artículos 9.3 CE, 12 del Código Civil y 6 de la Ley Orgánica del Poder Judicial. Por otra parte, si se considera que la naturaleza de dicho Acuerdo fuera convencional (el Acuerdo del Consejo de ministros aprueba a modo de ratificación el Acuerdo entre Administración y sindicatos) aún habría otra razón adicional para acercarse a la posición de la actora, pues las instrucciones y circulares no pueden alterar el Acuerdo, por virtud del principio pacta sunt servanda, principio con soporte no solo iusprivatista de los artículos 1.091 y 1.278 Código Civil, sino también
} 
Hay que tener en cuenta que las partes no podrán volverse contra lo acordado y, en consecuencia, carecerán de legitimación para impugnar después lo convenido, en base al principio de que no se puede ir contra los propios actos, tal como señala la STSJ de Navarra de 7 de mayo de 1997. En este supuesto el Sindicato de Enfermería impugnó los baremos de méritos en las convocatorias para la provisión por concurso-oposición de los puestos de trabajo del Servicio Navarro de Salud tras firmar los Acuerdos sobre condiciones de empleo de febrero de 1992 y de mayo de 1993, en los que se pactaban entre las partes los principios a seguir en su valoración, así como los concretos baremos de méritos a contemplar. La sentencia razona que: "efectivamente esta postura no solo es un venire contra propium factum, sino que alcanza el grado de causa de inadmisibilidad de recurso contencioso administrativo por falta de legitimación de la parte actora, firmante de los pactos, impugnante de lo que ella aprobó en su día"393.

Sobre si el contenido de los Pactos o Acuerdos puede o no empeorar condiciones de trabajo de los empleados públicos, hay que tener en cuenta, que el criterio jurisprudencial es el de no admitir la aplicación de la doctrina de los derechos adquiridos al personal funcionario y estatutario, por lo que lo convenido en Pacto o Acuerdo no genera condición más beneficiosa, y aquello que se convenga puede ser modificado por otro Acuerdo o Pacto posterior que disponga un empeoramiento de las condiciones de trabajo de los funcionarios, sin que nada obste a ello ${ }^{394}$.

Hay que tener en cuenta que cuando el objeto de la negociación es regular aspectos relativos a los derechos y garantías sindicales, los destinatarios de lo negociado son más bien las organizaciones sindicales y los representantes sindicales y del personal, no tanto los funcionarios y personal estatutario, que no pueden ejercitarlos como tales. Al fin y al cabo estos Acuerdos regulan derechos individuales, pero de ejercicio colectivo (art. 15 LEBEP). Por tanto, en los Acuerdos y Pactos sobre derechos sindicales el contenido de lo negociado habitualmente solo tiene efectos para la Administración y las organizaciones sindicales que se obligan con su firma. En este caso se confunde en los mismos sujetos el papel de negociador y de destinatario de lo negociado.

Nos preguntamos entonces ¿cómo afecta en estos supuestos lo pactado a las organizaciones sindicales que ni firman ni se adhieren a lo acordado por otras con la Administración? En los propios Acuerdos y Pactos sobre acción sindical se dispone el alcance de sus efectos. Lo convenido entre la Administración y las organizaciones sindicales no suele afectar a aquellas que no firmaron o que no se adhirieron posteriormente a lo convenido. Por tanto, para estas habrá que estar a lo que dispongan las normas que contienen las disposiciones mínimas sobre derechos y garantías sindicales: la LOLS, la LEBEP y la LEM.

en el campo del Derecho administrativo al regularse los Pactos entre los sindicatos y la Administración en la LORAP”, (AS 1996\2007).

393 (RJCA 19972264).

${ }^{394}$ STSJ de Andalucía de 6 de septiembre de 1996, Fundamento jurídico segundo, (AS 19962837). 
Capítulo IV. El ejercicio de la negociación colectiva del personal estatutario de los Servicios de salud en el marco legal de la negociación colectiva funcionarial

\subsection{9.- CLÁUSULAS DE VIGENCIA, PRÓRROGA Y PUBLICIDAD}

La vigencia del Pacto o Acuerdo será la que acuerden las partes, que pueden determinar una duración concreta en años, o bien dejar la fecha de fin abierta con una cláusula que establezca su vigencia hasta su sustitución por otro. En la práctica, difícilmente encontramos Acuerdos o Pactos de duración superior a cuatro años, siendo frecuentes los que establecen plazos inferiores, de uno o dos años. En el apartado 12 del artículo 38 LEBEP se prevé que: "La vigencia del contenido de los Pactos y Acuerdos una vez concluida su duración, se producirá en los términos que los mismos hubieren establecido".

Por ello, la prórroga puede ser tácita hasta que las partes convoquen la apertura del proceso negociador y se acabe firmando un Acuerdo o Pacto nuevo. Esta prórroga, salvo acuerdo en contrario, será de año en año "si no mediara denuncia expresa de una de las partes" (art. 38.11 LEBEP).

El apartado 6 del artículo 38 LEBEP incorpora el principio de publicidad ya visto antes, determinando que es necesaria la publicación de los Pactos y Acuerdos una vez firmados o ratificados por el órgano administrativo o el Consejo de Gobierno correspondiente: "Los Pactos celebrados y los Acuerdos, una vez ratificados, deberán ser remitidos a la Oficina Pública que cada Administración competente determine y la autoridad respectiva ordenará su publicación en el Boletín Oficial que corresponda en función del ámbito territorial”.

El titular del órgano administrativo con competencia para ello, en la respectiva Administración autonómica o en el Estado, dictará una resolución por la que ordenará su depósito y publicación.

En cuanto a los efectos de la falta de publicación de los Acuerdos y Pactos, se puede discutir hasta qué punto el incumplimiento del requisito de la publicación acarrea la falta de efectos de lo convenido. En este sentido, apunta Manzana Laguarda que la publicación es un presupuesto para que lo acordado tenga fuerza obligatoria y eficacia jurídica normativa, no solo obligacional, es decir, que se aplique a todos los funcionarios afectados por la negociación ${ }^{395}$.

Con respecto a la derogación, el apartado 13 del mismo precepto dispone que: "Los Pactos y Acuerdos que sucedan a otros anteriores los derogan en su integridad, salvo los aspectos que expresamente se acuerde mantener", que no es sino expresión del principio de modernidad en la sucesión de Acuerdos y Pactos.

\section{3.- EL CONTROL SOBRE LO ACORDADO}

Los efectos del acordado en Pacto o Acuerdo se extienden a regular las condiciones de trabajo del personal que tienen que ver con las materias objeto de negociación, como hemos visto. A la hora de la aplicación práctica de los Pactos y Acuerdos pueden surgir

${ }^{395}$ MANZANA LAGUARDA, R., Derechos y deberes de los funcionarios públicos, op.cit., pp. 278-279. 
conflictos en su interpretación, por lo que en atención a este hecho se prevén en los propios instrumentos normativos la existencia de Comisiones de Seguimiento, que también observarán su cumplimiento. Además de ello, hay que tener en cuenta que los órganos jurisdiccionales del orden contencioso administrativo son competentes para conocer de las impugnaciones de su contenido material o de sus aspectos de procedimiento y forma.

\subsection{1.- LAS COMISIONES DE SEGUIMIENTO}

Las Comisiones de seguimiento de los Acuerdos y Pactos están previstas en el artículo 38.5 de la LEBEP: "Se establecerán comisiones paritarias de los Pactos y Acuerdos con la composición y funciones que las partes determinen”. El carácter paritario de las Comisiones viene dado por el número de integrantes designados, que deberá ser el mismo por la parte sindical y por la Administración. En representación de la parte sindical los integrantes de la Comisión se deben designar por cada sindicato según criterios de proporcionalidad.

En relación con la naturaleza jurídica de las Comisiones de seguimiento hay que decir que no son órganos públicos, sino meramente privados, compuestos por representantes de la Administración correspondiente y de las organizaciones sindicales firmantes $\mathrm{o}$ adheridas a los respectivos Acuerdos o Pactos, que son quienes tienen derecho a participar en ellas.

La jurisprudencia constitucional considera ajustada a derecho la exclusión de las Comisiones de seguimiento de los convenios colectivos de aquellos sindicatos no firmantes o adheridos a los mismos ${ }^{396}$. La misma argumentación es aplicable a la negociación colectiva funcionarial y, más en concreto, del personal estatutario: la autoexclusión de un sindicato en la negociación colectiva de un Acuerdo conlleva la procedente ausencia en la Comisión de seguimiento del mismo.

La STS de 28 de junio de 2005, en un supuesto en el que se niega a CCOO el derecho a participar en la Comisión de seguimiento de un Acuerdo que no firmó con el Servicio de Salud del Principado de Asturias, considera que no existe vulneración del derecho a la negociación colectiva de dicho sindicato puesto que se autoexcluyó de la negociación al no firmar el Acuerdo ${ }^{397}$. En el mismo sentido la STSJ de Comunidad Valenciana de 3 de octubre de $2005^{398}$.

\footnotetext{
${ }^{396}$ Respecto a la negociación colectiva laboral, tiene declarado que la decisión de restringir la presencia en una Comisión de control y seguimiento de un Acuerdo colectivo a solo aquellos sindicatos firmantes o adheridos al mismo no puede ser calificada de arbitraria, sino, por el contrario, de adecuada a la finalidad perseguida y, en este sentido, objetiva. STC 9/1986, (RTC 19869) y STC 39/1986, (RTC 1986\39).

${ }^{397}$ Concluye la Sala que si la organización sindical “no participó en lo negociado, fue porque en virtud de una decisión propia no firmó el acuerdo de 2002, ni formó parte de las comisiones creadas; pero es que además la materia relativa a la aplicación de la nueva jornada, con respecto al personal que trabajaba en régimen de turno, ya figuraba en el Acuerdo de 5 de julio de 2002 que puso fin a la huelga, dejando constancia, en su pacto primero, relativo a la homologación del personal sanitario del Principado de Asturias donde se preveía la constitución de un grupo de trabajo que desarrolle la aplicación de la nueva jornada con respecto al personal que trabaja en régimen de turnos, grupo de trabajo, que no es otro, que la Comisión de Seguimiento creada por el Acuerdo, siendo las conclusiones a la que esta llegó las plasmadas en el acta de 29 de marzo de 2003, que la Administración hizo suya en 30 de abril de 2004, por vía reglamentaría, dictando instrucciones
} 
La jurisprudencia también niega que estas Comisiones tengan capacidad negociadora, ya que esta solo la poseen las Mesas de negociación. En este sentido se expresa la STS de 17 de octubre de 2003, que argumenta: “... existe una jurisprudencia consolidada, que distingue entre las Comisiones negociadoras y las de seguimiento. Las primeras se constituyen para establecer o modificar las condiciones de trabajo, respecto a las cuales todos los sindicatos, con representación legal bastante, tienen derecho a formar parte de ellas. Las segundas son meramente interpretativas y aplicadoras de lo que ya se ha convenido por las Comisiones Negociadoras. Para formar parte de estas están solo legitimados los sindicatos firmantes del Acuerdo" ${ }^{399}$.

Otro caso es que en esas Comisiones de seguimiento del Acuerdo o Pacto, en la práctica, se lleve a cabo una auténtica negociación, en cuyo caso los sindicatos que no firmaron el Acuerdo o Pacto sí tendrían derecho a participar en ellas porque ya no se trataría del derecho a participar en Comisiones de seguimiento, sino del derecho a negociar. Así se pronuncia la STSJ de Cantabria de 26 de octubre de 2004, que resuelve la impugnación del Acuerdo Marco para el desarrollo y la Mejora de la Sanidad en la Comunidad autónoma de Cantabria, en un supuesto en el que el Servicio Cántabro de Salud impidió la participación del Sindicato de Trabajadores de la Enseñanza de Cantabria en los grupos de trabajo derivados de aquel, justificando la decisión en que el sindicato no se adhirió al Acuerdo. El TSJ de Cantabria, siguiendo la doctrina constitucional, entiende que "las organizaciones sindicales que no se adhieren a un Acuerdo Marco, pero tienen derecho a participar en las Mesas, comisiones y grupos de trabajo, en la medida en que en el seno de estos órganos se ejerza realmente negociación colectiva, conservan este derecho que deriva de la libertad sindical, y no puede condicionarse a la adhesión a lo pactado por otros. Esto porque se ha de atender a la real naturaleza de las funciones que desempeña la Comisión, que es cierto que deberían ser meramente de seguimiento del cumplimiento de lo pactado, pero que en este caso tenía según el propio Acuerdo Marco funciones de negociación, interpretación, revisión, suscripción y prórroga del Acuerdo de selección de personal estatutario temporal” ${ }^{400}$.

El supuesto de hecho anterior no debería producirse porque los Acuerdos o Pactos que crean estas Comisiones de seguimiento no deben otorgarles funciones negociadoras, y si lo hacen, esas cláusulas serán nulas. La STSJ de Galicia de 23 de febrero de 2011 ha señalado respecto a la Comisión de seguimiento de un Acuerdo de personal estatutario del Servicio Gallego de Salud que "la cuestión estriba en determinar si las funciones atribuidas a estas Comisiones en los Acuerdos impugnados se limitan a su seguimiento o se le atribuyen facultades negociadoras de aspectos nuevos...", en cuyo caso sí se daría la anulación de las cláusulas del Acuerdo que atribuyen estas funciones de negociación ${ }^{401}$.

\footnotetext{
en materia de jornada, aplicación al personal con distintos turnos etc.; no se ha negado por lo tanto el derecho de CC.OO. a intervenir en las negociaciones debatidas sino que fue el mismo sindicato el que se autoexcluyó al no firmar los Acuerdos”, (RJ 2005\9054).

398 (JUR 20062549).

${ }^{399}$ (RJ 2003\7824).

${ }^{400}$ (RJCA 2004\1106).

${ }^{401}$ (RJCA 2011 286).
} 
Capítulo IV. El ejercicio de la negociación colectiva del personal estatutario de los Servicios de salud en el marco legal de la negociación colectiva funcionarial

Habitualmente las competencias de las Comisiones de seguimiento serán las de realizar actuaciones interpretativas y de control de la ejecución de los contenidos pactados, de manera similar a las Comisiones Paritarias de los convenios colectivos, ello independientemente de la denominación que se les dé en el Acuerdo de creación.

Así, la STS de 23 de enero de 2008, en cuanto a la exclusión del Sindicato de Auxiliares de Enfermería (SAE) de las Comisiones locales y de la Central de seguimiento de incentivos en el Servicio Canario de salud (sindicato con representación en la Mesa sectorial de Sanidad de esa Comunidad autónoma que, sin embargo, no había firmado el acuerdo) declaró que: "La cuestión principal de la actual casación es decidir la naturaleza que debe ser reconocida esas polémicas Comisiones Locales y Central de Seguimiento de Incentivos; esto es, si merecen la calificación de comisiones de negociación o, por el contrario, de mera aplicación de ese Acuerdo colectivo que se recurrió en el proceso de instancia. Ha de ser considerado de esta manera porque dicha lectura permite comprobar que, efectivamente, hacían funciones que no rebasaban el marco aplicativo (como son las de conocimiento de objetivos; y las de información y propuesta). Pero hay alguna otra que sí comporta una función de determinación del contenido económico final de un determinado concepto retributivo y, por esta razón, equivale a establecer o definir, aunque solo sea de manera muy limitada, una parte del contenido de la relación de servicios del personal afectado; así ocurre, al menos, con esa función de distribuir la cuantía que resulte como consecuencia de las economías por los objetivos no alcanzados, pues no aparece definido el criterio último con que dicha distribución se llevará a cabo [...] por lo que no puede compartirse la tesis de la Administración recurrente en esta casación de que las discutidas Comisiones solo tenían funciones de mera aplicación" ${ }^{402}$.

En este sentido también se expresa la STS de 24 de enero de 2012, relativa a la impugnación del Acuerdo Administración-Sindicatos 2008-2011 sobre la mejora de la calidad de los servicios de la Administración General de la Comunidad Autónoma de Cantabria, que argumenta que: "Lo relevante a la hora de afrontar cuestiones como la que se plantea en el presente recurso no debe ser la denominación formal con que aparece designada la Comisión sino los cometidos que le son efectivamente asignados y, trasladando estos razonamientos al presente caso, apreciamos que dichas Comisiones no eran meros órganos técnicos de seguimiento e interpretación por cuanto tenían conferidas concretas atribuciones de contenido negociador en relación con los procesos selectivos para ingreso en la Administración o en la delimitación con carácter definitivo de las distintas formas de colaboración de las organizaciones sindicales en el desarrollo de aquellos, así como en la configuración de un nuevo procedimiento de prolongación en el servicio activo después de haber cumplido la edad de jubilación forzosa, de manera que la exclusión del sindicato demandante en la instancia supuso, tal y como acertadamente apreció la Sala de instancia, el menoscabo injustificado de su derecho a la libertad sindical por cuanto se le privó de la posibilidad de intervenir en las materias y cuestiones que fueran objeto de configuración y negociación en dichos ámbitos" ${ }^{403}$.

\footnotetext{
402 (RJ 2008\1663).

${ }^{403}$ Fundamento jurídico cuarto, (RJ 2012\231).
} 
Estas Comisiones tienen funciones de vigilancia del cumplimiento y aplicación de los Acuerdos, para lo que necesitan y tienen derecho a obtener información relativa a cómo se cumple en la práctica lo acordado, obligación que incumbe a la Administración.

En las Comisiones de seguimiento también se ponen en común las posiciones de las partes sobre la interpretación de lo convenido y las soluciones que se deban dar ante los conflictos que se presenten en su aplicación. Las decisiones que se tomen en el seno de la Comisión de seguimiento son impugnables, entre otras cosas porque podrían excederse del contenido del Acuerdo o Pacto, y alterar sus disposiciones.

Sí cabe la regulación del funcionamiento de las Comisiones de seguimiento en una norma convencional al efecto, y es además deseable.

Ejemplo de esto es el Acuerdo de 16 de diciembre de 2003, del Gobierno de Aragón, que ratifica el Acuerdo Administración-Sindicatos sobre las Comisiones de Seguimiento de los Pactos y Acuerdos autonómicos. Se trata de un Acuerdo de la Mesa de la Función Pública que establece con carácter general la existencia de una Comisión de Seguimiento para llevar a cabo la interpretación y evaluación de cada uno de los Acuerdos y Pactos que se adopten en la Administración de la Comunidad autónoma. La finalidad de estas Comisiones es la de dilucidar los conflictos en materia de interpretación y aplicación de los Acuerdos y Pactos. En esta norma se regula la constitución de la comisión paritaria, su actuación, composición y funcionamiento ${ }^{404}$.

En definitiva, la jurisprudencia es clara en este aspecto: las Comisiones de seguimiento no pueden atribuirse funciones que impliquen manifestación de capacidad negociadora, sino tan solo de conocimiento, información y propuesta a las Mesas negociadoras correspondientes. La STS de 21 noviembre de 1997 destaca que no se pueden atribuir a una "Comisión Técnica de Planificación" competencias o potestades organizativas de la negociación con exclusión de las Mesas institucionales, porque estas son las que tienen atribuida por ley la legitimación negocial ${ }^{405}$.

\subsection{2.- CONTROL DE LEGALIDAD E IMPUGNACIÓN JURISDICCIONAL DE LOS PACTOS Y ACUERDOS}

A diferencia del control jurisdiccional de las posibles lesiones del derecho fundamental a la libertad sindical que puedan afectar a los sindicatos y trabajadores en general, que se lleva a cabo en el orden social, tanto la impugnación de los productos de la negociación colectiva de los funcionarios públicos y del personal estatutario, como la

\footnotetext{
${ }^{404}$ Artículo único: “1. Se establece con carácter general una Comisión de Seguimiento para llevar a cabo la interpretación y evaluación del desarrollo de cada uno de los Acuerdos y Pactos Administración-Sindicatos que se adopten. 2. En cada uno de los Acuerdos y Pactos que se alcancen habrá una Comisión de Seguimiento en el seno del órgano de negociación que lo haya adoptado. 3. Cada una de las Comisiones estarán compuestas por representantes de la Administración y de las Organizaciones Sindicales firmantes del Acuerdo que se adopte en el ámbito correspondiente. 4. Se reunirán siempre que sea pedida su convocatoria por una de las partes firmantes del Acuerdo con una antelación de 15 días”. Boletín Oficial de Aragón de 14 de enero de 2004.
}

${ }^{405}(R J 19978666)$. 
Capítulo IV. El ejercicio de la negociación colectiva del personal estatutario de los Servicios de salud en el marco legal de la negociación colectiva funcionarial

eventual lesión de la libertad sindical de este personal, son competencia del orden jurisdiccional contencioso administrativo, según el artículo 3 LJS, en sus apartados c) y e) ${ }^{406}$.

Estas exclusiones del orden social ya se preveían en el artículo 3 c) del Texto Refundido de la Ley de Procedimiento laboral, aprobado por Real Decreto Legislativo 2/1995, de 7 de abril, por lo que nos encontramos con que la jurisprudencia ha venido declarando que el conocimiento de la impugnación de los Acuerdos de personal funcionario o estatutario que se celebran en las Mesas correspondientes, así como los de las normas que los ratifican y aplican, quedan excluidos del ámbito jurisdiccional social y corresponden al orden contencioso administrativo ${ }^{407}$. Esto incluso en el supuesto de que el instrumento negociado regule conjuntamente condiciones de trabajo de personal funcionario y laboral (STS de 24 de enero de $1995^{408}$ ); y lo mismo para los procesos que se sigan sobre eventuales lesiones de la libertad sindical de las organizaciones sindicales en la negociación, con causa en la propia convocatoria de la Mesa de negociación, las incidencias en cuanto al número de representantes convocados, el respeto de los principios de la negociación...

Hasta el año 2005, la jurisprudencia en general, y en particular la del TS, interpretaba en base al artículo 45.2 LGSS de 1974 (declarado vigente por la Disposición derogatoria única, apartado 1 a) del Real Decreto Legislativo 1/1994, de 20 de junio, que aprobó el Texto Refundido de la Ley de la Seguridad Social), que la competencia para decidir los litigios entre las Entidades gestoras y el personal a su servicio era del orden social. Por el contrario, en general, consideraba que los conflictos que surgieran sobre la aplicación e interpretación de las normas reguladoras de la relación estatutaria, ya fueran de rango reglamentario o las negociadas de acuerdo con la LORAP, habían de ser impugnadas ante el orden contencioso administrativo de la jurisdicción: STS de 29 de abril de $1996^{409}$ y STS de 23 de enero de $1998^{410}$.

\footnotetext{
406 “No conocerán los órganos jurisdiccionales del orden social [...]: c) De la tutela de los derechos de libertad sindical y del derecho de huelga relativa a los funcionarios públicos, personal estatutario de los Servicios de salud y al personal a que se refiere la letra a) del apartado 3 del artículo 1 del Texto Refundido de la Ley del Estatuto de los Trabajadores" (personal cuya relación de servicios tiene carácter administrativo y se regula por las normativa funcionarial) [...] e) De los pactos o acuerdos concertados por las Administraciones públicas con arreglo a lo previsto en la Ley 7/2007, de 12 de abril, del Estatuto Básico del Empleado Público, que sean de aplicación al personal funcionario o estatutario de los Servicios de salud, ya sea de manera exclusiva o conjunta con el personal laboral; y sobre la composición de las Mesas de negociación sobre las condiciones de trabajo comunes al personal de relación administrativa y laboral".
}

\footnotetext{
${ }^{407}$ STS de 23 de enero de 1998, (RJ 1998\1007); STS de 19 de junio de 2006, (RJ 2006 6085$)$, STS de 5 de diciembre de 2006, (RJ 20069210).

408 (RJ 995\1523).

409 (RJ 19964137).

${ }^{410}$ Esta última, en relación con un supuesto de impugnación de un Acuerdo que puso fin a una huelga en el INSALUD, declaraba: “...aunque en el artículo 8.2 del RDL 17/1977, de 4 de marzo, se dispone que el pacto que ponga fin a la huelga tendrá la misma eficacia que lo acordado en convenio colectivo no por ello se altera en este caso la regla de la adscripción competencial al orden contencioso administrativo”, (RJ 1998\1007).
} 
Solo excepcionalmente nos encontramos en ese período con sentencias que argumentan la procedencia del orden jurisdiccional social para conocer de las impugnaciones de los Acuerdos y Pactos funcionariales ${ }^{411}$. La doctrina sobre la impugnación de los Pactos y Acuerdos fue unificada por STS de 13 de marzo de 2003, que declaró que el orden social carece de competencia para pronunciarse sobre la posible nulidad, cualquiera que sea su causa, de los Acuerdos propios de la negociación colectiva en la función pública ${ }^{412}$. Ello porque la negociación colectiva de los funcionarios públicos es una materia regulada por el Derecho administrativo, excepcionada de la jurisdicción social. De manera que es el orden contencioso administrativo el competente para conocer de las impugnaciones tanto de los Pactos como de los Acuerdos regulados en el estatuto funcionarial, tal como señala la STS de 17 de marzo de $2005^{413}$.

En cuanto a cual sea el objeto de impugnación, hay que decir que si se trata de un Pacto se podrá impugnar directamente este por los motivos que se considere que se deba declarar su nulidad; si se trata de un Acuerdo, se deberá impugnar el Acuerdo del Consejo de Gobierno que aprobó y ratificó su contenido, y que lo incorporó al ordenamiento jurídico.

Sobre los sujetos que pueden impugnar los Acuerdos o Pactos hay que tener en cuenta que la impugnación la pueden realizar tanto los sindicatos firmantes como los que no se manifestaron a favor de lo negociado, o no llegaron a formar parte de la Mesa negociadora, dependiendo de la causa de la impugnación. Sí se exige, en todo caso, que los sujetos que impugnen lo acordado posean un interés propio, cualificado y específico en el objeto del recurso, que la jurisprudencia entiende como la eventual obtención de beneficio o la desaparición de un perjuicio en el supuesto de que prospere la acción intentada que no necesariamente ha de revestir un contenido patrimonial.

La STS de 5 de junio de 2006, siguiendo la doctrina del TC, entiende que “...nuestra doctrina parte de un reconocimiento abstracto o general de la legitimación de los sindicatos para impugnar ante los órganos del orden jurisdiccional contencioso administrativo decisiones que afecten a los trabajadores, funcionarios públicos y personal

\footnotetext{
${ }^{411}$ La STS de 22 de enero de 1998 declaró que era competencia de la jurisdicción social el conocimiento de la impugnación de la cláusula de un Pacto sobre derechos sindicales del personal estatutario, en cuanto que este daba lugar a una práctica de empresa que afecta a un grupo genérico de trabajadores (art. 151 de la Ley de Procedimiento Laboral). Decía en su Fundamento jurídico tercero: “... este Pacto colectivo en el ámbito del INSALUD sobre facilidades de las representaciones sindicales en los centros sanitarios que repercute también directa o indirectamente en el personal laboral de los mismos, establece un vínculo u obligación de cumplimiento para la entidad gestora, cuya aplicación da lugar a una práctica de empresa con incidencia en los intereses de un grupo genérico de trabajadores...”, (RJ 1998\1006). En el mismo sentido la del TSJ Andalucía de 31 de marzo de 1998, que atribuyó al orden social las impugnaciones de Acuerdos de personal estatutario basadas en vulneración del derecho fundamental a la libertad sindical "por estar este sometido al orden social de la jurisdicción a tenor del artículo 45 de la LGSS y 16.1 de la LMRFP...”, (AS 199815488).

412 (RJ 2003\3379).

413 Fundamento jurídico cuarto, (RJ 2005\3877), STSJ de La Rioja de 23 de diciembre de 2004, (JUR 2005ר98470).
} 
Capítulo IV. El ejercicio de la negociación colectiva del personal estatutario de los Servicios de salud en el marco legal de la negociación colectiva funcionarial

estatutario [...] Ahora bien, desde la STC 101/1996 venimos exigiendo que esta genérica legitimación abstracta o general de los sindicatos tenga una proyección particular sobre el objeto de los recursos que entablen ante los Tribunales mediante un vínculo o conexión entre la organización que acciona y la pretensión ejercitada...[...] la legitimación procesal del sindicato en el orden jurisdiccional contencioso administrativo se ha de localizar en la noción de interés profesional o económico, interés que ha de entenderse referido en todo caso a un interés en sentido propio, cualificado o específico, y que doctrinalmente viene identificado en la obtención de un beneficio o la desaparición de un perjuicio en el supuesto de que prospere la acción intentada, y que no necesariamente ha de revestir un contenido patrimonial [...] una cosa es la legitimación para formar parte de la Mesa de negociación correspondiente, y otra muy distinta es la legitimación para recurrir sus Acuerdos, para lo que habrá que estarse a las reglas generales establecidas en la Ley Reguladora de la Jurisdicción contencioso administrativa..." ${ }^{414}$.

Habrá que tener en cuenta, además, el respeto del derecho fundamental a la tutela judicial efectiva (art. $24 \mathrm{CE}$ ) por lo que, en caso de duda sobre la legitimación de un sindicato para impugnar en vía contenciosa un Acuerdo, deberá decidirse por la admisión del recurso, según la STSJ de Castilla y León 2 de febrero de $2007^{415}$.

\subsection{3.- SUSPENSIÓN Y MODIFICACIÓN DEL CUMPLIMIENTO DE PACTOS Y ACUERDOS}

La LORAP guardaba silencio respecto a la posibilidad de suspensión o modificación unilateral por parte de la Administración de los Pactos y Acuerdos de personal estatutario basada en causas justificativas. Sin embargo, la LEBEP, establece el apartado 10 de su artículo 38 que: "Se garantiza el cumplimiento de los Pactos y Acuerdos, salvo cuando excepcionalmente y por causa grave de interés público derivada de una alteración sustancial de las circunstancias económicas, los órganos de gobierno de las Administraciones Públicas suspendan o modifiquen el cumplimiento de Pactos y Acuerdos y a firmados, en la medida estrictamente necesaria para salvaguardar el interés público. En este supuesto, las Administraciones Públicas deberán informar a las Organizaciones Sindicales de las causas de la suspensión o modificación”.

Puesto que el artículo 38.10 LEBEP exige en los supuestos de suspensión de efectos o modificación de lo acordado por la Administración concurra "causa grave de interés público derivada de una alteración sustancial de las circunstancias económicas", la Disposición adicional segunda del Real Decreto Ley 20/2012 determina qué se entiende como tal: "Cuando las Administraciones Públicas deban adoptar medidas o Planes de Ajuste, de Reequilibrio de las cuentas públicas o de carácter económico financiero para asegurar la estabilidad presupuestaria o la corrección del déficit público”.

\footnotetext{
${ }^{414}(R J 20063515)$

${ }^{415}$ Fundamento jurídico tercero: “... ha de solucionarse (la duda) adoptando la decisión que más se acomode a la admisión del recurso, ello en atención al principio pro actione, como manifestación del derecho constitucional a la tutela judicial efectiva reconocido en el artículo 24 de la CE”, (JUR 2007127429).
} 
No hay que confundir la opción legal que reconoce el artículo 38.10 LEBEP, que ampara tanto los supuestos de suspensión como de modificación de los efectos de lo acordado en determinadas condiciones, con la supresión del contenido de Pactos y Acuerdos mediante una norma de rango legal, que no es sino la aplicación del principio de jerarquía normativa, por el cual la ley posterior deroga lo convenido en Pactos, Acuerdos y Convenios colectivos cuyo contenido la contradiga.

A destacar varias consideraciones sobre la regulación del artículo 38.10 LEBEP:

$1^{\text {a }}$.- La suspensión del cumplimiento de lo pactado debe ser hecha por norma con suficiente rango jerárquico; en consecuencia, la suspensión de un Acuerdo negociado que en su momento se ratificó por Acuerdo del Consejo de Gobierno respectivo, requerirá también un Acuerdo del mismo órgano para llevarla a cabo, como mínimo. Y aunque el supuesto de la LEBEP contempla que la suspensión o modificación se lleve a término por los "órganos de gobierno de las Administraciones Públicas" lo que parece remitir a una norma de carácter reglamentario, esta puede llevarse a cabo también por una norma con rango de ley.

En cuanto al supuesto de que una norma con rango de ley modifique o deje sin efectos lo acordado mediante la negociación colectiva para el personal de la Administración Pública, es muy significativa la jurisprudencia de la AN en varios procesos de impugnación de la normativa derivada del Real Decreto Ley 8/2010, de 20 de mayo, que dejó sin efectos lo negociado en el Acuerdo Gobierno-Sindicatos para la función pública en el marco del Diálogo Social 2010-2012, en el que se adoptó un incremento salarial del 0,3\% para el año $2010^{416}$.

En estos procesos, la AN, basándose en la doctrina del TC -cita expresamente la STC $80 / 2000^{417}$, y la STC $85 / 2001^{418}$, concluyó que respecto a los funcionarios públicos cabe la aplicación del artículo 38.10 LEBEP, que excepciona la aplicación de los Pactos y Acuerdos cuando concurra causa grave de interés público derivada de una alteración sustancial de las circunstancias económicas, lo que considera justificado en la situación de crisis económica alegada por el Gobierno en la Exposición de motivos del propio Real Decreto Ley 8/2010, y con la comunicación realizada en la Mesa General de negociación de las Administraciones públicas en días previos a la promulgación de aquel ${ }^{419}$.

\footnotetext{
${ }^{416}$ SAN de 13 de julio de 2011, (RJ 2011 604), y de 21 de septiembre de 2011, (JUR 2011 345208), dictadas en recurso contencioso, conflicto colectivo, así como la de 25 de junio de 2012, (JUR 2012\155668).

${ }^{417}($ RTC 2000 80).

${ }^{418}(R T C 2001 \backslash 85)$.

${ }^{419}$ Los demandantes alegaban, entre otras, vulneración del derecho de libertad sindical en su vertiente del derecho a la negociación colectiva, al establecerse un nuevo régimen retributivo sin negociación previa con los sindicatos, lo cual suponía según su argumentación una "quiebra de la eficacia vinculante de los Acuerdos y Convenios en vigor en el sector público y del Acuerdo Gobierno-Sindicatos para la función pública, de 25 de septiembre de 2009, que había establecido una subida de las retribuciones en un 0,3\% para 2010".
} 
Esta resolución judicial consideró también que los Pactos y Acuerdos están subordinados a las normas con rango de ley y al principio de cobertura presupuestaria, no así los Convenios colectivos, ya que la consideración y alcance de los Pactos y Acuerdos para el personal laboral será el previsto en el artículo 83 TRET. En estos procesos la Audiencia Nacional termina por plantear la cuestión de constitucionalidad ante el TC por causa de esto último, ya que considera que los preceptos cuestionados vulneran el artículo 86.1 CE, al transgredir el límite material que para esta fuente dispone el citado precepto constitucional de no afectar a los derechos, deberes y libertades de los ciudadanos regulados en el Título I CE, pues al afectar a la intangibilidad y a la fuerza vinculante de un convenio colectivo en vigor han incido directamente en el derecho a la negociación colectiva (art. 37.1 CE), que forma parte también del contenido de derecho a la libertad sindical (art. 28.1 CE).

El TC resolvió varias cuestiones de constitucionalidad, en concreto, el Pleno la planteada el 28 de octubre de 2010, en el Auto de 7 de junio de 2011, concluyendo que la regulación contenida en el Real Decreto Ley 8/2010 no había infringido el límite material que el artículo $86 \mathrm{CE}$ impone a los Decretos Leyes de no afectar los derechos y libertades del Título I CE: "Así pues, los preceptos legales cuestionados no suponen una "afectación" en el sentido constitucional del término, del derecho a la negociación colectiva reconocido en el artículo 37.1 CE, en cuanto ni regulan el régimen general de dicho derecho, ni la intangibilidad del Convenio colectivo se configura como uno de sus elementos esenciales, por lo que no han franqueado el límite material que al decreto ley impone el artículo 86.1 $C E$ de no afectar a los derechos, deberes y libertades del Título 1 CE ${ }^{420 "}$.

La doctrina judicial de los TSJ, en consecuencia, siguió también esta línea. Así, la STSJ de Madrid de 5 de octubre de $2012^{421}$ declaró que el recurso por el Gobierno a la técnica de la suspensión o modificación de lo acordado es perfectamente válido, retomando la tesis de que no es de aplicación al personal funcionario y estatutario la doctrina constitucional de los derechos adquiridos ${ }^{422}$. Otras resoluciones, en el mismo sentido,

${ }^{420}($ RTC 2011\85).

${ }^{421}$ Dicho precepto (el art. 38.10 LEBEP) aplica en el ámbito de la negociación colectiva de los funcionarios públicos la cláusula "rebus sic stantibus", que permite a la Administración, excepcionalmente, la revisión, suspensión o modificación unilateral de las obligaciones pactadas en la negociación colectiva, por alteración sustancial de las circunstancias económicas, fundamentada en el interés público [...] El funcionario que ingresa al servicio de la Administración Pública se coloca en una situación jurídica objetiva, definida legal y reglamentariamente $y$, por ello, modificable por uno y otro instrumento normativo de acuerdo con los principios de reserva de ley y de legalidad sin que, consecuentemente, pueda exigir que la situación estatutaria quede congelada en los términos en que se hallaba regulada al tiempo de su ingreso, o que se mantenga la situación administrativa que se está disfrutando, porque ello se integra en las determinaciones unilaterales lícitas del legislador, al margen de la voluntad de quien entra al servicio de la Administración, quien, al hacerlo, acepta el régimen que configura la relación estatutaria funcionarial. Por tanto, no hay privación de derechos; solo alteración de su régimen en el ámbito de la potestad del legislador constitucionalmente permisible [...] no existen derechos adquiridos para los funcionarios o para el personal estatutario, dada su situación sometida a una regulación legal y reglamentaria y, por tanto, modificable, por el hecho de que un Acuerdo o una Ley de Presupuestos estableciese unas determinadas retribuciones anuales. Por tanto es posible que una norma legal posterior lo modifique, no con carácter retroactivo, sino a partir de su entrada en vigor", (RJCA 2012\921).

${ }^{422}$ STC 99/1987, (RTC 198入99). 
Capítulo IV. El ejercicio de la negociación colectiva del personal estatutario de los Servicios de salud en el marco legal de la negociación colectiva funcionarial

argumentan que el derecho a la negociación colectiva funcionarial no deriva del artículo 37 $\mathrm{CE}$, sino que es de creación legal, y aunque se integre en el contenido adicional del derecho a la libertad sindical se debe ajustar en su ejercicio a lo dispuesto en la ley reguladora, y "debe primar el principio de legalidad sobre el de autonomía colectiva": STSJ de Madrid de 6 de julio de $2011^{423}$ y STSJ de Canarias de 27 de octubre de $2011^{424}$.

Si seguimos la misma argumentación, habrá que tener en cuenta que para que el Acuerdo o el Pacto suspendido recuperen sus efectos, se deberá dictar otra norma de igual rango a aquella que produjo la suspensión, pero de contenido contrario.

$2^{a}$.- El uso de esta técnica se fundamenta en la existencia de "causa grave de interés público derivada de una alteración sustancial de las circunstancias económicas", por lo que se debería acreditar, no solo invocar, la concurrencia de esta causa, así como la finalidad de su reconocimiento, que es "salvaguardar el interés público". No obstante, la Disposición adicional segunda del Real Decreto Ley 20/2012, ya contiene, de antemano, la justificación sobre este aspecto que se entiende debería dar el ejecutivo en cada caso singular.

3a.- El artículo 38.10 LEBEP autoriza excepcionalmente la "suspensión o modificación" de los Acuerdos y Pactos, con lo que la norma negociada no pierde su validez, sino su eficacia. Los Pactos y Acuerdos dejarán de surtir efectos, de forma excepcional, durante un tiempo determinado. Se entiende que la modificación o suspensión de lo pactado implica la pervivencia de lo negociado, que puede tener de nuevo efectos en un momento futuro en el que mejoren las circunstancias, y se levante la suspensión o finalice la modificación dispuesta. Sin embargo, el artículo 38.10 LEBEP no exige que la suspensión señale un plazo o condición cumplidos los cuales la norma suspendida recupere sus efectos, por lo que, en la práctica, esa medida puede ser indefinida y casi equivalente a una derogación normativa.

$4^{\mathrm{a}}$.- En cuanto al deber de informar a las organizaciones sindicales en estos casos, la ley no exige formalidades especiales al respecto, pero es un requisito que deberá cumplir la Administración con antelación suficiente, y que parece que se debería realizar en el foro correspondiente, es decir, en la Mesa de negociación en la que se concertó el Acuerdo o Pacto.

\footnotetext{
${ }^{423}$ Fundamento jurídico cuarto, (JUR 201/1309667).

${ }^{424}$ La sentencia declara, en su Fundamento jurídico tercero, invocando el ATC de 7 de junio de 2011 que resuelve sobre el citado Real Decreto Ley, que "el artículo 37.1 CE, que reconoce el derecho a la negociación colectiva, no contempla como un contenido sustancial del mismo su inalterabilidad por una ley posterior", (JUR 2012\80543).
} 

CAPITULO V

EL CONTENIDO DE LA NEGOCIACIÓN COLECTIVA DE LOS DERECHOS SINDICALES DEL PERSONAL ESTATUTARIO DE LOS SERVICIOS DE SALUD ANTES Y DESPUÉS DE LAS MEDIDAS DE AJUSTE PRESUPUESTARIO 



\section{CAPITULO V}

\section{EL CONTENIDO DE LA NEGOCIACIÓN COLECTIVA DE LOS DERECHOS SINDICALES DEL PERSONAL ESTATUTARIO DE LOS SERVICIOS DE SALUD ANTES Y DESPUÉS DE LAS MEDIDAS DE AJUSTE PRESUPUESTARIO}

\section{1.- INTRODUCCION. OBJETO DE LA NEGOCIACIÓN}

Para entender el conjunto de derechos y garantías de que dispone el personal estatutario para hacer efectivo su derecho a la acción sindical, y en último extremo, su derecho a la libertad sindical, debemos partir de estas premisas:

$1^{\mathrm{a}}$.- El personal estatutario es un empleado público vinculado por una relación jurídica funcionarial especial (art. 1 LEM), por lo que le resulta de aplicación la regulación de los derechos colectivos que contiene la LEBEP (art. 15) y su propia ley específica (art. 18 LEM).

$2^{\mathrm{a}}$.- Su derecho a la negociación colectiva viene desarrollado en el Capítulo IV del Título III LEBEP (Derecho a la negociación colectiva, representación y participación institucional. Derecho de reunión), y se ajusta de lleno a las particularidades de la negociación colectiva funcionarial, con algunas peculiaridades propias que recoge la LEM.

$3^{\mathrm{a}}$.- Cuando hacemos mención a los derechos y garantías sindicales nos estamos refiriendo a los derechos, facultades, garantías y facilidades que se ponen a disposición de los representantes sindicales, de los del personal y de las organizaciones sindicales, en general, con el fin de proteger el desarrollo en libertad de la acción sindical.

Estos derechos se regulan a nivel internacional, para todos los trabajadores, en el Convenio de la OIT $\mathrm{n}^{\circ} 135$, relativo a la protección y facilidades que deben otorgarse a los representantes de los trabajadores en la empresa, cuyo artículo 2.1 dispone que: "Los representantes de los trabajadores deberán disponer en la empresa de las facilidades apropiadas para permitirles el desempeño rápido y eficaz de sus funciones" ${ }^{425}$.

El término facilidades puede ser muy amplio; no obstante, se concreta en una serie de garantías que se reconocen a los representantes para que el ejercicio de su función sindical sea más efectivo y que no les suponga consecuencias negativas en su relación laboral, que puede resentirse desde el punto de vista de sus derechos a nivel individual.

\footnotetext{
${ }^{425}$ El artículo 3 señala qué se entiende a los efectos del Convenio por representantes de los trabajadores: “Las personas reconocidas como tales en virtud de la legislación o la práctica nacionales, ya se trate de representantes sindicales, es decir, representantes nombrados o elegidos por los sindicatos o por los afiliados a ellos; o de representantes electos, es decir, representantes libremente elegidos por los trabajadores de la empresa, de conformidad con las disposiciones de la legislación nacional o de los contratos colectivos...”.
} 
Capítulo V. El contenido de la negociación colectiva de los derechos sindicales del personal estatutario de los Servicios de salud antes y después de las medidas de ajuste presupuestario

Estas garantías o facilidades se reconocen en nuestro ordenamiento jurídico para los empleados públicos en la LOLS, el TRET y la LEBEP, pero, a su vez, pueden ser ampliadas y desarrolladas a través de la negociación colectiva, en la medida en que estas normas lo permitan ${ }^{426}$. Es más, si se desea ampliar, concretar y desarrollar el régimen legal en esta materia para todos los empleados públicos, y para el personal estatutario en concreto, es obligado hacerlo a través del mecanismo de la negociación colectiva, de acuerdo con lo dispuesto en el artículo 37.1 h) LEBEP, y en el artículo 80.2 j) LEM.

Así se ha hecho a lo largo de los años de existencia del Sistema Nacional de Salud. Desde la creación del INSALUD, en su ámbito se han concertado Pactos y Acuerdos para regular esta materia, así como en las Administraciones autonómicas que iban asumiendo competencias en materia de sanidad. A partir del año 2002, en que se hacen efectivas las últimas transferencias sanitarias a las CC.AA. que aún no las tenían, y con ello se crean los Servicios de salud autonómicos que faltaban, se completa la negociación colectiva sobre derechos sindicales del personal a su servicio y en todas las Administraciones autonómicas nos encontramos con normas negociadas que regulan los derechos y garantías sindicales del personal de su Servicio de salud ${ }^{427}$.

Por lo general, en todos ellos la negociación en esta materia se ha ido sucediendo puntualmente tras los correspondientes procesos de elecciones sindicales, cuyos resultados renovaban la representatividad de los sindicatos en las Mesas de negociación. Estos Pactos y Acuerdos han sido negociados en ocasiones de forma exclusiva para el personal de instituciones sanitarias en las Mesas sectoriales de Sanidad, y en otras conjuntamente con el resto de los empleados públicos autonómicos en las Mesas Generales de negociación, pero en ambos casos tenían como objetivo regular la aplicación y el procedimiento de ejercicio de los derechos y facultades de naturaleza sindical que la ley reconoce a las organizaciones sindicales y a los representantes del personal.

El examen de su contenido evidencia que, de manera generalizada, incorporaban importantes mejoras con respecto a la normativa reguladora de estos derechos contenida en la LOLS, la LEBEP y el TRET:

El Acuerdo en materia de acción sindical de la Administración de la Comunidad autónoma de La Rioja, de 25 de mayo de 2011, a modo de introducción, decía que: "El presente Acuerdo tiene por objeto establecer un marco adecuado [...] mediante la amplia superación de los criterios que, sobre esta materia, se contiene en el artículo 10 de la Ley Orgánica de Libertad Sindical, que reconoce la posibilidad de constituir secciones sindicales en las empresas...".

\footnotetext{
${ }^{426}$ Así lo prevé el artículo 6 del Convenio nº 135 de la OIT.

${ }^{427}$ En el ámbito del INGESA continuaron vigentes los Pactos de 30 de junio de 1989, sobre permisos y uso de crédito horario para realización de funciones sindicales y de representación del personal al servicio de Instituciones sanitarias del INSALUD, modificados por el Pacto de 20 de diciembre de 1995, así como por el de 17 de junio de 1999 de la Mesa sectorial de Sanidad del INSALUD.
} 
Capítulo V. El contenido de la negociación colectiva de los derechos sindicales del personal estatutario de los Servicios de salud antes y después de las medidas de ajuste presupuestario

En particular, estos Pactos y Acuerdos sobre derechos sindicales, aplicables al personal estatutario de los Servicios de salud, han regulado principalmente estos aspectos:

1) Los requisitos para la constitución de las secciones sindicales en los centros de trabajo de instituciones sanitarias, así como la delimitación del concepto de centro de trabajo a estos efectos; es decir, la unidad electoral.

2) El número de delegados de las secciones sindicales, mejorando el mínimo legal regulado en la LOLS; así como sus derechos, facilidades y garantías.

3) La cesión y acumulación del crédito horario sindical de los representantes sindicales y de los representantes del personal; la formación y gestión de la bolsa de horas sindicales; las condiciones de disfrute del crédito horario y su procedimiento de solicitud y reconocimiento.

4) Los requisitos y el procedimiento de autorización de las liberaciones institucionales y el número de representantes de este tipo autorizados para cada organización sindical.

5) Los medios materiales puestos a disposición de los representantes sindicales y del personal para el desarrollo de su labor: el local sindical y sus requisitos de adecuación y dotación de material, así como los medios tecnológicos; los tablones de anuncios...

6) La dotación económica, las indemnizaciones y subvenciones a favor de las organizaciones sindicales y las condiciones generales para su concesión, vinculadas, generalmente, al dato de la representatividad obtenida por la organización sindical en el ámbito del Servicio de salud o en el de la Administración autonómica correspondiente.

7) El reconocimiento del principio de prohibición de la discriminación profesional y retributiva de los empleados públicos dispensados de su función para el ejercicio de la actividad sindical.

8) La existencia, composición y funciones de las Comisiones de seguimiento, con esta $\mathrm{u}$ otras denominaciones, en las que participan los sindicatos firmantes o adheridos a los Acuerdos y Pactos; sus competencias y funcionamiento: Comisión de Interpretación y Vigilancia, según el artículo 3 del Acuerdo de 2 de marzo de 2006, de la Administración de las Islas Baleares. Comisión Paritaria de Seguimiento, en el Acuerdo de la Junta de Andalucía, de 7 de julio de 2008. Órgano Paritario, en el Pacto del Servicio Murciano de Salud, de 18 de julio de 2003. Comisión de Seguimiento, en el Acuerdo de Aragón, de 4 de julio de $2008 \ldots$

Los Acuerdos y Pactos que nos servirán de punto de partida en este apartado son los últimos negociados en cada Comunidad autónoma, una vez completados los traspasos de servicios sanitarios en todas ellas a partir de 2002, que estaban vigentes y regulaban con normalidad la acción sindical del personal antes de que algunos gobiernos autonómicos anticiparan las políticas de suspensión, modificación y supresión que después llevará a término el Gobierno estatal mediante el Real Decreto Ley 20/2012. 
Capítulo V. El contenido de la negociación colectiva de los derechos sindicales del personal estatutario de los Servicios de salud antes y después de las medidas de ajuste presupuestario

Estos instrumentos, que fueron objeto de negociación en las Mesas autonómicas, bien generales o bien sectoriales de sanidad, son representativos de lo que ha sido una etapa de desarrollo de los derechos sindicales de los empleados públicos y, en especial, del personal de los Servicios de salud. Se trata de los siguientes:

1.- Administración de la Junta de Andalucía: el Acuerdo de 7 de julio de 2008, de la Mesa General de Negociación común para el personal funcionario, estatutario y laboral sobre derechos de representación y sindicales ${ }^{428}$.

2.- Administración de la Comunidad autónoma de Aragón: el Acuerdo de 4 de julio de 2008, de la Mesa sectorial de Sanidad, sobre derechos y garantías sindicales del personal funcionario y estatutario de los centros sanitarios del Servicio Aragonés de Salud ${ }^{429}$.

3.- Administración del Principado de Asturias: el Acuerdo de 25 de febrero de 2005, de la Mesa General de Negociación, sobre Derechos y Garantías sindicales ${ }^{430}$.

4.- Administración de la Comunidad autónoma de las Islas Baleares: el Acuerdo de 2 de marzo de 2006, de la Mesa General de Negociación sobre el desarrollo de la acción sindical de las Juntas de personal, de los Comités de empresa, de los Delegados de Personal y de las secciones sindicales de la Administración de la Comunidad de las Islas Baleares ${ }^{431}$.

5.- Administración de la Comunidad autónoma de Canarias: el Pacto de 29 de marzo de 2000, de la Mesa sectorial de Sanidad sobre permisos, secciones sindicales y uso del crédito horario para la realización de funciones sindicales y de representación del personal funcionario, estatutario y laboral al servicio de las instituciones sanitarias del Servicio Canario de Salud ${ }^{432}$.

6.- Administración de la Comunidad autónoma de Cantabria: el Pacto de 3 de octubre de 2003, entre la Consejería de Sanidad y Servicios Sociales y las Organizaciones Sindicales firmantes sobre permisos, secciones sindicales y uso del crédito horario para la

\footnotetext{
${ }^{428}$ Boletín Oficial de la Junta de Andalucía de 3 de noviembre de 2008.

${ }^{429}$ Boletín Oficial de Aragón de 15 de octubre de 2008. Aragón ha tenido tradicionalmente una nutrida normativa negociada en esta materia, específica para el personal del Servicio Aragonés de Salud: Acuerdo de 21 de febrero de 2000 entre la Diputación General de Aragón y las Organizaciones Sindicales UGT, CC OO, CSI-CSIF, CEMSATSE y USO de la Mesa de la Función Pública (Boletín Oficial de Aragón de 31 de marzo de 2000); Acuerdo Administración-Sindicatos sobre Derechos y Garantías Sindicales, de 21 de noviembre de 2003; Acuerdo Administración-Sindicatos sobre Derechos y Garantías Sindicales del personal funcionario y estatutario de centros sanitarios del Servicio Aragonés de Salud de la Mesa Sectorial de Sanidad de 21 de enero de $2004 \ldots$

${ }^{430}$ Boletín Oficial del Principado de Asturias de 10 de mayo de 2005.

${ }^{431}$ Boletín Oficial de las Islas Baleares de 15 de abril de 2006 y corrección de errores en el de 2 de mayo de 2006.

${ }^{432}$ Boletín Oficial de Canarias de 16 de junio de 2000.
} 
Capítulo V. El contenido de la negociación colectiva de los derechos sindicales del personal estatutario de los Servicios de salud antes y después de las medidas de ajuste presupuestario

realización de funciones sindicales y de representación del personal al servicio de las instituciones sanitarias del Servicio Cántabro de Salud ${ }^{433}$.

7.- Administración de la Junta de Comunidades de Castilla-La Mancha: el Pacto de Interlocución de la Mesa General de Negociación para el período 2008-2011, de 18 de noviembre de $2008^{434}$.

8.- Administración de la Junta de Castilla y León: el Pacto sobre derechos de representación sindical en el ámbito de la Administración de la Comunidad de Castilla y León de 27 de junio de $2006^{435}$.

9.- Administración de la Generalitat de Cataluña: el Pacto sobre derechos sindicales en el ámbito de la Administración de la Generalitat de Cataluña, suscrito por los representantes de la Dirección General de la Función Pública, y los representantes sindicales el 22 de diciembre de $2004^{436}$.

10.- Administración de la Junta de Extremadura: los Pactos en materia de derechos sindicales, de 4 de octubre de 2002 y de 22 de enero de 2003, entre el Servicio Extremeño de Salud y las Organizaciones Sindicales de la Mesa sectorial de Sanidad ${ }^{437}$.

11.- Administración de la Xunta de Galicia: el Pacto de 31 de octubre de 1995 sobre permisos retribuidos, uso y acumulación de crédito horario y caracterización de los delegados de sección sindical, de los representantes del personal al servicio de las instituciones sanitarias dependientes del Servicio Gallego de Salud, que fue objeto de modificación parcial mediante el Pacto de 1 de junio de 1999, suscrito por la Administración sanitaria autonómica con las organizaciones sindicales para la representación y participación del personal de Instituciones Sanitarias del Servicio Gallego de Salud ${ }^{438}$.

12.- Administración de la Comunidad autónoma de La Rioja: el Acuerdo en materia de acción sindical de 25 de mayo de 2011, entre la Administración de la Comunidad autónoma de la Rioja y las Organizaciones sindicales de la Mesa General de Negociación ${ }^{439}$.

\footnotetext{
${ }^{433}$ Boletín Oficial de Cantabria de 17 de octubre de 2003.

${ }^{434}$ Boletín Oficial de Castilla-La Mancha de 3 de diciembre de 2008.

${ }^{435}$ Boletín Oficial de Castilla y León de 20 de julio de 2006.

${ }^{436}$ Diario Oficial de la Generalitat Catalana de 21 de abril de 2005.

${ }^{437}$ Diario Oficial de Extremadura de 3 de junio de 2003.

${ }^{438}$ Diario Oficial de Galicia de 29 de noviembre de 1995 y de 17 de junio de 1999, respectivamente.

${ }^{439}$ Boletín Oficial de La Rioja de 27 de junio de 2011.
} 
Capítulo V. El contenido de la negociación colectiva de los derechos sindicales del personal estatutario de los Servicios de salud antes y después de las medidas de ajuste presupuestario

13.- Administración de la Comunidad autónoma de Madrid: el Acuerdo de 16 de septiembre de 2003, de la Mesa General de Negociación sobre jornada de trabajo y derechos sindicales del personal que presta sus servicios en instituciones sanitarias transferidas a la Comunidad de Madrid dependientes del Instituto Madrileño de la Salud ${ }^{440}$.

14.- Administración de la Comunidad autónoma de la Región de Murcia: el Pacto de la Mesa sectorial de Sanidad sobre el ejercicio sindical en el ámbito del Servicio Murciano de Salud, de fecha 18 de julio de $2003^{441}$. A pesar de su denominación, se le dio el tratamiento de un Acuerdo, ya que fue ratificado por el Consejo de Gobierno con fecha 27 de febrero de 2004.

15.- Administración de la Comunidad Foral de Navarra: el Acuerdo sobre derechos sindicales en la Administración de la Comunidad Foral de Navarra y sus organismos autónomos, de 18 de octubre de 1994, así como el Acuerdo de 4 de abril de 2000, que modifica el anterior ${ }^{442}$.

16.- Administración de la Generalitat Valenciana: el Acuerdo de 30 de diciembre de 2003, entre la Conselleria de Sanitat y las Organizaciones sindicales representadas en la Mesa sectorial de Sanidad sobre créditos horarios, acumulaciones horarias y constitución de Secciones Sindicales ${ }^{443}$.

17.- Administración de la Comunidad autónoma del País Vasco: el Acuerdo Marco sobre derechos sindicales y ejercicio de la actividad sindical en la Administración de la Comunidad Autónoma de Euskadi, de 15 de octubre de $1988^{444}$, así como Acuerdo regulador de las condiciones de trabajo del personal de Osakidetza-Servicio Vasco de Salud para los años 2010-2011 445 .

\section{2.- CONTENIDO DE LA NEGOCIACIÓN COLECTIVA DE LOS DERECHOS SINDICALES DEL PERSONAL ESTATUTARIO ANTES DE LAS MEDIDAS DE AJUSTE PRESUPUESTARIO}

Los Acuerdos y Pactos sobre derechos sindicales que acabamos de ver han venido desarrollando los aspectos relativos al ejercicio de la acción sindical que llevan a cabo las organizaciones sindicales, sus representantes y los representantes de los empleados públicos

\footnotetext{
${ }^{440}$ Boletín Oficial de la Comunidad de Madrid de 1 de octubre de 2003.

${ }^{441}$ Boletín Oficial de la Región de Murcia de 22 de abril de 2004.

${ }^{442}$ El primero no fue publicado. El segundo sí, en el Boletín Oficial de Navarra de 26 de mayo de 2000.

${ }^{443}$ No fue objeto de publicación en el Diario Oficial de la Generalitat Valenciana.

${ }^{444}$ Boletín Oficial del País Vasco de 18 de noviembre de 1988.

445 Incorporado al Decreto 83/2010 de 9 de marzo, publicado en el Boletín Oficial del País Vasco de 24 de marzo de 2010.
} 
Capítulo V. El contenido de la negociación colectiva de los derechos sindicales del personal estatutario de los Servicios de salud antes y después de las medidas de ajuste presupuestario

en las Administraciones autonómicas, o en sus correspondientes Servicios de salud, a lo largo de un período de tiempo que podemos considerar como una fase de desarrollo de la negociación colectiva en esta materia.

Con respecto a la materia objeto de negociación, interesa resaltar como la han determinado los propios Pactos y Acuerdos.

- Así, el Acuerdo de 4 de julio de 2008, de la Mesa sectorial de Sanidad del Servicio Aragonés de Salud, trataba los derechos y garantías sindicales del personal funcionario y estatutario de los centros sanitarios.

- El del Principado de Asturias de 25 de febrero de 2005, se refería en su título al contenido que regulaba como "derechos y garantías sindicales".

- Llevaban también el título de reguladores de los “derechos sindicales" los Pactos de 2002 y 2003 del Servicio Extremeño de Salud; el del Servicio Murciano de Salud de 2003; el del Servicio Canario de Salud de 2000; el de la Administración de la Generalitat de Cataluña de 2004, así como el Acuerdo del Instituto Madrileño de la Salud, del año 2003 y el Acuerdo de 1994 de la Administración Foral de Navarra.

- El Acuerdo Marco de 1988, de la Administración del País Vasco, también se refería a los "derechos sindicales y el ejercicio de la actividad sindical". A este último aspecto, el de la acción sindical, apelaban los Acuerdos de 25 de mayo de 2011, de la Administración de La Rioja y de 2 de marzo de 2006, de la Administración de la Comunidad autónoma de las Islas Baleares.

- Hacían mención a la "representación sindical y participación" el Pacto del Servicio Cántabro de Salud de 2003, que trataba los "permisos, secciones y uso del crédito horario para la realización de funciones sindicales y de representación del personal”, y el Pacto de la Administración de la Junta de Castilla y León.

- El Acuerdo de 30 de diciembre de 2003, de la Conselleria de Sanitat de la Generalitat Valenciana, regula los "créditos horarios, acumulaciones horarias y constitución de Secciones Sindicales", y el Pacto de 27 de julio de 2006, de la Junta de Castilla y León, los "derechos de representación sindical".

- El Pacto de 1999, del Servicio Gallego de Salud, trataba la "representación y participación”, y, por último, el de 18 de noviembre de 2008, de la Junta de Comunidades de Castilla-La Mancha, se denominó Pacto único de interlocución.

En los apartados siguientes veremos, en general, el contenido concreto de la negociación que se ha abordado en estos instrumentos negociados.

\subsection{1.- LA CONSTITUCIÓN DE SECCIONES SINDICALES Y LA DESIGNACIÓN DE DELEGADOS. SUS DERECHOS}

Este es uno de los principales aspectos de la negociación sobre derechos sindicales del personal estatutario, y tiene su fundamento legal en el artículo 8.1 a) LOLS, que regula el derecho de los sindicatos a la creación de secciones sindicales, tanto en el ámbito laboral común como en los centros de trabajo de las Administraciones Públicas: "Los trabajadores afiliados a un sindicato podrán, en el ámbito de la empresa o centro de 
Capítulo V. El contenido de la negociación colectiva de los derechos sindicales del personal estatutario de los Servicios de salud antes y después de las medidas de ajuste presupuestario

trabajo: a) constituir Secciones sindicales de conformidad con lo establecido en los Estatutos del sindicato".

La jurisprudencia ha estimado que las secciones sindicales no tienen personalidad jurídica propia, sino que son una parte de la estructura organizativa del sindicato (STS de 21 de marzo de 1995) ${ }^{446}$, considerándose órganos internos de la organización sindical implantados en el ámbito de la empresa o centro de trabajo (STC 28 de junio de 1993) ${ }^{447}$.

En cuanto al ámbito de constitución de la sección sindical, la LOLS se refiere a la empresa o centro de trabajo que, por lo que respecta a los Servicios de salud, habrá que entender como la unidad electoral o centro de centro de trabajo a efectos sindicales. En este último ámbito conviene no confundir la unidad electoral con el centro de trabajo desde el punto de vista organizativo, que para el personal estatutario es el centro sanitario ${ }^{448}$.

La unidad electoral en la regulación anterior del artículo 7 LORAP era el ámbito de representación de la Junta de Personal del personal estatutario y funcionario de instituciones sanitarias: el área de salud ${ }^{449}$. Esta estructura, creada por la $\operatorname{LGS}^{450}$ era, en términos sindicales, el centro de trabajo en el que ejercía la representación el órgano unitario del personal de instituciones sanitarias y, asimismo, el ámbito de constitución de las secciones sindicales a los efectos del artículo 10.1 LOLS.

${ }^{446}(R J 19952175)$.

447 “Son órganos internos del Sindicato con función descentralizadora de la actividad sindical, en cuanto se proyecta en el seno de la empresa o centro de trabajo, permitiendo tomar decisiones a dicho nivel, y al mismo tiempo instancias representativas a las que la Ley anuda determinadas funciones, ventajas y privilegios; es por ello que las normas a ellas referidas en la LOLS en cuanto regula, el contenido esencial del derecho fundamental de libertad sindical, han de reputarse normas mínimas de derecho necesario, y como tales indisponibles, que pueden ser mejoradas en su contenido por pacto o norma colectiva, pero cuya regulación nunca puede tener incidencia restrictiva en la configuración legal”, (RTC 1993\208).

${ }^{448}$ Real Decreto 1277/2003, de 10 de octubre, por el que se establecen las bases generales sobre autorización de centros, servicios y establecimientos sanitarios, define en su artículo 2.1 a) el centro sanitario como el "conjunto organizado de medios técnicos e instalaciones en el que profesionales capacitados, por su titulación oficial o habilitación profesional, realizan básicamente actividades sanitarias con el fin de mejorar la salud de las personas. Los centros sanitarios pueden estar integrados por uno o varios servicios sanitarios, que constituyen su oferta asistencial". Asimismo el apartado c) dice que establecimiento sanitario es básicamente lo mismo que el anterior, pero la actividad sanitaria consiste en la dispensación de medicamentos o de adaptación individual de productos sanitarios. Todos los centros y establecimientos sanitarios deben ser objeto de autorización y registro.

${ }^{449}$ Decía: "Se constituirá una Junta de Personal en cada una de las siguientes Unidades Electorales: 1.3.4: "Una para el personal al servicio de Instituciones Sanitarias Públicas del INSALUD, en cada área de salud [...] 3.3.2. Una en cada área de salud para el personal al servicio de Instituciones Sanitarias Públicas dependientes de la Comunidad Autónoma".

${ }^{450} \mathrm{El}$ artículo 56 de la LGS dispone: 1. "Las CC.AA. delimitarán y constituirán en su territorio demarcaciones denominadas áreas de salud, debiendo tener en cuenta a tal efecto los principios básicos que en esta ley se establecen para organizar un sistema sanitario coordinado e integral. 2. Las áreas de salud son las estructuras fundamentales del sistema sanitario, responsabilizadas de la gestión unitaria de los centros y establecimientos del Servicio de salud de la Comunidad autónoma en su demarcación territorial y de las prestaciones sanitarias y programas sanitarios a desarrollar por ellos”. 
Capítulo V. El contenido de la negociación colectiva de los derechos sindicales del personal estatutario de los Servicios de salud antes y después de las medidas de ajuste presupuestario

En este sentido, la STSJ de Castilla-La Mancha de 24 de junio de 1997, había declarado que: "El ámbito de actuación de la Junta de Personal se extiende al área de salud, y que la designación de los delegados sindicales es válida para el ámbito territorial de la Junta de Personal correspondiente. Por ello, en caso de traslado del delegado sindical con cambio de área de salud, el cese en ese puesto de trabajo supone el cese como representante sindical" ${ }^{\text {, }}$.

Este principio estaba del todo respaldado por la jurisprudencia. La STS de 1 de abril de 1995declaró que: "Si tenemos en cuenta [...] la finalidad de la LOLS, el ámbito equiparable e idóneo para llevar a cabo la acción sindical es, según acertadamente postula el sindicato de funcionarios apelante, el de las unidades electorales para la constitución de las Juntas de Personal por ser el único que permite la representatividad sindical en la forma regulada por el artículo 10.1 y 2 de la LOLS, en relación con el artículo 7 de la Ley 9/1987, de 12 junio...",452.

Sin embargo, desde la LEBEP se ha flexibilizado la delimitación de la unidad electoral de personal de las instituciones sanitarias, que ya no será necesariamente el área de salud: "Las Juntas de personal se constituirán en unidades electorales que cuenten con un censo mínimo de 50 funcionarios" (art. 39.3). No obstante, de forma habitual en los Pactos y Acuerdos sobre derechos sindicales que afectan al personal estatutario se ha venido estableciendo que la unidad electoral fuera el área de salud o la estructura organizativa similar, incluso en los instrumentos que se han negociado con posterioridad a la LEBEP ${ }^{453}$.

\footnotetext{
${ }^{451}$ Fundamento jurídico cuarto, (AS 19971931).

${ }^{452}$ Fundamento jurídico quinto, (RJ 1995\3225).

453 Así, el Pacto de 29 de marzo de 2000, sobre derechos sindicales del Servicio Canario de Salud, disponía que: "Para la constitución de Secciones sindicales que gocen de los derechos y garantías previstos en el artículo $10 \mathrm{LOLS}$, el ámbito personal y territorial de los centros de trabajo corresponderá a todos los centros y dependencias de la totalidad de las instituciones sanitarias sitas en cada área de salud, con independencia del número de trabajadores que ocupen”.
}

Al igual que el Pacto de Castilla-La Mancha, de 18 de noviembre de 2008, que estableció que el ámbito en el que se constituyeran las secciones sindicales fuera el área sanitaria (Capítulo V, sección primera).

En el Acuerdo de 25 de febrero de 2005, del Principado de Asturias, sin embargo, se consideraba centro de trabajo a los efectos de constituir secciones sindicales en Atención especializada: "Las instituciones hospitalarias que dispongan de órganos directivos propios, y otros concretos en atención a sus especiales características” (art. 5.3).

En el Pacto de sobre derechos de representación sindical en el ámbito de la Administración de Castilla y León, de 27 de junio de 2006, en el artículo 4.1, se concretaba el concepto de centro de trabajo a efectos sindicales: "A los efectos de definir en este Pacto el ámbito de las secciones sindicales y determinar el número de delegados sindicales, conformarán un único centro de trabajo: 1.- En lo que se refiere al personal al servicio de Instituciones Sanitarias: la totalidad de centros y establecimientos de atención primaria correspondientes a una misma área de salud. La totalidad de centros y establecimientos de atención especializada correspondientes a una misma área de salud”. 
Hay que tener en cuenta que la denominación de área de salud que creó la LGS ha sido modificada en algunos Servicios de salud por su normativa autonómica, denominándose ahora "Áreas sanitarias" en Castilla-La Mancha y Aragón; "Departamentos de salud" en la Comunidad Valenciana... No obstante, el concepto no ha variado, ya que se trata en todos los casos de estructuras propias para la prestación de la asistencia sanitaria, organizadas por demarcaciones geográficas.

No obstante, se pueden pactar otras unidades electorales diferentes del área de salud, según se estime conveniente en atención a las particularidades de la organización asistencial, ya que recordemos que ahora su delimitación se ha convertido en materia objeto de negociación con las organizaciones sindicales (art. 39.4 LEBEP).

La LOLS no exige un número mínimo de personal afiliado para constituir las secciones sindicales en la unidad electoral que corresponda, por lo que es suficiente un solo trabajador afiliado a un sindicato para constituir la sección sindical del mismo. Por tanto, el personal de instituciones sanitarias de los Servicios de salud, afiliado a un sindicato, podrá constituir su sección sindical en la unidad electoral correspondiente, independientemente de su volumen de plantilla y de la presencia o no del sindicato en el órgano de representación unitaria. Este derecho reconocido en la LOLS se suele trasladar de forma prácticamente literal a los Acuerdos y Pactos en materia de derechos sindicales ${ }^{454}$.

Hay que tener en cuenta que los instrumentos negociados han venido exigiendo el cumplimiento de determinados requisitos adicionales en cuanto a la constitución de las secciones sindicales para poder acceder a las garantías de la LOLS. Así, además de la comunicación de la constitución de la sección sindical y de sus modificaciones a la Oficina Pública de Registro, señalaban la obligación de hacerla también al órgano administrativo competente de la Administración autonómica o del Servicio de salud, con la finalidad de que este conociera la existencia de la sección sindical para poder cumplir con sus eventuales obligaciones $^{455}$.

Una vez constituidas, la LOLS garantiza a todas las secciones sindicales ciertas facultades de acción sindical: el derecho a celebrar reuniones previa notificación, que se entiende deberá dirigirse al órgano responsable de personal; recaudar cuotas entre sus afiliados, así como distribuir información sindical fuera de las horas de trabajo y sin perturbar la actividad normal del servicio público (art. 8.1 LOLS, apdos. b y c).

\footnotetext{
${ }^{454}$ A título de ejemplo, el apartado 1 de la Sección tercera del Pacto de 3 de octubre de 2003, del Servicio Cántabro de Salud, establecía: "Los trabajadores afiliados a un Sindicato podrán constituir Secciones Sindicales de conformidad con lo previsto en sus estatutos. La Sección Sindical es una manifestación de la libertad organizativa del Sindicato que viene amparada por el ejercicio de la acción sindical. Pueden, por tanto, los afiliados constituirla en cualquier centro de trabajo, independientemente del volumen de la plantilla y de la presencia o no del Sindicato en el órgano de representación unitaria". En el mismo sentido, el artículo 11 del Acuerdo de 4 de julio de 2008 del Servicio Aragonés de Salud.

455 El Acuerdo de 25 de febrero de 2005, de la Administración del Principado de Asturias, exigía que las secciones sindicales se constituyeran en los ámbitos y con las condiciones establecidas en ese Acuerdo; y que se comunicara la constitución de las mismas a la Dirección General de la Función Pública y a la Gerencia del área de salud, para su traslado a la Dirección de Recursos Humanos (art. 4).
} 
Capítulo V. El contenido de la negociación colectiva de los derechos sindicales del personal estatutario de los Servicios de salud antes y después de las medidas de ajuste presupuestario

Por su parte, el apartado 2 del artículo 8 LOLS reconoce determinados derechos a las secciones sindicales de los "sindicatos más representativos" (arts. 6 y 7 LOLS) y "de los que tengan representación en los Comités de empresa y en los órganos de representación que se establezcan en las Administraciones públicas o cuenten con Delegados de Personal" (al menos un representante), que consisten en:

$1^{\circ}$.- Poner a su disposición un tablón de anuncios con la finalidad de difundir información sindical que "deberá situarse en el centro de trabajo y en lugar donde se garantice un adecuado acceso al mismo de los trabajadores” (art. 8. 2 a) LOLS).

La referencia del apartado b) de este artículo al derecho a la negociación colectiva de esas secciones sindicales, tan importante en el ámbito laboral privado, no afecta al personal funcionario ni estatutario porque esa función, como ya vimos en el Capítulo anterior, le corresponde por ley a las organizaciones sindicales en exclusiva, que la llevan a efecto en las Mesas de negociación.

$2^{\circ}$.- Si, además, el centro de trabajo tiene más de 250 trabajadores, las secciones sindicales citadas en el punto anterior tendrán derecho a la "utilización de un local adecuado en el que puedan desarrollar sus actividades" (artículo 8.2. c LOLS).

En resumen, para que la sección sindical tenga más facultades y derechos de los que prevé el apartado 1 del artículo 8 LOLS, el sindicato tendrá que cumplir determinados requisitos de representatividad en una unidad electoral con una plantilla representada de más de doscientos cincuenta trabajadores ${ }^{456}$. En el ámbito sanitario, si la prestación del servicio es responsabilidad directa de la Administración o Servicio de salud, el requisito de que la plantilla representada se cumplirá prácticamente siempre, por requerimientos asistenciales $^{457}$.

En cuanto a la creación de secciones sindicales mixtas o conjuntas; es decir, aquellas formadas a la vez por personal funcionario o estatutario y personal laboral, ni la LORAP ni la jurisprudencia les reconocían los efectos de cargas a terceros, principalmente porque:"Las representaciones respectivas del personal funcionarial y laboral aunque pueden coexistir dentro de una misma sección sindical en virtud del principio de soberana autorregulación sindical de dicho sistema de presencia en y ante la empresa, tienen la extracción, la implantación y la representatividad derivadas de sus respectivos ámbitos de actuación, de donde se inferiría la imposibilidad de efectuar trasvases equilibradores de votos y de porcentajes de representación a fin de crear obligaciones para un tercero" ${ }^{458}$.

\footnotetext{
${ }^{456}$ STSJ de Madrid de 5 de octubre de 1999, Fundamento jurídico cuarto, (AS 1999\3531): “... tal exigencia de mínimos supone pedirle a ese sindicato que aunque no represente a demasiados sea alguien, y no se quede en un mero algo".

${ }^{457}$ Cuesta imaginar un área de salud o delimitación similar, que cuente con un número de personal funcionario y estatutario inferior al indicado. Por el mismo motivo, el órgano de representación del personal de instituciones sanitarias es la Junta de Personal, regulada en el artículo 39.3 LEBEP, que exige un mínimo de cincuenta funcionarios o estatutarios representados para su constitución.
}

${ }^{458}$ STS de 23 de diciembre de 2002, (RJ 2003\1427). En sentido similar, la STSJ de Madrid de 5 de octubre de 1999, (AS 1999\3531). 
Capítulo V. El contenido de la negociación colectiva de los derechos sindicales del personal estatutario de los Servicios de salud antes y después de las medidas de ajuste presupuestario

No obstante, en los Acuerdos y Pactos sobre derechos sindicales de los empleados públicos se ha venido reconociendo, durante años, la existencia de las secciones sindicales conjuntas de personal funcionario, estatutario y laboral, incluso se ha pactado que tuvieran ese carácter en todo caso, y con el reconocimiento de todos sus efectos. Esto era especialmente beneficioso para las organizaciones sindicales en el ámbito sanitario, donde el personal es mayoritariamente estatutario, pero también hay funcionarios y personal laboral $^{459}$.

Por otra parte, el artículo 10.1 LOLS regula la posibilidad de designar delegado o delegados sindicales de sección sindical, elegidos entre los trabajadores afiliados al sindicato y que actuarán como representantes de este en el ámbito electoral correspondiente, si este ocupa a más de 250 trabajadores, con el requisito de que se trate de sindicatos que hayan obtenido alguna representación en los órganos unitarios de personal: "En las empresas o, en su caso, en los centros de trabajo que ocupen a más de 250 trabajadores, cualquiera que sea la clase de su contrato, las secciones sindicales que puedan constituirse por los trabajadores afiliados a los sindicatos con presencia en los Comités de empresa o en los órganos de representación que se establezcan en las Administraciones públicas estarán representadas, a todos los efectos, por delegados sindicales elegidos por y entre sus afiliados en la empresa o en el centro de trabajo".

La STC 173/1992, de 29 de octubre, declaró plenamente constitucional este precepto, ya que el hecho de que determinadas secciones sindicales no puedan contar por imperativo legal con un delegado sindical, porque no alcanzan a tener representación en el órgano unitario de personal o el centro de trabajo no supera los 250 trabajadores, no impide el ejercicio de los derechos de los artículos 8 y 9 LOLS por sus respectivos titulares, y solo comporta la imposibilidad de acceder a los derechos del artículo 10.3 LOLS $^{460}$.

En los Acuerdos y Pactos de derechos sindicales esta exigencia de la LOLS relativa al número de trabajadores se solía obviar, por lo que se daba por cumplida, y se pactaban directamente las unidades electorales en las que se podían constituir secciones sindicales con todas las garantías.

El número de delegados sindicales que pueda designar el sindicato estará en función del personal representado, de acuerdo con una escala que va desde uno a cuatro ${ }^{461}$, siempre que se haya obtenido un mínimo del $10 \%$ de los votos en las elecciones sindicales.

\footnotetext{
${ }^{459}$ En el Pacto de 3 de octubre de 2003, del Servicio Cántabro de Salud, el punto 2 de su apartado III: "Las Secciones serán conjuntas para ambos tipos de personal: estatutario y laboral”. Igualmente en el Pacto de 2006 de la Junta de Castilla y León (art.4º 4.1). En el mismo sentido, el Pacto del Servicio Extremeño de Salud, de 4 de octubre de 2002, artículo 3.2: "Las Secciones Sindicales serán conjuntas para todo el personal, ya sea funcionario, estatutario o laboral".

${ }^{460}$ (RTC 1992\173).

${ }^{461}$ Artículo 10.2 LOLS: "A falta de acuerdos específicos al respecto, el número de delegados sindicales por cada sección sindical de los sindicatos que hayan obtenido el 10 por 100 de los votos en la elección al Comité de empresa o al órgano de representación en las Administraciones públicas se determinará según la siguiente escala [...] de 250 a 750 trabajadores: uno. De 751 a 2.000 trabajadores: dos. De 2.001 a 5.000 trabajadores: tres. De 5.001 en adelante: cuatro".
} 
Capítulo V. El contenido de la negociación colectiva de los derechos sindicales del personal estatutario de los Servicios de salud antes y después de las medidas de ajuste presupuestario

El número de delegados es ampliable por negociación colectiva: "Bien por acuerdo, bien a través de la negociación colectiva, se podrá ampliar el número de delegados establecidos en la escala a la que hace referencia este apartado [...] Las secciones sindicales de aquellos sindicatos que no hayan obtenido el 10 por 100 de los votos estarán representadas por un solo delegado sindical" (art. 10.2 LOLS).

Efectivamente, el número de delegados sindicales era normalmente uno de los aspectos principales objeto de mejora en los Pactos y Acuerdos sobre derechos sindicales, que solían aumentarlo por encima de la escala legal, Eso sí, en todos ellos se respeta la disposición de la LOLS en cuanto a la exigencia a las organizaciones sindicales del $10 \%$ de los votos en las elecciones sindicales a los órganos de representación del personal, para disfrutar de esta garantía.

- Por ejemplo, el Acuerdo de 4 de julio de 2008, del Servicio Aragonés de Salud, reconocía a los sindicatos firmantes un aumento del número de delegados sindicales de entre dos a cinco más con respecto a la escala de la LOLS "Los sindicatos firmantes del presente Acuerdo, además de los delegados que les corresponda de conformidad con lo dispuesto en el artículo referido (10.2 LOLS) podrán designar los delegados adicionales previstos en el artículo 13 b) del presente Acuerdo una vez ajustada su distribución a la proporción resultante de la nueva representación ostentada en la Mesa Sectorial de Sanidad" y también: "Para cada Organización Sindical presente en Mesa Sectorial de Sanidad se reconoce el número máximo de delegados sindicales, a designar entre el personal funcionario o estatutario".

- En el Acuerdo de 25 de febrero de 2005, de la Administración del Principado de Asturias, se mejoraba el mínimo de la escala de la LOLS, garantizando en todo caso el de cuatro delegados sindicales.

- En el Pacto de 27 de junio de 2006, de la Junta de Castilla y León, el artículo 4.2.1 disponía a favor de los sindicatos "con mayor nivel de implantación", es decir, aquellos que hubieran obtenido al menos el 15\% de los miembros de los órganos unitarios del personal, un mínimo de dos delegados en los centros de trabajo de 250 empleados públicos, sin tope máximo, y una proporción que en una plantilla de 5001 trabajadores -en cuyo caso la LOLS atribuye cuatro delegados sindicales-, confería dieciséis delegados. En el Servicio Extremeño de Salud se amplió el número máximo de delegados sindicales de la LOLS a cinco delegados, según sus Pactos de 4 de octubre de 2002 y de 22 de enero de 2003, artículo 3.5, en ambos casos: "El número de Delegados Sindicales por cada sección sindical de los sindicatos que hayan obtenido el $10 \%$ de los votos en la elección a órganos de representación del Servicio Extremeño de Salud, será mínimo de uno y máximo de cinco".En el Pacto de 1 de junio de 1999, del Servicio Gallego de Salud, se garantizaba un mínimo de dos delegados y un máximo de seis.

En cuanto al número de empleados públicos del centro de trabajo que se deben computar a efectos de designación de delegados sindicales con todas las ventajas legales, hay que señalar que es un criterio jurisprudencial que este se determina teniendo en cuenta tanto al personal con vinculación fija como a los interinos o sustitutos, ya que la LOLS habla de "trabajadores", sin excepciones ${ }^{462}$.

${ }^{462}$ STSJ de Cantabria de 8 de junio de 2005, (AS 2005\/485). 

de los Servicios de salud antes y después de las medidas de ajuste presupuestario

Ello, sin perjuicio, como señala la STSJ de Cantabria de 5 de noviembre de 2003, de que el número de los delegados sindicales se adecúe progresivamente a la evolución de la plantilla de trabajadores: “... una posterior reducción del número de trabajadores de la plantilla del centro por debajo del umbral mínimo legal, permita a la empleadora (Servicio de salud) controlar los presupuestos ex artículo 10.3 LOLS en orden a la asunción de las cargas y costes que le supone las correlativas prerrogativas de determinados delegados sindicales, tal como ha reconocido la STS de 11 de abril de 2001" ${ }^{463}$. Sin embargo, los Acuerdos y Pactos sobre derechos y garantías sindicales que afectaban al personal de los Servicios de salud no solían recoger esta estipulación, y no era una cláusula habitual la de adecuación del número de delegados sindicales a la evolución de la plantilla ${ }^{464}$.

En cuanto a los derechos de los delegados sindicales, hay que decir que el artículo 10.3 LOLS regula las garantías de los delegados sindicales, reconociéndoles las mismas que a los representantes del personal, en el supuesto de que no formen parte del órgano unitario de representación del personal, con lo cual les asegura el disfrute del crédito horario sindical, que reconoce el artículo 41.1 d) LEBEP para los miembros de la Junta de Personal, así como tener acceso a la misma información y documentación que la empresa ponga a disposición del órgano de representación del personal ${ }^{465}$. También podrán asistir a las reuniones de los Comités de empresa, y de los órganos internos de la empresa, en materia de seguridad e higiene o de la Junta de Personal, con voz pero sin voto, y ser oídos por la empresa previamente a la adopción de medidas disciplinarias que afecten a sus afiliados.

De las garantías que regula esta norma, la que se mejoraba habitualmente a través de la negociación colectiva era el aspecto del crédito horario de los delegados sindicales, reconociéndoles un número de horas para esta finalidad por encima de los mínimos legales.

\subsection{2.- EL CRÉDITO HORARIO SINDICAL}

Entre las garantías que la ley reconoce a los delegados sindicales y a los representantes unitarios del personal para facilitar el desarrollo de la actividad sindical, destaca la concesión de un crédito de horas mensuales, dentro de la jornada de trabajo, que se retribuyen como tales y que puede ser objeto de acumulación hasta el punto de relevar al trabajador de la prestación de sus servicios. Se trata de un cupo de horas libres que sus

\footnotetext{
463 (AS 2004 837$)$.
}

464 No obstante, en la Disposición adicional primera del Acuerdo de 25 de febrero de 2005, de la Administración del Principado de Asturias, sí se recogió expresamente esta estipulación: "Los derechos reconocidos en el presente Acuerdo a los delegados sindicales serán objeto de revisión siempre que se produzca una disminución sustancial del número de empleados en cualquiera de los colectivos incluidos en el ámbito de personal de este Acuerdo".

${ }^{465}$ En un supuesto de reclamación de información sobre contratación de personal por parte de la sección sindical de UGT en el Hospital Clínico Universitario de Valencia, la STSJ de la Comunidad Valenciana, de 27 de enero de 1998, en el Fundamento jurídico tercero, argumenta: “... el presupuesto de aplicación del artículo 10.3 LOLS sujeta las garantías que señala de los delegados sindicales (no de la sección sindical como se pretende) a que los mismos no formen parte del Comité de empresa o de los órganos de representación en las Administraciones públicas, (AS 19981830). 
Capítulo V. El contenido de la negociación colectiva de los derechos sindicales del personal estatutario de los Servicios de salud antes y después de las medidas de ajuste presupuestario

titulares pueden dedicar a la acción sindical, con la ventaja principal de ser consideradas tiempo de trabajo efectivo.

En el ámbito laboral común, el derecho al crédito sindical de los representantes de los trabajadores viene reconocido en el artículo 68 e) TRET, que regula el derecho de los representantes de los trabajadores a disponer de un número de horas libres al mes en función del número de trabajadores representados.

Para el personal funcionario y estatutario este derecho de los representantes del personal se regula en el artículo 41. 1 d) LEBEP, con la misma escala de horas libres mensuales que en el TRET, en función del número de funcionarios o estatutarios representados, como ya hizo en su día la LORAP ${ }^{466}$ : "1. Los miembros de las Juntas de Personal y los Delegados de Personal, en su caso, como representantes legales de los funcionarios, dispondrán en el ejercicio de su función representativa de las siguientes garantías y derechos [...] d) Un crédito de horas mensuales dentro de la jornada de trabajo y retribuidas como de trabajo efectivo, de acuerdo con la siguiente escala...Hasta 100 funcionarios: 15; de 101 a 250 funcionarios: 20; de 251 a 500 funcionarios: 30; de 501 a 750 funcionarios: 35 ; de 751 en adelante: 40”.

Los delegados sindicales tienen regulado este derecho a las horas libres para actividad sindical en el artículo 10.3. LOLS, como vimos antes: "Los delegados sindicales, en el supuesto de que no formen parte del Comité de empresa, tendrán las mismas garantías que las establecidas legalmente para los miembros de los comités de empresa o de los órganos de representación que se establezcan en las Administraciones públicas...".

Respecto al derecho a las horas sindicales, se discute si forma parte del contenido esencial o del adicional del de libertad sindical. A favor de la primera postura se manifiesta la STC 40/1985, de 13 de marzo, entendiendo que el disfrute del crédito horario sindical de los representantes sindicales está comprendido en el contenido esencial del derecho a la libertad sindical: “...el derecho a la libertad sindical consagrado en el artículo 28.1 de la Constitución comprende no solo el de los trabajadores a organizarse sindicalmente, sino además el de los sindicatos de ejercer aquellas actividades que permiten la defensa y protección de los intereses de los propios trabajadores". También hay ciertas garantías y facilidades de los representantes sindicales que de algún modo se incorporan al contenido esencial del derecho a la libertad sindical, siendo una de ellas la del artículo 68 e) del Estatuto de los Trabajadores: crédito de horas mensuales retribuidas para el ejercicio de sus funciones de representación (derecho de creación legal que pasa a formar parte del derecho fundamental a la libertad sindical)" ${ }^{467}$.

\footnotetext{
${ }^{466}$ El artículo 11 d) LORAP dispuso: "Los miembros de la Junta de Personal y los Delegados de Personal, en su caso, como representantes legales de los funcionarios, dispondrán en el ejercicio de su función representativa de las siguientes garantías y derechos: d) un crédito de horas mensuales dentro de la jornada de trabajo y retribuidas como de trabajo efectivo, de acuerdo con la siguiente escala...”.

${ }^{467}$ Fundamento jurídico primero, (RTC 1985\40).
} 
Capítulo V. El contenido de la negociación colectiva de los derechos sindicales del personal estatutario de los Servicios de salud antes y después de las medidas de ajuste presupuestario

Con respecto a los representantes unitarios de los empleados públicos, recoge también esta doctrina la STSJ de Canarias de 30 de abril de $1999^{468}$, que declaró comprendido el derecho al crédito horario del artículo $11 \mathrm{~d})$ LORAP en el contenido esencial de la libertad sindical.

Por el contrario, la STC 61/1989, de 3 de abril, lo entiende como parte del contenido adicional del derecho fundamental: “... además no ha de confundirse el ámbito del contenido esencial del derecho, límite que se impone a la actividad del legislador (art. 53.1 de la Constitución), con el ámbito de protección en amparo del derecho fundamental (art. 53.2 de la Constitución) que incluye el efectivo goce del derecho en el marco de su regulación legal, la cual puede, respetando ese contenido esencial, y dentro del margen de elección política, regular de forma más amplia o restrictiva los derechos o medios instrumentales que faciliten al sindicato y a sus afiliados el ejercicio de la actividad sindical de la empresa" ${ }^{469}$.

Hay que tener en cuenta que la discusión acerca de si las normas que conciernen al crédito horario sindical son un tema de mera legalidad ordinaria o bien forman parte del contenido, esencial o adicional, del derecho fundamental a la libertad sindical, tiene repercusión práctica, ya que determina el cauce procesal adecuado para los litigios que se deriven, en función de si se ve lesionado el derecho fundamental a la libertad sindical ${ }^{470}$.

En el ámbito funcionarial, el uso del tiempo libre para destinarlo a la actividad sindical se configura legalmente como un derecho individual del funcionario, que se ejercita como un permiso ${ }^{471}$. Por ese motivo el empleado público a cuyo favor se autoriza, se mantiene en situación administrativa de activo a todos los efectos, según dispone el artículo 48 c LEBEP, que regula entre los permisos de los funcionarios públicos el destinado a: “c) realizar funciones sindicales o de representación del personal, en los términos que se determine".

Este aspecto del crédito sindical es, precisamente, uno de los básicos que se regulan en los Pactos y Acuerdos que afectan al personal estatutario de los Servicios de salud, y cuyo contenido se ha ampliado fruto de la negociación colectiva, por encima de la regulación legal. Ello tanto para los delegados sindicales, como para los miembros de las Juntas de personal ${ }^{472}$.

\footnotetext{
468 (RJCA 1999\1403).

${ }^{469}$ Fundamento jurídico segundo, (RTC 1989\61).

${ }^{470}$ LUJAN ALCARAZ, J., Ámbito subjetivo del derecho a la acumulación de horas y contenido del derecho de libertad sindical, AS, volumen IV, (BIB 19971270).

${ }^{471}$ STSJ de Castilla-La Mancha de 18 de junio de 2002, (RJCA 2002\793).

${ }^{472}$ Véanse los Pactos de 4 de octubre de 2002 y de 22 de enero de 2003, del Servicio Extremeño de Salud. El crédito horario de los delegados sindicales era, en todo caso, el máximo dispuesto en la LOLS, sin exigencia de un mínimo de personal representado (40 horas). En la regulación de la LOLS este número de horas sindicales está previsto para los centros de trabajo con plantilla mínima de 751 trabajadores.
} 
Capítulo V. El contenido de la negociación colectiva de los derechos sindicales del personal estatutario de los Servicios de salud antes y después de las medidas de ajuste presupuestario

Las normas que reconocen el derecho a las horas libres retribuidas para actividad sindical a los representantes unitarios del personal (art. 68 d) TRET y 41.1 d) LEBEP) admiten la posibilidad de que ese crédito horario sea acumulado. El objeto de esa acumulación del tiempo libre para destinarlo a la actividad sindical es relevar del trabajo a alguno o algunos representantes para hacer más eficaz el ejercicio de ese derecho, convirtiéndose así el representante en lo que comúnmente se conoce como "liberado sindical".

Por otro lado, en los Acuerdos y Pactos sobre derechos y garantías sindicales de los empleados públicos, en general, y de los de personal estatutario en concreto, existe un tipo de permiso para actividad sindical un tanto singular, que vamos a tratar a continuación: la liberación de funciones institucional.

\subsubsection{1.- La liberación de funciones institucional}

Se trata de un tipo particular de liberación de funciones, que no viene dada en la ley porque no se produce como resultado de la acumulación del crédito de horas reconocido en ella, sino que tiene su origen en la negociación colectiva funcionarial. Su existencia se basa directamente en lo acordado entre la Administración pública y los sindicatos, y se caracteriza por recibir el empleado público beneficiado un permiso para actividad sindical, de forma totalmente independiente de las horas reconocidas para la misma finalidad a los delegados sindicales o representantes del personal.

La STC 118/2012, de 4 de junio, ha señalado que los liberados institucionales representan "un plus de crédito horario que la Administración reconoce aun cuando no está obligada a ello", y debe hacerlo en base a criterios de reparto no discriminatorios ${ }^{473}$.

El antecedente de esta institución en la negociación colectiva del personal estatutario lo encontramos en los Pactos sobre permisos y uso de crédito horario para la realización de funciones sindicales y de representación del personal al servicio de las Instituciones Sanitarias del INSALUD, de 30 de junio y 17 de julio de 1989.

En el primero de ellos, se reconocía a favor del personal propuesto por las organizaciones sindicales firmantes y "al objeto de que realicen sus actividades en las estructuras sindicales relacionadas con la Administración del INSALUD” hasta un número

\footnotetext{
Asimismo, en el Acuerdo de 16 se septiembre de 2003, sobre derechos sindicales del personal del Instituto Madrileño de Salud, el artículo 1 del Capítulo III disponía un crédito horario para los miembros de la Junta de Personal comprendido entre un mínimo de 40 h. hasta un máximo de 75 h. mensuales.
}

El Acuerdo Marco sobre Derechos Sindicales y Ejercicio de la Actividad Sindical en la Administración de la Comunidad Autónoma del País Vasco, de 15 de octubre de 1988 (apartado 2) reconocía directamente el crédito horario máximo previsto en la ley: “...tanto a los miembros de las Juntas de Personal y Comités de Empresa o Delegados de Personal, como a los delegados sindicales, un crédito de 40 horas mensuales, consideradas, a estos efectos, como de trabajo efectivo".

${ }^{473}$ Fundamento jurídico séptimo, (RTC 2012\118). 
Capítulo V. El contenido de la negociación colectiva de los derechos sindicales del personal estatutario de los Servicios de salud antes y después de las medidas de ajuste presupuestario

máximo de 250 permisos para la realización de funciones sindicales y de representación del personal, de los cuales, se distribuyeron 185 a partes iguales entre los firmantes, y el resto, hasta aquel máximo en función de la representatividad del sindicato, según los resultados de las elecciones a Juntas de Personal celebradas en diciembre de 1987, en las Instituciones Sanitarias del INSALUD.

En ambos Pactos se reconocía también que: "Quienes disfruten de estos permisos y reúnan además la condición de miembros de las Juntas de Personal o de Delegados Sindicales, podrán ceder el crédito horario al que por dicha condición y conforme a la Ley 9/1987, de 12 de junio o a la Ley Orgánica 11/1985 de Libertad Sindical, tuviesen derecho”. La interpretación de este apartado aclara que aquellos permisos reconocidos no se correspondían con el crédito que reconoce la ley a los representantes del personal en base a los resultados electorales.

El régimen de la liberación institucional se ha incorporado, generalmente, en los Acuerdos y Pactos sobre derechos sindicales, que determinaban el número concreto de liberaciones sindicales institucionales que podían reconocerse de forma simultánea a cada organización sindical. Alguno de estos instrumentos negociados incluso concretaba su concepto: "La liberación de funciones de carácter institucional es aquella que tienen reconocida las personas que, a propuesta de las organizaciones sindicales representativas en los órganos de negociación, queden exentas de prestar servicios para poder llevar a cabo actividades sindicales dentro del ámbito administrativo y/o dentro de la estructura de la organización sindical" (art. 16 del Acuerdo de 2 de marzo de 2006, de la Administración de la Comunidad autónoma de las Islas Baleares).

También este aspecto de la acción sindical puede ser objeto de negociación específica y separada en un instrumento negociado al efecto, como en el caso de la Administración de la Generalitat Valenciana, que reguló las liberaciones institucionales en los Acuerdos de 19 de junio de 1995 y de 30 de noviembre de 2004; o en el caso del Servicio Gallego de Salud, que las reguló en el Reglamento de 6 de noviembre de 2007, de su Mesa sectorial de Sanidad, fundándolas en el incremento de plantilla que había experimentado el Servicio de salud durante esos años a causa de la integración de personal procedente de fundaciones y empresas públicas y la carga de trabajo de las Comisiones de seguimiento de los Acuerdos aprobados relativos a diferentes materias (Disposición adicional $)^{474}$.

En cuanto al número de dispensas institucionales reconocidas en los distintos Acuerdos y Pactos, este era variable, y difícilmente comparable, porque desconocemos el número concreto de personal representado en cada Administración autonómica o Servicio de salud. La razón de ser de estos reconocimientos se fundamenta en los Acuerdos en la conveniencia de facilitar y promover la actividad sindical, la actividad negociadora y de participación del personal" o "la realización de funciones sindicales relacionadas con la actuación de la Mesa General de Negociación", y habitualmente su reparto se basaba en criterios de proporcionalidad según la representatividad de las organizaciones sindicales.

${ }^{474}$ Diario Oficial de Galicia de 25 de febrero de 2008. 
Capítulo V. El contenido de la negociación colectiva de los derechos sindicales del personal estatutario de los Servicios de salud antes y después de las medidas de ajuste presupuestario

- Por ejemplo, en el Acuerdo de 25 de febrero de 2005, de la Administración del Principado de Asturias se pactaron seis liberaciones para las organizaciones sindicales presentes en la Mesa sectorial de personal de instituciones sanitarias, en función de la representatividad que acreditaran en la misma, dentro de un total de cuarenta y cuatro para todas las Mesas de negociación de la Comunidad autónoma (art. 10).

- En el Acuerdo de 2 de marzo de 2006, de la Administración autonómica de las Islas Baleares, se establecieron dos para cada una de las organizaciones sindicales representativas presentes en la Mesa sectorial de Sanidad (art. 16); otros catorce para compensar las desigualdades en la estructura de la representación en cada ámbito (art. 17), y tres más a repartir entre las organizaciones sindicales más representativas. El número de liberados institucionales que reconocía este Acuerdo en el ámbito sanitario es de diecinueve sobre un total de cincuenta y siete para el conjunto de las Mesas de negociación. Además, en su Disposición transitoria segunda dispuso el reconocimiento de un liberado más para las organizaciones sindicales firmantes del Acuerdo "Con la finalidad de facilitar el desarrollo del Acuerdo Administración-organizaciones sindicales para el período 2005-2007 y las diversas tareas que la ejecución del Plan de estabilidad laboral requieren, como también permitir la constitución de los diferentes grupos de trabajo y de la Comisión de seguimiento del Acuerdo".

- El Acuerdo de 7 de julio de 2008, de la Junta de Andalucía, reconocía sesenta liberados institucionales, a repartir entre las organizaciones firmantes del mismo. "para la realización de funciones sindicales relacionadas con la actuación de la Mesa General de Negociación de la Administración de la Junta de Andalucía común para el personal funcionario, estatutario y laboral (art. 36.3 LEBEP) a distribuir de manera lineal entre las Organizaciones Sindicales que forman parte de la citada Mesa y firman el presente Acuerdo", (cláusula segunda, 2).

- El Acuerdo de 4 de julio de 2008, del Servicio Aragonés de Salud, dispuso a favor de las organizaciones sindicales firmantes cuarenta liberaciones institucionales a distribuir entre ellas, siendo treinta y seis a repartir en función de la representatividad y uno para cada una de las cuatro por ser parte de la Mesa sectorial de Sanidad.

- El Pacto del Servicio Canario de Salud, de 4 de abril de 2000, reconoció treinta y cinco liberaciones de este tipo, a repartir entre las organizaciones sindicales que contaran con un mínimo del $10 \%$ de representatividad en las elecciones sindicales de personal funcionario y estatutario.

- En el Acuerdo en materia de acción sindical, de 25 de junio de 2011, de la Comunidad autónoma de La Rioja, se aprobaron treinta y dos liberados institucionales a distribuir entre los sindicatos firmantes.

- El Pacto sobre derechos sindicales de la Administración de la Generalitat de Cataluña, de 22 de diciembre de 2004, en su artículo 4, reconoció sesenta liberaciones institucionales a favor de las organizaciones sindicales presentes en las cuatro Mesas de negociación que correspondían a la totalidad de los puestos de la parte social. Se pactó su distribución proporcional al número de representantes de cada organización sindical en cada Mesa de negociación.

- La Sección tercera del Capítulo V del Pacto Único de Interlocución de la Administración de la Junta de Comunidades de Castilla-La Mancha, de 18 de noviembre de 2008, reguló ciento cuatro liberaciones institucionales a repartir entre las organizaciones sindicales con representación en la Mesa General de Negociación de los Empleados Públicos, en las Mesas sectoriales y Comisión negociadora del VI Convenio colectivo del personal laboral. Consistían en: "dispensas de asistencia al trabajo de carácter institucional para facilitar el 
Capítulo V. El contenido de la negociación colectiva de los derechos sindicales del personal estatutario de los Servicios de salud antes y después de las medidas de ajuste presupuestario

desarrollo y eficacia de la negociación colectiva de las Organizaciones Sindicales presentes en las distintas mesas de negociación descritas en el presente Pacto..." y se basaban en una distribución proporcional al número de representantes legales obtenidos en las elecciones sindicales.

- El Pacto de 31 de octubre de 1995, del Servicio Gallego de Salud, autorizó cuarenta liberaciones sindicales institucionales a favor de las organizaciones firmantes del mismo para que pudieran "desarrollar idóneamente y sin constreñimientos su función de carácter representativo", a repartir proporcionalmente a la representación acreditada en el último proceso electoral.

Vemos que la distribución de las liberaciones sindicales se hacía según criterios objetivos de representatividad y proporcionalidad, pero en general solo para los sindicatos firmantes de los Acuerdos y Pactos. Esta práctica puede comprometer el criterio de no discriminación sindical que exige la jurisprudencia, al reconocer las liberaciones institucionales a favor de las organizaciones sindicales que se muestren coincidentes con la Administración en una negociación concreta, por este mero hecho.

\subsubsection{2.- La constitución de la bolsa de crédito horario y la liberación total y parcial de funciones}

La constitución y gestión de las bolsas de crédito horario sindical y de las dispensas sindicales, que se reconocen en base a ellas, es uno de los apartados principales de la negociación en los instrumentos negociados de derechos sindicales de los empleados públicos, y en particular de los que afectan al personal estatutario. Estas bolsas de horas sindicales surgen como resultado de la acumulación del crédito horario que tiene individualmente reconocido cada representante sindical y unitario, en cómputo anual, y que puede ser cedido para formar un total global acumulado a favor de su organización sindical $^{475}$.

Las horas que se acumulan para constituir la bolsa de crédito horario son las que corresponden a cada delegado sindical o representante unitario del personal, que tienen reconocidas en base a la LOLS (art. 10.3), y en la LEBEP para los representantes unitarios de los funcionarios y estatutarios (art. $41.1 \mathrm{~d}$ ); o en el TRET para el personal laboral (art. 68 e); o bien las que, en número superior, les reconozca el Acuerdo o Pacto de derechos y garantías sindicales que les sea de aplicación.

Previa a la acumulación de las horas, se debe dar la cesión de las mismas. La cesión de horas debe ser personal, expresa y manifestada por escrito. Supone la renuncia del

\footnotetext{
${ }^{475}$ Postura contraria a la posibilidad de acumulación del crédito horario de los delegados sindicales junto con el de los representantes unitarios del personal es la contenida en la STSJ Murcia, de 6 de febrero de 1998, Fundamento jurídico segundo, (AS 19981527). Es sin embargo, cláusula común en todos los Acuerdos de derechos sindicales que regulan esta cuestión. A título de ejemplo, el Pacto de la Administración de la Junta de Castilla y León, de 27 de junio de 2006, en su artículo 6, estableció que: "Mediante la acumulación, previa cesión por los titulares del mismo, del crédito horario correspondiente a los miembros de las Juntas de Personal, de los Comités de Empresa de Centro, Comité Intercentros y de los delegados sindicales, cada sindicato podrá constituir una bolsa de horas sindicales, que estará conformada por el total de los créditos cedidos".
} 
Capítulo V. El contenido de la negociación colectiva de los derechos sindicales del personal estatutario de los Servicios de salud antes y después de las medidas de ajuste presupuestario

derecho al crédito horario individual a favor de la organización sindical, teniendo habitualmente dicha un carácter irrevocable ${ }^{476}$. Es, además, un acto voluntario de su titular; por tanto, cabe la posibilidad de que, llegado el caso, el representante se niegue a realizar la cesión del crédito horario y desee conservarlo para sí.

En este sentido, la STSJ de Castilla-La Mancha de 18 de junio de 2002, respecto al crédito horario de los miembros de la Junta de Personal, declaró que: “... el derechogarantía de crédito horario se reconoce a los propios miembros de la Junta y se hace para el ejercicio de las tareas en dicho órgano [...] para las funciones que legalmente tienen asignadas [...] viniendo dicho derecho configurado como un derecho personal en cuanto miembros de la Junta y no como miembros de la candidatura por lo que la organización sindical no puede decidir sobre la cesión" ${ }^{477}$.

Usualmente se ha venido pactando que la cesión de crédito horario se debiera comunicar al órgano administrativo responsable de la gestión de la bolsa de horas sindicales, competencia que en el ámbito sanitario viene atribuida habitualmente al órgano directivo responsable de recursos humanos del Servicio de salud correspondiente ${ }^{478}$.

Una vez constituida la bolsa de horas estas se pueden emplear en la concesión de dispensas totales o parciales para el desempeño de actividad sindical a favor de otros representantes sindicales, a criterio de la organización sindical beneficiaria de la cesión del crédito y según su estrategia sindical. En los Acuerdos y Pactos reguladores de derechos sindicales del personal estatutario se suelen marcar unas directrices por motivos de eficacia en la gestión, como el límite mínimo de duración de las dispensas parciales, ya que en el ámbito sanitario el desempeño de la jornada de trabajo a turnos es la norma general y este hecho dificulta la concesión de permisos sindicales de corta duración ${ }^{479}$.

\footnotetext{
${ }^{476}$ Como ejemplo, el artículo 15.14 del Acuerdo de 4 de julio de 2008, del Servicio Aragonés de Salud, disponía: "Cuando un representante unitario o sindical, que ha cedido por un año natural su crédito horario para constituir la bolsa de horas, cause baja en el sindicato o cambie de afiliación sindical, no podrá recuperar las horas voluntariamente cedidas, que se mantendrán, por tanto, en la bolsa del sindicato a favor del que se cedieron".

${ }^{477}$ Fundamento jurídico tercero, (RJCA 2002\793).

${ }^{478}$ En el Pacto del Servicio Murciano de Salud, de 18 de julio de 2003, se reguló en el apartado 2 del Capítulo II, titulado "Bolsa de créditos horarios sindicales" que: "Para la constitución de la bolsa de horas será necesaria la cesión del crédito horario de cada representante en favor de su Organización Sindical, por medio del modelo que se acompaña como anexo al presente pacto, y que será dirigida a la Dirección General de Recursos del Servicio Murciano de Salud. La cesión de horas supondrá la renuncia a su ejercicio en favor de su Organización Sindical”.

${ }^{479}$ En el Pacto del Servicio Murciano de Salud, de 18 de julio de 2003, se regulaba en el Capítulo III, apartado 1 b), la "Licencia a tiempo parcial": "Comprenderá un mínimo de 5 días completos al mes, a razón de 5 horas por cada jornada de trabajo en el caso de que corresponda a turnos de mañana o tarde. En el resto de los supuestos, como es el caso de los turnos que se realizan en horario nocturno, así como aquellos otros en los que existe una jornada especial el número de horas necesario para la liberación será coincidente con el que debiera realizar el interesado. Las solicitudes se deberán dirigir al órgano administrativo que gestione la bolsa, con la antelación que señale el acuerdo. El disfrute del crédito horario tiene lugar hasta que se agote el total de horas disponibles, en cómputo anual”.
} 
En los Acuerdos y Pactos reguladores de esta materia las horas necesarias para autorizar una dispensa total anual variaban, dependiendo de cada Administración autonómica o Servicio de salud, aunque generalmente se trataba de un número inferior de horas a las de la jornada ordinaria reglamentaria del personal, establecida en su normativa autonómica $^{480}$. Esto representaba, en definitiva, una mejora sobre el régimen legal previsto, ya que en aplicación estricta de la LOLS, la LEBEP o el TRET, se deben compensar todas las horas que debe trabajar el representante para que este quede liberado de su trabajo habitual. Por tanto, uno de los aspectos que recogían de forma general estos Acuerdos y Pactos consistía en que las horas requeridas para autorizar una liberación completa por acumulación de crédito horario, fueran un número inferior al total de horas de jornada anual reglamentaria del trabajador liberado.

- El Acuerdo Marco sobre derechos sindicales y ejercicio de la actividad sindical en la Administración de la Comunidad Autónoma de Euskadi, de 15 de octubre de 1988, apartado 2 disponía: "Las Organizaciones Sindicales podrán proceder a acumular las horas sindicales correspondientes a sus representantes en las Juntas de Personal, y Comités de Empresa o Delegados de Personal y delegados sindicales a nivel de Comunidad Autónoma en aquellos casos en que se vaya a producir una dedicación a jornada completa a la Central Sindical correspondiente por un período no inferior a un año y comunicándolo con un mes de antelación. A este fin se acuerda que, es necesario acumular 1.260 horas para generar el derecho de liberación de una persona. En ningún caso se podrá efectuar a los efectos de acumulación de horas para obtener liberaciones anuales la transferencia de créditos horarios entre distintos sectores de actividad". En el caso del Servicio Vasco de salud, la jornada reglamentaria era, durante la vigencia de ese Acuerdo, de 1.592 horas $^{481}$.

- En el Pacto de Interlocución de la Administración de la Junta de Comunidades de CastillaLa Mancha, de 18 de noviembre de 2008, era tan solo necesaria la acumulación de 1.200 horas al año para conceder una liberación a tiempo completo, según el apartado 2 de su Sección Tercera, que disponía: "Dispensa total (por acumulación de crédito horario): las Organizaciones Sindicales podrán obtener la dispensa de asistencia al trabajo de un empleado público por acumulación de 100 horas mensuales de crédito horario de Representantes Legales y Delegados Sindicales, incluidas, en su caso, las suyas propias”.

- En la Comunidad Valenciana, eran necesarias 1.320 horas anuales para autorizar una dispensa sindical anual por tiempo completo, cuando la jornada reglamentaria anual del personal estatutario de sus instituciones sanitarias era, desde el año 2006, de 1.589 horas ${ }^{482}$ (apartado V del Acuerdo de 30 de diciembre de 2003).

${ }^{480}$ La jornada de trabajo del personal estatutario es materia, a su vez, de obligada negociación, al igual que la del resto de los empleados públicos, tanto con la LORAP, como ahora con la LEBEP (art. $37.1 \mathrm{~m}$ ), y estaba regulada en el correspondiente Acuerdo autonómico para el personal de cada Servicio de salud.

481 Artículo 27 del Decreto 235/2007, de 18 de diciembre, por el que se aprobó el Acuerdo regulador de las condiciones de trabajo del personal de Osakidetza-Servicio Vasco de salud, para los años 2007, 2008 y 2009 (Boletín Oficial del País Vasco de 31 de diciembre de 2007), y artículo 18 del Decreto 83/2010, de 9 de marzo, aprobando el Acuerdo regulador de las condiciones de trabajo del personal funcionario al servicio de la Administración de la Comunidad Autónoma de Euskadi y sus Organismos Autónomos (Boletín Oficial del País Vasco de 24 de marzo de 2010).

${ }^{482}$ Decreto 137/2003, de 18 de julio, del Consell de la Generalitat, por el que se regula la jornada y horario de trabajo, permisos, licencias y vacaciones del personal al servicio de las instituciones sanitarias de la Generalitat dependientes de la Conselleria de Sanitat (Diario Oficial de la Generalitat Valenciana de 24 de julio de 2003). 
- En el Acuerdo del Servicio Aragonés de Salud, de 4 de julio de 2008, eran necesarias 1.440 horas para una liberación total de funciones anual (120 horas mensuales, según su art. 15.2). Las mismas horas que las acordadas en el Pacto de 27 de junio de 2006, sobre derechos de representación sindical en el ámbito de la Administración de la Comunidad de Castilla y León (art. 6.4 f), y en el Acuerdo de 2 de marzo de 2006 de la Administración de las Islas Baleares (art. 14.4 b).

- El Acuerdo de 18 de septiembre de 2003, de la Mesa General de Negociación sobre jornada de trabajo y derechos sindicales del personal de instituciones sanitarias transferidas a la Comunidad de Madrid dependientes del Instituto Madrileño de la Salud, exigía 1.436 horas anuales para una liberación total (art. 1 del Capítulo III), y en el mismo instrumento establecía la jornada reglamentaria para todo el personal en 1.533 horas al año (art. 1 del Capítulo I)

- Uno de los textos más exigentes, en este sentido, era el Pacto del Servicio Canario de Salud, de 29 de marzo de 2000, que requería 1.560 horas para autorizar una dispensa total de asistencia al trabajo (130 horas al mes, según el apartado 5 B 2).

Un aspecto común al reconocimiento de las dispensas sindicales es que para proceder a su autorización, previamente, hay que seguir un procedimiento previsto al efecto. En general, se requiere de un preaviso al órgano directivo responsable del centro donde preste servicios el trabajador, que puede denegarla en casos justificados. Este aspecto del procedimiento de gestión de las dispensas es una cuestión que se recogía habitualmente en los Pactos y Acuerdos de derechos sindicales de personal estatutario de los Servicios de salud, contemplando el supuesto de denegación del permiso si la persona a cuyo favor se pedía la liberación de funciones fuera indispensable, por su especial formación o debido a la escasez de efectivos disponibles, y no se podía sustituir ${ }^{483}$.

Por otra parte, la dispensa parcial de funciones por acumulación de crédito horario consiste en el uso fraccionado del crédito horario de la bolsa que se utiliza para cuestiones sindicales puntuales y específicas a favor de determinados trabajadores. Generalmente se venían autorizando por jornadas completas, durante un período de tiempo inferior al año, aunque excepcionalmente algunos Acuerdos permitían su utilización por un número de horas inferior a una jornada de trabajo. Era frecuente establecer una cláusula por la que se exigía una duración mínima de las dispensas sindicales por acumulación de crédito horario, así como el porcentaje máximo de horas de la bolsa que se podía destinar a este fin ${ }^{484}$.

\footnotetext{
${ }^{483}$ El artículo 6 del Acuerdo de 4 de julio de 2008, del Servicio Aragonés de Salud, establecía en su apartado c, que: "No podrá concederse permiso sindical cuando la persona propuesta resulte indispensable por razones asistenciales para el adecuado funcionamiento de los servicios. A estos efectos se considerará indispensable a quien, por razones asistenciales, no pudiera ser sustituido. En este caso la Dirección de Recursos Humanos, mediante escrito motivado, deberá comunicar de inmediato esta circunstancia al Sindicato correspondiente para que efectúe nueva propuesta”. En el mismo sentido, el Pacto del Servicio Canario de Salud, de 29 de marzo de 2000, apartado II, 3 c); y el Pacto del Servicio Cántabro de Salud, de 3 de octubre de 2003, apartado c) del punto 1 del bloque 1 (Permisos retribuidos).
}

${ }^{484}$ El Acuerdo de 30 de diciembre de 2003, de la Conselleria de Sanitat de la Generalitat Valenciana, en el
apartado V 5, admitía incluso la utilización del crédito horario por días determinados, o número de horas
inferior al de un turno determinado. El Acuerdo del Servicio Aragonés de Salud, de 4 de julio de 2008, exigía
como requisito para autorizar las dispensas parciales que estas tuvieran una duración mínima de una jornada
laboral, y se determinaban un número máximo de 400 horas anuales para ser utilizadas en casos puntuales y
para tareas específicas en relación con la actividad sindical en la Administración Sanitaria (art. 15.16). El
Acuerdo de derechos sindicales, de 25 de junio de 2011 , de la Administración de la Comunidad autónoma de 
Del texto de Pactos y Acuerdos se desprende que, solo excepcionalmente, se admitía la cesión de crédito horario sindical a favor de trabajadores que carecieran de cargo representativo; es decir, de simples afiliados a la organización sindical ${ }^{485}$, supuesto que no tiene cabida en el artículo 41.1 d) LEBEP, que exige la condición de representante del personal para acumular crédito horario cedido, así como a los miembros del Comité de empresa o Delegados de Personal, en el artículo 68 e) TRET, y lo mismo para el caso de los delegados sindicales (art. 10 LOLS).

En los Pactos y Acuerdos de derechos sindicales comúnmente se atribuye la competencia para gestionar la bolsa de crédito horario al órgano directivo con atribuciones en materia de recursos humanos del Servicio de salud, que tendrá que realizar la comprobación y control de los datos y los procedimientos administrativos que conllevan las cesiones, solicitudes de las organizaciones sindicales, y los reconocimientos de las dispensas, así como las comunicaciones de las mismas a los centros a los que está adscrito el personal liberado ${ }^{486}$. Con frecuencia se establece la obligación de realizar las comunicaciones a ese órgano en modelo normalizado, incorporado al Pacto o Acuerdo como Anexo.

Dentro del procedimiento pactado se debían tener en cuenta los plazos de solicitud previos a la concesión que, dependiendo del tipo de liberación de que se tratara, eran más o menos amplios ${ }^{487}$.

la Rioja establecía que, en el ámbito sanitario, las liberaciones parciales tendrían una duración mínima de tres meses, para facilitar la sustitución de personal si fuera necesario por necesidades asistenciales. Por su parte, el Acuerdo de 25 de febrero de 2005, de la Administración del Principado de Asturias, dispuso que el porcentaje máximo de las horas de la bolsa de crédito horario que podían ser destinadas a este fin en el ámbito de su Servicio de salud era del 30\% (un mínimo del 70\% de las horas debían ser destinadas a liberaciones a tiempo completo). El mismo porcentaje se acuerda en el Pacto de 3 de octubre de 2003, del Servicio Cántabro de Salud (Sección IV).

${ }^{485}$ En el Acuerdo de 4 de julio de 2008, del Servicio Aragonés de Salud, se admite la cesión de crédito horario a afiliados sin la condición de representantes, de forma excepcional (art. 15.15). Al igual que en el Pacto de Cantabria de 3 de octubre de 2003 (IV, B, 13). Es más, el Acuerdo de la Administración de la Comunidad autónoma de las Islas Baleares de 2 de marzo de 2006, emplea la expresión "persona beneficiaria del crédito horario designada por el sindicato", que se puede interpretar en el sentido de no requerir ni siquiera la afiliación.

${ }^{486}$ En los Pactos del Servicio Extremeño de Salud, de 4 de octubre de 2002 y de 22 de enero de 2003, se señalaba en ambos casos en el artículo 5.2 que: "Dicho responsable solicitará a la Dirección de Recursos Humanos del Servicio Extremeño de Salud la liberación o semiliberación del empleado público con la suficiente antelación, haciendo constar en dicha solicitud la categoría profesional, régimen jurídico de pertenencia, tipo de relación contractual, centro de trabajo, crédito que le corresponde y periodo por el que se solicita la liberación o semiliberación. El efecto de esta designación y su posible sustitución se producirá al mes siguiente de su comunicación a la Dirección de Recursos Humanos”.

${ }^{487}$ El Pacto de 18 de julio de 2003, del Servicio Murciano de Salud, en el Capítulo III, apartado 4 disponía: "Las licencias sindicales se deberán solicitar con una antelación mínima de 15 días naturales en el caso de las licencias a tiempo completo y de 5 días naturales en las licencias a tiempo parcial. En este último caso, la ausencia al trabajo será comunicada a la Gerencia a la que se encuentre adscrito el liberado, con una antelación mínima de 24 horas". 

de los Servicios de salud antes y después de las medidas de ajuste presupuestario

Una cláusula común en la mayoría de instrumentos negociados, en cuanto a la gestión de la bolsa de crédito horario, era el compromiso de las organizaciones sindicales de distribuir el crédito horario y las liberaciones a tiempo total de forma proporcional, a fin de evitar disfunciones importantes en el funcionamiento de los centros sanitarios, con el fin de garantizar en todo caso la asistencia sanitaria ${ }^{488}$.

Un pacto habitual en estos Acuerdos es aquel por el cual no se computan como consumidas las horas sindicales empleadas por los representantes sindicales en reuniones a las que fueran convocados por la Administración, lo cual representaba también una mejora $^{489}$.

Como también lo era la cláusula por la que no se descontaban de la bolsa de horas el tiempo coincidente con la situación de baja por enfermedad, maternidad, adopción, acogimiento o riesgo durante el embarazo, excedencia por cuidado de hijos y lactancia del liberado sindical, que podían así reintegrarse a la bolsa para ser utilizadas. Con ello la Administración asumía, en esos supuestos, el pago de la retribución que le correspondiera al empleado público dispensado y la eventual sustitución en su puesto de trabajo, que no minoraba de esa forma el crédito total disponible para su organización sindical ${ }^{490}$.

Las causas de finalización de las autorizaciones de liberación sindical es otro aspecto que se ha negociado habitualmente. Se contemplaba la posibilidad de que simplemente llegara a su fin el período de tiempo para el que se reconocieron; pero, además, otra serie de razones como podían ser la mera decisión del sindicato, que podía solicitar al órgano administrativo responsable de la gestión de la bolsa la revocación de la dispensa, con el fin de sustituir al representante; por dimisión del liberado, que podía renunciar a seguir utilizando las horas de permiso para actividad sindical, así como por revocación del permiso por resolución de la Administración, basada en el incumplimiento o finalización del objetivo para el que se concedió la liberación; por concurrir causas asistenciales excepcionales que hicieran necesario e imprescindible la reincorporación al trabajo del liberado; por cambio de sector donde se ejerciera la actividad sindical o por realización de actividades

\footnotetext{
${ }^{488}$ El Pacto de Interlocución de la Administración de la Junta de Comunidades de Castilla-La Mancha para 2008-2011 establecía, en su Sección tercera, que: "En la utilización de estas dispensas, cada una de las Organizaciones Sindicales se compromete a distribuir los créditos horarios y las liberaciones a tiempo total de una forma proporcional, a fin de que no se produzcan disfunciones importantes que dificulten el funcionamiento de los Centros, atendiendo a las características de éstos y del personal que presta los servicios".
}

${ }^{489}$ Acuerdo de 4 de julio de 2008 del Servicio Aragonés de Salud (art. 15.13); Acuerdo de 25 de febrero de 2005, sobre Derechos y Garantías Sindicales de la Administración del Principado de Asturias (art. 7.4); Pactos del Servicio Extremeño de Salud (art. 5.7), Acuerdo de 2 de marzo de 2006, de la Administración de las Islas Baleares (art. 14.9)...

${ }^{490}$ El Pacto de 3 de octubre de 2003, del Servicio Cántabro de Salud, en el apartado IV, punto 5 establecía: "Cuando un liberado a tiempo total por utilización de la bolsa cause baja por enfermedad, las horas comprometidas y no consumidas pueden retornar a la bolsa a partir del décimo día al que se ha producido la baja. Idéntico tratamiento tendrán las horas comprometidas y no utilizadas de la bolsa por el representante que hace uso del crédito horario, y ello a partir del día siguiente en que se extienda el documento oficial de baja”. 
Capítulo V. El contenido de la negociación colectiva de los derechos sindicales del personal estatutario de los Servicios de salud antes y después de las medidas de ajuste presupuestario

incompatibles, según lo dispuesto en la Ley 53/1984, de 26 de diciembre, de incompatibilidades del personal al servicio de las Administraciones públicas, ya que, en todo caso, las horas libres que se reconocen a los representantes del personal y a los delegados sindicales para el ejercicio de la actividad sindical deben ser destinadas a finalidades adecuadas a esa función ${ }^{491}$.

\subsection{3.- OTRAS GARANTÍAS DE LA FUNCIÓN REPRESENTATIVA DE LOS DELEGADOS SINDICALES Y DE LOS REPRESENTANTES DEL PERSONAL ESTATUTARIO}

El derecho a utilizar un local o dependencia en el centro de trabajo que reúna unas condiciones mínimas para llevar a cabo la función representativa, tanto por parte de los delegados sindicales como de los miembros de la Junta de Personal, es otro de los aspectos habitualmente regulados en los Acuerdos y Pactos de derechos y garantías sindicales del personal estatutario.

Esta garantía vimos que se recoge en el artículo 8.2 c) LOLS, que la regula a favor de las secciones sindicales, cuando se acrediten determinadas condiciones: "Sin perjuicio de lo que se establezca mediante convenio colectivo, las Secciones Sindicales de los sindicatos más representativos y de los que tengan representación en los Comités de empresa y en los órganos de representación que se establezcan en las Administraciones públicas o cuenten con Delegados de Personal, tendrán los siguientes derechos: c) A la utilización de un local adecuado en el que puedan desarrollar sus actividades en aquellas empresas o centros de trabajo con más de 250 trabajadores".

En el ámbito sanitario se deben cumplir dos requisitos para que la sección sindical tenga derecho a usar un local o dependencia para su actividad:

$1^{\circ}$.- Por una parte, la legitimación, ya que se debe tratar de una sección sindical de un sindicato que tenga la consideración legal de más representativo, aunque en ese concreto órgano de representación careciera de representante, o bien que tenga algún representante en los órganos unitarios del personal.

$2^{\circ}$.- Además, que la unidad electoral, que vimos que generalmente es el área de salud, departamento o sector sanitario, tenga adscritos más de 250 trabajadores con relación jurídica estatutaria o funcionarial. Hay que tener presente que en el propio Acuerdo o Pacto regulador de derechos sindicales, se puede haber convenido este derecho independientemente de la plantilla adscrita o de su relación jurídica y que, en todo caso, rigen los siguientes principios jurisprudenciales a la hora de poner a disposición de las organizaciones sindicales los locales: local.

1.- El principio de igualdad de trato entre secciones sindicales en cuanto al uso del

\footnotetext{
${ }^{491}$ Pacto de 3 de octubre de 2003, del Servicio Cántabro de Salud, punto 1.6; Acuerdo de 7 de julio de 2008, de la Administración de la Junta de Andalucía, cláusula segunda, apartado 5.
} 
Capítulo V. El contenido de la negociación colectiva de los derechos sindicales del personal estatutario de los Servicios de salud antes y después de las medidas de ajuste presupuestario

La STC 168/1996, de 29 de octubre, reconoce: "el derecho de llevar a cabo una libre acción sindical, comprensiva de todos los medios lícitos y sin indebidas injerencias de terceros" ${ }^{492}$. La STSJ de la Comunidad Valenciana de 30 de abril de 2003, entiende que carece de justificación objetiva y razonable, suficientemente probada, la desigualdad de trato que recibe una sección sindical con respecto al resto de organizaciones sindicales, por la ubicación del local en lugar distinto ${ }^{493}$.

2.- El derecho se entiende al uso de un local adecuado, pero no necesariamente de uso exclusivo.

Según la jurisprudencia, el artículo 8.2 c) de la LOLS no obliga a facilitar local para uso exclusivo, pues lo que ordena el precepto es que sea adecuado. Esta condición ha de entenderse cumplida cuando en dicho local pueda desarrollarse eficazmente la actividad de la representación unitaria y de la sindical, ya que su uso puede ser compartido por ambas: STS de 3 de febrero de $1998^{494}$. También pueden compartirlo todas las secciones sindicales: STS de 24 de septiembre de $1996^{495}$.

Cuando el local sindical sea de uso compartido, las secciones sindicales deberán ponerse de acuerdo al respecto. En caso contrario, se suele pactar que sea el criterio de la representatividad del sindicato el que prime para decidir sobre los tiempos de su disfrute. Así, el artículo 22 del Acuerdo de 4 de julio de 2008, del Servicio Aragonés de Salud, disponía que: "El tiempo de utilización de dicho local deberá distribuirse mediante acuerdo de las secciones sindicales. En caso de no alcanzarse dicho acuerdo, la distribución será proporcional a la representación obtenida en las elecciones sindicales”.

3.- En cuanto a las características del espacio exigible y condiciones de habitabilidad, así como la dotación de material, equipamiento y mobiliario, ante la ausencia de regulación legal, algunas resoluciones judiciales interpretaron que esa carga correspondía a la propia sección sindical, no a la empresa.

La STSJ de Cataluña de 18 de mayo de 2006 declaró que la obligación de dotar el local, con los medios informáticos y con el material necesario, depende de lo pactado con la sección sindical, y en el caso de que carezca de esta dotación ello no afecta al núcleo esencial del derecho fundamental de libertad sindical, que queda garantizado si la empresa facilita el local sindical ${ }^{496}$.

492 (RTC 1996168).

${ }^{493}$ (AS 2003\1128).

494 (RJ 1998 1431). Por otro lado, la STSJ de Canarias de 10 de marzo de 2006, argumenta que si un local no se encuentre situado en el edificio donde trabaja la mayoría de la plantilla, pero sí lo está en las proximidades, en ese caso es igualmente adecuado porque son los representantes sindicales los que se desplazan a los centros de trabajo haciendo uso de su crédito horario, no los trabajadores a los locales sindicales, (AS 2006 1572).

495 (AS 199616851).

${ }^{496}$ (AS 200入196). 

de los Servicios de salud antes y después de las medidas de ajuste presupuestario

Ello no obsta a que, en opinión de la doctrina, si se ha llegado a un Acuerdo sobre la dotación del local para que esté equipado, esta obligación se pueda exigir por la vía procedimental correspondiente ${ }^{497}$.

Para los representantes de los trabajadores laborales, el derecho al local sindical se reconoce en el artículo 81 del TRET que establece que: "En las empresas o centros de trabajo, siempre que sus características lo permitan, se pondrá a disposición de los Delegados de Personal o del Comité de empresa un local adecuado en el que puedan desarrollar sus actividades y comunicarse con los trabajadores, así como uno o varios tablones de anuncios...

Por lo que respecta a los miembros de la Junta de Personal o Delegados de Personal, en su día se reguló este derecho en el artículo 42.4 LORAP, que lo reconocía expresamente: "En aquellos centros de trabajo en que presten servicio más de 250 funcionarios, se habilitará un local con dotación de material adecuado para uso de las Organizaciones Sindicales, Delegados de Personal o miembros de las Juntas de Personal, cuya utilización se instrumentará mediante acuerdo entre ellas".

Ahora, sin embargo, la LEBEP no contempla este derecho, por lo que cabe interpretar que este aspecto quedará reservado al ámbito de la negociación colectiva. Efectivamente, en los Acuerdos y Pactos sobre garantías sindicales que se han venido aplicando en los Servicios de salud nos encontramos con cláusulas que regulan el derecho a utilizar un local sindical, tanto para las secciones sindicales como para los miembros de la Junta de Personal, estableciendo incluso los requisitos que deben cumplir los locales para considerarlos aceptables a su finalidad, como son su superficie mínima o su equipamiento:

- Así, el Pacto de 27 de junio de 2006, de la Administración de la Junta de Castilla y León, en su artículo 3.4, estableció que el local sindical de la Junta de Personal, Comités de empresa y Comité Intercentros tendría una superficie de, al menos, 40 metros cuadrados. Además, cada una de las secciones sindicales de los sindicatos con mayor implantación o con especial audiencia tenía derecho a un local de veinticinco metros cuadrados y el resto de secciones sindicales tenía derecho a un local compartido entre todas ${ }^{498}$.

- En cuanto a la dotación de los locales, la Administración de la Junta de Castilla y León se obligaba a suministrar Mesa de reuniones, línea de teléfono, ordenadores, impresora, acceso a Internet y a intranet, correo electrónico, fax, fotocopiadora, material de oficina suficiente y un ejemplar del Boletín oficial de la Comunidad autónoma. Además de ello y para uso común por parte de los representantes del personal y de los delegados sindicales existiría una sala de reuniones, asumiendo incluso el compromiso de arrendar los locales en caso de no disponer de ellos.

\footnotetext{
${ }^{497}$ MORENO CALIZ, S, "Derecho al uso de local adecuado por sección sindical. Comentario a la STSJ de Cataluña de 18 de mayo de 2006", AS n² 2/2007.

${ }^{498}$ Según el artículo 2 del Pacto, eran sindicatos "con mayor nivel de implantación” los que hubieran obtenido, al menos, el 15\% de los Delegados de Personal, miembros de Comités de empresa y Juntas de Personal en el conjunto de los centros y servicios incluidos en su ámbito. Por su parte, se consideraban "sindicatos con especial audiencia" los que sin tener la consideración de mayor nivel de implantación, hayan obtenido, al menos, el 10\% de los Delegados de Personal, miembros de Comités de empresa y Juntas de Personal en alguno de los sectores de la Administración de la Comunidad de Castilla y León.
} 
Capítulo V. El contenido de la negociación colectiva de los derechos sindicales del personal estatutario de los Servicios de salud antes y después de las medidas de ajuste presupuestario

- El Acuerdo de 2 de marzo de 2006, de la Administración de la Comunidad autónoma de las Islas Baleares, regulaba el derecho de las secciones sindicales representativas a disponer de locales adecuados en los que pudieran desarrollar sus actividades, así como del mobiliario y equipamiento y el material de oficina necesario y suficiente (art. 8).

- En el Acuerdo de 18 de septiembre de 2003, de instituciones sanitarias del Instituto Madrileño de la Salud, las secciones sindicales de los sindicatos con mayor nivel de implantación tenían, según consta literalmente, "los siguientes beneficios": ampliación del número de delegados sindicales y "un local sindical provisto de teléfono, mobiliario y material de oficina necesarios para el desarrollo de su actividad representativa, procurándose el acceso a las tecnologías de la información”.

Hay que recordar que las controversias que se produzcan en relación con el disfrute de los locales por las organizaciones sindicales en el ámbito del personal estatutario se deberán conocer en la jurisdicción contencioso-administrativa ${ }^{499}$.

En cuanto al derecho al tablón de anuncios (no necesariamente exclusivo, puede ser también de uso compartido ${ }^{500}$ ), se regula en el artículo 8.2 a) LOLS a favor de las secciones sindicales de los sindicatos más representativos y de los que tengan representación en los comités de empresa y en los órganos de representación que se establezcan en las Administraciones públicas o cuenten con Delegados de Personal: "con la finalidad de facilitar la difusión de aquellos avisos que puedan interesar a los afiliados al sindicato y a los trabajadores en general...”. El tablón de anuncios deberá situarse en el centro de trabajo y en lugar "donde se garantice un adecuado acceso al mismo de los trabajadores".

En la regulación anterior que hizo la LORAP, el derecho de los representantes del personal a disponer de tablón de anuncios venía reconocido en el artículo 42.5, dentro del Capítulo V dedicado al derecho de reunión, que reconocía el derecho a los tablones de anuncios, en número adecuado al tamaño y estructura del centro, con el fin de dar publicidad de la forma más amplia posible a cualquier anuncio sindical, y especificaba que “... en todo caso, las unidades administrativas con ubicación independiente, cualquiera que sea su rango, deberán disponer de, al menos, un tablón de anuncios”.

Ahora, sin embargo, en la LEBEP se regula el derecho a la libre circulación de los representantes del personal y la distribución de información, pero la mención expresa al derecho de los representantes del personal al tablón de anuncios ha desaparecido. Según el artículo 41.1 los "representantes legales de los funcionarios, dispondrán en el ejercicio de su función representativa de las siguientes garantías y derechos: El acceso y libre circulación por las dependencias de su unidad electoral, sin que se entorpezca el normal funcionamiento de las correspondientes unidades administrativas, dentro de los horarios habituales de trabajo y con excepción de las zonas que se reserven de conformidad con lo dispuesto en la legislación vigente”. La distribución libre de las publicaciones que se refieran a cuestiones profesionales y sindicales".

\footnotetext{
${ }^{499}$ STSJ de Navarra de 16 de febrero de 2006, (AS 2006\689).

${ }^{500}$ STSJ de Canarias de 26 de febrero de 1999, (AS 1999\583).
} 
Este cambio en la LEBEP resulta razonable, teniendo en cuenta que el desarrollo y la generalización del uso de los medios tecnológicos favorecen otros cauces para la difusión de la información, en detrimento de su tradicional exposición escrita. Y es que, actualmente, tal como pone de manifiesto algún autor, la información sindical puede transmitirse también, incluso de forma preferente mediante el uso de medios informáticos, como el correo electrónico o el uso de la intranet de la empresa, que son semejantes al tradicional tablón de anuncios $^{501}$.

Desde la STC de 7 de noviembre de 2005, se entiende el derecho al uso del correo electrónico en la empresa como una derivación del derecho de información, que forma parte del contenido esencial del derecho a la libertad sindical, puesto que "el flujo de información entre el sindicato y los trabajadores es el fundamento de la participación, permite el ejercicio cabal de una acción sindical y propicia el desarrollo de la democracia y del pluralismo sindicales". No obstante, la empresa no tiene obligación de garantizar y disponer para uso sindical de correo electrónico, pero sí de facilitar su utilización sindical si este medio está implantado y funcionando ${ }^{502}$.

El derecho a la difusión de información sindical a través de los tablones de anuncios se ha venido tratando también en algunos Acuerdos y Pactos reguladores de derechos sindicales, tanto a favor de los órganos de representación del personal como para las secciones sindicales ${ }^{503}$.

Es importante recordar que la jurisprudencia ha declarado que el reconocimiento de estas garantías a los representantes sindicales o del personal se debe realizar atendiendo a la regulación legal o convencional sobre la materia, teniendo en cuenta que si la Administración las reconoce para una organización sindical que no tenga estricto derecho a ellas, deberá respetar entonces el principio de igualdad de trato sindical y, en consecuencia, reconocérselas a las demás que se encuentren en su mismo caso, o bien negárselo a todas ellas por igual $^{504}$.

${ }^{501}$ SEMPERE NAVARRO, A., "El uso sindical del correo electrónico a la luz de la STC 281/2005 de 7 de noviembre”, AS, $\mathrm{n}^{\circ}$ 17/ 2005, (BIB 2005 2568).

502 (RTC 2005\281).

${ }^{503}$ El Pacto de 27 de junio de 2006, de la Administración de la Junta de Castilla y León, lo reguló en los artículos 3.5 y 4.5, respectivamente. El Acuerdo de 18 de septiembre de 2003, de instituciones sanitarias del Instituto Madrileño de la Salud, señalaba en su artículo 1.3 el derecho de las Juntas de personal a disponer de "los tablones de anuncios necesarios para que bajo su responsabilidad coloquen cuantos avisos y comunicaciones hayan de efectuar y estimen pertinentes, sin más limitaciones que las expresamente señaladas por la Ley. Dichos tablones se instalarán en lugares claramente visibles para permitir que la información llegue al personal representado fácilmente”. El Acuerdo de 25 de febrero de 2005 del Principado de Asturias, lo trataba en el artículo 11, disponiendo que fuera de uso exclusivo para cada sección sindical.

${ }^{504}$ STSJ de la Comunidad de Madrid, de 7 de junio de 2000, Fundamento jurídico primero, sobre la utilización de un salón de actos para celebrar una asamblea: "Nada impide comunicar a todos los sindicatos por igual aquellas razones que le exonere -al Ayuntamiento- de acoger pretensiones que no le son exigibles, pero mientras ello no haga no puede, a su capricho, conceder diferenciadamente a determinadas centrales sindicales lo que a otras niega sin fundamento objetivo y razonable porque ello violenta su actitud sindical neutral...”, (AS 2000\3411). Por el contrario, la STSJ de Murcia, de 23 de abril de 1999, en el supuesto de facilitar el uso temporal de un local sindical a la sección sindical de un sindicato, sin presencia en el órgano de 

de los Servicios de salud antes y después de las medidas de ajuste presupuestario

Otra garantía a favor de los representantes del personal estatutario y de sus delegados sindicales es que por el mero ejercicio de su función no cambia su situación administrativa, que sigue siendo la de activo, ya que es esa la que se les requiere para poder acceder a la condición de representante del personal o sindical ${ }^{505}$. Esta situación administrativa, regulada en los artículos 85.1 a) y 86 LEBEP, es la que reconoce a los funcionarios su prestación de servicios en la Administración pública, con "todos los derechos inherentes a su condición de funcionarios" quedando sujetos a "los deberes y responsabilidades derivados de la misma”.

Tampoco cambia esa situación, aunque tengan autorizada una dispensa por acumulación de crédito horario sindical, puesto que la liberación sindical, ya sea total o parcial, no es más que el disfrute de un permiso, más o menos prolongado, destinado a la actividad sindical.

Ya los Pactos sobre derechos sindicales del INSALUD de 1989 disponían que: "Quienes disfruten de estos permisos permanecerán en situación de servicio activo y conservarán todos los derechos profesionales que les sean de aplicación, incluidos los de carácter retributivo..." (Permisos retribuidos, apartado 4).

En esta garantía se insiste, de forma unánime, en los posteriores Acuerdos y Pactos que se han concertado tanto en el INSALUD como en los Servicios de salud ${ }^{506}$.

En la misma línea, se ha venido pactando expresamente la garantía de reserva del puesto de trabajo y destino del representante al término de su liberación sindical, lo que en el ámbito sanitario tiene gran importancia dadas las diferencias que existen entre las funciones a desempeñar en las distintas unidades asistenciales dentro de la misma categoría y profesión sanitaria ${ }^{507}$.

representación del personal y sin ser más representativo, en un área de salud del INSALUD lo entiende como "manifestación de apoyo o promoción del hecho sindical a través de una medida que mejora lo dispuesto en la LOLS”, (AS 1999\1544).

${ }^{505}$ Artículo 14.3 a) del Real Decreto 1846/1994, de 9 de septiembre, que aprueba el Reglamento de elecciones a órganos de representación del personal al servicio de la Administración general del Estado.

${ }^{506}$ Pactos del Servicio Extremeño de Salud, de 4 de octubre de 2002 y de 22 de enero de 2003 (art. 5.2); Acuerdo de la Administración autonómica de las Islas Baleares de 2 de marzo de 2006 (art. 20.1); Acuerdo de 7 de julio de 2008, de la Junta de Andalucía, (cláusula segunda, 4); Acuerdo sobre garantías y derechos sindicales del Servicio Aragonés de Salud, de 4 de julio de 2008 (art. 17). Acuerdo de 30 de diciembre de 2003 de la Conselleria de Sanitat de la Generalitat Valenciana (cláusula VII); artículo 10 del Pacto sobre derechos de representación sindical en el ámbito de la Administración de la Junta de Castilla y León, de 27 de junio de 2006, etc.

${ }^{507}$ Por ejemplo, en los Pactos de derechos sindicales del Servicio Extremeño de Salud de 4 de octubre de 2002 y de 22 de enero de 2003: "El empleado público que cesare como liberado volverá al puesto que ocupare al liberarse, integrándose en las mismas condiciones laborales que tenía en ese momento, en turno, unidad y cupo o al que le correspondiera por causa de su promoción profesional” (art. 5.3, segundo párrafo). 
Capítulo V. El contenido de la negociación colectiva de los derechos sindicales del personal estatutario de los Servicios de salud antes y después de las medidas de ajuste presupuestario

Otro principio que se reconoce en los Acuerdos y Pactos sobre derechos sindicales es el de prohibición de la discriminación retributiva de los representantes sindicales. Este principio de indemnidad retributiva se contempla en el Convenio $\mathrm{n}^{\circ} 135$ de la OIT: "Los representantes de los trabajadores en la empresa deberán gozar de protección eficaz contra todo acto que pueda perjudicarlos..." (art.1) y en la Recomendación $\mathrm{n}^{\circ} 143$; y se completó en nuestro país con la jurisprudencia del extinto Tribunal Central de Trabajo ${ }^{508}$.

La garantía consiste en la prohibición de que los representantes del personal o delegados sindicales puedan sufrir menoscabo económico a causa del desempeño de sus funciones representativas, incluso durante el tiempo en que hagan uso de su crédito horario para finalidad sindical. Lo que en último extremo pretende proteger la ley es el ejercicio del derecho a la acción sindical, que se integra en el derecho fundamental a la libertad sindical. Debemos tener en cuenta que la jurisprudencia sobre esta cuestión es abundante, y tanto el $\mathrm{TS}^{509}$ como el $\mathrm{TC}^{510}$ han defendido la aplicación de esa garantía basándose en los artículos 14 y 28.1 CE.

Para los funcionarios públicos, el principio de indemnidad retributiva se reguló en el artículo 11 apartado d) de la LORAP, que indicaba que los representantes legales de los funcionarios tenían entre otros derechos el de disfrutar de un crédito de horas mensuales dentro de la jornada de trabajo y retribuidas como de trabajo efectivo.

Actualmente se reconoce en el artículo 41.2 de la LEBEP, que regula las garantías de la función representativa del personal, estableciendo que: "Los miembros de las Juntas de Personal y los Delegados de Personal no podrán ser discriminados en su formación ni en su promoción económica o profesional por razón del desempeño de su representación”.

Para los delegados sindicales este derecho se debe reconocer del mismo modo, dado que el artículo 10.3 LOLS les otorga las mismas garantías que a los representantes unitarios del personal.

En el ámbito del personal estatutario de los Servicios de salud, los representantes deberán percibir las mismas retribuciones, básicas y complementarias, durante el tiempo de

\footnotetext{
${ }^{508}$ STCT de 5 de octubre de 1988, (RTCT 1988\445). La STCT de 26 de octubre de 1988 señaló: “El crédito horario mensual reconocido a los representantes de los trabajadores y a los delegados sindicales, en el supuesto de que estos no formen parte del Comité de empresa, debe ser retribuido de tal manera que sus beneficiarios no sufran detrimento en su remuneración total, es decir, ese tiempo, ha de ser abonado en los mismos términos en que se satisface a los restantes compañeros o a ellos mismos si trabajaran realmente tales horas, de suerte que se supone que los representantes de los trabajadores han permanecido prestando servicios durante todas las horas dedicadas al ejercicio de sus funciones de representación y son acreedores a la retribución completa de la jornada ordinaria de trabajo...”, (RC 1988\496).

${ }^{509}$ STS de 20 de mayo de 1992, (RJ 1992\3581).

510 STC 173/2001, de 26 de julio: es conducta antisindical no abonar a un liberado sindical el plus compensatorio de jornada partida. Es necesario interpretar el carácter funcional del complemento ligándolo a la garantía de indemnidad del representante de los trabajadores, en el buen sentido de proscribir cualquier perjuicio en la situación retributiva por la realización de funciones sindicales. El artículo 28.1 CE es el precepto que protege frente a eventuales discriminaciones en el ámbito sindical, (RTC 2001 1739 ).
} 
disfrute del permiso sindical, además de las retribuciones asociadas a la prestación del servicio en jornada complementaria (guardias y atención continuada).

Respecto a las retribuciones del personal estatutario, estas se contemplan en el Capítulo IX de la LEM, distinguiendo entre básicas y complementarias. Las primeras se regulan en el artículo 42 LEM y son iguales para todo el personal estatutario y para todos los funcionarios públicos, que pertenezcan al mismo grupo o subgrupo de clasificación. Se determinan cada año en las correspondientes Leyes de Presupuestos, y no plantean dudas, ya que están asociadas al alta en un puesto de trabajo en situación administrativa de activo. Son el sueldo base, los trienios y las pagas extraordinarias ${ }^{511}$.

Las dificultades de determinación de los conceptos retributivos que se deberán abonar a los liberados sindicales, así como su procedimiento de cuantificación, se darán principalmente con respecto a las retribuciones complementarias, ya que como señala el artículo 43 LEM: "Las retribuciones complementarias van dirigidas a retribuir la función desempeñada, la categoría, la dedicación, la actividad, la productividad y cumplimiento de objetivos y la evaluación del rendimiento y de los resultados, determinándose sus conceptos, cuantías y los criterios para su atribución en el ámbito de cada Servicio de salud".

Dentro de las retribuciones complementarias se encuentran aquellas fijas y periódicas, como los complementos de destino o específico (art. 43.2 apartados a y b), que van asociados al puesto de trabajo que se desempeña, y que durante la dispensa sindical se siguen percibiendo en la misma cuantía que antes de su disfrute y, por tanto, tampoco son objeto de especial conflicto $^{512}$. En cuanto a la retribución complementaria que retribuye el grado de carrera profesional, al ser la situación de los representantes sindicales, incluso liberados, la de activo, estos pueden acceder y progresar en el sistema de carrera profesional cumpliendo el resto de requisitos que exija la normativa de su Administración autonómica (art. 40.1 en relación con el 43.2 e) LEM).

En la práctica, las retribuciones más controvertidas serán las que se corresponden con la actividad y dedicación al servicio, que se abonan mediante los conceptos de atención continuada y guardias médicas; así como los que se corresponden a la evaluación del rendimiento y el cumplimiento de objetivos asistenciales (productividad variable). El complemento de atención continuada, destinado a remunerar al personal para atender a los usuarios de los servicios sanitarios de manera permanente y continuada, según el artículo 43.2 d) LEM, se articula a través de unos conceptos de carácter mensual, que vienen dados en función de la nocturnidad y festividad trabajada, así como de la realización de la jornada de trabajo en régimen de turnicidad (alternancia de mañanas y tardes, como mínimo) ${ }^{513}$. El

\footnotetext{
${ }^{511}$ El sueldo asignado a cada categoría en función del título exigido para su desempeño, conforme a lo previsto en los artículos 6.2 y 7.2 de la LEM. Los trienios, que consisten en una cantidad determinada para cada grupo de clasificación, por cada tres años de servicios. La cuantía de cada trienio será la establecida para la categoría a la que pertenezca el interesado el día en que se perfeccionó. Las pagas extraordinarias serán dos al año y se devengarán preferentemente en los meses de junio y diciembre. El importe de cada una de ellas será, como mínimo, de una mensualidad del sueldo y trienios, al que se añadirá la catorceava parte del importe anual del complemento de destino.
}

512 STSJ de Andalucía de 20 de mayo de 2003, (AS 2003\2666), reconoce en el ámbito del Servicio Andaluz de salud el derecho de un facultativo a percibir un complemento denominado "indemnización por desplazamiento" por ser de carácter fijo y periódico, y por tanto, de carácter retributivo y no meramente indemnizatorio.

${ }^{513}$ El complemento de atención continuada también retribuye la participación en programas especiales, como son los de trasplantes, explantes, reducción de listas de espera, etc. 
Capítulo V. El contenido de la negociación colectiva de los derechos sindicales del personal estatutario de los Servicios de salud antes y después de las medidas de ajuste presupuestario

personal facultativo realiza la modalidad de guardias médicas, que son retribuidas en función de las horas de jornada complementaria realizadas, tanto de presencia física como en régimen de localización.

Decimos que son controvertidos porque se trata de conceptos de carácter funcional, es decir, que dependen de la forma en que se realice la prestación de servicios y en los que esta condiciona la percepción económica correspondiente. Estos complementos habitualmente tienen una finalidad compensatoria específica derivada de su causa, de forma que cuando esta desaparece no se devenga el complemento. Este principio aparece en aparente contradicción con la situación del liberado sindical que no presta servicios efectivos en su puesto estatutario sino que se dedica a funciones de índole sindical, lo que ha propiciado numerosos conflictos al respecto, que han originado una variada casuística en la jurisprudencia.

Las resoluciones judiciales han ido evolucionando, desde la idea inicial de que el personal estatutario con liberación sindical debía mantener solo aquellas retribuciones variables que viniera percibiendo antes del inicio del permiso sindical: Las STSJ de Castilla y León de 21 de noviembre de $1995^{514}$, y de 18 de marzo de $1996^{515}$, reconocen el derecho a percibir las cantidades por guardias médicas que se hubieran realizado, según la organización específica del equipo de atención primaria. La STSJ de Andalucía de 4 de junio de $1996^{516}$, consideró que correspondía a una auxiliar de enfermería, con turno fijo de noches, continuar percibiendo el complemento de atención continuada durante el uso del crédito sindical. Igualmente, la STS de la Rioja, de 11 de marzo de 1997, sobre el derecho a percibir el complemento de atención continuada por realización de pruebas clínicas específicas $^{517}$. También la STSJ de Andalucía de 11 de marzo de 2003 desestima la reclamación del importe de las guardias médicas a un facultativo liberado sindical que no realizaba con anterioridad al permiso sindical las guardias que reclamaba, por entender que el principio de indemnidad retributiva no amparaba este supuesto ${ }^{518}$. En el mismo sentido la STSJ de Cataluña de 2 de mayo de $2000^{519}$.

Hasta llegar a la postura más actual, que consiste en reconocer el derecho a la percepción de todos aquellos conceptos retributivos variables, que percibiría el trabajador si desempeñara servicios efectivos, abarcando este derecho incluso aquellas retribuciones de nueva implantación que surjan mientras el representante desempeña su función sindical. En este sentido, la STSJ de Andalucía de 4 de mayo de 2001, declara el derecho de un

\footnotetext{
${ }^{514}$ (AS 1995\4127).

${ }^{515}$ (AS 1996\138).

${ }^{516}$ (AS 19963561).

${ }^{517}$ (AS 19971176).

${ }^{518}$ (AS 2003\1916).

519 (AS 2000\1918).
} 
Capítulo V. El contenido de la negociación colectiva de los derechos sindicales del personal estatutario de los Servicios de salud antes y después de las medidas de ajuste presupuestario

enfermero con liberación sindical a percibir la misma retribución que perciben los compañeros de su centro de salud en concepto de guardias ${ }^{520}$.

Asimismo, la STSJ de Baleares de 14 de septiembre de 2001, reconoce que: "Si no cabe la aplicación del promedio mensual de la atención continuada para el cálculo de la cuantía que debe percibir el liberado, se estará a las noches y festivos que le hubieran correspondido realizar según el turno de trabajo preestablecido" ${ }^{521}$.

También la STSJ de Castilla y León de 2 de mayo de 2002, reconoce el derecho a percibir las guardias médicas que tenía previstas en su turno de trabajo a un facultativo miembro de la Junta de Personal con liberación sindical, en el período en que disfrutó el permiso sindical ${ }^{522}$.

Asimismo, la STSJ de la Comunidad Valenciana de 10 de mayo de 2005, determina que para la equiparación retributiva de los liberados sindicales con el resto de trabajadores se atienda a "la media que por dicho concepto hubieran percibido el personal de la misma categoría profesional y servicio que la actora y en la cuantía que la misma hubiera cobrado de permanecer en activo y ello sin atender a los importes percibidos en el período de los seis meses anteriores a la liberación sindical..."523.

En resumen, el principio de no discriminación retributiva comprende el derecho a todas aquellas retribuciones que percibiría el liberado si desempeñara su trabajo efectivo en su puesto de trabajo, con independencia de que, con anterioridad al permiso, las percibiera efectivamente o no. Partiendo de esa idea, los Pactos y Acuerdos en materia sindical han establecido procedimientos de cálculo de las retribuciones que deben percibir los trabajadores liberados del servicio:

- En el Pacto de 30 de junio de 1989, del INSALUD, se estableció el derecho de los liberados sindicales a percibir el promedio de la atención continuada realizada por el interesado en los seis meses anteriores al inicio del permiso o dispensa total sindical (Permisos retribuidos, apartado 4).

- El Acuerdo del Servicio Aragonés de Salud, de 4 de julio de 2008, en el artículo16, detallaba bajo el título "Retribuciones" la forma de cálculo y aplicación de una serie de conceptos retributivos de naturaleza funcional, no fijos y periódicos, como son los complementos de atención continuada, turnicidad, productividad variable...

- Cabe destacar también los Pactos del Servicio Extremeño de Salud, de 4 de octubre de 2002 y 22 de enero de 2003, que regularon las retribuciones del personal con liberación sindical detallándolas de manera pormenorizada, por conceptos, y distinguiendo entre personal de asistencia especializada y primaria. Así como el Acuerdo de 16 de septiembre de 2003, del

\footnotetext{
${ }^{520}($ AS 2001 1871$)$.

${ }^{521}$ (AS 2001 4482$)$.

522 (AS 2002\2098).

${ }^{523}$ (AS 2005\2103).
} 
Capítulo V. El contenido de la negociación colectiva de los derechos sindicales del personal estatutario de los Servicios de salud antes y después de las medidas de ajuste presupuestario

Instituto Madrileño de la Salud, que en el artículo 4 del Capítulo III regulaba con detalle las retribuciones del personal estatutario con liberación total.

De cualquier manera, para el cálculo concreto de las cantidades que se deban abonar hay que atender al contenido de lo convenido en el correspondiente Acuerdo o Pacto, que son de aplicación preferente, en cuanto mejoren el régimen legal establecido a favor de los representantes sindicales ${ }^{524}$. Sin olvidar que estos instrumentos normativos tan solo deben pretender establecer un sistema ágil y práctico de determinación del importe del complemento $^{525}$, y que en ningún caso pueden suponer una minoración en el derecho subjetivo que se atribuye al representante ${ }^{526}$.

El principio de indemnidad retributiva guarda también relación con el de prohibición de injerencias por parte de la Administración en la actividad sindical. En efecto, dentro del derecho de libertad sindical se comprende la prohibición de injerencias de la Administración y la prohibición de discriminaciones no razonables, abundando la jurisprudencia constitucional a este respecto $^{527}$.

Por otra parte, por lo que se refiere a otras garantías a favor de los representantes sindicales con liberación sindical en el ámbito del personal estatutario, hay que decir que estos tienen como personal en activo que son, el derecho y el deber de formarse. En este sentido, el artículo 17.1 c) LEM regula el derecho individual "a la formación continuada adecuada a la función desempeñada y al reconocimiento de su cualificación profesional en relación a dichas funciones". El artículo 19, por su parte establece la obligación del personal estatutario de los Servicios de salud a: "c) mantener debidamente actualizados los conocimientos y aptitudes necesarios para el correcto ejercicio de la profesión o para el desarrollo de las funciones que correspondan a su nombramiento, a cuyo fin los centros sanitarios facilitarán el desarrollo de actividades de formación continuada" ${ }^{\text {528 }}$.

El derecho a la formación de los liberados sindicales se recoge en algunos Acuerdos y Pactos de derechos sindicales:

- El Acuerdo del Servicio Aragonés de Salud, de 4 de julio de 2008 regulaba, en su artículo 19 , el derecho a la formación de los liberados sindicales en las mismas condiciones que el resto de empleados en las acciones formativas que se convocaran dentro del Plan de Formación Continuada.

\footnotetext{
${ }^{524}$ STSJ de Castilla-La Mancha de 19 de mayo de 2000, (AS 20002476).

${ }^{525}$ STSJ de Murcia de 26 de noviembre de 1997, Fundamento jurídico único, (AS 19974287).

${ }^{526}$ STSJ de Castilla y León de 12 de septiembre de 1995, (AS 1995\3251).

527 STC 23/1983, de 25 de marzo, (RTC 1983\23); STC 98/1985, de 29 de julio, (RTC 1985\98); STC 208/1989, de 14 de diciembre, (RTC 1989 208); STC 20/1985, de 14 de febrero, (RTC 1985 20); STC 184/1987, de 18 de noviembre, (RTC 198\184); STC 98/1985, de 29 de julio, (RTC 1985 98); STC 7/1990, de 18 de enero, (RTC 1990八7)...

528 Véase SEMPERE NAVARRO, A. "Los derechos individuales del personal estatutario. Comentario al artículo 17 de la Ley 55/2003”, AS n' 2, 2006.
} 
Capítulo V. El contenido de la negociación colectiva de los derechos sindicales del personal estatutario de los Servicios de salud antes y después de las medidas de ajuste presupuestario

- El Acuerdo Marco sobre derechos sindicales y ejercicio de la actividad sindical de la Administración de la Comunidad autónoma de Euskadi de 15 de octubre de 1988, estableció el crédito horario para formación sindical, del que podían hacer uso los representantes sindicales (apartado 5).

Resta por considerar si existe alguna garantía especial en cuanto al derecho a la promoción profesional del personal estatutario que ostente la condición de representante del personal o delegado sindical, a través del mecanismo legal de la promoción interna (art. 34 LEM), o la promoción interna temporal (art. 35 LEM); la participación en los procesos de movilidad voluntaria (art. 37 LEM) o la posibilidad de serle autorizada o prorrogada una comisión de servicios (art. 39 LEM) mientras se encuentre desempeñando la liberación sindical.

El artículo 34.2 LEM regula la promoción interna como la posibilidad del personal estatutario fijo para acceder, dentro de su Servicio de salud de destino, a nombramientos correspondientes a otra categoría, siempre que el título exigido para el ingreso sea de igual o superior nivel académico al de la categoría de procedencia, y sin perjuicio del número de niveles existentes entre ambos títulos ${ }^{529}$. A continuación, añade que los procedimientos para la promoción interna se desarrollarán de acuerdo a los principios de igualdad, mérito y capacidad y por los sistemas de oposición, concurso o concurso-oposición (apdo. 3). En cualquier caso, el personal con liberación sindical puede participar en los procesos selectivos, por el turno de promoción interna, en las mismas condiciones que cualquier otro trabajador en activo.

De hecho, el propio precepto exige como requisitos para participar en los procesos selectivos para la promoción interna los de ostentar la titulación requerida y estar en servicio activo con nombramiento como personal estatutario fijo durante, al menos, dos años en la categoría de procedencia (art. 34.4). El beneficio fundamental que deriva de la promoción interna es el de la preferencia en la elección de plaza respecto del personal seleccionado por el sistema de acceso libre (art. 34.6).

Respecto a la situación de promoción interna temporal, regulada en el artículo 35 LEM, recordemos que consiste en el desempeño temporal de funciones correspondientes a nombramientos de una categoría del mismo nivel de titulación o de nivel superior, siempre que se ostente la titulación correspondiente. La forma reglada de acceder a este tipo de nombramientos es previa selección del candidato inscrito en la lista de empleo temporal ${ }^{530}$, en la que los candidatos se priorizan en función de sus méritos y acceden al desempeño de los nombramientos temporales por orden de puntuación. Ante el caso de que en las listas de empleo temporal resultara seleccionado un candidato que se encontrara disfrutando de dispensa sindical en su puesto de trabajo de origen, incluso las resoluciones de los mismos órganos jurisdiccionales divergían a la hora de considerar si el liberado debía cesar en su dispensa sindical para poder incorporarse de forma efectiva al nuevo puesto obtenido por promoción interna temporal, o no.

\footnotetext{
${ }^{529}$ Hay que interpretar el concepto de nivel de titulación como grupo o subgrupo de clasificación, de los regulados en el artículo 76 y Disposición transitoria tercera LEBEP.

530 Las comúnmente denominadas bolsas de trabajo deben ser "objeto de negociación en las Mesas correspondientes”, según el inciso final del apartado 1 de este artículo.
} 
La STSJ de Andalucía de 17 de noviembre de 1998, en este supuesto, entendía que la incorporación del liberado sindical al puesto de trabajo desempeñado en mejora de empleo, debía ser efectiva y, por tanto, debía poner fin a su liberación, no reconociendo vulneración del derecho a la promoción profesional del liberado sindical por negarle la promoción interna temporal ${ }^{531}$. En sentido contrario, la STSJ de Andalucía de 23 de febrero de $2001^{532}$, favorable a que el liberado sindical pudiera pasar a desempeñar el nombramiento por promoción interna temporal sin cesar en la liberación sindical, fundándose en la tesis del reconocimiento a los liberados sindicales de las garantías y facilidades para el eficaz ejercicio de sus funciones y de la no discriminación en su promoción económica y profesional, por ser contraria al derecho a de libertad sindical.

Actualmente se considera que el personal con permiso sindical que esté inscrito en las listas de empleo temporal, puede pasar a desempeñar un nombramiento, del tipo que sea, por promoción interna temporal, sin poner fin a la dispensa sindical y sin hacer efectiva la incorporación al puesto, que le quedará reservado, tal como reconoce la jurisprudencia del TC. Así, la STC 241/2005, de 10 de octubre, resuelve otorgar el amparo al demandante, liberado sindical del Servicio Andaluz de salud, por incurrir lo contrario en vulneración del derecho fundamental a la libertad sindical al negarle un nombramiento de promoción interna temporal por su condición y haber manifestado intención de continuar con el permiso de actividad sindical $^{533}$.

En cuanto al supuesto en que el trabajador con liberación sindical participe en un proceso de movilidad voluntaria y obtenga destino en un centro que corresponda a otra unidad electoral diferente para la que se le designó como delegado sindical o miembro de la Junta de Personal, se entenderá que ese traslado implica el cese como tal representante, ya que esa designación vale para el ámbito electoral que la determinó.

Ello con independencia de que, si se trata de un delegado sindical, pueda el sindicato correspondiente designarle de nuevo como tal en la unidad electoral a la que se incorpore. No así si se trata de un miembro de la Junta de Personal, ya que el cese como representante unitario supone la extinción de su mandato, porque no es el sindicato quien lo ha elegido, sino el personal de su unidad electoral en las elecciones sindicales.

Sí nos podemos plantear qué ocurre en el caso de participar el liberado sindical en los procedimientos, frecuentes en el ámbito sanitario, de cambio de unidad funcional dentro del propio centro, que conlleva cambio de adscripción del puesto de trabajo en el que prestaba servicios y que usualmente se denominan "traslados internos". En estos supuestos el trabajador con liberación sindical puede participar y obtener una nueva adscripción de su puesto de trabajo a otra unidad o servicio, aunque no lo desempeñe de manera efectiva, dado que incluso tiene derecho a la movilidad voluntaria y a la reserva de su puesto.

\footnotetext{
${ }^{531}$ (AS 199814468).

${ }^{532}$ (AS 2001\1406).

${ }^{533}($ RTC 2005\241).
} 
Capítulo V. El contenido de la negociación colectiva de los derechos sindicales del personal estatutario de los Servicios de salud antes y después de las medidas de ajuste presupuestario

En la misma línea, la STC 336/2005, de 20 diciembre, considera contraria a la libertad sindical la resolución administrativa que deniega la prórroga de la comisión de servicios del empleado público por causa de su actividad sindical ${ }^{534}$. Y es que hay que recordar que en los casos en que la Administración pública limite las garantías de acción sindical por cualquier causa, deberá aportar la justificación de haber respetado el principio de proporcionalidad que exige cualquier limitación de un derecho fundamental; es decir, deberá justificar la idoneidad, necesidad y proporcionalidad en sentido estricto de la medida limitativa, teniendo en cuenta que se deberán aportar indicios razonables de esa lesión por quien la invoque, y, por otro lado, corresponderá a la Administración la carga de la prueba de que la limitación está justificada ${ }^{535}$.

Por último, en cuanto a la obligación de la Administración de sustituir a los liberados sindicales, es conocida la tradicional reivindicación por parte de las organizaciones sindicales de que se sustituyan todos los supuestos de liberación sindical con el fin de no repercutir la carga de trabajo del representante sindical en el resto de personal de su unidad, lo que podría provocar el rechazo hacia el ejercicio de ese derecho sindical.

La obligación de sustitución de los liberados sindicales se recogía en algunos Acuerdos; así en el apartado relativo a la gestión de la bolsa de horas sindicales del Acuerdo de 25 de febrero de 2005, de la Administración del Principado de Asturias, se disponía que: "los liberados a tiempo total, bien por utilización de horas de la bolsa, bien por disfrute de permisos retribuidos de los contemplados en el presente pacto serán sustituidos en la medida en que el Gerente del centro sanitario lo considere necesario. Se procurará proceder a la sustitución del mayor número posible de liberados sindicales siempre que lo permita la dotación presupuestaria y lo aconsejen las necesidades del servicio para que este esté convenientemente atendido”.

\section{3.- CONSIDERACIONES SOBRE LA NEGOCIACIÓN COLECTIVA DE LOS DERECHOS SINDICALES EN ESA ETAPA}

Entre estos Acuerdos y Pactos que hemos visto que regularon durante años los derechos y garantías sindicales en las Administraciones autonómicas, nos encontramos con un grupo de ocho instrumentos negociados que lo fueron específicamente para el personal de su Servicio de salud, en la correspondiente Mesa sectorial de Sanidad. Dentro de este grupo la mayoría de ellos tomaban la forma de Pacto.

Se trata del Acuerdo de 4 de julio de 2008, del Servicio Aragonés de Salud; el Pacto de 29 de marzo de 2000, del Servicio Canario de Salud; el Pacto de 3 de octubre de 2003, del Servicio Cántabro de Salud; el Acuerdo de 30 de diciembre de 2003, de la Conselleria de Sanitat de la Generalitat Valenciana; los Pactos de 4 de octubre de 2002 y de 22 de enero de 2003, del Servicio Extremeño de Salud; los Pactos de 10 de noviembre de 1995 y de 1 de

\footnotetext{
534 (RTC 2005\336).

535 STC 114/2002, de 20 de mayo, (RTC 2002/114); STC 111/2003, de 16 de junio, (RTC 2003, 111) y STC 216/2005, de 12 septiembre, (RTC 2005\216).
} 
Capítulo V. El contenido de la negociación colectiva de los derechos sindicales del personal estatutario de los Servicios de salud antes y después de las medidas de ajuste presupuestario

junio de 1999 del Servicio Gallego de Salud; el Acuerdo de 18 de septiembre de 2003 del Instituto Madrileño de la Salud, y el Pacto de 18 de julio de 2003, del Servicio Murciano de Salud.

En un segundo grupo se pueden incluir los nueve restantes, negociados en cada Mesa General de negociación autonómica para todos sus empleados públicos, que reviste en estos casos mayoritariamente la forma de Acuerdo.

Son el Acuerdo de 7 de julio de 2008, de la Junta de Andalucía; el Acuerdo de 25 de febrero de 2005, de la Administración del Principado de Asturias; el Acuerdo de 2 de marzo de 2006 de la Administración de la Comunidad autónoma de las Islas Baleares; el Pacto de 27 de junio de 2006, de la Administración de la Junta de Castilla y León; el Pacto de 18 de noviembre de 2008, de la Junta de Comunidades de Castilla-La Mancha; el Pacto de 22 de diciembre de 2004, de la Administración de la Generalitat de Cataluña; el Acuerdo de 25 de mayo de 2011, de la Administración de la Comunidad autónoma de La Rioja; el Acuerdo de 18 de octubre de 1994, de la Administración de la Comunidad Foral de Navarra y el Acuerdo Marco de 15 de octubre de 1988, de la Administración de la Comunidad autónoma de Euskadi.

Como vemos, predominan ligeramente las Administraciones autonómicas que han tratado la materia de derechos sindicales en sus Mesas Generales de negociación para todos sus empleados públicos. Ello con independencia de que después, en los propios Acuerdos, se establezcan apartados en los que se regulen algunas particularidades para el personal estatutario, que suelen venir motivadas por la peculiaridad de la prestación del servicio público sanitario, que requiere de cláusulas específicas para la aplicación del disfrute del crédito horario y de las dispensas para actividad sindical, o la delimitación de las unidades electorales, por ejemplo.

Respecto al motivo por el que lo convenido adopta la forma de Pacto o Acuerdo, en la práctica encontramos que lo acordado reviste una u otra forma con independencia de cuál sea el foro en el que se ha suscrito, ya se trate de una Mesa general o sectorial. Entendemos que el factor más determinante será el de la competencia sobre la materia a negociar, de modo que si el órgano administrativo que lo negocia necesita, según las normas autonómicas de organización y competencias, el respaldo de su Consejo de Gobierno respectivo para que lo acordado adquiera efectos, deberá firmarse un Acuerdo y, en caso contrario, un Pacto.

En el Sistema Nacional de Salud la negociación de las garantías sindicales del personal ha sido, como regla general, conjunta para funcionarios, estatutarios y laborales, afectando a todo el personal del Servicio de salud o de la Administración autonómica respectiva. Solo en dos Administraciones de las CC.AA. se separó la negociación sobre derechos sindicales de su personal funcionario y estatutario por una parte, y laboral por otro. Es el caso de la de Aragón, que reguló los derechos sindicales para el personal funcionario y estatutario en el Acuerdo de 4 de julio de 2008 y para su personal laboral en el Capítulo XII del Convenio Colectivo del personal laboral al servicio de la 
Capítulo V. El contenido de la negociación colectiva de los derechos sindicales del personal estatutario de los Servicios de salud antes y después de las medidas de ajuste presupuestario

Administración de la Comunidad autónoma de Aragón ${ }^{536}$; y la de la Comunidad Valenciana, que negoció por una parte el Acuerdo de 30 de diciembre de 2003, para el personal funcionario y estatutario de instituciones sanitarias y el Acuerdo de 27 de febrero de 2004, para su personal laboral (ninguno de estos instrumentos está publicado).

Las organizaciones sindicales presentes en la negociación y firma de estos Acuerdos y Pactos son las que reúnen los requisitos de representatividad y legitimación para ser parte, junto con la Administración pública competente, en las respectivas Mesas de negociación, como hemos visto con anterioridad. Del análisis de esta participación se pueden extraer los siguientes datos, que consideramos relevantes:

Las organizaciones sindicales más representativas, CC.OO. y UGT, han estado presentes en el proceso de negociación y firma de la totalidad de los instrumentos negociados sobre derechos sindicales de los empleados públicos autonómicos y del personal estatutario de los Servicios de salud ${ }^{537}$. De entre los sindicatos representativos de sector, según su porcentaje de participación en la negociación y firma de estos Acuerdos y Pactos, la tercera organización presente es CEMSATSE (70,59\%), y le sigue CSI-F $(64,71 \%)$.

En cuanto a los sindicatos más representativos a nivel de Comunidad autónoma hay que decir que CIG ha participado en la firma del Pacto del Servicio Gallego de Salud; y ELA-STV en la firma de los Acuerdos de derechos sindicales del personal de la Administración autónoma en Euskadi y Navarra.

En cuanto a la participación de otras organizaciones sindicales presentes en la firma y negociación de estos Acuerdos y Pactos, se constata la presencia de organizaciones sindicales integrantes de la Confederación de Sindicatos de trabajadores y trabajadoras de la Enseñanza-Intersindical (STEs-Intersindical), y así está presente STEI-Intersindical en el ámbito de la Administración autonómica de las Islas Baleares, STE RIOJA, Sindicato de trabajadores de la Enseñanza de la Rioja, así como el Sindicato de Trabajadores de la Salud del País Valencià- Intersindical Valenciana, en esta Comunidad.

Otras organizaciones sindicales con representación específica bien en el sanitario o bien en el ámbito de su Administración autonómica, que han participado exclusivamente en la negociación y firma de su Acuerdo o Pacto regulador son: en Castilla y León la USCAL (Unión de Sanitarios de Castilla y León) y en Cantabria, ATI: Agrupación de Trabajadores Independientes, que tienen representación exclusivamente en el ámbito sanitario. En Cataluña la IAC (Intersindical Alternativa de Cataluña, que es una agrupación de siete

\footnotetext{
${ }^{536}$ Publicado en el Boletín Oficial de Aragón de 18 de agosto de 2006. No obstante, su artículo 74 hace una remisión expresa a los "Acuerdos Administración-Sindicatos que se suscriban entre las Organizaciones Sindicales y la Administración de la Comunidad Autónoma de Aragón en materia de derechos, garantías sindicales y dispensa sindical, sin perjuicio de lo estipulado en la normativa vigente”.

537 CCOO se adhirió una semana después al Pacto de 3 de octubre de 2003, sobre permisos, secciones sindicales y uso de crédito horario para la realización de funciones sindicales y de representación del personal al servicio de las Instituciones Sanitarias del Servicio Cántabro de Salud, aunque había participado en su procedimiento de negociación (Boletín Oficial de Cantabria de 30 de octubre de 2003).
} 
Capítulo V. El contenido de la negociación colectiva de los derechos sindicales del personal estatutario de los Servicios de salud antes y después de las medidas de ajuste presupuestario

sindicatos de personal de servicios públicos de Cataluña). En Madrid también tiene participación CSIT-UP, que es una confederación de once sindicatos independientes de empleados públicos con representación en diferentes sectores de la Administración autonómica de Madrid. En Navarra, AFAPNA (Sindicato de trabajadores de empleados públicos de diferentes sectores de la Administración Navarra). En el Acuerdo de la Rioja participan también el Sindicato de Trabajadores de la Administración Riojana (STAR), y la Federación de Sindicatos de Educación y Sanidad (FSES) ${ }^{538}$. En la Tabla 1 se detalla la participación de las organizaciones sindicales en la negociación y firma de estos Acuerdos y Pactos.

El estudio de este período, sin embargo, no debe escapar de un análisis crítico, basado fundamentalmente en la falta de homogeneidad en la regulación y la general descoordinación de los diferentes Servicios de salud sobre los mismos aspectos del régimen sindical de su personal, puestos de manifiesto incluso por los propios agentes implicados ${ }^{539}$.

\section{4.- LA SUSPENSION Y MODIFICACION DE LOS ACUERDOS Y PACTOS DE DERECHOS SINDICALES DE LOS EMPLEADOS PÚBLICOS POR LOS GOBIERNOS AUTONÓMICOS}

A partir de diciembre de 2010 y hasta la entrada en vigor del Real Decreto Ley 20/2012, se constata la tendencia autonómica consistente en la suspensión de la vigencia de los Acuerdos y Pactos sobre garantías y derechos sindicales de los empleados públicos, e incluso en su supresión directa, a favor de la normativa mínima regulada en la LOLS, LEBEP y TRET.

El recurso a la técnica de la suspensión de efectos o modificación de lo acordado, se había fundamentado por los gobiernos autonómicos en el artículo 38.10 LEBEP, que parte de la norma general de garantía de los efectos de lo negociado, para establecer como excepción la posibilidad de que los órganos de gobierno: "Por causa grave de interés público derivada de una alteración sustancial de las circunstancias económicas, suspendan o modifiquen el cumplimiento de Pactos y Acuerdos ya firmados, en la medida estrictamente necesaria para salvaguardar el interés público”.

Los gobiernos autonómicos que durante este período hicieron uso de la posibilidad legal de suspensión o modificación de los efectos de los Acuerdos y Pactos de derechos sindicales de sus empleados públicos, directamente por acuerdo de su Consejo de Gobierno,

\footnotetext{
${ }^{538}$ Respecto a la Federación de Sindicatos de Educación y Sanidad (FSES) hay que decir que se trata de una Federación constituida en el año 2006, compuesta por tres organizaciones sindicales de los ámbitos sanitario y educativo: el Sindicato de Enfermería (SATSE), el Sindicato Médico (CESM) y el sindicato ANPE (nacido como Asociación Nacional de Profesores Estatales, hoy día se denomina ANPE-Sindicato Independiente). Recientemente se ha incorporado a la Mesa General de Negociación de la Administración de la Comunidad autónoma de Canarias.

539 Véase de REGUERA ANDRES, M.C., “Algunas consideraciones sobre el diálogo social en el Sistema Nacional de Salud”, Revista de Administración Sanitaria, agosto 2010, p. 101-111.
} 
Capítulo V. El contenido de la negociación colectiva de los derechos sindicales del personal estatutario de los Servicios de salud antes y después de las medidas de ajuste presupuestario

fueron los de la Comunidad autónoma de Aragón, de las Islas Baleares, de Castilla-La Mancha, de la Comunidad Valenciana y Galicia ${ }^{540}$.

Las medidas de suspensión y modificación se dispusieron, en general, solo para los Acuerdos y Pactos aplicables a los funcionarios y personal estatutario, ya que por lo que respecta al personal laboral, el artículo 32 LEBEP, remitiéndose a la normativa laboral, no hacía posible plantear la suspensión o modificación de los efectos de lo acordado para este personal. Este precepto, sin embargo, fue modificado posteriormente por el Real Decreto Ley 20/2012, para incluir la posibilidad de modificación o suspensión del cumplimiento de los Convenios colectivos y Acuerdos que afectan al personal laboral de la Administración pública.

En algunas CC.AA., sin embargo, en lugar de hacer uso el gobierno autonómico de esa facultad, la suspensión se llevó a cabo por ley de sus asambleas legislativas. Este es el caso de la Comunidad autónoma de Andalucía, de la Región de Murcia, de Cataluña y de la Comunidad Foral de Navarra.

Por último, en otras se recurrió no a la suspensión o modificación, sino a la derogación directa de estos Acuerdos y Pactos sobre derechos sindicales mediante una ley autonómica. Este fue el caso de las Comunidades autónomas de Madrid y de Canarias, probablemente porque se quiso incluir en la medida de suspensión al personal laboral y la LEBEP aún contemplaba ese supuesto.

A pesar de que la decisión de suspensión o modificación de lo acordado corresponde de manera unilateral a la Administración, en algunas Administraciones autonómicas se buscó el consenso y se negoció previamente con las organizaciones sindicales legitimadas la norma de suspensión de efectos. De esta forma nos encontramos con Acuerdos en los que se modifican los efectos de los Pactos y Acuerdos anteriores, para adaptar su contenido a la desfavorable situación económico-presupuestaria de su Administración. Ese fue el caso de las Administraciones autonómicas de La Rioja y de Castilla y León.

Estas medidas se enmarcan en las políticas de ajustes presupuestarios que vinculaban al Gobierno estatal y a los autonómicos. Debemos tener en cuenta que, a lo largo de 2012, todas las CCAA llevaron a cabo Planes económico-financieros de ajuste ${ }^{541}$, en aplicación de la Ley Orgánica 2/2012, de 27 de abril, de Estabilidad Presupuestaria y Sostenibilidad Financiera $^{542}$, que es desarrollo, a su vez, de la reforma del artículo $135 \mathrm{CE}$ el 27 de septiembre de 2011.

\footnotetext{
540 En estas dos últimas CC.AA. ni siquiera se dio publicidad a las medidas en el Diario Oficial correspondiente.

${ }^{541}$ La Ley Orgánica 2/2012, de 27 de abril, de Estabilidad Presupuestaria y Sostenibilidad Financiera distingue entre Planes de Reequilibrio, que se proponen por el Estado o las CC.AA. cuando, a pesar de la prohibición de incurrir en déficit estructural por encima de los límites establecidos, este se produce y hay que corregirlo: arículo 11 en relación con el artículo 22; y los Planes económico financieros, que se regulan en el artículo 21, y se deben elaborar por las Administraciones públicas que no cumplan el objetivo de estabilidad presupuestaria. Estos últimos están disponibles en: <http://www.minhap.gob.es> [consulta de 12 de julio de 2014].

${ }^{542}$ BOE de 30 de abril de 2012.
} 
Capítulo V. El contenido de la negociación colectiva de los derechos sindicales del personal estatutario de los Servicios de salud antes y después de las medidas de ajuste presupuestario

Este precepto en su nueva redacción estableció en su apartado 2: "El Estado y las CC.AA. no podrán incurrir en un déficit estructural que supere los márgenes establecidos, en su caso, por la Unión Europea para sus Estados miembros".

Efectivamente, tal como señala la sinopsis del precepto que se puede consultar en la página web del Congreso de los Diputados: “... el motivo de la reforma ha sido cumplir con los compromisos asumidos por España al integrarse en la Unión Económica y Monetaria Europea, un marco en el cual la estabilidad presupuestaria adquiere un valor estructural y condicionante de la capacidad de actuación financiera y presupuestaria de las Administraciones Públicas. Se concibe así la estabilidad presupuestaria como esencial para el mantenimiento y desarrollo del Estado Social que se proclama en el artículo 1.1 de la Constitución. Así pues, se opta por incluir en la Constitución y, por tanto, por otorgar a la estabilidad presupuestaria el máximo nivel normativo posible dentro de nuestro ordenamiento jurídico [...] las pautas que nos llegan en política económica desde Bruselas son cada vez más precisas, de forma que la potestad soberana de elaborar los Presupuestos Generales del Estado va a estar condicionada, por la política de gobernanza económica europea..."

Veamos cómo se desarrolló esta fase, que dura aproximadamente un año y medio, durante la cual en la mayoría de las CC.AA. se decidió la modificación, suspensión o supresión de los Acuerdos y Pactos sobre derechos sindicales de sus empleados públicos afectando, en consecuencia, al personal de su Servicio de salud.

\section{1.- Administración de la Comunidad autónoma de Madrid}

En esta se suprimieron todos los Acuerdos de derechos sindicales de sus empleados públicos, entre ellos el de 16 de septiembre de 2003, de la Mesa General de Negociación de funcionarios, sobre jornada de trabajo y derechos sindicales del personal que presta sus servicios en instituciones sanitarias transferidas a la Comunidad de Madrid dependientes del Instituto Madrileño de la Salud.

Esto se llevó a cabo en virtud de la Ley 9/2010, de 23 de diciembre, de Medidas Fiscales, Administrativas y Racionalización del Sector Público que en su Título III, Capítulo I, reguló los "Recursos humanos", disponiendo el artículo 16 respecto a los derechos sindicales que: "1. A partir de la entrada en vigor de la presente ley, y para el ámbito de actuación de la Mesa General de Negociación de los Empleados Públicos de la Administración Autonómica de la Comunidad de Madrid [...] todos aquellos derechos sindicales, que bajo ese título específico o bajo cualquier otra denominación, se contemplen en los Acuerdos para personal funcionario y estatutario y en los Convenios Colectivos para el personal laboral suscritos con las organizaciones sindicales, cuyo contenido exceda de los establecidos en el Real Decreto Legislativo 1/1995, de 24 de marzo, por el que se aprueba el Texto Refundido de la Ley del Estatuto de los Trabajadores, la Ley Orgánica 11/1985, de 2 de agosto, de Libertad Sindical, y la Ley 7/2007, de 12 de abril, del Estatuto Básico del Empleado Público, relativos a tiempo retribuido para realizar funciones sindicales y de representación, nombramiento de delegados sindicales, así como

${ }^{543}$ Disponible en: $<$ http://www.congreso.es/indice/sinopsis $>$. 
Capítulo V. El contenido de la negociación colectiva de los derechos sindicales del personal estatutario de los Servicios de salud antes y después de las medidas de ajuste presupuestario

los relativos a dispensas totales de asistencia al trabajo, se ajustarán de forma estricta a lo establecido en dichas normas" ${ }^{544}$.

Este precepto de la ley se podría considerar el antecedente legislativo de lo que más tarde será el artículo 10 del Real Decreto Ley 20/2012, ya que no emplea la técnica de la suspensión o modificación de los Acuerdos y Pactos sobre derechos sindicales, sino que directamente supone la supresión del ordenamiento jurídico de todo lo pactado, incluso en Convenio colectivo, cuyo contenido mejorase la normativa básica legal.

El mismo artículo prevé en el apartado 3 la constitución de la bolsa de crédito horario que se pueda formar con las horas de los delegados sindicales; en el apartado 4 regula las Juntas de personal que se puedan constituir en su Administración autonómica: siete en el ámbito de las instituciones sanitarias del Servicio Madrileño de Salud. En el apartado 5, la posibilidad de llegar a Acuerdos en la Mesa General de Negociación de los Empleados Públicos de la Administración Autonómica de la Comunidad de Madrid, para regular la modificación en la obligación o en el régimen de asistencia al trabajo de los representantes sindicales, "a efectos de que puedan desarrollar el ejercicio de sus funciones de representación y negociación en dichos ámbitos".

En efecto, solo un par de meses después, el 16 de febrero de 2011, se firmó el Acuerdo de la Mesa General de Negociación de los empleados públicos de la Administración de la Comunidad de Madrid para la estabilización de las relaciones laborales, cuya ratificación por el Gobierno autonómico en fecha 17 de febrero de 2011 ha sido publicada su boletín autonómico, no así su contenido ${ }^{545}$, que sabemos por los medios de comunicación que incluye rebajas sustanciales de los créditos horarios sindicales ${ }^{546}$.

\footnotetext{
${ }^{544}$ Boletín Oficial de la Comunidad de Madrid, de 29 de diciembre de 2010. Corrección de errores en el de 25 de febrero y 15 de abril de 2011.

${ }^{545}$ Boletín Oficial de la Comunidad de Madrid, de 22 de febrero de 2011.

${ }^{546}$ La prensa recogió este dato en su momento: "La Comunidad de Madrid y los sindicatos firman un acuerdo para reducir los liberados sindicales [...] que, en síntesis, supone limitar a un tercio la representación sindical en los organismos de la Comunidad de Madrid. CC.OO. y UGT se han mostrado insatisfechos con el acuerdo que han firmado, calificado por el consejero Francisco Granados de "histórico". Para el coordinador de Área Pública de CC. OO. de Madrid, Manuel Rodríguez, el acuerdo es histórico pero en otro sentido, "porque supone un recorte sin precedentes en los derechos sindicales en la Comunidad de Madrid". A su juicio, ha sido "casi un acuerdo forzado", producto de una legislación aprobada por la Asamblea de Madrid y que, en democracia, "hay que aceptarlo porque lo dice la ley" [...] El jueves, los representantes sindicales se levantaron de la mesa y dieron por "rotas" las negociaciones tras leer un nuevo apartado en el artículo 7 que hacía referencia a los centros del Servicio Madrileño de Salud y que limitaba la constitución de secciones sindicales a los centros con 5.000 trabajadores. En el resto de consejerías y organismos se aplica la definición de centro de trabajo con un mínimo de 250 empleados. La Comunidad ha retirado ese aspecto que pretendía establecer, según interpretan los sindicatos, porque los representantes sanitarios han sido, junto con los de educación, los que más han plantado cara a las políticas regionales, con manifestaciones y enfrentamientos directos tanto con el antiguo consejero de Sanidad, Juan José Güemes, como con la presidenta Esperanza Aguirre”. Diario El País [en línea], 16 de febrero de 2011, [consulta de 23 de octubre de 2014], disponible en: <http://www.elpais.com>.
} 
Capítulo V. El contenido de la negociación colectiva de los derechos sindicales del personal estatutario de los Servicios de salud antes y después de las medidas de ajuste presupuestario

Por lo que al ámbito sanitario se refiere, la Administración de la Comunidad de Madrid fue pionera en adoptar medidas con el fin de suprimir órganos de representación del personal, a través de la supresión de unidades electorales. Así, la Disposición adicional única de la Ley 6/2009, de 16 de noviembre, de Libertad de elección en la Sanidad de la Comunidad de Madrid, que modificó la Ley 12/2001, de 21 de diciembre, de Ordenación sanitaria de la Comunidad de Madrid, redujo a una sola área de salud las once preexistentes, con la correspondiente disminución de diez unidades electorales, lo que supuso la supresión de 800 permisos sindicales ${ }^{547}$.

\section{2.- Administración de la Comunidad autónoma de la Región de Murcia}

En virtud de la Ley 5/2010, de 27 de diciembre, de Medidas extraordinarias para la sostenibilidad de las finanzas públicas, se suspendió la aplicación del Acuerdo de la Mesa sectorial de Sanidad, de fecha 18 de julio de 2003, suscrito con las organizaciones sindicales sobre el ejercicio de la actividad sindical en el ámbito del Servicio Murciano de Salud ${ }^{548}$ : “Artículo 7: Crédito horario de los representantes del personal de la Administración Regional. 1. Los representantes del personal funcionario, estatutario y laboral de la Comunidad Autónoma de la Región de Murcia tendrán derecho a disfrutar en concepto de crédito horario para el ejercicio de la actividad sindical, exclusivamente del número de horas que venga establecido para ello por la legislación estatal, y en particular, por la LOLS, TRET, y LEBEP. Como consecuencia de ello, a partir del 1 de enero de 2011 quedarán sin efecto los acuerdos sindicales que se hubieran suscrito en el ámbito de la Administración Regional en todo aquello que suponga una mejora de los derechos que las citadas normas otorgan a los representantes sindicales o a las organizaciones de las que forman parte respecto de los créditos horarios destinados al ejercicio de la actividad sindical”.

En la Disposición adicional segunda estableció que: "Durante el ejercicio 2011 quedarán suspendidos [...] los siguientes pactos y acuerdos sindicales: [...] El Acuerdo de fecha 18 de julio de 2003, suscrito entre el Servicio Murciano de Salud y las Organizaciones Sindicales, sobre el ejercicio de la actividad sindical en el ámbito del Servicio Murciano de Salud”.

La STSJ de Murcia de 16 de marzo de 2012, ha declarado que la suspensión de los Acuerdos y Pactos que realiza esta ley, es una medida "justificada por la situación excepcional que atraviesa la Comunidad autónoma, obligada a cumplir un compromiso con el Gobierno de la nación de reducción de déficit público, lo que habilita para la aplicación del artículo 38.10 LEBEP a fin de modificar o suspender los Acuerdos que afectan a las condiciones de trabajo de los empleados públicos [...] la suspensión que denuncian los recurrentes es temporal, no definitiva" ${ }^{, 49}$.

\footnotetext{
${ }^{547}$ La prensa recoge en aquellas fechas las declaraciones de la entonces Presidenta de la Comunidad de Madrid, Esperanza Aguirre, en este sentido: "Un número tan elevado de liberados sindicales es un anacronismo y un escándalo en época de crisis”. SERRANO, M.I., Diario ABC [en línea] 10 de diciembre de 2009 [consulta de 20 de diciembre de 2013], disponible en:〈http://www.abc.es $>$.

${ }^{548}$ Boletín Oficial de la Región de Murcia de 31 de diciembre de 2010.

${ }^{549}$ Fundamento jurídico cuarto, (RJCA 2012\211).
} 
Capítulo V. El contenido de la negociación colectiva de los derechos sindicales del personal estatutario de los Servicios de salud antes y después de las medidas de ajuste presupuestario

Esta suspensión de efectos se mantuvo por Ley 6/2011, de 26 de diciembre, de Presupuestos Generales de la Comunidad Autónoma de la Región de Murcia para 2012 en su Disposición adicional vigesimosexta, apartado 7: "Medidas en materia de jornada, horario y gastos de personal. Crédito horario de los representantes del personal de la Administración Regional" ${ }^{\text {. } 550 .}$

\section{3.- Administración de la Comunidad autónoma de Canarias}

La Ley 11/2010, de 30 de diciembre, de Presupuestos Generales de la Comunidad autónoma de Canarias para 2011, en su Disposición adicional vigésima; y al año siguiente, la Ley 12/2011, de 29 de diciembre, de Presupuestos para 2012, en su Disposición adicional trigésimo tercera, con la misma redacción, optan por la supresión del régimen de derechos sindicales negociados y la vuelta a la regulación legal de la LEBEP: "Permisos retribuidos para la realización de actividades sindicales. El régimen jurídico de los permisos retribuidos y uso del crédito horario, para la realización de actividades sindicales y de representación del personal que presta servicios en los distintos sectores de la Administración autonómica, vendrá determinado por lo dispuesto en el Estatuto Básico del Empleado Público, sin perjuicio de aquellos acuerdos que puedan alcanzarse en el marco de la negociación colectiva y la concertación social”.

Por tanto, deja de tener vigencia -en ningún caso se habla de suspensión- el Pacto de 29 de marzo de 2000, entre el Servicio Canario de Salud y las organizaciones sindicales, adoptado en la Mesa sectorial de Sanidad, sobre permisos, secciones sindicales y uso del crédito horario para la realización de funciones sindicales y de representación del personal al servicio de instituciones sanitarias.

\section{4.- Administración de la Generalitat Valenciana}

El Gobierno valenciano llevó a cabo la revocación de la autorización de liberaciones institucionales autorizadas en su día en el marco de los Acuerdos de 19 de junio de 1995 y de 30 de noviembre de 2004, decisión que fue comunicada a la Mesa General de Negociación autonómica el 6 de septiembre de 2011, en el marco de las medidas contenidas en el Plan de Ajuste de la Generalitat, entre las que se encontraba la reincorporación de los liberados sindicales institucionales. Este Acuerdo del Gobierno autonómico no está publicado en el Diario Oficial de la Comunitat Valenciana, y se trata, en definitiva, de una modificación unilateral de lo acordado basada en el artículo 38.10 LEBEP $^{551}$.

550 “7.1 Los representantes del personal funcionario, estatutario y laboral de la Comunidad Autónoma de la Región de Murcia tendrán derecho a disfrutar en concepto de crédito horario para el ejercicio de la actividad sindical exclusivamente del número de horas que venga establecido para ello por la legislación estatal, y en particular, por la Ley Orgánica 11/1985, de 2 de agosto, de Libertad Sindical, el Real Decreto Legislativo 1/1995, de 24 de marzo, por el que se aprueba el Texto Refundido de la Ley del Estatuto de los Trabajadores, la Ley 31/1995, de 8 de noviembre, por la que se regula la prevención de riesgos laborales y la Ley 7/2007, de 12 de abril, del Estatuto Básico del Empleado Público.7.2 Como consecuencia de ello, durante el ejercicio 2012 quedarán suspendidos los acuerdos alcanzados con las organizaciones sindicales en todo aquello que suponga una mejora en materia de créditos horarios”. BOE de 15 de febrero de 2012.

551 En los medios de comunicación encontramos noticias como esta: "La Comunidad Valenciana se encuentra entre las autonomías con más funcionarios liberados para actividades sindicales, según se desprende de los últimos datos. La Administración de la Generalitat Valenciana cuenta con 731 delegados 
Capítulo V. El contenido de la negociación colectiva de los derechos sindicales del personal estatutario de los Servicios de salud antes y después de las medidas de ajuste presupuestario

\section{5.- Administración de la Xunta de Galicia}

En esta también se suprimieron liberaciones institucionales a lo largo del año 2011, modificando, en el ámbito del personal del Servicio Gallego de Salud, los Pactos de 30 de octubre de 1995, el Pacto de 1 de junio de 1999 y el Reglamento de la Mesa sectorial del Servicio Gallego de Salud de 2008. Tampoco esta decisión fue objeto de publicación, por lo que los datos que se poseen son los que se pueden obtener a través de los medios de comunicación ${ }^{552}$.

\section{6.- Administración de Comunidad autónoma de las Islas Baleares}

El Acuerdo del Consejo de Gobierno de 23 de septiembre de 2011, por el que se adoptan medidas para la reducción del déficit público, estableció la suspensión de la aplicación de los Pactos y Acuerdos suscritos entre la Administración de la Comunidad autónoma de las Islas Baleares y las organizaciones sindicales más representativas relativos al desarrollo de la acción sindical y, en consecuencia, dejó en suspenso la aplicación del Acuerdo de 2 de marzo de 2006, de la Mesa General de Negociación Común sobre

sindicales, una cifra que sólo la sitúa por detrás de Andalucía, Madrid y Castilla y León. La Administración valenciana está por delante de Cataluña, que tiene un mayor número de funcionarios. En Cataluña hay 163.804 funcionarios y 518 liberados. Los 731 delegados valencianos representan a un montante de 127.150 empleados públicos. El Consell ha ejecutado esta semana el plan para eliminar puestos de liberados sindicales con un tijeretazo de 165 plazas, ocupadas en buena parte por funcionarios que desempeñaban labores de dirección en los diferentes sindicatos. Tal como adelantó Levante-EMV, el Ejecutivo suprimirá todos los puestos posibles hasta dejarlos en el mínimo legal exigible. Van a salir los llamados liberados institucionales, es decir, aquellos que eran fruto de acuerdos que datan de los años 90 y que el Gobierno popular ratificó y mejoró con el tiempo. La decisión supone un recorte del $22 \%$ y un ahorro 6 millones al año. Las 17 autonomías de España acumulan cerca de un millón de empleados públicos de los que casi diez. mil están liberados para tareas de naturaleza sindical. Es decir, por cada diez funcionarios hay aproximadamente un liberado El reparto de los delegados viene definido en el Estatuto del Empleado Público, pero cada Comunidad autónoma tiene competencias para negociar con los sindicatos el reparto de horas para ejercer sus labores. El ajuste proyectado por el Consell supone un varapalo para las organizaciones sindicales que en algunos casos perderán casi la mitad de sus efectivos. A partir de ahora tendrán que apañárselas con los llamados liberados por horas a los que tienen derecho por la ley actual y que se distribuyen en función de su representación y por los resultados electorales.". La Generalitat es la cuarta Administración autonómica con más liberados sindicales, Diario Levante [en línea], 11 de septiembre de 2011, [consulta de 16 de noviembre de 2014], disponible en: 〈http://www. levante-emv.com>.

\footnotetext{
552 , “En su afán por recortar el gasto público, la Xunta ha empezado ya a meter mano a los sindicatos. Al igual que hizo Esperanza Aguirre en Madrid, el Gobierno gallego se ha propuesto reducir el número de liberados -aquellos representantes de los trabajadores que dedican el tiempo completo de su jornada laboral a tareas sindicales-. El recorte ha empezado por las áreas de sanidad y educación, donde ya se suprimieron un tercio de los liberados. En justicia existe un preacuerdo para rebajarlos en un $26 \%$ y en el resto de Departamentos de la Administración autonómica las negociaciones se iniciarán en septiembre. En el SERGAS el acuerdo con las centrales se cerró el pasado 5 agosto y solo se desmarcó CC.OO. y SATSE. En virtud de este pacto se redujo a 222 el número de delegados, un 35\% menos, y se rebajó de 77 a 52 el número de liberados de tipo institucional, que son los que quedan eximidos de su carga laboral por actuar de interlocutores en alguno de los órganos de diálogo o mesas de negociación que las centrales mantienen con el Ejecutivo gallego". PEREZ SANTIAGO, P. La Xunta recorta un 30\% los liberados sindicales en las áreas de sanidad y educación, Diario El Faro de Vigo [en línea], 28 de agosto de 2011, [consulta de 18 de noviembre de 2014], disponible en: http://www.elfarodevigo.es.
} 
Capítulo V. El contenido de la negociación colectiva de los derechos sindicales del personal estatutario de los Servicios de salud antes y después de las medidas de ajuste presupuestario

desarrollo de la acción sindical de los órganos de representación del personal y de las secciones sindicales.

En virtud de este Acuerdo de suspensión, el Gobierno autonómico decide que todos los derechos sindicales reconocidos en Acuerdos y Pactos para el personal funcionario, estatutario y laboral, debían ajustarse de forma estricta a lo dispuesto en la LEBEP, el TRET y la LOLS, y aunque dispuso la constitución de bolsas de crédito horario en los diferentes ámbitos de la Administración autonómica, se ajustó estrictamente a la normativa mínima en cuanto al crédito sindical.

Esta decisión se justificó en razones de interés público derivadas de la alteración sustancial de las circunstancias económicas en las que se suscribió el Acuerdo de derechos sindicales; sin embargo, no se estableció el plazo durante el que debía ser efectiva, por lo que es indefinida, y no se hace mención a ninguna condición bajo la cual lo acordado recuperará sus efectos. Por ello, nos parece que esta medida muy discutiblemente encaja en el artículo 38.10 LEBEP. Además, hay que ver que afectaba también a lo convenido en los Acuerdos o Pactos para el personal laboral conjuntamente con el personal funcionario y estatutario, que tiene para él efectos de Convenio colectivo (art. 38.8 LEBEP), y considerando que el artículo 32 LEBEP aún no había sido modificado por el Real Decreto Ley 20/2012, resulta de muy dudosa legalidad esta disposición reglamentaria.

En este caso tampoco existió consenso con los sindicatos, sino que la propia Administración autonómica tomó la decisión de forma unilateral, informando a las organizaciones sindicales afectadas diez días antes de su aprobación ${ }^{553}$.

Posteriormente, el Decreto Ley 5/2012, de 1 de junio ${ }^{554}$, del Gobierno autonómico balear, sobre reducción de gastos en materia de personal al servicio de su Administración, con la finalidad de conseguir los objetivos de reducción del déficit público establecidos en la legislación sobre estabilidad presupuestaria (art.1), estableció en su Disposición adicional novena, apartado 1, la suspensión de todos los Pactos y Acuerdos suscritos en el ámbito de personal funcionario y estatutario, en base al artículo 38.10 LEBEP, así como las cláusulas contractuales y condiciones reguladas por Acuerdos, Pactos y Convenios colectivos que afectaran al personal laboral (apdo. 2). Por último, la Disposición adicional primera del Decreto Ley 10/2012, de 31 de agosto, reduce a tres las unidades electorales del Servicio Balear de Salud ${ }^{555}$.

\section{7.- Administración de la Junta de Comunidades de Castilla-La Mancha}

Por Acuerdo de 13 de octubre de 2011, de su Consejo de Gobierno, por el que se adoptan medidas para la reducción del déficit público, se suspendieron los efectos del Pacto

\footnotetext{
${ }^{553}$ Publicado en el Boletín Oficial de las Islas Baleares de 27 de septiembre de 2011, entró en vigor ese día.

${ }^{554}$ Boletín Oficial de las Islas Baleares de 1 de junio de 2012.

${ }^{555}$ Haciéndolas coincidir con las áreas de salud de Mallorca, Menorca e Ibiza-Formentera. Boletín Oficial de las Islas Baleares de 1 de septiembre de 2012.
} 
Capítulo V. El contenido de la negociación colectiva de los derechos sindicales del personal estatutario de los Servicios de salud antes y después de las medidas de ajuste presupuestario

de Interlocución entre la Administración de la Junta de Comunidades de Castilla-La Mancha y las organizaciones sindicales para el período 2008-2011 ${ }^{556}$.

Recurrido este Acuerdo, la STSJ de Castilla-La Mancha de 5 de febrero de 2013, desestimó el recurso por entender que no existía violación del derecho a la negociación colectiva. Esto es porque considera que concurre una causa grave de interés público originada por la alteración sustancial de las circunstancias económicas que presidieron la firma del acuerdo, y que en este caso la ley no impone la negociación, por lo que "no puede hablarse de violación del derecho a la negociación colectiva, pues es la propia ley la que autoriza el ejercicio de la facultad excepcional de suspensión o modificación de los Pactos y Acuerdos $^{\prime \prime 5} 57$.

Solo dos meses después se firmó el Pacto de Interlocución entre la Junta de Comunidades de Castilla-La Mancha y las organizaciones sindicales de 22 de diciembre de 2011, para el período 2011-2015.

\section{8.- Administración de la Generalitat de Cataluña}

La Ley 5/2012, de 20 de marzo, de Medidas fiscales, financieras y $\operatorname{administrativas~}^{558}$, en su Disposición adicional séptima dispuso la suspensión parcial de todos los Pactos y Acuerdos sindicales que afectaran a los empleados públicos, referidos a liberaciones institucionales y totales de asistencia al trabajo. En su desarrollo, se adoptó en la Mesa General del Empleado público el Acuerdo de 2 de mayo de 2012, que modifica importantes aspectos relativos al crédito horario sindical acordado en su día en el Pacto de derechos sindicales de 22 de diciembre de 2004, que se refieren fundamentalmente a la reducción de los créditos horarios y liberaciones sindicales. Este Acuerdo, que entró en vigor el 1 de julio de 2012, pocos días antes de publicarse el Real Decreto Ley 20/2012, ha finalizado el 30 de junio de 2014.

\section{9.- Administración de la Comunidad autónoma de La Rioja}

El Acuerdo del Consejo de Gobierno de la Rioja, de 16 de diciembre de 2011, ratificó el de 13 de diciembre ${ }^{559}$, entre la Administración de la Comunidad autónoma de La Rioja y las organizaciones sindicales de la Mesa General de negociación colectiva, por el que se modifica el Acuerdo en materia de acción sindical de 25 de mayo de 2011.

Cabe destacar que este Acuerdo sí se tomó en la Mesa General de negociación por unanimidad de las partes representadas, y trata la gestión de la bolsa de crédito horario sindical que será común para el personal del Servicio Riojano de Salud y el del resto de la

\footnotetext{
${ }^{556}$ Diario Oficial de Castilla-La Mancha de 20 de diciembre de 2011.

${ }^{557}$ (JUR 2013\53405).

${ }^{558}$ Diario Oficial de la Generalitat Catalana de 23 de marzo de 2012.

${ }^{559}$ Boletín Oficial de la Rioja de 9 de enero de 2012.
} 
Capítulo V. El contenido de la negociación colectiva de los derechos sindicales del personal estatutario de los Servicios de salud antes y después de las medidas de ajuste presupuestario

Administración autonómica incluyendo las horas de los representantes del personal, de los delegados sindicales y las horas adicionales que reconoce el Acuerdo, que representa una reducción de las dispensas sindicales ${ }^{560}$.

\section{0.- Administración de la Junta de Castilla y León}

En esta se suspendió temporalmente la eficacia de una parte del Pacto sobre Derechos de Representación Sindical de 27 de junio de 2006, mediante el Pacto de suspensión parcial y temporal de sus efectos, de 24 de febrero de 2012, consensuado entre la Administración autonómica y todas las organizaciones sindicales firmantes del primero ${ }^{561}$.

La modificación que supuso este nuevo Pacto implicaba la reducción de liberados sindicales como consecuencia de la reducción de créditos horarios ${ }^{562}$.

\section{1.- Administración de la Comunidad Foral de Navarra}

Se suspendió parcialmente, para el año 2012, el Acuerdo sobre derechos sindicales en la Administración de la Comunidad Foral de Navarra y sus organismos autónomos, suscrito entre representantes de la Administración y de las organizaciones sindicales en fecha 18 de octubre de 1994, por Ley Foral 13/2012, de 21 de junio, de Medidas urgentes en materia de personal al servicio de las Administraciones Públicas de Navarra ${ }^{563}$.

En la exposición de motivos de esta ley se hace referencia al contenido de la suspensión parcial, que consiste en la reducción del crédito horario de los representantes

\footnotetext{
${ }^{560}$ En prensa: "El presidente del Gobierno de La Rioja ha anunciado esta mañana una reducción de 28 liberados sindicales en la Administración regional. Ello ha conllevado, por parte del Ejecutivo riojano, la modificación del acuerdo de derechos sindicales, aprobado por "unanimidad" en la mesa general de negociación, que contempla una notable reducción del número de liberados sindicales de la Administración regional. Según ha apuntado, el presidente riojano, en comparecencia de prensa, el ajuste, aceptado por todos los sindicatos, reduce a un máximo de 73 los liberados sindicales en la Administración General de la Comunidad Autónoma de La Rioja. Estos 73 liberados, 58 responden al mínimo legal (electos y Ley Orgánica de Libertad Sindical) y los 15 restantes al acuerdo tal y como ha quedado...”, Sanz anuncia una reducción de 28 liberados en la Administración regional, 16 de diciembre de 2011 consulta de 12 de octubre de 2014, disponible en: 〈http://www.europapress.es $>$.

${ }^{561}$ Publicado en el Boletín oficial de Castilla y León de 28 de febrero de 2012.

562 “El Consejo de Gobierno ha aprobado hoy la reducción del 31\% del número de liberados sindicales en la Junta, que pasarán de 950 a 658, lo que implica un ahorro de 13,6 millones de euros para las arcas autonómicas. La medida se acordó por unanimidad el pasado 23 de diciembre en la Mesa General del Empleado Público y se hará efectiva mediante la modificación del Pacto sobre Derechos de Representación Sindical en la Administración de la Comunidad de Castilla y León [...] La disminución se efectuará en dos fases: en 2012 se eliminará el 40\% de esa cantidad, y en 2013 el 60\% restante. Como consecuencia de ello, la Junta ahorrará 13,6 millones de euros [...] la nueva regulación entrará en vigor el 1 de marzo”, La Junta aprueba reducir en un 31\% los liberados sindicales, 23 de febrero de 2012, [consulta de 2 de julio de 2013], disponible en: <http://www.noticiascastillayleon.com>

${ }^{563}$ Boletín Oficial de Navarra de 28 de junio de 2012.
} 
Capítulo V. El contenido de la negociación colectiva de los derechos sindicales del personal estatutario de los Servicios de salud antes y después de las medidas de ajuste presupuestario

sindicales en un 10\%, "reducción que deberá imputarse al crédito existente por encima del fijado por la normativa vigente, tanto en el Estatuto del Personal al servicio de las Administraciones Públicas de Navarra como en la Ley Orgánica de Libertad Sindical”.

En el artículo 7, apartado 3 de la ley se concreta que: "Esta reducción conlleva la suspensión parcial de la aplicación del Acuerdo sobre derechos sindicales en la Administración de la Comunidad Foral de Navarra y sus organismos autónomos, suscrito entre representantes de la Administración y de las organizaciones sindicales con fecha 18 de octubre de 1994, así como de aquellos otros Acuerdos que pudieran existir en los diferentes ámbitos sectoriales de la misma”.

\section{2.- Administración de la Comunidad autónoma de Aragón}

El Acuerdo de 3 de julio de 2012, del Gobierno de Aragón, dispuso la suspensión parcial de los Acuerdos sobre derechos y garantías sindicales de los diferentes ámbitos de su Administración autonómica, entre ellos, el Acuerdo de 4 de julio de 2008 de la Mesa sectorial de Sanidad, sobre derechos y garantías sindicales del personal funcionario y estatutario de los centros sanitarios del Servicio Aragonés de Salud ${ }^{564}$.

La suspensión consistió en la aplicación estricta de la normativa legal (TRET, LEBEP y LOLS) en cuanto a la regulación de dispensas sindicales, designación de delegados y crédito horario de los representantes de los empleados públicos y sindicales, justificando esta decisión en: "La obligación de cumplir los objetivos de déficit público, impuestos por el Gobierno de la Nación [...] y adoptar una serie de medidas tendentes a la reducción de gastos, ya contempladas en el Plan Económico-Financiero de Reequilibrio 2012-2014, presentado por la Comunidad autónoma de Aragón ante el Consejo de Política Fiscal y Financiera...”.

\section{3.- Administración de la Junta de Andalucía}

La Ley 3/2012, de 21 de septiembre, de Medidas Fiscales, Administrativas, Laborales y en materia de Hacienda Pública para el reequilibrio económico-financiero de la Junta de Andalucía, dispuso la suspensión de su Acuerdo de derechos sindicales en el artículo 32 ${ }^{565}$ : "Los créditos horarios para el ejercicio de la libertad sindical serán los establecidos por la Ley Orgánica 11/1985, de 2 de agosto, de Libertad Sindical; el Real Decreto Legislativo 1/1995, de 24 de marzo, por el que se aprueba el texto refundido de la Ley del Estatuto de los Trabajadores; la Ley 31/1995, de 8 de noviembre, de Prevención de Riesgos Laborales, y la Ley 7/2007, de 12 de abril, del Estatuto Básico del Empleado Público, quedando suspendidos los acuerdos o pactos alcanzados con las organizaciones sindicales. Todo ello sin perjuicio de los posibles acuerdos que se pudieran adoptar”.

\footnotetext{
${ }^{564}$ Boletín Oficial de Aragón de 31 de julio de 2012.

565 Así como la supresión de las subvenciones a las organizaciones sindicales en el artículo 33: "Queda suspendida la vigencia de la Orden de la Consejería de Justicia y Administración Pública, de 2 de diciembre de 2009, por la que se establecen las bases reguladoras de los procedimientos para la concesión de subvenciones a organizaciones sindicales para la financiación de gastos corrientes"
} 
En definitiva, durante el período comprendido entre finales de 2010 y hasta la publicación por el Gobierno del Estado del Real Decreto Ley 20/2012, la mayoría de los Gobiernos autonómicos ya habían suspendido total o parcialmente los Acuerdos y Pactos sobre derechos sindicales de sus empleados públicos, en algunos casos incluso de forma consensuada con las organizaciones sindicales, en las correspondientes Mesas de Negociación.

En algunas Administraciones autonómicas incluso se había procedido a derogar directamente los Acuerdos para aplicar el régimen de derechos sindicales previsto en la normativa básica legal. Por ese motivo, cuando en julio de 2012 entre en vigor el Real Decreto Ley 20/2012, con el efecto principal de derogar los Pactos y Acuerdos en materia de garantías sindicales de los empleados públicos y rebajar el nivel de derechos al mínimo legal, sus disposiciones no tendrán repercusión en estas Administraciones que han tomado esas mismas medidas con anterioridad.

Sin embargo, sí desplegará todos sus efectos en el resto de Administraciones autonómicas, y en el ámbito del INGESA, que seguían aplicando en lo convenido en sus Pactos, Acuerdos y Convenios colectivos de derechos sindicales: es el caso de la Administración del Principado de Asturias, la de Cantabria, la de la Junta de Extremadura y del País Vasco.

\section{5.- LAS MEDIDAS DEL REAL DECRETO LEY 20/2012, DE 13 DE JULIO, SOBRE LOS DERECHOS SINDICALES DE LOS EMPLEADOS PÚBLICOS}

En la Exposición de Motivos, apartado II, del Real Decreto Ley 20/2012, encontramos los argumentos de la reforma que articula esta norma, y que el Gobierno del Estado justifica en la necesidad de alcanzar el objetivo de estabilidad presupuestaria mediante la contención de los gastos de personal ${ }^{566}$ : "La actual coyuntura económica y la necesidad de reducir el déficit público sin menoscabar la prestación de los servicios públicos esenciales" que "hace necesario mejorar la eficiencia de las Administraciones Públicas en el uso de los recursos públicos, con objeto de contribuir a la consecución del inexcusable objetivo de estabilidad presupuestaria, derivado del marco constitucional y de la Unión Europea”.

Entre otras, contiene una serie de medidas que van a incidir directamente en diferentes aspectos del derecho a la libertad sindical de los empleados públicos, y que analizaremos a continuación:

$\left.1^{a}\right)$ En su artículo 10 el Real Decreto Ley 20/2012 contiene una disposición que deroga drásticamente toda la negociación colectiva de los empleados públicos sobre derechos sindicales, que en ese momento aún esté vigente y contenga mejoras sobre el

\footnotetext{
566 Congelación de las retribuciones, suspensión de las aportaciones a Planes de Pensiones de empleo o contratos de seguro colectivo que incluyan la contingencia de jubilación, congelación de la Oferta de Empleo Público, aumento de la jornada de trabajo del sector público estatal ("medidas que avanzan en la optimización de recursos, la mejora en la gestión y en la transparencia de la Administración y el incremento de la productividad de los empleados públicos”).
} 
Capítulo V. El contenido de la negociación colectiva de los derechos sindicales del personal estatutario de los Servicios de salud antes y después de las medidas de ajuste presupuestario

régimen legal. La norma insiste en que en esta materia habrá que ajustarse estrictamente a lo dispuesto en la LOLS, LEBEP y TRET: "1. En el ámbito de las Administraciones Públicas y organismos, entidades, universidades, fundaciones y sociedades dependientes de las mismas a partir de la entrada en vigor del presente Real Decreto-ley, todos aquellos derechos sindicales, que bajo ese título específico o bajo cualquier otra denominación, se contemplen en los Acuerdos para personal funcionario y estatutario y en los Convenios Colectivos $y$ Acuerdos para el personal laboral suscritos con representantes $u$ organizaciones sindicales, cuyo contenido exceda de los establecidos en el Real Decreto Legislativo 1/1995, de 24 de marzo, por el que se aprueba el Texto Refundido de la Ley del Estatuto de los Trabajadores, la Ley Orgánica 11/1985, de 2 de agosto, de Libertad Sindical, y la Ley 7/2007, de 12 de abril, del Estatuto Básico del Empleado Público, relativos a tiempo retribuido para realizar funciones sindicales y de representación, nombramiento de delegados sindicales, así como los relativos a dispensas totales de asistencia al trabajo y demás derechos sindicales, se ajustarán de forma estricta a lo establecido en dichas normas. A partir de la entrada en vigor del presente Real Decreto Ley dejarán, por tanto, de tener validez y surtir efectos, todos los Pactos, Acuerdos y Convenios Colectivos que en esta materia hayan podido suscribirse y que excedan de dicho contenido [...] 2. Lo dispuesto en este artículo será de aplicación el 1 de octubre de 2012", 567 .

La doctrina advierte que esta medida no es la prevista en el artículo 38.10 LEBEP, que trata la suspensión y modificación de lo negociado por la Administración pública, cuando se den causas graves y excepcionales, de interés público, por alteración sustancial de las circunstancias económicas, sino una declaración legal de directa aplicación con efectos jurídicos inmediatos ${ }^{568}$.

Además, es inexplicable la contradicción de la norma en cuanto a la fecha de entrada en vigor de la disposición sobre la supresión de efectos de lo negociado en materia de derechos sindicales, ya que el Real Decreto Ley dice que “... a partir de la entrada en vigor de este Real decreto ley dejarán, por tanto, de tener validez y producir efectos" cosa que sucedió al día siguiente de su publicación; es decir, el 15 de julio de 2012, para, a continuación, disponer que "será de aplicación a partir del 1 de octubre de $2012^{569}$.

\footnotetext{
${ }^{567}$ Asimismo, en la Disposición final octava se establece una recomendación respecto a los derechos sindicales para el personal incluido en el ámbito de las fundaciones, sociedades mercantiles y resto de entidades que conforman el sector público, que dice: “deberán efectuar una adecuada gestión en el marco de la legislación vigente, de las materias relacionadas con la creación, modificación o supresión de órganos de representación, secciones y delegados sindicales, especialmente en lo que afecta a los créditos horarios, cesiones de estos créditos y liberaciones que deriven de la aplicación de normas o pactos que afecten a la obligación o al régimen de asistencia al trabajo. Todo ello con respeto de los derechos sindicales y de representación reconocidos en la legislación vigente.".
}

${ }^{568}$ LAHERA FORTEZA, J., VALDES ALONSO, A., Informe $n^{\circ} 300$ impacto en Convenios, Acuerdos y Pactos colectivos en el sector público del Real Decreto Ley 20/2012, de 13 de julio, sobre medidas para garantizar la estabilidad presupuestaria y de fomento de la competitividad, [consulta de 23 de diciembre de 2013], disponible en:<http://www.ugt.es/actualidad/2012>.

569. ROJO TORRECILlA, E, Análisis de los contenidos laborales del Real Decreto Ley 20/2012 ¿Hacia dónde va el Estado del bienestar en España? ¿Hacia dónde le lleva el Gobierno?, disponible en: $<$ http://slideshare.net/erojotorrecilla $>$. 
Capítulo V. El contenido de la negociación colectiva de los derechos sindicales del personal estatutario de los Servicios de salud antes y después de las medidas de ajuste presupuestario

$2^{a}$ ) Otra medida del Real Decreto Ley 20/2012 consiste en hacer extensiva la posibilidad de suspensión y modificación de lo acordado a los Convenios colectivos pactados por la Administración Pública con su personal laboral. El escollo de la naturaleza de la negociación colectiva laboral se salva así en el artículo 7 del Real Decreto Ley, que da nueva redacción al artículo 32 LEBEP, para incorporar el mecanismo de la suspensión o modificación de los Convenios colectivos también para los empleados públicos con esta relación jurídica: "Se garantiza el cumplimiento de los convenios colectivos y acuerdos que afecten al personal laboral, salvo cuando excepcionalmente y por causa grave de interés público derivada de una alteración sustancial de las circunstancias económicas, los órganos de gobierno de las Administraciones Públicas suspendan o modifiquen el cumplimiento de Convenios Colectivos o acuerdos ya firmados en la medida estrictamente necesaria para salvaguardar el interés público. En este supuesto, las Administraciones Públicas deberán informar a las Organizaciones Sindicales de las causas de la suspensión o modificación."

Con esta reforma legal las Administraciones públicas evitan la necesidad de acudir a procedimientos de modificación sustancial de las condiciones de trabajo de carácter colectivo o descuelgue de cláusulas de convenio previstas en la Ley 3/2012, de 6 de julio, de Medidas urgentes para la reforma del mercado laboral ${ }^{570}$.

$3^{\text {a) }}$ El artículo 12 del Real Decreto Ley determina el ámbito de las unidades electorales en la Administración General del Estado ${ }^{571}$. Los apartados 3 y 4 de este artículo señalan que esta norma producirá efectos cuando se produzca el vencimiento de los mandatos electorales en vigor o, en todo caso, el 1 de marzo de 2015, "fecha en que todos los mandatos en vigor o prorrogados se extinguirán como consecuencia de la elección de los nuevos órganos de representación, elección que deberá producirse en el plazo de diez. meses desde la fecha indicada", por lo que no parece justificado que una disposición que tiene que tener vigor al cabo de más de dos años se incorpore al contenido de un Real

\footnotetext{
${ }^{570}$ BOE de 7 de julio de 2012. También el artículo 14 del Real Decreto Ley 20/2012 regula las unidades electorales, créditos horarios y derechos sindicales en relación con el personal laboral que presta servicios en el exterior al servicio de la Administración General del Estado y sus Organismos Autónomos atribuyendo al Estado la competencia para la delimitación de las unidades electorales, con adecuación a la normativa estatal en cuanto al crédito horario.

571 Para los funcionarios son las siguientes: “a) Una por cada uno de los Departamentos ministeriales incluidos en ellos, sus Organismos Autónomos, Entidades gestoras y servicios comunes de la Administración de la Seguridad Social y todos los servicios provinciales de Madrid. b) Una para cada Agencia, ente público u organismo no incluido en el apartado anterior, para todos los servicios que tenga en la provincia de Madrid. c) Una en cada provincia y en las ciudades de Ceuta y de Melilla, en la Delegación o Subdelegación de Gobierno, en la que se incluirán los Organismos Autónomos, Agencias comprendidas en el ámbito de aplicación de la Ley 28/2006, de 18 de julio, las Entidades gestoras y servicios comunes de la Administración de la Seguridad Social y las unidades administrativas y servicios provinciales de todos los Departamentos Ministeriales en una misma provincia, incluidos los funcionarios civiles que presten servicios en la Administración militar. d) Una para cada ente u organismo público, no incluido en el apartado anterior, para todos los servicios que tenga en una misma provincia o en las ciudades de Ceuta y de Melilla. e) Una para los funcionarios destinados en las misiones diplomáticas en cada país, representaciones permanentes, oficinas consulares e instituciones y servicios de la Administración del Estado en el extranjero. Cuando no se alcance el censo mínimo de 50, los funcionarios votarán en los Servicios Centrales de los respectivos Departamentos Ministeriales. f) Una en cada provincia para el personal al servicio de la Administración de Justicia”.
} 
Capítulo V. El contenido de la negociación colectiva de los derechos sindicales del personal estatutario de los Servicios de salud antes y después de las medidas de ajuste presupuestario

Decreto Ley que se dicta "en caso de extraordinaria y urgente necesidad" (art. 86.1 CE)., teniendo en cuenta, además, que la delimitación de las unidades electorales es materia de obligada negociación con las organizaciones sindicales (art. 39.4 LEBEP).

No obstante, la determinación de las unidades electorales que contiene este artículo fue incorporada, sin modificaciones, con posterioridad al apartado 6 (Centros de Trabajo) del Acuerdo de 29 de octubre de 2012, de la Administración General del Estado.

$4^{\circ}$ ) Se establece en el artículo 13, la obligatoriedad de que las Administraciones públicas dispongan de un Registro de órganos de representación al servicio de las mismas y de sus organismos dependientes, en el que serán objeto de inscripción o anotación: "Los actos adoptados en su ámbito que afecten a la creación, modificación o supresión de órganos de representación del personal funcionario, estatutario o laboral, la creación modificación o supresión de secciones sindicales, los miembros de dichos órganos y delegados sindicales. Asimismo, serán objeto de anotación los créditos horarios, sus cesiones y liberaciones sindicales que deriven de la aplicación de normas o pactos que afecten a la obligación o al régimen de asistencia al trabajo”.

El Registro de órganos de representación del personal también tiene como antecedente lo dispuesto en el artículo 6 de la Ley 9/2010, de 23 de diciembre, de la Comunidad de Madrid, que suprimió el contenido de los Acuerdos y Pactos sobre derechos sindicales de su Administración autonómica. Esta disposición fue desarrollada, a su vez, por la Orden de 3 de julio de 2012, por la que se regula la organización y funcionamiento del Registro de órganos de representación del personal al servicio de la Comunidad de Madrid $^{572 .}$

En desarrollo de las previsiones del Real Decreto Ley 20/2012, en algunas CC.AA. se han creado los correspondientes Registros de órganos de representación del personal a su servicio. Por ejemplo, en la Administración del Principado de Asturias el Decreto 40/2014, de 30 de abril, crea y regula el Registro de órganos de representación del personal de la Administración del Principado de Asturias y el sector público autonómico ${ }^{573}$.

En la Administración autonómica de la Región de Murcia lo ha hecho la Ley 9/2012 de 8 de noviembre, de adaptación de la normativa regional en materia de función pública al Real Decreto Ley 20/2012 (art. 1) ${ }^{574}$.

\footnotetext{
572 Boletín Oficial de la Comunidad de Madrid de 13 de julio de 2012.

${ }^{573}$ Boletín Oficial del Principado de Asturias de 8 de mayo de 2014.

${ }^{574}$ BOE de 20 de febrero de 2013. El artículo 1 establece: “1.- En virtud del Real Decreto Ley 20/2012, se creará en la Administración Pública de la Región de Murcia, un Registro de Órganos de Representación del Personal al servicio del Sector Público de la Región de Murcia en el que serán objeto de inscripción o anotación, al menos, los actos que afecten a la creación, modificación o supresión de órganos de representación del personal funcionario, estatutario o laboral, la creación modificación o supresión de secciones sindicales, los miembros de dichos órganos y delegados sindicales. Asimismo, serán objeto de anotación los créditos horarios, sus cesiones y liberaciones sindicales que deriven de la aplicación de normas o pactos que afecten a la obligación o al régimen de asistencia al trabajo. 2.- Las actuaciones derivadas de la ejecución del presente Acuerdo serán objeto de inscripción en el citado Registro en el momento de su creación".
} 
Capítulo V. El contenido de la negociación colectiva de los derechos sindicales del personal estatutario de los Servicios de salud antes y después de las medidas de ajuste presupuestario

La Ley autonómica catalana 2/2014, de 27 de enero, de medidas fiscales, administrativas, financieras y del sector público ${ }^{575}$ ha añadido la disposición adicional vigésima octava al Texto único de la Ley de Función Pública de la Administración de la Generalitat de Cataluña, regulando la creación del Registro de órganos de representación del personal al servicio de la Administración de la Generalitat de Cataluña, de su sector público y de las universidades públicas catalanas y entidades dependientes ${ }^{576}$.

Sobre la obligatoriedad de creación de un Registro para que todos los ciudadanos, Administraciones públicas y organizaciones sindicales conozcan los actos inscribibles relacionados con los aspectos expuestos, creemos que no se puede poner ninguna objeción; es más, parece muy conveniente en cuanto a la protección última del derecho fundamental a la libertad sindical, siempre que el registro tenga efectivamente un carácter público.

$5^{\circ}$ ) El Real Decreto Ley 20/2012 solo admite la eventual negociación sobre garantías y derechos sindicales que se pueda llevar a cabo en las Mesas Generales de negociación. Así se expresa en su artículo 10.1, párrafo tercero: "Todo ello sin perjuicio de los Acuerdos que, exclusivamente en el ámbito de las Mesas Generales de Negociación, puedan establecerse, en lo sucesivo, en materia de modificación en la obligación o en el régimen de asistencia al trabajo de los representantes sindicales a efectos de que puedan desarrollar racionalmente el ejercicio de sus funciones de representación y negociación o adecuado desarrollo de los demás derechos sindicales”.

Vemos como se deja abierta la posibilidad de negociar en lo sucesivo la materia de derechos sindicales, pero solo en el ámbito de las Mesas Generales de negociación., que son las reguladas en el artículo 36.3 LEBEP, es decir, las comunes para el personal funcionario, estatutario y laboral. Esto no es más que una condición que ahora se impone a la negociación, que no contiene la LEBEP, puesto que esta no exige que los derechos

\footnotetext{
${ }^{575}$ Diario Oficial de la Generalitat de Cataluña, de 30 de enero de 2014.

576 “1. Se crea, bajo la dependencia del departamento competente en materia de función pública, el Registro de órganos de representación del personal al servicio de la Administración de la Generalitat de Cataluña, de su sector público y de las universidades públicas catalanas y entidades dependientes. 2. Son objeto de inscripción o anotación en el Registro al que se refiere el apartado 1 los actos adoptados por la Administración de la Generalitat, por su sector público y por las universidades públicas catalanas y entidades dependientes que afecten a las siguientes materias:
}

a) Creación, modificación y supresión de órganos de representación del personal funcionario, estatutario o laboral: juntas de personal, Delegados de Personal, comités de empresa y comités de seguridad y salud. b) Número e identidad de los miembros de los órganos mencionados, así como las variaciones que se produzcan en los mismos. c) Creación, modificación y supresión de secciones sindicales, así como el número y la identidad de los correspondientes delegados. d) Cesiones de créditos horarios legal o convencionalmente establecidos que den derecho a la dispensa total o parcial de asistencia al trabajo. e) Liberaciones institucionales que se deriven, en su caso, de lo dispuesto en las normas, pactos o convenios y cualquier otra modificación en la obligación o en el régimen de asistencia al trabajo.3. La gestión del Registro al que se refiere el apartado 1 debe ajustarse a lo dispuesto en la normativa vigente en materia de protección de datos de carácter personal". La Orden de 11 de junio de 2014 de la Consejería de Economía y Hacienda, regula la organización y el funcionamiento del Registro de Órganos de Representación del Personal al servicio del sector público de la Comunidad Autónoma de la Región de Murcia (Boletín Oficial de la Región de Murcia de 18 de julio de 2014). 
Capítulo V. El contenido de la negociación colectiva de los derechos sindicales del personal estatutario de los Servicios de salud antes y después de las medidas de ajuste presupuestario

sindicales se negocien necesariamente en una Mesa General, y pueden serlo en la Sectorial de Sanidad del Servicio de salud correspondiente, por ejemplo.

Cabe entender que tiene su causa en la preferencia del Gobierno del Estado por encauzar la negociación hacia un foro en el que, en último término, el Acuerdo que se firme deberá ser ratificado por el Gobierno autonómico correspondiente para tener validez.

$\left.6^{\circ}\right)$ En concordancia con estas disposiciones, el Real Decreto Ley 20/2012 modifica también el régimen de permisos de los empleados públicos regulado en el artículo 48 LEBEP, que hasta ese momento era aplicable de forma supletoria para el caso de ausencia de regulación en la Administración pública correspondiente. En su nueva redacción pasa a establecer que: “Los funcionarios públicos tendrán los siguientes permisos...”, con lo que el régimen de permisos y licencias negociado en Pacto o Acuerdo, que mejoraba en muchos casos sus disposiciones, también ha quedado suprimido y ahora pasa a ser norma imperativa en todo caso para, según su Exposición de motivos, homogeneizar la regulación de esta materia. El apartado c) del precepto recoge el permiso "para realizar funciones sindicales $o$ de representación del personal, en los términos que se determine”.

Tal como señala la Exposición de motivos de la norma, todas estas medidas adoptadas por el Gobierno se encaminan a limitar el tiempo retribuido para realizar funciones sindicales y de representación, el nombramiento de delegados sindicales, dispensas de asistencia al trabajo y demás derechos sindicales limitándolos a los estrictamente previstos por la normativa laboral, con el objetivo de favorecer el incremento de los tiempos de trabajo destinados directamente al servicio público.

Las primeras reacciones de las organizaciones sindicales ante este conjunto de reformas del régimen sindical de los empleados públicos que rebajaba su nivel de garantías y derechos sindicales a los mínimos legales, fueron de oposición y rechazo. En una primera etapa se planteó la posibilidad de interposición de recursos en vía judicial y se formularon quejas ante diversas instituciones. De esta forma, la Resolución de la Defensora del Pueblo de 15 de octubre de 2012, sobre el Real Decreto Ley 20/2012, desestimó la solicitud de interposición de recurso de inconstitucionalidad presentada por varios sindicatos por vulneración del derecho a la negociación colectiva de los empleados públicos, remitiéndose a los Fundamentos jurídicos del ATC 85/2011 que no admitió el recurso de inconstitucionalidad contra el Real Decreto Ley 8/2010.

Como ejemplo, el informe del Gabinete jurídico confederal de la Confederación General de Trabajadores sobre impugnación del Real Decreto Ley 20/2012 argumentaba: “... la única vía de impugnación es por vía indirecta. Esto se traduce en impugnar los instrumentos de aplicación del Real Decreto Ley 20/2012 que no tengan rango de ley en la jurisdicción contencioso administrativa, plantear conflictos colectivos en los ámbitos del personal laboral e interponer recursos individuales de los propios trabajadores y trabajadoras ante el Juzgado de lo Social o de lo Contencioso administrativo, según corresponda [...] a su vez se pueden plantear cuestiones de inconstitucionalidad a los órganos judiciales que están conociendo el asunto para que las eleven al TC "577.

${ }^{577}$ Confederación General de Trabajadores [en línea], disponible en: 〈http://www.cgt.org.es〉. 
Capítulo V. El contenido de la negociación colectiva de los derechos sindicales del personal estatutario de los Servicios de salud antes y después de las medidas de ajuste presupuestario

Por último, hay que recordar que, a modo de cierre, en el artículo 16 se dispone también la suspensión de todos los Acuerdos, Pactos y Convenios colectivos cuyo contenido se oponga en cualquiera de sus cláusulas a lo que dispone el Título I del Real Decreto Ley "Medidas de reordenación y racionalización de las Administraciones públicas", en el que, además de todas estas medidas que afectan al derecho a la negociación colectiva de los empleados públicos, se contienen las disposiciones que se refieren a la supresión de la paga extraordinaria de diciembre de 2012 para todo el personal de las Administraciones públicas: "Se suspenden y quedan sin efecto los Acuerdos, Pactos y Convenios para el personal del sector público definido en el artículo 22 de la Ley 2/2012, de 29 de junio, de Presupuestos Generales del Estado, suscritos por las Administraciones públicas y sus organismos y entidades que contengan cláusulas que se opongan a lo dispuesto en el presente título".

Como conclusión, el Real Decreto Ley 20/2012 supuso en el momento en que entró en vigor, una restricción de los derechos sindicales de los empleados públicos al mínimo legal contenido en la LOLS, la LEBEP y el TRET; sin embargo, vemos que dejó abierta la posibilidad de negociación en las Mesas Generales “... en materia de modificación en la obligación o en el régimen de asistencia al trabajo de los representantes sindicales a efectos de que puedan desarrollar racionalmente el ejercicio de sus funciones de representación y negociación o adecuado desarrollo de los demás derechos sindicales".

En desarrollo de esta disposición se tomó el Acuerdo de la Mesa General de Negociación de la Administración General del Estado, de 29 de octubre de 2012, sobre asignación de recursos y racionalización de las estructuras de negociación y participación, cuya vigencia está prevista hasta 31 de diciembre de 2015, y que es aplicable a las organizaciones firmantes o que se hubieran adherido de forma expresa (Disposición 20). En su ámbito está incluido también el personal estatutario del INGESA que, recordemos, gestiona también la sanidad pública en las ciudades autónomas de Ceuta y Melilla.

Este Acuerdo señala que tiene su antecedente en la reunión de la Mesa General de Negociación de las Administraciones Públicas de 21 de septiembre de 2012, que consideró necesario establecer un Acuerdo para dotar de recursos a las organizaciones sindicales para desarrollar racionalmente el ejercicio de sus funciones de representación y negociación, y que permitiera, al mismo tiempo, a la Administración ordenar y estructurar el ejercicio de estas funciones con criterios de austeridad y racionalidad.

En él se regula la estructura y el número de miembros que deben componer las Mesas Generales de Negociación previstas en la LEBEP, de las Mesas Delegadas de la Mesa General, así como de la Comisión Paritaria (CIVEA) y las Subcomisiones Delegadas dependientes de ella, en el ámbito del III Convenio Único para el personal laboral de la Administración General del Estado.

También concreta lo que se debe considerar "centro de trabajo" a efectos de la designación de delegados sindicales según lo dispuesto en el artículo 10 LOLS, y así se regulan como tales cada Departamento ministerial, organismo autónomo, entidad gestora y servicio común de la Administración de la Seguridad Social, y todos los servicios provinciales de Madrid; cada Agencia, organismo o ente público para todos los servicios que tenga en la provincia de Madrid; cada Delegación o subdelegación del Gobierno... (art.6.1). 
Por último se pactan "una serie de recursos y tiempos necesarios para la negociación, representación y participación institucional”, que consisten en el reconocimiento de 178 liberaciones institucionales, que bajo el título de "Recursos y garantías de las organizaciones sindicales" se distribuyen entre los sindicatos presentes en el conjunto de las Mesas generales de negociación, con la consideración de Recursos y medios para la negociación" (apdo. 8) o para la "participación institucional” (apdo. 9), más otras 15 en el ámbito de la CIVEA (anexo 3.1) ${ }^{578}$.

Llama la atención que se firme este Acuerdo el 29 de octubre de 2012, entre la Administración del Estado y las organizaciones sindicales representadas en la Mesa General de Negociación de la Administración General del Estado ${ }^{579}$, cuando pocos días antes, el 16 de octubre, las organizaciones sindicales más representativas habían denunciado la postura de la Defensora del Pueblo de no recurrir la constitucionalidad del Real Decreto Ley 20/2012 por lo que a la posible vulneración del derecho a la negociación colectiva se refiere ${ }^{580}$.

Hay que destacar que el Acuerdo de la Mesa General, en la cláusula 19, recoge el compromiso de las organizaciones sindicales firmantes o adheridas al mismo de desistir de "cuantas

\footnotetext{
${ }^{578}$ La distribución del crédito de horas sindicales que contempla el Acuerdo, así como las liberaciones sindicales institucionales, se realiza en base al porcentaje de representatividad que tienen acreditado las organizaciones sindicales según sus resultados electorales. Así, CCOO y UGT obtienen, con ligera ventaja para el primero, el $60 \%$ de los liberados en el conjunto de las Mesas Generales de negociación: la de las Administraciones públicas, la General de negociación de la Administración General del Estado y la General de negociación en la Administración General del Estado específica de funcionarios (72 de 120, Anexo 2.1). Del total de crédito horario reconocido para el funcionamiento de las Mesas delegadas (18.120 h., según el Anexo 2.2 y el Anexo 2.3) CCOO y UGT obtienen más de la mitad (56\%). En la CIVEA obtienen ambas OOSS 10 de los 15 liberados a tiempo completo que se autorizan en total, ya que en conjunto poseen en ese ámbito casi el $76 \%$ del porcentaje de representatividad (anexo 3.1). En las subcomisiones delegadas de la CIVEA los sindicatos más representativos se atribuyen prácticamente el $66 \%$ del crédito horario total, $3.880 \mathrm{~h}$. de un total de 5.880 h. (anexo 3.2). Por último, se autorizan 58 liberaciones sindicales institucionales a repartir entre las organizaciones sindicales que, en ámbito estatal, hayan obtenido un mínimo del $10 \%$ de representantes del personal. Nuevamente, CCOO y UGT superan de forma conjunta el $60 \%$ de los liberados institucionales (anexo 5).
}

${ }^{579}$ En esta Mesa de negociación tienen representación las siguientes organizaciones sindicales: Federación de Servicios a la Ciudadanía de CC.OO., Federación de Servicios Públicos de UGT, Central Sindical Independiente y de Funcionarios (CSI-F), Federación de Empleados Públicos de USO y Confederación Intersindical Gallega (GIC), sin perjuicio de su firma o adhesión por parte de otras centrales sindicales.

580 “El pasado martes 9 de octubre las Confederaciones Sindicales de Comisiones Obreras y de la Unión General de Trabajadores cursaron a la Defensora del Pueblo una solicitud a fin de que, en ejercicio de las facultades que le confieren la Constitución Española y la Ley Orgánica del Tribunal Constitucional, interpusiera recurso de inconstitucionalidad contra el Real Decreto-ley 20/2012, de 13 de julio, de medidas para garantizar la estabilidad presupuestaria y de fomento de la competitividad. Para UGT y CCOO la contestación remitida en el día hoy por la Defensora del Pueblo elude el examen riguroso de la fundamentación expuesta por ambas organizaciones sindicales y se emplea con perseverancia, tanto en justificar al Gobierno en el uso indebido y abusivo del Decreto-ley, con lo que se hurta su competencia y legitimidad a las Cortes, como en defender una reforma que, yendo mucho más allá que sus precedentes, vacía de contenido derechos básicos de los empleados públicos (vacaciones, protección por enfermedad, retribuciones...), y cercena gravemente la capacidad de defensa colectiva de sus derechos y condiciones de trabajo, al tiempo que atenta contra los derechos constitucionales de negociación colectiva y libertad sindical, avalados igualmente por la legislación internacional" [en línea] [consulta de 30 de noviembre de 2013], disponible en: $<$ http://www.ugt.es/actualidad/2012>. 
Capítulo V. El contenido de la negociación colectiva de los derechos sindicales del personal estatutario de los Servicios de salud antes y después de las medidas de ajuste presupuestario

acciones judiciales hubieran emprendido en relación con la interpretación de los artículos 10 y 12 del Real Decreto Ley 20/2012, comprometiéndose, además, a no plantear ninguna nueva en relación con las materias reguladas en el presente Acuerdo..."

El Acuerdo de 29 de octubre de 2012 justifica la nueva regulación contenida en el Real Decreto Ley 20/2012 en la coyuntura económica, y considera que los sucesivos Pactos en materia sindical, que se habían concertado con anterioridad a esa norma que "en principio podrían considerarse como una mejora en el ejercicio de los derechos sindicales y por ende del funcionamiento de los ámbitos de negociación, han dado lugar, sin embargo, a una situación de gran heterogeneidad, significativa dispersión e incremento sobre las previsiones iniciales, generando desajustes en la gestión ordinaria de estas materias". Es decir, el nuevo Acuerdo parte del principio de que la regulación anterior sobre derechos sindicales contenida en los Pactos y Acuerdos concertados en las distintas Administraciones públicas adolecía de defectos y desajustes que se debían corregir.

\section{6.- LA REGULACION ACTUAL DE LOS DERECHOS SINDICALES DEL PERSONAL ESTATUTARIO DE LOS SERVICIOS DE SALUD. LOS ACUERDOS AUTONÓMICOS DE ADECUACIÓN AL REAL DECRETO LEY 20/2012. SU CONTENIDO.}

A la vista de que lo dispuesto en el Real Decreto Ley 20/2012, respecto a la supresión de lo negociado en los Acuerdos y Pactos de derechos sindicales, debía entrar en vigor el 1 de octubre de 2012, en las Administraciones autonómicas se han ido concertando Acuerdos de adecuación al mismo, basándose en la posibilidad que deja abierta la norma para proceder a la negociación de esta materia en las Mesas Generales.

En efecto, no todas las Administraciones autonómicas los han negociado y, las que sí lo han hecho, los han firmado en poco más de diez meses, comprendidos entre el 28 de septiembre de 2012 (el de la Administración de la Comunidad autónoma de Aragón) hasta el 31 de julio de 2013 (el de la Administración autonómica de Canarias).

La negociación en las diferentes CC.AA. podría haber tomado, al menos teóricamente, un camino distinto a lo dispuesto en el Real Decreto ley 20/2012, que no ha derogado el derecho a la negociación colectiva de los empleados públicos, sino los instrumentos negociados en materia de acción sindical; sin embargo, aquellas están también vinculadas por sus Planes de ajuste presupuestario, con lo que, en general, la negociación posterior se ha adecuado a las líneas de contención dispuestas por la normativa estatal en materia presupuestaria y financiera hasta el punto de que buena parte de los Acuerdos firmados se autodenominan “de adecuación al Real Decreto Ley 20/2012”.

El Acuerdo de 29 de noviembre de 2012, de la Administración del Principado de Asturias en su título justifica su razón de ser: “... adaptación de derechos y garantías sindicales a lo dispuesto en el Real Decreto-Ley 20/2012, de 13 de julio, de Medidas para Garantizar la Estabilidad Presupuestaria y Fomento de la Competitividad, y al Plan Económico-Financiero de Reequilibrio del Principado de Asturias”. 
Capítulo V. El contenido de la negociación colectiva de los derechos sindicales del personal estatutario de los Servicios de salud antes y después de las medidas de ajuste presupuestario

\subsection{1.- LA DISPAR REGULACIÓN DE LOS DERECHOS SINDICALES DE LOS EMPLEADOS PÚBLICOS Y DEL PERSONAL ESTATUTARIO EN PARTICULAR}

Como veremos, se pueden distinguir tres grupos de Administraciones autonómicas según cuál ha sido su actuación ante la posibilidad que abre el Real Decreto Ley 20/2012 de una negociación de los derechos sindicales de sus empleados públicos: un primer grupo, mayoritario, formado por las ocho Administraciones autonómicas en las que se han alcanzado Acuerdos reguladores, más o menos amplios, en el reconocimiento de garantías y derechos de acción sindical para sus empleados públicos; otro segundo grupo, formado por otras cuatro, que han pactado un Acuerdo de adecuación sobre derechos sindicales, pero que a nuestro juicio adolece de deficiencias desde el punto de vista formal o material; y, por último, un tercero, en el que se pueden incluir las restantes cinco Administraciones autonómicas, en las que no se ha llevado a cabo negociación al respecto $\mathrm{y}$, o bien su regulación se basa en Acuerdos de suspensión o modificación propios y previos al Real Decreto Ley 20/2012, en teoría derogados, o bien simplemente tras esta última norma aplican la normativa básica en la materia: la LOLS, LEBEP y TRET.

\section{$\left.1^{\circ}\right)$ Administraciones autonómicas con Acuerdo de adecuación al Real Decreto Ley 20/2012 en materia de derechos sindicales}

\section{1.- Administración de la Comunidad autónoma de Aragón}

Cuando se publica el Real Decreto Ley 20/2012, está vigente en esta Comunidad autónoma el Acuerdo de 3 de julio de 2012 del Gobierno de Aragón, por el que se suspendieron parcialmente los Acuerdos sobre derechos y garantías sindicales de los diferentes ámbitos de su Administración autonómica, entre ellos el Acuerdo de 4 de julio de 2008 de la Mesa sectorial de Sanidad, sobre derechos y garantías sindicales del personal funcionario y estatutario de los centros sanitarios ${ }^{581}$.

Para adecuarse a las disposiciones del Real Decreto Ley 20/2012 se publicó el Acuerdo sobre derechos y garantías sindicales de 28 de septiembre de 2012, de la Mesa General de Negociación de la Administración de la Comunidad Autónoma de Aragón ${ }^{582}$, que es el que está actualmente en vigor hasta que sea sustituido por otro, desde el 1 de octubre de $2012^{583}$.

Este Acuerdo aprueba e incorpora, en su Anexo IV, el Acuerdo de 25 de septiembre de 2012 de la Mesa sectorial de Sanidad, por el que se adapta el sistema de derechos y garantías sindicales del personal funcionario y estatutario de los centros sanitarios del Servicio Aragonés de Salud a lo previsto en el artículo 10 del Real Decreto Ley 20/2012.

\footnotetext{
${ }^{581}$ Boletín Oficial de Aragón de 31 de julio de 2012.

582 Boletín Oficial de Aragón de 27 de noviembre de 2012.

${ }^{583}$ Artículo 2 del Acuerdo.
} 
Capítulo V. El contenido de la negociación colectiva de los derechos sindicales del personal estatutario de los Servicios de salud antes y después de las medidas de ajuste presupuestario

\section{2.- Administración del Principado de Asturias}

El Real Decreto Ley 20/2012 derogó el Acuerdo de 25 de febrero de 2005, entre la Administración del Principado y las Organizaciones sindicales de la Mesa General de Negociación sobre Derechos y Garantías Sindicales; común para todos los empleados públicos de la Administración del Principado de Asturias. Para adecuarse a la nueva normativa, que viene dada, además, por las exigencias del Plan Económico-Financiero de Reequilibrio del Principado de Asturias para 2012-2014, se ha concertado el Acuerdo de la Mesa General de Negociación de la Administración del Principado de Asturias de 23 de octubre de 2012, que fue ratificado por Acuerdo del Consejo de Gobierno de 19 de diciembre de 2012, y está vigente desde el día siguiente a su publicación para los ámbitos del personal funcionario, laboral y estatutario ${ }^{584}$.

Según su cláusula tercera, tendrá vigencia hasta el 1 de enero de 2015, "coincidente con el ámbito temporal del Plan Económico-Financiero de Reequilibrio del Principado de Asturias para el período temporal 2012-2014”, y a su término se entiende prorrogado por años sucesivos hasta la firma de un nuevo Acuerdo.

\section{3.- Administración de la Comunidad autónoma de Canarias}

Cuando se publicó el Real Decreto Ley 20/2012 en la Administración de la Comunidad autónoma de Canarias, el contenido de la negociación colectiva sobre los derechos sindicales de sus funcionarios y personal estatutario había sido ya suprimido por las Leyes autonómicas de presupuestos para 2011 y 2012, que habían derogado, entre otros, el Pacto de 29 de marzo de 2000 de la Mesa sectorial de Sanidad sobre permisos, secciones sindicales y uso del crédito horario para realización de funciones sindicales y de representación del personal de sus instituciones sanitarias, para aplicar el contenido de la LEBEP.

Actualmente está en vigor el Acuerdo sobre el crédito horario y otros derechos sindicales, de la Mesa General de Negociación de Empleados Públicos de la Comunidad Autónoma de Canarias, de 31 de julio de 2013, que entró en vigor el 1 de enero de $2014^{585}$. Como en el caso de la mayoría de Acuerdos se ha pactado su prórroga tácita anual, salvo denuncia de alguna de las partes (cláusula primera, apdo. 4).

\section{4.- Administración de la Junta de Castilla y León}

En esta Administración autonómica recordemos que se había acordado la suspensión de los efectos del Pacto sobre derechos de representación sindical en el ámbito de la Administración de la Comunidad de Castilla y León, de 27 de junio de 2006, de forma consensuada con las organizaciones sindicales a las que les era de aplicación, consistiendo la suspensión en la reducción de las liberaciones sindicales, de forma progresiva a lo largo

\footnotetext{
${ }^{584}$ Publicado en el Boletín Oficial del Principado de Asturias de 20 de diciembre de 2013, la corrección de errores con el texto definitivo se publicó en el del día 21 de diciembre de 2012.

${ }^{585}$ Boletín Oficial de Canarias de 27 de noviembre de 2013.
} 
Capítulo V. El contenido de la negociación colectiva de los derechos sindicales del personal estatutario de los Servicios de salud antes y después de las medidas de ajuste presupuestario

de dos años. El Acuerdo de suspensión recogía la previsión de que el Pacto originario recuperase su vigor una vez superadas las circunstancias que daban lugar a la suspensión (art. tercero).

Tras el Real Decreto Ley 20/2012, se vuelve a negociar otro Pacto, que es el actual sobre derechos de Representación sindical, de 30 de noviembre de 2012, con vigencia desde 1 de diciembre de 2012 hasta 31 de diciembre de $2015^{586}$. A destacar que lo acordado reviste la forma jurídica de Pacto con todas sus consecuencias, ya que el gobierno autonómico no ha ratificado su contenido, y aquél ha sido objeto de publicación directa una vez firmado.

Por lo que respecta a su contenido, hay que comentar que se puede considerar el menos restrictivo en el reconocimiento de derechos y garantías sindicales de sus empleados públicos de entre todos los Acuerdos de adecuación ${ }^{587}$.

\section{5.- Administración de la Comunidad autónoma de Cantabria}

En esta Administración no se habían suspendido los Pactos y Acuerdos reguladores de derechos sindicales de su personal (en Sanidad estaba vigente el Pacto de 3 de octubre de 2003 del Servicio Cántabro de Salud). El Acuerdo de adecuación al contenido del Real Decreto Ley 20/2012 es el Acuerdo de 30 de abril de 2013, de la Mesa General de negociación de la Administración de la Comunidad Autónoma de Cantabria, sobre derechos de representación sindical, en el marco de sostenibilidad de los Servicios Públicos de esta ${ }^{588}$.

En realidad se trata de un Pacto, ya que no ha sido ratificado por su Consejo de Gobierno, sino que ha sido firmado en la Mesa General de negociación y directamente se ha ordenado su publicación. Su vigencia se extiende desde el día siguiente a su firma, es decir, desde el 1 de mayo de 2013 hasta el 31 de diciembre de 2015, y está prevista su prórroga anual tácita (cláusula segunda, apdo 2).

\section{6.- Administración de la Generalitat Valenciana}

Tras las reducciones de las liberaciones sindicales institucionales acordadas por el Gobierno Valenciano en 2011, y la publicación del Real Decreto Ley 20/2012, se tomó el Acuerdo de 27 de septiembre de 2012, de la Mesa General de Negociación I sobre derechos sindicales, representación, negociación y acción sindical ${ }^{589}$, que en el ámbito sanitario fue

${ }^{586}$ Boletín Oficial de Castilla y León de 20 de diciembre de 2012.

${ }^{587}$ Dice en su preámbulo que: “En esta línea, la Junta de Castilla y León considera que el contenido del Pacto suscrito en su día (se refiere al de 2006) se configura, en sus elementos esenciales, como un instrumento plenamente adecuado para el ejercicio de los derechos de representación sindical en el ámbito de la Administración de esta Comunidad Autónoma, optando por el mantenimiento de su núcleo básico”. A continuación expresa que se reconocen el mismo número de liberaciones sindicales que fueron pactadas unos meses antes en el Acuerdo de suspensión del mismo: 508 liberados.

${ }^{588}$ Boletín Oficial de Cantabria de 7 de junio de 2013.

${ }^{589}$ Diario Oficial de la Comunidad Valenciana de 1 de octubre de 2012. 
Capítulo V. El contenido de la negociación colectiva de los derechos sindicales del personal estatutario de los Servicios de salud antes y después de las medidas de ajuste presupuestario

desarrollado por el Pacto del Sector de Sanidad de 24 de diciembre de 2012, sobre acumulación del crédito horario para el ejercicio de la función representativa de los empleados públicos y uso del correspondiente permiso, que no ha sido publicado.

Este Acuerdo trató simplemente de la adecuación de la acción sindical en el ámbito de la Administración General de la Generalitat Valenciana a lo dispuesto en el artículo 10 del Real Decreto Ley 20/2012, así como "determinadas cuestiones técnicas y organizativas relativas a la acción sindical”. La vigencia es de dos años y básicamente ajusta los créditos horarios de los representantes de los empleados públicos y sindicales a la normativa básica. Contiene también la regulación sobre la formación de bolsas de horas en cada sector de la Administración de la Generalitat, habilitando para la negociación de este aspecto a las Mesas sectoriales y determinando, en su apartado octavo, que en el plazo de tres meses se adoptaría en la Mesa General de Negociación otro Acuerdo en "materia de modificación en la obligación o en el régimen de asistencia al trabajo de los representantes sindicales”.

En efecto, justo tres meses después se firma el Acuerdo de 27 de diciembre de 2012, de la Mesa General de Negociación I de Personal Funcionario, Estatutario y Laboral para el desarrollo racional de la negociación y los demás derechos sindicales ${ }^{590}$, que tiene vigencia para el período comprendido entre el 1 de enero de 2013 hasta el 31 de diciembre de 2014, fecha a partir de la cual se prevé su prórroga tácita anual (apdo. quinto).

\section{7.- Administración de la Comunidad autónoma de la Región de Murcia}

Recordemos que la Ley 5/2010 de 27 de diciembre (art. 7) había suspendido los efectos de los Acuerdos y Pactos de derechos sindicales de sus empleados públicos para aplicar la normativa básica en esa materia, suspensión que se mantuvo en virtud de la Ley de Presupuestos de la Comunidad autónoma de la Región de Murcia para 2012.

Tras la publicación del Real Decreto Ley 20/2012, en esta Administración se toma el Acuerdo de la Mesa General de Negociación, de 3 de octubre de 2012, sobre adecuación de derechos sindicales a lo dispuesto en el Real Decreto Ley 20/2012, ratificado el 11 de octubre de 2012 por el Consejo de Gobierno autonómico, y con vigencia de un año desde ese mismo día, prorrogado de forma tácita desde entonces ${ }^{591}$.

Este Acuerdo solo ha reunido la conformidad de dos de las organizaciones sindicales presentes en la Mesa General de Negociación: la Confederación Estatal de Sindicatos Médicos y Federación de Sindicatos de Educación y Salud, pero es aplicable, no obstante, a todas las que tienen representación unitaria o sindical en el ámbito de la Administración Pública de la Región de Murcia (apdo. primero, 2) ${ }^{592}$.

\footnotetext{
${ }^{590}$ Diario Oficial de la Comunidad Valenciana de 20 de febrero de 2013.

${ }^{591}$ Boletín Oficial de la Región de Murcia de 25 de octubre de 2012.

${ }^{592}$ Véase en prensa: Sin acuerdo de reducción de derechos sindicales, "La Federación de sanidad y servicios sociosanitarios de CCOO Región de Murcia (FSS-RM CCOO) no ha firmado el acuerdo de reducción de derechos sindicales presentado por el Gobierno regional, al que acusa de no negociar con los representantes sindicales, sino de imponer [...] En esta ocasión, (Javier) Lanza dice que se plantea una reducción drástica de representantes de los trabajadores, que ya fueron reducidos en el año anterior por la Ley que el Gobierno
} 
Capítulo V. El contenido de la negociación colectiva de los derechos sindicales del personal estatutario de los Servicios de salud antes y después de las medidas de ajuste presupuestario

\section{8.- Administración de la Junta de Extremadura}

La Administración de la Junta de Extremadura era una de las pocas que no había suspendido ni modificado los instrumentos negociados sobre derechos y garantías sindicales de sus empleados públicos antes del Real Decreto Ley 20/2012. Por lo que respecta al personal de su Servicio de salud, hasta la publicación de esta norma, recordemos que se aplicaban los Pactos sobre derechos sindicales de 4 de octubre de 2002 y de 22 de enero de 2003.

Actualmente está en vigor, desde el día siguiente a su publicación, el Acuerdo de 22 de octubre de 2012, de la Mesa General de Negociación de Empleados Públicos de la Administración de la Comunidad Autónoma de Extremadura sobre derechos y garantías sindicales, ratificado por su Consejo de Gobierno el 26 de octubre de $2012^{593}$.

$\left.2^{\circ}\right)$ Administraciones autonómicas con Acuerdo de adecuación al Real Decreto Ley 20/2012 en materia de derechos sindicales, que presenta ciertas peculiaridades

Entre todos los Acuerdos de adecuación sobre derechos sindicales, participación o acción sindical que nos encontramos en vigor en estos momentos, destacan varios casos que presentan particularidades que valoramos como defectos, por carencia de un amplio consenso en la negociación, o por incumplimiento de requisitos formales, como la necesaria publicidad en los boletines oficiales. Es el caso de las siguientes Administraciones autonómicas:

\section{1.-Administración de la Junta de Andalucía}

En su momento estaba vigente, como vimos, el Acuerdo de 7 de julio de 2008, de la Mesa General de Negociación Común del Personal Funcionario, Estatutario y Laboral de la Administración de la Junta de Andalucía, que tenía vigencia hasta el 31 de diciembre de 2011, con prórroga tácita anual. Este acuerdo no había sido objeto de modificación ni suspensión por el gobierno autonómico. Tras la entrada en vigor del Real Decreto Ley 20/2012, se ha publicado el Acuerdo de 29 de octubre de 2012, de la misma Mesa de negociación, ratificado por Acuerdo del Consejo de Gobierno andaluz de 4 de diciembre de 2012, y vigente actualmente, a cuyo contenido no se ha dado publicidad en el Boletín Oficial de la Junta de Andalucía ${ }^{594}$, razón por la cual solo sabemos de su contenido a través de los medios de comunicación ${ }^{595}$.

regional creó al efecto. Pues bien, la Federación de Sanidad de CCOO ha insistido en que no va a firmar ningún acuerdo con un Gobierno que está vulnerando constantemente los derechos de los trabajadores que representamos.... Diario La Opinión de Murcia [en línea], 4 de octubre de 2012, [consulta de 23 de octubre de 2014], disponible en:<laopiniondemurcia.es>.

${ }^{593}$ Diario Oficial de Extremadura de 13 de noviembre de 2012.

${ }^{594}$ El Acuerdo formalmente está publicado en el Boletín Oficial de la Junta de Andalucía de 7 de diciembre de 2012, pero no consta su contenido.

595 “La Junta de Andalucía ahorrará 12,68 millones de euros al año tras el recorte de horas para liberados sindicales acordado este lunes por la Consejería de Hacienda y Administración Pública y los sindicatos CSIF, 
Capítulo V. El contenido de la negociación colectiva de los derechos sindicales del personal estatutario de los Servicios de salud antes y después de las medidas de ajuste presupuestario

\section{2.- Administración de la Junta de Comunidades de Castilla-La Mancha}

En esta Administración está en vigor actualmente el Pacto de Interlocución suscrito entre la Administración de la Junta de Comunidades de Castilla-La Mancha y las Organizaciones Sindicales para el período 2011-2015, de 22 de diciembre de 2011, que tiene vigencia hasta el 31 de diciembre de $2015^{596}$. Hay que destacar que ha sido firmado (tras suspender el Consejo de Gobierno el anterior Pacto de interlocución para 2008-2011, en fecha 13 de octubre de 2011) solo con dos organizaciones sindicales ${ }^{597}$.

Este Acuerdo, a su vez, ha sido modificado parcialmente por el Acuerdo de 25 de marzo de $2013^{598}$, que se adopta para subsanar los defectos de nulidad de determinados apartados impugnados en vía judicial (la STSJ de Castilla-La Mancha 335/2013, de 2 de mayo, anuló parte de su contenido por contener cláusulas que vulneraban el principio de igualdad de trato sindical por parte de la Administración pública ${ }^{599}$ ). No obstante, esta modificación de 2013 solo ha sido firmada por las mismas organizaciones sindicales, aunque con efectos para todos los sindicatos.

UGT y CCOO. Un comunicado de la Consejería de Hacienda y Administración Pública ha explicado que este acuerdo, alcanzado en la Mesa General de Negociación Común del Personal Funcionario, Estatutario y Laboral de la Administración de la Junta de Andalucía, aplica la reducción de horas para liberados sindicales prevista en el Real Decreto Ley aprobado por el Gobierno central y al aumento de la jornada ordinaria de los empleados públicos. Esta reducción de los créditos horarios, conforme a lo establecido en el Estatuto de los Trabajadores, en la Ley Orgánica de Libertad Sindical y en el Estatuto Básico del Empleado Público, supone una minoración de 15,376 horas mensuales. El acuerdo establece una reducción de 67 liberados institucionales, que son los disfrutan de dispensa total de asistencia al trabajo, cifra que podría elevarse hasta 113 una vez que se produzca la adaptación a la nueva jornada laboral de los empleados públicos, según el comunicado. Estos criterios se aplicarán a "todos los ámbitos sectoriales" de la Administración de la Junta de Andalucía: Administración General, personal docente no universitario, justicia y sanidad", Diario El Mundo [on line] 26 de noviembre de 2012, [consulta de 16 de diciembre de 2012], disponible en: <http://www.elmundo.es $>$, edición Andalucía.

${ }^{596}$ Diario Oficial de Castilla-La Mancha de 30 de enero de 2012.

${ }^{597}$ CSI-F y FES.

${ }^{598}$ Diario Oficial de Castilla-La Mancha de 25 de abril de 2013.

599 Fundamento jurídico tercero: "Siendo esto así, puede observarse cómo en el borrador del Acuerdo impugnado se preveía un determinado número de licencias para los sindicatos con presencia en las mesas generales, y otro -muy inferior lógicamente-para los que, sin tener representación en las mesas generales, la tuvieran en alguna sectorial. Sin embargo, en la redacción definitiva, desaparece esta última previsión, se elimina cualquier dispensa para los sindicatos con representatividad sólo sectorial, y se aumenta en número de dispensas para los que tengan presencia en las mesas generales, sindicatos que son justamente, por cierto, los mismos que firman el acuerdo en que tal medida se adopta. Es lógico que quienes tienen presencia en las mesas Generales, y además también la tienen en las sectoriales, tengan un número de dispensas mayor que otros sindicatos. Ahora bien, lo que no es lícito es otorgar esta ayuda a la negociación íntegra y exclusivamente a dichos sindicatos, sin dejar siquiera una mínima a los demás sindicatos que, en su ámbito sectorial de actuación, poseen también una representatividad legalmente reconocida y que es la que precisamente hace que puedan participar en la correspondiente mesa sectorial". 
Capítulo V. El contenido de la negociación colectiva de los derechos sindicales del personal estatutario de los Servicios de salud antes y después de las medidas de ajuste presupuestario

\section{3.- Administración de la Xunta de Galicia}

Hay que recordar que en esta Administración, en el año 2011, el Gobierno autonómico decidió la modificación de los Pactos sobre derechos sindicales que afectaban al personal del Servicio Gallego de Salud, reduciendo las liberaciones institucionales. Desde entonces conocemos que se ha aprobado el Acuerdo de adecuación de 8 de febrero de 2013, del que solo se tiene noticia a través de los medios de comunicación ${ }^{600}$, ya que tampoco ha sido publicado en el Diario Oficial de Galicia.

\section{4.- Administración de la Comunidad autónoma de la Rioja}

En esta se ha firmado el Acuerdo en materia de Acción sindical, de 26 de diciembre de 2012, que tampoco ha sido objeto de publicación en el Boletín Oficial de la Rioja, pero de cuya existencia sabemos a través de la publicación de la Resolución de la Secretaría General Técnica de la Consejería de Presidencia y Justicia, de 3 de noviembre de 2014, por la que se dispone la publicación del resumen del Convenio suscrito entre el Gobierno de la Rioja, a través de la Consejería de Administración Pública y Hacienda y las Organizaciones sindicales para la concesión de subvenciones en materia de Acción sindical para el ejercicio $2014^{601}$. Desconocemos, por tanto, su contenido y qué organizaciones sindicales han sido las firmantes ${ }^{602}$.

$3^{\circ}$ ) Se puede distinguir otro grupo, formado por las Administraciones de las CC.AA. en las que no se ha llevado a cabo ninguna negociación sobre derechos sindicales de los empleados públicos desde la entrada en vigor del Real Decreto Ley 20/2012 y, por tanto, el régimen regulador de los derechos sindicales de su personal viene dado en la práctica en su anterior normativa autonómica de suspensión y modificación de

\footnotetext{
600 “Las negociaciones que Función Pública y los sindicatos iniciaron en vísperas de las autonómicas de octubre, para concretar la aplicación en la Administración gallega del Real decreto que obliga a reducir liberados sindicales, concluyeron ayer (08/02/2013) en acuerdo. La Xunta y los sindicatos han pactado la reducción de casi 200 liberados, que se suman a los 140 ya rebajados en el 2011. En total, Función Pública cifra en 333 los representantes sindicales a tiempo completo que se habrán reincorporado a su trabajo desde el 2009. Según sus cálculos, la Administración gallega contaba entonces con 894 liberados, de los que tras este segundo ajuste quedarán 561 [...] El acuerdo garantiza 149 y la opción de sumar horas para tener 412 más...”. SERAFIN LORENZO, Xunta y sindicatos pactan reducir 200 liberados y blindan hasta 561. Diario La voz de Galicia [en línea], 9/02/2013, [consulta de 8 de octubre de 2014], disponible en: <http://www.lavozdegalicia.es>.

${ }^{601}$ Boletín Oficial de la Rioja de 10 de noviembre de 2014.

${ }^{602}$ Sí se tiene constancia de que no cuenta con el consenso de UGT a través de la prensa: FSP-UGT renuncia a la subvención del Gobierno de La Rioja en materia de Acción Sindical, "La Federación de Servicios Públicos del sindicato no recibirá los 20.245 euros que le correspondería. Esta decisión fue comunicada ayer a la Dirección General de Función Pública del Gobierno de La Rioja. En esta época en la que, con la disculpa de la crisis, se ha penalizado a los empleados públicos en sus condiciones laborales, no se entendería que por un lado nos negásemos a firmar determinados acuerdos, que suponen un esfuerzo para el conjunto de los empleados públicos (como el de ayudas sociales) y por otro lado estuviéramos firmando otros para recoger esta subvención del Gobierno”. Rioja2.com [en línea], 23 de octubre de 2014, [consulta de 23 de noviembre de 2014], disponible en: 〈http://www.rioja2.com. $>$.
} 
Capítulo V. El contenido de la negociación colectiva de los derechos sindicales del personal estatutario de los Servicios de salud antes y después de las medidas de ajuste presupuestario

Acuerdos, o bien en la normativa mínima legal (LOLS, la LEBEP o el TRET). Es el caso de las Administraciones públicas de las CC.AA. de Cataluña, las Islas Baleares, Madrid, Navarra, y País Vasco.

\section{1.- Administración de la Generalitat de Cataluña}

Esta Administración no ha firmado aún ningún Acuerdo de adecuación a lo previsto en el Real Decreto Ley 20/2012, porque como vimos arriba, previamente a éste, su Ley autonómica 5/2012, de 30 de marzo, ya había suspendido la aplicación del Pacto de 22 de diciembre de 2004, sobre derechos sindicales de la Administración de la Generalitat de Cataluña.

Efectivamente, en la Disposición adicional séptima dispuso la suspensión parcial de los Pactos y Acuerdos sindicales y la inaplicación de las cláusulas de los Convenios colectivos relativos a las liberaciones institucionales y las dispensas por tiempo completo; así como el número de horas de crédito horario sindical de los delegados sindicales y representantes del personal funcionario, estatutario y laboral. En desarrollo de esta norma se pactó en la Mesa General de negociación el Acuerdo de 2 de mayo de 2012, cuya vigencia estaba prevista hasta el 30 de junio de 2014, fecha a partir de la cual las partes se comprometieron a tener firmado otro Acuerdo que lo sustituyera ${ }^{603}$.

El contenido de este Acuerdo dispone el aumento de las horas mensuales para acceder a una liberación total por acumulación de horas, así como la reducción en un 30\% de las liberaciones institucionales y el mismo porcentaje respecto de los créditos horarios de las secciones sindicales.

\section{2.- Administración de la Comunidad autónoma de las Islas Baleares}

$\mathrm{Su}$ normativa negociada sobre derechos sindicales, que venía dada fundamentalmente en el Acuerdo de 2 de marzo de 2006, ya había sido suspendida desde un año antes de la publicación del Real Decreto Ley 20/2012, por Acuerdo de su Consejo de Gobierno, de 23 de septiembre de 2011, que ya vimos cuando tratamos la suspensión y modificación de los Acuerdos y Pactos sobre derechos sindicales por los gobiernos autonómicos.

Este Acuerdo de suspensión tan solo reguló las bolsas de crédito horario, que se establecen por sectores: Administración general, personal docente y personal sanitario, como resultado de acumular las horas que estrictamente y en función de la normativa básica corresponden a cada representante, con el fin de que cada organización sindical pueda distribuir las horas de crédito sindical libremente según su criterio. Asimismo, dispuso la necesidad de 140 horas mensuales para poder acumular un crédito horario sindical a tiempo completo, lo cual no representa ventaja alguna con respecto a la jornada reglamentaria para un trabajador liberado.

\footnotetext{
${ }^{603}$ Firmaron, por la parte sindical, CC.OO., UGT e IAC. Este último son las siglas de Intersindical Autónoma de Cataluña, coalición formada por cuatro organizaciones sindicales, con el fin de reunir suficiente representatividad para formar parte de la Mesa de negociación: CATAC -Técnicos y Administrativos de la Generalitat catalana-; CAU (ámbito de la Administración de Justicia); CATAC-CTS (ámbito sanitario) y USTEC (ámbito de educación).
} 
Capítulo V. El contenido de la negociación colectiva de los derechos sindicales del personal estatutario de los Servicios de salud antes y después de las medidas de ajuste presupuestario

Por otro lado, hay que recordar que el Decreto ley 10/2012 supuso la reducción de las unidades electorales en el ámbito del Servicio Balear de Salud, con la consiguiente disminución de Juntas de personal y de representantes.

El Real Decreto Ley 20/2012 no hace más que derogar definitivamente su Acuerdo regulador $^{604}$, con lo que el contenido actual de la regulación sobre derechos y garantías sindicales en la Administración de las Islas Baleares es el legal que se contiene en la LOLS para las organizaciones sindicales, la LEBEP para su personal funcionario y estatutario, y el TRET para su personal laboral.

A la disminución del crédito horario sindical que se produjo con la derogación de su Acuerdo de 2006, se tiene que sumar el incremento que ha experimentado la jornada anual reglamentaria del personal, en concreto, del estatutario del Servicio Balear de la Salud, que actualmente ha quedado en 1.657 horas y 30 minutos anuales, lo que provoca un consumo mayor del crédito horario sindical que la ley reconoce a los representantes sindicales para acceder a una dispensa o liberación sindical a tiempo completo ${ }^{605}$.

\section{3.- Administración de la Comunidad autónoma de Madrid}

Se está aplicando el Acuerdo de 16 de febrero de 2011, de la Mesa General de Negociación de los empleados públicos de la Administración de la Comunidad de Madrid para la estabilización de las relaciones laborales, en la medida en que no le hayan afectado las disposiciones del Real Decreto Ley 20/2012 ${ }^{606}$.

Este Acuerdo básicamente dispuso la delimitación de las unidades electorales, y en cuanto al número de representantes del personal en cada unidad electoral y el crédito de horas mensuales retribuido para actividad sindical, se limita a transcribir los artículos 39 y 41.1 LEBEP, así como el 68 TRET, con lo que no mejora en absoluto los términos de estas normas, como tampoco el número de delegados a designar por las secciones sindicales, que se ajusta estrictamente a lo dispuesto en el artículo 10 LOLS.

Las novedades del Acuerdo consisten, por un lado, en el reconocimiento de las liberaciones sindicales institucionales a favor de cada las organizaciones sindicales de cada ámbito de negociación integrado en la Mesa General de Negociación (de 3 liberados a 15, en función de la escala de empleados representados; y, además, 55 liberados para cada una de las organizaciones sindicales presentes en la Mesa General de Negociación de empleados

\footnotetext{
${ }^{604}$ Con lo que las organizaciones sindicales han visto suprimidas también las subvenciones previstas en el Acuerdo de 2006, ahora derogado.

${ }^{605}$ El Acuerdo del Consejo de Gobierno de 28 de marzo de 2014, ratifica el Acuerdo de la Mesa Sectorial de Sanidad, de 17 de marzo de 2014, por el que se establece una nueva jornada ponderada anual para los años 2013 y 2014 en el Servicio de Salud de las Islas Baleares (Boletín Oficial de las Islas Baleares de 29 de marzo de 2014).

${ }^{606}$ Boletín Oficial de la Comunidad de Madrid, de 22 de febrero de 2011.
} 
Capítulo V. El contenido de la negociación colectiva de los derechos sindicales del personal estatutario de los Servicios de salud antes y después de las medidas de ajuste presupuestario

públicos de la Administración de la Comunidad de Madrid) ${ }^{607}$; y, por otro, en la facultad de constituir secciones sindicales en el ámbito del Servicio Madrileño de Salud, en aquellos centros en los que por su nivel de plantilla y dispersión geográfica fuera necesario.

Este último apartado del Acuerdo fue desarrollado por otro, de fecha 28 de julio de 2011, en la Mesa sectorial de Sanidad de Madrid, que exigía en estos casos que los sindicatos tuvieran representación en todas las Juntas de personal del Servicio Madrileño de Salud. Impugnado el Acuerdo por determinados sindicatos que carecían de esa representación y, por tanto, no podían constituir secciones sindicales en determinados hospitales, se desestimó esta por STSJ de Madrid de 7 de marzo de 2013.

\section{4.- Administración de la Comunidad Foral de Navarra}

En Navarra vimos que la Ley Foral 13/2012, de 21 de junio, dispuso, entre otras medidas de carácter urgente, la suspensión parcial de la aplicación del Acuerdo sobre derechos sindicales de los empleados públicos de 18 de octubre de 1994, que consistía en la reducción del $10 \%$ del crédito horario sindical de las organizaciones sindicales para el ejercicio de sus funciones (art.7).

Los efectos de esta medida, dispuestos para el ejercicio 2012, se han prolongado para el año 2013 en virtud del Acuerdo del Gobierno de Navarra de 5 de diciembre de 2012, que dispone el mantenimiento de la misma reducción de los créditos horarios, respetando en todo caso lo dispuesto en la LOLS y el Texto Refundido del Estatuto del personal al servicio de las Administraciones públicas de Navarra ${ }^{608}$. Este Acuerdo del Gobierno autonómico reconoce que esta reducción conlleva la suspensión parcial de la aplicación del Acuerdo sobre derechos sindicales de 18 de octubre de 1994.

Esta disposición hace referencia a que su contenido "ha sido sometido a la negociación colectiva con los representantes sindicales en la Mesa General de Negociación del personal funcionario y estatutario al servicio de las Administraciones públicas de Navarra", pero no consta la fecha de ese Acuerdo, ni sabemos qué partes lo han concertado porque no ha sido, a su vez, publicado en el Boletín Oficial de Navarra. Para el año 2014 no ha sido publicada ninguna disposición al respecto.

Sí cabe destacar que la Administración Foral de Navarra da publicidad a los datos de los empleados públicos con liberación sindical y el crédito horario consumido, en base a la Ley Foral 11/2012, de 21 de junio, de la Transparencia y del Gobierno Abierto ${ }^{609}$.

\footnotetext{
${ }^{607}$ Las organizaciones sindicales firmantes del Acuerdo son CC.OO., UGT y CSIT (Coalición Sindical Independiente de Trabajadores, que aúna a doce sindicatos de empleados públicos al servicio de la Administración pública en la Comunidad autónoma de Madrid).

${ }^{608}$ Boletín Oficial de Navarra de 21 de diciembre de 2012.

${ }^{609}$ Boletín Oficial de Navarra de 28 de junio de 2012. En su página web esta Administración ofrece información relativa al número de empleados públicos con liberación sindical, así como el crédito horario consumido para actividad sindical. Se identifican los miembros de los órganos de representación del personal y el número de liberados sindicales existentes en los distintos departamentos y organismos públicos, identificando la organización sindical a la que pertenecen, así como los costes que estas liberaciones generan
} 
Capítulo V. El contenido de la negociación colectiva de los derechos sindicales del personal estatutario de los Servicios de salud antes y después de las medidas de ajuste presupuestario

\section{5.- Administración de la Comunidad autónoma del País Vasco}

Tampoco se ha concertado, hasta la fecha, ningún Acuerdo sobre derechos sindicales para adaptarse a las disposiciones del Real Decreto Ley 20/2012, por lo que cabe entender que derogadas las disposiciones de su Acuerdo Marco sobre derechos sindicales y ejercicio de la actividad sindical en la Administración de la Comunidad autónoma de Euskadi, de 15 de octubre de 1988, se aplica lo dispuesto en la LOLS, la LEBEP y el TRET.

\subsection{2.- ASPECTOS COMUNES DE LA NUEVA REGULACIÓN SOBRE DERECHOS SINDICALES EN LOS ACUERDOS DE ADECUACIÓN AL REAL DECRETO LEY $20 / 2012$}

El objetivo general de los Acuerdos que se han pactado, como se suele indicar en los mismos, es:"la adecuación de la acción sindical a lo dispuesto en el artículo 10 del Real Decreto Ley 20/2012"610 , y “están en la línea de los objetivos fijados por el Real Decreto Ley 20/2012 y no sobrepasan, en su conjunto, los límites que la normativa básica en esta materia establece" "611, ya que "no tienen repercusión económica por no suponer incremento de gasto" ${ }^{12}$.

En el Acuerdo de 30 de abril de 2013, de la Administración de la Comunidad autónoma de Cantabria, se argumentan las medidas que obligan a la adopción de restricciones en esta materia: "La obligación de cumplir los objetivos de déficit público impuestos por el Gobierno de la Nación exige la máxima racionalización de los recursos públicos y la adopción de medidas tendentes a la reducción y control del gasto público, medidas que se enmarcan en los planes económico-financieros y de reequilibrio de las Comunidades Autónomas, entre los cuales se encuentra el correspondiente a la Comunidad Autónoma de Cantabria, aprobados en el Consejo de Política Fiscal y Financiera. Éstas han impulsado la puesta en marcha de un proceso de racionalización y reorganización, entre otras materias, en lo que afecta a los derechos sindicales, propiciando reformas legislativas que deben enmarcarse en el contexto actual de control del gasto público, directo o indirecto, y de reducción del déficit público...

Eso al menos formalmente, porque a pesar de lo que exponen (que se pactan los aspectos procedimentales necesarios para el desarrollo de la acción sindical, sin que ello suponga el aumento de las horas dedicadas a la actividad sindical por encima del régimen legal previsto en la LEBEP, en el TRET o en la LOLS) su contenido no siempre se ajusta de

para los Departamentos y Organismos Públicos correspondientes. Asimismo se da información sobre el número de horas sindicales utilizadas. Disponible en: 〈http://www.gobiernoabierto.navarra.es〉.

${ }^{610}$ Artículo primero del Acuerdo de adecuación, de 22 de octubre de 2012, de la Comunidad autónoma de Extremadura.

${ }^{611}$ Pacto de la Administración de la Junta de Castilla y León, de 30 de noviembre de 2012.

${ }^{612}$ Exposición de antecedentes del Acuerdo de la Administración de la Comunidad autónoma de la Región de Murcia, de 3 de octubre de 2012, y del Acuerdo de la Administración de la Comunidad autónoma de Canarias, de 31 de julio de 2013 . 
Capítulo V. El contenido de la negociación colectiva de los derechos sindicales del personal estatutario de los Servicios de salud antes y después de las medidas de ajuste presupuestario

forma estricta a esa normativa legal sobre derechos y garantías sindicales, como veremos, e incorporan casi todos la institución de la liberación sindical institucional.

En cuanto al objeto de la negociación, los Acuerdos que hasta la fecha se han pactado tratan, según sus propios términos, sobre "los derechos sindicales" derechos y garantías sindicales" ${ }^{14}$; "el crédito horario y otros derechos sindicales"615; "los derechos de representación sindical",616, o todo ello: "derechos sindicales, representación, negociación y acción sindical"617; así como "interlocución”,618.

Su finalidad no es más que ordenar la modificación en la obligación o en el régimen de asistencia al trabajo de los representantes sindicales a efectos de poder desarrollar racionalmente el ejercicio de sus funciones de representación y negociación o el adecuado desarrollo de los demás derechos sindicales ${ }^{619}$.

En cuanto a las organizaciones sindicales que han participado en su negociación y firma, hay que decir que en casi todos los casos encontramos a las organizaciones sindicales más representativas: CC.OO. y UGT, y a CSI-F. También tiene participación en la negociación y firma CEMSATSE, como organización sindical más representativa del ámbito sanitario, siendo la presencia de otros sindicatos más residual. A pesar de ello, hay que destacar el hecho de que los Acuerdos que se han tomado en las Mesas Generales de negociación de Murcia y Castilla-La Mancha no han sido aceptados por las organizaciones sindicales más representativas, y sí por la Federación de Sindicatos de Educación y Sanidad (FSES), cuya presencia en las Mesas de negociación autonómicas se está haciendo cada vez más patente y que no estaba presente en la firma de los Acuerdos y Pactos de derechos sindicales con anterioridad (Tabla II).

Interesa también observar como los actuales Acuerdos de adecuación autonómicos afectan en particular al personal estatutario de sus Servicios de salud. Debemos tener en cuenta que los Acuerdos se han alcanzado en las Mesas Generales de Negociación, ya que según lo dispuesto en el Real Decreto Ley 20/2012 únicamente pueden llevarse a efecto en

${ }^{613}$ Acuerdo de la Administración de la Comunidad autónoma de la Región de Murcia, de 3 octubre de 2012.

614 Acuerdo de la Administración de la Comunidad autónoma de Aragón, de 29 de septiembre de 2012; Acuerdo de la Administración del Principado de Asturias, de 23 de octubre de 2012 y Acuerdo de la Junta de Extremadura de 22 de octubre de 2012.

${ }^{615}$ Acuerdo de la Administración de la Comunidad autónoma de Canarias, de 31 de julio de 2013.

${ }^{616}$ Pacto de la Junta de Castilla y León de 23 de noviembre de 2012, y Acuerdo de la Administración de Cantabria de 30 de abril de 2013.

${ }^{617}$ Acuerdo de la Generalitat Valenciana de 27 de septiembre de 2012.

${ }^{618}$ Pactos de la Junta de Comunidades de Castilla-La Mancha de 22 de diciembre de 2011 y de 25 de marzo de 2013.

${ }^{619}$ Acuerdo de 27 de septiembre de 2012 de la Administración de la Generalitat Valenciana, apartados primero y octavo. 
ese foro, y afectan, por lo general, conjuntamente al personal funcionario, estatutario y laboral dependiente de la Administración de la respectiva Comunidad autónoma ${ }^{620}$.

Por esta razón, cada instrumento negociado dispone una regulación general para todos los empleados públicos que están bajo su ámbito subjetivo, y solo de manera accesoria tratan -y no todos- reglas específicas para el personal de sus Servicios de salud.

- En una postura más estricta, el Acuerdo de la Administración de la Región de Murcia, de 3 de octubre de 2012, señala la competencia exclusiva de su Mesa General Común para la negociación de los derechos sindicales y de todos aquellos que afecten a la negociación colectiva, representación y participación institucional, con lo que excluye una eventual participación posterior de cualquiera de sus Mesas sectoriales (apartado segundo).

- En el mismo sentido se expresa el Acuerdo de la Administración de la Comunidad autónoma de Canarias, de 31 de julio de 2013 (estipulación segunda).

En los casos en que los Acuerdos de adecuación incluyen cláusulas específicas para el personal de su Servicio de salud, se ha procedido de diferentes formas:

- El Acuerdo de 30 de abril de 2013, de la Administración de la Comunidad de Cantabria, en el "Adenda A", incorpora las disposiciones específicas para el personal al servicio de las instituciones sanitarias.

- También nos encontramos con el caso del Acuerdo de la Administración de Aragón, en la que se han llevado a efecto Acuerdos en sus Mesas sectoriales de negociación, que una vez aprobados por la Mesa General de Negociación, se han incorporado al Acuerdo final de adecuación sobre derechos sindicales de 28 de septiembre de 2012, que a su vez ratifica su Consejo de Gobierno ${ }^{621}$.

- En el Acuerdo de 29 de noviembre de 2012, de la Administración del Principado de Asturias, su Anexo III incorpora las cláusulas particulares sobre derechos y garantías sindicales del personal del Servicio de Salud del Principado de Asturias.

- De forma similar, el Acuerdo de 27 de septiembre de 2012 de la Mesa General de negociación I en la Administración de la Generalitat Valenciana, ha sido desarrollado para el personal de sus instituciones sanitarias a través de un Pacto posterior, el de 24 de diciembre de 2012, concertado en su Mesa sectorial de Sanidad que regula la gestión de la bolsa de crédito horario sindical.

En cuanto a la vinculación de lo negociado en estos Acuerdos, hay que decir que algunos tienen efectos solo para las organizaciones sindicales firmantes o que se adhieran con posterioridad a lo negociado, lo que sería la regla general en cualquier Acuerdo sobre esta materia:

\footnotetext{
${ }^{620}$ El de la Administración de la Comunidad autónoma de Aragón, como excepción, solo se dirige al personal funcionario y estatutario, no al laboral.

${ }^{621}$ Se incorporan al Acuerdo de 28 de septiembre de 2012 como Anexo, el Acuerdo de 10 de septiembre de 2012, de la Mesa Sectorial de Administración General; el de 18 de septiembre de 2012 de la Mesa Sectorial de Educación; el de 21 de septiembre de 2012 de la Mesas Sectorial de Justicia, y el de 25 de septiembre de 2012 de la Mesa Sectorial de Sanidad, por el que se adapta el sistema de derechos y garantías sindicales del personal funcionario y estatutario de los centros sanitarios del Servicio Aragonés de Salud.
} 
Capítulo V. El contenido de la negociación colectiva de los derechos sindicales del personal estatutario de los Servicios de salud antes y después de las medidas de ajuste presupuestario

- Acuerdo de 28 de septiembre de 2012, de la Administración de la Comunidad autónoma de Aragón (Disposición adicional segunda).

- Acuerdo de 29 de noviembre de 2012, de la Administración del Principado de Asturias (cláusula segunda);

- Acuerdo de 31 de julio de 2013, de la Administración de la Comunidad autónoma de Canarias (cláusula primera, apdo. 2).

- Acuerdo de 30 de abril de 2013, de la Administración autonómica de Cantabria (cláusula primera).

- Acuerdo de 27 de diciembre de 2012, de la Administración de la Generalitat Valenciana (apdo. segundo).

Y otros, sin embargo, vinculan a todas las organizaciones sindicales en su ámbito objetivo de aplicación y tienen efectos generales para todas ellas, aunque no hayan aceptado el Acuerdo.

- Es el caso del Pacto de Interlocución 2011-2012 de la Administración de la Junta de Comunidades de Castilla- La Mancha, de 22 de diciembre de 2011 (Disposición adicional segunda);

- El Acuerdo de 3 de octubre de 2012, de la Administración de la Región de Murcia (apdo. primero, punto 2) y

- Acuerdo de 22 de octubre de 2012, de la Administración de la Junta de Extremadura (apdo. segundo).

- En la misma línea ha ido el Pacto de sobre derechos de representación sindical, de 30 de noviembre de 2012 de la Administración de Castilla y León, pero con la particularidad de que recoge tres niveles de representatividad sindical, que distingue a las organizaciones sindicales a la hora de disfrutar los derechos y garantías del Pacto (cláusula segunda) ${ }^{622}$ :

- Sindicatos con "mayor nivel de implantación": los que hayan obtenido, al menos, el 15\% de los Delegados de Personal, miembros de Comités de Empresa y Juntas de personal en el conjunto de los centros y servicios incluidos en el ámbito de aplicación del Pacto.

- Sindicatos con "especial audiencia": los que no tienen la consideración de mayor nivel de implantación, pero han obtenido, al menos, el 10\% de los Delegados de Personal, miembros de Comités de Empresa y Juntas de Personal en alguno de los sectores de la Administración de la Comunidad de Castilla y León.

- Resto de organizaciones sindicales, las que han obtenido representación en los órganos de representación unitarios, pero en porcentaje inferior a los anteriores.

\footnotetext{
${ }^{622}$ Esta regulación ya existía en el anterior Pacto sobre derechos de representación sindical de 27 de junio de 2006 (art. 2). Hay que hacer notar que los sindicatos con mayor nivel de implantación y con especial audiencia son precisamente los que han firmado el Pacto por estar legitimados para formar parte de la Mesa General de negociación autonómica. La misma clasificación también se daba con idéntica denominación y condiciones en el derogado Acuerdo de 16 de septiembre de 2003, del Instituto Madrileño de Salud, y en el Pacto Único de Interlocución de 25 de febrero de 2005 de la Administración de la Junta de Comunidades de Castilla-la Mancha, el primero que estuvo vigente tras las transferencias en materia sanitaria a esta Comunidad autónoma y al que sustituyó el Pacto de Interlocución 2008-2011 (Diario Oficial de Castilla-La Mancha de 16 de marzo de 2005).
} 
En general, en todos los Acuerdos se facilita la adhesión al mismo de los sindicatos no firmantes, ya que solo se les requiere para llevarla a efecto haber obtenido alguna representación en los órganos unitarios de personal, y el cumplimiento de un simple trámite en el que basta la mera comunicación al órgano administrativo competente ${ }^{623}$.

- Por el contrario, el Acuerdo de 27 de diciembre de 2012, de la Administración de la Generalitat Valenciana solo permite la adhesión por parte de las organizaciones sindicales con presencia en la Mesa General de Negociación I, la común de todos los empleados públicos, por lo que excluye de esa posibilidad a los sindicatos que no tengan legitimación suficiente para formar parte de ella (apdo. segundo).

En cuanto a los aspectos concretos de la acción sindical que regulan estos Acuerdos, hay que decir que, de manera general, tratan el derecho a constituir secciones sindicales en los centros de trabajo o unidades electorales de su ámbito; los requisitos y condiciones de designación de sus delegados sindicales; el crédito horario para finalidad sindical que se reconoce a estos, así como el crédito horario de los representantes del personal; las liberaciones sindicales que se reconocen de forma adicional al crédito horario que corresponde a los representantes sindicales y del personal; la gestión de la bolsa de horas sindicales y las correspondientes dispensas sindicales; así como las garantías retributivas y profesionales de estos, al igual que los medios materiales que se ponen a disposición de las organizaciones sindicales, y la regulación de la composición y funciones de las Comisiones de seguimiento que interpreten y solucionen los conflictos derivados de su interpretación.

Por último, es destacable que se incluya en estos Acuerdos la cláusula por la que se prevé la adecuación de la representatividad a los futuros resultados electorales que obtengan los sindicatos en las elecciones sindicales, o a las variaciones de plantilla, no por no ser perfectamente ajustada a la legalidad, sino porque no era habitual en los Acuerdos y Pactos de derechos sindicales que se concertaron con anterioridad a las medidas de ajuste de los Gobiernos autonómicos y del Real Decreto Ley 20/2012. En estos, no era común encontrar cláusulas por las que las partes se comprometieran a adaptar el número de delegados sindicales a los aumentos y disminuciones de plantilla ${ }^{624}$.

\footnotetext{
${ }^{623}$ El Acuerdo de 25 de septiembre de 2012, de la Mesa Sectorial de Sanidad, del Servicio Aragonés de Salud es aplicable a las organizaciones sindicales firmantes y adheridas, pero permite la adhesión de cualquier sindicato con representación en el Servicio Aragonés de Salud: "Las Organizaciones Sindicales con representación en el SALUD, que no estén presentes en Mesa Sectorial, deberán solicitar por escrito su adhesión al presente Acuerdo para acceder a las condiciones del mismo en lo que les sea de aplicación”, (Disposición adicional segunda). El Acuerdo de 29 de noviembre de 2012, de la Administración del Principado de Asturias parece admitir la posibilidad de adhesión a cualquier organización sindical, ya que no exige ningún requisito en particular (cláusula segunda, apdo. tercero).
}

El Acuerdo de la Administración autonómica de Canarias, de 31 de julio de 2013, se expresa de forma similar: solo requiere a los sindicatos que pretendan adherirse al Acuerdo alguna representación en los órganos unitarios del personal y es suficiente la comunicación a la Dirección General de la Función pública (cláusula primera, apdo. 2).

${ }^{624}$ Sí las incluyeron el Acuerdo de 25 de febrero de 2005, de la Administración del Principado de Asturias en su Disposición adicional primera, aunque solo para supuestos de "disminuciones sustanciales del número de empleados públicos en cualquiera de los colectivos incluidos en el Acuerdo" y el Pacto de 3 de octubre de 2003, de la Administración de la Comunidad autónoma de Cantabria en su apartado III (Secciones sindicales), 
Capítulo V. El contenido de la negociación colectiva de los derechos sindicales del personal estatutario de los Servicios de salud antes y después de las medidas de ajuste presupuestario

Precisamente esa ausencia de pacto sobre esa adecuación podía interpretarse como una mejora sobre el régimen legal. Ahora, sin embargo, es una estipulación común en casi todos los Acuerdos de derechos sindicales, que contemplan una eventual adecuación del número de representantes del personal, de los créditos horarios y del número de delegados sindicales o de la posibilidad de su designación, a los cambios que pueden darse en la plantilla del colectivo de empleados públicos representados o las transferencias de personal $^{625}$.

Los resultados de las elecciones sindicales afectan al número de representantes que obtienen las organizaciones sindicales y, en consecuencia, a sus créditos horarios, cuestión que se ha previsto en la mayoría de Acuerdos de adecuación ${ }^{626}$.

punto 5: "Si en los centros de trabajo relacionados en el Anexo I se produjera una disminución del número de trabajadores por debajo de los 250, desaparecería automáticamente el derecho a nombrar delegados sindicales con derecho a crédito horario en estos centros. En sentido contrario se actuaría en cado de que el número de trabajadores se situara por encima de los 250 en centros no recogidos actualmente en el citado Anexo I".

625 "Si durante la vigencia del presente Pacto se produjeran procesos de transferencias que implicasen incremento sustancial en el número de empleados al servicio de la Comunidad Autónoma, las partes podrán revisar y adecuar el número de Delegados Sindicales y el número de las exenciones de asistencia al trabajo de carácter institucional previstas”. Pacto de 30 de noviembre de 2012, de la Administración de Castilla y León, cláusula transitoria primera.

"Si en los centros de trabajo relacionados en el punto 2 se produjera una disminución del número de trabajadores por debajo de los doscientos cincuenta, desaparecerá automáticamente el derecho a nombrar delegados sindicales con derecho a crédito horario en estos centros. En sentido contrario se actuaría en caso de que el número de trabajadores se situara por encima de los doscientos cincuenta en centros no recogidos actualmente en el anterior punto 2". Acuerdo de 30 de abril de 2013, de la Administración de la Comunidad autónoma de Cantabria sobre derechos de representación sindical, cláusula tercera, apartado 3.

626 “Dado que la vigencia del Pacto no se hace coincidir exactamente con la duración del mandato de los representantes sindicales a que afecta, si como resultado de nuevos procesos electorales se constatase una variación en la representatividad sindical tenida en cuenta a la firma del mismo, la aplicación del Pacto se adaptará a la nueva representatividad que resulte de dichos nuevos procesos electorales". Pacto de 30 de noviembre de 2012 de la Administración de Castilla y León, cláusula undécima.

"En el supuesto de prórroga y tras la celebración de elecciones sindicales se procederá a realizar los ajustes necesarios conforme a los nuevos resultados y de conformidad con lo establecido en el presente acuerdo", apartado quinto, punto 2, del Acuerdo de 27 de diciembre de 2012 de la Administración de la Generalitat Valenciana.

"Los créditos horarios totales que dispondrán los representantes del personal en todos los ámbitos de negociación, se adecuarán automáticamente cada vez que se produzca una variación como consecuencia de la celebración de procesos electorales. A estos efectos, las Direcciones Generales competentes en materia de personal de los sectores de educación, administración y servicios y sanidad notificarán a las organizaciones sindicales el crédito horario que les corresponde, disponiendo las organizaciones sindicales de un plazo de 10 días a para proceder a su adecuación a partir de dicha notificación”. Acuerdo de la Administración de la Región de Murcia, de 3 de octubre de 2012, apartado cuarto. 
Capítulo V. El contenido de la negociación colectiva de los derechos sindicales del personal estatutario de los Servicios de salud antes y después de las medidas de ajuste presupuestario

\subsection{3.- CONTENIDO DE LOS DERECHOS SINDICALES DE LOS EMPLEADOS PÚBLICOS EN LOS ACUERDOS DE ADECUACION}

A pesar de las diferencias que se advierten en el contenido de los diferentes Acuerdos de adecuación al Real Decreto Ley 20/2012, se pueden extraer una serie de aspectos comunes que tratan de manera general, aunque no con la misma profundidad, todos ellos, y que se veremos a continuación.

\subsubsection{1.- El derecho a la constitución de secciones sindicales y la delimitación del centro de trabajo o unidad electoral}

Respecto al derecho de las organizaciones sindicales a constituir secciones sindicales en las unidades electorales, los Acuerdos de adecuación, en general, se remiten a lo dispuesto en el artículo 8 LOLS, reiterando lo que se dispone en él y ha declarado la jurisprudencia en cuanto a la libertad de constitución de secciones sindicales ${ }^{627}$, insistiendo en la necesidad de que los trabajadores que la integren estén afiliados a la organización sindical $^{628}$, y estableciendo, la exigencia de determinados requisitos de representatividad y plantilla representada para acceder a los derechos del artículo 10 LOLS.

Por lo que se refiere a la delimitación del centro de trabajo en el que se constituyen las secciones sindicales, en el ámbito sanitario, en concreto, se dispone generalmente que lo sea el área de salud, tal como se venía pactando con anterioridad ${ }^{629}$. Esta unidad electoral

\footnotetext{
${ }^{627}$ Sirvan como ejemplos el Acuerdo de la Mesa General de Negociación de Cantabria, de 30 de abril de 2013, estipulación tercera, apartado 1, que dispone: "Los trabajadores afiliados a un Sindicato podrán constituir secciones sindicales de conformidad con lo previsto en sus estatutos. La sección sindical es una manifestación de la libertad organizativa del Sindicato que viene amparada por el ejercicio de la acción sindical. Pueden, por tanto, los afiliados constituirla en cualquier centro de trabajo, independientemente del volumen de la plantilla y de la presencia o no del Sindicato en el órgano de representación unitaria”.
}

"Las organizaciones sindicales podrán constituir secciones sindicales de conformidad con lo dispuesto en la Ley Orgánica 11/1985, de 2 de agosto de Libertad sindical” Acuerdo de la Mesa General de Negociación de la Administración autonómica de la Región de Murcia, de 3 de octubre de 2012, sobre adecuación de Derechos Sindicales a lo dispuesto en el Real Decreto-Ley 20/2012, apartado tercero, punto 2.

${ }^{628}$ Acuerdo de 29 de noviembre de 2012, de la Administración del Principado de Asturias (cláusula cuarta).

629 "En lo que se refiere al Servicio Cántabro de Salud y para el personal al servicio de las Instituciones Sanitarias, la totalidad de los centros y establecimientos que correspondan a cada una de las Áreas de Salud; en concreto, una sección por cada Gerencia asistencial de Atención Primaria o Especializada dependiente del Servicio Cántabro de Salud, excluido el personal que presta servicios en la Dirección Gerencia Central" (Acuerdo de la Mesa General de Negociación de Cantabria, de 30 de abril de 2013, estipulación tercera, apartado 2, c).

“A los efectos de definir en este Pacto el ámbito de las secciones sindicales y determinar el número de delegados sindicales, conformarán un único centro de trabajo: 1.- En lo que se refiere al personal al servicio de Instituciones Sanitarias (SACYL) la totalidad de centros y establecimientos de atención primaria correspondientes a una misma área de salud. La totalidad de centros y establecimientos de atención especializada correspondientes a una misma área de salud". (Pacto sobre derechos de representación sindical en el ámbito de la Administración de la de la Comunidad de Castilla y León, de 30 de noviembre de 2012 (cláusula cuarta, apartado 4.1). 
Capítulo V. El contenido de la negociación colectiva de los derechos sindicales del personal estatutario de los Servicios de salud antes y después de las medidas de ajuste presupuestario

es el ámbito de la Junta de Personal, órgano unitario de representación del personal con relación jurídica de naturaleza administrativa ${ }^{630}$. En los casos, frecuentes, en que la unidad electoral no se concreta en el Acuerdo, se entiende que este tema deberá ser tratado a propósito de los correspondientes procesos electorales sindicales ${ }^{631}$.

Generalmente se pacta expresamente que las secciones sindicales serán conjuntas, incluyendo al personal funcionario, estatutario y laboral ${ }^{632}$, lo cual tiene el efecto, favorable

En el Servicio Aragonés de Salud la unidad electoral es el centro hospitalario con órganos directivos propios, y para Atención Primaria, el Sector sanitario (Capítulo III del Acuerdo de 28 de septiembre de 2012 de la Mesa Sectorial de Sanidad): "A efectos de constitución de las Secciones Sindicales que gocen de los derechos y garantías previstos en el artículo 10.3 de la LOLS., atendiendo al ámbito de elección de los Órganos de Representación, constituirán centros de trabajo para Atención Especializada el Centro Hospitalario con órganos directivos propios y para Atención Primaria el Sector Sanitario, asimismo constituirá Centro de trabajo la Gerencia de Urgencias y Emergencias Sanitarias de Aragón. La composición y funcionamiento de tales secciones se ajustará a lo establecido en el artículo 10 de la LOLS".

En el ámbito del Servicio Canario de Salud es asimismo el área de salud, cláusula cuarta, apdo. 1 del Acuerdo de la Administración autonómica de Canarias, de 31 de julio de 2013.

En el mismo sentido, el Acuerdo de 29 de noviembre de 2012, de la Administración del Principado de Asturias: "Personal al servicio de los centros e instituciones sanitarias dependientes del Servicio de Salud del Principado de Asturias. A efectos de la constitución de secciones sindicales en el Servicio de Salud del Principado de Asturias, se considerará centro de trabajo el área sanitaria”, cláusula 5.3.

${ }^{630}$ La cláusula séptima, apartado 1 A b), del Acuerdo de 30 de abril de 2013, de la Administración autonómica de Cantabria, dispone que: "Se constituirá una Junta de Personal en cada una de las siguientes Unidades Electorales: Una en cada Área de Salud para el personal funcionario y estatutario, sanitario o no, al servicio de las Instituciones Sanitarias Públicas dependientes del Servicio Cántabro de Salud excluido el personal que presta servicios en la Dirección Gerencia Central”.

631 “1". Las Organizaciones Sindicales podrán constituir Secciones Sindicales de conformidad con lo establecido en la Ley Orgánica 11/1985, de 2 de agosto, de Libertad Sindical. A los efectos de la aplicabilidad del artículo 10 de la precitada ley se entenderá que el centro de trabajo se corresponde con la totalidad de establecimientos de la unidad electoral del ámbito del órgano de representación legal correspondiente sobre la que se vaya a constituir la Sección Sindical”. Pacto de Interlocución 2011-2015 de la Junta de Castilla-La Mancha, Capítulo V (Derechos y garantías sindicales), Sección Primera (De las secciones sindicales).

632 “En los centros de trabajo [...] que ocupen a más de doscientos cincuenta empleados públicos, se constituirán secciones sindicales conjuntas que integrarán al personal funcionario, estatutario y laboral de los citados centros que puedan constituirse con los empleados públicos afiliados a los sindicatos con presencia en los Comités de Empresa y/o en las Juntas de Personal y estarán representadas por delegados sindicales elegidos por y entre sus afiliados en el centro de trabajo". Acuerdo de la Mesa General de Negociación de Cantabria, de 30 de abril de 2013, estipulación tercera, apartado 3, a).

"Las Secciones Sindicales incluirán en su ámbito personal de actuación a todos los afiliados al sindicato con independencia de que su relación con la Administración Autonómica sea de carácter administrativo, estatutario o laboral" (Pacto sobre derechos de representación sindical en el ámbito de la Administración de la de la Comunidad de Castilla y León, de 30 de noviembre de 2012, cláusula cuarta, apartado 4.1.4).

"A los efectos de la constitución de las secciones sindicales que gocen de los derechos y garantías previstos en el artículo 10 de la Ley Orgánica 11/1985, de 2 de agosto, de Libertad Sindical, el ámbito de actuación y representación de las secciones sindicales, que serán conjuntas para todo el personal, ya sea funcionario, estatutario o laboral...", (Apartado cuarto del Acuerdo de la Mesa General de Negociación de empleados 
Capítulo V. El contenido de la negociación colectiva de los derechos sindicales del personal estatutario de los Servicios de salud antes y después de las medidas de ajuste presupuestario

a la acción sindical, de que todos los empleados públicos computan para determinar los correspondientes derechos de representación ${ }^{633}$.

Sí se suelen regular los requisitos para la válida constitución de las secciones sindicales, estableciendo la obligación de comunicar ese hecho al órgano administrativo responsable de Recursos Humanos, así como sus variaciones. En el ámbito del personal estatutario esta comunicación se hace tanto a los órganos directivos de la unidad electoral en la que se constituye la sección sindical como a los del Servicio de salud con competencias en materia de personal $^{634}$.

públicos de la Administración de la Comunidad autónoma de Extremadura sobre derechos y garantías sindicales, de 22 de octubre de 2012).

633 "Las secciones sindicales serán conjuntas por cada organización sindical y centro de trabajo. Para determinar el número de trabajadores de cada centro de trabajo -de los definidos en el apartado primero de la presente cláusula-a efectos de aplicar la escala prevista en el artículo 10.2 de la LOLS o, en su caso, norma que la sustituya- en la fecha de entrada en vigor del presente Acuerdo y, en su caso, en la fecha de inicio de cada una de sus prórrogas se computará en cada uno de ellos al conjunto de empleados públicos (personal funcionario, estatutario y laboral)". Acuerdo sobre el crédito horario y otros derechos sindicales, de 31 de julio de 2013, en la Mesa General de Negociación de Empleados Públicos de la Comunidad Autónoma de Canarias. Estipulación cuarta, apartado 2.

El Acuerdo de 29 de noviembre de 2012, de la Administración del Principado de Asturias no obliga, sino que permite que las secciones sindicales sean conjuntas (cláusula cuarta).

634 “Los actos de constitución y de modificación, así como los de designación de los delegados sindicales, producirán efectos en los términos fijados en este Acuerdo mediante la correspondiente comunicación al órgano de gestión de personal competente al efecto. Deberá acreditarse con la presentación y entrega de certificación del acta correspondiente, a los efectos de que la sección sindical sea reconocida como tal, y sus representantes puedan disfrutar, si procede, de los derechos y garantías que las leyes les reconocen". Acuerdo de la Mesa General de Negociación de Cantabria, de 30 de abril de 2013, estipulación tercera, apartado 4.

“Los afiliados al Sindicato deberán comunicar a la correspondiente Gerencia de Sector el acto de constitución de la Sección, y ello con el fin de que la misma sea reconocida como tal, y sus representantes puedan disfrutar, si procede, de los derechos y garantías que las leyes les reconocen. Por la Gerencia de Sector se dará traslado de esta información a la Dirección de Recursos Humanos, para su conocimiento y efectos". Acuerdo de 25 de septiembre de 2012 de la Mesa sectorial de Sanidad del Servicio Aragonés de Salud (art. 4).

"La organización sindical deberá comunicar a la Dirección General de la Función Pública, el acto de constitución de sus secciones, en el plazo de diez días hábiles desde que se produzca la misma, para su conocimiento y que sus representantes puedan disfrutar, si procede, de los derechos y garantías que las leyes les reconocen. En el caso de que la comunicación del acto de constitución se haga una vez transcurrido este plazo, el disfrute de los derechos y garantías en el ámbito de este Acuerdo, en caso de proceder, sólo será exigible desde la fecha de comunicación. En el ámbito del Servicio de Salud del Principado de Asturias, se comunicará la constitución a la correspondiente gerencia del área sanitaria, así como a la Dirección de Recursos Humanos, para toma de conocimiento y demás efectos establecidos en el párrafo anterior”. Acuerdo de 29 de noviembre de 2012, de la Administración del Principado de Asturias (cláusula cuarta, apdo.3). 
Capítulo V. El contenido de la negociación colectiva de los derechos sindicales del personal estatutario de los Servicios de salud antes y después de las medidas de ajuste presupuestario

\section{sindical \\ 5.6.3.2.- Designación de delegados sindicales, su número y crédito horario}

En cuanto a los requisitos que deben cumplir las secciones sindicales para poder designar delegados sindicales, hay que decir que los Acuerdos de adecuación se suelen remitir a la LOLS.

Por ese motivo se sigue la norma general de que las secciones sindicales solo podrán designar delegados sindicales en los centros de trabajo con más de 250 trabajadores y si han obtenido representación en los órganos unitarios de personal, o bien se trata de las organizaciones sindicales más representativas ${ }^{635}$.

En cuanto al número de delegados sindicales que se pueden designar, normalmente su número de adecua a la LOLS ${ }^{636}$. Hasta tal punto es así que en los Acuerdos de adecuación se contempla la posibilidad de que desaparezca el derecho a delegado sindical si en cualquier momento disminuye la plantilla por debajo del límite legal, cláusula que no era habitual encontrar en el texto de los anteriores Pactos y Acuerdos sobre derechos sindicales ${ }^{637}$.

\footnotetext{
635 "Para designar delegados sindicales, será necesario que el centro de trabajo ocupe a más de doscientos cincuenta funcionarios, estatutarios o personal laboral en su caso, y que la organización sindical a la que corresponda la sección tenga presencia en el correspondiente órgano de representación". Acuerdo de 29 de noviembre de 2012, de la Administración del Principado de Asturias (cláusula quinta).
}

636 “Corresponderá a dichas secciones sindicales designar a un delegado, salvo que el porcentaje de voto obtenido sobre la totalidad del colectivo sea igual o mayor al $10 \%$ de los votos válidos, en cuyo caso se atenderá a la escala establecida en el artículo 10.2 de la Ley Orgánica de Libertad Sindical”. Acuerdo de la Mesa General de Negociación de Cantabria de 30 de abril de 2013, estipulación tercera, apartado 3, a.

El Acuerdo de derechos y garantías sindicales de la Mesa Sectorial de Sanidad del Servicio Aragonés de Salud, de 25 de septiembre de 2012, incorporado al Acuerdo de la Mesa General de Negociación de 28 de septiembre como Anexo IV, dispone en su artículo 5 que: "Las Organizaciones Sindicales con presencia en los órganos de representación del personal funcionario y estatutario de los Centros Sanitarios del Servicio Aragonés de Salud, en función del porcentaje de votos obtenidos, podrán designar el número de delegados sindicales que se determina en el artículo 10.2 de la Ley Orgánica 11/85 de Libertad Sindical, y que se encuentra detallado en el anexo I".

“Las secciones sindicales constituidas en centros de trabajo con más de 250 funcionarios y estatutarios por una parte o trabajadores por otra, de aquellas organizaciones sindicales que hayan obtenido el diez por ciento o más de los votos en las elecciones al Comité de empresa o a la Junta de Personal de cada área y que tengan presencia en los citados órganos, podrán designar el número de delegados/as sindicales, que corresponda conforme a la escala prevista en el artículo 10.2 párrafo $2 .^{\circ}$ de la Ley Orgánica 11/1985, de 2 de agosto, de Libertad Sindical. Las secciones sindicales, constituidas en centros de trabajo con más de 250 empleados públicos, de aquellas organizaciones sindicales que no alcancen el diez por ciento de los votos podrán disponer de un delegado/a por cada uno de los órganos de representación unitaria que corresponda siempre que tengan presencia en los citados órganos". Acuerdo de 29 de noviembre de 2012, de la Administración del Principado de Asturias, cláusula 5.3, tercer y cuarto párrafo).

637 “Si en los centros de trabajo [...] se produjera una disminución del número de trabajadores por debajo de los doscientos cincuenta, desaparecerá automáticamente el derecho a nombrar delegados sindicales con derecho a crédito horario en estos centros". (Acuerdo de la Mesa General de Negociación de Cantabria, de 30 de abril de 2013, estipulación tercera, apartado 3, b). 
Capítulo V. El contenido de la negociación colectiva de los derechos sindicales del personal estatutario de los Servicios de salud antes y después de las medidas de ajuste presupuestario

Excepcional es la cláusula cuarta, apartado 4.2.1, del Pacto sobre derechos de representación sindical, de 30 de noviembre de 2012, de la Administración de Castilla y León, que establece una escala de delegados sindicales para los sindicatos con mayor nivel de implantación, que les reconoce un mínimo de dos delegados sindicales por centro de trabajo de hasta 250 empleados públicos; cuatro de 251 a 500; cinco de 501 a 750 ; seis de 751 a 1.000 ; siete de 1.001 a 1.250 ; y de 1251 en adelante, 1 más por cada 500 o fracción superior a 250. Asimismo, a los sindicatos con especial audiencia les reconoce otra escala que va desde 1 delegado sindical cuando hayan hasta 250 trabajadores; 3 si hay de 251 a 1.000 trabajadores; 4 desde 1.001 a 5.000 y 5 si hay más de 5.000 trabajadores representados en la unidad electoral. Con lo que nos encontramos con una mejora de lo dispuesto en la ley.

En todo caso continúa diciendo esta cláusula en su apartado C) que: "las secciones sindicales de aquellos sindicatos con presencia en los órganos de representación unitaria del personal al servicio de la Administración de la Comunidad de Castilla y León con implantación inferior a la requerida en los apartados anteriores estarán representados por un único delegado sindical. Se entiende incluido en este apartado lo dispuesto en el artículo 10.2 de la LOLS, que en todo caso actuará como mínimo de derecho necesario".

Este contenido actual que se ha pactado es el mismo que reconocía el Pacto sobre derechos de representación sindical de 27 de junio de 2006, en su artículo 4, apartado 4.2.1, que fue derogado por el Real Decreto Ley 20/2012.

En cuanto al crédito horario de los delegados sindicales, en general, hay una remisión estricta a lo dispuesto en la LOLS (art. 10.3), y por tanto, ningún beneficio adicional sobre ese mínimo legal ${ }^{638}$, a excepción de los siguientes, que sí han pactado mejoras al respecto:

- El Pacto sobre derechos de Representación sindical, de 30 de noviembre de 2012, de la Administración de Castilla y León, regula el crédito horario de los delegados sindicales reconociéndoles 45 horas al mes en todo caso (cláusula cuarta, 4.2.3). A este crédito suman el que pudiera corresponderles como representantes unitarios (cláusula cuarta 4.2.4) y tienen, además, hasta 80 horas al año para la celebración de asambleas dentro de la jornada de trabajo (cláusula cuarta, 4.3).

- El Acuerdo de la Mesa General de Negociación de la Comunidad autónoma de Extremadura, sobre derechos y garantías sindicales, de 22 de octubre de 2012, regula como

\footnotetext{
638 "El número de horas que corresponda a los delegados de la sección sindical, constituidas según lo establecido en este Acuerdo, será el que resulte de aplicar lo establecido en el artículo 10 de la Ley Orgánica de Libertad Sindical”. (Acuerdo de la Mesa General de Negociación de Cantabria, de 30 de abril de 2013, estipulación tercera, apartado 4, segundo párrafo).
}

\footnotetext{
“Las Organizaciones Sindicales con presencia en los Órganos de Representación del personal funcionario y estatutario de los Centros Sanitarios del Servicio Aragonés de Salud, en función del porcentaje de votos obtenidos, podrán designar el número de delegados sindicales que se determina en el art. ${ }^{o} 10.2$ de la Ley Orgánica 11/85 de Libertad Sindical, y que se encuentra detallado en el anexo I', (art. 5 del Acuerdo de 25 de septiembre de 2012 de la Mesa sectorial de Sanidad del Servicio Aragonés de Salud).
} 
Capítulo V. El contenido de la negociación colectiva de los derechos sindicales del personal estatutario de los Servicios de salud antes y después de las medidas de ajuste presupuestario

norma general que los créditos sindicales se ajustan a la LOLS ${ }^{639}$. Sin embargo, para el ámbito del Servicio Extremeño de Salud establece un régimen transitorio, por el cual se conservan vigentes "los Pactos en materia de derechos sindicales en lo que se refiere a la regulación de las secciones sindicales y los créditos asociados a las mismas".

- En este sentido, el artículo 3.6 de los Pactos entre el Servicio Extremeño de Salud y las organizaciones sindicales de 4 de octubre de 2002, y de 22 de enero de 2003, establecían que: "El número de horas de crédito horario de los Delegados Sindicales será de 40 horas mensuales. El Delegado Sindical deberá prestar servicios en el Área de Salud en el que se ha constituido la Sección Sindical”. Además de ello, el artículo 4 de los mismos Pactos reconocía 1.080 horas al mes para los delegados sindicales de cada organización sindical de la Mesa sectorial de Sanidad firmante de los Pactos.

- El Acuerdo de 28 de septiembre de 2012 de la Mesa sectorial de Sanidad del Servicio Aragonés de Salud establece, en su Anexo I, el número de delegados sindicales para las distintas secciones sindicales de las unidades electorales y el crédito horario mensual que se les reconoce. No tenemos y datos para poder comprobar que esa disposición represente una mejora de lo que según el régimen legal corresponde, sobre todo teniendo en cuenta que el propio Acuerdo establece en su artículo 5 que: "Las Organizaciones Sindicales con presencia en los órganos de representación del personal funcionario y estatutario de los centros sanitarios del Servicio Aragonés de Salud, en función del porcentaje de votos obtenidos, podrán designar el número de delegados sindicales que se determina en el artículo 10.2 de la Ley Orgánica 11/85 de Libertad Sindical, y que se encuentra detallado en el anexo I".

- El Acuerdo de 29 de noviembre de 2012, de la Administración del Principado de Asturias regula en su cláusula sexta el crédito horario de los delegados de sección sindical, estableciéndolo en 40 horas al mes, el máximo legal directamente, para todos ellos.

\subsubsection{3.- El crédito horario de los representantes del personal}

El crédito horario de los representantes del personal era habitualmente objeto de mejora también en los Pactos y Acuerdos anteriores. Ahora, en general, los Acuerdos de adecuación hacen una remisión directa a lo dispuesto en la normativa reguladora sobre el crédito horario de los representantes de los empleados públicos: artículo 41.1 d) LEBEP y el artículo 68 e) TRET, con lo que las horas destinadas a actividad sindical de los representantes unitarios se ajustan ahora estrictamente a la ley, en la línea de lo que dispone el Real Decreto Ley 20/2012

\footnotetext{
639 “Los créditos horarios de los representantes del personal empleado público se ajustarán a lo dispuesto en los artículos 39 y 41 de la Ley 7/2007, de 12 de abril, del Estatuto Básico del Empleado Público; en los artículos 66 y 68 del Real Decreto Legislativo 1/1995, de 24 de marzo, por el que se aprueba el texto refundido de la Ley del Estatuto de los Trabajadores y en el artículo 10 de la Ley Orgánica 11/1985, de 2 de Agosto, de Libertad Sindical”, apartado cuarto.

640 “Los créditos horarios de los representantes del personal empleado público se ajustarán a lo dispuesto al respecto en la Ley 7/2007, de 12 de abril, del Estatuto Básico del Empleado Público, en el Real Decreto Legislativo 1/1995, de 24 de marzo, por el que se aprueba el Texto Refundido de la Ley del Estatuto de los Trabajadores y en la Ley Orgánica 11/1985, de 2 de agosto, de Libertad Sindical”, artículo quinto del Acuerdo de la Mesa General de Negociación I de personal funcionario, estatutario y laboral de la Administración de la Generalitat Valenciana, de 27 de septiembre de 2012 sobre derechos sindicales, representación, negociación y acción sindical (Créditos horarios).
} 
Capítulo V. El contenido de la negociación colectiva de los derechos sindicales del personal estatutario de los Servicios de salud antes y después de las medidas de ajuste presupuestario

- El Pacto de la Administración de Castilla y León, de 30 de noviembre de 2012, incrementa el tiempo retribuido para actividad sindical de los miembros de las Juntas de personal, Comités de empresa y Comité Intercentros, reconociendo a todos ellos 45 horas mensuales, retribuidas como de trabajo efectivo (cláusula tercera, 3.1), sobrepasando el máximo de 40 horas que contempla la LEBEP.

- El mismo Pacto reconoce 60 horas anuales a favor de los miembros de las Juntas de personal y Comités de empresa para celebrar reuniones en horas de trabajo, al margen del resto de su crédito horario (cláusula tercera, 3.3).

- El Acuerdo de 29 de noviembre de 2012, de la Administración del Principado de Asturias, en su cláusula séptima contempla el "crédito horario de los órganos de representación unitaria", disponiendo que los órganos de representación unitaria en del personal funcionario y estatutario al servicio de los centros e instituciones sanitarias del Servicio de Salud del Principado de Asturias, dispondrán de 40 de crédito horario mensuales. Ese es el crédito que dispone la LEBEP para una escala de personal representado de 751 funcionarios en adelante, por lo que en la medida en que las unidades electorales de su Servicio de salud no alcancen esa plantilla mínima, esa estipulación sí representará una mejora del régimen legal.

Vemos que independientemente de lo que argumenten los Acuerdos, su contenido sí refleja en ocasiones algunas mejoras adicionales sobre lo dispuesto en la normativa mínima de referencia, que para este aspecto es la LEBEP y el TRET.

\subsubsection{4.- El reconocimiento de las liberaciones institucionales}

Solo de forma excepcional los Acuerdos de adecuación hacen referencia expresa con esa denominación a las liberaciones sindicales institucionales, a pesar de este término se utilizaba abiertamente en los Acuerdos y Pactos sobre derechos sindicales antes de las medidas de suspensión y modificación de los gobiernos autonómicos y de las del Real Decreto Ley 20/2012 $2^{641}$. Ahora estas liberaciones sindicales se reconocen, o bien con la denominación y la forma de permisos de jornada completa, en cómputo anual, a favor de los empleados públicos que de esta manera quedan dispensados del trabajo ${ }^{642}$; o bien, como

\footnotetext{
"Los miembros de Juntas de Personal, como representantes legales del personal funcionario y estatutario, dispondrán del crédito de horas mensuales que les corresponde de conformidad a la escala establecida en el artículo 41.1.d) del Estatuto Básico del Empleado Público. 2. Los miembros de Comités de Empresa como representantes legales del personal laboral dispondrán del crédito de horas mensuales que les corresponde de conformidad a la escala establecida en el artículo 68.e) del Estatuto de los Trabajadores”. Acuerdo de la Administración de la Comunidad autónoma de Cantabria, de 30 de abril de 2013, estipulación cuarta.

${ }^{641}$ Ese es el caso del Pacto sobre derechos de representación sindical en el ámbito de la Administración de la Comunidad de Castilla y León, de 30 de noviembre de 2012. Las liberaciones institucionales se regulan en la cláusula octava: "Con el carácter de liberados a tiempo total, los sindicatos con mayor nivel de implantación o que cuenten con especial audiencia, de acuerdo con lo establecido en este Pacto, podrán disponer, sin cargo a la bolsa sindical, hasta 150 liberaciones institucionales, de las que un máximo de 50 corresponderán a personal docente [...] Dichas 150 liberaciones serán distribuidas según el porcentaje de representatividad de cada organización a nivel global de la Administración Autonómica”.
}

642 “Los permisos supondrán la dispensa total de obligación de asistencia al puesto de trabajo, con liberación de la integridad del cumplimiento de la jornada [...] tendrán la duración mínima de un año, excepto causa 
horas adicionales de crédito horario, que se suman al legal cedido por los representantes sindicales y unitarios para formar la bolsa de horas sindicales ${ }^{643}$; o incluso de las dos formas, como en el Pacto de 30 de noviembre de 2012, de la Administración de la Junta de Castilla y León ${ }^{644}$.

Normalmente el reconocimiento de estos permisos sindicales se basa en la necesidad de las organizaciones sindicales de atender sus responsabilidades en las Mesas de

justificada debidamente acreditada, y finalizarán con la vigencia del Acuerdo. Con cada prórroga del Acuerdo será precisa una nueva solicitud de permiso, pudiendo recaer en el mismo empleado público....”. Acuerdo de la Administración de la Comunidad autónoma de Cantabria, de 30 de abril de 2013, estipulación sexta (Recursos para la negociación), apartado 2.2.b) y c).

El Acuerdo de 27 de diciembre de 2012, de la Administración de la Generalitat Valenciana reconoce 55 liberaciones institucionales, a las que se refiere como "dispensas totales de asistencia al trabajo", que se asignarán entre las organizaciones sindicales presentes en la MGN I, de forma proporcional al número de representantes unitarios obtenidos en las elecciones sindicales, que se distribuirá por cada organización sindical prioritariamente de forma proporcional a los resultados obtenido en cada sector de la Administración (apdo. sexto, puntos 2 y 3 ).

El Acuerdo de la Administración de la Junta de Extremadura, de --, dispone en el apartado Sexto, que trata las Funciones de representación y negociación: “... Se establecerá la modificación en la obligación o en el régimen de asistencia al trabajo de los representantes sindicales, a razón de tres representantes sindicales en cada uno de los distintos ámbitos de negociación (personal docente no universitario, personal funcionario, personal laboral, personal estatutario) para cada una de las organizaciones sindicales presentes en las correspondientes mesas de negociación [...] a la Comisión Paritaria del Convenio Colectivo [...] le corresponden tres representantes por cada una de las centrales sindicales firmantes del Convenio Colectivo vigente. Además, la Mesa General de Funcionarios contará con un representante sindical por sindicato y ámbito para cada una de las organizaciones presentes en la misma [...] Las centrales sindicales podrán distribuir las horas correspondientes a dichos representantes de la forma expuesta en el apartado quinto (bolsa de horas)”.

${ }^{643}$ En el Acuerdo de adecuación de la Administración autonómica de Canarias se regula la "bolsa adicional de crédito horario", en la cláusula quinta, apartado 2, que reconoce a cada una de las organizaciones sindicales legitimadas para estar presentes en la Mesa General de negociación, firmantes o adheridas al Acuerdo, la cantidad de 2.500 horas mensuales de crédito horario adicional al que les corresponda según la normativa legal de aplicación. Asimismo, a cada una de las que tengan presencia en las Mesas sectoriales de la Administración de la Comunidad autónoma de Canarias, firmantes o adheridas al mismo, se les reconoce un crédito horario adicional de 600 horas al mes.

En la modificación del Pacto de Interlocución de la Administración de Castilla-La Mancha para 2011-2015, firmado el 25 de marzo de 2013 en la Mesa General Negociación de los empleados públicos, se autoriza para cada organización sindical 1 hora al mes por cada 39 empleados públicos representados en cada Mesa de negociación (la General de todos los empleados públicos; la General de personal Funcionario; la Sectorial de Funcionario de Administración General; la Sectorial de Funcionario docente no universitario; la Sectorial de Sanidad y la Comisión negociadora del Convenio colectivo del personal laboral), apartado $3^{\circ}$ del Capítulo III, "Negociación Colectiva). Además, 1 hora al año por cada 120 empleados públicos representados en cada una de esas Mesas (apartado $4^{\circ}$ de la Sección Tercera del Capítulo V, Derechos y garantías sindicales).

${ }^{644}$ En la cláusula octava regula las liberaciones institucionales y en la sexta, apartado 1, segundo párrafo, las horas adicionales de crédito horario sindical a favor de los sindicatos con mayor nivel de implantación y con especial audiencia: la cantidad de multiplicar por 240 el número de representantes obtenidos por cada uno de ellos en las elecciones sindicales. 
negociación en las que están presentes, y su número concreto se distribuye entre ellas en función de su representatividad en esos foros ${ }^{645}$.

En cuanto al número de liberaciones institucionales que reconocen los Acuerdos de adecuación, van desde los 150 liberados institucionales para los sindicatos con mayor nivel de implantación o especial audiencia, del Pacto de la Administración de Castilla y León ${ }^{646}$; el máximo de 6 para cada organización sindical en la Administración autonómica de Cantabria $^{647}$; o como mucho de 18 para cada sindicato de los legitimados para formar parte de las Mesas de negociación en la Junta de Extremadura ${ }^{648}$, o los 55 que reconoce el Acuerdo de la Administración de la Generalitat Valenciana a distribuir entre todas las organizaciones de la Mesa General de Negociación ${ }^{649}$. Número total que no se puede valorar en términos absolutos, porque habría que considerar el número total de empleados públicos representados en cada Administración autonómica.

El único Acuerdo que trata de forma específica las liberaciones sindicales institucionales del personal de su Servicio de salud es el de la Administración de la Junta de Extremadura, que mejora para este personal el régimen general que contiene en su apartado sexto para el resto de sus empleados públicos.

Establece que al personal del Servicio Extremeño de Salud "no le será de aplicación lo dispuesto en el apartado sexto del presente Acuerdo, aplicándose el régimen que en materia de representación por mesas de negociación aparece en los citados Pactos (los de 2002 y 2003) con una reducción de las horas cedidas para la acción sindical de un 10\%” (apdo. séptimo).

645 “Las Organizaciones Sindicales representadas en cada una de las Mesas Generales de Negociación previstas en los artículos 34 y 36.3 del Estatuto Básico del Empleado Público dispondrán, para el ejercicio de las funciones de negociación, de la posibilidad de dispensar totalmente de asistencia al trabajo a un empleado público por cada una de las mesas anteriormente referenciadas en las que se encuentren representadas. En los mismos términos, las organizaciones sindicales que hayan obtenido representación en la totalidad de los órganos de representación unitaria en el ámbito de aplicación de este Acuerdo tendrán la posibilidad de dispensar totalmente de asistencia al trabajo a otro empleado público". (Acuerdo de la Comunidad autónoma de Cantabria, de 30 de abril de 2013, estipulación sexta).

${ }^{646}$ Cláusula octava del Acuerdo de 30 de noviembre de 2012.

${ }^{647}$ En la cláusula sexta del Acuerdo de Cantabria se regulan los “Recursos para la negociación”. Bajo este título se reconocen las liberaciones institucionales a favor de las organizaciones sindicales presentes en las Mesas Generales de negociación de la Administración autonómica: un liberado por cada Mesa en la que tengan representación (la General, más otras 4 Sectoriales), y otro más si tienen representación en todas ellas. Estas liberaciones tendrán una duración mínima de un año, y se autorizan para actividades de representación, negociación y un apropiado desarrollo del resto de sus funciones sindicales.

${ }^{648}$ Apartado sexto del Acuerdo de 22 de octubre de 2012.

${ }^{649}$ Su distribución consta en el Anexo al Acuerdo, resultando 13 liberados para UGT, 12 para CC.OO., 12 para CSI-F, 9 para la FSES y 9 para la Intersindical Valenciana. Este número se redistribuirá entre los sindicatos que compongan la Mesa General de Negociación I tras las correspondientes elecciones sindicales, sin aumentar en ningún caso sus número total, apartado sexto, punto 4 del Acuerdo de 27 de diciembre de 2012. 
Capítulo V. El contenido de la negociación colectiva de los derechos sindicales del personal estatutario de los Servicios de salud antes y después de las medidas de ajuste presupuestario

Esto nos remite al artículo 4 de los mencionados Pactos, que reconocía 1.080 horas al mes para los delegados sindicales de cada organización sindical presente en la Mesa sectorial de Sanidad, más las horas que se especifican a continuación: UGT 1.595 horas/mes; CC.OO. 1.595 horas/mes; CSI-CSIF 1.595 horas/mes. Estas horas experimentarán ahora la reducción de un $10 \%$ establecida en el Acuerdo de adecuación, pero de cualquier manera suponen una mejora, sobre el régimen legal del crédito horario y sobre lo acordado para el resto de empleados públicos en el apartado sexto del mismo Acuerdo ${ }^{650}$.

\section{sindicales \\ 5.6.3.5.- Procedimiento de gestión de las bolsas de crédito horario y dispensas}

Una de las razones principales para negociar los Acuerdos de adecuación al Real Decreto Ley 20/2012, una vez suprimidos los Acuerdos y Pactos reguladores de derechos sindicales de los empleados públicos, es precisamente la necesidad de regular el procedimiento de gestión del crédito horario sindical, ya que este es un aspecto que no regula la ley y debe ser concretado mediante el ejercicio de la negociación colectiva.

Además, aunque parezca un tema meramente formal, puede tener repercusión sobre el derecho a la libertad sindical de los empleados públicos afectados (pensemos en el caso de que una solicitud de dispensa sindical que se deniegue por el órgano administrativo competente para su reconocimiento, sin apoyar su decisión en razones fundadas y objetivas).

De cualquier manera, el procedimiento de gestión de las dispensas sindicales ha sido tradicionalmente uno de los temas omnipresentes en los Acuerdos y Pactos de derechos sindicales de los empleados públicos, y lo sigue siendo ahora en los Acuerdos de adecuación, que lo tratan de manera reglada ${ }^{651}$.

Para empezar, en algunos Acuerdos de adecuación la bolsa de crédito horario se constituye por sectores dentro de la Administración autonómica, que suelen ser coincidentes con los ámbitos de sus Mesas sectoriales: Administración General, personal Docente, de Justicia y personal de su Servicio de Salud. Ese es el caso de la Administración del Principado de Asturias o la Generalitat Valenciana ${ }^{652}$.

\footnotetext{
${ }^{650}$ Que reconoce tres representantes dispensados en cada una de las Mesas de negociación: personal docente no universitario, personal funcionario, personal laboral, personal estatutario; otro más en la Mesa general de negociación de personal funcionario y otro en la Mesa General de Negociación de los empleados públicos.

651 “La concesión de estos permisos sindicales se ajustará al siguiente procedimiento..." Acuerdo de la Administración de Cantabria, de 30 de abril de 2013, estipulación sexta 2.2.3.

652 Acuerdo de 29 de noviembre de 2012, de la Administración del Principado de Asturias: “Existirá una bolsa de horas de crédito horario en cada uno de los ámbitos de actuación incluidos en el presente Acuerdo, siendo la resultante de acumular las horas generadas por los representantes de cada organización sindical en los órganos de representación unitaria y de acumular las horas correspondientes a los delegados de las secciones sindicales de cada organización sindical”, cláusula octava, bolsa de horas.
}

"Las bolsas de crédito horario se formarán con los créditos horarios del personal empleado público de cada sector y tendrán carácter autonómico...”. Apartado sexto del Acuerdo de 27 de septiembre de 2012, de la Administración de la Generalitat Valenciana. 
Capítulo V. El contenido de la negociación colectiva de los derechos sindicales del personal estatutario de los Servicios de salud antes y después de las medidas de ajuste presupuestario

La bolsa de horas sindicales, en el ámbito del personal del Servicio de salud se gestiona habitualmente por el órgano directivo que tiene competencias en materia de personal $^{653}$.

De cualquier manera, el procedimiento se inicia, en primer lugar, por la cesión personal por parte de los representantes sindicales y unitarios del crédito horario que les reconoce la ley a favor de una bolsa común de horas. Una vez completadas todas las cesiones, ello da como resultado un total anual de crédito horario ${ }^{654}$.

Se suele pactar que la cesión del crédito horario sea irrevocable por parte del representante que la realiza, aunque se admiten excepciones ${ }^{655}$. El sindicato interesado deberá presentar una solicitud de acumulación de determinado número de esas horas sindicales a favor de los concretos trabajadores que disfrutarán la dispensa sindical, de forma total o parcial a lo largo del año ${ }^{656}$.

${ }^{653}$ La Dirección General de Recursos Humanos del Servicio de salud, en el Acuerdo de 29 de noviembre de 2012 de la Administración del Principado de Asturias, cláusula 1.1 del Anexo III; así como en el Acuerdo de 25 de septiembre de 2012 del Servicio Aragonés de Salud (art.6); la Dirección Gerencia del Servicio Cántabro de Salud, Adenda A, I A, del Acuerdo de la Administración autónoma de Cantabria, de 30 de abril de 2013.

${ }^{654}$ El artículo 6 del Acuerdo de 25 de septiembre de 2012, de la Mesa sectorial de Sanidad del Servicio Aragonés de Salud, regula la constitución de la bolsa de horas: "1. Los miembros de las Juntas de Personal de la misma candidatura y los delegados sindicales de los Sindicatos firmantes del presente Acuerdo, que se designen conforme al Capítulo III, podrán ceder sus créditos horarios para la creación de una bolsa de horas en el ámbito del Servicio Aragonés de Salud. Dicha bolsa se conformará con la totalidad de los créditos correspondientes a los 12 meses del año natural y será gestionada por la Dirección de Recursos Humanos de dicho Organismo".

"Se constituirá una bolsa de horas, con los créditos correspondientes a los miembros de los órganos de representación unitaria de la misma candidatura, y con los créditos correspondientes a los delegados sindicales de la misma organización sindical. Dicha bolsa se conformarán con la totalidad de los créditos correspondientes a los doce meses del año natural.", Acuerdo de 29 de noviembre de 2012 de la Administración del Principado de Asturias, cláusula 1.1 del Anexo III.

${ }^{655}$ El Acuerdo de la Administración autonómica de Canarias, excepcionalmente, reconoce el supuesto de retirada del crédito horario por el titular del mismo, en cuyo caso se restará de la respectiva bolsa el crédito horario del cedente correspondiente a los meses naturales siguientes al de la retirada, así como el no dispuesto por este en dicho mes (cláusula sexta, 1 e).

También el Acuerdo de 29 de noviembre de 2012, del Principado de Asturias, prevé en su Anexo III para el personal de su Servicio de salud, la cláusula por la cual: "Cuando un representante unitario o sindical que ha cedido por un año natural su crédito horario para constituir la bolsa de horas, cause baja en la organización sindical, no podrá recuperar las horas voluntariamente cedidas en ese año, que se mantendrán, por tanto, en la bolsa de horas de la organización sindical a favor de la que se cedieron. Finalizado el año, el crédito retornará al representante electo quien podrá disponer de él en la forma que considere y bajo los criterios señalados en el presente este acuerdo", apartado 2.11 .

${ }^{656}$ El Acuerdo de la Administración autonómica de Canarias define lo que entiende como tal: “a) Dispensa total. Se entenderá por tal la que comprenda, por meses naturales, la dispensa de asistir al puesto de trabajo durante la totalidad de la jornada ordinaria que viniera obligado a cumplir el interesado [...] b) Dispensa parcial. Se entenderá por dispensa parcial la que comprenda un periodo inferior al mes natural. Supondrá el uso de un número de horas de crédito horario coincidente con la jornada ordinaria de trabajo que, en todo 

de los Servicios de salud antes y después de las medidas de ajuste presupuestario

Se regulan plazos mínimos para presentar la solicitud de dispensa sindical con antelación $^{657}$, y el concreto contenido que debe reunir esta. En algunos Acuerdos se anexan los modelos de escritos normalizados que se utilizarán en cada fase del procedimiento de gestión del crédito horario ${ }^{658}$.

Por último, el órgano administrativo competente para la gestión y reconocimiento de las dispensas sindicales deberá resolver la solicitud, pactándose normalmente que lo sea de forma expresa, aunque en algún Acuerdo se ha establecido que en caso de silencio administrativo los efectos sean desestimatorios ${ }^{659}$.

Si el crédito sindical no es producto del reconocido en la ley para los representantes, sino que tiene su origen en lo acordado de forma adicional por las partes (bolsa de horas adicional, liberaciones institucionales...) el procedimiento es similar y también deberá presentarse por parte de la organización sindical una solicitud para proceder a su utilización a favor de determinados representantes, eso sí, cumpliendo las condiciones específicas que se establezcan en el Acuerdo ${ }^{660}$.

caso, viniera obligado a realizar el interesado en su puesto de trabajo durante el día o los días solicitados", (cláusula séptima, tipos de dispensas sindicales).

"Se entiende por dispensa total la acumulación del crédito horario de la bolsa en un mismo empleado público en cómputo total anual. La determinación del número de dispensas anuales correspondientes se realizará dentro de cada uno de los ámbitos funcionales de acuerdo con las especificaciones que se recogen en los anexos del presente acuerdo [...] Se entiende por dispensa parcial el uso fraccionado del crédito horario de la bolsa. Sus condiciones se reflejarán para cada sector en los anexos del presente acuerdo". Acuerdo de 29 de noviembre de 2012, de la Administración del Principado de Asturias, cláusula novena.

${ }^{657}$ El artículo 7.8 del Acuerdo de 25 de septiembre de 2012, de Mesa Sectorial de Sanidad del Servicio Aragonés de Salud exige que las dispensas parciales se presenten, como mínimo, con 48 horas de antelación (es el plazo más común). Las totales se deben presentar con quince días de antelación (artículo 7.3).

El Acuerdo de la Administración autonómica de Canarias exige dos o tres días hábiles, dependiendo de si el empleado público dispensado desempeña o no su trabajo a turnos, porque en este último caso hay que prever la organización de estos con algo más de antelación (cláusula octava, apdo. 2).

Este mismo supuesto se contempla en el Acuerdo de 29 de noviembre de 2012 de la Administración del Principado de Asturias (cláusula 2.9 del Anexo III).

${ }^{658}$ El Acuerdo de la Administración autonómica de Cantabria, de 30 de abril de 2013, es uno de los más completos en este sentido.

${ }^{659}$ Acuerdo de la Administración autonómica de Cantabria, de 30 de abril de 2013, estipulación sexta 2.2.3.

${ }^{660}$ El Acuerdo de la Administración de la Comunidad autónoma de Canarias, cláusula sexta, regula las bolsas de crédito horario por sectores dentro de la Administración pública autonómica de Canarias, “agrupando en cada ámbito sectorial el crédito horario mensual de miembros de juntas de personal, miembros de comités de empresa, Delegados de Personal y delegados de sección sindical de la misma organización sindical, así como el crédito horario adicional a que hace referencia el apartado segundo de la cláusula quinta, en los términos previstos en el mismo". 
Capítulo V. El contenido de la negociación colectiva de los derechos sindicales del personal estatutario de los Servicios de salud antes y después de las medidas de ajuste presupuestario

Una cláusula que se suele mantener en los Acuerdos de adecuación sobre derechos sindicales de los empleados públicos, es la que establece que el tiempo destinado a asistencia a reuniones convocadas por la Administración pública no consume crédito horario sindical $^{661}$.

El número de horas de crédito sindical que requieren los diferentes Acuerdos de adecuación para autorizar una dispensa a tiempo completo varía entre ellos. Así, en el Servicio Aragonés de Salud son necesarias 124 horas mensuales ${ }^{662} ; 127$ horas al mes en la Administración de la Comunidad autónoma de Cantabria ${ }^{663}$; 138 horas al mes en la Administración autonómica de Canarias ${ }^{664} ; 140$ horas en la Administración de la Junta de Castilla y León ${ }^{665}$ y en la de la Región de Murcia ${ }^{666}$; y 150 horas en la Administración de la Junta de Extremadura ${ }^{667}$, y en el ámbito del Servicio de Salud del Principado de Asturias ${ }^{668}$.

661 “Las horas utilizadas en reuniones convocadas por la propia Administración no se computarán como uso de crédito horario a los empleados públicos que asistan a la misma atendiendo a la convocatoria efectuada. Esta garantía se aplicará al número de empleados públicos que coincida con el número de asistentes que corresponda a cada Organización Sindical en las Mesas de Negociación y Comisiones constituidas en función de la representatividad de la organización sindical”. Acuerdo de la Administración autonómica de Cantabria, de 30 de abril de 2013, cláusula sexta 3.

"No se incluirá en el cómputo de horas de los miembros del Comité de empresa, Junta de Personal y Delegados Sindicales el usado en las actuaciones y reuniones llevadas a cabo por iniciativa de la Administración". Pacto de la Administración de Castilla y León de 30 de noviembre de 2012, cláusula decimosegunda, apartado c).

"No computará como uso de crédito horario la asistencia a reuniones de órganos de negociación y comisiones técnicas y/o trabajo dimanantes de los mismos, cuando hayan sido convocadas a instancias de la Administración”. Acuerdo de 31 de julio de 2013, de la Administración de Canarias, cláusula quinta, apdo. 4.

En el mismo sentido se expresan, el Pacto de Interlocución de la Administración de la Junta de Comunidades de Castilla-La Mancha para el período 2011-2015 (sección segunda, apartado 3º); así como el artículo 4.2 del Acuerdo de 28 de septiembre de 2012, de la Mesa General de negociación de la Administración de la Comunidad autónoma de Aragón; y el Acuerdo de 29 de noviembre de 2012, de la Administración del Principado de Asturias: "Se devolverá a la bolsa el crédito horario utilizado para asistir a reuniones de negociación convocadas por los órganos competentes de la Administración”, cláusula séptima, 7.4.(Asistencia a reuniones convocadas por la Administración).

${ }^{662}$ Artículo 7.2 del Acuerdo de 25 de septiembre de 2012, de la Mesa Sectorial de Sanidad.

${ }^{663}$ Sin descontar, además, las horas sindicales que se corresponden al mes de vacaciones y a los días de libre disposición: apartado B, punto 2 .

${ }^{664}$ Cláusula octava del Acuerdo de 31 de julio de 2013, de la Administración de la Comunidad autónoma de Canarias.

${ }^{665}$ Cláusula sexta, apartado 6.4 A f) del Pacto de 30 de noviembre de 2012.

${ }^{666}$ Apartado séptimo, 2 c) del Acuerdo de su Mesa General de Negociación, de 3 de octubre de 2012.

${ }^{667}$ Cabría esperar algo más de concreción en esta cláusula, porque a no ser que se descuente el mes de vacaciones, las horas que se exigen superan la jornada reglamentaria de los empleados públicos. Apartado quinto, c) del Acuerdo de la Mesa General de Negociación de la Administración de la Comunidad autónoma de Extremadura, de 22 de octubre de 2012. 
Capítulo V. El contenido de la negociación colectiva de los derechos sindicales del personal estatutario de los Servicios de salud antes y después de las medidas de ajuste presupuestario

En la medida en que las horas de crédito horario sindical requeridas para autorizar una dispensa a tiempo completo a favor de un empleado público son inferiores a la jornada reglamentaria, esto supone una mejora negociada de este aspecto concreto.

La Ley 2/2012 de 29 de junio de Presupuestos Generales del Estado, estableció en la Disposición adicional septuagésima primera, como norma básica, que la jornada de trabajo del personal en todas las Administraciones públicas no puede ser inferior a 37,5 horas semanales de trabajo efectivo de promedio en cómputo anual. No obstante, en las diferentes Administraciones públicas se ha reglamentado una jornada efectiva que difiere ligeramente entre ellas. Este dato hay que tenerlo en cuenta para entender si las cláusulas del Acuerdo sobre las horas requeridas para autorizar una dispensa a tiempo completo son o no una mejora sobre la jornada reglamentaria.

Así, por ejemplo, teniendo en cuenta que la jornada de trabajo del personal de los centros sanitarios del Servicio Aragonés de Salud para 2014 es de 1.638 horas anuales, según el Acuerdo del Gobierno de Aragón de 4 de marzo de 2014, la exigencia de 124 horas mensuales de crédito horario, que representa menos de 1.500 al año, resulta una ventaja para la acción sindical.

El Acuerdo de la Administración de la Generalitat Valenciana, de 27 de septiembre de 2012, por el contrario, se ajusta estrictamente a la ley y no contiene ninguna mejora en este sentido: "Para la tramitación de las dispensas de asistencia al trabajo se detraerá de la bolsa de horas el número de horas necesarias para la concesión de los permisos sindicales conforme a la legislación vigente" (apartado sexto). Esta disposición se deberá interpretar en el sentido de considerar que se tendrán que compensar con cargo a la bolsa de crédito sindical todas las horas de trabajo efectivo que deba prestar el empleado público.

En cuanto al personal que puede ser beneficiario de la dispensa sindical, se exige normalmente, en base a los requisitos del a LOLS y el artículo 41.1 LEBEP, que se trate de representantes sindicales o del personal, aunque excepcionalmente pueden serlo otros empleados públicos afiliados a la organización sindical solicitante ${ }^{669}$.

Las dispensas pueden ser revocadas por determinadas causas que regulan los Acuerdos. Esta cuestión ya se trataba en los anteriores Acuerdos y Pactos de derechos sindicales y su tratamiento no difiere significativamente ahora; como ejemplo, en la cláusula novena, apartado 2 del Acuerdo de adecuación de 31 de julio de 2013, de la Administración autonómica de Canarias, se regulan las siguientes: a) a solicitud del interesado. b) a petición

${ }_{668}$ Apartado 2.2 del Anexo III del Acuerdo de 29 de noviembre de 2012, de la Administración del Principado de Asturias.

${ }^{669}$ Acuerdo de 29 de noviembre de 2012, de la Administración del Principado de Asturias: "Con carácter general, sólo podrán hacer uso de las dispensas totales y parciales y de las horas de libre uso reguladas en este acuerdo aquellos empleados públicos de la Administración del Principado de Asturias que cumplan el requisito de ser miembros de órganos de representación unitaria o delegados de sección sindical y respecto del ámbito en el que ejerzan la representación. No obstante, se permitirá la dispensa de empleados públicos afiliados que no cumplan el requisito establecido en el párrafo anterior, siempre y cuando la dispensa se haga con cargo a la bolsa de horas, medie consentimiento previo y expreso, acreditado documentalmente, del representante unitario o sindical de cuyas horas se trate y tenga por fin la atención y preparación de los asuntos a tratar en las distintas mesas de negociación existentes en el ámbito de la Administración del Principado de Asturias", cláusula décima. 
Capítulo V. El contenido de la negociación colectiva de los derechos sindicales del personal estatutario de los Servicios de salud antes y después de las medidas de ajuste presupuestario

de la correspondiente organización sindical. c) por minoración de los créditos horarios que dieron lugar a la misma. d) por razón de cese por alguna de las causas legalmente previstas. e) por pérdida de la condición de representante que habilita para obtener dispensa. f) por realización de actividades incursas en causa de incompatibilidad, con arreglo a la normativa vigente en cada momento sobre incompatibilidades del personal al servicio de las Administraciones Públicas. A las anteriores cabe añadir la de llegada a término del plazo por el que se reconoció la liberación sindical o por constatarse un uso indebido para otra finalidad $^{670}$.

\subsubsection{6.- Derechos retributivos y otras garantías de la función representativa}

La situación administrativa de los empleados públicos que ejerzan los cargos de representantes sindicales o del personal, se reconoce expresamente como de activo, a todos los efectos ${ }^{671}$, con lo que esto no ha cambiado en relación con los Acuerdos y Pactos de garantías sindicales anteriores.

Por otra parte, aunque no sería necesario porque la situación de activo no supone baja en el puesto de trabajo, se reconoce expresamente el derecho a su reserva a favor de los empleados públicos en situación de dispensa sindical ${ }^{672}$; así como el derecho del personal estatutario a la situación de promoción interna temporal ${ }^{673}$.

${ }^{670}$ Acuerdo de la Administración autonómica de Cantabria, de 30 de abril de 2013, cláusula sexta 2.4.

671 "Quienes disfruten de estos permisos permanecerán en situación de activo y conservarán todos los derechos profesionales que les sean de aplicación, incluidos los de carácter retributivo”. Acuerdo de la Administración autonómica de Cantabria, de 30 de abril de 2013, estipulación sexta 2.2.d).

"Los trabajadores a quiénes se les conceda permiso o licencia sindical conforme a lo previsto en el presente Pacto quedan en situación de servicio activo con los derechos inherentes a esta situación a todos los efectos" Pacto de la Administración de Castilla y León, de 30 de noviembre de 2012, cláusula décima.

"Los representantes sindicales que se encuentren dispensados de asistencia al trabajo, permanecerán en situación de servicio activo y conservarán todos los derechos profesionales que les sean de aplicación, incluidos los de carácter retributivo". Acuerdo de 29 de noviembre de 2012, de la Administración del Principado de Asturias, cláusula decimotercera.

672 “El empleado público dispensado total o parcialmente de conformidad con lo previsto en el presente Acuerdo, permanecerá en situación de servicio activo con reserva, en su caso, del puesto de trabajo que estuviera desempeñando, conservando todos los derechos profesionales que le sean de aplicación, incluidos los de carácter retributivo con el alcance previsto en la cláusula siguiente. No podrá ser discriminado en su formación ni en su promoción económica o profesional por razón del desempeño de su labor de representación”, cláusula novena del Acuerdo de adecuación de la Administración de la Comunidad autónoma de Canarias de 31 de julio de 2013.

${ }^{673}$ El artículo 9 del Acuerdo de 25 de septiembre de 2012 de la Mesa Sectorial de Sanidad del Servicio Aragonés de Salud dispone: "En caso de que al dispensado a tiempo total le asignen otro puesto por el procedimiento de promoción interna podrá continuar disponiendo de dicho permiso pasando a percibir las retribuciones correspondientes al nuevo puesto asignado". 

de los Servicios de salud antes y después de las medidas de ajuste presupuestario

El derecho a la formación o al reciclaje profesional se recoge también en algún Acuerdo de adecuación ${ }^{674}$. Asimismo, se mantiene en los Acuerdos de adecuación el reconocimiento de todos los derechos profesionales, incluidos los de carácter retributivo, de los empleados públicos dispensados del trabajo por motivos de actividad sindical, en aplicación, como vimos anteriormente, de los principios jurisprudenciales relativos a la indemnidad retributiva y a la protección del derecho a la libertad sindical de los trabajadores con cargo sindical ${ }^{675}$.

Encontramos el fundamento de esta protección recogido expresamente en el Acuerdo de la Administración autonómica de Canarias, de 31 de julio de 2013: "La regulación de los derechos retributivos de los empleados públicos dispensados total o parcialmente en los términos previstos en el presente Acuerdo tiene como objetivo que la dedicación de los interesados a la actividad sindical no suponga una merma de las retribuciones que le correspondería percibir en caso de prestar servicios efectivos en su puesto de trabajo, así como que el uso de dicha dispensa no dé lugar a una mejora de la retribución que le correspondería percibir en dicha situación" $" 676$.

En algunos Acuerdos de adecuación se han regulado con detalle los conceptos retributivos que tiene derecho a percibir el personal con dispensa sindical, que son tanto las retribuciones básicas como complementarias de su puesto de trabajo, y también las variables (especialmente importantes en el ámbito sanitario, en el que ya vimos que existe la retribución por la realización de guardias médicas y atención continuada) ${ }^{677}$.

\footnotetext{
${ }^{674}$ El Acuerdo de 25 de septiembre de 2012, de la Mesa Sectorial de Sanidad del Servicio Aragonés de Salud establece que: "Los dispensados podrán participar en las mismas condiciones que el resto de empleados en las acciones formativas que se convoquen dentro del Plan de Formación Continuada. En todo caso, para el personal facultativo $u$ otro personal altamente especializado, se habilitarán fórmulas que permitan su permanente actualización profesional” (art.12)
}

675 "Derechos retributivos del personal que disfrute de licencia sindical.: 1.- La regulación de los derechos retributivos del personal que disfrute de licencia sindical tiene como objetivo que la dedicación de los interesados a la actividad sindical no suponga una merma de las retribuciones que hubieran percibido en caso de continuar prestando servicios, y en coherencia con ello, a que el disfrute de dicha licencia no suponga una mejora de la retribución que hubiera obtenido de continuar ejerciendo su puesto de trabajo". Para el personal dependiente del Servicio Murciano de Salud se prevé la aplicación de los criterios retributivos que incorporaba el Pacto sobre ejercicio de la actividad sindical de 18 de julio de 2003". Apartado Noveno del Acuerdo de la Administración de la Región de Murcia, de 3 de octubre de 2012.

Este mismo Acuerdo recoge en su apartado Decimotercero, no solo el derecho a la formación, sino la posibilidad de la Administración de obligar al personal que haya disfrutado de una dispensa sindical de más de cuatro años a "realizar tareas encaminadas a la actualización de sus conocimientos profesionales a través de los procedimientos que se estimen más adecuados al efecto ...”.

${ }^{676}$ Cláusula décima.

677 "Las retribuciones básicas que le corresponda en función del grupo al que se encuentre adscrito su cuerpo/escala/categoría. Las retribuciones complementarias de su puesto de trabajo, y los promedios retributivos anuales de las retribuciones variables ligadas a la actividad, al rendimiento y a la atención continuada del personal de la misma categoría (entre los que reúnan igualdad de condiciones que el liberado), servicio o unidad a que esté adscrito", cláusula décima del Acuerdo de la Comunidad autónoma de Canarias, de 31 de julio de 2013. 

de los Servicios de salud antes y después de las medidas de ajuste presupuestario

Por lo que respecta al compromiso de dotar a las organizaciones sindicales con ayudas, dietas y subvenciones, hay que decir que los anteriores Acuerdos y Pactos reguladores de derechos sindicales contenían estipulaciones por las que la respectiva Administración autonómica se comprometía a facilitar esos medios económicos ${ }^{678}$.

La cláusula 4 del Anexo III del Acuerdo de 29 de noviembre de 2012, de la Administración del Principado de Asturias regula con detalle las retribuciones de los liberados sindicales de su Servicio de salud, según trabajen en el ámbito de atención hospitalaria o primaria, especificando las retribuciones fijas y periódicas que tienen derecho a percibir, así como las complementarias de atención continuada y productividad variable.

${ }^{678}$ El Acuerdo de 4 de julio de 2008, sobre derechos y garantías sindicales del Servicio Aragonés de Salud, reguló la subvención económica de las organizaciones sindicales con representación en el ámbito de los centros sanitarios para el año 2007 en su artículo 21.

El Acuerdo de 25 de febrero de 2005, de la Administración del Principado de Asturias, dedicaba el artículo 12 a regular el régimen de subvenciones, reconociéndolas para las organizaciones sindicales "con implantación en los ámbitos del Acuerdo”; es decir, la Mesa general de negociación de la Comunidad autónoma, así como otra para las Juntas de personal y comités de empresa "de forma proporcional a la representatividad ostentada”.

El Acuerdo de 2 de marzo de 2006, de la Administración de las Islas Baleares, regulaba en su Título VIII el "Fondo de acción social" con el objeto de contribuir a la realización de las funciones de las organizaciones sindicales con presencia en los órganos de representación comprendidos en el ámbito de aplicación del Acuerdo, repartiendo la cuantía total teniendo en cuenta el criterio de la representatividad en cada ámbito y el de la proporción de representantes sindicales obtenidos.

En el Pacto de interlocución de Castilla-La Mancha, de 18 de noviembre de 2008, se regulaban las subvenciones en el Capítulo VI (Medios Materiales y Subvención Sindical), siguiendo un sistema de compensación económica por cada uno de los representantes obtenidos en las elecciones sindicales y por la presencia de las organizaciones sindicales en las distintas Mesas.

En el Pacto de Castilla y León, de 27 de junio de 2006, esta obligación de la Administración se recogió en el artículo 14, sin regular ninguna cantidad concreta, con el fin de que los sindicatos pudieran "hacer frente a los compromisos económicos derivados de su acción sindical. Para la distribución, en su caso, de dichas cantidades se tendrá en cuenta en todo caso el nivel de representatividad así como el número y tipo de medios materiales de que haya sido dotado cada sindicato".

En el Pacto de 22 de diciembre de 2004, de la Administración de la Generalitat de Cataluña, se regula un sistema de indemnizaciones por gastos de manutención y viajes para los miembros de las Mesas de negociación y de las Juntas de personal.

El Acuerdo de 16 de septiembre de 2003, de instituciones sanitarias del Instituto Madrileño de la Salud, estableció, en su Disposición adicional tercera, un fondo anual a distribuir entre los sindicatos presentes en la Mesa Sectorial del personal al servicio de instituciones sanitarias públicas del Instituto Madrileño de la Salud según su representatividad.

El Pacto del Servicio Murciano de Salud, de 18 de julio de 2003, estableció en su Capítulo VIII que este ente subvencionaría “a las Organizaciones Sindicales con presencia en la Mesa sectorial de sanidad para el desarrollo de las funciones y actividades sindicales que legalmente le estén atribuidas. La cuantía global de la subvención vendrá determinada en la correspondiente partida presupuestaria, y se distribuirá en proporción al número de representantes obtenidos en las elecciones sindicales celebradas en el Servicio Murciano de Salud, de acuerdo con los requisitos y forma de justificación que se establezca”. 
Capítulo V. El contenido de la negociación colectiva de los derechos sindicales del personal estatutario de los Servicios de salud antes y después de las medidas de ajuste presupuestario

Sin embargo, ahora, el único Acuerdo de adecuación que las contiene es el Pacto de la Administración de la Junta de Castilla y León, que prevé el pago por la Administración autonómica de las indemnizaciones y dietas de los representantes del personal y sindicales, y además, el empleo de un sistema mixto a favor de las organizaciones sindicales, que consiste en facilitarles tanto medios materiales como ayuda económica, con el fin de que puedan hacer frente a los compromisos económicos de su acción sindical ${ }^{679}$.

Otras garantías que se regulan en los nuevos Acuerdos son el uso del tablón de anuncios, o el acceso de los sindicatos a la intranet de la Administración autonómica ${ }^{680}$, así como la cesión de locales sindicales, tanto a las secciones sindicales como para las reuniones de los órganos de representación del personal, con dotación de material necesario $^{681}$.

679 "Con el fin de apoyar y financiar un eficaz funcionamiento de las Organizaciones Sindicales en el ejercicio de su labor, así como facilitar el desarrollo de sus funciones, se podrá articular un procedimiento mixto basado en dotar a aquéllas de los medios materiales (locales, material de oficina, etc.) a los que se hace referencia en los capítulos anteriores y/o, en sustitución o como complemento de aquellos, subvencionarlas para que puedan hacer frente a los compromisos económicos derivados de su acción sindical. Para la distribución, en su caso, de dichas cantidades se tendrá en cuenta en todo caso el nivel de representatividad así como el número y tipo de medios materiales de que haya sido dotado cada sindicato". Pacto de la Administración de Castilla y León de 30 de noviembre de 2012, cláusula decimocuarta (De las ayudas institucionales).

"Los gastos de desplazamientos y dietas de los miembros de Comité de empresa, Junta de Personal y Delegados Sindicales, así como de los miembros de los órganos institucionales de negociación, correrán a cargo de la Administración, siempre que estén motivados o relacionados con actividades sindicales que afecten a la Administración. En el supuesto de actuaciones individuales y que no obedezcan a convocatoria expresa de la Administración se presumirá que el miembro del Comité o de la Junta de Personal actúa en la representación que ostenta, cuando dicha actuación responda a una encomienda o mandato del órgano colegiado. Los gastos de desplazamiento y dietas de los miembros de los Comités de Empresa y Juntas de Personal, originados por las reuniones periódicas de dicho órgano de representación hasta un máximo de una al mes, así como las que fueren convocadas por la Administración, serán abonados por ésta...”. Pacto de 30 de noviembre de 2012 de la Administración de Castilla y León, cláusula decimosegunda.

${ }^{680}$ El Pacto de 30 de noviembre de 2012, de la Administración de Castilla y León, dispone en la cláusula Duodécima: “e) "Se pone a disposición de cada sindicato en el entorno de la Intranet de la Administración Autonómica, un tablón de anuncios virtual que permita que la publicidad de las hojas informativas de los sindicatos se haga a través de dicho tablón facilitando así la comunicación de los sindicatos con los trabajadores. f) Acceso sindical a intranet: Se dotará a cada sindicato con presencia en la Mesa General de Negociación de un equipo informático. La Administración dotará a cada Sección Sindical perteneciente a alguna de las organizaciones sindicales con presencia en la Mesa General de Negociación cuenta de correo electrónico, a fin de que las secciones sindicales puedan comunicarse a través de este medio con los empleados públicos que así lo deseen”, cláusula tercera, 3.4 y 3.5 .

"Las secciones sindicales de las organizaciones sindicales más representativas y de los que tengan presencia en los comités de empresa y en las juntas de personal o cuenten con Delegados de Personal, dispondrán, en cada centro de trabajo, de un tablón de anuncios en lugar claramente visible y de uso exclusivo. [...] Tanto la Administración como las organizaciones sindicales firmantes del presente acuerdo se comprometen a potenciar en este ámbito el uso de los medios electrónicos a disposición del personal de esta Administración, sin que esto pueda suponer, en ningún caso, un mayor gasto”, cláusula undécima, tercer y cuarto párrafo, del Acuerdo de 29 de noviembre de 2012, de la Administración del Principado de Asturias.

${ }^{681}$ En el caso del Servicio Aragonés de Salud son de uso exclusivo para las organizaciones sindicales firmantes del Acuerdo, y de uso compartido para las demás: "Para el desarrollo de sus actividades, cada 
Capítulo V. El contenido de la negociación colectiva de los derechos sindicales del personal estatutario de los Servicios de salud antes y después de las medidas de ajuste presupuestario

\subsubsection{7.- El seguimiento de los Acuerdos de adecuación y el compromiso de resolución de conflictos}

Casi todos los Acuerdos de adecuación actuales han constituido una Comisión de seguimiento para la interpretación y control de lo acordado ${ }^{682}$. Excepcionalmente, el Acuerdo de 31 de julio de 2013, de la Mesa General de Negociación de Empleados Públicos de la Comunidad Autónoma de Canarias, opta por atribuir estas funciones directamente a la Mesa de negociación y prescinde de la creación de la Comisión de seguimiento (cláusula decimosegunda).

organización sindical firmante del presente Acuerdo tendrá a su disposición un local propio en el ámbito de cada Sector Sanitario. La distribución de la superficie de estos locales entre las distintas Organizaciones Sindicales será proporcional a la representatividad obtenida por las mismas en cada elección sindical. Las secciones sindicales constituidas por las Organizaciones Sindicales presentes en los órganos de representación del personal funcionario-estatutario tendrán a su disposición un local adecuado en cada centro de trabajo con más de 250 trabajadores. El tiempo de utilización de dicho local deberá distribuirse mediante acuerdo de las secciones sindicales. En caso de no alcanzarse dicho acuerdo, la distribución será proporcional a la representación obtenida en las elecciones sindicales. Igualmente por la Gerencia de Sector correspondiente, previa petición, se facilitará un local adecuado para las reuniones de los órganos de representación del personal. Dichos locales estarán dotados del material de oficina e informático necesario para facilitar su actividad", artículo 15 del Acuerdo de 25 de septiembre de 2012, de la Mesa Sectorial de Sanidad del Servicio Aragonés de Salud.

Destaca en este sentido el Pacto de la Administración de Castilla y León, de 30 de noviembre de 2012, que para los sindicatos con mayor nivel de implantación reconoce el derecho al uso de un local en Valladolid para el desarrollo de su actividad sindical, con dotación de material, así como, sin especificar su ubicación, otro local para los sindicatos con especial audiencia. En cuanto a la dotación material a los sindicatos, este mismo Pacto dispone, en su cláusula quinta, que: "A los Sindicatos con mayor nivel de implantación y con especial audiencia la Administración Autonómica les dotará para los siguientes conceptos: a) compensaciones económicas por la participación en órganos colegiados. b) Acceso a los Boletines Oficiales de Castilla y León y del Estado. c) A los Sindicatos con mayor nivel de implantación un local en Valladolid para desarrollar su actividad sindical con la dotación de mobiliario necesario para su funcionamiento, incluidos los medios técnicos al uso (teléfono, fax, conexión a Internet e intranet, fotocopiadora, equipos informáticos, etc.) y material de oficina. A los sindicatos con especial audiencia, la Administración los dotará de un local con los medios mencionados en el apartado anterior. d) franqueo concertado".

Acuerdo de 29 de noviembre de 2012, de la Administración del Principado de Asturias. "Tendrán derecho al uso de un local los órganos de representación unitaria y las secciones sindicales de las organizaciones sindicales más representativas y de los que tengan presencia en los órganos de representación unitaria. Los locales cumplirán las normas de seguridad y salud establecidas en la legislación específica, y estarán dotados del mobiliario necesario para su funcionamiento, incluidos los medios técnicos al uso, y material de oficina", cláusula undécima, primer y segundo párrafo.

${ }^{682}$ Como ejemplo, el Acuerdo de la Administración autonómica de Cantabria, de 30 de abril de 2013 , estipulación octava, dispone: "Se constituye una Comisión Paritaria de Seguimiento de las garantías establecidas en este Acuerdo, que estará compuesta por un miembro de cada una de las Organizaciones Sindicales firmantes e igual número de miembros de la Administración. Los acuerdos de la Comisión requerirán la mayoría de cada una de las partes. La mayoría social se determinará en proporción a la representatividad alcanzada en este ámbito por cada Organización Sindical. 2. Esta comisión tendrá las siguientes funciones: a) Vigilancia, control, seguimiento y evaluación de los contenidos de este Acuerdo. b) Interpretación que pueda derivarse de su clausulado. c) Adecuación, con los criterios contemplados en el Acuerdo, de los permisos, dispensas y horas derivadas de los resultados de los procesos electorales. 
Capítulo V. El contenido de la negociación colectiva de los derechos sindicales del personal estatutario de los Servicios de salud antes y después de las medidas de ajuste presupuestario

Asimismo, en el Acuerdo de adecuación de la Administración de la Región de Murcia, de 3 de octubre de 2012, se opta por atribuir la función de seguimiento a una Comisión Permanente de la Mesa General Común, aunque prevé que podrá constituirse una Comisión de seguimiento (apdo. undécimo).

Por otra parte, por lo que se refiere a las cláusulas sobre el compromiso de las organizaciones sindicales firmantes o adheridas a los Acuerdos de no impugnar en vía administrativa o judicial los mismos, que ya vimos que se refleja también en el Acuerdo de la Mesa General de Negociación de la Administración General del Estado de 29 de octubre de 2012, se recoge en los términos siguientes: "Tanto las organizaciones sindicales firmantes, como aquellas que se adhieran de forma expresa al presente Acuerdo, en los términos previstos en el apartado tercero de la cláusula primera, se comprometen a resolver sus controversias a través de los mecanismos y mesas de negociación previstos en el EBEP y en la Mesa General, así como a no plantear acciones en vía administrativa o judicial en relación con las materias reguladas en el presente acuerdo, sin haber agotado previamente los mecanismos previstos en el citado Estatuto". Acuerdo de 31 de julio de 2013, de la Mesa General de Negociación de Empleados Públicos de la Comunidad Autónoma de Canarias, estipulación decimotercera.

Y en los casos en que no existe esta cláusula anterior, sí se establece la vinculación a la totalidad del Acuerdo como una unidad, que no puede ser impugnada por partes separadas $^{683}$.

Resulta muy particular la cláusula que encontramos en el Acuerdo de 22 de octubre de 2012 de la Junta de Extremadura, en la que se ha pactado con respecto a su personal laboral, en el apartado noveno del Acuerdo, que las organizaciones sindicales se comprometen a no promover elecciones sindicales en el ámbito de personal laboral, a cambio de la creación de una bolsa de 7.800 horas mensuales, que se distribuirá entre las firmantes del mismo ${ }^{684}$.

En algún Acuerdo que ha incorporado esta cláusula se prevé que la Comisión de seguimiento se encargue de la función de adecuar las dispensas y horas sindicales a los

\footnotetext{
683 “El presente acuerdo deberá entenderse con carácter global, pudiendo ser denunciado por las partes que lo suscriben en caso de incumplimiento de cualquiera de sus puntos. La denuncia del pacto se realizará en escrito motivado que indique la causa de la misma, del que tendrán que tener conocimiento todas las partes que lo suscriben”. Acuerdo de la Generalitat Valenciana, apartado décimo.
}

"El presente Acuerdo constituye un todo orgánico único e indivisible, basado en el equilibrio de las recíprocas obligaciones y mutuas contraprestaciones asumidas por las partes y, como tal, será objeto de consideración conjunta. En consecuencia, no podrán tomarse aisladamente alguna o algunas de las materias pactadas que, a efectos de su aplicación práctica, serán consideradas globalmente”. Acuerdo de 3 de octubre de 2012 de la Administración de la Región de Murcia, apartado decimosexto.

"Las cláusulas del presente Acuerdo constituyen un todo orgánico único e indivisible a efectos de su aplicación, asumiendo las partes su cumplimiento con vinculación a la totalidad del mismo”. Acuerdo de la Administración autonómica de Canarias, de 31 de julio de 2013, cláusula decimocuarta.

684 “Con la siguiente distribución: UGT: 3.067; CC.OO: 2.521; CSI-F: 2.212”. 
Capítulo V. El contenido de la negociación colectiva de los derechos sindicales del personal estatutario de los Servicios de salud antes y después de las medidas de ajuste presupuestario

resultados electorales $^{685}$, pero cabe entender que, si no se establece nada en el Acuerdo, dicha atribución corresponde a la Mesa General de negociación.

${ }^{685}$ Acuerdo de la Administración autonómica de Cantabria, de 30 de abril de 2013, estipulación octava, punto $2 \mathrm{c})$. 
TABLAS 



\section{TABLAS}

Tabla I.- Participación en la negociación y firma de los Pactos y Acuerdos sobre derechos y garantías sindicales aplicables al personal estatutario vigentes con anterioridad a las medidas de ajuste presupuestario

\begin{tabular}{|l|l|}
\hline ADMINISTRACION AUTONÓMICA & \multicolumn{1}{c|}{ ORGANIZACIONES SINDICALES } \\
\hline ANDALUCIA & CCOO, UGT, CSI-CSIF \\
\hline ARAGON & CCOO, UGT, CSI-CSIF, CEMSATSE \\
\hline P. ASTURIAS & CCOO, UGT, CEMSATSE,SAE \\
\hline ISLAS BALEARES & CCOO,UGT, CEMSATSE,STEI, \\
\hline CANARIAS & CCOO,UGT, CEMSATSE,SAE \\
\hline CANTABRIA & CCOO, UGT, CEMSATSE, CSI-CSIF, ATI \\
\hline CASTILLA Y LEON & CCOO, UGT, CEMSATSE, CSI-CSIF,SAE-USCAL \\
\hline CASTILLA-LA MANCHA & CCOO, UGT, CSI-CSIF \\
\hline CATALUÑA & CCOO, UGT, CEMSATSE, IAC, \\
\hline COMUNIDAD VALENCIANA & CCOO,UGT, CEMSATSE, CSI-CSIF,SAE,STSPV-IV \\
\hline EXTREMADURA & CCOO,UGT, CEMSATSE, CSI-CSIF,SAE \\
\hline GALICIA & CCOO, UGT,CEMSATSE, CSI-CSIF, CIG \\
\hline MADRID & CCOO, UGT, CEMSATSE, CSIT-UP,CSI-CSIF \\
\hline MURCIA & CCOO,UGT, CEMSATSE, CSI-CSIF,SAE \\
\hline NAVARRA & CCOO, UGT, AFAPNA, LAB, ELA-STV \\
\hline LA RIOJA & CCOO, UGT, CSI-CSIF, STAR, FSES, STE-RIOJA, USAE \\
\hline PAIS VASCO & CCOO, UGT, ELA-STV \\
\hline
\end{tabular}

Tabla II.- Participación en la negociación y firma de los Acuerdos autonómicos de adecuación al Real Decreto Ley 20/2012 en materia de derechos sindicales de los empleados públicos

\begin{tabular}{|l|l|}
\hline ADMINISTRACION AUTONÓMICA & \multicolumn{1}{c|}{ ORGANIZACIONES SINDICALES } \\
\hline ARAGON & CCOO, UGT, CSI-F y CEMSATSE \\
\hline P. ASTURIAS & CC.OO., UGT, CSIF, CEMSATSE, SAIF, \\
\hline CANARIAS & CCOO, UGT, SEEPP Canarias, Intersindical Canaria \\
\hline CANTABRIA & CCOO, UGT, CSI-F, FSES \\
\hline CASTILLA-LA MANCHA & CSIF, FSES \\
\hline CASTILLA Y LEON & CCOO, UGT, CSI-F, FSES \\
\hline COMUNIDAD VALENCIANA & CCOO, UGT, CSI-F, FSES \\
\hline EXTREMADURA & CCOO, UGT, CSI-F \\
\hline MURCIA & CEMS, FSES \\
\hline
\end{tabular}





\section{CONCLUSIONES}





\section{CONCLUSIONES}

PRIMERA.- Una estructura administrativa tan compleja como es hoy día la Administración pública sanitaria en España es fruto, en buena parte, de la evolución histórica de nuestras instituciones. En España, el binomio avance-retroceso, a nivel político y social ha sido una constante que ha condicionado el desarrollo de la Sanidad como servicio público.

Con la aparición del Estado moderno, que pone fin al modelo anterior medieval de reparto del poder entre los distintos estamentos bajo la autoridad del Rey, aparece la figura del monarca, que concentra y dispone de todas las competencias sobre sus súbditos, que carecen de derechos. Así, nos encontramos con que en el siglo XVI la Corona asume todos los poderes y los funcionarios son meros servidores del Rey para la realización de sus intereses.

A partir de la Revolución francesa de 1789, en el marco de los nuevos ideales liberales, surge el concepto de Administración pública puesta al servicio de los ciudadanos, ante los que el Estado deberá asumir nuevas responsabilidades. Esta nueva concepción del Estado, no obstante, tardará en arraigar en nuestro país.

En España a lo largo de los siglos XVIII y XIX, además de múltiples problemas sociales y políticos, existe un considerable atraso de la ciencia médica y de la cobertura sanitaria a la población. Esta se presta a los pobres como manifestación de la caridad cristiana por la Iglesia y los Ayuntamientos; el resto de la población tiene que atenderla con sus medios particulares de forma individual o colectiva.

La responsabilidad de prestar asistencia sanitaria a la población surge durante el auge del Estado liberal, en respuesta a las reivindicaciones del Movimiento Obrero, que también reclama el derecho de libre asociación, la protección social y el reconocimiento de derechos políticos. Desde mediados del siglo XIX tiene lugar en los países europeos más avanzados la aprobación de medidas legislativas de protección social para satisfacer las exigencias de la población, que demanda la asistencia sanitaria como un derecho de los trabajadores.

En nuestro país, durante esa etapa, la atención sanitaria es una de las reivindicaciones sociales más urgentes. Supone, además, una gran presión sobre los gobiernos conservadores de la época, hasta el punto de que es precisamente durante el auge del Estado liberal cuando van a ver la luz las primeras normativas que intentan articular un servicio público sanitario, prestado por las entidades locales, bajo control estatal, y dotado de unos mínimos medios personales para poder funcionar de forma permanente. La atención sanitaria deja de entenderse como expresión de la caridad, pasando a ser una manifestación de la beneficencia pública. 


\section{Conclusiones}

Así, se tratará de articular una organización sanitaria elemental, cuya responsabilidad recae en los entes locales, a través de Ley del Servicio General de Sanidad de 1855, norma que, además, incorpora una regulación elemental de derechos y deberes de la relación de servicios del personal facultativo con la Administración pública. Para los funcionarios, su normativa se establece en el Estatuto de Bravo Murillo de 1852.

En los años siguientes, producto de la Revolución de 1868 que termina con el reinado de Isabel II, se aprobará la Constitución de 1869 que, al menos sobre el papel, reconoce una declaración amplia de derechos. Posteriormente, la Constitución de 1876, que proclama el derecho de asociación, servirá de base a Ley de Asociaciones de 1887, que permitirá la constitución de sindicatos.

Ya entrados en el siglo XX, se aprueban las primeras medidas legislativas de previsión social: la Ley de Accidentes de Trabajo de 1900; la Instrucción general de Sanidad de 1904, que incorpora una pormenorizada regulación de todos los aspectos sanitarios y crea el Cuerpo de Médicos Titulares; el Instituto Nacional de Previsión se funda en 1908; la regulación del Seguro obligatorio de retiro obrero tiene lugar en 1919; el Código de Trabajo en el año 1922; el Seguro Obligatorio de Maternidad en 1929... En cuanto a la libertad sindical, la Ley de 27 de abril de 1909 legitima el derecho de huelga.

Por lo que respecta a los funcionarios, al mismo tiempo, durante esos períodos, se producen varios intentos destacables de modernizar y unificar su normativa, destacando el Estatuto Maura en 1918. Este último, entre otros, reconoce el derecho de asociación a los funcionarios públicos. En cuanto a las competencias y organización de las entidades locales son particularmente importantes el Estatuto Municipal de 1924 y el Provincial de 1925, que atribuyen a las entidades locales responsabilidades en materia sanitaria e higiene pública.

Durante el período de la Segunda República se produce el reconocimiento constitucional del derecho a la libertad sindical de los trabajadores, se afianzan las bases del Derecho del Trabajo, y a la vez se esboza lo que pudo llegar a ser un Sistema sanitario público, con lo que nos encontramos con la etapa del Estado Social.

A lo largo de las primeras décadas del siglo XX se produce en España un desarrollo legislativo de los derechos laborales y sindicales de los trabajadores, que alcanzará su momento cumbre con la Constitución de 1931, que proclama, entre otros, el derecho a la libertad sindical que, sin embargo, no incluye a los funcionarios públicos.

En efecto, es durante la etapa de la Segunda República cuando triunfan los postulados del Estado Social, por lo que se refiere a la protección de los derechos laborales y sindicales, y a la vez, se supera la idea de la asistencia sanitaria como manifestación de la beneficencia pública del Estado liberal. En este sentido, destaca la aprobación de la Ley de Coordinación Sanitaria de 1934 y las medidas normativas encaminadas a ordenar el régimen jurídico funcionarial del personal al servicio de la Administración sanitaria, con la aprobación del Reglamento del Cuerpo de Médicos de Asistencia Pública Domiciliaria en 1934 y el del Cuerpo Médico de la Sanidad Nacional, en 1935. 
Terminada la Guerra Civil, a falta del reconocimiento de los derechos civiles y políticos, el legislador intenta recomponer el elemental sistema de previsión social y la maltrecha organización sanitaria, para instaurar un modelo de protección general para la población basado en la condición de asegurado. Este objetivo intenta articularse a través, fundamentalmente, de la Ley del Seguro Obligatorio de Enfermedad de 1942, cuya gestión se encarga al Instituto Nacional de Previsión, y después, con la aprobación de la Ley de Bases de Sanidad, de 1944, que centraliza en el Estado la competencia pública en materia sanitaria. Asimismo, se produjeron intentos de regular la relación de servicios del personal sanitario, destacando el Reglamento de los servicios sanitarios del Seguro Obligatorio de Enfermedad de 1948. No obstante, las notas características de la regulación durante esta etapa fueron la falta de coordinación entre las diferentes entidades, entes locales y el Estado que prestaban la asistencia sanitaria por separado y la ausencia de unificación de criterios en sus políticas sanitarias.

Por otra parte, durante el régimen franquista desaparece del ordenamiento jurídico cualquier reconocimiento real de derechos sociales y políticos. No se reconoce la libertad sindical y el régimen establece un modelo de sindicalismo único y obligatorio, del todo ajeno a la voluntad de los sujetos implicados. La asociación sindical se regula en el Fuero del Trabajo de 1938, en la Ley de Bases de la Organización Sindical de 6 de diciembre de 1940 y, más tarde, en la Ley de 17 de febrero de 1971 sobre asociación profesional, que ni siquiera fue aplicable a los funcionarios públicos.

SEGUNDA.- La relación jurídica del personal estatutario tiene su origen en la creación del Sistema público de Seguridad Social en España en los años sesenta del siglo pasado. En la opción del legislador de la época por este régimen jurídico para el personal influyeron de forma decisiva las presiones de la Organización médica colegial, que no deseaba para el colectivo médico de la Seguridad Social una regulación funcionarial, y prefería este otro régimen jurídico que quedaba en un terreno ambiguo, dado que se contenía en normas reglamentarias independientes de las leyes funcionariales y tenía alguna semejanza con la relación jurídico laboral, como era la competencia de la vía jurisdiccional social para conocer de los litigios del personal con su empleadora, la Administración sanitaria.

Así, en los años sesenta se pone en marcha el Sistema público de Seguridad Social, dependiente de la Administración Pública estatal, que tiene su inicio con la Ley de Bases de la Seguridad Social de 1963, con vocación de cobertura más amplia que el anterior de 1944, $y$ en el que la asistencia sanitaria es una de sus prestaciones fundamentales.

Para llevarla a la práctica se requiere de suficientes medios materiales y personales, por lo que se construyen numerosos centros sanitarios y el legislador determina que la relación jurídica de los profesionales que trabajen en la sanidad pública quede a medio camino entre la laboral y la funcionarial, regulada por sus normas específicas: es el personal estatutario de la Seguridad Social.

En esta decisión fue decisiva la influencia del Consejo General de Colegios oficiales de médicos, favorable a la regulación de una relación jurídica no funcionarial para su 


\section{Conclusiones}

colectivo, que colaboró tanto en la elaboración de la normativa de desarrollo de Ley de Bases de 1963, como en la posterior regulación del Estatuto Jurídico del personal Médico.

En efecto, el Texto Articulado de la Ley de Bases de la Seguridad Social de 1963 preveía la regulación del régimen jurídico de este personal, que finalmente vino dada en el Decreto 3160/1966, de 23 de diciembre, que aprobó el Estatuto Jurídico del personal Médico de la Seguridad Social. Posteriormente se aprobaron el Estatuto de personal no sanitario al servicio de instituciones sanitarias de la Seguridad Social, por Orden del Ministerio de Trabajo de 5 de julio de 1971, y el Estatuto de personal Auxiliar Sanitario Titulado y Auxiliar de Clínica de la Seguridad Social, por Orden de 26 de abril de 1973, vigentes, aunque con múltiples modificaciones, durante más de treinta años. Al margen de este régimen jurídico específico quedaron, sin embargo, los Médicos titulares y el resto de Cuerpos funcionariales de Facultativos y Médicos, como el de la Sanidad Nacional, destinados a servicios de higiene y prevención que serían el germen de lo que hoy es el modelo de Salud pública.

Así arranca el Sistema español de servicio público sanitario que, apoyado después en el cambio político y en el reconocimiento de los derechos y las libertades de los ciudadanos en la Constitución española de 1978, derivará en el actual que disfrutamos: el Sistema Nacional de Salud.

TERCERA.- Efectivamente, en la Constitución de 1978 tiene su origen también el Sistema Nacional de Salud. Este sistema es un modelo asistencial para la prestación del servicio público sanitario, que tiene su fundamento en el reconocimiento constitucional del derecho a la protección de la salud de los ciudadanos por parte de los poderes públicos (art. $43 \mathrm{CE}$ ) y en las competencias compartidas entre el Estado y las CC.AA. para legislar en lo básico, el primero, y gestionar, las segundas, los Servicios de salud de los que se compone. Estos tienen mayoritariamente naturaleza jurídico-administrativa; no obstante, hay que advertir que en determinadas Administraciones autonómicas su legislador ha decidido un régimen jurídico que los sujeta en parte al Derecho privado.

El Sistema Nacional de Salud sustituye al modelo anterior en el que la asistencia sanitaria la prestaba el Estado directamente a los asegurados a través de los centros y con el personal de la Seguridad Social. Completar el funcionamiento del Sistema Nacional de Salud ha llevado casi dos décadas, hasta su culminación en 2002, año en que termina el proceso con las últimas transferencias a las CC.AA.

Su origen legislativo está en la Ley 14/1986, de 24 de abril, General de Sanidad, que lo crea, y que, junto con normas como la Ley 16/2003, de 28 de mayo, de Cohesión y Calidad del Sistema Nacional de Salud ha permitido su organización y desarrollo hasta alcanzar en el momento actual un volumen y calidad en sus prestaciones como quizá ningún otro servicio de titularidad pública, pese a sufrir directamente las medidas de ajuste presupuestario que la situación económica en nuestro país nos ha impuesto en los últimos años. No obstante, la reforma operada por el Real Decreto Ley 16/2012, de 20 de abril, de Medidas Urgentes para garantizar la Sostenibilidad del Sistema Nacional de Salud y mejorar la calidad y seguridad de sus prestaciones, ha incidido fundamentalmente en el principio de 


\section{Conclusiones}

universalidad de la prestación sanitaria para todos los ciudadanos y lo ha transformado en un Sistema basado en la condición de asegurado.

Existen diecisiete Servicios de salud autonómicos, tantos como Comunidades autónomas, que por regla general toman o bien la forma jurídica de organismo autónomo de carácter administrativo dependiente del Departamento de Salud o Consejería de Sanidad autonómicos, o bien la forma de ente público. Sin embargo, presentan singularidades en su régimen jurídico regulador, por someterse en cierta medida al Derecho privado: el Servicio Catalán de la Salud, el Servicio Vasco de Salud, y el Servicio Madrileño de Salud.

Además, dependiente del Estado, el INGESA gestiona la asistencia sanitaria en las ciudades autónomas de Ceuta y Melilla, la Organización Nacional de Trasplantes y el Centro Nacional de Dosimetría de Valencia.

CUARTA.- Del Sistema Nacional de Salud cabe decir, sin riesgo de exagerar, que los profesionales que prestan sus servicios en él son la pieza fundamental que sustenta la organización y que posibilita el éxito o determina el fracaso de las políticas que lo impulsan. Ese conjunto de recursos humanos, heterogéneo por su formación, categorías profesionales y relaciones jurídicas, tiene hoy día reconocida mayoritariamente la condición de personal estatutario. El legislador estatal ha determinado, en base a sus competencias constitucionales, que el régimen jurídico del personal estatutario de los Servicios de salud sea de naturaleza funcionarial especial. Así lo establece el artículo 1 de la Ley 55/2003, de 16 de diciembre, reguladora del Estatuto Marco del personal estatutario de los Servicios de salud.

El legislador estatal ha decidido que la naturaleza jurídica de la relación de servicios del personal de la Administración pública sanitaria sea administrativa, incorporando esa disposición en una norma que tiene carácter de ley básica, en uso de las competencias que le atribuye el artículo 149.1.18 CE. Por ello, el legislador autonómico no puede decidir otra regulación, al contrario; se constata la tendencia a la estatutarización del personal de todo el Sistema Nacional de Salud que tiene, por motivos diversos, una relación funcionarial común o laboral a través de procesos de integración en el régimen jurídico estatutario. Únicamente se da el caso excepcional del personal del Servicio Navarro de Salud, que en aplicación de su normativa foral tiene la condición de funcionario autonómico.

No obstante, hay que señalar que en los casos en que los Servicios de salud autonómicos tienden hacia una regulación dada en normas de Derecho privado, o las Administraciones autonómicas recurren a fórmulas de prestación indirecta de la asistencia sanitaria para gestionar sus instituciones sanitarias, como es el caso de la gestión por concesión administrativa, se desplaza también el régimen jurídico del personal a su servicio hacia el campo del Derecho laboral.

QUINTA.- Durante la Transición se incorpora a nuestro ordenamiento jurídico la normativa internacional que protege el derecho a la libertad sindical, que ha sido fundamental para sentar la base de su reconocimiento constitucional posterior, y que estuvo ausente de nuestro ordenamiento jurídico durante casi cuarenta años. 


\section{Conclusiones}

El derecho a la libre sindicación se contiene en Declaración Universal de los Derechos Humanos de la Organización de Naciones Unidas y en el Convenio $\mathrm{n}^{\mathbf{0}} 87$ de la OIT, ambos de 1948. Este Convenio trata de manera amplia el derecho a la libertad sindical, y se complementa con el $\mathrm{n}^{\circ} 98$, que trata los principios del derecho de sindicación y de la negociación colectiva, de 1 de julio de 1949. Hay que tener en cuenta también el Convenio $\mathrm{n}^{\circ} 135$, de 1971, que trata sobre la protección y facilidades que deben reconocerse a los representantes de los trabajadores en la empresa.

Para que nuestro texto constitucional pudiera reconocer los derechos fundamentales y las libertades públicas, organizar las instituciones y sentar los principios del sistema democrático, se debía producir previamente una puesta al día de nuestro ordenamiento jurídico; y entre otras cosas, la incorporación de estos Convenios de la OIT. Así, estos se ratificaron por España el 13 de abril de 1977, junto con el Pacto internacional de derechos civiles y políticos y el Pacto de derechos económicos, sociales y culturales de la ONU, de 16 de diciembre de 1966. Al mismo tiempo se publicó la Ley 19/1977, de 1 de abril, de Asociación sindical; el Real Decreto 873/1977, de 22 de abril, que legalizó las organizaciones sindicales y, por lo que se refiere a los funcionarios públicos, se reguló su derecho de asociación sindical en el Real Decreto 1522/1977, de 17 de junio.

En los años siguientes a la promulgación de la CE, España ratificó otros instrumentos internacionales que tratan el derecho a la libertad sindical, poco antes de publicarse la LOLS: el Convenio de la OIT n ${ }^{\circ} 151$ que, además del derecho de libertad sindical de los funcionarios públicos, trata los procedimientos para determinar sus condiciones de empleo, en junio de 1984; así como el Convenio n ${ }^{\circ} 154$, que trata el derecho a la negociación colectiva laboral, en julio de 1985.

SEXTA.- El personal estatutario de los Servicios de salud tiene reconocido plenamente en la CE el derecho fundamental a la libertad sindical (art. 28.1), considerando ciertas peculiaridades que le afectan al igual que a la mayoría de los funcionarios públicos (art. 103.3).

La Ley Orgánica 11/1985, de 2 de agosto, que desarrolla el derecho fundamental a la libertad sindical (LOLS), regula sus principales aspectos de forma común para todos los trabajadores, en sentido amplio, y por tanto, incluye, salvo excepciones, a los funcionarios públicos y, en consecuencia, al personal estatutario de los Servicios de salud.

Además de lo dispuesto en la LOLS, debemos tener en cuenta la jurisprudencia del TC que ha contribuido especialmente a completar la interpretación del derecho fundamental a la libertad sindical, sentando la doctrina sobre el contenido esencial y adicional de este derecho, que va más allá de la literalidad del artículo 28.1 CE, y abarca los aspectos relacionados con todas aquellas funciones que reconoce el artículo $7 \mathrm{CE}$ a las organizaciones sindicales.

Tras la primera regulación que hizo la LORAP en 1987 de las peculiaridades del derecho a sindicación de los funcionarios públicos a que se refiere la $\mathrm{CE}$, y que afectan a sus particulares órganos de representación, a la determinación de las condiciones de trabajo y la participación del personal al servicio de las Administraciones públicas, esta regulación se 
contiene actualmente en el Capítulo IV del Título III LEBEP (Derecho a la negociación colectiva, representación y participación institucional. Derecho de reunión).

SÉPTIMA- Por consiguiente, en nuestro ordenamiento jurídico, los derechos colectivos del personal estatutario de los Servicios de salud se enmarcan dentro del conjunto de derechos colectivos de los empleados públicos, junto con los de los funcionarios, y tienen el mismo fundamento constitucional (art. 28.1 y $7 \mathrm{CE}$ ) y la misma base normativa: la LOLS, la LEBEP, y la Ley reguladora de su Estatuto Marco, que contiene algunas disposiciones específicas, como son la existencia del Foro Marco para el Diálogo Social y la Mesa sectorial de Sanidad en cada Servicio de salud autonómico.

Los derechos colectivos del personal estatutario son: la libre sindicación, el derecho a la actividad sindical, el derecho de huelga, el de negociación colectiva, el de órganos de representación del personal y participación en la determinación de las condiciones de trabajo, el de reunión, así como el derecho a disponer de servicios de prevención y órganos representativos en materia de seguridad laboral (art. 18 LEM).

OCTAVA.- Entre los derechos colectivos del personal estatutario de los Servicios de salud destaca el de negociación colectiva. Este mecanismo legal para la determinación de las condiciones de trabajo del personal estatutario ha tenido una gran importancia a lo largo de los años de existencia del Sistema Nacional de Salud, y ha permitido regular los aspectos principales de su régimen jurídico. Esto es así porque la vía de la negociación colectiva abre para todos los empleados públicos, y para el personal estatutario en particular, un camino de mejoras de las condiciones legales que establece su normativa reguladora. Este derecho a la negociación colectiva del personal estatutario de los Servicios de salud es de naturaleza funcionarial y se ajusta a los principios y a la estructura de negociación de la LEBEP y la LEM.

La jurisprudencia distingue entre el derecho a la negociación colectiva laboral, que tiene reconocimiento constitucional en el artículo $37 \mathrm{CE}$, pero considera que el de los funcionarios públicos no tiene ese origen, sino que emana directamente de normas con rango de ley (actualmente: art. 31 y ss. LEBEP; arts. 78 y ss . LEM). Las diferentes consecuencias en cada caso alcanzarían a una eventual protección constitucional del derecho a la negociación colectiva en caso de lesión. Sin embargo, hay que tener en cuenta que en el ámbito funcionarial existe la peculiaridad de que la ley atribuye el ejercicio de la negociación colectiva directamente a las organizaciones sindicales, en función de los resultados obtenidos en las elecciones a representantes del personal, y a la Administración pública, que la llevan a cabo en los foros de negociación correspondientes. Es en estos foros o Mesas de negociación donde tiene lugar el ejercicio del derecho de negociación colectiva sobre determinadas materias, para las que la ley dispone este cauce en cuanto a la determinación de las condiciones de trabajo del personal con relación jurídicoadministrativa.

Los órganos unitarios de representación del personal funcionario y estatutario (Juntas de personal y Delegados de Personal) carecen de legitimación legal para la negociación de las condiciones de trabajo del personal al que representan; solo tienen 


\section{Conclusiones}

legitimación para la negociación las organizaciones sindicales que obtengan una representación mínima del 10\% de los representantes unitarios del personal en el ámbito de negociación del foro que corresponda.

Por ese motivo destacamos que el derecho a la negociación colectiva en el ámbito del personal estatutario de los Servicios de salud, como personal con relación jurídico funcionarial, se ejerce efectivamente por las organizaciones sindicales; es decir, por los mismos sujetos que también actúan en el ámbito privado en defensa de los derechos de los trabajadores. Es por eso que el derecho a la negociación colectiva funcionarial entendemos que sí encaja en el precepto constitucional junto con la negociación colectiva de los trabajadores del ámbito común, porque la ejercen los mismos sujetos con reconocimiento constitucional: las organizaciones sindicales.

Sobre todo teniendo en cuenta que si no fuera así, si no hubiera una determinada conexión constitucional del derecho a la negociación colectiva funcionarial, por la mera decisión del legislador se podría suprimir por completo el derecho a la negociación colectiva de los funcionarios para la determinación de sus condiciones de trabajo, y perdería sentido el papel que el propio artículo $7 \mathrm{CE}$ reconoce a los sindicatos para la defensa de los intereses de todos los trabajadores.

NOVENA.- El derecho a la negociación colectiva del personal estatutario de los Servicios de salud, como negociación funcionarial que es, solo se puede llevar a cabo, de forma válida, en los foros de negociación que prevé la ley, entre los sujetos legitimados y sobre las materias que la ley ha previsto. Esta postura está del todo clara en la jurisprudencia, que considera que no cabe negociación válida en otros foros diferentes a los que prevé la ley. Los requisitos y presupuestos de ejercicio de la negociación colectiva funcionarial vinculan tanto a las organizaciones sindicales como a la Administración pública, que no puede llevar la negociación a foros sin legitimación sindical con el fin de obtener respaldo a sus posturas, porque eso no es negociación colectiva.

El foro de negociación específico del personal estatutario de los Servicios de salud ha sido durante años la Mesa sectorial de Sanidad de cada Servicio de salud autonómico, donde se ha negociado sobre las materias que le afectan de forma particular. No obstante, la negociación colectiva sobre materias comunes a personal con diferentes relaciones jurídicas se puede llevar a cabo en las Mesas Generales de negociación, en las que cabe incluir al resto del personal al servicio de la Comunidad autónoma, ya sea funcionario, e incluso laboral, desplegando diferentes efectos para el personal afectado, ya que en el caso de que tenga una relación jurídico-administrativa lo pactado tendrá efectos de Acuerdo o Pacto, y para el personal laboral efectos de Convenio colectivo.

En el caso de los Acuerdos, a diferencia de los Pactos y Convenios colectivos, requiere la ley el requisito de la ratificación para que surta efectos (art. 38.3 LEBEP); es decir, la aprobación del órgano de gobierno correspondiente respaldando el contenido de lo negociado. 
DÉCIMA.- Derechos colectivos y derechos sindicales de los empleados públicos no son sinónimos. A pesar de la indefinición de la expresión derechos sindicales, que se utiliza en ocasiones como sinónimo de derechos colectivos, desde nuestro punto de vista aquellos se refieren más bien al conjunto de derechos, facultades y garantías que se integran, a su vez, en el derecho a la acción sindical de las organizaciones sindicales y facilitan la actuación de los representantes sindicales y de los del personal. Los derechos y garantías sindicales de los empleados públicos, y los del personal estatutario de los Servicios de salud, en concreto, son ampliables por la vía de la negociación colectiva, mediante la concertación de Acuerdos y Pactos que pueden mejorar las condiciones mínimas que regulan la LEBEP y la LEM.

En efecto, los Acuerdos y Pactos son, precisamente, una fuente normativa especialmente rica en el reconocimiento de derechos y garantías para el personal funcionario y estatutario, en especial por lo que se refiere a sus derechos y garantías sindicales, si bien las beneficiarias últimas de esta negociación son las organizaciones sindicales, que amplían su capacidad de acción mediante el reconocimiento de efectivos personales a través de las dispensas o liberaciones sindicales.

Sin embargo, las políticas legislativas que se han llevado a cabo en los últimos años, particularmente desde la publicación del Real Decreto Ley 20/2012, de 13 de julio, de medidas para garantizar la estabilidad presupuestaria y de fomento de la competitividad, han supuesto una regresión en el nivel de derechos sindicales alcanzado por los empleados públicos, en general, y por los profesionales de la sanidad pública, en particular, que pueden tener a no muy largo plazo serias repercusiones en todos los demás aspectos que componen su régimen jurídico, ya que casi todos estos son materia de negociación obligatoria.

UNDÉCIMA.- La negociación colectiva sobre derechos sindicales del personal estatutario durante estos años ha pasado por una serie de fases o etapas sucesivas en el tiempo, constatándose la tendencia actual de pérdida de derechos y garantías sindicales de los empleados públicos, y en concreto del personal estatutario de los Servicios de salud.

La primera fase, que podríamos denominar fase de desarrollo de la negociación colectiva, arranca con los primeros traspasos de servicios a las CC.AA. en 1981, y termina en diciembre de 2001, ya que a partir de enero de 2002 todas ellas asumen la gestión de sus Servicios de salud. Esta etapa culmina a finales de 2005 y se mantiene sin incidencias hasta finales del año 2010.

Durante esta fase se alcanzan Acuerdos y Pactos reguladores sobre derechos y garantías sindicales en todas las Administraciones autonómicas, bien de forma exclusiva para el personal de sus Servicios de salud, bien de forma conjunta con el resto de sus empleados públicos. Estos instrumentos negociados reconocen un alto nivel de derechos sindicales, mejorando habitualmente todos los aspectos que deja abiertos la ley: las condiciones de constitución de las secciones sindicales, la designación de delegados sindicales, su número, el crédito horario sindical, tanto para los representantes sindicales como para los del personal; las ayudas y subvenciones a las organizaciones sindicales, y los medios materiales que la Administración se compromete a poner a su disposición para 


\section{Conclusiones}

facilitar la acción sindical. Estos acuerdos se iban actualizando para adecuarse a los cambios en la composición de las Mesas de negociación tras las sucesivas elecciones sindicales.

En consecuencia, durante esta fase se desarrolla a nivel autonómico una fructífera negociación colectiva con las organizaciones sindicales, relevante tanto en la cantidad como en la calidad de su contenido, que en materia de derechos sindicales dará como resultado un alto grado de garantías y protección, por lo que se refiere a las facilidades para el ejercicio de la acción sindical, desde el punto de vista humano y material. No obstante, las debilidades de este sistema vienen dadas por la ausencia de coordinación entre los agentes implicados a la hora de tratar los mismos aspectos del régimen sindical y la consecuente falta de uniformidad en su regulación en las diferentes Administraciones autonómicas.

Hay que destacar también que estos Acuerdos y Pactos contaron con el respaldo de las organizaciones sindicales más representativas, CC.OO. y UGT, en el 100\% de ellos; y en un porcentaje alto con la participación de los sindicatos representativos en la Administración pública y en el sector sanitario: CSI-F, firmó casi el 65\% y CEMSATSE el $71 \%$.

A continuación se sucede una segunda fase, que se da entre finales de $2010 \mathrm{y}$ hasta la publicación del Real Decreto Ley 20/2012, de 13 de julio, de Medidas para garantizar la estabilidad presupuestaria y de fomento de la competitividad, que podríamos denominar de crisis. Se trata de una fase de declive en la negociación colectiva funcionarial y estatutaria, que comprende el período de tiempo entre finales de 2010 hasta mediados de 2012, coincidente con el agravamiento de la crisis financiera y económica iniciada en 2007.

Durante este período la actividad negociadora es escasa y, si bien se firma aún algún Acuerdo o Pacto con el fin de adaptarlos a los resultados de las últimas elecciones sindicales (el último de ellos es el de 25 de junio de 2011, de la Comunidad de La Rioja) nos encontramos con que en la mayoría de los casos los Acuerdos y Pactos sobre derechos sindicales siguen en vigor en virtud de su cláusula de prórroga tácita y no se han renovado (Pacto de Cantabria de 2003, los de Extremadura de 2002 y 2003, el Acuerdo de la Comunidad Valenciana también de 2003... ).

En este tiempo se empieza a producir la aprobación de diversa normativa de suspensión, modificación y supresión de efectos de los Pactos y Acuerdos sobre diversos aspectos del régimen jurídico de los empleados públicos, sobre todo en materia de retribuciones (medidas contenidas en el Real Decreto Ley 8/2010, de 20 de mayo, por el que se adoptan medidas extraordinarias para la reducción del déficit público; suspensión generalizada de los Acuerdos de carrera profesional del personal estatutario de los Servicios de salud...).

A partir de ese momento se suceden las modificaciones, suspensiones de efectos y supresión de los Acuerdos y Pactos de derechos y garantías sindicales, por Acuerdo de los Gobiernos autonómicos e incluso por Ley de sus Asambleas legislativas en algunos casos. Generalmente las medidas de ajuste van dirigidas a la reducción de los créditos horarios sindicales y, en especial, a la supresión de parte de las liberaciones sindicales institucionales autorizadas. 
Estas políticas toman fuerza a raíz de la modificación del artículo 135 CE, en septiembre de 2011, que incorpora el principio de estabilidad presupuestaria, prohibiendo al Estado incurrir en un déficit estructural que supere el límite establecido por la Unión Europea. Este precepto fue desarrollado por la Ley Orgánica 2/2012, de 27 de abril, de Estabilidad Presupuestaria y Sostenibilidad Financiera, y a lo largo de ese año en todas las CCAA se aprueban Planes económico-financieros de ajuste, que incluyen, entre otras muchas, medidas de reducción de los derechos sindicales de los empleados públicos.

Al final de esta fase tiene lugar la aprobación por el Gobierno del Estado del Real Decreto Ley 20/2012, de 13 de julio, que, en esencia, dispone la supresión de todo lo acordado en materia de garantías sindicales de los empleados públicos y sujeta su regulación a lo estrictamente dispuesto en la normativa legal de aplicación: la LOLS, la LEBEP y el TRET.

Las disposiciones del Real Decreto Ley 20/2012 van a tener efectos jurídicos desiguales en las diferentes Administraciones autonómicas debido, precisamente, a que algunas de estas ya se habían adelantado a tomar las mismas decisiones de ajuste. En la propia Exposición de motivos del Real Decreto Ley 20/2012 se hace referencia a que muchas de las medidas que se incorporan en la norma ya aparecen recogidas en los Planes Económico-Financieros de Reequilibrio 2012-2014 de las Comunidades Autónomas aprobados por el Consejo de Política Fiscal y Financiera.

Todo ello conforma el marco jurídico en el que el Gobierno toma estas medidas contenidas en el Real Decreto Ley 20/2012, que terminan por derogar el contenido de los Pactos y Acuerdos que durante años regularon los derechos y garantías sindicales de los empleados públicos, no habiendo prosperado los recursos de constitucionalidad contra esa norma.

A partir de ahí se puede considerar que entramos en una tercera y última fase, que se corresponde con el momento actual, en la que se ha dado una reanudación de la negociación colectiva sobre derechos y garantías sindicales de los empleados públicos en las Administraciones autonómicas y en la Administración General del Estado, pero dentro de las limitaciones que se basan en razones presupuestarias y que afectan a su contenido (este debe adecuarse a lo dispuesto en el Real decreto Ley 20/2012), y al foro en el que puede llevarse a cabo (solo son posibles los Acuerdos en las Mesas de Negociación Generales).

Esta exigencia determinará una negociación colectiva sobre derechos sindicales más limitada en número de instrumentos negociados, y cabe entender que al ignorar la norma el papel de las Mesas sectoriales de negociación, el personal estatutario pierde las ventajas de tratar en un foro específico de negociación sus particularidades en esta materia.

Este condicionante de llevar obligadamente la negociación a las Mesas Generales comunes de empleados públicos no ha impedido, no obstante, que en alguna Administración autonómica, de manera muy acertada a nuestro entender, se haya derivado la negociación de los aspectos concretos que afectan al personal estatutario de su Servicio de salud a su Mesa sectorial de Sanidad, al igual que para el resto de personal de sus diferentes sectores. 
DUODÉCIMA.- La posibilidad que deja abierta el Real Decreto Ley 20/2012 de negociar nuevos Acuerdos de derechos sindicales que se ajusten a esta norma, no se ha llevado a la práctica en todas las Administraciones de las CC.AA. De esta forma nos encontramos con el siguiente panorama jurídico, que pasamos a analizar, y que evidencia que la regulación normativa sobre derechos sindicales que se aplica a los empleados públicos autonómicos y al personal estatutario de los Servicios de salud no es homogénea en todo el Estado.

En algunas Administraciones autonómicas sí se ha negociado un Acuerdo de adecuación al Real Decreto Ley 20/2012 en materia de derechos sindicales para sus empleados públicos; son las de las CC.AA. de Aragón, Canarias, Castilla y León, Cantabria, Comunidad Valenciana, Principado de Asturias, Región de Murcia y Extremadura.

También, aunque con particularidades, que más bien son deficiencias, en Andalucía, Castilla-La Mancha, Galicia y La Rioja.

En el resto de Administraciones autonómicas no se ha llevado a cabo ningún tipo de negociación en esta materia hasta la fecha, por lo que, en aplicación de las disposiciones del Real Decreto Ley 20/2012, los derechos sindicales de sus empleados públicos se habrían de ajustar a lo dispuesto en la LOLS, en la LEBEP para el personal funcionario y estatutario, y en el TRET para su personal laboral: Administración autonómica de Cataluña, de la de las Islas Baleares, la de la Comunidad autónoma de Madrid, la de la Comunidad Foral de Navarra y la del País Vasco. A pesar de ello la situación es confusa y parece que en algún caso, como en la Administración de la Comunidad de Madrid o la de Cataluña, siguen aplicando en la práctica su normativa autonómica de suspensión.

DECIMOTERCERA.- Los Acuerdos de adecuación al Real Decreto Ley 20/2012 en materia de derechos sindicales contienen una regulación dispar $\mathbf{y}$ descoordinada. El recurso a estas medidas tan restrictivas ha dado lugar a la situación actual de desigualdad entre los empleados públicos de las diferentes Administraciones autonómicas a la hora de ejercitar sus derechos sindicales.

En las Administraciones autonómicas en las que se han llevado a efecto estos Acuerdos reguladores en sus Mesas Generales de negociación, su análisis evidencia contenidos y alcances muy diferentes, lo cual redunda en una situación de desigualdad en el reconocimiento y protección de las garantías en el ejercicio de la actividad sindical para los empleados públicos en general, y para el personal estatutario, en concreto.

Si bien es cierto que los Acuerdos se pueden adoptar por cada Administración autonómica de forma completamente independiente de las demás, hay que observar que ahora se está dando una negociación con contenidos y formas bien diferentes unos de otros.

Algunos de estos Acuerdos adolecen de defectos muy criticables: el de la Junta de Andalucía, el de la Xunta de Galicia, y el de la Administración autonómica de La Rioja ni siquiera han sido publicados en los Boletines oficiales de las respectivas CC.AA, además de existir un hermetismo total a la hora de publicitar su contenido en otros medios. 


\section{Conclusiones}

En Castilla-La Mancha su Acuerdo solo se ha consensuado con dos organizaciones sindicales, sin participación de las más representativas, y tras haber sido declarado parcialmente nulo por lesión del derecho a la negociación colectiva por diversas sentencias de su Tribunal Superior de Justicia, es de nuevo objeto de modificación con los mismos sindicatos firmantes...

Mientras, en otras Administraciones, como la de la Junta de Castilla y León, su Pacto sobre derechos de representación sindical muestra un reconocimiento de derechos sorprendentemente elevado en relación con el contenido de lo pactado en la mayoría de Administraciones autonómicas.

En otras simplemente no hay ningún Acuerdo y los derechos sindicales de sus empleados públicos están al nivel de la normativa básica en esa materia: Islas Baleares, País Vasco...

DECIMOCUARTA.- Las políticas legislativas que se han llevado a cabo durante la etapa que hemos denominado de crisis, por lo que respecta a los derechos sindicales, vacían de contenido el derecho de negociación colectiva de los empleados públicos, y además suponen una pérdida de facultades y medios de acción de los sindicatos, que no se limitan a restringir las prerrogativas de las organizaciones sindicales, sino que repercuten directamente en el nivel de derechos del que posteriormente serán titulares los empleados públicos.

Además, por lo que se refiere al ámbito del Sistema Nacional de Salud, se constata que la actuación del Foro Marco para el Diálogo Social, órgano participativo del que forman parte las organizaciones sindicales representativas en el sector sanitario y los representantes de todas las Comunidades autónomas, que debería desempeñar el doble papel que la LEM le reconoce en su artículo 11, como órgano asesor y como ámbito de negociación, es prácticamente inexistente, por las reticencias del Ministerio a convocarlo. Este último ha sustituido, durante los últimos años, el consenso que debería darse en el Foro Marco para el Diálogo Social por otro en el seno de diferentes órganos profesionales que no tienen ninguna legitimación sindical.

Sería muy conveniente que se le comunicaran, como es obligado, los Acuerdos que se toman en las Mesas sectoriales y generales que afectan al personal del sector sanitario (art. 11.3 LEM), de lo contrario se pierde la posibilidad de que este órgano conozca su contenido y pueda trasladarlo a la Comisión de Recursos Humanos del Sistema Nacional de Salud para procurar una cierta coordinación.

DECIMOQUINTA.- En el ámbito sanitario es relevante destacar la conexión directa que existe entre el desarrollo de la sanidad como servicio público y el desarrollo de los derechos sindicales de su personal.

Hay que advertir que las políticas que tienden a reducir las competencias públicas sanitarias y las prestaciones sanitarias a los ciudadanos tienen repercusión, en último extremo, también en los derechos colectivos del personal de este sector. Ello por la 
disminución que conllevan en número de efectivos destinados a este servicio público, por los cambios en el régimen jurídico que vincula al personal y por el propio diseño de nuestro sistema de representación colectiva en el ámbito funcionarial, que depende de la fortaleza y estabilidad de las organizaciones sindicales y del conjunto de profesionales públicos a quienes representa.

DECIMOSEXTA.- Por último, cabe reflexionar acerca de la relación de estas medidas de contención sindical con las que pretenden, a la vez, la limitación de las prestaciones y coberturas sanitarias del Sistema Nacional de Salud, como las contenidas en el Real Decreto Ley 16/2012, que han acabado con el principio de universalidad de la asistencia sanitaria para transformar la prestación sanitaria en la de un seguro, medidas que afectan de forma trascendente al diseño original de este modelo sanitario. 
BIBLIOGRAFÍA 



\section{BIBLIOGRAFÍA}

AAVV, Derecho del Trabajo, Tirant lo Blanch, Valencia, 3ª ed., 2013.

ALBIOL MONTESINOS, I., BLASCO PELliCER, A., Proceso de tutela de la libertad sindical y otros derechos fundamentales, Tirant lo Blanch, Valencia, 1997.

ALFONSO MELLADO, C., "Libertad sindical y derecho de asociación", en AAVV, Derecho del Trabajo, Tirant lo Blanch, Valencia, $3^{\mathrm{a}}$ ed., 2013.

ALFONSO MELLADO, C.L., "Cuestiones actuales en torno a la eficacia de la negociación colectiva de los empleados públicos”, Revista de Derecho Social n 27, 2004.

ALFONSO MELlaDO, C. L., Los Derechos Colectivos de los empleados públicos en el Estatuto Básico, Bomarzo, Albacete, 2008.

ALONSO SECO, J.M., GONZALO GONZÁLEZ, B., La asistencia social y los Servicios sociales en España, BOE, Madrid, $2^{\mathrm{a}}$ ed., 2000.

ALVAREZ SACRISTAN, I., "Las complicadas normas y doctrinas del personal estatutario de la Seguridad Social”, Actualidad Jurídica Aranzadi n 424, 2000, (BIB 1999\1808).

APARICIO TOVAR, J., La Seguridad Social y la protección de la Salud, Civitas, Madrid, 1989.

ARIAS CRIDADO, B., "El personal estatutario de los Servicios de salud. Cuestiones diversas. Cuestiones polémicas", Noticias jurídicas, [en línea] septiembre 2011.

BANDO CASADO, H. C., "Evolución histórica de la protección de la salud en España: desde 1812 hasta la Ley General de Sanidad", Revista de Estudios sobre Consumo, $\mathrm{n}^{\circ}$ 8, 1986.

BLASCO LAHOZ, J.F., "El Sistema Nacional de Salud y la ordenación de los servicios sanitarios", Aranzadi Social n ${ }^{\circ}$ 15/2001, (BIB 2001\1516).

CANTERO MARTINEZ, J., "La negociación colectiva en el ámbito de la función pública", en AA.VV., Régimen jurídico de la función pública, Lex Nova, Valladolid, 2013.

CASTILLO BLANCO, F.," El Estatuto Marco del personal estatutario", en AA.VV., La Reforma del Sistema Nacional de Salud, Marcial Pons, Barcelona, 2003.

DAMIAN MORENO, J. R., "La negociación colectiva de las condiciones de trabajo básicas de los funcionarios públicos tras la reforma de la LORAP", Actualidad Jurídica Aranzadi, $n^{\circ} 720 / 2006$. 


\section{Bibliografía}

DE LA VILLA GIL, L.E., La formación histórica del Derecho del Trabajo, Comares, Granada, 2003.

DEL REY GUANTER, S., Comentarios a la Ley de Órganos de representación y determinación de las condiciones de trabajo y participación del personal al servicio de las Administraciones públicas, Ministerio para las Administraciones Públicas, Madrid, 1988.

DE PALMA DEL TESO, A., Los Acuerdos procedimentales en el Derecho Administrativo, Tirant lo Blanch, Valencia, 2000.

DEL REY GUANTER, S., Estado, sindicatos y relaciones colectivas en la Función pública, Ministerio para las Administraciones públicas, Madrid, 1986.

DESDENTADO BONETE, A., DESDENTADO DAROCA, E., "El sistema normativo de la relación de servicios del personal estatutario de las instituciones sanitarias de la Seguridad Social”, Aranzadi Social, no 16/2000, (BIB 2000\1893).

DIAZ REVORIO, F. J. El derecho a la negociación colectiva de los empleados públicos: algunas ideas desde la perspectiva constitucional, Repertorio Aranzadi del Tribunal Constitucional, Aranzadi, Pamplona, 1998.

FERNANDEZ ORRICO, F.J., "La Seguridad Social en el XXV aniversario de la Constitución”, Revista del Ministerio de Trabajo y Asuntos Sociales, nº 49.

FERNANDEZ, J.J., AGRA VIFORCOS, B., ALVAREZ CUESTA, H., Derechos colectivos de los funcionarios públicos, Bosch, Barcelona, 2006.

GARCIA ABELlAN, J., Curso de Derecho Sindical, Universidad de Murcia, 2a ed., 1986.

GARCIA COBOS, S., "Naturaleza jurídica de la relación estatutaria, Sentencias de TSJ y AP y otros Tribunales", Tribuna Social, n 174/2005.

GARCIA MURCIA, J., CASTRO ARGUELLES, M. A., "El Estatuto Marco del personal estatutario de los Servicios de salud: Una Presentación", Aranzadi Social no 21/2003, (BIB 2004162).

GIUGNI, G., Derecho sindical, Ministerio de Trabajo y Seguridad Social, Madrid, 1983.

GOMEZ DE HITA, J.L., Formas jurídicas de la organización sanitaria, Escuela Andaluza de Salud Pública, 2000.

GONZALEZ FERNANDEZ, A., "La comisión de reformas sociales. Reformismo y clases trabajadoras en la Sevilla del s. XIX.", Revista de Historia Contemporánea, nº 6, 1995.

HUERTAS, R., "Política sanitaria: de la Dictadura de Primo de Rivera a la II República", Revista Española de Salud Pública, monográfico, 2000. 


\section{Bibliografía}

JIMENEZ-LUCENA, I., "El Estado como aliado. Los médicos y el proceso de estatalización de los servicios sanitarios en la Segunda República española”, disponible en: $<$ http://asclepio.revistas. csic.es>.

LAHERA FORTEZA, J., La titularidad de los derechos colectivos de los trabajadores y funcionarios, Consejo Económico y Social, Madrid, 2000.

LAHERA FORTEZA, J., VALDES ALONSO, A., Informe $n^{\circ} 300$ impacto en Convenios, Acuerdos y Pactos colectivos en el sector público del Real Decreto Ley 20/2012, de 13 de julio, sobre medidas para garantizar la estabilidad presupuestaria y de fomento de la competitividad, disponible en: 〈http://www.ugt.es/actualidad/2012〉.

LAMATA COTANDA, F., Manual de Administración Sanitaria, Ediciones Díaz de Santos, Madrid, 1998.

LANDA ZAPIRAIN, J.P., La reforma de la sanidad pública y del régimen jurídico de su personal, Consejo Económico y Social, Madrid, 1999.

LINDE PANIAGUA, E., "Notas sobre la naturaleza, el ámbito y el desarrollo del Estatuto Básico del Empleado Público, en AA.VV., El Estatuto Básico del Empleado Público y su desarrollo por el Estado y las CC.AA, Colex, Madrid, 2008.

LORENZO DE MEMBIELA, J.B., "Análisis sucinto del Estatuto Básico del Empleado Público, Ley 7/2007, de 13 de abril”, Actualidad Jurídica Aranzadi no 733/2007, (BIB 200入1083).

LUJAN ALCARAZ, J., Ámbito subjetivo del derecho a la acumulación de horas y contenido del derecho de libertad sindical, Aranzadi Social, volumen IV, (BIB 199入1270).

MANZANA LAGUARDA, R., Derechos y deberes de los funcionarios públicos, Tirant lo Blanch, Valencia, 1996.

MARIN ALONSO, I., "La congelación salarial de los funcionarios públicos mediante determinación unilateral del correspondiente ministro para las Administraciones Públicas a propósito de la SAN de 7 noviembre 2000”, Aranzadi Social n 20/2000, (BIB 2001\311).

MARSET CAMPOS, P, SAEZ GOMEZ, J.M, MARTINEZ NAVARRO, F., "La Salud pública durante el Franquismo", Revista Dynamis, nº 15, 1995.

MARTINEZ GAYOSO, M.N., El derecho a la negociación colectiva de los funcionarios públicos en la Constitución, Universidad del País Vasco, 2002.

MARTINEZ MOYA, J., "La ley 55/2003 de 16 de diciembre, del Estatuto marco del personal estatutario de los Servicios de salud ¿Un marco propicio para soltar amarras definitivamente y declarar la incompetencia del orden social?", Revista de Derecho Social $n^{\circ} 28 / 2004$. 


\section{Bibliografía}

MARTINEZ MOYA, J., "Personal estatutario y jurisdicción social: fin de una larga despedida", Aranzadi Social no 20/2005, (BIB 2005\2708).

MONEREO PEREZ, MOLINA NAVARRETE Y MORENO VIDA, Manual de Derecho Sindical, Comares, Granada, 8a ed., 2013.

MONLAU I ROCA, P., Elementos de higiene pública, Imprenta Pablo Riera, Barcelona, 1847.

MORENO CALIZ, S, "Derecho al uso de local adecuado por sección sindical. Comentario a la STSJ de Cataluña de18 de mayo de 2006”, Aranzadi Social n²/2007.

OIT, El diálogo social en los Servicios de salud: Instituciones, capacidad y eficacia, Ginebra, 2002.

ORTEGA ALVAREZ, L., Los derechos sindicales de los funcionarios públicos, Tecnos, Madrid, 1983.

PALOMAR OLMEDA, A., "El fuero jurisdiccional de enjuiciamiento de las cuestiones de aplicación del régimen estatutario del personal sanitario", Aranzadi Social no 9/2005, (BIB 2005\15539).

PALOMAR OLMEDA, A., "Formas de organización y régimen de personal de los Servicios públicos sanitarios", AAVV, La Organización de los Servicios Públicos Sanitarios, Marcial Pons, Barcelona, 2000.

PALOMAR OLMEDA, A., Derecho de la Función Pública, Dykinson, Madrid, 1996.

PALOMAR OLMEDA, A., El nuevo Estatuto del Empleado Público, Aranzadi, Navarra, 2007.

PALOMEQUE LOPEZ, M.C., Derecho del Trabajo e Ideología, Tecnos, Madrid, 2011.

PAREJO, L., PALOMAR, A., VAQUER, M., La reforma del Sistema Nacional de Salud, Marcial Pons, Barcelona, 2003.

PELAYO OLMEDO, J.D., "El derecho de asociación en la historia constitucional española, con particular referencia a las leyes de 1887 y 1964", Revista electrónica de Historia Constitucional, $\mathrm{n}^{\circ} 8$, septiembre 2007.

PEREZ CHARCO, J. "El foro Marco para el diálogo social en el Estatuto Marco de personal estatutario de los Servicios de salud", Revista de Derecho Social, $\mathrm{n}^{\circ}$ 25, enero 2004.

PEREZ GALVEZ, J.F., Comentarios al Estatuto Marco del personal estatutario de los Servicios de salud, Bosch, Barcelona, 2004. 


\section{Bibliografía}

PEREZ GALVEZ, J.F., Incidencia del Estatuto Básico del empleado público en el acceso al empleo del personal de los Servicios de salud, Instituto Nacional de Administración Pública, 2011.

REDONDO RINCON, M.G., El seguro obligatorio de enfermedad en España: responsables técnicos y políticos de su implantación durante el franquismo, (tesis doctoral), Universidad Complutense, 2012.

REGUERA ANDRES, M.C., "Algunas consideraciones sobre el diálogo social en el Sistema Nacional de Salud", Revista de Administración Sanitaria, agosto 2010.

RIVERO LAMAS, J., DE VAL TENA, A. L. El derecho a la negociación colectiva de los funcionarios públicos, Revista del Ministerio de Trabajo y Asuntos Sociales, $\mathrm{n}^{\circ} 68$.

RODRIGUEZ IZQUIERDO, R., "La tutela de la Libertad sindical", Manual de Derecho Sindical, AAVV, Atelier, Barcelona, $2^{\mathrm{a}}$ ed., 2007.

RODRIGUEZ OCAÑA, E., "La Salud Pública en España en el contexto europeo, 18901925”, Revista Sanitaria de Higiene Pública, nº 68, 1994.

ROJO TORRECILLA, E, Análisis de los contenidos laborales del Real Decreto Ley 20/2012 ¿Hacia dónde va el Estado del bienestar en España? ¿Hacia dónde le lleva el Gobierno?, disponible en: 〈http://slideshare.net/erojotorrecilla〉.

ROQUETA BUJ, R. La negociación colectiva en la función pública, Tirant lo Blanch, Valencia, 1996.

ROQUETA BUJ, R., "Derechos individuales ejercidos colectivamente", AA.VV., El Estatuto Básico del Empleado Público y su desarrollo por el Estado y las Comunidades autónomas, Colex, Madrid, 2008, Director: Enrique Linde Paniagua.

ROQUETA BUJ, R., El derecho de negociación colectiva en el Estatuto Básico del Empleado Público, La Ley, Valladolid, 2007.

SALA FRANCO, T., "El personal laboral. La relación laboral especial de empleo público", en AAVV, Comentarios a la Ley del Estatuto Básico del Empleado Público, Lex Nova, Valladolid, 2007.

SALA FRANCO, T., El Estatuto Marco del Personal estatutario de los Servicios de salud, Tirant lo Blanch, Valencia, 2004.

SALA FRANCO, T., ROQUETA BUJ, R., Los derechos sindicales de los funcionarios públicos, Tirant lo Blanch, Valencia, 1995.

SANCHEZ MORON, M., "Objeto y ámbito de aplicación -de la LEBEP", AAVV, Comentarios a la Ley del Estatuto Básico del Empleado Público, Lex Nova, Valladolid, 2007. 


\section{Bibliografía}

SANCHEZ MORON, M., Derecho de la función Pública, Tecnos, Madrid, 6ª ed., 2011.

SEMPERE NAVARRO, A. "Los derechos individuales del personal estatutario. Comentario al artículo 17 de la Ley 55/2003", Aranzadi Social n 2, 2006.

SEMPERE NAVARRO, A., "Personal estatutario y jurisdicción social, contradicciones y paradojas", Aranzadi Social, Vol. IV, 1997, (BIB 199入1263).

SEMPERE NAVARRO, A., MARTIN JIMÉNEZ, R.," La formación del Derecho del Trabajo en España", AAVV, Derecho del Trabajo, Aranzadi, Navarra, 2012.

VAZQUEZ GARRANZO, J., "El profesional sanitario al servicio de la Administración", AAVV, Marco jurídico de las profesiones sanitarias, Lex Nova, Valladolid, 2007.

VAZQUEZ GARRANZO, J., "Regímenes estatutario, funcionario y laboral. Jerarquía, convivencia normativa y escenario de aplicación en los Servicios de salud", Actualidad del Derecho sanitario, $\mathrm{n}^{\circ} 146$.

VICENTE PACHES, F. DE, "La libertad sindical en el Derecho español", AAVV, Manual de Derecho Sindical, Atelier, Barcelona, 2a ed., 2007.

VIDA FERNANDEZ, J., "Las prestaciones sanitarias del Sistema Nacional de Salud: Catálogo de Prestaciones y Carteras de Servicios", AA.VV., La Reforma del Sistema Nacional de Salud, Marcial Pons, Barcelona, 2003.

VIÑES RUEDA, J. J., "La Sanidad Española en el siglo XIX a través de la Junta Provincial de la Sanidad Navarra (1870-1902)", Gobierno de Navarra, 2006.

OBSERVACIONES:

En la cita de bibliografía contenida en páginas web se ha seguido la norma ISO 690-2. 
PAGINAS WEB DE LOS SERVICIOS DE SALUD 



\section{PAGINAS WEB DE LOS SERVICIOS DE SALUD}

\section{Autonómicos}

<http://www.juntadeandalucia.es/servicioandaluzdesalud $>$ Servicio Andaluz de Salud. $<$ http://www.aragon.es/sas $>$ Servicio Aragonés de Salud.

$<$ http://asturias.es $>$ Servicio de Salud del Principado de Asturias.

$<$ http://www3.gobiernodecanarias.org/sanidad $>$ Servicio Canario de Salud.

$<$ http://www.scsalud.es $>$ Servicio Cántabro de Salud.

$<$ http://www.sescam.castillalamancha.es $>$. Servicio de Salud de Castilla-La Mancha.

<http://www.saludcastillayleon.es $>$ Consejeria de Sanidad de la Junta de Castilla y León.

<http://www.gencat.cat/ics> Institut Català de la Salut;

<http://www.catsalut.gencat.cat $>$ Servei Català de la Salut.

$<$ http://saludextremadura.gobex.es $>$ Servicio Extremeño de Salud.

<http://www.sergas.es $>$ Servicio Gallego de Salud.

<http://www.san.gva.es> Conselleria de Sanitat de la Generalitat Valenciana.

$<$ http://www.ibsalut.es $>$ Servei de Salut de les Illes Balears.

$<$ http://www.madrid.org $>$ Servicio Madrileño de Salud.

<http://www.murciasalud.es $>$ Servicio Murciano de Salud.

$<$ http://www.navarra.es> Servicio Navarro de Salud (Osasunbidea).

$<$ http://www.riojasalud.es $>$ Servicio Riojano de Salud.

< http://www.osakidetza.euskadi.eus> Servicio Vasco de Salud (Osakidetza).

\section{Estatal}

<http://www.ingesa.msc.es> INGESA. 